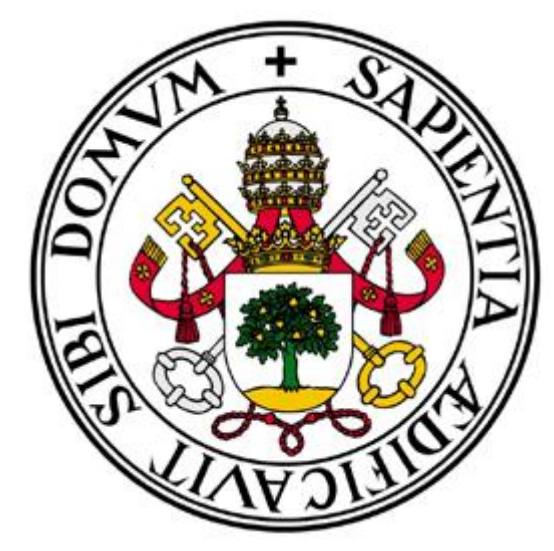

FACULTAD DE EDUCACIÓN Y TRABAJO SOCIAL

DEPARTAMENTO DE DIDÁCTICA DE LAS CIENCIAS EXPERIMENTALES, SOCIALES Y DE LA MATEMÁTICA

TESIS DOCTORAL:

\title{
ANÁLISIS HISTÓRICO DE LAS DEMOSTRACIONES EN LIBROS DE TEXTO SOBRE LOS TEOREMAS DE LÍMITES Y CONTINUIDAD. DE LA LEY GENERAL DE EDUCACIÓN A LA LEY ORGÁNICA DE EDUCACIÓN
}

Presentada por Laura Conejo Garrote para optar al grado de Doctora por la Universidad de Valladolid

Dirigida por:

Tomás Ortega del Rincón 

Memoria presentada para optar al grado de Doctora por la Universidad de Valladolid por la licenciada Da. Laura Conejo Garrote en el Programa de Doctorado: Investigación en Didáctica de las Ciencias Sociales, Experimentales y de la Matemática.

Director de la tesis: Dr. Tomás Ortega del Rincón. Departamento de Didáctica de las Ciencias Experimentales, Sociales y de la Matemática. Universidad de Valladolid. 

TOMÁS ORTEGA DEL RINCÓN, CAUN de Didáctica de la Matemática de la Universidad de Valladolid,

\section{CERTIFICA:}

Que la presente memoria, Análisis histórico de las demostraciones en libros de texto sobre los teoremas de límites y continuidad. De la Ley General de Educación a la Ley Orgánica de Educación, ha sido realizada por Dña. Laura Conejo Garrote bajo mi dirección en la Universidad de Valladolid.

Valladolid, agosto de 2015.

Fdo.: Tomás Ortega del Rincón. 



\section{Agradecimientos}

En primer lugar, quiero expresar mi agradecimiento a mi director de tesis, el Dr. Tomás Ortega, por su inestimable ayuda, su tiempo, su constante guía y apoyo, y sus sabios consejos y orientaciones. Ha sido un placer conocer y trabajar con un gran investigador y una mejor persona.

En segundo lugar, quiero agradecerle a mi familia que haya estado a mi lado durante todo este proceso: a mi padre y a mi hermano, su constante apoyo en todas mis decisiones; a Fernando, su comprensión y ánimo en los momentos de flaqueza; a todos ellos, su infinito cariño.

Por último, mi más sincero agradecimiento a todos aquellos que, de una manera u otra, tanto en lo personal como en lo profesional, han realizado una aportación al trabajo, bien sea a través de sus conocimientos, de sus consejos o de su apoyo. 

A mi madre 



\section{ÍNDICE DE CONTENIDOS}

Índice de contenidos..........................................................................................................................I

Índice de figuras ................................................................................................................... V

Índice de gráficos .......................................................................................................................IX

Índice de tablas................................................................................................................XI

Siglas y abreviaturas......................................................................................................... XVII

CAPÍTULO 0: INTRODUCCIÓN.............................................................................1

CAPÍTULO I: ANTECEDENTES DE LA INVESTIGACIÓN..................................... 5

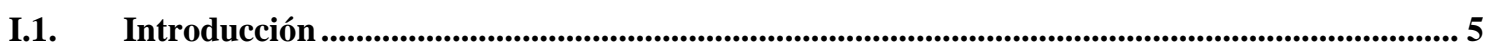

I.2. Investigaciones en torno a la demostración matemática ............................................................... 5

I.3. Investigaciones en torno al libro de texto ................................................................................ 13

I.4. Investigaciones que integran la demostración matemática y los libros de texto ...................... 16

I.5. Investigaciones en torno a los conceptos analizados: límites y continuidad. ............................ 22

CAPÍTULO II: OBJETIVOS E HIPÓTESIS DE INVESTIGACIÓN. MARCO TEÓRICO.......................................................................................................... 27

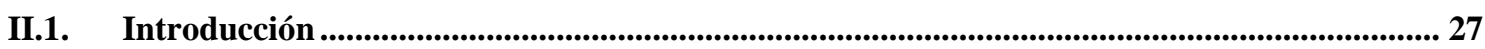

II.2. Objetivos e hipótesis de investigación ................................................................................................ 28

II.3. Apunte curricular ...................................................................................................................... 29

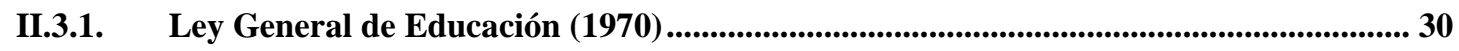

II.3.2. Ley Orgánica de Ordenación General del Sistema Educativo (1990) .............................. 33

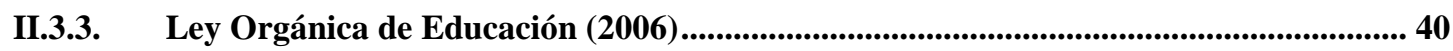


II.3.4. Ley Orgánica para la Mejora de la Calidad Educativa (2013)....................................... 43

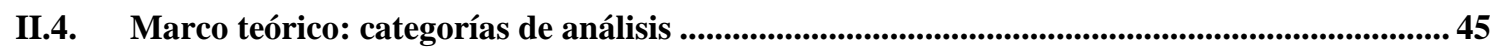

II.4.1. Clase de justificación utilizada (esquemas de prueba) ................................................ 46

II.4.2. Técnicas empleadas .............................................................................................................5 51

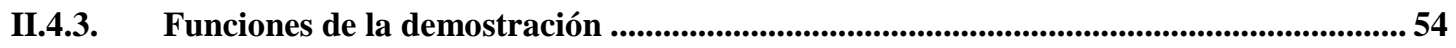

II.4.4. Reconocimiento y distinción de procesos ...........................................................................60

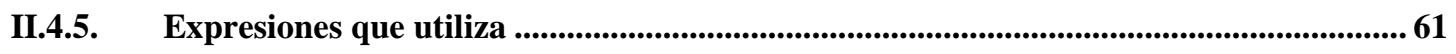

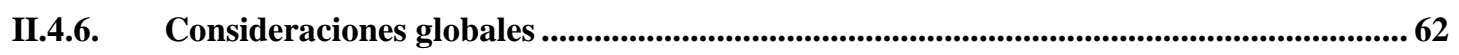

II.4.7. Tablas resumen de las categorías de análisis .............................................................. 62

CAPÍTULO III: MARCO METODOLÓGICO.............................................................65

III.1. Introducción ................................................................................................................................................ 65

III.2. Marco metodológico.....................................................................................................................66

III.2.1. Planteamiento de la investigación ...................................................................................69

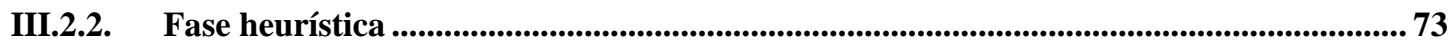

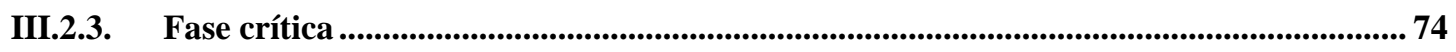

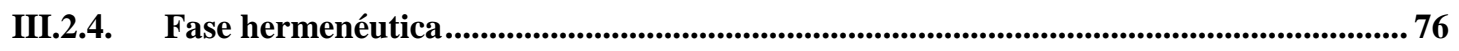

III.2.5. Exposición de la investigación ............................................................................................ 77

CAPÍTULO IV: SOBRE LOS TEOREMAS DE LÍMITES........................................81

IV.1. Introducción ....................................................................................................................................................... 81

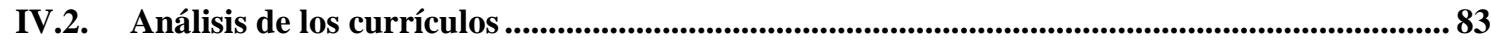

IV.3. Los límites en los libros de texto ...................................................................................................86

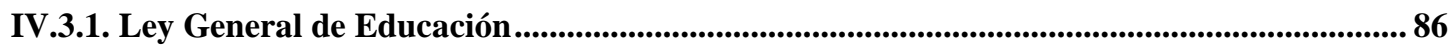

IV.3.2. Ley Orgánica de Ordenación General del Sistema Educativo ............................................... 91

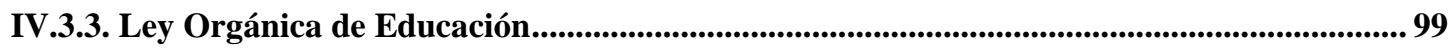

IV.4. Resultados y justificaciones asociados al concepto de límite ................................................... 104

IV.4.1. Resultados y justificaciones en la editorial Anaya ................................................................. 105

IV.4.2. Resultados y justificaciones en la editorial Santillana........................................................... 108

IV.4.3. Resultados y justificaciones en la editorial SM....................................................................... 111

IV.4.4. Resultados y justificaciones en la editorial Vicens-Vives................................................. 114

IV.4.5. Comentarios a los análisis previos .......................................................................................... 117

IV.5. Resultados asociados al concepto de límite ........................................................................... 122

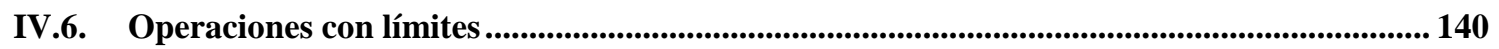


IV.7. Resultados asociados a familias de funciones e indeterminaciones 147

IV.7.1. Límite del cociente de polinomios en un punto .............................................................. 148

IV.7.2. Límite del cociente de polinomios en el infinito ........................................................... 151

IV.7.3. Límite de las funciones de tipo potencial-exponencial que conducen a la indeterminación $\rightarrow 1^{\rightarrow \infty}$

IV.7.4. Límite de funciones exponenciales y logarítmicas .......................................................... 160

IV.7.5. Límite de familias de funciones elementales ................................................................. 163

IV.7.6. Resultados asociados a los infinitésimos o infinitos equivalentes............................... 170

IV.7.7. Límite en cero de $x / \operatorname{sen}(x)$, en $\operatorname{tg}(x) / x$ o en $(\cos (x)-1) / x$ y límite en infinito de $\operatorname{sen}(x) / x 173$

IV.8. Interpretación de los datos 184

IV.8.1. Esquemas de prueba 184

IV.8.2. Técnicas usadas en la demostración .................................................................................. 187

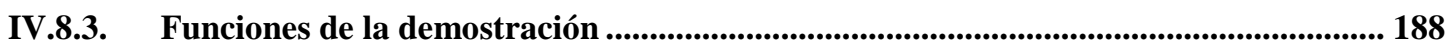

IV.8.4. Reconocimiento de procesos................................................................................ 189

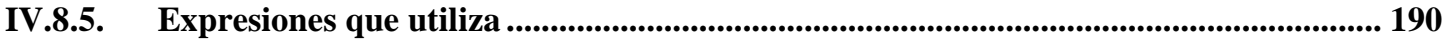

IV.8.6. Consideraciones globales ............................................................................................... 191

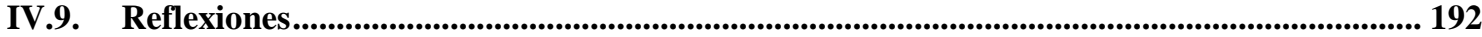

CAPÍTULO V : SOBRE LOS TEOREMAS DE CONTINUIDAD ......................... 197

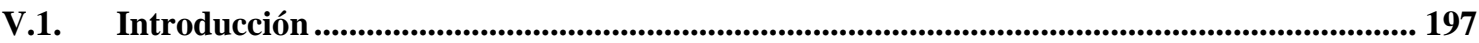

V.2. Análisis de los currículos ........................................................................................................ 199

V.3. La continuidad en los libros de texto................................................................................................ 201

V.3.1. Ley general de educación ............................................................................................. 202

V.3.2. Ley Orgánica de Ordenación General del Sistema Educativo ......................................... 208

V.3.3. Ley Orgánica de Educación .................................................................................................... 213

V.4. Resultados y justificaciones asociados al concepto de continuidad ........................................ 217

V.4.1. Resultados y justificaciones en la editorial Anaya .......................................................... 218

V.4.2. Resultados y justificaciones en la editorial Santillana .............................................. 221

V.4.3. Resultados y justificaciones en la editorial SM ........................................................... 2223

V.4.4. Resultados y justificaciones en la editorial Vicens-Vives............................................... 225

V.4.5. Comentarios a los análisis previos ................................................................................... 227

V.5. Aritmética y propiedades de funciones continuas............................................................ 233

V.6. Teoremas de continuidad en entornos e intervalos .......................................................... 246

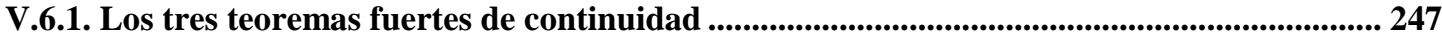


V.6.2. Otros teoremas sobre la continuidad en entornos e intervalos ............................................. 278

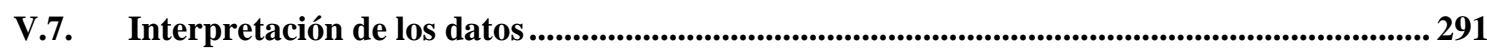

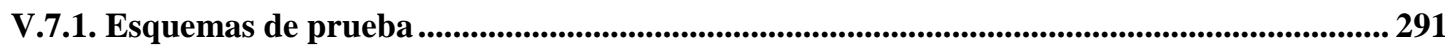

V.7.2. Técnicas usadas en las demostraciones sobre continuidad.................................................... 293

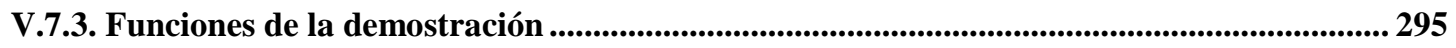

V.7.4. Reconocimiento de procesos.....................................................................................................296

V.7.5. Expresiones que utiliza .............................................................................................................297

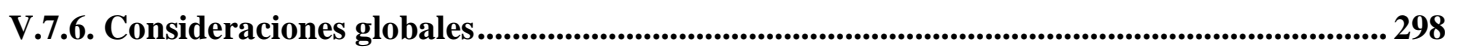

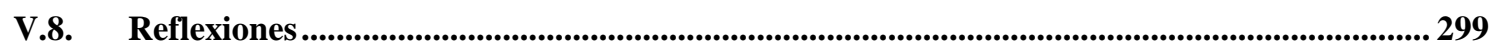

CAPÍTULO VI: CONCLUSIONES, PROPUESTA DIDÁCTICA, APORTACIONES, DIFICULTADES Y FORTALEZAS, Y PERSPECTIVAS DE FUTURO ..........................................................................................................................303

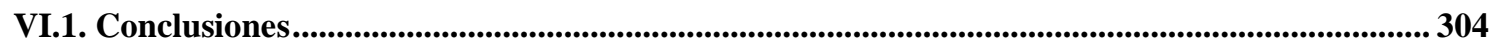

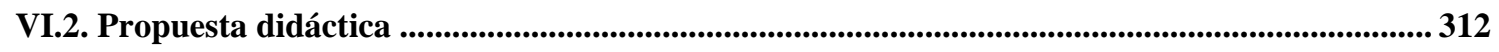

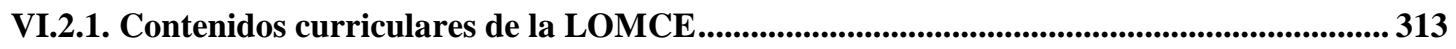

VI.2.2. Propuesta didáctica para límite de una función ...................................................................315

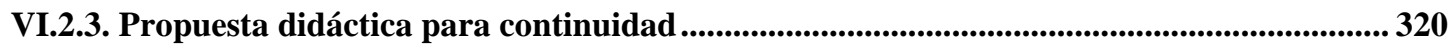

VI.3. Aportaciones de la tesis ...............................................................................................................3 323

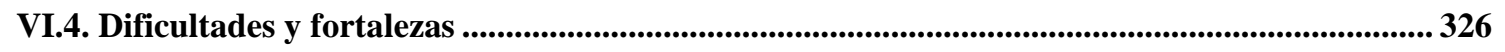

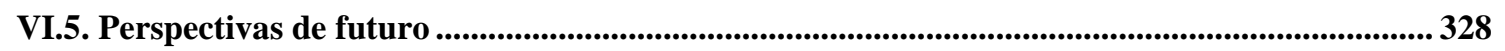

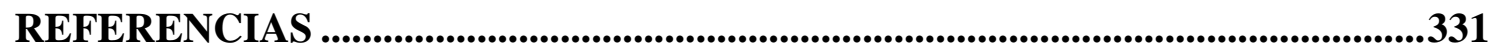

ANEXOS

Anexo 1: Libros de texto utilizados en la muestra ................................................................................... 349 


\section{ÍNDICE DE FIGURAS}

Figura II.4.1.1

Figura II.4.3.5.1. Función de descubrimiento en la demostración del teorema de Bolzano del LT de $2^{\circ}$ de Bachillerato de SM (2010).

Figura IV.5.1. Concepto de límite en Vicens-Vives (1998), de $1^{\circ}$ de Bachillerato de LOGSE.

Figura IV.5.2. Representación del límite $\left(1^{\circ}\right.$ de Bachillerato de LOGSE de SM, 1996).

Figura IV.5.3. Representación del límite ( $2^{\circ}$ de BUP de Vicens-Vives, 1980)

Figura IV.5.4. Representación del límite ( $2^{\circ}$ de BUP de SM, 1977)

Figura IV.5.5. Representación del límite $\left(2^{\circ}\right.$ de Bachillerato de LOE de SM, 2010).

Figura IV.5.6. Representación del límite $\left(2^{\circ}\right.$ de Bachillerato de LOE de SM, 2001).

Figura IV.5.7. Representación del límite ( $2^{\circ}$ de BUP de Anaya, 1976)

Figura IV.5.8. Representaciones del límite lateral y en un punto $\left(2^{\circ}\right.$ de Bachillerato de LOGSE de Anaya, 2003)............................................

Figura IV.5.9. Representación del límite finito en un punto (Santillana, 2008 (izquierda) y 2009 (derecha), correspondientes a $1^{\circ}$ y $2^{\circ}$ de Bachillerato respectivamente.

Figura IV.5.10. Representación del límite finito en un punto $\left(2^{\circ}\right.$ de BUP de Santillana, 1991).

Figura IV.5.11. Justificación ( $2^{\circ}$ de BUP de SM, 1977) 
Figura IV.6.1. Justificación del producto de límites (2º de BUP de Anaya, 1976)... 145

Figura IV.6.2. Justificación del producto de límites ( $2^{\circ}$ de BUP, SM, 1977)............. 146

Figura IV.7.1.1. Enunciado de la regla para el cálculo de límites de cocientes de funciones polinómicas en valores en los que se anula el denominador ( $2^{\circ}$ de BUP de Anaya, 1987)........................................... 148

Figura IV.7.1.2. Límite del cociente de polinomios en un punto en el que se anulan ambos polinomios ( $1^{\circ}$ de Bachillerato de Anaya, 2002).

Figura IV.7.1.3. Límite del cociente de polinomios en un punto en el que se anulan ambos polinomios ( $2^{\circ}$ de Bachillerato de Vicens-Vives, 1999).

Figura IV.7.2.1. Justificación (prueba preformal) y enunciado del límite de funciones racionales ( $2^{\circ}$ de Bachillerato de $\left.S M, 2010\right)$.

Figura IV.7.3.1. Justificación de la regla para el cálculo de límites de la forma $f(x)^{g(x)}$ cuando $f(x) \rightarrow 1$ y $g(x) \rightarrow \infty \quad\left(2^{\circ}\right.$ de Bachillerato de Anaya, 2009).

Figura IV.7.3.2. Justificación del teorema que permite resolver de forma general la indeterminación $\rightarrow 1^{\rightarrow \infty}$ ( $2^{\circ}$ de Bachillerato de Vicens-Vives, 1999).

Figura IV.7.4.1. Justificación mediante ejemplos gráficos del límite de las funciones exponenciales ( $2^{\circ}$ de Bachillerato de Santillana, 2009)....

Figura IV.7.4.2. EP inductivo de un caso para el límite de las funciones exponenciales y logarítmicas ( $2^{\circ}$ de Bachillerato de Vicens-Vives, 1999). La inducción se aprecia en el primer párrafo.

Figura IV.7.5.1. PP para los límites de funciones de los tipos xn (arriba) y $1 / x^{n}$ (abajo) ( $2^{\circ}$ BUP de Santillana, 1976).

Figura IV.7.5.2. EP inductivo sistemático en el LT de Santillana (2009), de $2^{\circ}$ de Bachillerato para las funciones con potencias.

Figura IV.7.5.3. EP inductivo sistemático en el LT de Vicens-Vives (1998) de $1^{\circ}$ de Bachillerato.

Figura IV.7.5.4. Justificación del límite de una función del tipo $\mathrm{f}(\mathrm{x})=x^{2}+k\left(2^{\circ} \mathrm{de}\right.$ Bachillerato de Vicens-Vives, 1999).

Figura IV.7.7.1. Justificación ( $2^{\circ}$ de BUP de Vicens-Vives, 1980)

Figura IV.7.7.2. Justificación ( $2^{\circ}$ de Bachillerato de LOGSE Santillana, 1997)..........

Figura IV.7.7.3. Justificación ( $1^{\circ}$ de Bachillerato LOGSE de SM, 1996).

Figura IV.7.7.4. Justificación del límite de límite de $\operatorname{sen}(x) / x$ y $(\cos (x)-1) / x$ en $x=0$ ( $2^{\circ}$ de Bachillerato LOGSE de SM, 2001) 
Figura IV.7.7.5. Justificación en el LT del límite en cero de $x / \operatorname{sen}(x)\left(1^{\circ}\right.$ de Bachillerato LOGSE de Vicens-Vives, 1998).

Figura IV.7.7.6. Justificaciones del límite en cero de $\operatorname{sen}(x) / x$ en cero en los LT de $2^{\circ}$ de Bachillerato LOGSE de Vicens-Vives (1999) a la izquierda y de $2^{\circ}$ de Bachillerato LOE de Vicens-Vives (2009) a la derecha.......

Figura IV.7.8.1. Ejemplos utilizados para justificar que el límite en el infinito de las funciones polinómicas coinciden con los límites de sus términos dominantes en el LT de Vicens-Vives (1998) de $1^{\circ}$ de Bachillerato. Las gráficas no se corresponden con las funciones

Figura IV.7.8.2. EP inductivo sistemático $\left(1^{\circ}\right.$ de Bachillerato de Vicens-Vives, 2003).

Figura V.5.1. Ilustración de la continuidad utilizando entornos o valor absoluto (SM, $2^{\circ}$ de Bachillerato, 2010)

Figura V.5.2. Ilustración de la continuidad utilizando el límite (Vicens-Vives, $2^{\circ}$ de Bachillerato, 1999). 236

Figura V.5.3. Definición ingenua de continuidad (Vicens-Vives, $\mathbf{1}^{\mathrm{o}}$ de Bachillerato, 1998)

Figura V.5.4. Justificación de la continuidad de la suma (SM, 2010, pp. 232).

Figura V.5.5. Justificación de la definición de $f+g$ en $a$ (Santillana, 1976, pp. 231)

Figura V.5.6. Suma en Vicens-Vives (1980, pp. 150)

Figura V.5.7. Justificación de la composición de la continuidad de funciones (Santillana, 1976, pp. 232 y 233).

Figura V.5.8. Justificación de la continuidad de la función recíproca (Santillana, 1976, pp. 233).

Figura V.5.9. Imagen para ilustra la continuidad del producto de una función por una constante (Vicens-Vives, $2^{\circ}$ BUP, 1980, 151).

Figura V.5.10. Justificación de la continuidad de las funciones contante e identidad (Santillana, 1976, pp. 234).

Figura V.5.11. Justificación de la continuidad de las funciones contante e identidad (Vicens-Vives, 2009, pp. 185).

Figura V.6.1.2.1. EP inductivo de varios casos para el teorema de los valores absolutos de Weierstrass (Santillana, 2009).

Figura V.6.1.4.1. Justificación errónea para el teorema de Weierstrass (Anaya, 1989). 
Figura V.6.1.4.2. Utilización de coordenadas en la justificación del teorema de Bolzano en Santillana (2009).

Figura V.6.1.4.3. Función de descubrimiento en el LT de SM (2010)........................... 274

Figura V.6.1.4.4. Errores en la representación gráfica del teorema de Darboux en Vicens-Vives (1979). ......................................................................................

Figura V.6.1.4.5. Ilustración del teorema de Bolzano en el LT de SM (1980).

Figura V.6.1.4.6. Santillana (1981) representa gráficamente tanto la posibilidad de que exista más de un punto, como la necesidad de las hipótesis para el teorema de Bolzano...........................................................................

Figura V.6.1.4.7. Gráfica para el Teorema de Darboux en Vicens Vives (1999)........... 277

Figura V.6.1.4.8. Gráficas para el Teorema de Darboux en SM (2010)......................... 278 


\section{ÍNDICE DE GRÁFICOS}

Gráfico IV.4.5.1. Porcentaje de EP utilizados en cada editorial.

Gráfico IV.4.5.2. Evolución de cada tipo de justificación por periodos educativos, mostrada en números absolutos (abajo) y en porcentajes (arriba).... 118

Gráfico IV.4.5.3. Porcentaje (arriba) y número (abajo) de resultados justificados en cada editorial, por legislaciones.

Gráfico IV.4.5.4. Porcentaje de resultados justificados en cada uno de los LT de cada editorial. Se observa la evolución temporal.

Gráfico V.4.5.1. Porcentaje de EP utilizados en cada editorial.

Gráfico V.4.5.2. Evolución de cada tipo de justificación por periodos educativos, mostrada en números absolutos (arriba) y en porcentajes (abajo).... 229

Gráfico V.4.5.3. Porcentaje (abajo) y número (arriba) de resultados justificados en cada editorial, por legislaciones.

Gráfico V.4.5.4. Número de resultados justificados en cada uno de los LT de cada editorial. Se observa la evolución temporal. 



\section{ÍNDICE DE TABLAS}

Tabla II.3.2.1. Referencias a la demostración o procesos argumentativos en el Bachillerato de LOGSE. Matemáticas I y II.

Tabla II.3.2.2. Referencias a la demostración o procesos argumentativos en el Bachillerato de LOGSE. Matemáticas aplicadas a las Ciencias Sociales I y II.

Tabla II.3.2.3. Referencias a la demostración o procesos argumentativos en Matemáticas I y II del Bachillerato de LOGSE en la modificación de 2001 del currículo de enseñanzas mínimas y el currículo completo estatal.

Tabla II.3.2.4. Referencias a la demostración o procesos argumentativos en Matemáticas I y II del currículo de Bachillerato de LOGSE en Castilla y León, en la modificación 2001

Tabla II.3.2.5. Referencias a la demostración o procesos argumentativos en el Bachillerato de LOGSE de Matemáticas aplicadas a las Ciencias Sociales I y II en el currículo de enseñanzas mínimas, en el currículo completo estatal y en el de Castilla y León en la modificación de 2001.

Tabla II.3.3.1. Referencias a la demostración o procesos argumentativos en Matemáticas I y II del Bachillerato de LOE en el currículo de enseñanzas mínimas, en el currículo completo estatal y en el currículo de Castilla y León.

Tabla II.3.3.2. Referencias a la demostración o procesos argumentativos en Matemáticas aplicadas a las Ciencias Sociales I y II del Bachillerato de LOE en el currículo de enseñanzas mínimas, en el currículo completo estatal y en el currículo de Castilla y León. 
Tabla II.4.1.1. Clasificación de los esquemas de prueba de los alumnos desarrollada por Ibañes y Ortega.......................................................................... 47

Tabla II.4.7.1. Resumen de las categorías de esquemas de prueba. ....................................... 63

Tabla II.4.7.2. Resumen de las categorías de técnicas empleadas........................................... 63

Tabla II.4.7.3. Resumen de las categorías de funciones............................................................... 63

Tabla II.4.7.4. Resumen de las categorías de reconocimiento de procesos. ......................... 64

Tabla II.4.7.5. Resumen de las categorías de expresiones que utiliza. ................................. 64

Tabla II.4.7.6. Resumen de las categorías de consideraciones globales. .............................. 64

Tabla III.2.1. Combinación de las fases de Ruiz-Berrio con las etapas de Fox para la metodología propia de la investigación...................................................6 68

Tabla III.2.1.1. Muestra de libros de texto localizados y analizados....................................... 72

Tabla IV.4.1.1. Resultados y justificaciones asociados al límite en los libros de texto

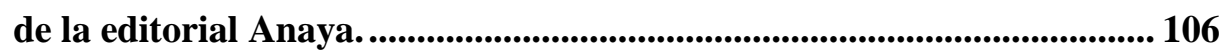

Tabla IV.4.1.2. Resultados y justificaciones asociados al límite en los libros de texto de la editorial Anaya.

Tabla IV.4.2.1. Resultados y justificaciones asociados al límite en los libros de texto de la editorial Santillana.

Tabla IV.4.2.2. Resultados y justificaciones asociados al límite en los libros de texto de la editorial Santillana.

Tabla IV.4.3.1. Resultados y justificaciones asociados al límite en los libros de texto de la editorial SM.

Tabla IV.4.3.2. Resultados y justificaciones asociados al límite en los libros de texto de la editorial SM.

Tabla IV.4.4.1. Resultados y justificaciones asociados al límite en los libros de texto de la editorial Vicens-Vives.

Tabla IV.4.4.2. Resultados asociados a cada esquema de prueba o prueba preformal en los libros de texto de la editorial Vicens-Vives.

Tabla IV.5.1. Tipos de definiciones de límites funcionales que se encuentran en los libros de texto analizados.

Tabla IV.5.2. Análisis de las justificaciones asociadas al teorema de caracterización en los LT de la LGE. 
Tabla IV.5.3. Análisis de las justificaciones asociadas al teorema de caracterización en los LT de la LOE...............................................................134

Tabla IV.5.4. Análisis de las justificaciones asociadas a la unicidad del límite en los LT de la LGE.

Tabla IV.5.5. Análisis de las justificaciones asociadas a la unicidad del límite en los LT de la LOGSE.

Tabla IV.5.6. Análisis de las justificaciones asociadas a la unicidad del límite en los LT de la LOE.

Tabla IV.6.1. Presentación (o no) de la suma y justificaciones utilizadas en los LT.....142

Tabla IV.6.2. Análisis de la justificación asociada al límite de la suma de funciones en los LT de $2^{\circ}$ de BUP de todas las editoriales.

Tabla IV.6.3. Análisis de la justificación asociada al límite de la suma de funciones ( $2^{\circ}$ de Bachillerato de Santillana, 1997).

Tabla IV.7.1.1. Análisis de la justificación asociada al límite del cociente de polinomios en un punto en el que ambos se anulan en los LT de $2^{\circ}$ de BUP de las editoriales Anaya y Santillana.

Tabla IV.7.1.2. Análisis de la justificación asociada al límite del cociente de polinomios en un punto en el que ambos se anulan en dos LT de LOGSE de las editoriales Anaya y Vicens-Vives.

Tabla IV.7.2.1. Análisis de la justificación asociada al límite del cociente de polinomios en el infinito en el período de la LGE ( $2^{\circ}$ de BUP de Santillana, 1976).

Tabla IV.7.2.2. Análisis de la justificación asociada al límite del cociente de polinomios en el infinito en LT del periodo LOGSE de las editoriales Anaya y Vicens-Vives.

Tabla IV.7.2.3. Análisis de la justificación asociada al límite del cociente de polinomios en el infinito ( $2^{\circ}$ de BUP de Santillana, 1976).

Tabla IV.7.3.1. Presencia de las funciones potenciales-exponenciales en los libros de texto.

Tabla IV.7.6.1. LT que consideran los infinitos o los infinitésimos equivalentes.

Tabla IV.7.7.1. Resultados relacionados con funciones trigonométricas y libros en los que se aparecen y se justifican.

Tabla IV.7.8.1. EP utilizados en los LT para justificar el límite de las funciones 
Tabla IV.8.1.1. Resumen del número de EP encontrados en los LT por legislaciones y cursos.

Tabla IV.8.1.2. Media de resultados justificados por libro en cada curso y periodo legislativo 185

Tabla IV.8.1.3. Media de resultados enunciados por libro en cada curso y periodo legislativo

Tabla IV.8.1.4. Número (y porcentaje) de resultados de cada tipo que son justificados.

Tabla V.4.1.1. Resultados y justificaciones asociados a la continuidad en los libros de texto de la editorial Anaya.

Tabla V.4.1.2. Resultados y justificaciones asociados a la continuidad en los libros de texto de la editorial Anaya.

Tabla V.4.2.1. Resultados y justificaciones asociados a la continuidad en los libros de texto de la editorial Santillana.

Tabla V.4.2.2. Resultados y justificaciones asociados a la continuidad en los libros de texto de la editorial Santillana.

Tabla V.4.3.1. Resultados y justificaciones asociados a la continuidad en los libros de texto de la editorial SM.

Tabla V.4.3.2. Resultados y justificaciones asociados a la continuidad en los libros de texto de la editorial SM.

Tabla V.4.4.1. Resultados y justificaciones asociados a la continuidad en los libros de texto de la editorial Vicens-Vives.

Tabla V.4.4.2. Resultados y justificaciones asociados a la continuidad en los libros de texto de la editorial Vicens-Vives.

Tabla V.5.1. Caracterizaciones de la continuidad en los LT. Utilización de gráficas.

Tabla V.5.2. LT que justifican resultados asociados a las operaciones con límites $y$ a la continuidad de funciones elementales.

Tabla V.6.1.1. Título del teorema, del epígrafe y enunciado para el teorema de Bolzano en los LT de COU de la LGE.

Tabla V.6.1.2. Título del teorema, del epígrafe y enunciado para el teorema de Bolzano en los LT de $2^{\circ}$ de Bachillerato de la LOGSE. 
Tabla V.6.1.3. Título del teorema, del epígrafe y enunciado para el teorema de Bolzano en los LT de $2^{\circ}$ de Bachillerato de la LOE.

Tabla V.6.1.4. Título del teorema, del epígrafe y enunciado para el teorema de Weierstrass en los LT de $2^{\circ}$ de Bachillerato de la LGE.

Tabla V.6.1.5. Título del teorema, del epígrafe y enunciado para el teorema de Weierstrass en los LT de $2^{\circ}$ de Bachillerato de la LOGSE. . .253

Tabla V.6.1.6. Título del teorema, del epígrafe y enunciado para el teorema de Weierstrass en los LT de $2^{\circ}$ de Bachillerato de la LOE.

Tabla V.6.1.7. Título del teorema, del epígrafe y enunciado para el teorema de Darboux en los LT de $2^{\circ}$ de Bachillerato de la LGE

Tabla V.6.1.8. Título del teorema, del epígrafe y enunciado para el teorema de Darboux en los LT de $2^{\circ}$ de Bachillerato de la LOGSE.

Tabla V.6.1.9. Título del teorema, del epígrafe y enunciado para el teorema de Darboux en los LT de $2^{\circ}$ de Bachillerato de la LOE.

Tabla V.6.1.1.1. Análisis de las justificaciones utilizadas en los LT de LGE para el teorema de los ceros de Bolzano.

Tabla V.6.1.1.2. Análisis de las justificaciones utilizadas en los LT de LOGSE para el teorema de los ceros de Bolzano.

Tabla V.6.1.1.3. Análisis de las justificaciones utilizadas en los LT de LOE para el teorema los ceros de Bolzano.

Tabla V.6.1.1.4. EP reflejados en los LT de la muestra para el teorema de los ceros de Bolzano

Tabla V.6.1.2.1. Análisis de las justificaciones utilizadas en los LT de LGE para el teorema de los valores extremos de Weierstrass.

Tabla V.6.1.2.2. Análisis de las justificaciones utilizadas en los LT de LOGSE para el teorema de los valores absolutos de Weierstrass

Tabla V.6.1.2.3. Análisis de las justificaciones utilizadas en los LT de LOE para el teorema de los valores absolutos de Weierstrass

Tabla V.6.1.2.4. EP reflejados en los LT de la muestra para el teorema de los valores absolutos de Weierstrass.

Tabla V.6.1.3.1. Análisis de las justificaciones utilizadas en los LT de LGE para el teorema de los valores intermedios de Darboux. 
Tabla V.6.1.3.2. Análisis de las justificaciones utilizadas en los LT de LOGSE para el teorema de los valores intermedios de Darboux

Tabla V.6.1.3.3. Análisis de las justificaciones utilizadas en los LT de LGE para el teorema de los valores intermedios de Darboux

Tabla V.6.1.3.4. EP reflejados en los LT de la muestra para el teorema de los valores intermedios de Darboux.

Tabla V.6.2.1. Otros teoremas relacionados con la continuidad que se justifican en los LT.

Tabla V.6.2.2. LT que justifican los resultados enunciados en la Tabla V.6.2.1.

Tabla V.7.1.1. Resumen del número de EP encontrados en los LT por legislaciones y cursos.

Tabla V.7.1.2. Media de resultados justificados por libro en cada curso y periodo legislativo

Tabla V.7.1.3. Media de resultados enunciados por libro en cada curso y periodo legislativo.

Tabla V.7.1.4. Número (y porcentaje) de resultados de cada tipo que son justificados.

Tabla VI.1.1. Número de teoremas de límites y continuidad enunciados, de EP presentados y de ellos, EP axiomáticos y transformacionales, por cursos y el total por legislaciones.

Tabla VI.1.2. Medias de EP de los teoremas de límites y continuidad en los LT por curso y por legislaciones.

Tabla VI.2.1.1. Contenidos, criterios de evaluación y estándares de aprendizaje en torno al límite en el currículo de Bachillerato de LOMCE.

Tabla VI.2.1.2. Contenidos, criterios de evaluación y estándares de aprendizaje en torno a la continuidad en el currículo de Bachillerato de LOMCE.

Tabla VI.2.2.1. Ejemplo de tabla para el cálculo numérico del límite de una función en un punto, aplicando la definición.

Tabla A1.1. Libros de texto pertenecientes al periodo LGE.

Tabla A1.2. Libros de texto pertenecientes al periodo LOGSE 350

Tabla A1.3. Libros de texto pertenecientes al periodo LOE. 350 


\section{SIGLAS Y ABREVIATURAS}

AM Análisis Matemático

APA American Psychological Association

Aprox. Aproximación

Bach. Bachillerato

BUP Bachillerato Unificado Polivalente

c. signo Conservación de signo

CERME $99^{\text {th }}$ Congress of European Research in Mathematics Education

CN Condición necesaria

CNS Condición necesaria y suficiente

Coord. Coordinador

Coords. Coordinadores

COU Curso de Orientación Universitaria

CS Condición suficiente

CSi $\quad$ Se refiere a sus consecuencias

DEJ Distingue entre el enunciado y la justificación

Ed. Editor 
Eds. Editores

EP Esquema de prueba

EP0 No hay justificación

EPa EP axiomático

EPi1 EP inductivo de 1 caso

EPiS EP inductivo sistemático

EPiV EP inductivo de varios casos

EPt EP transformacional

ES Existencia simple

Exp Expresiones

Figs. $\quad$ Figuras

GEAMJA Grupo de enseñanza del Análisis Matemático de Jaén

GIDAM Grupo de Investigación de Didáctica del Análisis Matemático

GP Explica globalmente el proceso

I Imposibilidad

LGE Ley General de Educación

LOCE Ley Orgánica de Calidad de la Educación

LOE Ley Orgánica de Educación

LOGSE Ley de Ordenación General del Sistema Educativo

LOMCE Ley Orgánica para la Mejora de la Calidad Educativa

LT Libro de texto

NCTM National Council of Teachers of Mathematics

NE No existencial

OCDE Organización para la Cooperación y el Desarrollo Económicos

OV Señala otras posibles vías de justificación

PIAAC Programa internacional para la evaluación de las competencias de 
la población adulta

PISA Programa para la evaluación internacional de los alumnos

PME International Group for the Psychology of Mathematics Education

PP Prueba preformal

pp. Páginas

RA Reducción al absurdo

RC Se refiere a sus consecuencias

RD Real Decreto

REBIUN Red de Bibliotecas Universitarias Españolas

RP Reflexiona sobre el procedimiento (RP);

Sant. Santillana

SEIEM Sociedad Española de Investigación en Educación Matemática

sg Signo

Sig Explica su significado

SR Sistemas de representación

TD Tesis doctoral

TM Tesis de maestría

trad. Traducción

U Unicidad

USA United States of America

Valor abs. Valor absoluto

VV Vicens-Vives 



\section{CAPÍTULO 0}

\section{INTRODUCCIÓN}

Desde el punto de vista matemático, la demostración matemática es considerada uno de los procedimientos más importantes de las matemáticas, su motor de desarrollo. En el campo de la educación matemática, Hanna (1995) defiende que contribuye a la comprensión de los conceptos matemáticos. Además, la demostración matemática es portadora de los conocimientos matemáticos, ya que contiene los métodos, herramientas, estrategias y conceptos que se necesitan para resolver problemas, y éstos elementos suponen la esencia principal de las matemáticas (Hanna y Barbeau, 2010).

Entendiendo que es un elemento de las matemáticas de vital importancia, nos interesa conocer cómo se realiza su enseñanza en la educación preuniversitaria y, para ello, se analizará cómo es tratada en los libros de texto por ser éstos uno de los elementos más importantes en los procesos de enseñanza-aprendizaje en este nivel educativo. Entendemos como libro de texto (LT), manual escolar o libro escolar los libros que utilizan los profesores y alumnos, a lo largo de un curso escolar, en el proceso de enseñanza-aprendizaje de un área de conocimiento (González, 2002). Se le atribuyen diferentes funciones: simbólica, pedagógica, social, ideológica y política, y cómo defiende Schubring (1987), los libros de texto, en la práctica, determinan la enseñanza de un país más que los decretos de los distintos gobiernos, ya que considera que tienen mayor influencia en la práctica educativa que los currículos educativos promulgados por las órdenes 
ministeriales. Además, su análisis nos proporciona información acerca del conocimiento matemático que una sociedad considera pertinente en un determinado momento histórico (González, 2002), ya que influyen en qué y cómo deben aprender los alumnos (García-Rodeja, 1997).

A lo largo de los años las investigaciones realizadas en torno a estos elementos han sido muy numerosas: sobre la DM, los trabajos de De Villiers (1993), Harel \& Sowder (1998), Hanna (1989, 1990), Balacheff (1987), Bell (1976) o van Asch (1993) sobre la enseñanza y el aprendizaje de la demostración, las funciones de la demostración, niveles de demostración e investigaciones sobre la demostración en el aula, y en España los trabajos de Ibañes y Ortega $(1997,2004)$ y Dos Santos (2010) sobre los esquemas de prueba y, en torno a los LT, los de González (2002), Herdeiro (2010), López (2011) o Monterrubio y Ortega (2012). Sin embargo, no existen apenas investigaciones en las que se conjuguen ambos elementos, la demostración matemática y los libros de texto.

A raíz de los trabajos de Ibañes (2001) e Ibañes y Ortega (2001b) sobre los esquemas de prueba (EP) de los alumnos hemos decidido realizar un análisis de cómo aparece tratada la demostración en los LT, y responder a los siguientes interrogantes: ¿qué importancia conceden los LT a las demostraciones matemáticas? Cuando no se demuestra, ¿qué tipo de justificaciones aparecen? ¿Qué función tienen las demostraciones en los LT? ¿Cómo ha evolucionado la demostración con los sucesivos cambios recientes de legislación?

El trabajo que aquí se presenta muestra un análisis del tratamiento que hacen los LT sobre las demostraciones en límites y continuidad en los últimos currículos de $2^{\circ}$ de BUP y COU de la Ley General de Educación (LGE, Jefatura del Estado, 1970) de 1970 y el Bachillerato de la Ley de Ordenación General del Sistema Educativo (LOGSE, Jefatura del Estado, 1990) de 1990 y de la Ley Orgánica de Educación (LOE, Jefatura del Estado, 2006) de 2006. El objetivo principal de éste trabajo de investigación es determinar la evolución de la demostración en los LT de los cursos citados, clasificar los EP utilizados según el modelo de Ibañes y Ortega (2001) y determinar los procesos de enseñanza de las matemáticas a través de los LT en relación con las pruebas de los teoremas.

Para realizar este trabajo de investigación se ha utilizado una metodología desarrollada "ad hoc" en la que se combinan el método histórico de investigación en educación de Ruiz-Berrio (1976) y el modelo de fases de investigación 
educativa de Fox (1981). En la última fase de nuestra metodología se incluye la elaboración de la presente memoria, en la que se recoge todo el trabajo de investigación desarrollado y los elementos que intervienen en él.

En el capítulo I de este trabajo se presenta la revisión bibliográfica relacionada con los elementos centrales de nuestro trabajo: en primer lugar, los estudios relacionados con la demostración matemática y otros procesos de justificación, y que luego darán lugar al marco teórico que nos permite realizar el análisis de los libros de texto; en segundo lugar, los estudios relacionados con el libro de texto, especialmente aquellos realizados en el ámbito de las matemáticas; en tercer lugar, una especial mención a las investigaciones y los trabajos que conjugan ambos elementos, la demostración matemática y los libros de texto, aunque no son muy abundantes; finalmente, en los últimos apartados se considera una breve revisión de las investigaciones en torno a los conceptos matemáticos de los que hemos realizado el análisis de las justificaciones: los límites y la continuidad.

En el capítulo II se incluyen los objetivos y las hipótesis de investigación y el marco teórico desarrollado para nuestro trabajo. Se han considerado estos elementos en el mismo capítulo debido a que los objetivos e hipótesis, unidos a algunos de los referentes bibliográficos mencionados anteriormente dan lugar al desarrollo de nuestro marco teórico (esquemas de prueba, pruebas preformales, funciones de la demostración...) El marco teórico se ha descrito detalladamente y se ha acompañado de ejemplos para facilitar una clara comprensión de las categorías de análisis consideradas así como una replicabilidad del estudio a otros conceptos o en otros libros de texto.

En el capítulo III se describe la metodología desarrollada para nuestro trabajo y que mencionamos anteriormente, así como la determinación de la muestra que hemos analizado, la descripción de las diversas etapas de desarrollo del trabajo de investigación y algunos apuntes curriculares sobre la demostración.

En los capítulos $I V$ y $V$ se recogen los análisis de las justificaciones de los dos conceptos matemáticos considerados: el análisis correspondiente al límite funcional en el capítulo $I V$, y el correspondiente a la continuidad en el capítulo $V$. Ambos capítulos siguen una estructura similar, aunque con algunas adaptaciones internas a las características de los datos encontrados en cada caso. En líneas generales se presentan los siguientes apartados: introducción, apunte curricular sobre el concepto matemático analizado (límites o continuidad), 
descripción de la presentación del concepto en los libros de texto, un primer análisis cuantitativo de los resultados presentados y justificados en cada libro, un análisis más extenso de las justificaciones utilizadas atendiendo al marco teórico descrito en el capítulo 2, la discusión e interpretación de los datos y las conclusiones del capítulo.

Por último, en el capítulo VI se presentan las conclusiones finales del trabajo, una propuesta didáctica, las aportaciones de la investigación, dificultades y fortalezas que han surgido en el proceso y perspectivas de futuro

El siguiente esquema representa una síntesis de la memoria de la tesis doctoral:

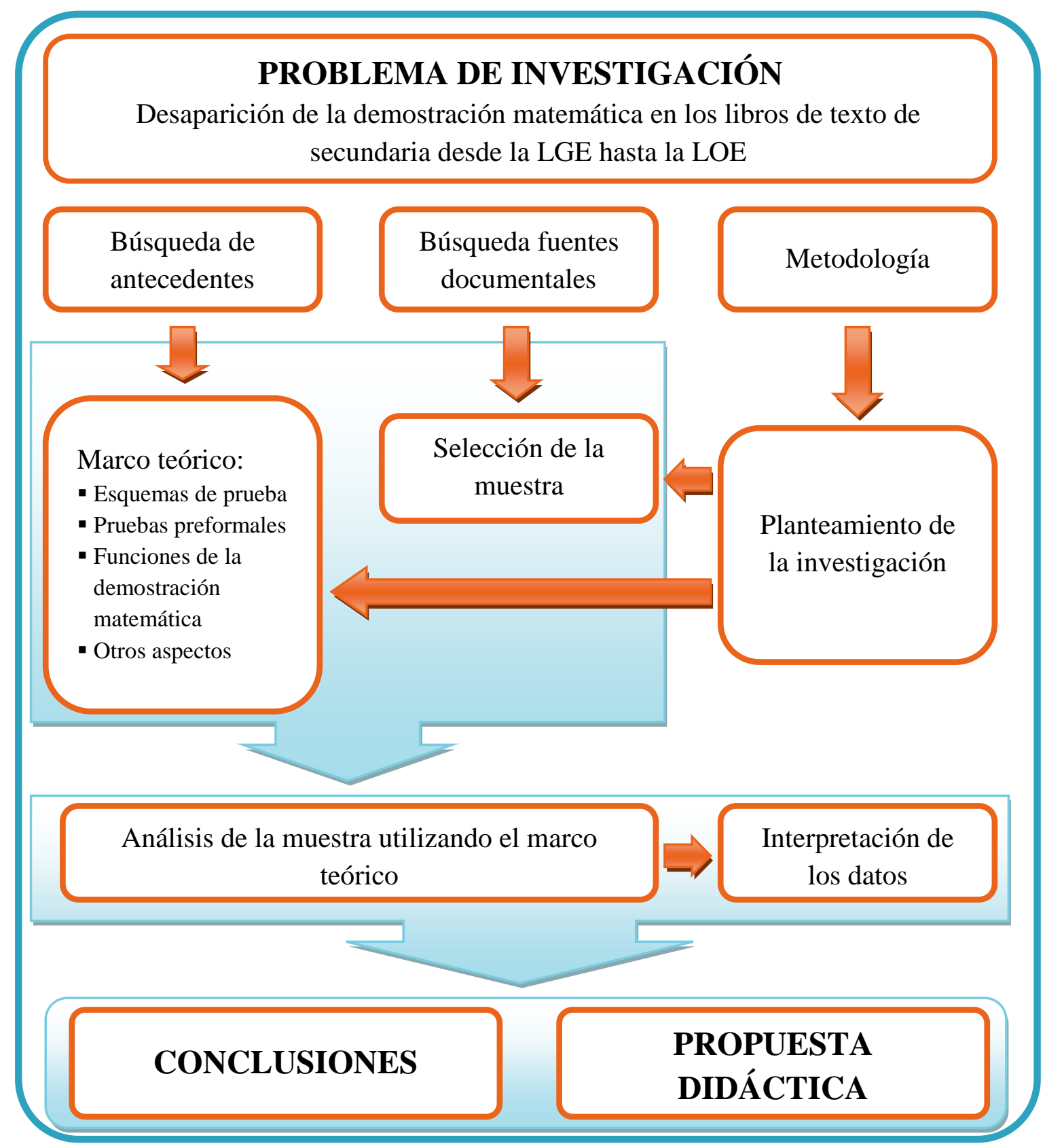




\section{CAPÍTULO I}

\section{ANTECEDENTES DE LA INVESTIGACIÓN}

\section{I.1. INTRODUCCIÓN}

En el presente capítulo se describen diferentes estudios relacionados con los dos ejes principales de este trabajo, la demostración matemática y los libros de texto, y con los conceptos que hemos seleccionado para el análisis, el límite funcional y la continuidad. Si bien el número de estudios realizados a nivel internacional en torno a los dos ejes principales del trabajo y a los dos conceptos analizados es realmente extenso, el presente capítulo se centra en aquellos estudios que han marcado notablemente este trabajo, o que están íntimamente ligados a esta investigación. En el primer apartado se describen los estudios relacionados con la demostración matemática, en el segundo, con el libro de texto, en el tercero, aquellos que integran los dos elementos anteriores y en el último, los estudios sobre el límite y la continuidad.

\section{I.2. INVESTIGACIONES EN TORNO A LA DEMOSTRACIÓN MATEMÁTICA}

Se considera que la demostración matemática es uno de los procedimientos más importantes de las matemáticas $\mathrm{y}$, sin duda, ella tiene poder de incorporar los nuevos descubrimientos que se producen en esta ciencia, posee la capacidad de 
aceptación o rechazo de conjeturas que, por muy plausibles que sean, no formaran parte real de las matemáticas mientras que no se haya establecido una demostración de las mismas. En el campo de las matemáticas, su definición no es trivial, ya que depende en gran medida de las épocas, de los avances de esta ciencia, de las corrientes ligadas a los descubrimientos e, incluso, de las distintas áreas de conocimiento que la matemática. Por ejemplo, desde el punto de vista de una definición formal, Bourbaki (1970) la describe como teoría que comprende términos y relaciones siguiendo unas determinadas reglas, Bouvier y George (1984) explicitan las significaciones de la demostración formal del cálculo de predicados y de la demostración formal del cálculo de proposiciones, así como otros ejemplos que se encuentran descritos en Ibañes y Ortega (2005). Desde el punto de vista de la Didáctica de la Matemática el interés se centra en otros aspectos de la demostración, como pueden ser los niveles o las funciones de la demostración (Bell, 1976, de Villiers, 1993). Tal y como defienden Ibañes y Ortega (2002a), se considera que el principal valor de la demostración es el de su función de explicación, aunque no sea único, y que ésta puede ser sustituida por otro tipo de pruebas. Además, siguiendo las ideas de Hanna (1995), la demostración matemática contribuye a la comprensión de los conceptos matemáticos y, de acuerdo con Hanna y Barbeau (2010), la demostración matemática es portadora de los conocimientos matemáticos, ya que contiene los "métodos, herramientas, estrategias y conceptos que se necesitan para resolver problemas" (Rav, 1999, p. 6), y éstos elementos suponen la esencia principal de las matemáticas.

A lo largo de los años, numerosos autores han realizado múltiples estudios desde diversas perspectivas: sobre sus funciones, sobre los elementos que la componen, sobre tipos de justificación, sobre la enseñanza y el aprendizaje de la demostración matemática, sobre experiencias de aula,... Se trata de un campo de investigación tan amplio que resultaría imposible describir en este trabajo todos los estudios que se han realizado sobre el tema, así que sólo se señalan aquellos que son más relevantes o que están más relacionados con este trabajo.

El punto de partida de este trabajo lo proporciona la tesis doctoral de Ibañes (2001), y los estudios posteriores que continuaron su investigación (Ibañes y Ortega, 2001a, 2001b, 2002a, 2002b, 2004, 2005). En ellos, los autores realizan un estudio detallado de los esquemas de prueba que poseen los alumnos de $1^{\circ}$ de Bachillerato, basándose en el concepto de esquema de prueba creado por Harel \& 
Sowder (1998). Aparte de este elemento, consideran otros aspectos de la demostración, como las técnicas utilizadas (Ibañes y Ortega, 1997), las funciones de la demostración (Bell, 1976; de Villiers, 1993), y otros aspectos generales que les lleva a desarrollar una serie de categorías de análisis de la demostración matemática (u otros procesos de justificación) bastante exhaustiva. A partir de sus trabajos sobre los esquemas de prueba de los alumnos, realizan algunos análisis sobre libros de texto (Ibañes y Ortega, 2002b), en el que aplican sus categorías de análisis a los resultados de trigonometría que aparecen en los libros de $1^{\circ}$ de Bachillerato vigentes en esa época, hecho que constituye un nuevo formato de análisis. Dichas categorías de análisis supusieron el origen del marco teórico que se ha considerado en la presente investigación. Este nuevo marco, adaptado a las necesidades de la investigación que se realiza, se describirá en el capítulo II, apartado 4 de la presente memoria.

No obstante, si bien este trabajo se centra en los antecedentes anteriormente descritos, se han realizado numerosos estudios en torno a la demostración matemática desde la perspectiva de la didáctica de la Matemática. Ibañes (2001) proporciona una amplia visión de los trabajos realizados en torno a la demostración matemática hasta entonces. Este autor los clasifica en cuatro grandes grupos o líneas de investigación: investigaciones en torno al aprendizaje de la demostración, investigaciones en torno a las funciones de la demostración, investigaciones que definen niveles de demostración e investigaciones sobre la demostración en el aula. Siguiendo este esquema, se han comentado brevemente los trabajos que el propio Ibañes describe, y algunos posteriores que encajan en esta clasificación y que también tienen influencia en nuestro trabajo. Además, se ha incorporado una nueva categoría en la que se mencionan los trabajos sobre argumentación, que sin versar sobre la demostración matemática propiamente dicha, son muy próximos a ésta.

- Trabajos generales sobre la enseñanza y el aprendizaje de la demostración.

En este apartado incluye las investigaciones que exponen una visión general de la demostración en la educación matemática: Lakatos (1978), Kitcher (1983), Arsac (1988), Alibert y Thomas (1991), Hanna (1989, 1990, 2010), Ibañes y Ortega (2002b, 2004b), Camargo y Gutiérrez (2010), Dos Santos (2010), González (2012). Es evidente que Lakatos (1978), con su discurso sobre las pruebas 
matemáticas, es el punto de partida de otros trabajos. Así, Kitcher (1983) sugiere que la primera influencia para el convencimiento de la veracidad de un enunciado procede de percepciones externas, Arsac (1988) hace una revisión sobre las investigaciones realizadas sobre la demostración y Alibert y Thomas (1991) proponen alternativas a la demostración matemática. Ibañes destaca a Hanna, quien defiende que en la aceptación de un teorema es más importante el significado global, la comprensión del resultado y los conceptos subyacentes que la existencia de una demostración rigurosa. Enuncia una serie de factores para la aceptación de un teorema: comprensión, relevancia, reputación y existencia de un argumento convincente. Además, mantiene que el papel que desempeña la demostración en matemáticas es tan importante que ella debe formar parte de cualquier currículo. En Ibañes y Ortega (2002b, 2004b), además, se encuentran sendos análisis de la demostración en los libros de texto de $1^{\circ}$ de Bachillerato en torno a los teoremas relacionados con la Trigonometría y, como ya se ha indicado, el marco teórico que han considerado ha servido como punto de partida del que aquí se presenta y las conclusiones de estos trabajos nos han orientado para la realización de éste que trabajo. En Camargo y Gutiérrez (2010), que proponen una "vía metodológica para analizar el aprendizaje de la demostración matemática en un grupo de estudiantes como participación en una comunidad de práctica de clase (Clark, 2005)", visto desde la perspectiva de la teoría de la práctica social de Wenger (1998), se encuentran referencias a trabajos anteriores sobre la enseñanza y el aprendizaje de la demostración, desde diferentes perspectivas, con estudiantes de matemáticas o con futuros profesores de matemáticas (Cañadas y Castro, 2003; de la Torre, 2003; Cobo y otros, 2005; Vicario y Carrillo, 2005; Fiallo y Gutiérrez, 2006, 2007).

\section{- Trabajos sobre las funciones de la demostración.}

Bell (1976), Hersh (1993), De Villiers (1993, 2007, 2012), Reid (1996), Ibañes y Ortega (2001b, 2002a, 2002b), Dos Santos (2010). Hersh (1993) contrapone el convencimiento como finalidad primordial de la demostración en la investigación matemática frente a la explicación como fin de la demostración en el aula, teniendo como misión clarificar por qué el teorema es verdad. Por su parte, Reid (1996), pretende conciliar los puntos de vista de los estudiantes y de los profesionales de las matemáticas sobre la demostración, argumentando, por 
ejemplo, que la demostración no establece la certeza absoluta o que los estudiantes usan las demostraciones para explicar. Aunque su fin primordial siempre se ha considerado como verificar la proposición objeto de estudio, Bell (1976) establece tres funciones principales para la demostración matemática (verificación o justificación, iluminación y sistematización) y que son completadas por de Villiers (1993), quien asigna cinco funciones a la demostración: verificación, explicación (profundización en porque es verdad), sistematización, descubrimiento (nuevos resultados), comunicación (transmisión de conocimiento matemático). Estas funciones son las que consideran Ibañes (2001) en su tesis doctoral e Ibañes y Ortega (2001, 2002a, 2002b) en sus estudios posteriores, y que se han mantenido porque se considera que puede aportar una visión interesante en el análisis de las pruebas matemáticas que presenten los libros de texto. También Dos Santos (2010) las incluye en su marco teórico, aunque en su caso estudia la demostración matemática desde el punto de vista del profesor. Nosotros coincidimos con Ibañes y Ortega (2001) que defienden que, en la docencia, uno de los principales valores de la demostración es el de su función de explicación, aunque no sea el único procedimiento para justificar un teorema, ya que éstas pueden ser sustituidas por otro tipo de pruebas.

En este mismo sentido, sobre la función de explicación, Dolev \& Even (2015) defienden que el papel de la demostración matemática en las matemáticas escolares es el de explicar, dar a conocer, y avanzar en la comprensión y en el aprendizaje significativo. Según Dolev \& Even (2015) ha habido otros autores (Arcavi, 2003; Balacheff, 1988; Dreyfus, 1999; Hanna 1990, 2000; Hersh, 1993; Mariotti, 2006; Yackel \& Hanna, 2003), que publicaron sus trabajos mucho antes $\mathrm{y}$, de una $\mathrm{u}$ otra forma, también consideran que la función explicativa proporciona un aprendizaje más significativo. Pero estos autores también defienden la idea de utilizar otros tipos de justificación diferentes como alternativa a las pruebas formales, precisamente, por su valor explicativo.

\section{- Trabajos sobre niveles de demostración.}

Son muchos los autores que han realizado investigaciones sobre niveles de la demostración matemática, más propiamente de pruebas matemáticas que van desde las más intuitivas hasta las axiomáticas: Bell (1979), Van Dormolen (1977), Balacheff (1987), Blum and Kirsch (1991), Van Asch (1993), Harel \& 
Sowder (1998, 2007), Ibañes y Ortega (1997, 2005), Mizayaki (2000), Stacey \& Vincent (2009), Harel \& Rabin (2010), Dolev \& Even (2015)... Bell (1979) distingue tres dimensiones en el desarrollo de la comprensión y el uso de las demostraciones; Van Dormolen (1977), siguiendo la teoría de van Hiele, también distingue tres niveles de demostración correspondientes a los niveles de abstracción en los que trabaja el alumno; Balacheff (1987) distingue entre pruebas pragmáticas, pruebas intelectuales y demostraciones; Blum y Kirsch (1991) distinguen tres niveles de pruebas: demostraciones (pruebas), demostraciones pre-formales, y demostraciones formales; Miyazaki (2000) establece seis niveles entre las pruebas inductivas y las demostraciones algebraicas, en el ámbito de la Lower Secondary School en Japón (13-15 años). Para esta investigación, el punto de partida es la tesis doctoral de Ibañes (2001), quien destaca el estudio inicial de Harel \& Sowder (1998), de los cuales toma la noción de esquema de prueba, como aquello que constituye certeza y persuasión para una persona, y a partir de la clasificación propuesta por ellos, establece unas categorías para la clasificación de los esquemas de prueba que nos resultarán útiles en nuestro análisis. La clasificación de Harel \& Sowder (1998, 2007), ha servido como punto de partida a otros trabajos que la han desarrollado. Es el caso de Stacey \& Vincent (2009), que realizan un análisis de los modos de razonamiento que se encuentran en las explicaciones presentadas en libros de textos australianos de octavo curso (13-14 años). Estos autores comparan diversas clasificaciones de tipos de justificación, como los esquemas de prueba de Harel \& Sowder mencionados anteriormente; los niveles de demostración en un contexto educativo de Blum \& Kirsch (1991), que los clasifican en verificaciones experimentales, pruebas pre-formales y pruebas formales; y la distinción de Sierpinska (1994) entre explicaciones científicas y explicaciones didácticas, indicando que las segundas deben complementar a las primeras en un entorno escolar. Por su parte, Stacey \& Vincent consideran una clasificación que, según indican, es cercana a la de EP de Harel \& Sowder, pero que han preferido denotar "modos de razonamiento" debido a que consideran que los libros de texto no reflejan realmente si el razonamiento presentado convence o no al autor, sino que puede haberse considerado únicamente con un fin didáctico. Las categorías que consideran son las siguientes: llamada a la autoridad, analogía cualitativa, concordancia de una regla con un modelo, demostración 
experimental, deducción usando un modelo, deducción usando un caso específico y deducción usando un caso general.

Además, tal y como indican Dolev \& Even (2015), considerar otros tipos de demostración distintos a las formales es algo valorado en las matemáticas escolares, ya que, como indican las investigaciones que citan (Baker, 2003; Ball \& Bass, 2003; Krummheuer, 1995; Schwarz, Hershkowitz \& Prusak, 2010; Yackel \& Cobb, 1996; Yackel \& Hanna, 2003), la participación en actividades argumentativas, que anime a los estudiantes a justificar sus ideas e hipótesis, favorece la comprensión significativa y el pensamiento profundo.

\section{- Trabajos sobre la demostración en el aula.}

Es evidente que los textos matemáticos están relacionados con las actividades que se desarrollan en las aulas y las pruebas matemáticas constituyen parte de esas actividades. En la literatura aparecen numerosos investigadores que han tratado el tema desde diferentes perspectivas: Bell (1976), Galbraith (1981), Fishbein (1982), Martin y Harel (1989), Hanna (1990), Bero (1994), Ibañes y Ortega (2001, 2002a, 2002b), Pfeiffer (2010), Stylianides \& Al-Murani (2010), Dos Santos (2010), Mariotti (2012), González (2012), Dos Santos y Ortega (2013), Mills (2014).

Por ejemplo, Galbraith (1981) relata una investigación con alumnos de Secondary School en Australia cuya finalidad es estudiar la comprensión que tienen los estudiantes sobre algunos objetos matemáticos relacionados con la explicación y la demostración; Pfeiffer (2010) investiga la evaluación de demostraciones y la comparación con otras pruebas matemáticas alternativas de los alumnos de primer año de universidad; Stylianides \& Al-Murani (2010) estudian la existencia de un posible error conceptual de los alumnos que consideran que existen demostraciones y contraejemplos para la misma aserción; Mariotti (2012) discute sobre la adecuación de los software de Geometría dinámica para introducir a los estudiantes al pensamiento teórico, especialmente en la demostración; Bero (1994) propone seis etapas basadas en la investigación sobre la comprensión y el uso de las pruebas deductivas para evaluar las habilidades de los estudiantes en la demostración; Martin y Harel (1989) describen una experiencia con alumnos de magisterio de la Universidad de Illinois (USA) en la que se les solicitó decidir sobre la corrección de 
verificaciones inductivas y deductivas de determinadas proposiciones. Estos autores descubrieron importantes deficiencias de los alumnos sobre reconocimiento, distinción, veracidad y falsedad de los "esquemas de prueba". Ibañes y Ortega (2001, 2002a, 2002b) describen como los alumnos de $1^{\circ}$ de Bachillerato están en un estado de transición entre los esquemas de prueba inductivos de un caso y los axiomáticos y ello influye en la comprensión de enunciados de los teoremas y en la distinción de procesos. Dos Santos y Ortega (2013) describen perfiles de profesorado sobre la enseñanza y uso de la demostración matemática. Mills (2014) realiza un estudio de los ejemplos que utilizan cuatro instructores en sus justificaciones. Nosotros queremos subrayar a González (2012), que realiza un estudio de contraste sobre las preferencias de los alumnos sobre pruebas formales y pruebas preformales, el cuál toma la idea de "prueba preformal" (PP) de van Asch (1993), y que se ha incluido en el marco teórico considerado en este trabajo.

\section{- Trabajos sobre la argumentación}

Aunque no consideran exclusivamente la demostración matemática, existen otros trabajos relacionados íntimamente con ésta como son los que versan sobre la argumentación: Crespo (2005), Lin (2005), Ibañes y Ortega (2004a) Pedemonte (2005), Goizueta y Planas (2012). Por ejemplo, Ibañes y Ortega relacionan la argumentación con la persuasión, el convencimiento y la explicación Goizueta y Planas analizan las argumentaciones realizadas por profesores de educación secundaria, aunque ubican la argumentación entre la explicación y la demostración, siguiendo el ejemplo de Gutiérrez (2005).

Por último, para completar la información relacionada con la demostración matemática, se considera que puede ser de interés consultar algunos trabajos en los que se recoge una recopilación de estudios realizados en torno a la demostración matemática. Un ejemplo de estos trabajos es el desarrollado por Fiallo, Camargo y Gutiérrez (2013), que realizan una recopilación bibliográfica de investigaciones acerca de la enseñanza y el aprendizaje de la demostración. Para ello, las han agrupado en diferentes líneas de investigación: consideraciones histórico-epistemológicas de la demostración, la demostración en el currículo, las concepciones y dificultades de los estudiantes al demostrar, las relaciones entre 
argumentación y demostración y propuestas didácticas para la enseñanza de la demostración.

Otro ejemplo de trabajo recopilatorio interesante en el desarrollo de investigaciones en torno a la demostración matemática es el trabajo de Mariotti (2006), que presenta una recopilación de estudios presentados durante 30 años en los congresos del International Group for the Psychology of Mathematics Education (PME). En su trabajo, Mariotti organiza la discusión en torno a tres categorías: las demostraciones en el colegio, las dificultades de los estudiantes en torno a la demostración y las intervenciones de los profesores para resolver dichas dificultades. También tienen en cuenta la perspectiva epistemológica desde la que realiza la discusión de los trabajos que describe, lo que permite conocer la posición de la autora con respecto a ellos.

\section{I.3. INVESTIGACIONES EN TORNO AL LIBRO DE TEXTO}

Se entiende como libro de texto (LT), manual escolar o libro escolar los libros que utilizan los profesores y alumnos, a lo largo de un curso escolar, en el proceso de enseñanza-aprendizaje de un área de conocimiento (González, 2002). Se le atribuyen diferentes funciones: simbólica, pedagógica, social, ideológica y política, y cómo defiende Schubring (1987), los libros de texto, en la práctica, determinan el currículo de enseñanza más que los decretos de los distintos gobiernos, ya que considera que tienen mayor influencia en la práctica educativa que las órdenes ministeriales. Además, su análisis proporciona información acerca del conocimiento matemático que una sociedad considera pertinente en un determinado momento histórico (González, 2002), ya que influyen en qué y cómo aprenden los alumnos (García-Rodeja, 1997). Está idea también se apunta en Dolev \& Even (2015). Como indican las autoras, las investigaciones realizadas en diferentes países sugieren que los materiales curriculares, y en especial los libros de texto, influencian la práctica educativa. Además, afirman que, si bien la investigación ha mostrado que el currículo promulgado no es el mismo que el que escrito, y que los profesores lo interpretan al llevarlo a cabo de diferentes formas, los libros de texto de matemáticas son frecuentemente la 
principal fuente que utilizan los profesores para planificar las lecciones, para elegir los contenidos a enseñar y las actividades a realizar.

López (2011), en su tesis doctoral, en la que analiza manuales y libros de texto para la formación de maestros, recoge distintas investigaciones realizadas sobre el libro de texto. La autora indica que las investigaciones generales que encontramos en torno a este elemento son numerosas, pero no tanto desde el punto de vista de la Didáctica de la Matemática. Dentro de las investigaciones generales sobre el LT se encuentran las que consisten en la búsqueda de situaciones comunicativas dentro del aula, aunque de manera ficticia y como fuente de investigación histórica. Entre los autores que han realizado este tipo de investigaciones podemos encontrar a Carroll (1980), Petitjean (1982), la Commission Pédagogie du Texte (1985a, 1985b), Perelman (1986), Mansfield (1993), Calsamiglia (1994) o Camps (1994a, 1994b, 1998). No obstante, aunque este tipo de investigaciones son numerosas, apenas se han realizado trabajos en matemáticas, según Choppin (1993), debido a dos razones: por la falta de formación matemática de los historiadores o por el escaso interés de los matemáticos por ese tema.

Dentro de las investigaciones de corte general, en España se puede destacar el Proyecto MANES, desarrollado por la UNED, y cuyo objetivo es la investigación de los manuales escolares producidos en España, Portugal y América Latina entre los años 1808 y 1990.

En cuanto a las investigaciones realizadas en el contexto de la Educación Matemática hay que destacar a Schubring (1987), que estudia la evolución en la enseñanza de los números negativos en los manuales alemanes y franceses entre 1795 y 1845; a Howson (1995) que realiza un estudio comparativo de LT para niños de 13 años en 8 países diferentes y hace distinción entre estudios "a priori”, que son escasos (Pepin et al. (2001)) y “a posteriori”, que son más numerosos; Chevallard (1985) y Chevallard y Joshua (1982) cuyas investigaciones giran en torno a la transposición didáctica y el saber a enseñar reflejado en los LT; Pimm (1987, 1994) y sus estudios sobre aspectos relativos al lenguaje y la legibilidad.; Otte (1986) y la presentación de contenidos; Dormolen (1986), que realiza clasificaciones de los elementos imprescindibles en un LT de matemáticas; Lowe y Pimm (1996) y sus estudios en torno a la tétrada asociada al LT: lector, escritor, profesor y libro; Dhombres (1984) y Schubring (1987) que desarrollan 
una metodología de análisis histórico de LT y Cantoral (1995), Filloy y Rojano (1984) y Puig (1997) que comparan procesos utilizados por los alumnos en la comprensión del conocimiento matemático y los utilizados en los libros o textos históricos de matemáticas.

Si se considera el panorama español, se encuentran los siguientes trabajos en torno al LT en el contexto de la Didáctica de la Matemática: Sierra, Rico y Gómez (1997) que estudian la evolución de la aritmética y la geometría desde el Antiguo Régimen hasta la república; Sanz (1995) y los tipos y funciones de los gráficos de datos en los LT de primaria; Gómez (1995a, 1995b, 1996 y 1999), que estudia métodos de cálculo de la aritmética; Maz (TM (2000), TD (2005)) y Maz y Rico (2007, 2009a, 2009b) y los números negativos en textos entre los siglos XVIII y XIX; Maz, Torralbo y Rico (Eds.) (2006), Maz y Rico (2009a) y las liciones de matemáticas de T. Cerdán; Gómez (2001) que estudia la regla de los signos en LT; Sierra, González y López que desarrollan trabajos sobre la evolución de los conceptos de límites de funciones y continuidad en LT de secundaria $(1999,2003)$ y la evolución histórica de la enseñanza matemática (2005) y el seminario de investigación sobre el análisis del LT en el XIII Simposio SEIEM (Universidad de Cantabria, 2009): Sierra (2009), Maz (2009) y Monterrubio y Ortega (2009). Gómez (2000) considera lo que son los libros de texto, y describe varios aspectos con respecto a este elemento: desarrollo, polémica en su creación y utilización, los programas curriculares... Posteriormente, Gómez (2011) analiza la ambigüedad del signo radical en los libros de texto, ambigüedad que provoca dificultades en el aprendizaje y que no ha sido resulto desde el punto de vista didáctico. En este trabajo, Gómez observa que existen discrepancias en el tratamiento que hacen del radical y las raíces en los libros de texto y advierte sobre el hecho de basar el aprendizaje exclusivamente en los manuales escolares. Destacar también las últimas tesis doctorales desarrolladas en torno al análisis del libro de texto de Herdeiro (2010), en la que realiza un análisis del tópico resolución de problemas en los libros de texto de matemáticas de $9^{\circ}$ curso (14 años) portugueses y Monterrubio (2007) que desarrolló una valiosa herramienta para el análisis general de los libros de texto.

La herramienta desarrollada por Monterrubio (2007) ha dado lugar a otros trabajos de investigación en torno al análisis de libros de texto, que se describen a continuación: Monterrubio y Ortega (2011 y 2012) presentan el proceso de 
elaboración de modelos de análisis y valoración de textos escolares de matemáticas, junto con algunos ejemplos de puesta en práctica, o bien un modelo en concreto, más exhaustivo, que permitan al profesorado de Educación Secundaria tanto facilitar la tarea de elección de un LT como la creación de sus propios materiales curriculares. En el último de los trabajos además presentan una validación del modelo partiendo de cuestionarios que han pasado a profesores de Educación Secundaria sobre el modelo.

También se han encontrado otros trabajos en los que se analiza algún aspecto relacionado con diferentes conceptos matemáticos en libros de texto, como por ejemplo, el trabajo de Gea, Batanero, Cañadas, y Contreras (2013) que estudian las situaciones usadas para contextualizar la correlación y la regresión, y recogen otras investigaciones en torno a la estadística y la probabilidad en libros de texto (Ortiz, 1999; Cobo y Batanero, 2004; Azcárate y Serradó, 2006). También se han realizado investigaciones en torno a la correlación y la regresión en libros de texto (Sánchez Cobo, 1998). Muñoz, Oller, y Ortega (en prensa) analizan los problemas de proporcionalidad compuesta en textos de $2^{\circ}$ de ESO.

Hasta ahora, se han señalado algunas investigaciones en torno al libro de texto, lo que ha proporcionado una visión de la importancia que tiene esta herramienta de trabajo en la Educación Matemática, pero no se ha considerado ninguna cuyo elemento a analizar sea la demostración matemática. Estas investigaciones se recogen en el apartado siguiente, por ser las que están más cerca del presente trabajo.

\section{I.4. INVESTIGACIONES QUE INTEGRAN LA DEMOSTRACIÓN MATEMÁTICA Y LOS LIBROS DE TEXTO}

Como ya se ha visto en los epígrafes anteriores, el libro de texto es ampliamente utilizado en la investigación en educación, debido a su alta presencia en las aulas, y su gran influencia en los procesos de enseñanza aprendizaje. Por otro lado, también se ha visto que la comunidad investigadora en Educación Matemática tiene un gran interés en la demostración matemática, por ser ésta un elemento clave en el desarrollo y comprensión de las matemáticas como ciencia. Por esta razón, no es de extrañar que ya se hayan realizado investigaciones en torno a 
cómo se presenta la demostración matemática en los libros de texto. No obstante, las investigaciones que conjugan ambos elementos son relativamente recientes, aunque han aumentado en los últimos años.

Si bien existen otros estudios anteriores en torno a estos elementos, uno de los primeros que hemos encontrado con más referencias en estudios posteriores, similares al nuestro, ha sido el realizado por Hanna \& de Bruyn (1999). En este estudio, los autores realizan un estudio sobre las oportunidades de aprender a demostrar que aparecen en los libros de texto de Ontario de duodécimo curso (17-18 años). Según indican los autores, Howson (1995) apunta que en aquel momento había poca investigación reciente en torno a la demostración matemática en los libros de texto, aunque a partir de entonces el número de estudios se incrementó. Hanna \& de Bruyn, en la investigación que realizan, observan la frecuencia con que aparecen varios tipos de pruebas y de ítems relacionados con la construcción de la demostración en dos libros de texto diferentes que son utilizados en el $80 \%$ de las clases de grado 12 en Canadá. Al igual que en el presente trabajo, la división en ítems de análisis en los libros de texto (resultados o demostraciones a analizar) puede variar de unos libros a otros y eso hace que sea difícil establecer comparaciones entre diferentes libros de texto. En su estudio, clasifican las demostraciones como directas e indirectas, y dentro de las directas, como pruebas directas básicas, pruebas directas por análisis, pruebas directas de existencia o construcción, pruebas directas por inducción y pruebas directas misceláneas. En este caso, al igual que este trabajo, el objetivo es hacer un recuento de las justificaciones utilizadas en los libros de texto y clasificarlas atendiendo a ciertas características de la prueba. No obstante, se consideran que las características establecidas por Hanna \& de Bruyn son demasiado generales y en ellas se mezclan algunos aspectos que podrían ser diferenciados, y por esta razón, consideramos que las categorías de análisis que se utilizan en la investigación que aquí se describe permiten una clasificación más fina.

Tras el trabajo de Hanna \& de Bruyn (1999), se han realizado numerosos estudios en torno a la demostración matemática en los libros de texto en todos los niveles y relacionadas con diferentes conceptos de la matemática. Uno de los más antiguos que se ha encontrado, ya mencionado, y que ha servido como punto de partida para este trabajo, es el desarrollado por Ibañes y Ortega (2002b y 2004b), en él se analizan el tratamiento de la demostración matemática en los libros de 
texto de primero de Bachillerato (16-17 años). Como marco teórico utilizan las funciones de la demostración (de Villiers, 1993) y los esquemas de prueba de Harel \& Sowder (1998) desarrollados por Ibañes y Ortega (2001b), en las categorías de análisis de la demostración de Ibañes y Ortega (1997). Dado que este trabajo supone el punto de partida, no se realiza una descripción más exhaustiva de estos elementos aquí, ya que se hará en el capítulo siguiente, en el apartado en el que se describe el marco teórico.

Son numerosos los autores que han estudiado la demostración en los libros de texto en el ámbito de la geometría (Han, 2005; Fujita, Jones and Kunimune, $2009, \ldots$ ), quizás porque es una rama en la que se pueden realizar demostraciones asequibles a los niveles educativos preuniversitarios. Han (2005) compara las verificaciones intuitivas que utilizan los libros coreanos para cuatro proposiciones geométricas, frente a las pruebas rigurosas mostradas en los libros rusos. Por su parte, Fujita, Jones, and Kunimune (2009) realizan un análisis de los libros de texto que se usan en Japón para la enseñanza de la demostración en geometría en la Educación Secundaria. Tal y como se indica en el currículo japonés, los razonamientos deductivos aparecen de manera notable en los libros de texto. Sin embargo, la forma de presentar las justificaciones muestra a la geometría de manera muy formal y en estos libros de texto no se diferencia de las pruebas formales y las verificaciones experimentales, lo que impide a los estudiantes apreciar la noción de "generalidad de una prueba". Estos autores abogan por un diseño que implemente actividades instructivas más efectivas para mostrar esta noción de generalidad. Otros autores también se han interesado por las justificaciones presentadas en los LT en torno a la Geometría, como por ejemplo Otten, Males \& Gilbertson (2014), que se centran en las oportunidades de razonamiento y prueba que ofrecen seis libros de texto de geometría destinados para alumnos de 13 a 16 años. Sea en torno a la geometría u otras áreas, hemos encontrado varios estudios que se centran en estas oportunidades de razonamiento que los libros de texto ofrecen a los estudiantes, más que en una clasificación en sí, como son los estudios de Johnson, Thompson \& Senk (2010), Thomson, Senk \& Jhonson (2012), Davis (2012), Sears \& Chávez (2014), Bieda, Ji, Drwencke \& Picard (2014), Davis, Smith, Roi, \& Bilgic (2014), McCrory \& Stylianides (2014), Cai \& Cirillo (2014) y Thompson (2014).

En la misma línea de clasificar los tipos de justificaciones utilizados que se siguen en el presente trabajo, y que fue precedida por Hanna \& de Bruyn (1999) 
e Ibañes y Ortega (2004), se encuentra las investigaciones desarrolladas por Nordström \& Löfwall (2005), Llanos, Otero y Banks Leite (2007), Stacey \& Vincent (2008, 2009), Pelczer \& Voica (2008), Senk, Thompson \& Johnson (2008), Dolev (2011), Dolev \& Even (2015) y Silverman \& Even (2015).

Por ejemplo, Llanos, Otero y Banks Leite (2007) analizan 137 libros de texto argentinos de diferentes niveles (divididos en grupos de 12 a 14 años, de 15 a 17 años y los cursos de ingreso a la universidad) de acuerdo a algunos aspectos de la demostración que las autoras han considerado importantes: las tradiciones, el inicio de la argumentación, el grado de argumentación, la relación entre las imágenes externas y la argumentación. Su estudio también es longitudinal en el tiempo, y establecen relaciones entre el nivel educativo al que están dirigidos los textos y el tipo de argumentación utilizado. En relación al tipo de argumentación, las autoras definen tres tipos: las pruebas empírico-inductivas, las pruebas deductivas informales y las demostraciones puramente matemáticas.

Stacey \& Vincet (2008 y 2009) toman como referencia a Harel \& Sowder (2007), al igual que hicieron en su día Ibañes (2001) e Ibañes y Ortega (2004), en torno al concepto más abierto de demostración, que Harel \& Sowder denotan por esquema de prueba, pero que llaman modos de razonamiento. En Stacey \& Vincent (2009) se desarrolla el trabajo resumido en Stacey \& Vincent (2008). Estos autores realizan un análisis de libros de texto australianos de octavo curso (13-14 años) clasificando las justificaciones según distintos modos de razonamientos. En concreto, definen son los siguientes: llamada a la autoridad, analogía cualitativa, concordancia de una regla con un modelo, demostración experimental, deducción usando un modelo, deducción usando un caso específico (entendiendo como deducción la acción de deducir y no el método por el cual se procede lógicamente de lo universal a lo particular, aunque sería más correcto utilizar inducción), deducción usando un caso general. Si bien estas categorías tienen características similares a las que nosotros describimos, creemos que no se adaptan tan bien a este estudio, y que esto puede deberse a los distintos niveles educativos en los que se centra cada análisis. Sin embargo, en el futuro nos proponemos profundizar en ambas clasificaciones para determinar que similitudes y diferencias existen entre ellas. Por su parte, los autores concluyen en su estudio que, si bien el número de conceptos analizados es limitado, por lo que las comparaciones entre LT se deben hacer con cautela, observan que algunos libros dan una mayor importancia al razonamiento matemático que otros, 
pero salvo algunas excepciones, los LT no indican qué explicaciones constituyen una verdadera demostración matemática. No obstante, si bien las únicas justificaciones aceptables desde el punto de vista del matemático son las explicaciones de tipo deductivo, el resto (exceptuando la llamada a la autoridad) tienen una componente didáctica que busca favorecer la comprensión, aunque desde el punto de vista del alumno, debería completarse con la diferenciación entre los modos de razonamiento matemáticamente aceptables y aquellos que sólo tienen una intención pedagógica. Los libros de texto deberían mostrar esta diferenciación.

La clasificación de Stacey \& Vincent $(2008,2009)$ de modos de razonamiento es utilizada por Dolev (2011), Dolev \& Even (2015) y Silverman \& Even (2015). Dolev (2011), en su tesis doctoral, analiza seis libros de texto de matemáticas israelís de séptimo curso (12-13 años). El estudio se centra en examinar la aproximación de los libros de texto a las justificaciones y explicaciones de los enunciados matemáticos. Observa dos aspectos, las justificaciones que presentan los libros de texto y las oportunidades que ofrecen a los alumnos de justificar. Estos dos aspectos los observan en los tópicos matemáticos de la resolución de ecuaciones algebraicas y las propiedades geométricas de los triángulos. Utilizan el marco teórico desarrollado por Stacey \& Vincent (2009), que se acaba de describir muy brevemente, y observan que algunos de los textos ofrece más de una justificación a los enunciados que presentan, que existen diferencias en entre los tipos de justificación relativos al algebra y a la geometría, y que existe también gran diversidad entre las justificaciones que presenta cada libro de texto. Dolev \& Even (2015) realizan un estudio, que continua el descrito anteriormente, en el que analizan seis libros de texto israelís de matemáticas para séptimo curso, es decir, para alumnos de 12-13 años. En este estudio examinan el grado en que los estudiantes están obligados a justificar y explicar su trabajo matemático, cuando los estudiantes tienen que justificar enunciados propuestos por el libro de texto, y cuando estos enunciados los ha propuesto el propio alumno al resolver problemas. Este estudio lo realizan en torno a la resolución de ecuaciones en álgebra y a las propiedades geométricas de los triángulos. También Silverman \& Even (2015) utilizan las categorías de Stacey \& Vincet para analizar los modos de razonamiento de los libros de texto de séptimo curso, y comparan las justificaciones presentadas en el ámbito de la geometría y del álgebra, y en los libros del enfoque limitado (alumnos con bajo rendimiento) frente a los del 
enfoque regular o extendido (los alumnos en general). Aunque estos estudios combinan los dos elementos centrales del presente trabajo, existen diferencias que los alejan enormemente: el nivel educativo al que van dirigidos los libros de texto, ya que no se puede exigir el mismo rigor matemático a los 12 años que a los 16, 17 o 18, y los conceptos matemáticos que se analizan, que en nuestro caso corresponden al Análisis Matemático, y no al Álgebra o la Geometría.

Por su parte, en el ámbito nacional, las investigaciones en torno a la demostración matemática en los libros de texto son menos numerosas. Sin embargo, existen algunos estudios que han dado lugar a este trabajo, como el de Ibañes y Ortega (2002b), en el que analizan las demostraciones matemáticas en los libros de texto de $1^{\mathrm{o}}$ de Bachillerato de LOGSE para los conceptos de trigonometría. En este estudio, los autores estudian la mayoría de los aspectos que luego tendrán en cuenta en la descripción de su marco teórico, y que sirve de punto de partida para el del presente trabajo. En este análisis, observan algunos sucesos que se corroboran en nuestro estudio y que causa preocupación a los autores ya que los LT parecen limitarse a incluir las demostraciones como un elemento que debe estar y debe ser riguroso, pero no muestran preocupación alguna por la comprensión de dichas demostraciones, y deberían incluir algunas medidas para favorecer dicha comprensión como emplear recursos, diseñar materiales de apoyo o resaltar las características de la justificación, entre otros (no contienen ninguna intencionalidad didáctica). Se completa este estudio en Ibañes y Ortega (2004b). En este trabajo, los autores realizan un estudio similar, centrado en el teorema de coseno, en libros de $1^{\circ}$ de Bachillerato, pero se describe con mayor precisión el marco teórico que utilizan y cómo lo aplican al análisis. Las conclusiones de este trabajo son similares a las del caso anterior.

Por último, se mencionan los trabajos desarrollados en el Área de Didáctica de la Matemática de la universidad de Valladolid. En ellos se utiliza el marco teórico de este trabajo en la presente versión o en otras anteriores menos evolucionadas. Estos trabajos son los siguientes: Conejo y Ortega $(2013,2014)$ y Conejo, Arce y Ortega $(2014,2015)$.

No obstante, si bien los estudios que se han encontrado conjugan estos elementos, la mayoría realizan comparaciones entre libros de texto correspondientes a un mismo intervalo temporal. No se han encontrado estudios en los que se realice una comparativa longitudinal en el tiempo, estudiando la 
evolución que experimenta la demostración matemática al sucederse las diferentes legislaciones educativas.

\section{I.5. INVESTIGACIONES EN TORNO A LOS CONCEPTOS ANALIZADOS: LÍMITES Y CONTINUIDAD.}

Por último, se describen algunas investigaciones relacionadas con los conceptos que se analizan en el presente estudio: el límite funcional y la continuidad. Si bien la continuidad no ha sido de gran interés para la comunidad investigadora en Didáctica de la Matemática, el límite funcional ha sido ampliamente estudiado debido a los problemas de comprensión que genera. Los siguientes apartados relacionan algunas de las investigaciones realizadas en torno a estos elementos para aportar una perspectiva de la particularidad de estos elementos.

\section{I.5.1. Límites}

El límite funcional es considerado uno de los conceptos más difíciles de comprender del Análisis Matemático. Por esta razón, no es de extrañar que se hayan llevado a cabo numerosas investigaciones en torno a este concepto en el campo de la Didáctica de la Matemática.

Blázquez (1999), en su trabajo sobre la noción de límite funcional en las Matemáticas aplicadas a las Ciencias Sociales, realiza una recopilación de antecedentes en torno a los trabajos de límites y los agrupa en los siguientes apartados: trabajos sobre las concepciones de límite funcional de los estudiantes, trabajos sobre errores, dificultades u obstáculos, trabajos sobre el tratamiento del límite en los manuales y trabajos en los que se desarrollan secuencias de enseñanza-aprendizaje para el límite funcional. En el primer grupo, el de concepciones de los estudiantes sobre el límite funcional, consideran, entre otras aportaciones, la de Tall y Vinner (1981), que señalan algunas de las imágenes que tienen los alumnos sobre el concepto de límite secuencial, y las relacionan con la instrucción recibida; en esa misma línea se encuentra Vinner (1991), que señala algunas imágenes conceptuales de los alumnos que les llevan a error (una sucesión no debe alcanzar su límite, una sucesión debe ser monótona...); Cornu 
(1983) indica que los alumnos identifican "tender a" con aproximarse, aproximarse sin llegar..., o tienen como conceptualización del límite ideas como que el límite es algo inmóvil y alcanzable, o que el límite es algo inmóvil inalcanzable...; Sierra, González y López (1998) proponen cinco concepciones del límite que aparecen en la historia (aproximación mediante procesos geométricos iterados, idea centrada en aspectos relacionales de la función sin tener en cuenta entornos, idea de aproximación, concepción asociada al proceso de aritmetización del análisis, concepción topológica de Hausdorff). En esta misma línea de investigación sobre concepciones de los alumnos encontramos los trabajos de Blázquez y Ortega (1999, 2000, 2001a, 2001b, 2002), que proponen una nueva conceptualización de límite, rigurosa pero menos formal que las habituales expresadas en términos de $\varepsilon$ - $\delta$, y que es utilizada en trabajos posteriores (Blázquez, Gatica, Ortega y Benegas, 2006; Blázquez, Gatica y Ortega, 2007), y en los trabajos de Fernández-Plaza (2011), Fernández-Plaza, Ruiz-Hidalgo y Rico (2012), Fernández-Plaza, Castro, Rico y Ruiz-Hidalgo (2012), Fernández-Plaza, Ruiz-Hidalgo, Rico y Castro (2013) y Pons, Valls y Llinares (2013) en los que también estudian las concepciones de los estudiantes de Bachillerato en torno al límite. También estudian las concepciones de límite que tienen los profesores Ward, Inzunsa, Hernández y López (2013). Finalmente, Claros, Sánchez y Coriat (2009) hacen una revisión amplia de este tipo de investigaciones y aplican un análisis local para determinar la fenomenología asociada al concepto.

De los trabajos antes mencionados nos interesa especialmente el de Blázquez, Gatica y Ortega (2007), en el que realizan un estudio, desde la perspectiva didáctica, de las diversas conceptualizaciones del límite funcional en diferentes manuales universitarios, y comparan con la conceptualización propuesta por Blázquez y Ortega (2002). En él se descubren diferencias significativas en las formulaciones, y que las orientaciones didácticas mostradas en los textos son muy dispares, llegando a ser ausentes en algunos e incluso erróneas en otros. También realizan una serie de reflexiones didácticas o recomendaciones (introducción del concepto, motivación, tipo de definición, tratamiento verbal, dependencia del entorno, aplicaciones de la definición, propiedades y ejercicios, tratamiento gráfico, límites laterales e intencionalidad didáctica), algunas de las cuales tendremos en cuenta para la secuencia didáctica que propondremos en el capítulo final del presente trabajo. 
En cuanto a las investigaciones en torno a los errores, dificultades u obstáculos mencionan a Macnab y Cummine (1992), que clasifican las dificultades en cuatro grupos (dificultades que surgen del desarrollo cognitivo infantil, atribuibles a la escuela, y que son debidas a actitudes hacia las matemática y a la naturaleza de la asignatura); Artigue (1995) distingue tres grupos de dificultades (asociadas con la complejidad de los objetos básicos del cálculo, a la conceptualización y formalización de la noción de límite y vinculadas a la ruptura de modos de pensamiento algebraico); Cornu (1983), detecta cuatro obstáculos epistemológicos; Sierpinska (1985, 1987, 1990), también analiza los actos de comprensión y los obstáculos epistemológicos asociados; y Sánchez (1997) que realiza un estudio institucional. En esta misma línea, Ward, Inzunsa, Hernández, y López (2013) también citan a Oehrtmann (2009), como autor que ha trabajado en torno a las dificultades de comprensión del límite, y a Courant y Robins (2002) que indican que la importancia del concepto de límite en matemáticas y ciencias está en que muchos conceptos y números importantes se definen como el límite de funciones y sucesiones, por lo que el concepto de límite es central para el desarrollo del pensamiento matemático avanzado.

En cuanto a las investigaciones sobre el concepto de límite en los manuales se consideran los siguientes autores: Sánchez (1997) hace un un estudio del tratamiento didáctico que se ha dado a la noción de límite de una función en manuales de los siglos XIX y XX; Espinoza (1998), que estudia las organizaciones matemáticas y didáctica en torno al objeto de límite funcional, y analiza las reconstrucciones escolares propuestas en los programas y libros de texto de $2^{\circ}$ de BUP.

Por último, algunos autores que Blázquez (1999) cita sobre investigaciones en torno a la enseñanza de límite son: Robinet (1983), que elabora secuencias de enseñanza dentro de la metodología de la Ingeniería Didáctica; Tall y Schwarzenberger (1978); Berthelot y Berthelot (1983), que proponen una situación fundamental para el límite; Delgado (1995) plantea una situación didáctica que intenta provocar un conflicto cognitivo en el alumno. En esta misma línea, Henning \& Hoffkamp (2013) proponen una actividad que utiliza un software de geometría dinámica y está basada en ofrecer visualizaciones interactivas que fomentan la idea dinámica de límite y dirigen a una visión de objeto de la derivada. 


\section{I.5.2. Continuidad}

En general, el concepto de continuidad se considera más sencillo y asequible para los estudiantes que el concepto de límite, aunque su definición se apoye en este último, y la investigación en Didáctica de la Matemática en torno a este concepto es menos numerosa que en torno al concepto de límite. Además, en muchas veces aparecen ambos ligados, y se estudia en el contexto de las investigaciones en torno al concepto de límite funcional. Por esta razón, se han encontrado menos antecedentes en torno al concepto de continuidad.

Uno de los estudios globales en torno a la enseñanza y aprendizaje del Análisis Matemático que comprende al concepto de continuidad es un proyecto de investigación desarrollado por el grupo GEAMJA (grupo de enseñanza del Análisis Matemático de Jaén) en torno al año 1997, y que se describe en Contreras (2001). En este trabajo estudian los conceptos elementales del Análisis Matemático, entre los que se encuentra la continuidad, desde la perspectiva de los obstáculos epistemológicos y los actos de comprensión de Sierpinska (1997), tratando de buscar estrategias de enseñanza y aprendizaje adecuadas para el tratamiento de dichos conceptos. Entre otros, estudian los manuales escolares, en los que se recoge el saber escolar y nace de los problemas detectados en la enseñanza del Análisis Matemático en $1^{\circ}$ y $2^{\circ}$ de Bachillerato y primer curso de Universidad. Otros trabajos anteriores a los que se hacen referencia son el de El Bouazzaoui (1988), en el que analiza obstáculos y concepciones del concepto de continuidad, o de Campillo (1999), en el que se analiza la noción de continuidad desde la perspectiva de los niveles de Van Hiele. En su trabajo, Contreras (2001) expone la idea apuntada anteriormente y comenta que aunque la idea de continuidad sea un concepto más asequible que el de límite, y los estudiantes son capaces de estudiar la continuidad de funciones definidas a trozos utilizando la concepción de Cauchy, éstos presentan dificultades a la hora de definir la continuidad en un punto. Además, indica que se produce un deslizamiento didáctico hacia la algebrización del concepto, es decir, saben aplicar un método (en este caso de estudio de la continuidad de funciones definidas a trozos) de forma mecánica, pero no comprenden el concepto. En este sentido, nuestra intención en el presente trabajo es observar si el tratamiento de las justificaciones asociadas a la continuidad contribuye a que se produzca dicho deslizamiento. 
Otro estudio en esta línea es el de Contreras, Luque y Ordoñez (2003), que presentan algunos resultados del proyecto anteriormente descrito.

Otros estudios en torno a la continuidad de funciones son los de Aparicio y Cantoral (2003 y 2006), en torno a la continuidad puntual; Gatica et al. (2010), que estudian las ideas de continuidad en estudiantes de ciencias económicas; Karatas, Guven y Cekmez (2011) comparan la comprensión de los conceptos de límite y continuidad entre estudiantes de diferentes niveles, siendo los futuros maestros los que menos éxito obtuvieron en los cuestionarios sobre representaciones algebraicas, verbales y gráficas de dichos conceptos.

Un estudio que ha suscitado gran interés por la proximidad al nuestro es el de Sierra, González y López (2003); en él se analizan la evolución del concepto de continuidad en los manuales escolares españoles de enseñanza secundaria de la segunda mitad del siglo XX. En relación a la continuidad observan una evolución en la forma de presentar y tratar el concepto. Consideran que antes de la LGE, con la influencia de la matemática moderna, se presenta en primer lugar la idea intuitiva de continuidad, y luego se define a partir del límite, en la que se utiliza la definición topológica. También afirman que, tras la implantación de la LGE, se mezclan los conceptos de continuidad y límite, dependiendo de los autores el orden de presentación, se incorpora la definición métrica, aunque se acompaña de la noción intuitiva y otras definiciones. Finalmente, consideran que, tras la implantación de LOGSE, la continuidad se trata de forma exhaustiva en poco espacio, con poca profundidad, lo que puede dar lugar a un descenso de las justificaciones asociadas a este concepto, lo que estudiaremos posteriormente. 


\section{CAPÍTULO II}

\section{OBJETIVOS E HIPÓTESIS DE INVESTIGACIÓN. MARCO TEÓRICO}

\section{II.1. INTRODUCCIÓN}

En el capítulo anterior se ha expuesto una revisión de los antecedentes relacionados con alguno de los elementos que forman parte de nuestro trabajo. $\mathrm{Si}$ bien no hemos realizado una revisión completa y exhaustiva de toda la investigación realizada en torno a dichos elementos (demostración matemática, libro de texto, límite funcional y continuidad), los trabajos descritos nos dan suficiente información sobre estos elementos y son suficientes para comprender la importancia que tienen en la educación matemática y el porqué de ser objetos de investigación.

En el presente capítulo se tratarán dichos elementos con más detalle y considerando todo aquello que dé forma a nuestro trabajo: en primer lugar, se establecen los objetivos de nuestra investigación, junto con nuestras hipótesis de partida, que se derivan de dichos objetivos. Esto permitirá delimitar nuestro trabajo; a continuación se recoge un breve apunte curricular que enmarca el elemento central de nuestro trabajo, la demostración matemática, en los respectivos marcos curriculares legales, marcos que deben ser respetados por los libros de texto correspondientes; por último, se describe de forma detallada y minuciosa el marco teórico desarrollado para el presente trabajo, teniendo en 
cuenta las investigaciones anteriores de las que parte y los conceptos en los que nos hemos basado.

\section{II.2. OBJETIVOS E HIPÓTESIS DE INVESTIGACIÓN}

El análisis de las investigaciones realizado en el capítulo anterior permite delimitar el problema de investigación ya planteado en la introducción: la desaparición paulatina en los últimos cursos de educación preuniversitaria de la demostración matemática. En el presente estudio, el foco de atención se centra en uno de los componentes de los procesos de enseñanza y aprendizaje cuyo análisis da información de la enseñanza de un determinado momento, el libro de texto. Por consiguiente, el objetivo general de nuestra investigación es estudiar la presencia de la demostración matemática en los libros de texto de $3^{\circ}$ de BUP, COU de la LGE y $1^{\circ}$ y $2^{\circ}$ de Bachillerato de la LOGSE y de la LOE. A partir de este estudio, la intención es determinar la evolución de la demostración en los libros de texto de los cursos citados, clasificar los esquemas de prueba utilizados según el modelo de Ibañes y Ortega (2001b) y determinar los procesos de enseñanza de las matemáticas a través de los LT en relación con la demostración o justificaciones alternativas. Este objetivo se desglosa en los siguientes:

O1. Analizar la presencia de la demostración en los libros de texto de las tres últimas leyes educativas.

O2. Establecer una clasificación de los tipos de justificación utilizados según los niveles (esquemas de prueba), la tipología, las funciones de la demostración.

O3. Determinar la evolución de las justificaciones de los teoremas en los periodos en vigor de estas leyes educativas.

O4. Descubrir posibles errores relativos a la presentación de los enunciados y de las justificaciones de los teoremas.

O5. Proponer una secuencia didáctica que integre los resultados encontrados.

De los objetivos anteriormente propuestos se derivan las siguientes hipótesis de partida, que reflejan la posición de la investigadora al respecto del problema de investigación descrito. Estas hipótesis, en cierto modo, guiarán en el trabajo, ya que nuestro estudio se orientará a la comprobación o refutación de éstas. 
H1. La demostración matemática ha perdido paulatinamente importancia en la enseñanza preuniversitaria, reflejándose en los libros de texto con menor presencia de ésta última, desde los años 70.

H2. Los esquemas de prueba utilizados por los libros de texto tienden a una menor formalidad y rigor matemático con el paso de los años, procediendo a convencer desde la intuición antes que desde el razonamiento.

H3. Cada cambio de legislación ha rebajado, tanto la utilización de demostraciones, como el rigor de las mismas.

H4. La demostración matemática y la consiguiente fundamentación de los teoremas están desapareciendo y ello puede conducir a errores tanto en la presentación como en el significado de los resultados propuestos.

H5. Es necesario hacer una propuesta fundamentada sobre el uso de la demostración matemática y de sus posibles alternativas: los Esquemas de Prueba y las Pruebas Preformales.

Una vez fijadas las hipótesis de partida se puede acometer el estudio propuesto inicialmente. Para ello, en primer lugar, se concreta el marco teórico que será la guía del análisis de los libros de texto y que parte de los algunos de los antecedentes descritos anteriormente: Ibañes y Ortega (1997, 2001a, 2001b, 2002a, 2002b, 2004a, 2004b y 2005), Harel \& Sowder (1998, 2007), Van Asch (1993), Bell (1976) y de Villiers (1993), Dos Santos (2010) y González (2012).

\section{II.3. APUNTE CURRICULAR}

Antes de acometer el análisis de los libros de texto, es necesario conocer qué expectativas se puede tener con respecto a la demostración matemática en los niveles educativos considerados. Como ya se ha indicado anteriormente, se ha centrado el presente trabajo en el estudio de los libros de texto editados desde los años 70 , es decir, correspondientes a tres de las cuatro últimas legislaciones educativas de este país (la última aún no se ha implantado en el nivel de Bachillerato, por lo que todavía no existen libros de texto correspondientes con ese nivel). Dichas leyes son la Ley 14/1970, de 4 de agosto, General de Educación y Financiamiento de la Reforma Educativa (LGE; Jefatura del Estado, 1970), la Ley Orgánica 1/1990, de 3 de octubre de 1990, de Ordenación General 
del Sistema Educativo (LOGSE; Jefatura del Estado, 1990) y la Ley Orgánica 2/2006, de 3 de mayo, de Educación (LOE; Jefatura del Estado, 2006). En el año 2002, el gobierno de la nación promulgó una nueva ley, la Ley Orgánica 10/2002, de 23 de diciembre, de Calidad de la Educación (LOCE; Jefatura del Estado, 2002), pero debido al cambio de gobierno durante su periodo de implantación, está no llego a aplicarse, con lo que no se tendrá en cuenta en el análisis curricular, ya que no llegaron a editarse libros de texto correspondientes a esta ley. Recientemente se ha promulgado una nueva legislación educativa, la Ley Orgánica 8/2013, de 9 de diciembre, para la mejora de la calidad educativa (LOMCE; Jefatura del Estado, 2013), que modifica la anterior, LOE, pero que no llega a implantarse en Bachillerato durante el desarrollo de ésta tesis, por lo que únicamente realizamos un breve apunte sobre ella.

Debido a que los LT tienen que seguir las pautas ministeriales, antes de realizar el análisis de los textos, es interesante conocer cuáles son las indicaciones respecto del objeto de estudio, la demostración matemática. Por ello, a continuación se presenta una descripción de los planes educativos que rigen este estudio, prestando especial atención a las referencias que hacen a la demostración matemática u otros procesos relacionados.

\section{II.3.1. Ley General de Educación (1970)}

En 1970 se marca un hito en la educación española, se promulga la primera ley que estructura todo el sistema Educativo Español, la Ley General de Educación de 1970 (LGE; Jefatura del Estado, 1970). Esta Ley trae reformas importantes respecto de las directrices anteriores, en cuanto a organización y enseñanzas, y diseña un sistema unitario y flexible que se estructura en cuatro etapas: Preescolar, Educación General Básica, Enseñanzas Medias y Enseñanza Universitaria.

La descripción de las materias en los documentos legislativos de la LGE no es muy extensa. Se relacionan de forma general los contenidos correspondientes a cada una de ellas y se acompañan de algunas orientaciones metodológicas que se exponen a continuación. En la propia ley se puede apreciar un enfoque estructuralista en el ámbito de las Matemáticas desde la Educación General Básica. 
El primer documento en el que encontramos desarrollados el programa correspondiente al Bachillerato Unificado Polivalente (BUP) es la Orden de 22 de marzo de 1975 por la que se desarrolla el Decreto 160/1975, de 23 de enero, que aprueba el Plan de Estudios del Bachillerato y se regula el Curso de Orientación Universitaria (Ministerio de Educación y Ciencia, 1975a), según la cual, el primer curso de Bachillerato se implantaría en el año académico 1975-76, $2^{\circ}$ de BUP en 1976-77, $3^{\circ}$ de BUP 1977-1978 y COU, en el 1978-79. Anteriormente, aunque existían directrices sobre la organización y materias que debían componer los diferentes cursos, estás no estaban desarrolladas de forma específica. El Curso de Orientación Universitaria (COU) tenía un carácter especial ya que estaba estrechamente ligado al ámbito universitario. Se trata de un curso de la Universidad que se impartía en los Institutos de Enseñanza Secundaria por el profesorado de estos centros. Pasó por una primera fase de experimentación previa (a partir del año 1971) en la que no había uniformidad en el territorio español y las directrices que dictaban las Universidades. Más adelante, a partir de la Orden citada anteriormente y que regulaba dicho curso, se desarrolló un programa, con validez temporal desde el año académico 1975-76, hasta su implantación definitiva en el 1978-79. Dicho programa temporal lo desarrollaba la Resolución de las Direcciones Generales de Ordenación Educativa y de Universidades e Investigación por la que se desarrolla la disposición transitoria cuarta de la Orden de 22 de marzo de 1975, sobre el Curso de Orientación Universitaria (Ministerio de Educación y Ciencia, 1975b), y considera dos asignaturas de Matemáticas: Matemáticas comunes, que fueron obligatorias para todos los alumnos, y las Matemáticas especiales, de carácter optativo, pero obligatorias para los "Alumnos de Ciencias". Previamente a la implantación definitiva de COU, la Resolución por la que se establecen los contenidos y orientaciones metodológicas del Curso de Orientación Universitaria y se dictan instrucciones sobre el mismo de 17 de marzo de 1978 (Ministerio de Educación y Ciencia, 1978) concreta el programa de las asignaturas de COU descritas en la Orden citada al inicio de este párrafo (Ministerio de Educación y Ciencia, 1975a). En este programa, la asignatura de Matemáticas aparece en las materias, como optativa de la opción A (opción relacionada con las Humanidades y Ciencias Sociales) y como obligatoria en la opción B (opción orientada a la Ciencias), aunque ambas coinciden siendo una 
única materia. Después se publican algunas modificaciones, pero son tan poco relevantes que no merece la pena considerarlas aquí.

Debido a que tanto los cursos de BUP como COU se implantan a partir del año académico 1975-76, los libros que se utilizarán en la investigación están editados a partir de dicho curso. Además, el Decreto 2531/1974 de 20 de julio, sobre autorizaciones de libros de texto y material didáctico (Ministerio de Educación y Ciencia, 1974) exige la autorización por el Ministerio de los libros de texto y el material didáctico utilizado en los centros docentes, y obliga a éstos a seguir las directrices curriculares de la citada Orden y las concreciones posteriores.

En BUP, las Matemáticas aparecen dentro del Área de las Ciencias Matemáticas y de la Naturaleza y, tal y como se describe:

Tratará de capacitar al alumno para comprender los fenómenos naturales, científicos y técnicos de su entorno. Se resaltará la importancia del mecanismo lógico implícito en el razonamiento científico habituando al alumno a los métodos deductivo e inductivo y a la experimentación. (Ministerio de Educación y Ciencia, 1975a, pp. 8064)

Aunque no aparezca de forma explícita la palabra "demostración" (pero sí métodos deductivos), en el currículo de BUP se encuentran referencias que nos inducen a pensar que ésta debería estar presente (lo estaba) en estos cursos, como por ejemplo, las referencias a los métodos deductivo e inductivo o el estudio de teoremas en $3^{\circ}$ de BUP. Además, tal y como mencionan Ibañes y Ortega (2002a), desde la Educación General Básica ya hay una clara tendencia al formalismo, lo que induce a pensar que no se prescindirá de estos procesos. Por su parte, en COU no se encuentra ninguna referencia a la demostración matemática, aunque indica que el carácter del curso aconseja la preparación para el acceso a la enseñanza superior y las diferentes especialidades a las que puede acceder el alumno (estudios de matemáticas, ciencias experimentales e ingenierías) aconsejan que la enseñanza sea adecuada a estos fines, por lo que la demostración será necesaria en numerosos casos.

Los cursos de Bachillerato descritos anteriormente no sufrirán modificaciones durante la legislación, si se exceptúa la reorganización de las opciones A y B de tercer curso, en el que las Matemáticas pasan a ser una optativa en ambas opciones, aunque desarrollan el mismo programa. Sin embargo, a lo largo de la experiencia en la enseñanza de COU, y dado su carácter preparatorio para el acceso a estudios superiores, se consideró que las dos únicas vías qué existían 
para COU no cubrían adecuadamente la formación necesaria para el amplio abanico de estudios universitarios, por lo que se modifica la estructura de las enseñanzas mediante la Orden de 3 de septiembre de 1987 por la que se modifican las Ordenes de 22 de marzo de 1975 y de 11 de septiembre de 1976, en los apartados relativos al Curso de Orientación Universitaria (Ministerio de Educación y Ciencia, 1987), y que su principal reforma se basa en ampliar de dos opciones de materias optativas a cuatro, cada una de ellas formada por dos obligatorias y cuatro optativas, de las cuales, los alumnos deben cursar las dos obligatorias y dos de las optativas. En lo que a matemáticas se refiere, el plan diferencia dos asignaturas: Matemáticas I (obligatoria en la opción A, Científicotecnológica y optativa en la B, Biosanitaria) y Matemáticas II (obligatoria en la opción C, Ciencias Sociales y optativa en la D, Humanística-lingüística). En el caso de Matemáticas I, las directrices curriculares son las mismas que estaban vigentes en la asignatura anterior de Matemáticas de COU, pero se concretan en las Matemáticas II en la Resolución de 20 de enero de 1988 de las Direcciones Generales de Enseñanza Superior y de Renovación Pedagógica, por la que se aprueba el programa y orientaciones pedagógicas de las «Matemáticas II» del Curso de Orientación Universitaria (Ministerio de Educación y Ciencia, 1988). Esta reforma se implanta a partir del año académico 1988-89.

El desarrollo curricular de las Matemáticas II, al estar orientadas a los alumnos de Ciencias Sociales y Humanidades, está desprovisto de formalismo y procesos justificativos. Además, se observa que los conceptos que se estudian se abordan como noción, y que no se requiere profundización. Por esta razón, la muestra se ha limitado a los LT de la opción Matemáticas I.

\section{II.3.2. Ley Orgánica de Ordenación General del Sistema Educativo (1990)}

En 1990, agotado el ciclo de la LGE, el gobierno promulgó una nueva ley educativa, la Ley Orgánica 1/1990, de 3 de octubre de 1990, de Ordenación General del Sistema Educativo (LOGSE; Jefatura del Estado, 1990). Esta ley supuso importantes reformas, entre ellas, la descentralización por primera vez del sistema educativo español, asignando a las autonomías ciertas competencias, entre ellas, la decisión de un porcentaje del currículo. Esta descentralización no 
fue inmediata, ya que la derivación de las competencias educativas a las autonomías no ocurrió de forma conjunta, si no que se hizo de manera gradual durante los años 90. Hasta las modificaciones del año 2000, muchas Comunidades Autónomas no tenían sus propias concreciones curriculares.

Sin embargo, ciertos aspectos estructurales se regulan de manera estatal. Por ejemplo, la estructura del Bachillerato se establece en 1991, en el Real Decreto 1700/1991, de 29 de noviembre, por el que se establece la estructura del Bachillerato (Ministerio de Educación y Ciencia, 1991), aunque su implantación no se lleva a cabo hasta el año académico 1997-98 para el $1^{\circ}$ curso de Bachillerato y 1998-99 para el 2. La parte común del currículo, válida para todo el territorio español la regula el Real Decreto 1178/1992, de 2 de octubre, por el que se establecen las enseñanzas mínimas del Bachillerato (Ministerio de Educación y Ciencia, 1992b); el resto de concreciones dependen de su autonomía, en los casos en los que las competencias ya estuvieran derivadas, o del siguiente Real Decreto, el Real Decreto 1179/1992,de 2 de octubre, por el que se establece el currículo del Bachillerato (Ministerio de Educación y Ciencia, 1992d), para las centros que dependen directamente del Ministerio de Educación y Ciencia.

El currículo de Bachillerato de LOGSE se desarrolla en cuatro modalidades diferentes: Artes, Ciencias de la Naturaleza y Salud (en la que encontramos dos asignaturas de matemáticas: Matemáticas I y II), Humanidades y Ciencias Sociales (también con dos asignaturas de matemáticas: Matemáticas aplicadas a las ciencias sociales I y II) y Tecnología (que también considera las matemáticas de la modalidad de Ciencias de la Naturaleza y de la Salud). En este periodo se observa una gran diferencia en el desarrollo del programa con respecto a la etapa anterior, que ahora se organiza en lo que llamamos currículo, entendiendo "por currículo del Bachillerato el conjunto de objetivos, contenidos, métodos pedagógicos y criterios de evaluación que han de regular la práctica docente en estas enseñanzas" (Ministerio de Educación y Ciencia, 1992a y 1992b). En ambos cursos, el programa de Matemáticas I y II es más amplio y comprende al de Matemáticas aplicadas a las Ciencias Sociales I y II, por lo que en nuestro estudio se ha limitado la muestra a los LT de las opciones de Ciencias. En las Tablas II.3.2.1 y II.3.2.2 se muestran las referencias a la demostración que encontramos en los dos Reales Decretos descritos anteriormente, ya que el RD 
1179/1992 completa algunos de los contenidos del RD 1178/1992 y coincide en el resto de elementos.

\begin{tabular}{|c|c|}
\hline \multicolumn{2}{|c|}{ Matemáticas I y II } \\
\hline Introducción & $\begin{array}{l}\text { - Les caracteriza la naturaleza lógico-deductiva de su versión acabada, el tipo de } \\
\text { razonamientos que utilizan y la fuerte cohesión interna dentro de cada campo y } \\
\text { entre unos campos y otros. } \\
\text { - El conocimiento matemático en el Bachillerato debe tener un cierto respaldo } \\
\text { teórico. Las definiciones, demostraciones y los encadenamientos conceptuales y } \\
\text { lógicos, en tanto que dan validez a las intuiciones y confieren solidez y sentido a } \\
\text { las técnicas aplicadas, deben ser introducidos en estas asignaturas. Sin embargo, } \\
\text { éste es el primer momento en que el alumno se enfrenta con cierta seriedad a la } \\
\text { fundamentación teórica de las Matemáticas, y el aprendizaje, por tanto, debe ser } \\
\text { equilibrado y gradual. }\end{array}$ \\
\hline Objetivos & $\begin{array}{l}\text { 4. Utilizar, con autonomía y eficacia, las estrategias características de la investigación } \\
\text { científica y los procedimientos propios de las matemáticas (plantear problemas, } \\
\text { formular y contrastar hipótesis, planificar, manipular y experimentar) para realizar } \\
\text { investigaciones y, en general, explorar situaciones y fenómenos nuevos. } \\
\text { 6. Mostrar actitudes asociadas al trabajo científico y a la investigación matemática, } \\
\text { tales como la visión crítica, la necesidad de verificación, la valoración de la } \\
\text { precisión, el cuestionamiento de las apreciaciones intuitivas, la apertura a nuevas ideas. } \\
\text { 7. Utilizar el discurso racional para plantear acertadamente los problemas, justificar } \\
\text { procedimientos, adquirir rigor en el pensamiento científico, encadenar } \\
\text { coherentemente los argumentos y detectar incorrecciones lógicas. }\end{array}$ \\
\hline $\begin{array}{l}\text { Criterios de } \\
\text { evaluación I }\end{array}$ & $\begin{array}{l}\text { 9. Organizar y codificar informaciones, seleccionar estrategias, comparándolas y } \\
\text { valorándolas, para enfrentarse a situaciones nuevas con eficacia, y utilizar las } \\
\text { herramientas matemáticas adquiridas. } \\
\text { - Se pretende que el alumno utilice la modelización de situaciones, la reflexión } \\
\text { lógico-deductiva, los modos de argumentación propios de las matemáticas y } \\
\text { las destrezas matemáticas adquiridas para realizar investigaciones enfrentándose } \\
\text { con situaciones nuevas. }\end{array}$ \\
\hline $\begin{array}{l}\text { Criterios de } \\
\text { evaluación II }\end{array}$ & $\begin{array}{l}\text { 8. Realizar investigaciones en las que haya que organizar y codificar informaciones, } \\
\text { seleccionar, comparar y valorar estrategias para enfrentarse a situaciones nuevas con } \\
\text { eficacia, eligiendo las herramientas matemáticas adecuadas en cada caso. } \\
\text { - Se pretende evaluar la madurez del alumno para enfrentarse con situaciones } \\
\text { nuevas utilizando la modelización de situaciones, la reflexión lógico-deductiva, } \\
\text { los modos de argumentación propios de las matemáticas y las destrezas } \\
\text { matemáticas adquiridas. }\end{array}$ \\
\hline
\end{tabular}

Tabla II.3.2.1. Referencias a la demostración o procesos argumentativos en el Bachillerato de LOGSE. Matemáticas I y II.

Aunque en ambas opciones, Matemáticas I y II y Matemáticas Aplicadas a las Ciencias Sociales I y II, aparecen referencias a los procesos justificativos tales como la comprobación y refutación de hipótesis, la necesidad de verificación, la justificación, la utilización de modos de argumentación propios de la matemática,..., son más exigentes en este sentido las opciones de Ciencias, lo que reafirma la idea de limitar la muestra a los LT de estas opciones. Como se aprecia en la tabla, son numerosas las referencias relacionadas con la 
demostración, por lo que la ausencia de ésta en los libros de texto estaría injustificada.

\begin{tabular}{|c|c|}
\hline \multicolumn{2}{|c|}{ Matemáticas aplicadas a las Ciencias Sociales I y II } \\
\hline Introducción & $\begin{array}{l}\text { c) Las estrategias generales o heurísticas necesarias en la resolución de problemas } \\
\text { como análisis de tareas, búsqueda de regularidades y pautas, expectativas de } \\
\text { resultados, comprobación y refutación de hipótesis. } \\
\text { - La fuerte abstracción simbólica, rigor sintáctico y exigencia probatoria que } \\
\text { definen el saber matemático, deben tener una presencia menor en las Matemáticas } \\
\text { aplicadas a las Ciencias Sociales I. Por el contrario, las Matemáticas aplicadas a } \\
\text { las Ciencias Sociales II proporcionan conocimientos e instrumentos más técnicos, } \\
\text { que permiten interpretar y abordar problemas de mayor complejidad matemática; } \\
\text { entre ellos, especialmente los relacionados con el mundo de la economía. } \\
\text { Teniendo en cuenta los posibles estudios posteriores de los alumnos, habrá que prestar } \\
\text { también cierta atención a la fundamentación teórica. }\end{array}$ \\
\hline Objetivos & $\begin{array}{l}\text { 3. Elaborar juicios y formar criterios propios sobre fenómenos sociales y económicos, } \\
\text { utilizando tratamientos matemáticos, y expresar críticamente opiniones, } \\
\text { argumentando con precisión y rigor y aceptando la discrepancia y los puntos de vista } \\
\text { diferentes. } \\
\text { 4. Mostrar actitudes propias de la actividad matemática como la visión crítica, la } \\
\text { necesidad de verificación, la valoración de la precisión, el cuestionamiento de las } \\
\text { apreciaciones intuitivas y la apertura a nuevas ideas. } \\
\text { 6. Utilizar el discurso racional para plantear acertadamente los problemas, justificar } \\
\text { procedimientos, adquirir cierto rigor en el pensamiento científico, encadenar } \\
\text { coherentemente los argumentos y detectar incorrecciones lógicas. }\end{array}$ \\
\hline $\begin{array}{l}\text { Criterios de } \\
\text { evaluación I }\end{array}$ & $\begin{array}{l}\text { 9. Organizar y codificar informaciones, seleccionar estrategias, comparándolas y } \\
\text { valorándolas para enfrentarse a situaciones nuevas con eficacia, y utilizar las } \\
\text { herramientas matemáticas adquiridas. } \\
\text { - Se pretende que el alumno utilice la modelización de situaciones, la reflexión } \\
\text { lógico-deductiva, los modos de argumentación propios de las matemáticas y } \\
\text { las destrezas matemáticas adquiridas para resolver problemas y realizar } \\
\text { investigaciones enfrentándose con situaciones nuevas. }\end{array}$ \\
\hline $\begin{array}{l}\text { Criterios de } \\
\text { evaluación II }\end{array}$ & No hay. \\
\hline
\end{tabular}

Tabla II.3.2.2. Referencias a la demostración o procesos argumentativos en el Bachillerato de LOGSE. Matemáticas aplicadas a las Ciencias Sociales I y II.

Tras una década de implantación de la LOGSE, la experiencia recogida en los distintos centros de Bachillerato, así como diferentes informes realizados por grupos de expertos en Educación, motivaron una modificación de algunos aspectos del currículo de Bachillerato. Además, en ese momento, numerosas autonomías ya han desarrollado sus propias concreciones curriculares tras la determinación de derivar ciertas competencias educativas desde el Ministerio de Educación y Ciencia. Por esta razón se promulga el Real Decreto 3474/2000, de 29 de diciembre, por el que se modifican el Real Decreto 1700/1991, de 29 de noviembre, por el que se establece la estructura del Bachillerato, y el Real Decreto 1178/2009, de 2 de octubre, por el que se establecen las enseñanzas mínimas del Bachillerato (Ministerio de Educación, Cultura y Deporte, 2001a), 
que fija las enseñanzas mínimas y tiene validez en todo el territorio español, y el Real Decreto 938/2001, de 3 de agosto, por el que se modifica el Real Decreto 1179/1992, de 2 de octubre, por el que se establece el currículo de Bachillerato (Ministerio de Educación, Cultura y Deporte, 2001b), que tiene validez para los centros comprendidos en el ámbito de gestión directa del Ministerio de Educación y Ciencia, pero que aporta una visión aproximada a un currículo completo de Bachillerato, aunque cada comunidad pueda fijar el suyo.

\begin{tabular}{|l|l|}
\hline Matemáticas I y II \\
\hline $\begin{array}{l}\text { Introducción } \\
\text { (enseñanzas } \\
\text { mínimas) }\end{array}$ & $\begin{array}{l}\text { Los procedimientos matemáticos provienen de otros contenidos de tipo } \\
\text { conceptual que, a su vez, pueden venir clasificados como definiciones o como } \\
\text { proposiciones demostrables. Estos contenidos conceptuales son los que } \\
\text { conforman y dan estructura a la matemática misma y, en la mayoría de los casos, } \\
\text { requieren de un lenguaje formal cuyo dominio resulta imprescindible para su } \\
\text { mejor comprensión. }\end{array}$ \\
- En las matemáticas de esta modalidad, y sobre todo en las de segundo curso, los \\
alumnos deben alcanzar el grado de madurez necesario, en el manejo del lenguaje \\
formal y de los procesos lógicos deductivos, que les permitan, por ejemplo, \\
seguir, interpretar y desarrollar demostraciones que no sean excesivamente \\
complicadas, plantear conjeturas, analizar procesos lógicos y obtener \\
conclusiones, generalizaciones, etc.
\end{tabular}

Tabla II.3.2.3. Referencias a la demostración o procesos argumentativos en Matemáticas I y II del Bachillerato de LOGSE en la modificación de 2001 del currículo de enseñanzas mínimas y el currículo completo estatal.

A modo de ejemplo, se incluyen también las referencias del currículo de Castilla y León (elegido por ser la Comunidad de la autora y al director de la tesis), que se encuentran en el Decreto 70/2002, de 23 de mayo, por el que se establece el currículo de Bachillerato en la Comunidad de Castilla y León (Conserjería de Educación y Cultura de Castilla y León, 2002), que servirá para ver si existen diferencias notables con el currículo estatal. En las Tablas II.3.2.3, II.3.2.4 y 
II.3.2.5 se recogen las referencias a la demostración y otros procesos argumentativos que aparecen en los documentos curriculares citados anteriormente.

Como se puede observar, y al igual que ocurría en currículos anteriores, apenas existen diferencias entre el currículo de enseñanzas mínimas y el currículo completo estatal, al menos en cuanto a la demostración. Sin embargo, el currículo de Castilla y León sí que amplia algunos aspectos del currículo de enseñanzas mínimas, añadiendo un contenido y realizando una introducción más extensa.

\begin{tabular}{|c|c|}
\hline \multicolumn{2}{|c|}{ Matemáticas I y II } \\
\hline Introducción & $\begin{array}{l}\text { - Se deben introducir las definiciones, los teoremas, las demostraciones y la } \\
\text { realización de encadenamientos lógicos, pero debe hacerse de una forma suave y } \\
\text { graduada. Empezar en primer curso con razonamientos fáciles, para llegar en } \\
\text { segundo a demostraciones con alguna complejidad. Las definiciones, los } \\
\text { teoremas, las demostraciones y los razonamientos que aparecen en los libros, } \\
\text { no son sino el fruto de muchas horas de trabajo hechas por muchas personas que } \\
\text { empezarían seguramente con intuiciones, con la observación de analogías en } \\
\text { cosas sensiblemente distintas, con la necesidad de resolver un problema concreto } \\
\text { o de explicar un hecho. Transmitir esto servirá para aproximar a los alumnos a la } \\
\text { realidad de la materia. } \\
\text { - Del buen hacer, tanto en el aspecto teórico como en el práctico, va a depender } \\
\text { que las Matemáticas cumplan su papel formativo. Las capacidades de análisis y } \\
\text { síntesis, de abstracción y concreción, de generalización y particularización, de } \\
\text { formulación de conjeturas y su comprobación, de crítica, de rigor y de } \\
\text { formalización, presentes en el hacer normal de la asignatura, deben llegarle al } \\
\text { alumno de forma natural, y contribuir así a mejorar su intelecto y a adquirir unos } \\
\text { hábitos y actitudes que trascienden del ámbito de las propias Matemáticas. }\end{array}$ \\
\hline Objetivos & $\begin{array}{l}\text { 4. Utilizar las estrategias características de la investigación científica y los } \\
\text { procedimientos propios de las matemáticas (plantear problemas, formular y } \\
\text { contrastar hipótesis, planificar, manipular y experimentar) para realizar } \\
\text { investigaciones y explorar situaciones y fenómenos nuevos. } \\
\text { 6. Adquirir, desarrollar y mostrar actitudes propias de la actividad matemática, } \\
\text { como la visión crítica, la necesidad de verificación, la valoración de la precisión, } \\
\text { el gusto por el rigor o la necesidad de contrastar apreciaciones intuitivas. } \\
\text { 7. Utilizar el discurso racional para plantear acertadamente los problemas, } \\
\text { justificar procedimientos, adquirir cierto rigor en el pensamiento científico, } \\
\text { encadenar coherentemente los argumentos, detectar incorrecciones lógicas y } \\
\text { analizar y criticar los resultados. } \\
\text { 11. Desarrollar el gusto por la belleza presente en teorías, demostraciones, formas } \\
\text { y figuras matemáticas, y apreciar la relación entre las matemáticas y las artes. }\end{array}$ \\
\hline $\begin{array}{l}\text { Criterios de } \\
\text { evaluación I y II }\end{array}$ & No hay. \\
\hline
\end{tabular}

Tabla II.3.2.4. Referencias a la demostración o procesos argumentativos en Matemáticas I y II del currículo de Bachillerato de LOGSE en Castilla y León, en la modificación 2001.

Por otra parte, al igual que ocurría en currículos anteriores, las asignaturas de Matemáticas Aplicadas a las Ciencias Sociales I y II comprenden un temario 
más reducido y menos formalista $y$, por esta razón, las referencias a la demostración son menores que en las Matemáticas I y II. Este hecho reafirma de nuevo la selección de la muestra prescindiendo de ejemplares correspondientes a estas asignaturas.

\begin{tabular}{|c|c|}
\hline \multicolumn{2}{|c|}{ Matemáticas aplicadas a las Ciencias Sociales I y II } \\
\hline \multicolumn{2}{|c|}{ Currículo de enseñanzas mínimas de Bachillerato y currículo completo estatal } \\
\hline Introducción & $\begin{array}{l}\text { - Por otra parte, determinadas características como el rigor formal, la abstracción o } \\
\text { los procesos deductivos que estructuran y definen el método matemático no } \\
\text { pueden estar ausentes de las matemáticas de Bachillerato, cualquiera que sea su } \\
\text { nivel y modalidad. }\end{array}$ \\
\hline Objetivos & $\begin{array}{l}\text { 4. Mostrar actitudes propias de la actividad matemática como la visión crítica, la } \\
\text { necesidad de verificación, la valoración de la precisión, el gusto por el rigor o la } \\
\text { necesidad de contrastar apreciaciones intuitivas. } \\
\text { 5. Utilizar el discurso racional para plantear acertadamente los problemas, } \\
\text { justificar procedimientos, adquirir cierto rigor en el pensamiento científico, } \\
\text { encadenar coherentemente los argumentos y detectar incorrecciones lógicas. }\end{array}$ \\
\hline $\begin{array}{l}\text { Criterios de } \\
\text { evaluación I y II }\end{array}$ & No hay. \\
\hline \multicolumn{2}{|c|}{ Currículo de Bachillerato de Castilla y León } \\
\hline Introducción & No hay. \\
\hline Objetivos & $\begin{array}{l}\text { 4. Adquirir actitudes propias de la actividad matemática como la visión crítica, la } \\
\text { necesidad de verificación, la valoración de la precisión, el gusto por el rigor o la } \\
\text { necesidad de contrastar apreciaciones intuitivas. } \\
\text { 5. Utilizar el discurso racional para plantear acertadamente los problemas, } \\
\text { justificar procedimientos, adquirir cierto rigor en el pensamiento científico, } \\
\text { encadenar coherentemente los argumentos y detectar incorrecciones lógicas. } \\
\text { 11. Desarrollar el gusto por la belleza presente en teorías, demostraciones, formas } \\
\text { y figuras matemáticas, y apreciar la relación entre las matemáticas y las artes. }\end{array}$ \\
\hline $\begin{array}{l}\text { Criterios de } \\
\text { evaluación I y II }\end{array}$ & No hay. \\
\hline
\end{tabular}

Tabla II.3.2.5. Referencias a la demostración o procesos argumentativos en el Bachillerato de LOGSE de Matemáticas aplicadas a las Ciencias Sociales I y II en el currículo de enseñanzas mínimas, en el currículo completo estatal y en el de Castilla y León en la modificación de 2001.

No obstante, en la misma línea que en las asignaturas Matemáticas I y II, las referencias a la demostración que hay en el currículo completo estatal son las mismas que en el currículo de enseñanzas mínimas, y sólo observamos una pequeña ampliación (un contenido más) en el currículo de Castilla y León (el contenido número 11, desarrollar el gusto por la belleza presente en teorías, demostraciones, formas y figuras matemáticas, y apreciar la relación entre las matemáticas y las artes). 


\section{II.3.3. Ley Orgánica de Educación (2006)}

Tras la paralización de la LOCE en 2004, en 2006, el gobierno promulgó la ley educativa vigente en la actualidad, o al menos en los cursos que nos ocupan: la Ley Orgánica 2/2006, de 3 de mayo, de Educación (LOE; Jefatura del Estado, 2006). Esta ley recibe la influencia de los documentos y programas de evaluación desarrollados desde finales de la década de los 80, como son los Estándares Curriculares del National Council of Teachers of Mathematics de 1989 (NCTM, 1991 y 2000), las competencias PISA (OCDE, 1999 y 2003) y el Danish KOM Project (Niss, 2002). Esta influencia hace que, frente a legislaciones anteriores, se incluya en su currículo las competencias básicas como novedad, pero sólo para la Educación Primaria y Secundaria, por lo que éstas no aparecen en los currículos de Bachillerato. Por su parte, la estructura del sistema educativo es similar al de la legislación anterior, LOGSE, y no se observan modificaciones importantes que se deban considerar aquí.

El Bachillerato se estructura en tres modalidades diferentes, Artes, Ciencias y Tecnología, y Humanidades y Ciencias Sociales. Dentro de cada modalidad, los alumnos deberán cursar materias comunes, materias de la modalidad y materias optativas, debiendo cursar un mínimo de seis materias de la modalidad entre los dos cursos, cinco de las cuales deben ser específicas de la modalidad elegida. Sólo las modalidades de Ciencias y Tecnología, y Humanidades y Ciencias Sociales cuentan con matemáticas entre sus materias de modalidad, que reciben el nombre de Matemática I y II en el primer caso y Matemáticas Aplicadas a las Ciencias Sociales I y II en el segundo.

Tal y como ocurría en el periodo anterior, las competencias educativas están derivadas a las Comunidades Autónomas, por lo que el entonces Ministerio de Educación y Ciencia, más tarde Ministerio de Educación, Política Social y Deporte y, actualmente el Ministerio de Educación, Cultura y Deporte, sólo fija un porcentaje del currículo, siendo las Autonomías las que regulan el resto. Dichas concreciones mínimas, comunes para todo el territorio español, se encuentran en el Real Decreto 1467/2007, de 2 de noviembre, por el que se establece la estructura del Bachillerato y se fijan sus enseñanzas mínimas (Ministerio de Educación y Ciencia, 2007). Además, para los centros que dependen directamente del ámbito de gestión del Ministerio, se promulga el siguiente documento: ORDEN ESD/1729/2008, de 11 de junio, por la que se 
regula la ordenación y se establece el currículo del Bachillerato (Ministerio de Educación, Política Social y Deporte, 2008), que completa el currículo anterior. Tras revisar ambos documentos, se observa que, en el ámbito de las Matemáticas, ambos coinciden casi en su totalidad, exceptuando que la Orden completa los contenidos de las asignaturas y añade un criterio de evaluación a Matemáticas I y II. Se muestran las referencias de ambos documentos en las mismas tablas (Tabla II.3.3.1 para Matemáticas I y II y Tabla II.3.3.2 para Matemáticas Aplicadas a las Ciencias Sociales I y II). En esta legislación, el currículo de Castilla y León es muy similar al que desarrolla el Estado e, incluso, se observa que en relación con la demostración y procesos similares, es más escueto que el estatal. Por esta razón, se incluye una referencia diferente que aparece en la introducción del currículo de Castilla y León, pero no se incluyen las tablas correspondientes pues no aportan nada nuevo y repiten lo que se incluyen en las

Tablas II.3.3.1 y II.3.3.2.

\begin{tabular}{|c|c|}
\hline \multicolumn{2}{|c|}{ Matemáticas I y II } \\
\hline $\begin{array}{l}\text { Introducción } \\
\text { (currículo } \\
\text { de } \\
\text { enseñanzas } \\
\text { mínimas y } \\
\text { estatal) }\end{array}$ & $\begin{array}{l}\text { Las definiciones formales, las demostraciones (reducción al absurdo, contraejemplos) y } \\
\text { los encadenamientos lógicos (implicación, equivalencia) dan validez a las intuiciones y } \\
\text { confieren solidez a las técnicas aplicadas. Sin embargo, este es el primer momento en } \\
\text { que el alumno se enfrenta con cierta seriedad al lenguaje formal, por lo que el } \\
\text { aprendizaje debe ser equilibrado y gradual. El simbolismo no debe desfigurar la esencia } \\
\text { de las ideas fundamentales, el proceso de investigación necesario para alcanzarlas, o el } \\
\text { rigor de los razonamientos que las sustentan. Deberá valorarse la capacidad para } \\
\text { comunicar con eficacia esas ideas aunque sea de manera no formal. Lo importante es que } \\
\text { el estudiante encuentre en algunos ejemplos la necesidad de la existencia de este } \\
\text { lenguaje para dotar a las definiciones y demostraciones matemáticas de universalidad, } \\
\text { independizándolas del lenguaje natural. }\end{array}$ \\
\hline $\begin{array}{l}\text { Introducción } \\
\text { (currículo } \\
\text { de Castilla y } \\
\text { León) }\end{array}$ & $\begin{array}{l}\text { - En Bachillerato se comienza, de forma suave y gradual, a dar respaldo teórico a los } \\
\text { conocimientos matemáticos mediante la introducción de definiciones, la } \\
\text { demostración de teoremas y la realización de encadenamientos lógicos. } \\
\text { - Las capacidades de análisis y síntesis, de abstracción y concreción, de generalización } \\
\text { y particularización, de formulación de conjeturas y su comprobación, de crítica, de } \\
\text { rigor y de formalización, presentes en el hacer normal de la materia, deben llegarle al } \\
\text { alumno de forma natural, y contribuir así a mejorar su intelecto y a adquirir unos } \\
\text { hábitos y actitudes que trascienden del ámbito de las propias Matemáticas. }\end{array}$ \\
\hline Objetivos & $\begin{array}{l}\text { 2. Considerar las argumentaciones razonadas y la existencia de demostraciones } \\
\text { rigurosas sobre las que se basa el avance de la ciencia y la tecnología, mostrando una } \\
\text { actitud flexible, abierta y critica ante otros juicios y razonamientos. } \\
\text { 3. Utilizar las estrategias características de la investigación científica y las destrezas } \\
\text { propias de las matemáticas (planteamiento de problemas, planificación y ensayo, } \\
\text { experimentación, aplicación de la inducción y deducción, formulación y aceptación o } \\
\text { rechazo de las conjeturas, comprobación de los resultados obtenidos) para realizar } \\
\text { investigaciones y en general explorar situaciones y fenómenos nuevos. } \\
\text { 6. Utilizar el discurso racional para plantear acertadamente los problemas, justificar } \\
\text { procedimientos, encadenar coherentemente los argumentos, comunicarse con } \\
\text { eficacia y precisión, detectar incorrecciones lógicas y cuestionar aseveraciones carentes }\end{array}$ \\
\hline
\end{tabular}




\begin{tabular}{|c|c|}
\hline & $\begin{array}{l}\text { de rigor científico. } \\
\text { 7. Mostrar actitudes asociadas al trabajo científico y a la investigación matemática, tales } \\
\text { como la visión crítica, la necesidad de verificación, la valoración de la precisión, el } \\
\text { interés por el trabajo cooperativo y los distintos tipos de razonamiento, el } \\
\text { cuestionamiento de las apreciaciones intuitivas y la apertura a nuevas ideas. }\end{array}$ \\
\hline $\begin{array}{l}\text { Criterios de } \\
\text { evaluación I }\end{array}$ & $\begin{array}{l}\text { 7. Realizar investigaciones en las que haya que organizar y codificar informaciones, } \\
\text { seleccionar, comparar y valorar estrategias para enfrentarse a situaciones nuevas con } \\
\text { eficacia, eligiendo las herramientas matemáticas adecuadas en cada caso. } \\
\text { Se pretende evaluar la madurez del alumnado para enfrentarse con situaciones nuevas } \\
\text { procediendo a su observación, modelado, reflexión y argumentación adecuada, usando } \\
\text { las destrezas matemáticas adquiridas. Tales situaciones no tienen por qué estar } \\
\text { directamente relacionadas con contenidos concretos; de hecho, se pretende evaluar la } \\
\text { capacidad para combinar diferentes herramientas y estrategias, independientemente del } \\
\text { contexto en que se hayan adquirido. }\end{array}$ \\
\hline $\begin{array}{l}\text { Criterios de } \\
\text { evaluación } \\
\text { II }\end{array}$ & $\begin{array}{l}\text { 7. Utilizar los medios tecnológicos para obtener y procesar información que faciliten la } \\
\text { interpretación y la resolución de problemas sobre aspectos propios de la realidad. } \\
\text { - Se pretende que el alumnado maneje la información extraída de diversas fuentes y } \\
\text { que utilice las tecnologías a su alcance para realizar investigaciones, modelizar } \\
\text { situaciones, facilitar los cálculos, extraer información, hacer interpretaciones y } \\
\text { comprobaciones, y procesar datos de naturaleza matemática, evaluando la reflexión } \\
\text { lógico-deductiva, los modos de argumentación y las destrezas propios de las } \\
\text { matemáticas. } \\
\text { 8. Realizar investigaciones en las que haya que organizar y codificar informaciones, } \\
\text { seleccionar, comparar y valorar estrategias para enfrentarse a situaciones nuevas con } \\
\text { eficacia, eligiendo las herramientas matemáticas adecuadas en cada caso. } \\
\text { - Se pretende evaluar la madurez del alumnado para enfrentarse a situaciones nuevas } \\
\text { procediendo a su observación, modelado, reflexión y argumentación adecuada, } \\
\text { usando las destrezas matemáticas adquiridas. Tales situaciones no tienen que estar } \\
\text { directamente relacionadas con contenidos concretos; de hecho, se pretende evaluar } \\
\text { la capacidad para combinar diferentes herramientas y estrategias, } \\
\text { independientemente del contexto en el que se hayan adquirido. }\end{array}$ \\
\hline
\end{tabular}

Tabla II.3.3.1. Referencias a la demostración o procesos argumentativos en Matemáticas I y II del Bachillerato de LOE en el currículo de enseñanzas mínimas, en el currículo completo estatal y en el currículo de Castilla y León.

Se puede observar que el currículo promulgado en esta legislación es mucho más extenso y detallado que sus predecesores, al menos en relación a las referencias localizadas en torno a la demostración matemática y a otros procesos de justificación. Se mencionan algunas técnicas concretas de justificación (reducción al absurdo, contraejemplos), menciones que no se realizaban anteriormente en los documentos curriculares.

Por otra parte, se observa el mismo patrón que en las legislaciones anteriores: las referencias a la demostración son más escasas en las asignaturas de Matemáticas Aplicadas a las Ciencias Sociales I y II, lo que vuelve a reafirmar en limitar la selección de la muestra a los textos de Matemáticas I y II. 


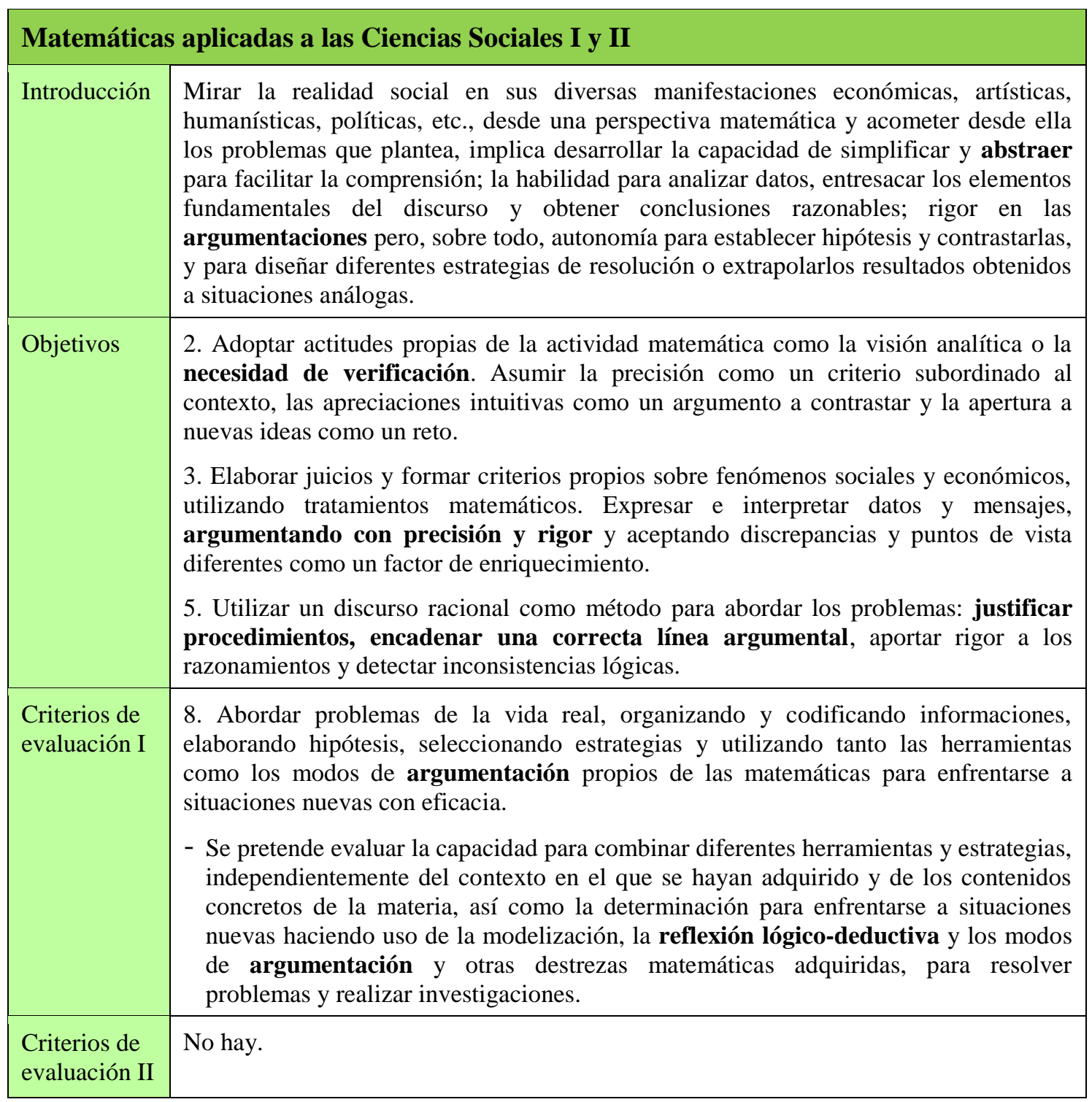

Tabla II.3.3.2. Referencias a la demostración o procesos argumentativos en Matemáticas aplicadas a las Ciencias Sociales I y II del Bachillerato de LOE en el currículo de enseñanzas mínimas, en el currículo completo estatal y en el currículo de Castilla y León.

\section{II.3.4. Ley Orgánica para la Mejora de la Calidad Educativa} (2013)

En el año 2013, el Gobierno promulga una nueva ley de educación, la Ley Orgánica 8/2013, de 9 de diciembre, para la mejora de la calidad educativa (Jefatura del Estado, 2013), que modifica algunos aspectos de la legislación vigente, LOE. Entre ellos, modifica el Bachillerato, redefiniendo los itinerarios, el currículo y estableciendo una prueba de evaluación final cuya superación será necesaria para la obtención del título. Su implantación se llevará a cabo a partir 
del curso 2015-16, realizándose en dicho curso la implantación de $1^{\circ}$ de Bachillerato, y en el curso siguiente, la implantación de $2^{\circ}$ de Bachillerato y de la prueba de evaluación final, aunque ésta última no tendrá validez académica hasta el curso 2017-18. Entre otras modificaciones, encontramos que la estructura y elementos del currículo han cambiado: los objetivos ya no se definen por materia, sino de forma común para toda la etapa. Por otro lado, cada materia está organizada en contenidos, criterios de evaluación y estándares de aprendizaje (Jefatura del Estado, 2013).

La primera concreción del currículo de Bachillerato para esta nueva legislación la encontramos en el Real Decreto 1105/2014, de 26 de diciembre, por el que se establece el currículo básico de la Educación Secundaria Obligatoria y del Bachillerato (Ministerio de Educación, Cultura y Deporte, 2015), promulgado a principios de enero de 2015. En él se especifican los contenidos, los criterios de evaluación y los estándares de aprendizaje que deberían tratarse en estas etapas. Como novedad frente a las concreciones curriculares anteriores, se ha incorporado un bloque transversal en todas las asignaturas de Matemáticas llamado Procesos, métodos y actitudes hacia las matemáticas que incluye una serie de contenidos no relacionados específicamente con ningún área de las matemáticas sino más relacionado con el propio quehacer matemático. En este bloque es donde se localizan las referencias a la demostración matemática, pero estas referencias no garantizan su existencia.

En el caso de las Matemáticas Aplicadas a las Ciencias Sociales (I y II, relativas a $1^{\circ}$ y $2^{\circ}$ de Bachillerato respectivamente) no se encuentran referencias a la demostración matemática, exceptuando una mención a la argumentación en la introducción de la asignatura. Sin embargo, en los contenidos del bloque 1 Procesos, Métodos y Actitudes en Matemáticas, correspondientes a las Matemáticas I y II ( $1^{\circ}$ y $2^{\circ}$ de Bachillerato) aparece lo siguiente:

Iniciación a la demostración en matemáticas: métodos, razonamientos, lenguajes, etc.

- Métodos de demostración: reducción al absurdo, método de inducción, contraejemplos, razonamientos encadenados, etc.

- Razonamiento deductivo e inductivo.

- Lenguaje gráfico, algebraico, otras formas de representación de argumentos.

- Elaboración y presentación oral y/o escrita de informes científicos sobre el proceso seguido en la resolución de un problema o en la demostración de un resultado matemático. 
(Ministerio de Educación, Cultura y Deporte, 2015, pp. 414 y 419)

Estos contenidos se acompañan de criterios de evaluación y estándares de aprendizaje evaluables relacionados con ellos, en los que también se menciona la demostración. Por ejemplo, para ambos cursos, el criterio de evaluación 3 dice lo siguiente:

3. Realizar demostraciones sencillas de propiedades o teoremas relativos a contenidos algebraicos, geométricos, funcionales, estadísticos y probabilísticos.

(Ministerio de Educación, Cultura y Deporte, 2015, pp. 414 y 419)

Este criterio de evaluación se acompaña de los siguientes estándares de aprendizaje evaluables, también comunes a ambos cursos:

3.1. Utiliza diferentes métodos de demostración en función del contexto matemático.

3.2. Reflexiona sobre el proceso de demostración (estructura, método, lenguaje y símbolos, pasos clave, etc.).

(Ministerio de Educación, Cultura y Deporte, 2015, pp. 414 y 419)

En esta nueva legislación el aprendizaje de la demostración es obligatorio y se considera transversal a todos los contenidos, como se refleja en los criterios y estándares de evaluación correspondientes a los contenidos descritos en la cita anterior. No obstante, dado que los libros de texto de un curso no se publican hasta que se implanta dicho curso, no existirán libros correspondientes al Bachillerato de LOMCE hasta el curso 2015-16, que es el primero en el que se imparte, y por tanto, no se incluyen en este análisis. Sin embargo, de deja abierta la posibilidad de analizar estos textos en un futuro inmediato y estudiar cómo se han reflejado estas novedades y nuevas menciones sobre la demostración, a las técnicas y a otros aspectos relacionados con el proceso de demostrar en los libros correspondientes a esta nueva legislación.

\section{II.4. MARCO TEÓRICO: CATEGORÍAS DE ANÁLISIS}

Una vez revisados los trabajos realizados en torno a los dos ejes que vertebran nuestra investigación, la demostración matemática y los libros de texto, se han seleccionado los elementos que permiten organizar el análisis y obtener la información buscada. Se considera, como referencia inicial, el trabajo desarrollado por Ibañes (2001) en su tesis doctoral y los trabajos relacionados con ésta (Ibañes y Ortega, 1997, 2001a, 2001b, 2002a, 2002b, 2004b, 2005) 
sobre los esquemas de prueba y otros elementos de análisis de la demostración matemática. Una primera revisión de estos trabajos permitió establecer una primera versión de las categorías de análisis con la que se empezó el análisis, fundadas en las categorías consideradas por Ibañes y Ortega en sus trabajos, pero con las modificaciones necesarias para adaptarlas al objeto de este estudio, los libros de texto, en lugar de los estudiantes, en los que se centra el trabajo de Ibañes y Ortega. En el transcurso del análisis, dichas categorías tuvieron que ser revisadas y, en su caso, eliminadas, modificadas y añadidas a las que ya se tenían, debido a las necesidades que surgían al considerar los datos que se encontraban en los textos.

Dada la importancia que tiene un buen marco teórico, y la posible replicabilidad de un estudio, se consideró que era de gran importancia realizar una descripción minuciosa de cada una de las categorías utilizadas y, para mayor claridad, mostrar un ejemplo de aquellas que presenten más dificultades. Con esto, se pretende que cualquier lector comprenda perfectamente cada uno de los elementos que se considera en el análisis.

Las categorías de análisis que se consideran se organizan en seis grandes grupos: esquemas de prueba (Harel \& Sowder, 1998, Ibañes, 2001b, y Dos Santos, 2010), técnicas empleadas (Ibañes y Ortega, 2001a, 2002b), funciones de la demostración (Bell, 1976; de Villiers, 1993), reconocimiento de procesos, expresiones que utiliza y consideraciones globales (Ibañes y Ortega, 1997, 2002b, 2004b). A continuación se presenta su descripción detallada, así como ejemplos ilustrativos de las categorías descritas.

\section{II.4.1. Clase de justificación utilizada (esquemas de prueba)}

El esquema de prueba (EP) de una persona, tal y como lo definen Harel \& Sowder (1998), y que ha sido utilizado por Ibañes (2001) y Dos Santos (2010), consiste en lo que constituye persuasión y convencimiento para esa persona, entendiendo como convencimiento el proceso utilizado por un individuo para eliminar sus dudas sobre la veracidad de una afirmación y como persuasión el proceso utilizado por un individuo para eliminar las dudas de otros sobre la veracidad de una afirmación. En este caso, no se analizan los esquemas de prueba personales, sino los que aparecen en los libros de texto (LT), por lo que se 
debe puntualizar dicha definición, aunque se mantenga la perspectiva del aprendiz. No obstante, los aprendices o lectores de los LT son variados y diversos y, en el presente trabajo, no se trata de indicar cuáles son los esquemas de prueba de dichos aprendices (se estarían considerando de nuevo los esquemas de prueba personales), sino los procesos de justificación que muestran los LT y que reúnen características similares a los esquemas de prueba personales definidos por Harel \& Sowder.

Por tanto, se dice que un esquema de prueba de un libro de texto consiste en $l o$ que el libro de texto muestra que podría constituir persuasión y convencimiento para un posible lector, en este caso, un estudiante de matemáticas del nivel para el que está diseñado el libro, entendiendo como convencimiento el proceso impreso en el LT que podría eliminar las dudas del posible lector sobre la veracidad de una afirmación y como persuasión, el proceso del libro, con el cual, el posible lector podría eliminar las dudas de otros sobre la veracidad de una afirmación.

La consideración de este marco teórico y de la definición de esquema de prueba parte de los resultados de los estudios que se han citado anteriormente sobre los esquemas de prueba de los alumnos (Harel \& Sowder, 1998), enriquecido por (Ibañes y Ortega, 2001) en los que comprobaron que los alumnos se encuentran en estados de transición entre varios esquemas de prueba, especialmente desde los empíricos (inductivos de un caso) hasta los axiomáticos (dinámicos y estáticos). Los alumnos consideran válido alguno de ellos en detrimento de los demás, eligiendo entre los de la Tabla II.4.1.1 generada por estos autores.

\begin{tabular}{|l|l|l|l|l|}
\hline \multicolumn{2}{|l|}{ Esquemas de prueba } \\
\hline \multirow{2}{*}{$\begin{array}{l}\text { De } \\
\text { convicción } \\
\text { externa }\end{array}$} & Empíricos & Experimentales & Estático/Dinámico & Analíticos \\
\cline { 3 - 4 } & Transformacionales & $\begin{array}{l}\text { Estático/dinámico } \\
\text { Particular/general } \\
\text { Incompleto/completo }\end{array}$ \\
\cline { 3 - 3 } & Falso/ auténtico & & \\
\cline { 3 - 3 } & Un caso/varios casos & & \\
\cline { 5 - 5 } & $\begin{array}{l}\text { Sistemático/no } \\
\text { sistemático }\end{array}$ & \multicolumn{3}{|l|}{ Intuitivo-Axiomáticos } \\
\hline
\end{tabular}

Tabla II.4.1.1. Clasificación de los esquemas de prueba de los alumnos desarrollada por Ibañes y Ortega.

Sin embargo, como ya se ha mencionado anteriormente, el objetivo no es clasificar esquemas de pruebas personales, sino los esquemas de prueba que aparecen escritos en los libros de texto, y por esta razón, se están analizando los procesos que aparecen en los LT cuyas características coinciden con alguna de 
las categorías descritas por Ibañes y Ortega y que, por tanto, pueden inducir a los alumnos a considerar ese proceso como un tipo de esquema de prueba válido.

Esta puntualización influye en la descripción de las categorías de clasificación de los EP. Si bien se ha partido de aquellas descritas por Ibañes (2001) e Ibañes y Ortega (2001), no todas son susceptibles de aparecer reflejadas en los LT. En nuestra opinión, carece de sentido considerar los EP de convicción externa o algunos de los inductivos descritos en Ibañes (2001) en los LT, debido la naturaleza de dichos EP. Sin embargo, sí que se deben incluir en las categorías de EP de los LT las pruebas preformales (PP), descritas por van Asch (1993) y analizadas por González (2012), ya que pueden constituir persuasión y convencimiento para un posible lector. Se entiende por prueba preformal una línea de razonamiento, que podría formalizarse a una prueba formal, y en la cual la idea esencial de la demostración se encuentra reflejada (van Asch, 1993). Este tipo de pruebas, sin ser una verificación experimental de un resultado, muestra un razonamiento matemático correcto, pero realizado sobre un elemento concreto y no general. Tras la definición de los EP y las PP, y siguiendo a Ibañes y Ortega (2001), se consideran las siguientes categorías:

1. No se hace ningún tipo de justificación del enunciado (EP0).

2. EP inductivo de un caso (EPi1): se trata de convencer de la validez de una conjetura mediante la evaluación cuantitativa de un caso particular.

3. EP inductivo de varios casos (EPiV): como en el caso anterior, pero se realiza con varios casos particulares.

4. EP inductivo sistemáticos (EPiS): como en los casos anteriores, pero los ejemplos particulares se eligen de forma organizada, cubriendo las posibles diferentes casuísticas.

5. EP transformacionales (EPt): se realizan transformaciones de imágenes o signos por medio de la deducción.

6. EP axiomáticos (EPa): se realiza la demostración a partir de axiomas, entendiendo como tales los enunciados primarios y los resultados que se han deducido mediante las correspondientes demostraciones.

7. Pruebas preformales (PP): se incluye como EP por su carácter de convencimiento y persuasión. Refleja la esencia de una demostración 
formal (EPt y EPa) y, por tanto, hereda el carácter axiomático y transformacional de estos EP.

Estas categorías no son excluyentes $\mathrm{y}$, de hecho, se pueden encontrar combinaciones de más de una de ellas en algunos casos. A continuación se muestran algunos ejemplos de algunas de las categorías expuestas anteriormente.

Teorema de Bolzano: sea $f(x)$ una función continua en intervalo cerrado y acotado [ $a$, $b$ ] de $\mathbb{R}$ y tal que signo de $f(a)$ y el signo de $f(b)$ son distintos, entonces existe al menos un punto $c$ del intervalo $[a, b]$ tal que $f(c)=0$.

Si no se considera ningún tipo de justificación ni explicación, entonces se trata de un EP0. También se podrían encontrar ejemplos en los que se verifique el teorema, pero no se induce el resultado a otras funciones.

\section{Esquema de Prueba:}

Consideremos una función que cumpla las hipótesis del enunciado, por ejemplo $f(x)=$ $x^{2}-1$, que es continua y acotada en el intervalo [0,3]. Evaluamos la función en los extremos del intervalo.

$$
f(0)=-1 \text { y } f(3)=8
$$

La función cambia de signo en los extremos del intervalo y para el punto $x=1, f(1)=0$, tal y como nos indica el teorema, por lo tanto, dicho resultado es cierto.

En este caso, nos encontramos ante un EPil, ya que considera un ejemplo, comprueba que el teorema se verifica, y de dicha comprobación induce que será cierto para cualquier función que verifique las condiciones pedidas.

Si dicha comprobación se realiza con varios ejemplos diferentes, entonces se trata de un EPiV, y si los ejemplos se eligen de forma sistemática, cubriendo varias posibles opciones diferentes (funciones afines, cuadráticas, racionales, trigonométricas,...), entonces es un EPiS. Obsérvese un ejemplo en el que se busquen los casos de forma sistemática:

Para el mismo teorema se trata de considerar todos los casos de funciones elementales. Para las funciones polinómicas el ejemplo anterior, para las trigonométricas $f(x)=\operatorname{sen}(x)$ en el intervalo $[-\pi / 2, \pi / 2]$, para las racionales $g(x)=\frac{x}{x^{2}+1}$ en $[-1,1]$.

Para las exponenciales $h(x)=\mathrm{e}^{x}-2$ en $[0,2]$.

Para las logarítmicas $k(x)=\log (x-1)$ en $[3 / 2,3]$.

Continuando con el teorema de Bolzano, veamos un ejemplo de PP. En este tipo de prueba se tienen que recoger las líneas claves del razonamiento de la demostración axiomática. 
Sea $f(x)=x^{2}-1$. Esta función es continua y acotada en el intervalo [0, 3] y, por tanto, cumple la hipótesis del teorema. Evaluemos la función en los extremos del intervalo.

$$
f(0)=-1 \text { y } f(3)=8
$$

Podemos pensar que si cambia de signo, por ser continua, en algún punto dentro del intervalo la función tomará el valor 0. Para verificar si existe dicho punto, vamos a reducir el intervalo. Consideramos el punto medio del intervalo [0,3], $x=3 / 2$.

$$
f(3 / 2)=5 / 4>0
$$

Si la función en $3 / 2$ hubiera tomado el valor 0 , habríamos encontrado nuestro punto, y demostrado el teorema. Como toma valor positivo, el nuevo intervalo [0, 3/2] cumple las hipótesis del teorema y tiene una amplitud que es la mitad que el intervalo anterior. Realizamos la misma operación, considerando el punto medio del nuevo intervalo, $x=3 / 4$.

$$
f(3 / 4)=-5 / 16<0
$$

Si hubiera tomado el valor 0 en el punto $x=3 / 4$, entonces habríamos acabado, pero al ser negativo, el nuevo intervalo [3/4, 3/2], cuya amplitud es la mitad que la del intervalo anterior, cumple las hipótesis del teorema, por lo que podemos repetir el proceso.

Si se sigue realizando la misma operación, o bien se encuentra un valor de $x$ para el que la función se anula (imposible en este caso por la irracionalidad de $\sqrt{2}$, o bien repetiremos el proceso indefinidamente, obteniendo siempre intervalos encajados en los anteriores que cumplen las hipótesis del teorema, y cuya amplitud es siempre la mitad del intervalo anterior. Si consideramos la sucesión de las amplitudes de dichos intervalos, $3,3 / 2,3 / 4, \ldots, 3 / 2^{\mathrm{n}}, \ldots$, cuando $n$ tiende a $\infty$, dicha sucesión tiende a 0 , y por el principio de los intervalos encajados, la intersección de todos ellos es el punto $x=1$. Si $f(1)>0$, existiría un entorno de $x=1$ en el que la función sería positiva; pero esto es imposible ya que dicho entorno contiene a infinitos intervalos de la sucesión anterior y en todos sus extremos la función tiene signos diferentes; por tanto, $f(1) \leq 0$. Con un razonamiento análogo se establecería que $f(1) \geq 0$ y, en consecuencia $f(1)=0$.

EPt y EPa: Es frecuente que estos dos tipos de esquema de prueba se utilicen como parte de una demostración analítica tal es el caso de la prueba del teorema de Lagrange que se reproduce a continuación.

Teorema de Lagrange. Si $\mathrm{f}$ es continua en el intervalo $[a, b]$ y derivable en $(a, b)$, entonces existe algún punto $x_{0}$ perteneciente a $(a, b)$, tal que: $\frac{f(b)-f(a)}{b-a}=f^{\prime}\left(x_{0}\right)$.

Demostración: Se considera transformacional la función

$$
g(x)=f(x)-f(a)-\frac{f(b)-f(a)}{b-a}(x-a)
$$

Esta función cumple las hipótesis del Teorema de Rolle, $g(x)$ es una función continua en $[a, b]$ por serlo $f(x)$ y $g(a)=g(b)=0 \mathrm{y}$, por tanto, se puede aplicar su tesis y, en consecuencia: 
Existe al menos un punto $x_{0}$ perteneciente a $(a, b)$ en el que $g^{\prime}\left(x_{0}\right)=0$.

$g^{\prime}\left(x_{0}\right)=(b-a) \cdot f^{\prime}\left(x_{0}\right)-[f(b)-f(a)]=0$.

Por tanto,

$$
\frac{f(b)-f(a)}{b-a}=f^{\prime}\left(x_{0}\right) .
$$

Una prueba más transformacional que la anterior de este mismo teorema consiste en aplicar un cambio de sistema de coordenadas, haciendo que la secante ( $a$, $f(a))-(b, f(b))$ sea paralela al eje de abscisas. La Figura II.4.1.1 muestra esta transformación.

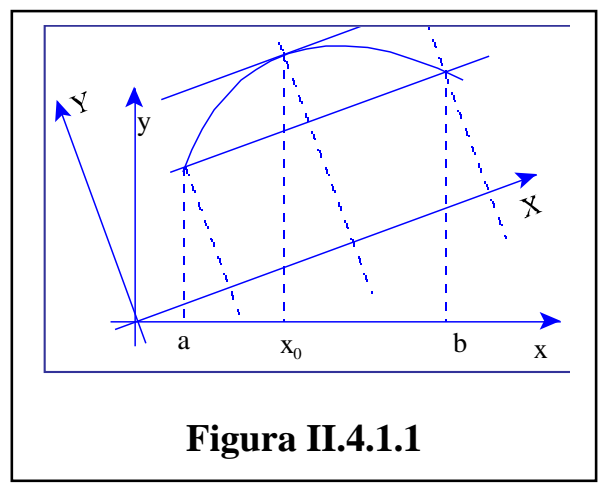

\section{II.4.2. Técnicas empleadas}

Se utiliza la clasificación de demostraciones realizada por Ibañes y Ortega (1997) desde la perspectiva de la propia matemática. Se clasifican los esquemas de prueba de los LT atendiendo a las técnicas empleadas para la demostración, esto es, atendiendo al tipo, método, estilo y modo de EP utilizado. Se describen brevemente las características de cada una de estas técnicas:

1. Tipo: atendemos a la estructura lógica del enunciado, ya que consideramos que la forma de enunciar éste influye en el tipo de EP utilizado.

a. En relación a la implicación puede ser de condición necesaria $(\mathrm{CN})$, suficiente $(\mathrm{CS})$, y necesaria y suficiente.

b. En relación al cuantificador universal, puede ser de existencia simple, imposibilidad, y existencia y unicidad.

La clasificación de los enunciados según estas categorías resulta inmediata si los enunciados de los teoremas contienen a los conectores que son propios de cada una. Sin embargo, tanto en la práctica, como en los libros de texto, aparecen otros enunciados cuya estructura no parece ajustarse a estos tipos, ya que no utilizan dichos conectores de forma explícita, y que puede suponer una dificultad a la hora de reconocer los teoremas por parte de los alumnos, como ya estudiaron Ibañes y Ortega (1997). Los tipos de enunciados que describe Ibañes son los siguientes:

- Enunciado "si..., entonces". 
- Hipótesis y tesis mezcladas. Ejemplo: Las bisectrices de dos ángulos adyacentes suplementarios son perpendiculares.

- Hipótesis implícita. Ejemplo: $\operatorname{sen}(2 x)=2 \cdot \operatorname{sen}(x) \cdot \cos (x)$.

- Cuantificador universal explícito. Ejemplo: Para todo triángulo, los lados son proporcionales a los senos de los ángulos opuestos.

- Enunciado de "condición suficiente". Ejemplo: Dos triángulos son semejantes si tienen dos de sus ángulos respectivamente iguales.

- Enunciado de "condición necesaria y suficiente". Ejemplo: Si dos rectas paralelas son cortadas por una transversal, entonces forman ángulos correspondientes congruentes y, recíprocamente, si dos rectas forman ángulos correspondientes congruentes al ser cortadas por una transversal, entonces son paralelas.

La estructura de estos enunciados condiciona el tipo de prueba. Sin embargo, no es un objetivo de la tesis analizar los enunciados de los teoremas propiamente sino las justificaciones. Dejamos como problema para futuras investigaciones el estudio de la relación existente, si la hay, en los libros de texto entre los enunciados mostrados y los tipos de EP utilizados en los libros.

2. Método: atendemos a los procedimientos lógicos utilizados en el EP. Puede ser por silogismo, por casos, por reducción al absurdo, por inducción completa, constructivo, ya sea de ejemplo o contraejemplo, por analogía y por dualidad. Únicamente tiene sentido considerar estás categorías en los EP axiomáticos, transformacionales o en las Pruebas Preformales.

El tipo y el método son dos categorías sobradamente conocidas en la comunidad matemática, por lo que no creemos que sea necesario mostrar ejemplos que las ilustren.

3. Estilo: atendiendo a los procedimientos matemáticos. El estilo depende de la rama de las matemáticas en la que nos encontramos. En este caso, como estudiamos las justificaciones de los resultados correspondientes al Análisis Matemático, el estilo más habitual será el propio del área (Álgebra, Geometría, Análisis,...), aunque puede ser de dos tipos: global, cuando se aplican teoremas y local, si realiza una discusión en un entorno. También podemos encontrar estilos gráficos, utilizando coordenadas, y 
algebraicos, de los que estos últimos están caracterizados principalmente por la manipulación simbólica. En general, esta categoría tiene sentido si se trata de EP axiomáticos, transformacionales o PP, pero en el caso de EP inductivos de uno o varios casos y sistemáticos haremos la distinción de si el EP es algébrico o gráfico.

$\mathrm{Si}$ se considera la prueba preformal del teorema de Bolzano descrita anteriormente, se aprecia que el razonamiento se realiza en un entorno del punto, observando lo que ocurre cuando se realizan razonamientos en el infinito; estaríamos hablado de una estilo del análisis matemático local. Sin embargo, si se considera el teorema de Darboux justificado de la siguiente manera, se aprecia otro estilo:

Teorema de Darboux o de los Valores Intermedios: Sea $f(x)$ una función continua en el intervalo cerrado y acotado $[a, b], f(a) \neq f(b)$ y sea $k$ un punto comprendido entre $f(a)$ y $f(b)$. Entonces, existe al menos un punto $c$ del intervalo $[a, b]$ tal que $f(c)=k$.

\section{Demostración:}

Sea $f(x)$ una función continua en el intervalo $[a, b]$, supongamos que $f(a)<f(b)$ y sea $k$ tal que $f(a)<k<f(b)$. Consideremos la función auxiliar $g(x)$ definida de la siguiente manera:

$$
g(x)=f(x)-k
$$

Dicha función es continua en $[a, b]$, por ser diferencia de una función continua y una constante, y además tiene distinto signo en los extremos del intervalo:

$$
g(a)=f(a)-k<0 \text { y } g(b)=f(b)-k>0
$$

Entonces, $g$ cumple las hipótesis del teorema de Bolzano, y por tanto, existe $c$ perteneciente a $[a, b]$ tal que:

$$
g(c)=0 \Rightarrow f(c)-k=0 \Rightarrow f(c)=k
$$

En esta demostración, el estilo es del Análisis Matemático, pero en este caso se aplica un teorema anterior de manera general, sin hacer razonamientos en el infinito, por lo que se clasificaría como global.

Veamos a continuación el teorema de conservación de signo:

Teorema de conservación de signo: Si $f$ es una función continua en $x_{0}$ y $f\left(x_{0}\right) \neq 0$, existe un entorno de $x_{0}$ en el cual $f$ tiene el mismo signo que $f\left(x_{0}\right)$.

\section{Demostración:}

Supongamos que $f\left(x_{0}\right)>0$. Tomamos $\varepsilon=\frac{f\left(x_{0}\right)}{2}$. Por ser $f$ continua en $x_{0}$, existe un entorno $\mathrm{E}\left(x_{0}, \delta\right)$ tal que si $x$ pertenece al entorno, entonces

$$
f\left(x_{0}\right)-\frac{f\left(x_{0}\right)}{2}<f(x)<f\left(x_{0}\right)+\frac{f\left(x_{0}\right)}{2}
$$


es decir, $f(x)>\frac{f\left(x_{0}\right)}{2}>0$, por lo tanto tiene el mismo signo que $f\left(x_{0}\right)$. Análogamente se demostraría para $f\left(x_{0}\right)<0$.

Como se observa, en este caso el razonamiento realizado es local, ya que se estudia el comportamiento en un entorno del punto, recurriendo a procesos en el límite.

4. Modo: en función del procedimiento de exposición. Puede ser sintético o directo, y analítico o indirecto.

a. El modo sintético o directo: se utilizan los conceptos básicos para razonar.

b. El modo analítico o indirecto, se utilizan elementos que ya han sido justificados anteriormente.

Veamos la diferencia entre ambos modos:

Halla la derivada de la función $f(x)=\frac{x}{x^{2}-2}$ en $x=2$.

Directa: Utilizamos la definición de derivada y evaluamos en el punto.

$$
\begin{aligned}
& f^{\prime}(2)=\lim _{x \rightarrow 2} \frac{\frac{x}{x^{2}-2}-1}{x-2}=\lim _{x \rightarrow 2} \frac{x-x^{2}+2}{\left(x^{2}-2\right)(x-2)}= \\
& =\lim _{x \rightarrow 2} \frac{-(x-2)(x+1)}{\left(x^{2}-2\right)(x-2)}=\lim _{x \rightarrow 2} \frac{-(x+1)}{\left(x^{2}-2\right)}=\frac{-3}{2}
\end{aligned}
$$

Analítica: Utilizamos las reglas de derivación que se han obtenido: Derivada del cociente de dos funciones derivables.

$$
\left.\frac{1\left(x^{2}-2\right)-x \cdot 2 x}{\left(x^{2}-2\right)^{2}}\right|_{x=2}=\left.\frac{x^{2}-2-2 x^{2}}{\left(x^{2}-2\right)^{2}}\right|_{x=2}=\frac{-6}{4}=\frac{-3}{2}
$$

El modo es una categoría que, al igual que el estilo o el método, sólo tiene sentido en el caso de EP axiomático, transformacionales y pruebas preformales.

Estas categorías permiten clasificar diversos aspectos de la demostración matemática, lo que nos ofrece una visión más amplia de la clasificación de las justificaciones.

\section{II.4.3. Funciones de la demostración}

El primer modelo considerado es de Bell (1976) y el segundo el que, basándose en éste, construyó posteriormente de Villiers (1993). Este modelo sobre las funciones de la demostración ha sido considerado en varias investigaciones sobre 
la demostración matemática. Para realizar la investigación que aquí se describe, también son interesantes las investigaciones de Ibañes (2001) y Dos Santos (2010). En el primer modelo, Bell únicamente consideraba tres funciones: verificación o justificación, iluminación (una buena demostración debe proporcionar ideas de por qué la proposición es cierta) y sistematización. Posteriormente, de Villiers modifica dicha clasificación y propone cinco funciones de la demostración matemática: verificación, explicación, sistematización, descubrimiento y comunicación. Este autor sostiene que la demostración no es un requisito para la convicción, sino al contrario. En muchas ocasiones, la intuición es la que convence de la veracidad de un resultado y una vez llegado a ese convencimiento, se motiva la demostración. Por esta razón destaca la explicación como una función primordial en la enseñanza de la demostración y de las matemáticas (Ibañes, 2001). En esta misma línea, Hersh (1993) distingue entre la finalidad de las demostraciones en investigación matemática y en el aula: en el primer caso, su finalidad es convencer, siendo el público a convencer los expertos en la materia; en el segundo caso, el fin de la demostración es explicar el resultado, clarificar por qué el teorema es verdad, lo que ayuda a convencer a los estudiantes. Las funciones de la demostración que se han considerado en esta investigación son las postuladas por de Villiers y a continuación se describe la significación de las mismas que se ha considerado:

1. Verificación: concerniente a la veracidad de una afirmación.

2. Explicación: profundización en por qué es verdad.

3. Sistematización: la organización de varios resultados dentro de un sistema de axiomas, conceptos fundamentales y teoremas. Esta función se supone que el autor del LT ya la ha realizado antes de diseñarlo. No obstante, podría ocurrir que en algunos casos la sistematización no se hubiera realizado de forma correcta.

4. Descubrimiento: cuando la demostración de un resultado lleva implícita la demostración de otros y permite el "descubrimiento" o "invención" de nuevos resultados.

5. Comunicación: la transmisión del conocimiento matemático.

Se ha aplicado este modelo a cada EP que aparece en los LT tratando de descubrir cuáles de estas funciones son consideradas. También se ha considerado 
la posibilidad de que no aparezca explícitamente ninguna de las funciones y de que se observen otras diferentes. Este análisis puede reflejar la intencionalidad del autor: verificativa, explicativa,... Para ver más claramente cómo se reflejan dichas funciones, se describen los siguientes ejemplos.

\section{II.4.3.1. Sistematización}

En este primer ejemplo consideraremos una justificación del teorema de Bolzano, en la que podemos apreciar la función de sistematización.

Consideramos varias funciones:

$$
\begin{aligned}
& f(x)=x^{3}+2 x-2 \\
& g(x)=\operatorname{sen}(x-1) \\
& h(x)=\log (x-1)
\end{aligned}
$$

Para ver si esas funciones se anulan, es decir, si sus gráficas cortan al eje de abscisas, se puede observar en cada caso si tienen signo distinto algunos de los valores de cada función. Después se puede considerar que esos valores de la variable en los que la función cambia de signo se pueden considerar extremos de un intervalo en el que la función es continua.

$$
\begin{aligned}
f(0) & <0 \text { y } f(1)>0 \\
g(0) & <0 \text { y } g(3)>0 \\
h(5 / 4) & <0 \text { y } h(9 / 4)>0
\end{aligned}
$$

Parece razonable pensar que si cambia de signo en los extremos de los intervalos considerados antes pueda existir, en cada uno, un punto en el que la función se anule. Podríamos reducir cada intervalo un poco por la izquierda y otro poco por la derecha sin que la función cambie el signo en estos extremos del que tenía en los extremos anteriores.

$$
\begin{aligned}
& f(1 / 4)<0 \text { y } f(3 / 4)>0 \\
& g(1 / 4)<0 \text { y } g(7 / 4)>0 \\
& h(1,3)<0 \text { y } h(2,3)>0
\end{aligned}
$$

También podríamos considerar la mitad de la izquierda o la mitad de la derecha de dicho intervalo considerando el punto medio como nuevo extremo u origen.

$$
\begin{gathered}
f(1 / 2)<0 \text { y } f(1)>0 \\
g(0)<0 \text { y } g(3 / 2)>0 \\
h(7 / 4)<0 \text { y } h(9 / 4)>0
\end{gathered}
$$

Aquí se podría ver la importancia de que las funciones se anulen o cambien de signo en los nuevos extremos.

Pudiera ser que en los extremos de alguno de los subintervalos, la función correspondiente se anulara, pero si esto no sucede podemos volver a plantear una nueva 
reducción de intervalos. De esta manera, en cada caso se obtiene, o bien un cero, o bien una sucesión de intervalos encajados. Con estos procedimientos se obtendrían sucesiones de intervalos encajados de tal manera que el diámetro de un intervalo sería la mitad que la del anterior y, por tanto la sucesión de amplitudes tendería a cero (podríamos haber considerado otra formas de reducir los intervalos, pero generando siempre sucesiones de intervalos cuyo diámetro tendiera a cero)

El proceso más sencillo es cuando se consideran puntos intermedios, ya que se puede obtener una formulación general. La sistematización consiste en la iteración del proceso de considerar los intervalos $\left[a_{i}, b_{i}\right]$ siendo $a_{i}=a_{i-1}$ y $b_{i}$ el punto medio de $\left[a_{i-1}, b_{i-1}\right]$ o $a_{i}$ el punto medio del intervalo y $b_{i}=b_{i-1}$ de manera que $f\left(a_{i}\right) \cdot f\left(b_{i}\right)<0$ (el objetivo es encontrar un nuevo intervalo en el que se cumpla que las imágenes de los extremos tiene distinto signo). Esta iteración, que se puede generalizar a una función genérica, $f(x)$, y que formará parte de la demostración formal y rigurosa, ejemplifica un caso de sistematización, en el que se incorpora dicho procedimiento al corpus de la teoría matemática.

Como los libros presentan las demostraciones ya cerradas y no aparecen los procesos previos, la sistematización no aparece como tal dentro de una prueba determinada pero sí que aparece una sistematización más general en el constructo de los sucesivos enunciados y pruebas que deben guardar un orden de construcción matemática (que no tiene por qué ser única). En este análisis se examina si dicha sistematización se realiza de manera correcta, y sólo se considera esta función en los casos en que, o bien se muestre de forma explícita como en el ejemplo, o bien no se tenga en cuenta y sea necesario señalarlo. En los demás, se asume dicha función en la propia construcción y naturaleza del LT pero no se señala.

\section{II.4.3.2. Verificación}

La verificación del teorema es clara porque justamente la prueba justifica la veracidad del enunciado como algo irrefutable, que no necesita ejemplos, ni deja abierta la posibilidad de que existan contraejemplos. En el ejemplo anterior, el teorema de Bolzano se cumple, es decir, siempre que una función continua tenga signos contrarios en los extremos de un intervalo cerrado y acotado, existe al menos un punto interior en el que la función se anula y, aunque no es necesario, 
pero se puede comprobar con cualquier función continua que cumple con las hipótesis, hecho que ya lo verifica la propia demostración.

\section{II.4.3.3. Comunicación}

Esta función está clara dentro de la comunidad matemática creativa; entre los alumnos es más difícil de identificar pero se podría pensar en el siguiente ejemplo: plantear a los alumnos la hipótesis de que $f$ y $g$ son dos funciones continuas en $[a, b]$ y tales que $f-g$ cambia de signo en a y b, con la intención de que induzcan el siguiente resultado, a partir del teorema de Bolzano: deben probar que existe $x_{0}$ pertenece a $[a, b]$ tal que $f\left(x_{0}\right)=g\left(x_{0}\right)$ y comunicarlo al resto de la clase.

Cuando se analizan los LT, la función de comunicación podríamos considerarla entre el LT, que expone unos resultados, y el alumno, que los estudia a partir de la exposición hecha en el texto. Dicha función podrá ser más eficaz en función de la claridad expositiva del libro. No obstante, dicha eficacia se hace patente si el libro considera la función de explicación, por lo que en general, se presentan justificaciones con el objetivo de comunicarlas a los alumnos.

Esta función tiene que ver con los tipos de lenguaje que pueda utilizar el texto. Por tanto, aunque se estudiarán las expresiones utilizadas en el apartado correspondiente, estarán relacionadas con el grado de función comunicativa que tenga una demostración. Entre otros aspectos, algunos indicadores a observar relacionados con la función comunicativa y el lenguaje son los siguientes:

- Uso del lenguaje habitual.

- Uso del lenguaje simbólico específico.

- Se utilizan diagramas, esquemas, para representar la información.

- Sintaxis, semántica y semiótica.

- Vocabulario comprensible.

- Lenguaje explicativo.

- Lenguaje argumentativo.

- Lenguaje imperativo e interrogativo. 
- Se realizan transformaciones de un lenguaje verbal a un lenguaje simbólico y viceversa.

- Se realizan generalizaciones usando el lenguaje simbólico.

Se considera que puede haber una vinculación entre el tipo de EP utilizado por los libros de texto y el grado de función explicativa en las justificaciones, y que la combinación de ambos aspectos puede categorizar a los libros de texto en niveles explicativos. No obstante, esta clasificación quedaría fuera del alcance del presente trabajo y se deja como una línea abierta para futuros trabajos.

\section{II.4.3.4. Explicación}

En el discurso de la prueba del teorema de Bolzano, siguiendo el modelo de creación de la sucesión de intervalos encajados de amplitud $\delta / 2$, se justifican cada uno de los pasos. Veamos el siguiente ejemplo:

Toda función derivable en $x=a$ es continua en $x=a$.

$$
\begin{gathered}
f^{\prime}(a)=\lim _{x \rightarrow a} \frac{f(x)-f(a)}{x-a} \\
\lim _{x \rightarrow a}(f(x)-f(a))=\lim _{x \rightarrow a} \frac{f(x)-f(a)}{x-a} \cdot(x-a)= \\
=\lim _{x \rightarrow a} \frac{f(x)-f(a)}{x-a} \cdot \lim _{x \rightarrow a}(x-a)=f^{\prime}(a) \cdot \lim _{x \rightarrow a}(x-a)=0 \\
\left.\Rightarrow \lim _{x \rightarrow a} f(x)=f(a)\right)
\end{gathered}
$$

Esta prueba no explica por qué es cierta la proposición, no tiene la función explicación. Sería más interesante buscar una justificación que muestre la razón por la cual dicha proposición es cierta, pues contribuye a que los alumnos recuerden mejor las proposiciones. En esa misma línea, Hanna (1995) valora la función de explicación por encima de las otras funciones en la enseñanza y considera que una buena demostración, desde el punto de vista de la didáctica, debería explicar el resultado. Además, esta autora piensa que en la aceptación de un teorema es más importante el significado global de la demostración y la comprensión del resultado que el rigor de la misma (Ibañes y Ortega, 2005). En la propuesta didáctica, se buscará que las justificaciones propuestas sean lo más explicativas posibles. En el ejemplo precedente se deberían explicar por qué se pueden establecer todas las igualdades. Otro posible ejemplo sería una prueba del teorema de Bolzano, en la que se refleje de forma gráfica la imposibilidad de 
pasar de un valor negativo al positivo (o viceversa) sin corta al eje OX, como se van formando los subintervalos, por qué en todos los entornos de $\mathrm{x}_{0}$ tiene que haber infinitos subintervalos...

\section{II.4.3.5. Descubrimiento}

La prueba de Bolzano por intervalos encajados tiene de forma implícita la regla de bisección para la obtención de ceros de la función de forma aproximada con un error menor que $\delta / 2^{\mathrm{n}}$. Si se considera que el cero aproximado es el punto medio de ese subintervalo la aproximación tendría un error menor que $\delta / 2^{\mathrm{n}+1}$. Es un ejemplo claro de cómo una prueba conduce al descubrimiento de otros resultados, y que reflejaría la importancia de justificar en los libros de texto con EP transformacionales o axiomáticos y no sólo con inductivos o no justificar. En la siguiente Figura II.4.3.5.1 se muestra un ejemplo de descubrimiento:
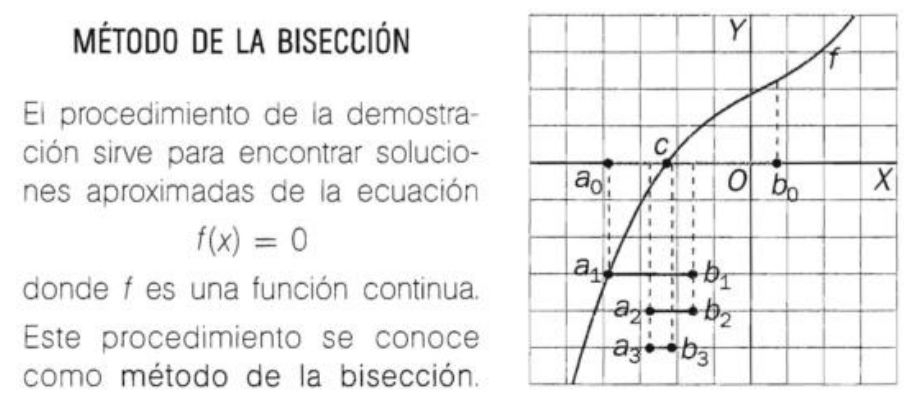

Figura II.4.3.5.1. Función de descubrimiento en la demostración del teorema de Bolzano del LT de $2^{\circ}$ de Bachillerato de SM (2010).

\section{II.4.4. Reconocimiento y distinción de procesos}

Tal y como indica Ibañes (2001, pp. 225), "uno de los requisitos para entender demostraciones es su reconocimiento". A partir de sus investigaciones, realizadas con estudiantes de $1^{\circ}$ de Bachillerato, Ibañes concretó en qué consiste el reconocimiento de procesos matemáticos y, en particular, de las demostraciones.

Reconocer demostraciones comprende distinguirlas de otros procesos e identificarlas cuando se está en presencia de una de ellas, así como identificar el enunciado que expresa lo que se ha demostrado. Pero, reconocer demostraciones también significa ser consciente de sus consecuencias; por ejemplo, que se debe aplicar el resultado cuando proceda, que no se precisa de posteriores comprobaciones, que resulta imposible encontrar contra-ejemplos, etcétera. (Ibañes, 2001, pp. 225) 
Según Ibañes, algunos alumnos confunden las demostraciones con meras comprobaciones y cálculos, y aunque algunos identifican correctamente las demostraciones, luego no son conscientes de las implicaciones de éstas: por ejemplo, que no sea necesario comprobar la veracidad de un enunciado demostrado mediante la aplicación de un resultado una vez que ha sido demostrado, y que es imposible encontrar un contraejemplo. En este caso, no se hará un análisis de las identificaciones que pudieran realizar los alumnos, sino los LT, diseñados por expertos en Matemáticas que tienen clara esta distinción. No obstante, la presentación de los resultados y sus justificaciones pueden inducir a confusiones en aquellos alumnos que no hubieren aprendido esta propiedad de las demostraciones.

Por tanto, el principal objetivo de este apartado consiste en analizar los indicadores de reconocimiento de procesos que encontramos en los LT que puedan facilitar o dificultar dicho reconocimiento a los alumnos. Es decir, si indican o no que el enunciado mostrado es un teorema (y, por tanto, requiere de demostración), si se revela que la justificación que lo acompaña, en caso de haberla, es una demostración o se advierte que no se demuestra cuando no lo hacen, si se hacen referencias al proceso de justificar, y si se indica alguna consecuencia de haber justificado el teorema.

\section{II.4.5. Expresiones que utiliza}

Una parte importante en las matemáticas es el lenguaje específico de esta ciencia, y que determina la comunicación. Las diferentes nomenclaturas o formas de expresar los diferentes conceptos pueden confundir a los alumnos, debido a que, como lectores no especializados, no dominan el lenguaje matemático. Además, diferentes notaciones pueden dar lugar a diferentes maneras de demostrar. Se considera interesante analizar el tipo de expresiones utilizadas tanto en el enunciado como en la demostración. Ya se ha detallado un análisis del enunciado en función del tipo de éste, y se han comentados algunos aspectos del lenguaje en el apartado de la función de explicación, pero también es interesante realizar un análisis semántico, debido a que, en ocasiones, diferentes acciones verbales pueden inducir a resultados diferentes. También clasificaremos los sistemas de representación utilizados. Siguiendo el ejemplo de Janvier (1987), los 
clasificaremos en los siguientes cuatro tipos: descripción verbal (que puede realizarse con lenguaje coloquial o con lenguaje específicamente matemático), tabla, gráfica y fórmula (lenguaje simbólico o algebraico). Estos aspectos, junto con aquellos descritos en el apartado de la función de comunicación y el tipo de enunciado, conforman los aspectos relativos al lenguaje que se analizarán. También se indica si se explican las expresiones utilizadas o las relaciones entre diferentes sistemas de representación.

\section{II.4.6. Consideraciones globales}

En este último apartado se consideran aspectos que no se habían estudiado en los puntos anteriores. Por ejemplo, si el LT explica globalmente el proceso que ha utilizado, aspecto que no hay que confundir con el reconocimiento de procesos. En este caso, únicamente observamos si el LT realiza una breve descripción de los pasos que dará en la demostración, o si directamente la presenta. Para el público no especializado sería interesante dicha descripción breve, ya que ofrece una visión general del proceso y facilita su comprensión.

Otro aspecto a observar es si se comenta el significado del resultado (no confundir con las consecuencias de haberlo demostrado). En este caso observamos si indica qué significa el enunciado, qué relaciones establece con otros resultados, la utilidad de éste...

Para enfatizar en el reconocimiento de procesos, se observará si se diferencia claramente entre enunciado y demostración, diferencia que podemos encontrar explícita en el texto (etiquetas, indicaciones...) o implícita (un simple cambio en la tipografía). Esta distinción es importante, ya que de no hacerse, un alumno podría confundir los papeles de ambos. Por último, se indicará si, en los casos en los que se justifiquen dichos resultados, se señalan otras posibles vías de justificación (aunque no se desarrollen).

\section{II.4.7. Tablas resumen de las categorías de análisis}

La consideración de todas estas categorías da lugar a las tablas que se muestran a continuación en las que se resume el marco teórico de análisis que vamos a 
utilizar. Estas tablas sirven de soporte para realizar la recogida de datos en los libros de texto y el posterior análisis.

\section{Esquemas de prueba}

EP de un LT: lo que el libro de texto muestra que podría constituir persuasión y convencimiento para un posible lector, en este caso, un estudiante de matemáticas del nivel para el que está diseñado el libro, entendiendo como convencimiento el proceso utilizado por el LT que podría eliminar las dudas del posible lector sobre la veracidad de una afirmación y como persuasión, el proceso del libro que, utilizado por el posible lector, podría eliminar las dudas de otros sobre la veracidad de una afirmación.

\begin{tabular}{|c|c|}
\hline EP0 & No se hace ningún tipo de justificación del enunciado \\
\hline EPi1 & $\begin{array}{r}\text { Se trata de convencer de la validez de una conjetura mediante la evaluación cuantitativa de } \\
\text { un caso particular. }\end{array}$ \\
\hline EPiV & Como en el caso anterior, pero se realiza con varios casos particulares. \\
\hline EPiS & $\begin{array}{r}\text { Como en los casos anteriores, pero los ejemplos particulares se eligen de forma organizada, } \\
\text { cubriendo las posibles diferentes casuísticas. }\end{array}$ \\
\hline EPa & $\begin{array}{r}\text { Se realizan transformaciones de imágenes por medio de la deducción. } \\
\text { primarios y los resultados que se han deducido mediante las correspondientes } \\
\text { demostraciones. }\end{array}$ \\
\hline PP & $\begin{array}{r}\text { Línea de razonamiento, que podría formalizarse a una prueba formal, y en la cual la idea } \\
\text { esencial de la demostración se encuentra reflejada. Hereda el carácter axiomático y } \\
\text { transformacional de estos EP. }\end{array}$ \\
\hline
\end{tabular}

Tabla II.4.7.1. Resumen de las categorías de esquemas de prueba.

\begin{tabular}{|c|c|}
\hline \multicolumn{2}{|c|}{ Técnicas empleadas } \\
\hline Tipo & $\begin{array}{r}\text { Estructura lógica del enunciado. Condición necesaria (CN), condición suficiente (CS), } \\
\text { necesaria y suficiente (CNS). Cuantificador universal, no existencial (NE), existencia simple } \\
\text { (ES), imposibilidad (I), unicidad (U). }\end{array}$ \\
\hline Método & $\begin{array}{r}\text { Procedimientos lógicos: Silogismo, por casos, reducción al absurdo, inducción completa, } \\
\text { constructivo (ejemplo o contraejemplo), analogía o dualidad. }\end{array}$ \\
\hline Estilo & $\begin{array}{r}\text { Procedimientos matemáticos: del análisis matemático, ya sea global o local, gráfico, de las } \\
\text { coordenadas, o algebraico. }\end{array}$ \\
\hline Modo & Procedimiento de exposición: sintético o directo y analítico o indirecto. \\
\hline
\end{tabular}

Tabla II.4.7.2. Resumen de las categorías de técnicas empleadas.

\begin{tabular}{|c|c|}
\hline \multicolumn{2}{|c|}{ Funciones de la demostración } \\
\hline Verificación & Concerniente a la veracidad de una afirmación \\
\hline Explicación & Profundización en por qué es verdad. \\
\hline Sistematización & Organización de varios resultados dentro de un sistema de axiomas, \\
& conceptos fundamentales y teoremas. \\
\hline Descubrimiento & Descubrimiento o invención de nuevos resultados. \\
\hline Comunicación & Transmisión del conocimiento matemático. \\
\hline
\end{tabular}

Tabla II.4.7.3. Resumen de las categorías de funciones. 


\begin{tabular}{|c|c|}
\hline \multicolumn{2}{|c|}{ Reconocimiento de procesos } \\
\hline $\begin{array}{c}\text { ¿Reflexiona sobre el } \\
\text { procedimiento? }\end{array}$ & El LT reconoce o no el EP utilizado como tal, es decir, como una \\
justificación del resultado enunciado.
\end{tabular}

Tabla II.4.7.4. Resumen de las categorías de reconocimiento de procesos.

\begin{tabular}{|c|c|}
\hline \multicolumn{2}{|c|}{ Expresiones que utiliza } \\
\hline Expresiones & $\begin{array}{r}\text { Expresiones utilizadas, tanto en el enunciado, como en la demostración, } \\
\text { sistemas de representación. Análisis semántico. }\end{array}$ \\
\hline $\begin{array}{c}\text { ¿Explica su } \\
\text { significado? }\end{array}$ & $\begin{array}{c}\text { Si se utilizan expresiones propias de las matemáticas, si explica su } \\
\text { significado. }\end{array}$ \\
\hline
\end{tabular}

Tabla II.4.7.5. Resumen de las categorías de expresiones que utiliza.

\begin{tabular}{|c|c|}
\hline \multicolumn{2}{|c|}{ Consideraciones globales } \\
\hline $\begin{array}{c}\text { ¿Explica globalmente el } \\
\text { proceso? }\end{array}$ & $\begin{array}{c}\text { Explicación de las líneas generales que se han seguido en la } \\
\text { demostración en sí. }\end{array}$ \\
\hline ¿Comenta su significado? & Lo que significa el teorema, las relaciones que establece, su utilidad. \\
\hline $\begin{array}{c}\text { ¿Distingue entre el } \\
\text { enunciado y la justificación? }\end{array}$ & $\begin{array}{c}\text { Si separa con claridad el enunciado de la justificación. En caso } \\
\text { contrario se pueden confundir los papeles de ambos. }\end{array}$ \\
\hline $\begin{array}{c}\text { ¿Señala otras posibles vías } \\
\text { de justificación? }\end{array}$ & Si indica otras demostraciones u otras clases de justificación. \\
\hline
\end{tabular}

Tabla II.4.7.6. Resumen de las categorías de consideraciones globales. 


\section{CAPÍTULO III}

\section{MARCO METODOLÓGICO}

\section{III.1.INTRODUCCIÓN}

En el presente capítulo se describe el marco metodológico que se ha utilizado en el presente trabajo. Al tratarse de un análisis de libros de texto, en el que se observa un aspecto concreto (es decir, el marco teórico está determinado por el aspecto a estudiar, en este caso, la demostración matemática) y que se realiza de forma longitudinal en el tiempo, se han considerado dos metodologías: el método histórico de investigación en educación (Ruiz-Berrio, 1976) y la metodología de investigación en educación de Fox (1981). Ambas metodologías, que se describen a continuación, se han combinado para dar lugar a un método de análisis propio adaptado a nuestro estudio.

En primer lugar se describen brevemente las dos metodologías, indicándose a continuación cómo se han combinado para dar lugar a la propia del trabajo. Posteriormente, y siguiendo las etapas de Ruiz-Berrio (1976), se describe el trabajo llevado a cabo en cada una de ellas, organizado atendiendo a las etapas de Fox (1981). Estas descripciones permiten conocer los aspectos metodológicos del estudio, como son la selección de la muestra, los instrumentos de análisis y el método de trabajo. 


\section{III.2.MARCO METODOLÓGICO}

Según Fox (1981), la investigación histórica en educación tiene como objetivo resolver problemas actuales mediante el estudio intensivo de materiales que ya existen. En nuestro caso, el problema que se aborda está relacionado con la enseñanza y el aprendizaje de la demostración matemática, elemento imprescindible en esta ciencia, y que ofrece ciertas dificultades en el campo de la Educación Matemática. Como ya se ha mencionado, su enseñanza y aprendizaje ofrece dificultades, y se ha observado que este proceso ha desaparecido paulatinamente de los libros de texto (Dos Santos, 2010). Queda justificado que el problema es actual. Por otro lado, los materiales que estudiamos son los libros de texto correspondientes a las últimas tres legislaciones educativas españolas (LGE, LOGSE y LOE), con el objetivo de acercarse a los procesos de enseñanza de la demostración matemática. Se trata de un material existente que cumple, tal y como indican González y Sierra (2003), que las fuentes de las que se extrae la información existen antes de que el investigador formule una tesis (unas hipótesis de investigación), seleccione un tópico o diseñe un plan de investigación.

Son varios los autores que han realizado interpretaciones del método histórico de investigación en educación. Ruiz-Berrio (1976) describe dicho método construyéndolo a partir de las etapas clásicas del método histórico que completa para el caso de la educación, es decir, de la investigación histórica de la educación. Dichas etapas son las siguientes:

$>$ Planteamiento de la investigación: esta etapa incluye la selección del tema, la determinación del periodo cronológico significativo desde el punto de vista pedagógico, la revisión del estado de la cuestión, el sondeo de los fondos documentales existentes y la elaboración de una programación.

Fase heurística, que se compone de la búsqueda, selección y clasificación de los documentos.

Fase crítica, que el autor denomina crítica histórico-pedagógica, y que divide en dos tipos: crítica externa, que se preocupa de determinar la autenticidad de las fuentes documentales, y crítica interna, que se ocupa de la comprensión e interpretación de los documentos. 
Fase hermenéutica: consiste en la explicación histórico-pedagógica del análisis realizado, es decir, la interpretación de los textos.

Exposición de la investigación.

Por su parte, Fox (1981), en su obra El proceso de investigación en educación, describe una metodología de análisis dividida en 17 etapas secuenciales, estructuradas en tres partes, que organizarían el desarrollo de una investigación. Este modelo se basa en los puntos que el autor considera importantes en el proceso de investigación, aunque admite flexibilidad y alteración del orden de las etapas. Dichas etapas son las siguientes:

Primera parte: diseño del plan de investigación

1. Idea o necesidad impulsora y área problemática

2. Examen inicial de la Bibliografía

3. Definición del problema concreto de la investigación

4. Estimación del éxito potencial de la investigación planteada

5. Segundo examen de la bibliografía

6. Selección del enfoque de la investigación

7. Formulación de las hipótesis de la investigación

8. Selección de métodos y técnicas de recogida de datos

9. Selección y elaboración de los instrumentos de recogida de datos

10. Diseño del plan de análisis de datos

11. Diseño del plan de recogida de datos

12. Identificación de la población y muestra a utilizar

13. Estudios pilotos del enfoque de recogida de datos, métodos e instrumentos y del plan de análisis de datos

Segunda parte: ejecución del plan de investigación

14. Ejecución del plan de recogida de datos

15. Ejecución del plan de análisis de datos

16. Preparación de los informes de la investigación

Tercera parte: aplicación de los resultados 
17. Diseminación (difusión) de los resultados y propuestas de medidas de actuación

Estos métodos ya se han utilizado en otras investigaciones en el campo de la Educación Matemática: González (2002), en su tesis doctoral utiliza el método histórico de Ruiz-Berrio y en González y Sierra (2003) describen dicho método y su aplicación a diferentes trabajos realizados por ambos; por su parte, López (2011) en su tesis doctoral también utiliza con éxito este método para el desarrollo de su investigación. Por otra parte, Zamora (2014) aplicó la metodología de Fox en un análisis que llevo a cabo de las pruebas de acceso a las universidades de Castilla y León. Estos usos exitosos nos han inclinado en favor de la utilización de este método para revisar los textos que corresponden a la LGE y a la LOGSE.

\begin{tabular}{|c|l|}
\hline \multicolumn{2}{|c|}{ Metodología de la investigación } \\
\hline $\begin{array}{c}\text { Método histórico de investigación } \\
\text { en Educación (Ruiz-Berrio, 1976) }\end{array}$ & \multicolumn{1}{|c|}{ Metodología de investigación en educación de Fox (1981) } \\
\hline Planteamiento de la investigación & $\begin{array}{l}\text { 1. Idea impulsora y área problemática } \\
\text { 2. Examen inicial de la bibliografía } \\
\text { 3. Definición del problema de investigación } \\
\text { 4. Estimación del éxito potencial de la investigación } \\
\text { 12. Identificación de la población y muestra a utilizar }\end{array}$ \\
\hline Fase heurística & $\begin{array}{l}\text { 5. Segundo examen de la bibliografía } \\
\text { 6. Selección del enfoque de la investigación } \\
\text { 7. Formulación de las hipótesis de investigación } \\
\text { 8. Selección de los métodos y técnicas de recogidas de datos } \\
\text { 9. Selección y elaboración de los instrumentos de recogida de } \\
\text { datos }\end{array}$ \\
\hline Fase crítica & $\begin{array}{l}\text { 10. Diseño del plan de análisis de datos } \\
\text { 11. Diseño del plan de recogida de datos } \\
\text { 13. Estudios pilotos del enfoque de recogida de datos, métodos e } \\
\text { instrumentos y del plan de análisis de datos } \\
\text { 14. Ejecución del plan de recogida de datos }\end{array}$ \\
\hline Fase hermenéutica & 15. Ejecución del plan de análisis de datos \\
\hline Exposición de la investigación & $\begin{array}{l}\text { 16. Preparación de los informes de la investigación } \\
\text { 17. Diseminación (difusión) de los resultados y propuestas de } \\
\text { medidas de actuación }\end{array}$ \\
\hline
\end{tabular}

Tabla III.2.1. Combinación de las fases de Ruiz-Berrio con las etapas de Fox para la metodología propia de la investigación.

Para este trabajo, dado que se analizan tanto libros de texto correspondientes a legislaciones ya derogadas, y por tanto, de carácter histórico, y libros de texto vigentes en la actualidad, se combinan ambos métodos para dar lugar a una 
metodología "ad hoc", diseñada específicamente para esta investigación. Para ello, se sigue el modelo histórico de Ruiz-Berrio descrito anteriormente, pero combinándolo con el esquema propuesto por Fox, que nos ayuda a concretar las acciones realizadas en cada fase. De hecho, es fácil combinar ambas metodología, ya que las 17 etapas de Fox encajan perfectamente en las fases de Ruiz-Berrio. En la Tabla III.2.1 se muestra el esquema de la metodología diseñada en la que se combinan las etapas y fases de ambas metodologías. En el siguiente apartado, teniendo presente este esquema, se describirán las acciones propias de cada fase.

\section{III.2.1. Planteamiento de la investigación}

Esta primera fase comprende todas las acciones relacionadas con el planteamiento, delimitación y planificación de la investigación. En primer lugar, en relación a la primera etapa de Fox, se considera la idea o necesidad impulsora que da lugar al planteamiento de la investigación. Esta idea surge de la experiencia del director de la tesis en la Enseñanza Secundaria, y la contrastación con otros profesores de dicho nivel, que han notado una reducción en el formalismo y en la utilización de la demostración en la clase de matemáticas. Además, se observa una tendencia generalizada en el profesorado a considerar un declive en la formación matemática de cada generación de estudiantes, muchas veces achacado a la pérdida de formalismo y rigor en esta ciencia. Este suceso también ha sido observado por Dos Santos (2010) y Dos Santos y Ortega (2013), en los que se apunta el problema de la paulatina desaparición del tratamiento de la demostración y de las dificultades del profesorado para justificar enunciados matemáticos.

Teniendo en cuenta esta idea impulsora que motiva este estudio, se ha realizado una primera revisión bibliográfica (segunda etapa de Fox), que permitió ver la importancia de la demostración matemática en la enseñanza de las matemáticas y la especial atención que ha recibido desde la Didáctica de la Matemática. Esta revisión, realizada desde diversas perspectivas (Ibañes y Ortega, 2005), junto con la idea impulsora, reafirmó en la idea sobre la necesidad de la demostración matemática en la educación escolar y permitió formular una primera hipótesis de partida, que la demostración matemática está desapareciendo en la educación escolar, lo que llevó a la definición del problema concreto de investigación 
(tercera etapa): la disminución de la presencia o desaparición de la demostración matemática en los libros de texto de los últimos cursos de educación preuniversitaria y sus consecuencias en la enseñanza y el aprendizaje (ya se ha hecho una descripción más detallada de esta situación en el apartado 2 del capítulo II, sobre la que hay que seguir indagando en mayor profundidad).

Para comprobar tal hipótesis, es necesario delimitar el periodo cronológico al que corresponden los textos analizados. En este caso concreto, dicho periodo comienza con la promulgación de la primera ley educativa que estructuró todo el sistema educativo español y finaliza en la actualidad, es decir, los currículos correspondientes a la Ley 14/1970, de 4 de agosto, General de Educación y Financiamiento de la Reforma Educativa (LGE, Jefatura de Estado, 1970) de 1970, a la Ley Orgánica 1/1990, de 3 de octubre de 1990, de Ordenación General del Sistema Educativo (LOGSE, Jefatura de Estado, 1990) y a la Ley Orgánica 2/2006, de 3 de mayo, de Educación (LOE, Jefatura de estado, 2006). No consideramos la última legislación educativa, la Ley Orgánica 8/2013, de 9 de diciembre, para la mejora de la calidad educativa (LOMCE, Jefatura de Estado, 2013), debido a que esta ley no ha sido implantada en los niveles educativos que se consideran en este trabajo en el momento de elaboración de la memoria.

Pero carece de sentido realizar una investigación sin considerar antes cuál será el objetivo final que se pretende alcanzar, y en el ámbito de la Educación Matemática, este objetivo es proporcionar una mejora en la enseñanza y el aprendizaje de la matemática. En este caso, dicha mejora está orientada a la Educación Secundaria. Las matemáticas constituyen una ciencia constructiva, en la que partiendo de unas premisas básicas y unas definiciones, el razonamiento permite construir el enunciado de teoremas y propiedades, que más adelante, darán lugar a nuevos resultados. Pero esta construcción sólo se lleva a cabo si cada paso que se da (cada resultado que se enuncia) es comprobado, verificado, demostrado mediante la lógica y el razonamiento. De dicha construcción surge también la pasión por esta ciencia, por su exactitud y rigor, lo que además facilita la comprensión de los conceptos, ya que se incorporan a la estructura mental del alumnado que los comprende. Por esta razón, la demostración matemática, como explicación y justificación de los teoremas, favorece la comprensión y, sobre todo, la aceptación de éstos, lo que influye positivamente en el aprendizaje de las matemáticas y en el aspecto emocional que estas representan para los alumnos. 
Por tanto, no sería admisible que este proceso desapareciera de la Educación Secundaria.

Por otro lado, cabe destacar que el declive en la formación matemática básica en España es evidente a la vista de los últimos resultados de las evaluaciones de PISA (Instituto Nacional de Evaluación Educativa, 2014) y PIAAC (Instituto Nacional de Evaluación Educativa, 2013), lo que nos lleva a preguntarnos por los motivos de éste suceso. El análisis del tratamiento de la demostración en el pasado nos permitirá establecer ciertas conclusiones sobre su relación con los pésimos resultados en matemáticas y realizar propuestas para el futuro de secuencias didácticas que favorezcan el aprendizaje y consideren la demostración matemática.

La realización de esta investigación permitirá detectar posibles errores relativos a la presentación de los enunciados y de las justificaciones de los teoremas. Como consecuencia, se podrán elaborar propuestas didácticas orientadas a subsanar dichos errores. Estas propuestas serán difundidas a la comunidad de profesores de matemáticas (cuarta etapa), especialmente de Educación Secundaria, que son, en última instancia, los responsables de la enseñanza en cada aula de esta etapa educativa.

En último lugar, dentro de esta fase del trabajo, debemos seleccionar la muestra que utilizaremos en nuestro análisis (etapa 12). Esta muestra se ha extraído de la población objeto de nuestro estudio, población formada por los libros de texto de educación preuniversitaria desde la Ley General de Educación. La muestra se ha delimitado con los siguientes criterios:

$\checkmark$ Nivel educativo: dada el nivel de complejidad de razonamiento matemático de nuestro objeto de estudio, carece de sentido realizar su estudio en niveles en los que su consideración fuera inviable, por lo que se estableció que los libros de texto analizados cursos de los dos últimos cursos antes del acceso a la universidad, es decir, $3^{\circ}$ de BUP y COU para la LGE, y $1^{\circ}$ y $2^{\circ}$ de Bachillerato para LOGSE.

Editoriales: Con el objetivo de generalizar al máximo las conclusiones de nuestro estudio, y dada la inviabilidad de analizar todos los libros de texto escritos para los cursos seleccionados, se han seleccionado cuatro editoriales atendiendo a dos criterios: que fueran editoriales conocidas y muy utilizadas, y que hubieran tenido continuidad en el tiempo. El primer criterio nos pareció 
importante por dos razones: porque la muestra fuera lo más representativa posible y porque los libros fueran más accesibles, sobre todo los correspondientes a las legislaciones que ya no están en vigor. Por otro lado, es importante que las editoriales tengan continuidad en el tiempo para que las conclusiones extraídas tras el análisis de los diferentes libros de texto no sean dependientes de la editorial en sí, sino de la legislación a la que corresponden. Las editoriales finalmente seleccionadas han sido Anaya, Santillana, SM y Vicens Vives. A pesar de ser editoriales conocidas y de amplia difusión, se han encontrado serias dificultades para localizar ejemplares correspondientes a las cuatro editoriales y a las tres leyes, dado el carácter efímero de este tipo de libros.

$\checkmark$ Concepto: por último, se ha limitado el estudio al análisis de la demostración de algunos de los conceptos del Análisis Matemático, en concreto, límites y continuidad. Se han seleccionados estos conceptos por varios motivos: en primer lugar, por afinidad de la autora y del director de tesis, como matemáticos, con estos conceptos; en segundo lugar, por la susceptibilidad de los resultados (algunos al menos) relacionados con estos conceptos a ser demostrados en los cursos elegidos; en tercer, y último lugar, por ser concepto relacionados con el pensamiento matemático avanzado, al igual que lo está el proceso de nuestro estudio (Azcárate y Camacho, 2003).

\begin{tabular}{|l|l|l|l|l|}
\hline LGE & $\begin{array}{l}\text { Anaya (1977) } \\
\text { Anaya (1987) }\end{array}$ & $\begin{array}{l}\text { Santillana (1976) } \\
\text { Santillana (1991) }\end{array}$ & SM (1977) & Vicens-Vives (1980) \\
\hline $2^{\circ}$ BUP & $\begin{array}{l}\text { Anaya (1977) } \\
\text { Anaya (1988) }\end{array}$ & Santillana (1977) & SM (1981) & Vicens-Vives (1977) \\
\hline COU & Anaya (1989) & Santillana (1988) & SM (1980) & Vicens-Vives (1979) \\
\hline LOGSE & Anaya (2002) & Santillana (1996) & SM (1996) & Vicens-Vives (1998) \\
\hline $1^{\circ}$ Bachillerato & Anaya (2003) & Santillana (1997) & SM (2001) & Vicens-Vives (2003) \\
\hline $2^{\circ}$ Bachillerato & Vicens-Vives (1999) \\
\hline LOE & Anaya (2008) & Santillana (2008) & SM (2008) & Vicens-Vives (2008) \\
\hline $1^{\circ}$ Bachillerato & Anay & SM (2010) & Vicens-Vives (2009) \\
\hline $2^{\circ}$ Bachillerato & Anaya (2009) & Santillana (2009) & SM
\end{tabular}

Tabla III.2.1.1. Muestra de libros de texto localizados y analizados.

Una vez definidos estos criterios, se realizó la búsqueda de ejemplares de libros de texto que atendieran a dichas características. No obstante, los conceptos de 
límites y continuidad no siempre se consideran en $3^{\circ}$ de BUP, lo que obligó a incorporar a la muestra, para el periodo LGE, libros de texto de $2^{\circ}$ de BUP. Finalmente se localizaron 33 libros de texto para realizar el análisis. Se presentan en la Tabla III.2.1.1 (se completa la información de la muestra en el anexo A1). Para facilitar la identificación de cada libro en el texto, se han denotado con el código editorial (año de edición), que resulta más cómodo para la realización del análisis que el uso de citas de la normativa APA.

No obstante, en algunas ocasiones, y para facilitar la lectura e identificación de los textos, se añadirá al código utilizado en cada texto el curso al que corresponde dicho libro de texto.

\section{III.2.2. Fase heurística}

En esta fase, que se compone de la búsqueda, selección y clasificación de las fuentes documentales (Ruiz-Berrio, 1976) se desarrollan las etapas 5, 6, 7, 8 y 9 de la metodología de Fox (1981). Una vez determinada la muestra y definido el problema concreto de investigación, se procedió a un segundo examen más minucioso de la bibliografía (etapa 5) relacionada con nuestro trabajo, clasificando la documentación en tres grandes grupos: investigaciones en torno a la demostración matemática, investigaciones en torno a los libros de texto e investigaciones en torno a los elementos del Análisis Matemático que se han utilizado para estudiar la demostración. A pesar de estas agrupaciones, se ha segregado un cuarto grupo que resulta de la intersección de los dos primeros, es decir, las investigaciones de la demostración matemática en los libros de texto, ya que son los antecedentes más próximos a este trabajo. Dicha revisión ya ha sido descrita en el capítulo I de esta memoria. Esta segunda revisión de la bibliografía nos permitió seleccionar las investigaciones en las que nos apoyaríamos para desarrollar el marco teórico considerado (etapa 6). Dicho marco teórico está descrito de forma minuciosa en el capítulo anterior (Capítulo II, apartado II.4). Esta descripción está precedida de las hipótesis de investigación de las que partimos en nuestro trabajo y que se derivan de los objetivos considerados (etapa 7). En relación con las etapas 8 y 9 (selección de métodos y técnicas de recogidas de datos y selección y elaboración de los instrumentos de recogida de datos) se han realizado las siguientes acciones: en 
primer lugar, hay que señalar que, en nuestra investigación, ambas etapas se combinan en una sola. En segundo lugar, por el tipo de trabajo que se está desarrollando, los métodos, técnicas e instrumentos de recogida de datos se derivan del marco teórico utilizado. Es decir, el método de recogida de datos utilizado ha consistido en la revisión de cada libro de texto tomando nota de la información necesaria relacionada con cada uno de los aspectos del marco teórico. Por esto, el instrumento que conduce la recogida de datos es una tabla que condensa las categorías del marco teórico (una tabla que reúna a las tablas del apartado II.4.7). Para cada libro de texto, y cada resultado enunciado, se puede completar una tabla recogiendo todos esos aspectos del marco teórico. Esas tablas nos permiten organizar la información para su posterior análisis e interpretación.

\section{III.2.3. Fase crítica}

En esta fase, según Ruiz-Berrio (1976), se realiza la crítica histórico-pedagógica, que se divide en dos tipos. En primer lugar, hay que determinar la autenticidad de las fuentes documentales (crítica externa), pero en nuestro caso esta autenticidad está garantizada por la naturaleza de las fuentes: los propios libros de texto. En segundo lugar, hay que ocuparse de la comprensión e interpretación de los textos (crítica interna). Para ello, y siguiendo las etapas 10 y 11 de Fox, se diseña el plan de análisis y recogida de datos. En este trabajo, al igual que ocurría con las etapas 8 y 9 descritas en el apartado anterior, las etapas 10 y 11 van juntas. El plan que se seguirá consiste en utilizar la tabla de análisis que se desprende del marco teórico, y que se ha mencionado en el apartado anterior, para registrar las observaciones de cada libro de forma minuciosa, sistemática y ordenada. Además, dentro de la planificación del análisis, se crearán unidades de análisis dentro de los libros de texto, organizados en niveles. El primer nivel consta de dos unidades de análisis, asociados a los conceptos a analizar: límites y continuidad. Dentro de cada una de estas unidades, consideramos un segundo nivel, con las mismas subunidades para los dos casos: definiciones, enunciados de teoremas y justificaciones de teoremas. Principalmente, estas unidades se localizan en los apartados dedicados a los contenidos de los libros de texto, pero en algunas ocasiones, el propio libro nos remitirá a algún apartado posterior (como por ejemplo, un apartado de ejercicios y problemas resueltos). Sólo en 
esos casos, que se indicarán en el análisis, se considerarán otros apartados que no sean los propios de contenidos del texto. Se podrían tener en cuenta las relaciones entre los análisis de las diferentes subunidades de análisis, pero los análisis de dichas relaciones superarían en exceso los límites de este trabajo, por lo que se deja dicho estudio para el futuro.

Además, en la redacción de la presente memoria se han elaborado otras tablas en las que se presentaba de forma resumida algunos de los aspectos que se han considerado destacables en cada caso. Estas tablas de recogida y organización sistemática de los datos han sufrido modificaciones a lo largo del trabajo para adaptarse a las necesidades surgidas en el transcurso del análisis: incorporación de observaciones, creación de tablas complementarias,... Esta evolución se ha visto condicionada por los trabajos parciales desarrollados en el contexto de la elaboración de esta tesis doctoral (etapa 13) en los que se han utilizado las distintas versiones de la tabla de forma provisional. Por ejemplo, en Conejo y Ortega (2013) se puede ver una primera descripción del marco teórico y un primer análisis de libros de texto para el caso de límites. Este análisis, por una parte, sirvió para comprobar si el trabajo se enfocaba en la dirección correcta y, por otra, para testar la primera tabla de análisis. Esta primera comprobación permitió profundizar en el marco teórico, originándose una nueva tabla de análisis que se ha utilizado para la organización de un taller en un seminario del Grupo de Investigación de Didáctica del Análisis Matemático (GIDAM), de la Sociedad Española de Investigación en Educación Matemática (SEIEM), realizado en marzo del año 2013, en el que recabamos opiniones de otros expertos en el tema que permitieron refinar la tabla y subsanar errores. En dicho taller, se presentó una selección de la muestra (dos teoremas, Bolzano y Weierstrass de tres libros de texto diferentes) junto con la tabla resumen del marco teórico y varias tablas de análisis. Los expertos realizaron un análisis de las demostraciones presentadas con el fin de que aportaran elementos (indicadores) de análisis. En este seminario-taller surgieron algunas observaciones que nos permitieron refinar la tabla de análisis (por ejemplo, se realizó una concreción de la categoría de estilos, y se matizó la diferencia entre las consecuencias de la demostración y el significado del teorema, que parecían solaparse en un principio). Posteriormente se realizaron otros trabajos en los que ya se recogieron dichos cambios (Conejo y Ortega, 2014; Conejo, Arce y Ortega, 2014, 2015). En el último (Conejo, Arce y Ortega, 2015), el marco teórico y un 
ejemplo de su aplicación fue presentado, como comunicación oral, en el $9^{\text {th }}$ Congress of European Research in Mathematics Education (CERME 9), durante el cual también fue sometido a la valoración de los expertos en el campo de la argumentación y la demostración matemática. El trabajo en este congreso sirvió para reflexionar sobre la definición de "esquema de prueba de un libro de texto" ya que, tal y como estaba definido no quedaba suficientemente claro el objetivo del trabajo. Sin embargo, el trabajo de clasificación de justificaciones y el consiguiente análisis fue valorado positivamente por los expertos. Tras las diferentes modificaciones de la tabla de análisis, se ha procedido a la recogida completa de los datos, partiendo de los que ya se tenían y considerando los aspectos incorporados hasta la última versión (etapa 14).

\section{III.2.4. Fase hermenéutica}

En esta fase el objetivo es explicar de forma histórico-pedagógica el análisis realizado; es decir, interpretar los datos extraídos del análisis. Esta explicación se ha realizado al mismo tiempo que la extracción de datos, dado que el volumen de éstos últimos exigía hacer pequeñas revisiones para cada concepto analizado (límites y continuidad). Tras la realización del análisis correspondiente a los resultados de cada concepto, se ha llevado a cabo un tercer análisis del trabajo, más completo (etapa 15), que nos ha permitido extraer conclusiones sobre la evolución de la demostración. Además, se ha acompañado cada recogida de datos y el subsiguiente análisis de informes de investigación que facilitaran la posterior elaboración de la memoria de tesis y la consiguiente difusión de resultados. Para ambos conceptos, el análisis se ha organizado de la siguiente manera: una primera descripción de cómo se organiza el concepto en el libro de texto: resultados considerados, orden de presentación de dichos resultados, definiciones consideradas... y otros aspectos relevantes para la organización del análisis de las justificaciones. Este primer estudio ha permitido organizar los resultados en grupos que faciliten la comparación entre los libros de texto, ya que la extensión de la muestra y la enorme cantidad de resultados y justificaciones encontrados dificultan la extracción de resultados globales que permitan comprobar o refutar las hipótesis establecidas y, por ende, conseguir los objetivos propuestos. Además, antes de acometer el análisis detallado, se ha mostrado un breve resumen cuantitativo, por editoriales, de los esquemas de prueba encontrados en 
los libros de texto, por tratarse del aspecto más importante que estudiamos en el presente trabajo. No obstante, la organización de la información en la presente memoria se encuentra descrita en el siguiente apartado, en el que se recoge cómo se ha elaborado la memoria de investigación para su posterior difusión.

\section{III.2.5. Exposición de la investigación}

En esta última fase (etapas 16, de elaboración de informes, y 17, de difusión de resultados) se recoge el proceso de elaboración de la presente memoria. Conviene señalar que, tal y como se ha mencionado en el apartado III.2.3, algunos resultados parciales del presente trabajo ya se han difundido a la comunidad investigadora. Los debates que se han producido en la difusión han permitido mejorar el presente trabajo y facilitar la elaboración de este documento.

Aunque se ha presentado la estructura general de éste trabajo en la introducción, la consideración de los marcos permite dotar de significado a la estructura general por esta razón a continuación se presentará con algún detalle técnico cada capítulo de la memoria: el orden de presentación de los resultados, la codificación de colores utilizada... Los aspectos teóricos (antecedentes, objetivos e hipótesis y marco teórico) y los aspectos metodológicos (marco metodológico) se han considerado en primer lugar, en sus capítulos correspondientes (capítulos I, II y II de la memoria), aunque cronológicamente su elaboración y desarrollo se haya solapado con los análisis recogidos en los capítulos siguientes. Se ha organizado la información siguiendo una estructura clásica en este tipo de trabajos, que permita a futuros investigaciones conocer el proceso de elaboración esta tesis doctoral y utilizar aquellos aspectos que puedan serle de su interés.

Por su parte, la elaboración de los capítulos IV y V, en los que se recogen los análisis de las justificaciones de los resultados de límites y continuidad respectivamente, ha sido más difícil y ha supuesto un reto en algunos casos. La extensión de la muestra, la diversidad de resultados a analizar y la diversidad de comportamientos observados en los libros de texto, no permitían una fácil comparación entre ellos, y lo que es más, no facilitaban la extracción de conclusiones generales en torno a la evolución de la demostración. Para ello, se ha recurrido a la descripción de varios análisis, cada uno de ellos más profundo 
que el anterior, lo que permite adquirir una visión de conjunto de la evolución y el tratamiento de la demostración. En la introducción de cada capítulo se describe el contenido de éste y se realiza una referencia a las directrices curriculares en relación con el concepto analizado. A continuación, se describe brevemente el tratamiento del concepto analizado en los libros de texto: en qué cursos aparece, que resultados se enuncian, en qué orden... Una vez realizada dicha descripción, se muestra una primera clasificación de los esquemas de prueba encontrados en los libros de texto de cada editorial, tras las cuales, se muestran gráficos que resumen dicha información y permiten comparar los diferentes libros de texto, tanto por editoriales, como por periodos legislativos, por esquemas de prueba, o por combinaciones de las anteriores categorías. Tras este pequeño análisis de carácter más cuantitativo, se realiza el análisis completo (considerando todos los aspectos del marco teórico) de los teoremas o resultados, distinguiendo dos casos: los enunciados que, de forma general, se enuncian y demuestran en todos los periodos legislativos, y aquellos que aparece únicamente en algunos ejemplares de la muestra. A su vez, este análisis se ha organizado en grupos asociados a los tipos de resultados (resultados asociados al concepto, operaciones o propiedades del concepto, y aplicaciones del concepto). Para los enunciados recurrentes, se han construido tablas de datos en las que se muestran todas las categorías descritas en el marco teórico, una para cada periodo legislativo. Además, para facilitar la lectura e identificar en cada caso a qué periodo se corresponden los libros de texto de los que se hace mención, se han utilizado colores diferentes en función del periodo legislativo considerado: rosa para la LGE, azul para LOGSE y verde para LOE. Esta codificación en colores se ha utilizado a lo largo de todo el trabajo. Las tablas en las que se recogen los datos comprenden todos los LT de ese mismo periodo que justifican el teorema considerado. De esta manera, se facilita la comparación en el tratamiento de la demostración en los LT de un mismo periodo y curso. Para los enunciados que aparecen de forma puntual en algunos LT, se realiza una descripción del análisis de la demostración sin utilizar las tablas, ya que la inclusión de éstas aumentaría en bastantes páginas la amplitud de la memoria de forma innecesaria. Por último, se presenta en cada capítulo la interpretación del análisis realizado y algunas reflexiones sobre las observaciones realizadas.

En el último capítulo se recogen las conclusiones finales del estudio, extraídas tras la realización de los análisis de los dos conceptos considerados, así como las 
implicaciones y perspectivas del trabajo para el futuro, y las propuestas didácticas que han sido diseñadas a partir del estudio realizado con el objetivo de mejorar los procesos de enseñanza y aprendizaje tanto de la demostración como de los conceptos considerados (límites y continuidad). Si bien esta memoria pueda pretender por si sola ser un medio de difusión de los resultados obtenidos, la intención de la autora es realizar otras publicaciones que faciliten dicha difusión, aparte de las que ya se han realizado en el transcurso de esta investigación y que la avalan. 



\section{CAPÍTULO IV}

\section{SOBRE LOS TEOREMAS DE LÍMITES}

\section{IV.1.INTRODUCCIÓN}

El concepto de límite, posiblemente, es uno de los conceptos más difíciles que se introducen en la Educación Secundaria. No obstante, su definición e inclusión en las teorías matemáticas supuso una revolución y fue el culmen de un largo trabajo por parte de los matemáticos de la época (Bolzano, Cauchy, Weierstrass...) En este concepto aparece la idea del infinito potencial y actual, cuya comprensión no es sencilla ni inmediata, hecho que apunta Spivak (1981). Sin embargo, aunque es un concepto especialmente difícil, es de vital importancia para el Análisis Matemático, ya que lo fundamenta. De él dependen otros conceptos posteriores como la continuidad o la derivabilidad de funciones. Dada su importancia para el desarrollo del pensamiento matemático avanzado, y las dificultades que se han detectado en la comprensión de este concepto por parte de los alumnos (Cornu, 1983; Blázquez y Ortega 1999, 2001b, entre otros), el límite ha sido ampliamente estudiado en el campo de la Educación Matemática, tal y cómo se deduce de los numerosos estudios que se describen en el capítulo II.

En los textos avanzados sobre cálculo infinitesimal, el límite se considera de forma diferente según el autor: según Spivak (1981) se trata del concepto más importante del cálculo infinitesimal y, quizá, también el más difícil. También señala que los demás conceptos del Análisis Matemático se definen a partir de él 
$\mathrm{y}$, por tanto, es el elemento sobre el que se construye esta rama de las Matemáticas. Este autor no comienza definiendo el límite propiamente dicho sino explicando la noción de función que tiende hacia un límite, noción que dota de sentido a este concepto. En cuanto a los resultados sobre límites, Spivak se limita a enunciar y demostrar la unicidad del límite, el límite de la suma, del producto y de la función inversa $(1 / g)$ y todo ello, considerando límites en un punto. Menciona brevemente, y deja como ejercicio para su profundización, la consideración de límites laterales, o de límites infinitos, ya que, como el mismo autor indica, "la idea general que se oculta tras las definiciones debe quedar clara una vez que se ha comprendido la definición de límites ordinarios" (Spivak, 1981, pp. 131).

Por su parte, Salas Hille (1994) comienza con la idea intuitiva (utilizando términos de proximidad y tendencia, indistintamente) acompañada de múltiples ejemplos para, a continuación, presentar el concepto con la definición métrica. Enuncia un resultado de equivalencia de definiciones, aunque deja la demostración como ejercicio. Tras definir los límites laterales, relaciona la existencia y coincidencia de estos últimos con la existencia de límite (siempre considerando el límite en un punto, aunque también deja como ejercicio esta demostración). El siguiente epígrafe reúne algunos teoremas sobre límites: unicidad, operaciones (suma, producto por constante y producto), límites de polinomios, recíprocos $(1 / g)$ y cocientes, cociente de polinomios, no existencia del límite del cociente cuando el denominador tiende a cero; este autor justifica todos los teoremas propuestos, bien sea en el capítulo, o en una sección complementaria inmediatamente a continuación. Sigue con la idea de continuidad y, tras tratarla, considera los límites de funciones trigonométricas.

Estos dos autores de textos universitarios sobre el límite funcional muestran algunas diferencias en su tratamiento. En este sentido, Blázquez, Gatica y Ortega (2009) realizaron un estudio sobre la conceptualización del límite funcional en manuales universitarios de Análisis Matemático que corrobora esta idea de la diversificación en la manera de presentar y tratar este concepto. Tal y como indican los autores, la definición de límite no es única e inmutable, y se observa la existencia de numerosas diferencias en la conceptualización, la subjetividad, la acción, el orden, el simbolismo, las representaciones gráficas, etc. 
Ciertamente, los textos citados no son de los niveles educativos que estamos analizando aquí, y tan solo se trata de unos apuntes para destacar la importancia del concepto y la diferencia del tratamiento entre textos universitarios, que pueden ser guías superiores (más amplias y profundas) para el profesorado que los propios libros de texto de Bachillerato. Además, esta diversidad también se encuentra en los libros de texto de los cursos pre-universitarios, y dificulta el análisis y la comparación entre ellos.

En el presente capítulo, tras hacer un apunte sobre las disposiciones de las cuatro leyes orgánicas de educación acerca del concepto de límite, se muestra el análisis de las justificaciones relativas a los resultados de límites que se encuentran en los libros de texto. En primer lugar se realiza una descripción de lo que los libros de texto presentan en relación con el límite funcional, lo que nos permite tener una idea de los diferentes tratamientos que recibe el concepto en función del libro de texto considerado y de en qué cursos se considera cada resultado. Eso ha permitido agrupar los resultados en tres categorías para facilitar el análisis posterior: resultados asociados al concepto de límite, operaciones con límites y resultados asociados a indeterminaciones. Previo a dicho análisis se presenta un resumen de los esquemas de prueba que utilizan los libros de texto, y los resultados asociados a dicho análisis. Tras ello, en epígrafes diferentes, se muestra un análisis más fino de los esquemas de prueba asociados a cada categoría de resultados, además de los otros aspectos descritos en el marco teórico, junto con un breve análisis de las definiciones de límite utilizadas en los LT. Se acaba el capítulo con algunas reflexiones sobre el análisis realizado y su relación con los objetivos del estudio.

\section{IV.2.ANÁLISIS DE LOS CURRÍCULOS}

En el currículo de Matemáticas correspondiente a las legislaciones que se estudian, el límite funcional ha estado siempre presente. Respecto a la LGE, se observa que únicamente aparecen referencias a límites en los contenidos relativos a $2^{\circ}$ de BUP (Ministerio de Educación y Ciencia, 1975a) ya que en $3^{\circ}$ de BUP y en COU, se estudia la derivabilidad. Por esta razón, consideramos hacer un estudio de los esquemas de prueba de los resultados relativos a límites en los libros de texto de $2^{\circ}$ de BUP, aunque éstos no formaban parte de la muestra 
inicial. No obstante, algunas editoriales, a modo de recordatorio, incluyen nociones sobre límites en sus textos de COU antes de abordar la derivabilidad, por lo que se incluirán en el análisis aunque los documentos curriculares no hagan referencia a ellos. Para el periodo LOGSE, las referencias a los límites en este currículo no son explícitas en el primer curso. En él sólo mencionan la tendencia de evolución de funciones en los criterios de evaluación de Matemáticas I. Sin embargo, sí que son explícitas en el segundo curso: en los contenidos de Matemáticas II encontramos "introducción al concepto de límite" (Ministerio de Educación y Ciencia, 1992a y 1992b), que incluye el cálculo de límites y su aplicación al estudio y representación de funciones; también se hacen referencias a este concepto en los criterios de evaluación de la misma asignatura. En la modificación realizada en 2001 se observa que los currículos desarrollados tanto a nivel estatal como en Castilla y León son más completos y descriptivos que sus predecesores: en el primer curso se estudia el concepto intuitivo de límites, su cálculo y su aplicación al estudio de funciones; en segundo curso el tratamiento del concepto de límite se amplía, se hace más completo, más teórico, más riguroso y más profundo. Así, por ejemplo en los contenidos del primer curso se lee:

Concepto intuitivo de límite de una función en un punto. Límites laterales. Límites en el infinito. Cálculo de límites. Asíntotas verticales y horizontales de una función (Ministerio de Educación, Cultura y Deporte, 2001, pp. 33840)

Sin embargo, no se menciona el límite en los criterios de evaluación del citado documento. En cambio, en los contenidos del segundo curso aparece de forma explícita el concepto:

Límite de una sucesión. Límite de una función. Cálculo de límites (Ministerio de Educación, Cultura y Deporte, 2001, pp. 33841)

Y en los criterios de evaluación:

Desarrollar las destrezas más usuales para el cálculo de límites [...]. (Ministerio de Educación, Cultura y Deporte, 2001, pp. 33841)

En el periodo LOE se encuentran referencias a los límites también en los dos cursos, aunque en este caso de forma explícita en ambos. Según el currículo estatal (Ministerio de Educación, Política Social y Deporte, 2008), en los contenidos de Matemáticas I se menciona lo siguiente: "aproximación al concepto de límite de una función en un punto", y en Matemáticas II se estudia el concepto, el 
cálculo de límites, los límites infinitos y en el infinito, y las asíntotas. En ambos cursos, según los criterios de evaluación, se aplican al estudio de funciones, interpretación de fenómenos naturales o tecnológicos... Por su parte, en Castilla y León se describen los contenidos de forma más extensa aunque en la misma línea que marcan las directrices estatales:

Aproximación al concepto de límite de una función, tendencia y continuidad. Técnicas elementales del cálculo de límites. Límites y comportamiento asintótico de una función. (Contenidos Matemáticas I, Consejería de Educación de Castilla y León, 2008, pp. 11358)

Concepto de límite de una función. Cálculo de límites. Límites en el infinito. Comportamiento asintótico de una función. (Contenidos Matemáticas II, Consejería de Educación de Castilla y León, 2008, pp. 11358)

Por último, se observa que en la nueva legislación, LOMCE, también se considera el límite funcional, tanto en el primer curso como en el segundo. Algunas de las referencias que se pueden encontrar en el Real Decreto 1105/2014, que establece el currículo de Educación Primaria, Secundaria y Bachillerato (2015), entre otras, son las siguientes:

Concepto de límite de una función en un punto y en el infinito. Cálculo de límites. Límites laterales. Indeterminaciones. (Contenidos de Matemáticas I)

2.1 Comprende el concepto de límite, realiza las operaciones elementales de cálculo de los mismos, y aplica los procesos para resolver indeterminaciones.

2.2 Determina la continuidad de la función en un punto a partir del estudio de su límite y del valor de la función. (Estándares de aprendizaje de Matemáticas I)

Límite de una función en un punto y en el infinito. (Contenidos de Matemáticas II).

1.2 Aplica los conceptos de límite y de derivada, así como los teoremas relacionados, a la resolución de problemas.

2.1 Aplica la regla de L'Hôpital para resolver indeterminaciones en el cálculo de límites. (Estándares de aprendizaje de Matemáticas II)

(Ministerio de Educación, Cultura y Deporte, 2015, pp. 36-47)

En resumidas cuentas, su tratamiento en los cursos considerados en nuestro estudio es ineludible, debe hacerse de forma obligada y, por tanto, se debería encontrar este concepto y los resultados asociados a él en todos los LT. Sin embargo, no se explicitan qué resultados deben aparecer, lo que implica que la organización del concepto de límite, qué teoremas y propiedades se enuncien y en qué orden, puede variar de unos libros a otros a criterio de los autores, lo que se comprobará en el análisis de los LT de nuestra muestra. 


\section{IV.3. LOS LÍMITES EN LOS LIBROS DE TEXTO}

En el presente epígrafe presentamos un breve resumen de cómo se presentan los límites en los libros de texto. Dicho resumen está ordenado, en primer lugar, la antigüedad de la legislación a la que corresponde, del curso más bajo al más alto, y por editoriales, ordenadas por orden alfabético. Este resumen muestra una primera idea de los resultados que analizaremos bajo la perspectiva de nuestro marco teórico.

\section{IV.3.1. Ley General de Educación}

Como ya hemos indicado anteriormente, los límites no se estudian en $3^{\circ}$ de BUP, ya que la organización curricular del periodo legislativo de la LGE considera que su tratamiento debe realizarse en el curso anterior. Por esta razón se ha ampliado la muestra para este concepto a los libros de texto de $2^{\circ}$ de BUP. También incluimos las referencias que se encuentran en algunos de los textos de COU, ya que, de manera general, los límites se suponen estudiados en este nivel, pero algunas editoriales los incluyen a modo de recuerdo. Veamos las líneas generales del tratamiento que hacen los LT de éste periodo para los límites.

\section{IV.3.1.1. Libros de $2^{\circ}$ BUP}

Anaya: en la muestra se consideran con dos ejemplares de este curso para esta editorial, uno de 1976 y el otro de 1987. Es conveniente el análisis de ambos ejemplares, aunque correspondan al mismo curso, misma editorial y mismo periodo, debido a que al estar tan espaciados en el tiempo (uno está editado al comienzo de la ley y el otro al final). Así, se podrá observar si esta editorial experimenta alguna evolución a lo largo de este periodo.

El ejemplar más antiguo (Anaya, 1976) considera en un primer tema la definición del concepto de límite en un punto, de límites infinitos y de límites en el infinito, introduciendo el tema con una explicación intuitiva del concepto (además, en temas anteriores consideró las sucesiones y, por tanto, el límite de sucesiones). A continuación se presenta un tema en el que se considera el cálculo de límites de funciones (tema 6). En este tema se refieren únicamente a límites finitos de 
funciones en un punto, y en él, en primer lugar, se presentan los infinitésimos, junto con sus propiedades (que se usarán más adelante para justificar las de límites) y las propiedades de los límite y aplicaciones al cálculo. En el siguiente tema se considera el cálculo de límites en el infinito, y en él se hacen referencias a los resultados sobre sucesiones, lo que se puede considerar una generalización (o esquema de prueba inductivo) si se consideran a las sucesiones como un caso particular de funciones. De esta manera, se limitan a enunciar los resultados sin justificarlos.

En el ejemplar más reciente (Anaya, 1987), en primer lugar, se introducen también las sucesiones y el límite de sucesiones. Más adelante, una vez consideradas las funciones, se acomete el estudio del límite de funciones. Tras introducir una idea intuitiva de límite, el libro considera los límites en el infinito y a continuación, el límite de una función en un punto. En el siguiente tema se presenta el cálculo de límites, siguiendo el mismo orden que en el anterior: en primer lugar el cálculo de límites en el infinito (e indeterminaciones) y, en segundo, el cálculo de límites en un punto. Este libro no enuncia reglas, ya que considera que se pueden calcular aplicando propiedades de los números, y únicamente muestra ejemplos, a excepción del límite de una función potencialexponencial, cuya base tiende a 1 y cuyo exponente a infinito. Sin embargo, si incluye el tratamiento de algunas indeterminaciones o familias concretas de funciones como, por ejemplo, el límite de un polinomio, de la función raíz cuadrada y de las funciones racionales.

Santillana: al igual que en el caso de Anaya, tenemos dos ejemplares de esta editorial correspondientes a este curso en nuestra muestra, Santillana (1976) y Santillana (1991). Si bien este último texto está editado tras la promulgación de la siguiente ley orgánica, la LOGSE, es habitual que exista un periodo de convivencia entre las dos legislaciones hasta que la segunda es completamente implantada, y dado que los cursos analizados son de los de mayor nivel, estos no entraron en vigor hasta los años 1997 y 1998.

En el primer ejemplar, Santillana (1976), el texto considera en una unidad el tratamiento de las funciones reales, de los límites y de la continuidad, separado en temas diferentes. Esta unidad está precedida por la de sucesiones, en el que ya se han estudiado los límites de sucesiones y propiedades sobre ellos. En el tema 
de límite de funciones, el libro de texto, en primer lugar, presenta una introducción a la idea intuitiva del límite de una función en un punto para definirlo formalmente a continuación. Seguidamente considera algunas propiedades de los límites o reglas de cálculo (aplicación de la regla de Ruffini a funciones racionales, el límite de la diferencia de una función y su límite en un punto es cero, función constante, unicidad, acotación, conservación del signo), seguidas de las operaciones. En los siguientes apartados presenta los límites infinitos, los límites en el infinito, asíntotas y límites laterales. Finalmente, enuncia algunas propiedades como teoremas. Este LT presenta numerosas justificaciones de los resultados que enuncia.

En el ejemplar más reciente, Santillana (1991), los límites y la continuidad de funciones se presentan en el mismo tema, debido a que define la continuidad a partir de los límites. Para presentar el tema del límite, muestra primero un ejemplo concreto en el que una función se aproxima a un valor en las inmediaciones de un punto. Luego da una primera noción, utilizando sucesiones y las imágenes de sucesiones, para acabar enunciando la definición épsilon-delta. En la parte de propiedades muestra las operaciones (hasta ahora sólo ha considerado los límites en un punto), y demuestra el caso de la suma por considerarlo sencillo. El resto (producto por contante, producto de funciones, cociente de funciones, potencia por constante y potencia de funciones), aunque indica que las podría demostrar, considera que llevaría demasiado tiempo, que la dificultad es excesiva, que no ayuda a la comprensión del concepto, y no las justifica. Menciona las indeterminaciones, como casos en los que aplicando las propiedades se llega a una expresión sin sentido, y que en esos casos hay que estudiar cada caso particular.

A continuación define los límites laterales, y enuncia la unicidad del límite. Para justificar dicha unicidad se remite a las sucesiones. También indica los pasos para una posible demostración utilizando la definición épsilon-delta. A continuación define los infinitésimos, considera dos propiedades importantes (la suma de infinitésimos es un infinitésimo, y la posibilidad de sustitución de infinitésimos cuando intervienen en factores). Luego trata los límites infinitos y en el infinito y menciona que las operaciones descritas anteriormente se pueden generalizar teniendo en cuenta que pueden aparecer indeterminaciones. En el tema siguiente se presenta el cálculo de límites de funciones, que se reduce a 
resolver indeterminaciones que aparecen tras la aplicación de las propiedades descritas anteriormente y como trabajar los cocientes de funciones.

SM: disponemos de un único ejemplar de esta editorial correspondiente a $2^{\circ}$ de BUP, del año 1977. Este texto comienza por el tema de sucesiones de números reales y límites de sucesiones. Se aborda también el número $e$ y el cálculo de límites de sucesiones. A continuación presenta un tratamiento defunciones de variable real, límites de funciones y continuidad de las funciones. En cuanto al límite de funciones, la definición de límite de una función en un punto se enuncia en los términos $\varepsilon-\delta$ y diferencia de valores absolutos. Se enuncia de manera verbal y se presenta la simbología. Se matiza la no importancia de lo que sucede en el punto. A continuación se define el límite finito en el infinito, y el límite infinito. Sigue con las propiedades de los límites de las funciones (unicidad, coincidencia del límite de dos funciones cuyas imágenes en un entorno reducido coinciden y criterio del sándwich (encaje) aunque no lo nombra así). Continúa con las propiedades asociadas al cálculo de límites (suma, diferencia, producto, cociente, potencias, raíces, funciones exponenciales, logarítmicas y trigonométricas). Indica que la primera regla de cálculo de límites es sustituir la variable independiente de la función por el valor al que tiende, pero esto puede dar lugar a casos extremos, a indeterminaciones. Se estudian las indeterminaciones y se introducen los infinitésimos y su uso para resolver indeterminaciones. Por último, se estudian los límites indeterminados de la forma $\rightarrow 1^{\infty}$.

Vicens-Vives: este texto, aunque data de 1980, es la cuarta edición del libro de texto aprobado en 1976. En este texto el orden que se presenta es diferente de otros textos de la época ya que se trabajan antes los límites de funciones que los de sucesiones: define el límite a partir de los conceptos de continuidad y discontinuidad, luego considera los límites, seguidos de la derivabilidad, y en última instancia, las sucesiones y el límite de sucesiones.

En el apartado de límite de una función aborda las discontinuidades evitables, y como evitarlas. Luego trata el límite de una función en un punto de discontinuidad evitable. Una vez estudiado el límite en un punto con discontinuidad evitable, indica que si la función es continua, el límite coincide 
con el valor de la función en el punto (la continuidad ha sido definida con anterioridad, en el capítulo dedicado al estudio de funciones). A partir de aquí hace un estudio de límite de una función en un punto, considerando la unicidad, las operaciones con límites, el límite de la función compuesta, los límites laterales y, por último, con analogía a los límites, define la continuidad por la derecha y por la izquierda. A continuación considera los límites infinitos y en el infinito.

\section{IV.3.1.2. Libros de COU}

En este curso se considera que los límites de funciones ya han sido estudiados con anterioridad ( $2^{\circ}$ de BUP) y, por tanto, los libros de texto los consideran de forma somera o superficial o ni siquiera los consideran.

Anaya: el ejemplar de este curso corresponde al año 1989, y en él se presentan los límites de sucesiones en un tema, y los límites de funciones ligados al tema de continuidad. Respecto a los límites de funciones, el libro se limita a enunciar las definiciones, empezando por los límites en el infinito e infinitos, y dejando para el final la definición de límite finito en un punto. Todas las definiciones son métricas, salvo en este último caso, que realiza una caracterización a partir de los límites laterales aunque indica que es equivalente a la definición métrica, tanto expresada en términos de valor absoluto como de entornos. Por último, menciona algunas técnicas para el cálculo, como sustituir por el valor al que tiende $x$ en los puntos de continuidad y también da algunas pautas para la resolución de indeterminaciones. Menciona que la regla de L'Hôpital, que se enuncia más adelante (junto a derivabilidad) enriquecerá el cálculo de límites. A partir de aquí sigue con continuidad.

Santillana: en este texto (Santillana, 1981) no se presentan los límites de funciones.

SM: en este LT, de 1980, el concepto de límite se presenta en el tema de continuidad de una función, suponemos que se presenta como necesidad para estudiar la continuidad. En primer lugar se considera la definición formal, junto a 
otras definiciones alternativas, considerando los casos infinitos además del límite de una función en un punto. Define los límites laterales y enuncia el primer resultado: condición necesaria y suficiente para que una función tenga límite en un punto. A partir de ahí se estudia la continuidad.

Vicens-Vives: en este texto, de 1979, no se describen los límites. Aparecen referencias a ellos en el apartado de continuidad, pero se considera que se han estudiado previamente y son sobradamente conocidos.

\section{IV.3.2. Ley Orgánica de Ordenación General del Sistema Educativo}

Para este periodo legislativo, todos los libros de texto presentan los límites y algunos resultados sobre ellos en ambos cursos. No obstante, dependiendo de la editorial e, incluso dentro de la misma, de la colección, el tratamiento que se realiza en cada uno de ellos es diferente. A continuación se presenta el resumen correspondiente a los textos de este periodo.

\section{IV.3.2.1. Libros de $1^{\circ}$ de Bachillerato}

Anaya: este texto data de 2002, cerca del final de este periodo legislativo y es posterior a la modificación de 2001. En la introducción del tema relaciona el concepto de límite de funciones con los procesos de cambios. Para introducir el concepto habla de la imposibilidad, en ocasiones, de obtener el valor exacto directamente, por lo que es necesario buscar sucesivas aproximaciones. Este texto introduce primero el concepto de continuidad y luego los límites, ya que usa el límite para estudiar la continuidad en un punto y las asíntotas verticales. Relaciona el concepto de tender con aproximarse ${ }^{1}$ a un determinado valor. Una vez que ha descrito que significa que " $x$ se acerque a $c$ ", explica el significado de límite de $f(x)$ cuando $x$ tiende a $c$ por la derecha o por la izquierda, para que, en el caso de que coincidan, la función $f$ tenga límite en $c$. En primer lugar estudia el límite por la izquierda ${ }^{2}$, luego por la derecha, y por último relaciona la existencia

\footnotetext{
${ }^{1}$ Más adelante encontraremos además asociado al verbo aproximar, la expresión "tanto como queramos".

${ }^{2}$ Los autores del texto hablan de valores cada vez "más negativos” para explicar el límite a $-\infty$.
} 
de ambos y la continuidad. En el apartado siguiente se centra en el cálculo del límite de una función en un punto analizando los casos, en su mayoría triviales, en lo que parece un intento de sistematizar el estudio de estos y dar al alumno una "receta" para calcular límites. Los casos que, por este orden, describen son: límite en un punto en el que la función es continua; límite cuando la función está definida a trozos y, ambos "trozos" son continuos en el punto dónde se "cambia" de "trozo"; el cociente de dos polinomios y, dentro de este caso, si el denominador se anula, si lo hace el numerador o si lo hacen ambos. Sigue con el estudio de los límites en el infinito, realizando un planteamiento similar a los límites en un punto (explicación, cálculo del límite de algunos tipos de función como las polinómicas o racionales). Continúa con las asíntotas, sigue una breve explicación del comportamiento al tender a $-\infty$ y acaba el tema con el comportamiento de funciones trigonométricas, exponenciales y logarítmicas. En ningún momento habla de propiedades de los límites ni de la aritmética.

Santillana: LT de 1996. Expone el concepto intuitivo de límite de una función en un punto como tendencia de las variables dependiente e independiente y destaca la notación simbólica. Utiliza ejemplos para ilustrar el concepto, sin dar una definición en concreto. A continuación considera los límites laterales, de los que muestra una definición más detallada aunque sin ser demasiado formal y rigurosa, y caracteriza la existencia del límite de una función en un punto como la existencia y coincidencia de límites laterales. Considera los límites infinitos, que asocia a las asíntotas verticales, y los límites en el infinito, que relaciona con tendencias y asíntotas horizontales, aunque en ningún caso los definen, sino que ilustra la idea con ejemplos. Al igual que hacía el texto de Anaya, compara el límite con tendencia hacia menos infinito con hacerse cada vez "más negativos". En los temas siguientes, relativos al estudio de funciones exponenciales, logarítmicas y trigonométricas, al hablar de las propiedades menciona las tendencias de dichas funciones en el infinito. En este texto el límite funcional se considera principalmente para definir la continuidad y la derivabilidad.

SM: el ejemplar de esta editorial data de 1996, y es de los primeros cursos en los que se encuentran LT relativos a esta ley. En el caso de los límites, primero estudia los límites de sucesiones, aunque solo examina casos concretos y límite 
infinito y menos infinito, pero no trabajan propiedades, operaciones... En el caso de límite de funciones, comienza con la idea intuitiva, en la que estudia varios ejemplos diferentes avanzando los conceptos de límites laterales, límites finitos, límites infinitos y límites en el infinito. En el epígrafe siguiente enuncia una definición más formal, a partir de sucesiones. Esta definición es general para límites en un punto, en el infinito, por la derecha, por la izquierda, y límites finitos e infinitos. Considera unas pautas para el cálculo de límites, estableciendo en primer lugar una distinción entre casos determinados e indeterminados (en el margen apunta los tipos de indeterminaciones) y continua con indicaciones para la resolución de algunas indeterminaciones: límite de funciones racionales y de funciones irracionales (en lugar de establecer teoremas, se puede considerar que utiliza técnicas de cómo transformarlos en un caso determinado). Por último, estudia algunos límites relacionados con funciones trigonométricas: $\operatorname{sen}(x) / x$ cuando $x$ tiende a cero, ídem para $\operatorname{tg}(x) / x$ y finalmente, tras presentar las funciones equivalentes y el teorema que permite sustituir funciones equivalentes cuando actúan como factor o cociente en una expresión, el límite en cero de (1$\cos (x)) / x$.

Vicens-Vives: para esta editorial se consideran dos libros de texto, uno de 1998 y otro de 2003. El primer ejemplar, Vicens-Vives (1998), realiza una presentación un poco diferente a lo que suelen hacer los otros LT, y que mantiene en el LT de $2^{\circ}$ de Bachillerato de la misma colección: realiza la presentación previa, de forma inductiva y considerando casos particulares, para formalizar el concepto al final. En este texto se trabajan al mismo tiempo las funciones y los límites, y éstos últimos se presentan dentro del estudio de funciones. Define el límite como necesidad para estudiar las funciones en los extremos de los intervalos de dominio, dando definiciones ingenuas (no formales). Empieza con los límites en el infinito ligados a asíntotas horizontales (límites finitos), seguidos de los límites en un punto ligados a asíntotas verticales (y por tanto infinitos). Las definiciones las hace atendiendo a ejemplos. Continua con la idea de continuidad, y a continuación los casos $\rightarrow k l \rightarrow \infty$ y $\rightarrow k / \rightarrow 0^{3}$ (no indican que son límites, los trata como a números). Tras varios ejemplos induce cuál es el límite de un cociente en

\footnotetext{
${ }^{3}$ La notación que utiliza es $k / \infty$ y $k / 0$, al igual que hacen la mayoría de LT. No debe utilizarse esta notación ya que los "cocientes" considerados no son números, sino que expresan tendencias de funciones, lo que desaparece con esta notación.
} 
los casos anteriores. Indica, como observación, que una función no cambia de signo entre puntos de corte con el eje OX y los extremos de los intervalos de definición, pero no lo justifica. Continúa con el estudio de funciones y gráficas de funciones, que suponen el eje principal de estas unidades temáticas, y establece el comportamiento en el infinito de funciones polinómicas y funciones racionales, justificando los resultados en ambos casos. Enuncia la aritmética de límites finitos sin justificar y lo extiende a la aritmética de límites infinitos, también sin justificar. Por último, menciona los límites en los puntos de continuidad (no los considera interesantes al coincidir con la función en ese punto) y dedica una ampliación al tratamiento de indeterminaciones.

En el segundo ejemplar, Vicens-Vives (2003), que es de una colección diferente, el concepto de límite se ha visto anteriormente, en el tema de sucesiones numéricas, en el que también aparece el número $e$ como límite de una sucesión. La continuidad y los límites se tratan en el mismo tema, ya que se utiliza el concepto de límite para introducir la idea de continuidad. Antes de empezar con los epígrafes del tema, se introducen dos ideas a través de historias: Aquiles y la tortuga, y el concepto de límite. Relacionan el concepto con aproximarse tanto como queramos (idea ligada a la subjetividad), y plantea la posibilidad de que el límite no pueda alcanzarse, indicando que el límite es que sucede en las proximidades de un punto, y no en el punto. Una vez introducida la idea de límite, de aproximarse con la precisión deseada (aunque no lo expresa así), define los límites laterales. Acto seguido define el límite de una función en un punto utilizando sucesiones (para sucesiones ha utilizado la definición con épsilon- $\mathrm{n}_{0}$ ) y luego lo relaciona con la existencia de límites laterales. No verifica que ambas definiciones son equivalentes. Por último, lo vincula con la definición de épsilon- $\mathrm{n}_{0}$. A continuación presenta los límites infinitos en un punto. Para ello, pone dos ejemplos de funciones. Luego recurre a la definición métrica. Matiza que indicar infinito muestra una tendencia, ya que infinito no es un número, e indica que, entonces, en el punto hay una asíntota vertical. Por último, considera los límites en el infinito y habla de las asíntotas horizontales. Para ilustrar las diferentes posibilidades de límites en el infinito, muestra ejemplos de funciones. Una vez vistos los diferentes tipos de límites, presenta la aritmética de límites, si bien, no prueba ninguno de los resultados de las operaciones, limitándose a mostrar ejemplos de aplicación. A continuación se dan indicaciones para el cálculo de límites (evaluar la función en el punto, estudiar los casos particulares, 
las indeterminaciones...) Se escriben cocientes indebidos $(0 / 0, \ldots$, en lugar de $\rightarrow 0 / \rightarrow 0$ ) en las indeterminaciones, y se dan indicaciones de cómo resolverlas, siempre mediante ejemplos. También presenta las funciones definidas a trozos. Por último, en cuanto a los límites, considera el cálculo de límites en el infinito, considerando diferentes tipos de funciones e indeterminaciones. Aplica el límite de la sucesión que se aproxima a $e$, aunque solo lo vincula como un "recuerda" (en el capítulo correspondiente no lo demuestra, aunque indica que se podría hacer y recurre a la intuición, induciendo el resultado a través de un ejemplo tabular). El último epígrafe considera la continuidad de una función en un punto.

\section{IV.3.2.2. Libros de $2^{\circ}$ de Bachillerato}

Anaya: ejemplar de 2003. En la introducción del tema habla de la importancia del límite como herramienta básica del análisis. También menciona que el estudio de los límites se realizará de dos formas, en la primera de forma intuitiva, $\mathrm{y}$, en la segunda, formal y rigurosa. Comienza el tema con el concepto de límite de una sucesión, concepto que ya ha sido presentado el curso anterior. En primer lugar, muestra ejemplos utilizando términos de sucesiones y, a continuación, representaciones gráficas, tanto para ilustrar los límites finitos como infinitos. Continúa con una exposición más formal aunque utiliza expresiones como, "tanto como queramos" o "por pequeño que sea". Para operaciones, propiedades y cálculo, se refiere a los de límites de funciones, y acaba exponiendo la típica sucesión, cuyo límite es el número $e$. Una vez estudiados los límites de sucesiones, presenta el estudio de límite de funciones: comienza estudiando comportamiento de funciones cuando $x$ tiende a infinito (positivo), y señala los posibles casos (que la función tienda a un número real, crezca indefinidamente o decrezca indefinidamente, o no exista el límite). Esto lo muestra con ejemplos gráficos y luego pasa a un estudio detenido de cada caso. Utiliza expresiones del tipo "tanto como queramos", "suficientemente grandes", "arbitrariamente pequeño", "tan grande como sea necesario", que implican subjetividad. A continuación describe las operaciones con límites finitos (en el infinito) aunque no las demuestra, pero sí que presenta ejemplos de aplicación Asimismo, describe los límites infinitos (definiciones y algunos cálculos de límites infinitos, con ejemplos de aplicación). Muestra la comparación de infinitos, es decir, presenta los órdenes de infinitos. Define qué se entiende por un infinito de orden 
superior, o del mismo orden. También muestra algunos ejemplos, operaciones con infinitos, y por último, indeterminaciones, como casos en los que no podemos operar simplemente con el valor de los límites, por lo que hay que tratarlos con mayor profundidad. En la siguiente unidad se muestra como calcular límites de tipos de funciones concretas: cociente de polinomios, cocientes de otras expresiones infinitas, diferencias, potencias, el número $e, \mathrm{y}$ a continuación, las expresiones del tipo $\rightarrow 1^{\infty}$. Ninguno de los ejemplos mostrados del caso $e$ se demuestra o justifica, pero si se demuestra la regla práctica para las expresiones de tipo $\rightarrow 1^{\infty}$. Luego aborda el caso de los límites en el infinito (negativo), definición y cálculo, remitiendo a los casos de infinito positivo. Por último, aborda el límite de una función en un punto, considerando los límites laterales infinitos, los finitos, y define el límite finito en un punto, relacionando con el resultado de existencia de laterales y su coincidencia. Por último, presenta el cálculo de límites en un punto y las indeterminaciones.

Santillana: este ejemplar, del año 1997, es de la misma colección que el de $1^{\circ}$ Bachillerato. Empieza explicando el límite de sucesiones como paso previo para el límite funcional. En el límite funcional, comienza con la idea intuitiva, y habla de tendencia tanto para la variable independiente como la dependiente, para, a continuación, definir el límite de una función en un punto mediante sucesiones que tienden a dicho punto. Justifica que los términos de la sucesión elegida deben ser distintos de $a$. Muestra dos ejemplos, uno en el que existe la imagen en el punto y otro que no, utilizando tres sistemas de representación gráfico, tabla y algebraico. Introduce una definición mediante entornos, análoga a la que hizo para límite de una sucesión, hablando por primera vez de la unicidad del límite: "El procedimiento seguido en los ejemplos anteriores[...] nos selecciona el único valor de y que es candidato a ser límite" (Santillana, 1997, pp. 220). En primer lugar expone la definición de forma verbal y a continuación la expone utilizando el leguaje simbólico junto con un gráfico ilustrando la situación. Por último, traduce la definición anterior a términos de distancias, utilizando la definición tradicional $\varepsilon-\delta$. Define los límites laterales como concepto "debilitado" de límite, utilizando la definición mediante tendencia, entornos y $\varepsilon-\delta$. Se enuncia el teorema de caracterización del límite (existencia y coincidencia de los límites laterales), pero no lo justifica. De hecho, el único ejemplo que expone es en el 
caso de no coincidencia de los límites laterales. Para el caso de los límites infinitos, los autores hacen referencia a las nociones que han dado sobre la topología de la recta real. Definen los entornos de números reales, puesto que lo utilizarán en las definiciones de límite, continuidad... y, para abarcar el caso de los límites infinitos, hace una extensión de la definición de entorno de un punto $a$, y radio $r$, a "entornos del infinito". Para ello, introduce el concepto de compactación de la recta real, sin explicarlo y de forma poco rigurosa, y esta manera le permite hablar de entornos de $\infty$ de frontera $a$. Esto lo utiliza en el texto para definir el límite infinito en un punto, únicamente sustituyendo en la definición anterior los entornos de puntos por entornos de $\infty$. Al igual que en los casos anteriores, los autores presentan tres definiciones: utilizando tendencias ${ }^{4}$, entornos, y la notación habitual $\varepsilon-\delta$. Este LT considera ejemplos en los que se pide "demostrar":

Dada la función $f(x)=1 / x$ :

Demuestra que para cualquier entorno de $\infty$ existe un entorno de 0 cuyos puntos tienen imágenes en el entorno de $\infty$. (Santillana $2^{\circ}, 1997$, pp. 222)

De la misma manera que se definen los límites infinitos, los autores presentan la definición de límites en el infinito sustituyendo de forma adecuada en las definiciones anteriores y considerando varias formulaciones (entornos, distancias). Enuncia las propiedades de los límites y sus operaciones e indica que las más sencillas se encuentran detalladas en el apartado Ejercicios y problemas resueltos, en el que encontramos las justificaciones de la unicidad del límite, $\lim _{x \rightarrow a} K=K, \lim _{x \rightarrow a} x=a \quad$ y $\quad \lim _{x \rightarrow a}(f(x)+g(x))=\lim _{x \rightarrow a} f(x)+$ $\lim _{x \rightarrow a} g(x)$. A diferencia del curso anterior, los autores en este texto advierten de los abusos de notación realizados en los ejemplos: $2 / 0, \infty+1, \ldots$ Se incluyen tres "Recuerdas" en los que aparecen algunos razonamientos. En uno de ellos justifica $\lim _{x \rightarrow 0} \frac{x}{\operatorname{sen}(x)}=1$, utilizando el criterio del sándwich, aunque no menciona dicha técnica.

SM: este ejemplar es del año 2001. Aunque introduce el tema con propiedades de los números reales, una vez tratados los conceptos de dominio y recorrido, expone el límite finito de una función en el infinito. La definición está expresada

\footnotetext{
${ }^{4}$ Cuando introduce la definición para límites infinitos, habla directamente de tender a $\infty$ sin explicar su significado.
} 
en términos de $\varepsilon$, y de forma verbal. Previamente muestra un ejemplo, y define separadamente el caso positivo y negativo. A continuación trata otros casos de comportamiento en el infinito (que tienda a más o a menos infinito, o la no existencia). Seguidamente, introduce los límites laterales, habiendo presentado anteriormente un ejemplo con representación tabular y gráfica, también en términos de $\varepsilon-\delta$, para, a continuación, definir el límite de una función en un punto. Dice que este existe si existen los laterales y coinciden, y deduce la expresión de la definición en términos $\varepsilon$ - $\delta$. No lo enuncia como resultado la equivalencia con la existencia de límites laterales y coincidencia. Luego muestra dos casos sencillos, el de la función constante, y el de la función identidad, pero no los demuestra, simplemente justifica verbalmente sin hacer un uso riguroso de la definición. A continuación trata el límite infinito en un punto. Se muestran ejemplos, y se enuncia la definición. Una vez establecidas las definiciones, pasa a enunciar las propiedades (suma, diferencia, producto, constante por función, cociente, valor absoluto, potencia, composición) de límites finitos, todas sin justificar. Luego muestra técnicas de cálculo de límites, y el caso de las indeterminaciones. No se demuestra nada, se presentan ejemplos para mostrar cómo se aplica la regla descrita, no para justificar. Por último, se muestran los límites de dos funciones trigonométricas: $\operatorname{sen}(x) / x$ y $(\cos (x)-1) / x$. Apenas se enuncian resultados, y los pocos que se enuncian no se demuestran.

Vicens-Vives: contamos con dos ejemplares de $2^{\circ}$ de Bachillerato, ambos de las mismas colecciones que sus correspondientes predecesores de $1^{\circ}$ de Bachillerato.

En el primer texto, Vicens-Vives (1999), el tratamiento que se realiza de límites es más extenso que en el correspondiente de $1^{\circ}$ de Bachillerato. Se aprecia una diferenciación de dos partes: en la primera se realiza un tratamiento más ingenuo y en la segunda más formal. Sin definir el límite, presenta el límite de algunas funciones sencillas a partir de las gráficas de algunos ejemplos $\left(x^{n}, 1 / x, 1 / x^{2}, x^{2+k}\right.$, $\checkmark x$ ). A continuación se enuncia la aritmética extendida para límites infinitos (en un punto o en el infinito), acompañados de ejemplos. Sigue con el límite de un polinomio en el infinito y el límite del cociente de polinomios en el infinito (no menciona ni a las funciones polinómicas ni a las racionales). Continúa con los infinitos, y enuncia dos teoremas (que demuestra): suma de infinitos equivalente al sumando de mayor orden, sustitución de un infinito por otro equivalente en productos o cocientes. Sigue con el estudio de las funciones exponenciales y logarítmicas y, por tanto, sus límites (enuncia algunos resultados: infinito de 
orden superior en exponenciales, una función exponencial de base $>1$ es un infinito superior a una función potencial, comparación de logaritmos y potenciales). Se presenta el álgebra de límites, primeramente finitos (límites en un punto, en el infinito, sin justificar, y se mencionan las indeterminaciones) y luego los límites infinitos, también con indeterminaciones y sin justificar. Considera el cociente de polinomios con alguna raíz en común $(\rightarrow 0 / \rightarrow 0)^{5}$ y deduce de la equivalencia a haber factorizado ambos polinomios. Sigue con varias indeterminaciones y calcula el límite $\operatorname{sen}(x) / x$ cuando $x$ tiende a 0 , y acaba con los infinitésimos, enunciando y demostrando la sustitución por equivalentes.

El otro ejemplar, Vicens-Vives (2004), presenta en el mismo tema los límites de sucesiones y de funciones, por lo que algunos de los resultados de límites de funciones similares a los de sucesiones han sido enunciados previamente para éstas. En el caso de límites de funciones, comienza estableciendo una definición para el límite en un punto que depende de sucesiones (la misma que en primero) aunque la sustituye a continuación por la definición métrica (sin justificar la equivalencia). Continúa con los límites laterales, y establece que la condición necesaria y suficiente para la existencia de límites es que existan los límites laterales y que coincidan, pero no justifica que sea equivalente a las definiciones anteriores. Considera algunas pautas para el cálculo de límites, y pasa a límites infinitos y límites en el infinito, de los que enuncia sus definiciones. Considera unas pautas para el cálculo de límites en el infinito, y establece el límite de las funciones polinómicas, racionales y exponenciales. A continuación considera la aritmética de límites (suma, diferencia, cociente, $f(x)^{g(x)}$ ) sin justificar, la aritmética extendida (también sin justificar) y algunas indeterminaciones. Este texto repite muchas de las cosas que se hacen en primero y únicamente añade las definiciones más formales (aunque no se utilizan).

\section{IV.3.3. Ley Orgánica de Educación}

Veamos cuál es el tratamiento que reciben los límites en los libros de texto relativos a la Ley Orgánica de Educación. Todos los ejemplares de $1^{\circ}$ de Bachillerato es editaron el mismo año, 2008. Los correspondientes a $2^{\circ}$ de

\footnotetext{
${ }^{5}$ La notación que utiliza es $0 / 0$.
} 
Bachillerato son de 2009, a excepción de SM, que es de 2010, aunque pertenece a la misma colección que su correspondiente de $1^{\circ}$.

\section{IV.3.3.1. Libros de $1^{\circ}$ de Bachillerato}

Anaya: el texto, editado en el año 2008, es prácticamente igual (cambian algunos aspectos de maquetación y parte de los ejercicios propuestos) que en el periodo legislativo anterior, así que, al igual que en el caso anterior, no hay resultados, todo está basado en el cálculo de límites, no se dan las propiedades de los límites ni su aritmética y por tanto, apenas aparecen justificaciones.

Santillana: este texto presenta los límites de funciones tras el estudio del concepto de función y una revisión sobre sucesiones y el límite de sucesiones. En sucesiones, enuncia la definición de límite, y la unicidad, aunque sin justificar. Sigue con el cálculo de límites de sucesiones, considerando casos concretos: límite de potencias, de polinomios, de cociente de polinomios. Seguidamente se describe la aritmética de límites de sucesiones, pero no demuestra ninguna de las operaciones descritas. Se abordan también las indeterminaciones que se pueden encontrar, presentando ejemplos de cada caso y cómo se pueden resolver dichas indeterminaciones. Sin embargo, no se enuncian como resultados y no se justifican. A continuación presenta el límite de funciones, siguiendo un esquema similar: definición de límite (aunque añaden la definición el límite en un punto que no se consideraba en sucesiones), indeterminaciones, ramas infinitas... y por último continuidad de una función. No se presentan como resultados ni se justifican. En la definición, "el límite de una función $f(x)$ cuando $\mathrm{x}$ tiende a $+\infty$, es un número real L, cuando para valores muy grandes de $\mathrm{x}$, los valores de la función se aproximan al número L", no hace distinción entre que L sea un número, o L "pueda ser" $\infty$.

SM: Dentro del mismo tema, encontramos los conceptos de: función, límite de funciones, continuidad, y sucesiones y sus límites. Estudia el límite como el comportamiento de una función en un punto. La definición es explicativa, pero no rigurosa, habla de tomar valores próximos pero no menciona que siempre se pueden mejorar las aproximaciones. No obstante, se trata de una definición intuitiva. En ningún caso la vincula a la definición métrica o topológica. Utiliza 
este tipo de definición también para los límites laterales, los límites finitos en el infinito y los límites infinitos. En el enunciado de límites laterales caracteriza la existencia del límite mediante la existencia y coincidencia de los límites laterales. A continuación procede a tratar el cálculo de límites. En primer lugar expone los casos en los que la función está definida en el punto donde se quiere calcular el límite y aclara que basta con sustituir la variable por el valor al que tiende. Luego expone las indeterminaciones como "lugares" dónde al sustituir el valor en la función, lo que obtenemos no tiene sentido en $\mathbb{R}$. Describe las indeterminaciones que se pueden obtener, así como las operaciones con límites ${ }^{6}$. Por último, aborda las asíntotas, tanto verticales, como horizontales y oblicuas, y el procedimiento de cálculo. A continuación, tras abordar la continuidad, explica las sucesiones de números reales y, dentro de éstas, el cálculo de límites de sucesiones. Para ello, aplica todo lo explicado en los límites de funciones, y en este epígrafe como resolver algunas de las indeterminaciones que habían salido anteriormente, aunque sólo para el caso de sucesiones. En este texto no hace un tratamiento muy profundo de los límites, menciona las cuestiones básicas para poder calcularlos y no trata el concepto con rigor y formalismo.

Vicens-Vives: este texto, del año 2008, empieza el tema por los límites de funciones, una vez que se han visto éstas en el tema anterior, y con una definición de límite ingenua (utiliza la expresión "tanto como queramos"), sin introducir el concepto. A continuación considera un ejemplo concreto, la función $f(x)=x^{2}+1$ cuando $x$ tiende a 1 , para la que muestra una tabla con valores menores que 1 pero cada vez más próximos a 1, y el valor de la función para dichos valores, con la que establece el límite lateral por la izquierda. Repite el proceso con valores superiores a 1, pero cada vez más próximos, estableciendo el límite lateral por la derecha. Como los límites laterales coinciden, indica que, entonces, el límite existe y concluye que, en general, para que exista el límite de una función en un punto tienen que existir los dos límites laterales y ser iguales. A continuación procede a analizar diversos ejemplos en los que se muestran varias posibilidades en cuanto a la existencia del límite y el valor de la función en dicho punto: que exista el límite pero no coincida con el valor de la función, o

\footnotetext{
${ }^{6}$ Si dos funciones $f$ y $g$ cumplen que en un punto $x=a, \lim _{x \rightarrow a} f(x)=b$ y $\lim _{x \rightarrow a} g(x)=c$, donde $a, b$ y $c$ pueden ser infinito,... En estos casos estarían incluidas las indeterminaciones. Presenta las operaciones para cualquier tipo de límite, y menciona "siempre que tengan sentido los resultados obtenidos".
} 
que la función no esté definida, que no coincidan los límites laterales... El estudio de los límites lo hace siempre utilizando tablas de doble entrada en la que se recogen, por un lado, valores que se acercan cada vez más al punto en el que se estudia el límite y, por otro, las imágenes de dichos valores. A continuación se estudia el concepto de límite infinito y sigue con el cálculo de límites. Para estudiar el cálculo de límites, primero expone los límites de las operaciones con funciones y, a continuación, las indeterminaciones. Ninguna de las operaciones se prueba, ni se presentan ejemplos, aunque sí que se presentan para las indeterminaciones.

\section{IV.3.3.2. Libros de $2^{\circ}$ de Bachillerato}

Anaya: al igual que ocurría con el LT de $1^{\circ}$ de Bachillerato, esta editorial no ha realizado apenas cambios del libro de 2003 de LOGSE al libro de 2009 de LOE. Únicamente cambian algún ejemplo o gráfico, algunos ejercicios resueltos o propuestos, pero se mantienen los mismo resultados.

Santillana: en el mismo tema considera los límites y la continuidad. Empieza con el límite de una sucesión, tanto finito como infinito, sigue con límite de una función en el infinito, tanto finito como infinito, las operaciones con límites, que muestra sin justificar, y de forma resumida y el cálculo de límites de funciones elementales básicas. Indica la aritmética extendida para los casos infinitos (es decir, las operaciones que están definidas con funciones que tienden a infinito), y una vez consideradas, muestra cómo resolver algunas indeterminaciones. Continúa con el concepto de límite en un punto, empezando con los límites laterales, y definiendo el límite en un punto como la igualdad de los límites laterales. Concluye con un ejemplo de la indeterminación $\rightarrow 0 / \rightarrow 0$, aunque no enuncia un resultado generalizable a cualquier función de ese tipo.

SM: en el mismo tema, en primer lugar, se presentan los límites de sucesiones y, en segundo, los límites de funciones. Para el límite funcional, la definición inicial que utiliza en el tema es ingenua, utilizando el término aproximación, al igual que hacía en el primer curso, sin hacer referencia a ninguna definición formal (métrica, ya sea expresada en términos de valor absoluto o de entornos). Define 
los límites laterales, e indica que para que una función tenga límite es necesario y suficiente que posea dos límites laterales y que estos coincidan. A continuación se muestran los límites infinitos y en el infinito. En propiedades de los límites se enuncian la unicidad del límite, las operaciones con límites finitos en un punto, de familias de funciones y la no existencia de los límites en el infinito de funciones trigonométricas. En el margen, enuncia las propiedades (concretamente las operaciones) de límites infinitos y en el infinito, y a continuación se presentan las indeterminaciones y algunas pautas para el cálculo de límites. También se enuncian el límite de polinomios en el infinito, del cociente de polinomios en el infinito y de las funciones tipo $(1+1 / f(x))^{f(x)}$, cuando $f(x)$ tiende hacia infinito. En una nota al margen se menciona que se utilizará la regla de L'Hôpital para resolver indeterminaciones, pero se estudiará más adelante (junto a las derivadas). Se presentan los infinitésimos y se enuncia la conservación del límite cuando se sustituyen infinitésimos equivalentes que actúan como factores en una expresión. Por últimos se enuncian las definiciones métricas de todos los tipos de límites estudiados y que se etiquetan como formales.

Vicens-Vives: el LT comienza con una idea intuitiva de lo que es el límite finito de una función en un punto, describe los límites laterales, establece la equivalencia (existencia e igualdad) y menciona que no afecta el valor en el punto, ni si existe, acabando con que si no existen los laterales o son distintos, el límite no existe. Sigue con la definición métrica de límite infinito en un punto (aunque primero establece casos para explicar lo que es, ejemplos). Por último, realiza un tratamiento similar con el límite de una función en el infinito. Una vez establecidas las definiciones, enuncia (sin justificar) los límites de operaciones con funciones (de forma general para límites en un punto y en el infinito). A continuación considera las indeterminaciones y qué técnicas adoptar para resolverlas: funciones racionales en el infinito, $\rightarrow 1^{\rightarrow^{\infty}}$, y finalmente, límites de funciones trigonométricas $(\operatorname{sen}(x) / x, \operatorname{tg}(x) / x$, que ya fueron estudiados el curso anterior). 


\section{IV.4.RESULTADOS Y JUSTIFICACIONES ASOCIADOS AL CONCEPTO DE LÍMITE}

Se ha visto que el tratamiento de los límites y sus propiedades es muy diverso en función del libro de texto considerado, tanto en orden de presentación, en la forma de considerar los resultados que se presentan, y en las justificaciones que se utilizan. Por tanto, su análisis desde el punto de vista de los esquemas de prueba o las pruebas preformales es complicado, dado que no resulta posible una comparación directa entre resultados al no enunciarse los mismos en todos los libros, pero también es necesario para establecer con rigor las diferencias de tratamiento y su evolución en los libros de texto que corresponde a las tres leyes consideradas. Para organizar este análisis se han seguido varios pasos: en primer lugar, hemos realizado un recuento de los resultados que se enuncian en cada texto, considerando como resultado cualquier enunciado que el libro presente como algo que se cumple en determinadas condiciones (en ocasiones, las mismas propiedades se encuentran muy atomizadas en unos textos y resumidas en un enunciado más general en otros). Junto al número de resultados que se enuncian, se ha considerado el recuento de los tipos de esquemas de prueba o pruebas preformales que se utilizan, lo que ofrece una primera idea del tratamiento justificativo que realiza el libro y que se muestra por editoriales.

En los siguientes apartados (IV.4.1, IV.4.2, IV.4.3 y IV.4.4) se presenta el recuento descrito anteriormente para cada texto, organizado por editoriales y presentado en dos tablas para cada editorial: la primera muestra el número de resultados que se enuncian en cada texto de dicha editorial y de las justificaciones utilizadas. Como ya hemos mencionado anteriormente, debido a la diversidad existente en el tratamiento de este tema, se han computado todos los enunciados que los libros enuncian de forma separada y dándoles un aura de "teorema": por ejemplo, en algunos casos, las operaciones con límites se enuncian varias veces en función del tipo de límite (finito, infinito, en un punto, en el infinito) o se desglosa una misma propiedad en varios casos (límite de funciones exponenciales cuando la base es mayor que 1 o está entre 0 y 1). Esto hace que el recuento sea muy variado en número, ya que una mayor atomización de las propiedades da lugar a un número alto de resultados, aunque no significa que hagan un tratamiento del límite más extenso, sino solamente más detallado. Cada resultado lo hemos clasificado en una única columna correspondiente a un 
tipo de EP o PP. Hay algunas pruebas que son susceptibles de ser clasificadas en más de un apartado, por ejemplo, algunas tienen carácter transformacional y axiomático al mismo tiempo (casi todos los axiomáticos tienen algún tipo de transformación algebraica), pero con el fin de no duplicar el recuento de algunos resultados, se ha clasificado en el tipo de justificación predominante, y se ha detallado en el análisis posterior si se observa algún tipo de EP o PP adicional.

La segunda tabla complementa la información de la primera: resume los resultados que se justifican en cada libro de texto con cada tipo de justificación. Esto nos aporta más información sobre el interés en justificar que tienen los libros de nuestra muestra, si justifican los teoremas propiamente dichos (es decir, aquellos que son aceptados como teoremas por la comunidad matemática) o justifican algunos tipos de indeterminación. Ambas tablas siguen la codificación en colores mencionada anteriormente en función del periodo al que pertenece el LT: rojo claro para LGE, turquesa claro para LOGSE y verde claro para LOE.

Estos primeros análisis de los esquemas de prueba presentes en los libros, que llamaremos análisis previos, nos permiten organizar los resultados y las justificaciones utilizadas, así como comparar entre LT y editoriales. A continuación se describe el análisis previo de cada editorial.

\section{IV.4.1. Resultados y justificaciones en la editorial Anaya}

Esta editorial presenta un comportamiento particular que no hemos observado en otras editoriales: los libros de texto del periodo LOE coinciden prácticamente en su totalidad con los libros del periodo de LOGSE, diferenciándose en algunos detalles a los que haremos referencia a lo largo del análisis. Además, es una de las dos editoriales que incluye referencias a los límites en COU, aunque el tratamiento que reciben los límites de funciones en este texto es muy conciso, limitándose a recordar las definiciones y algunas técnicas de cálculo, lo que se aprecia en el número de resultados que se enuncian, que son sólo 2. En relación a los libros de $2^{\circ}$ de BUP, se aprecia un gran cambio desde el texto de 1976 al de 1987: la formalidad con que se trata este elemento es mucho menor en el último, y los resultados que se enuncian se reducen, así como el número de los que se justifican. 
En los libros de LOGSE (y LOE) vemos que el número de resultados que se enuncia en $1^{\circ}$ aumenta considerablemente en $2^{\circ}$, aunque no las justificaciones. Es decir, se consideran con mayor detalle algunas propiedades sobre las operaciones con límites o técnicas asociadas al cálculo, pero no se profundiza en el concepto. Se trata de una mayor mecanización del cálculo del concepto.

\begin{tabular}{|c|c|c|c|c|c|c|c|c|}
\hline \multirow{2}{*}{$\begin{array}{l}\text { Libros de texto de } \\
\text { Anaya }\end{array}$} & \multicolumn{7}{|c|}{ Esquemas de prueba } & \multirow{2}{*}{$\begin{array}{l}\text { Resultados } \\
\text { totales }\end{array}$} \\
\hline & EPO & EPil & EPiV & $E P i S$ & $E P t$ & $E P a$ & $P P$ & \\
\hline Anaya $2^{\circ}(1977)$ & 28 & 1 & 0 & $\overline{0}$ & 2 & $\overline{6}$ & $\overline{0}$ & 37 \\
\hline Anaya $2^{\circ}(1987)$ & 3 & 1 & 0 & 2 & 0 & 0 & 0 & 6 \\
\hline Anaya COU (1989) & 1 & 0 & 0 & 0 & 1 & 0 & 0 & 2 \\
\hline Anaya $1^{\circ}(2002)$ & 5 & 4 & 1 & 0 & 1 & 0 & 0 & 11 \\
\hline Anaya $2^{\circ}(2003)$ & 42 & 1 & 0 & 0 & 3 & 0 & 0 & 46 \\
\hline Anaya $1^{\circ}(2008)^{7}$ & 5 & 4 & 1 & 0 & 1 & 0 & 0 & 11 \\
\hline Anaya $2^{\circ}(2009)$ & 42 & 1 & 0 & 0 & 3 & 0 & 0 & 46 \\
\hline TOTALES & 126 & 12 & 2 & 2 & 11 & 6 & 0 & 159 \\
\hline
\end{tabular}

Tabla IV.4.1.1. Resultados y justificaciones asociados al límite en los libros de texto de la editorial Anaya.

Una primera lectura sobre el total de resultados que se enuncian y las justificaciones que se utilizan manifiesta que la mayor parte de los resultados, un $79,2 \%$, no se justifican. Estos se han denotado como EP0. Este dato por sí solo indica que las justificaciones son muy escasas y de, ellas, las más abundantes son las inductivas de un caso, 7,5\%, las transformacionales alcanzan un porcentaje similar y las axiomáticas se reducen a la mitad.

En una segunda lectura, examinando cada libro de texto, se observa que en los libros de LGE, la mayoría de los resultados (75,7\% en el Anaya de 1977, y 50\% en los Anaya de 1987 y 1989) no justifican los resultados. En el Anaya de $2^{\circ}$ de BUP de 1977, el EP más utilizado es el EP axiomático, con un 16,2\% de los resultados justificados con este $\mathrm{EP}$, seguido de los transformacionales y los EP inductivos de un caso (5,4\% y 2,7\% respectivamente), aunque son bastante escasos. En el LT de $2^{\circ}$ de BUP de Anaya (1987), en el que se ha producido un descenso notable de los resultados enunciados, el EP más utilizado es el EP transformacional $(33,3 \%)$ aunque también se utiliza un EP inductivo de un caso (16,7\%). El LT de COU sólo utiliza un EP transformacional, que supone un 50\% de los resultados enunciado. En cuanto a los periodos de LOGSE y LOE (en esta

\footnotetext{
${ }^{7}$ Los libros de texto de Anaya del periodo LOE son prácticamente idénticos a sus correspondientes de LOGSE, por tanto, los datos relativos al análisis son los mismos.
} 
editorial los LT son iguales en ambos periodos), observamos una gran diferencia entre el primer curso y el segundo. Si bien en $1^{\circ}$ de Bachillerato la diferencia entre los porcentajes de resultados sin justificar y de EP inductivos de un caso no es próximo muy grande (45,5\% y $36,4 \%$ respectivamente), en $2^{\circ}$ de Bachillerato el porcentaje notablemente más alto es el de resultados sin justificar (91,3\%). Además, dentro de los resultados que se justifican, el EP más utilizado en $1^{\circ}$ es el EP inductivo de un caso, y en $2^{\circ}$, el EP transformacional $(6,5 \%)$.

\begin{tabular}{ll}
\hline Libros de texto & Esquemas de prueba \\
\hline Anaya $2^{\circ}(1977)$ & EPi1: límite de funciones compuestas. \\
& EPt: límite en un punto de funciones tipo $x^{n}$ y $k \cdot f(x)$, donde $k$ es una constante. \\
& EPa: deducción de la definición métrica de límite de una función en punto a \\
partir de la definición mediante límites laterales, suma de infinitésimos, límite \\
en un punto de la suma, del producto de funciones, de funciones contantes y \\
del cociente de polinomios.
\end{tabular}

Tabla IV.4.1.2. Resultados y justificaciones asociados al límite en los libros de texto de la editorial Anaya.

Por último, si observamos la evolución de los EP que aparecen en los LT de esta editorial, vemos que el número de resultados que no se justifican ha aumentado en las últimas legislaciones (si atendemos al periodo entero y no curso por curso). Los EP inductivos de un caso son utilizados en todas las legislaciones, aunque los porcentajes más altos se encuentran en los LT de $2^{\circ}$ de Bachillerato de LOGSE y LOE. Los EP axiomáticos desaparecen completamente con el tiempo y, de hecho, sólo se encuentran en el LT más antiguo de LGE. Sin embargo, si se 
aprecia un aumento en los LT transformacionales, aunque su utilización no es muy extensa. Por último, en ningún LT se utilizan las PP.

En cuanto a los resultados que se justifican, no se observa una continuidad a lo largo del tiempo en esta editorial. Únicamente los resultados relacionados con el cociente de polinomios (sea en un punto o en el infinito) se justifican en textos diferentes y, además, se hacen con EP diferentes en función del libro. Por ejemplo, el cociente de polinomios en el infinito se justifica con un EP axiomático en Anaya (1976), con EP inductivo sistemático en Anaya (1987) y con EP inductivo de un caso en Anaya (2003) y en Anaya (2009). Sólo se justifican algunas operaciones con límites, o algunas propiedades relacionadas con el concepto, en el LT de 1976; en el resto, las justificaciones que se realizan, de tipo inductivo o axiomático, se refieren a resultados asociados con la resolución de indeterminaciones, es decir, con el cálculo de límites: límite del cociente de polinomios en el infinito, en un punto en el que se anulan, de funciones exponenciales y logarítmicas...

Tal y como se aprecia en los datos de las tablas, la presencia de la demostración matemática ha disminuido a los largo de los años en la editorial Anaya, promoviéndose una mayor mecanización del cálculo. En general, los EP axiomáticos desaparecen, en ningún caso se consideran pruebas preformales, aunque la utilización de los EP transformaciones que se incluyen está ligada en todos los casos a resultados asociados a familias de funciones o resolución de indeterminaciones. Sin embargo, se observa un aumento de EP inductivos, y de una mayor atomización de los resultados, lo que nos hace suponer que se esta editorial ha tendido más hacia la mecanización del cálculo y ha prescindido de la formalización del concepto.

\section{IV.4.2. Resultados y justificaciones en la editorial Santillana}

El planteamiento desde el punto de vista de las justificaciones en esta editorial es ligeramente diferente al de Anaya. Como se puede apreciar en la Tabla IV.4.2.1, apenas se utilizan EP de tipo inductivos, y se pueden encontrar EP axiomáticos en libros de los tres periodos legislativos considerados, aunque el mayor número de ellos se encuentra en el texto de $2^{\circ}$ de BUP más antiguo, el Santillana (1976); incluso dentro del mismo periodo, el texto de 1991, que corresponde con el final 
de la LGE (en ese momento conviven dos legislaciones), se aprecia un descenso tanto en las justificaciones como en el número de resultados. En los periodos de LOGSE y LOE se observa que esta editorial considera que los enunciados y propiedades sobre límites deben considerarse en el curso superior $\left(2^{\circ}\right.$ de Bachillerato) y en el $1^{\circ}$ se limitan a enunciar el límite: por esta razón no se encuentran justificaciones en los textos de $1^{\circ}$ de Bachillerato.

\begin{tabular}{|c|c|c|c|c|c|c|c|c|}
\hline \multirow{2}{*}{$\begin{array}{l}\text { Libros de texto de } \\
\text { Santillana }\end{array}$} & \multicolumn{7}{|c|}{ Esquemas de prueba } & \multirow{2}{*}{$\begin{array}{l}\text { Resultados } \\
\text { totales }\end{array}$} \\
\hline & $E P O$ & EPil & $E P i V$ & $E P i S$ & $E P t$ & $E P a$ & $P P$ & \\
\hline Santillana $2^{\circ}$ (1976) & 13 & 0 & 0 & 0 & 1 & 9 & 2 & 25 \\
\hline Santillana $2^{\circ}(1991)$ & 14 & 0 & 0 & 0 & 1 & 3 & 0 & 18 \\
\hline Santillana $1^{\circ}(1996)$ & 1 & 0 & 0 & 0 & 0 & 0 & 0 & 1 \\
\hline Santillana $2^{\circ}$ (1997) & 34 & 0 & 0 & 0 & 2 & 5 & 0 & 41 \\
\hline Santillana $1^{\circ}(2008)$ & 0 & 0 & 0 & 0 & 0 & 0 & 0 & 0 \\
\hline Santillana $2^{\circ}(2009)$ & 36 & 0 & 0 & 2 & 1 & 0 & 0 & 39 \\
\hline TOTALES & 99 & 0 & 0 & 2 & 5 & 16 & 2 & 124 \\
\hline
\end{tabular}

Tabla IV.4.2.1. Resultados y justificaciones asociados al límite en los libros de texto de la editorial Santillana.

En una primera lectura sobre el total de resultados que se enuncia, vemos que el $79 \%$ de los resultados que se enuncian en los LT no se justifican (clasificados como EP0). Dentro de los EP que se utilizan, el más común es el EP axiomático, que alcanza un $13,7 \%$ de los resultados, seguido por los EP transformacionales (4\%). En esta editorial no se utilizan EP inductivos de un caso ni de varios casos y muy pocos de sistemáticos $(1,6 \%)$, al igual que las pruebas preformales $(1,6 \%)$.

Si observamos el comportamiento en cada LT, vemos que hay dos libros de texto en los que no se utiliza ningún esquema de prueba: el LT de $1^{\circ}$ de Bachillerato de LOGSE (Santillana $1^{\circ}$, 1996) que no justifica el único resultado que enuncia y el LT de $1^{\circ}$ de Bachillerato de LOE (Santillana $1^{\circ}$, 2008) que no enuncia ningún resultado y, por lo tanto, no realiza ninguna justificación. Los LT de la LGE son los que más justificaciones incluyen (justifican el $48 \%$ y el $22,2 \%$ de los resultados que enuncian) aunque observamos que hay un descenso tanto en los resultados enunciados como en las justificaciones que se presentan desde el libro más antiguo (Santillana 2º 1976) al libro más moderno (Santillana 2º 1991). Además, el tipo de justificación más utilizado en ambos LT es el EP axiomático (36\% y 16,7\% respectivamente), seguido en el LT de 1976 por las pruebas preformales (8\%) y en el LT de 1991, por los EP transformacionales (5,6\%). En el LT de LOGSE que se incluyen justificaciones (Santillana $2^{\circ}$, 1999) no se 
utilizan EP inductivos de ningún tipo, y la justificación más utilizada es el EP axiomático. En el LT de LOE (Santillana $2^{\circ}$, 2009) no hay EP axiomáticos, y se justifican sólo tres resultados con dos EP inductivo sistemáticos y un EP transformacional.

\begin{tabular}{ll}
\hline Libros de texto & Esquemas de prueba \\
\hline $\begin{array}{l}\text { Santillana } 2^{\circ} \\
(1976)\end{array}$ & $\begin{array}{l}\text { EPt: límite de funciones racionales en un punto cuando se anula denominador y } \\
\text { numerador } \\
\text { EPa: equivalencia de } \lim _{x \rightarrow a} f(x)=L \text { y } \lim _{x \rightarrow a} f(x)-L=0 \text {, límite de la } \\
\text { función constante y la identidad, unicidad del límite, acotación en un entorno si } \\
\text { existe el límite, suma (de límites en un punto), límite de funciones tipo } c \cdot x^{n} \text { (con } \\
c \text { una constante y } n \text { natural), suma (de límites en el infinito), límite de funciones } \\
\text { racionales en el infinito. } \\
\text { PP: límite en un punto de funciones tipo } x^{n} \text { y límite en el infinito de funciones } \\
\text { tipo } 1 / x^{n} .\end{array}$ \\
$\begin{array}{l}\text { EPt: límite en un punto del cociente de funciones que se anulan } \\
\text { Santillana } 2^{\circ}\end{array}$ & $\begin{array}{l}\text { EPa: límite de la suma en un punto, unicidad del límite, conservación del signo } \\
\text { en un entorno si existe el límite. }\end{array}$ \\
$\begin{array}{l}\text { Santillana } 2^{\circ} \\
(1997)\end{array}$ & $\begin{array}{l}\text { EPt: límite en cero de } f(x)=x / s e n(x), \text { límite en el infinito de } g(x)=\operatorname{sen}(x) / x . \\
\text { mediante entornos, unicidad del límite, límite de la función identidad, límite de } \\
\text { la función constante, límite de la suma. }\end{array}$ \\
Santillana $2^{\circ}$ & $\begin{array}{l}\text { EPiS: límite en el infinito de funciones tipo } x^{n} \text {, límite en el infinito de funciones } \\
\text { exponenciales. } \\
\text { EPt: límite en el infinito de funciones racionales. }\end{array}$ \\
\hline
\end{tabular}

Tabla IV.4.2.2. Resultados y justificaciones asociados al límite en los libros de texto de la editorial Santillana.

Por último, en cuanto a la evolución de los EP a lo largo de los años, ya hemos indicado anteriormente que se aprecia un descenso de los EP axiomáticos en los libros de la LGE, pero ese descenso continúa en el resto de legislaciones hasta desaparecer en LOE. No obstante, este descenso se debe más bien a un descenso global de las justificaciones utilizadas, ya que tampoco se observa un aumento notable de otras justificaciones, por lo que podríamos suponer que esta editorial se ha decantado por eliminar la demostración matemática y por no sustituirla por otros tipos de justificación.

Tal y como se observa en la Tabla IV.4.2.2, la naturaleza de los resultados que se justifican en cada LT varía a lo largo del tiempo. En el LT de 2º de BUP de 1976 se justifican numerosos resultados asociados a las propiedades de los límites, lo que tiende a desaparecer en los LT siguientes, en los que aumentan las justificaciones asociadas a resultados relacionados con indeterminaciones. Sólo el LT de 1976 utiliza alguna PP, y aunque disminuyen los EP axiomáticos utilizados, se siguen utilizando mínimamente los EP transformacionales, en el 
mismo tipo de resultados en todos los LT, y no se aprecia un aumento significativo de EP inductivos (sólo se utilizan 2 en el LT de LOE), lo que parece indicar que el libro prescinde la justificación en general, y no sustituye demostraciones formales por otras formas de razonamiento.

\section{IV.4.3. Resultados y justificaciones en la editorial SM}

El tratamiento de los límites y de sus justificaciones que se realiza en los textos de SM es dispar. Cabe destacar que es una de las dos editoriales que presentan los límites en COU, aunque se limita a las definiciones. No obstante, presenta varias definiciones métricas (con entornos y utilizando la terminología $\varepsilon-\delta$ ), estableciendo como resultado la equivalencia entre ellas, tanto para límites en un punto, como en el infinito. El resultado que justifica es la caracterización del límite de una función mediante la existencia y coincidencia de límites laterales, resultado que apenas se justifica en los libros de texto.

\begin{tabular}{|c|c|c|c|c|c|c|c|c|}
\hline \multirow{2}{*}{$\begin{array}{l}\text { Libros de texto de } \\
\text { SM }\end{array}$} & \multicolumn{7}{|c|}{ Esquemas de prueba } & \multirow{2}{*}{$\begin{array}{l}\text { Resultados } \\
\text { totales }\end{array}$} \\
\hline & EPO & EPil & EPiV & EPiS & $E P t$ & $E P a$ & $P P$ & \\
\hline $\operatorname{SM} 2^{\circ}(1977)$ & 5 & 0 & 0 & 0 & 5 & 5 & 0 & 15 \\
\hline SM COU (1980) & 4 & 0 & 0 & 0 & 0 & 1 & 0 & 5 \\
\hline $\mathrm{SM} 1^{\circ}(1996)$ & 1 & 0 & 0 & 0 & 3 & 0 & 0 & 4 \\
\hline $\operatorname{SM} 2^{\circ}(2001)$ & 22 & 0 & 0 & 0 & 2 & 0 & 0 & 24 \\
\hline $\mathrm{SM} 1^{\circ}(2008)$ & 6 & 1 & 0 & 0 & 0 & 0 & 0 & 7 \\
\hline $\operatorname{SM} 2^{\circ}(2010)$ & 47 & 0 & 0 & 0 & 1 & 0 & 1 & 49 \\
\hline TOTALES & 85 & 1 & 0 & 0 & 11 & 6 & 1 & 104 \\
\hline
\end{tabular}

Tabla IV.4.3.1. Resultados y justificaciones asociados al límite en los libros de texto de la editorial SM.

Por otro lado, los LT de LOGSE pertenecen a colecciones diferentes, como ya hemos mencionado anteriormente, así que no podemos establecer si el comportamiento en cada texto es propio de la editorial en ese periodo o si en cada colección han tomado políticas diferentes.

En una primera lectura de la Tabla IV.4.3.1 observamos que el $81,7 \%$ de los resultados enunciados en los LT de la editorial SM no se justifican. EL EP más utilizado es el EP transformacional (10,6\%) seguido por el EP axiomático $(5,8 \%)$. Se incluye únicamente un EP inductivo de un caso y una prueba 
preformal. No obstante, hay que desatacar que se trata de la editorial que menos resultados enuncia de las cuatro editoriales consideradas.

Realizando una lectura por LT, vemos comportamientos dispares en los LT de la misma legislación. En el periodo LGE, no se enuncia un gran número de resultados en ninguno de los LT, aunque este hecho era esperable en el LT de COU (no se suelen considerar los límites ya que se supone que han sido tratados en cursos anteriores y, por tanto, se incluyen a modo de recordatorio). Sin embargo, hay que destacar que el LT de $2^{\circ}$ de BUP (SM $2^{\circ}$, 1977) tiene el porcentaje más bajo de resultados sin justificar en comparación con otros LT de la época (33,3\%). Sin embargo, los únicos EP utilizados, EP axiomático y EP transformacional, se utilizan por igual (un 33,3\% respectivamente, que es más alto que en los textos de las editoriales consideradas antes). En los LT de LOGSE (SM 1ㅇ, 1996 y SM 20 2001) vemos un comportamiento dispar entre ambos cursos (recordemos que se trata de LT de distintas colecciones y muy separados en el tiempo), ya que en LT de $1^{\circ}$ apenas se enuncian resultados (4) pero se justifica el 75\% de ellos con EP transformacionales y, sin embargo, en el LT de $2^{\circ}$ de Bachillerato, se enuncian bastantes resultados (24) pero sólo se justifican el 8,3\% de ellos (también con EP transformacionales). Los LT de LOE (SM 1º, 2008 y SM $2^{\circ}$ 2010) también tienen una gran diferencia en el número de resultados enunciados en $1^{\circ}$ y en $2^{\circ}$ ( 7 y 49 respectivamente) pero ambos dejan sin justificar la mayoría de los resultados (85,7\% y 95,9\% respectivamente). En estos LT cambian los EP que se utilizan: en el LT de $1^{\circ}$ se utiliza un EP inductivo de un caso y en el LT de $2^{\circ}$, un EP transformacional y una prueba preformal.

Por último, si observamos la evolución de los EP a lo largo de los años, observamos que se produce un descenso notable tanto en el número de justificaciones que se presentan, como en el número de EP axiomáticos que se utilizan. Los EP transformacionales se mantienen en LOGSE, aunque también descienden en LOE. No se produce un aumento de los EP inductivos, de ningún tipo, y tampoco es significativo el aumento de pruebas preformales.

En relación a los EP utilizados, observamos que prácticamente todos los EP axiomáticos se encuentra en el LT de $2^{\circ}$ de BUP, a excepción de uno que se encuentra en el LT de COU (SM, 1980). Por el contrario, se utilizan EP transformacionales en todos los LT (a excepción del LT de COU), y el LT de $2^{\circ}$ de Bachillerato de LOE utiliza una prueba preformal (algo inusual en los LT de 
este periodo). Al contrario que en otras editoriales, no se aprecia un aumento de los EP inductivos, que casi no son utilizados por esta editorial. También se observa que, al igual que otras editoriales, en los cursos de $1^{\circ}$ de Bachillerato de LOGSE y LOE apenas se enuncian resultados asociados al límite, y estos aumentan de forma significativa en los LT del $2^{\circ}$ curso.

\begin{tabular}{|c|c|}
\hline Libros de texto & Esquemas de prueba \\
\hline $\operatorname{SM} 2^{\circ}(1977)$ & $\begin{array}{l}\text { EPt: coincidencia del límite de una función comprendida entre otras dos, } \\
\text { diferencia de límites, cociente de límites, límite de funciones racionales en el } \\
\text { infinito, límite de la función } f(x)=(1+1 / x)^{x} \text { en el infinito. } \\
\text { EPa: unicidad, coincidencia del límite si dos funciones coinciden en un entorno, } \\
\text { suma de un número finito de límites, producto de límites, funciones tipo } k \cdot f(x) \text {. }\end{array}$ \\
\hline SM COU (1980) & EPa: caracterización del límite en punto mediante los límites laterales. \\
\hline $\operatorname{SM} 1^{\circ}(1996)$ & $\begin{array}{l}\text { EPt: Límite en cero de las funciones } f(x)=\operatorname{sen}(x) / x, g(x)=\operatorname{tg}(x) / x \text { y } h(x)= \\
(\cos (x)-1) / x \text {. }\end{array}$ \\
\hline $\operatorname{SM} 2^{\circ}(2001)$ & EPt: Límite en cero de las funciones $f(x)=\operatorname{sen}(x) / x, g(x)=(\cos (x)-1) / x$. \\
\hline $\mathrm{SM} 1^{\circ}(2008)$ & EPi1: caracterización del límite en un punto mediante los límites laterales. \\
\hline $\operatorname{SM} 2^{\circ}(2010)$ & $\begin{array}{l}\text { EPt: sustitución de infinitésimos equivalentes. } \\
\text { PP: Cociente de polinomios en el infinito. }\end{array}$ \\
\hline
\end{tabular}

Tabla IV.4.3.2. Resultados y justificaciones asociados al límite en los libros de texto de la editorial SM.

En cuanto a los resultados que se justifican (Tabla IV.4.3.2), observamos que en el periodo LGE se justifican principalmente resultados asociados al concepto de límite y operaciones, en el periodo de LOGSE, se justifican únicamente los límites de unas funciones $(f(x)=\operatorname{sen}(x) / x, g(x)=(\cos (x)-1) / x, \ldots)$ y en el periodo LOE se justifican tanto un resultado relacionado con el concepto (caracterización del límite en un punto a partir de la existencia y coincidencia de los límites laterales) como otros asociados a indeterminaciones (sustitución de infinitésimos equivalentes y cociente de polinomios en el infinito).

Se trata de la editorial que menos justificaciones incluye en sus LT, al menos en lo referente al concepto de límite. Llegados a este punto, pensamos que sería interesante comparar con el análisis de las justificaciones relacionadas con la continuidad (capítulo $\mathrm{V}$ del presente trabajo). 


\section{IV.4.4. Resultados y justificaciones en la editorial Vicens- Vives.}

En la tabla apreciamos sensibles diferencias entre el número de resultados que se muestran en cada texto de la editorial Vicens-Vives, pero esto se debe principalmente a la atomización de las propiedades que hacen los libros: por ejemplo, el Vicens-Vives $2^{\circ}$ (1999) enuncia las operaciones con límites finitos separadas de los límites infinitos, y considerando todas las casuísticas posibles en cada operación: exponenciales de base mayor que 1 o comprendida entre 0 y 1 ; lo mismo para logarítmicas, algunas familias de funciones... En otros textos únicamente se presentan las operaciones básicas (suma, diferencia, producto y cociente) por lo que el recuento es inferior.

\begin{tabular}{|c|c|c|c|c|c|c|c|c|}
\hline $\begin{array}{l}\text { Libros de texto de } \\
\text { Vicens-Vives }\end{array}$ & $\begin{array}{l}\text { Esqu } \\
E P O\end{array}$ & $\begin{array}{r}\text { mas de } \\
E P i 1\end{array}$ & $\begin{array}{r}\text { rueba } \\
E P i V\end{array}$ & $E P i S$ & $E P t$ & $E P a$ & $P P$ & $\begin{array}{l}\text { Resultados } \\
\text { totales }\end{array}$ \\
\hline$\overline{\text { VV } 2^{\circ}(1980)}$ & 21 & $\overline{0}$ & $\overline{0}$ & $\overline{0}$ & 2 & 3 & $\overline{0}$ & 26 \\
\hline VV $1^{\circ}(1998)$ & 16 & 2 & 5 & 0 & 1 & 0 & 1 & 25 \\
\hline VV $2^{\circ}$ (1999) & 35 & 3 & 0 & 2 & 7 & 1 & 1 & 49 \\
\hline $\mathrm{VV} 1^{\circ}(2003)$ & 9 & 0 & 0 & 2 & 0 & 0 & 0 & 11 \\
\hline VV $2^{\circ}(2004)$ & 23 & 0 & 0 & 0 & 0 & 0 & 0 & 23 \\
\hline VV $1^{\circ}(2008)$ & 9 & 2 & 0 & 0 & 0 & 0 & 0 & 11 \\
\hline VV $2^{\circ}(2009)$ & 9 & 2 & 0 & 0 & 1 & 0 & 0 & 12 \\
\hline TOTALES & 122 & 9 & 5 & 4 & 11 & 4 & 2 & 157 \\
\hline
\end{tabular}

Tabla IV.4.4.1. Resultados y justificaciones asociados al límite en los libros de texto de la editorial Vicens-Vives.

En una primera lectura sobre las justificaciones utilizadas en esta editorial, vemos que un $77 \%$ de los resultados no se justifica, y que se utilizan todos los tipos de justificación en algún LT. Los tipos de EP más utilizados en esta editorial son los EP inductivos de un caso $(5,7 \%)$ y los EP transformacionales (7\%). El siguiente tipo más utilizado es el EP inductivo de varios casos $(3,2 \%)$ y los EP axiomáticos se reducen a un 2,5\% del total. Apenas se incluyen pruebas preformales.

Si observamos cada LT por separado, vemos que en el LT de LGE (Vicens-Vives $\left.2^{\circ}, 1980\right)$ deja sin justificar la mayoría de los resultados $(80,8 \%)$, pero dentro de las justificaciones que muestra, el 11,5\% son EP axiomáticos y el resto, EP transformacionales. Por su parte, en los LT de LOGSE se observan comportamientos dispares en función de la colección: las más antiguas (Vicens- 
Vives $1^{\circ}, 1998$ y Vicens-Vives $\left.2^{\circ}, 1999\right)$ justifican un mayor porcentaje de resultados en ambos cursos (36\% y 28,6\% de resultados respectivamente) que las más modernas (Vicens-Vives $1^{\circ}, 2003$ y Vicens-Vives $2^{\circ}$, 2004), que justifican un $18,2 \%$ de los resultados en $1^{\circ}$ y un $0 \%$ en segundo. Este hecho, unido al descenso de resultados que se enuncian en la segunda editorial, indica un descenso notable de la demostración en este periodo educativo en esta editorial. En el LT de $1^{\circ}$ de la colección más antigua, el EP más utilizado es el EP inductivo de un caso, seguido del EP inductivo de varios casos. Además no se incluyen EP axiomáticos y se consideran muy pocos transformacionales o pruebas preformales ( $4 \%$ cada uno). Sin embargo, en el LT de $2^{\circ}$ de esta misma colección, se presentan justificaciones de todos los tipos, siendo la más abundante el EP transformacional (14,3\%) seguido por el EP inductivo de un caso $(6,1 \%)$. Por su parte, el LT de $1^{\circ}$ de la colección más moderna únicamente utiliza EP inductivos de varios casos mientras que el LT de $2^{\circ}$ no realiza ninguna justificación. En cuanto a los LT del periodo LOE (Vicens-Vives $1^{\circ}, 2008$ y Vicens-Vives $2^{\circ}, 2009$ ), ambos dejan sin justificar un alto porcentaje de resultados, aunque en este caso, el mayor número de justificaciones se encuentran en $2^{\circ}$, y los EP más utilizados son el EP inductivo de un caso tanto en $1^{\circ}$ como en $2^{\circ}(18,2 \%$ y $16,7 \%$ respectivamente $)$ y el LT de $2^{\circ}$ además utiliza EP transformacionales.

En cuanto a la evolución de los EP utilizados a lo largo del tiempo, observamos un notable descenso en los EP axiomáticos, ya que únicamente aparecen en el LT de LGE y en el de $2^{\circ}$ de Bachillerato de la colección más antigua de LGE. El comportamiento del resto de tipos de justificación es irregular, produciéndose repuntes en las categorías EP inductivos de un caso y en los EP transformacionales en la colección más antigua de LOGSE, descienden en la colección más moderna, y vuelven a ascender en LOE. Los EP inductivos de varios casos y las pruebas preformales aparecen únicamente en los LT de LOGSE.

Si bien el recuento que se presenta en la Tabla IV.3.4 no es muestra del rigor y formalismo con el que se acomete el tratamiento de límites, se pueden apreciar sensibles diferencias entre los textos a lo largo del tiempo. Vemos que el mayor número de EP axiomáticos se encuentra en el texto de $2^{\circ}$ de BUP y que a partir de 1999, los textos de la muestra tienden a una reducción en el número de resultados que justifican. Este suceso avala nuestra hipótesis de que la 
demostración matemática en particular, y las justificaciones en general, han ido desapareciendo de los libros de texto a lo largo de los años y, por tanto, de la enseñanza secundaria.

\begin{tabular}{|c|c|}
\hline Libros de texto & Esquemas de prueba \\
\hline VV $2^{\circ}(1980)$ & $\begin{array}{l}\text { EPt: infinitos equivalentes, límite en cero de } f(x)=x / \operatorname{sen}(x) \\
\text { EPa: unicidad del límite, suma de límites finitos en un punto, límite en el } \\
\text { infinito de funciones logarítmicas }\end{array}$ \\
\hline VV $1^{\circ}(1998)$ & $\begin{array}{l}\text { EPil: límites de los tipos } \rightarrow k / \rightarrow \infty \mathrm{y} \rightarrow k / \rightarrow 0 \text {. } \\
\text { EPiV: límites en el infinito de funciones polinómicas, límites en el infinito de } \\
f(x)=x^{n}, g(x)=x^{-n}, h(x)=x^{l / n} \text { y límites de funciones exponenciales. } \\
\text { EPt: límite en cero de } f(x)=x / \operatorname{sen}(x) \text {. } \\
\text { PP: límite en el infinito de funciones racionales. }\end{array}$ \\
\hline $\operatorname{VV} 2^{\circ}(1999)$ & $\begin{array}{l}\text { EPi1: límite en el infinito de } f(x)=x^{2}+k \text {, límites de funciones exponenciales y } \\
\text { logarítmicas. } \\
\text { EPiS: límite en el infinito de } f(x)=1 / x^{n} \text {, límite en el infinito de } f(x)=x^{n} \\
\text { EPt: límites en un punto de funciones racionales }(\rightarrow 0 / \rightarrow 0) \text {, límite en cero de } \\
f(x)=\operatorname{sen}(x) / x \text {, suma de infinitos, infinitos equivalentes, infinitésimos } \\
\text { equivalentes, límites de }(1+f(x))^{1 / f(x)} \text { y } f(x)^{g(x)} \text { (cuando son formas } \\
\text { indeterminadas, } \rightarrow 1^{\rightarrow \infty} \text { ) } \\
\text { EPa: límites en el infinito de funciones racionales. } \\
\text { PP: límites en el infinito de funciones polinómicas. }\end{array}$ \\
\hline $\mathrm{VV} 1^{\circ}(2003)$ & $\begin{array}{l}\text { EPiS: límites en el infinito de funciones polinómicas y funciones } \\
\text { exponenciales. }\end{array}$ \\
\hline $\mathrm{VV} 1^{\circ}(2008)$ & $\begin{array}{l}\text { EPi1: equivalencia de la existencia e igualdad de los límites laterales a la } \\
\text { definición de límite, límites en el infinito de funciones racionales. }\end{array}$ \\
\hline VV $2^{\circ}(2009)$ & $\begin{array}{l}\text { EPi1: equivalencia de la existencia e igualdad de los límites laterales a la } \\
\text { definición de límite, límites en el infinito de funciones racionales. } \\
\text { EPt: límite en cero de } f(x)=\operatorname{sen}(x) / x\end{array}$ \\
\hline
\end{tabular}

Tabla IV.4.4.2. Resultados asociados a cada esquema de prueba o prueba preformal en los libros de texto de la editorial Vicens-Vives.

En cuanto a los resultados que se enuncia, como vemos en la Tabla IV.4.4.2, en los libros de LOGSE se justifican resultados asociados a indeterminaciones y no se realiza ninguna justificación de propiedades u operaciones de los límites. La unicidad y la suma se justifican en el LT de la LGE, y en LOE se justifica el teorema de caracterización, aunque con un EP inductivo. A diferencia de otras editoriales, en el ejemplar de $2^{\circ}$ de BUP de esta editorial no abundan las justificaciones, y únicamente aparecen tres EP axiomáticos. En los LT de LOGSE se encuentran las únicas PP de toda la editorial (una en $1^{\circ}$ de 1998 y otra en $2^{\circ}$ de 1999), y es en el LT de 1999 donde se justifican un mayor número de resultados (la mayoría con EP transformacionales). Cabe destacar la diferencia en el tratamiento del límite y de las justificaciones que hay entre las dos colecciones de LOGSE, aunque podrían estar relacionadas con un cambio de política en la editorial debido a la modificación del currículo de 2001. Al igual que ocurría en 
las editoriales de Santillana y SM, en los periodos LOGSE y LOE se realiza un tratamiento más superficial del límite en los LT, abundando en este concepto en el segundo curso.

\section{IV.4.5. Comentarios a los análisis previos}

Tal y como hemos visto anteriormente, el comportamiento de cada editorial es diferente en cuanto al concepto de límite funcional y las justificaciones relacionadas, aunque se pueden observar algunas similitudes.

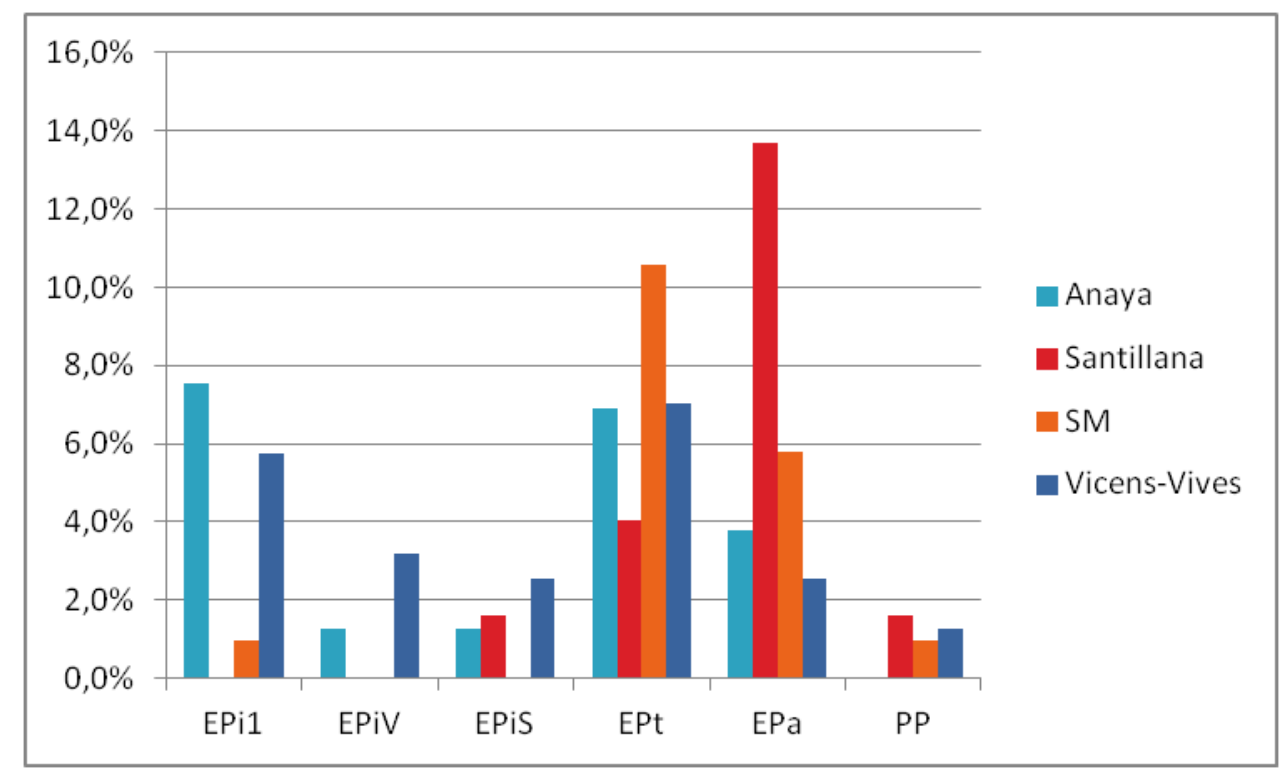

Gráfico IV.4.5.1. Porcentaje de EP utilizados en cada editorial.

En el Gráficos IV.4.5.1 se muestra el porcentaje total de cada tipo de justificación por editoriales. En el eje horizontal se representa cada tipo de justificación de justificación de nuestra clasificación (EP inductivos de un caso, de varios casos, sistemáticos, transformacionales, axiomáticos y pruebas preformales) a excepción de la categoría EP0 (no se justifica), debido a que el alto porcentaje de resultados sin justificar conllevaría una mayor altura del eje vertical, y su lectura sería más incómoda. En el eje vertical se representa el porcentaje de justificaciones de cada tipo que se encuentran en cada editorial. Por último, cada editorial tiene asignado un color, que se utiliza en las barras de cada tipo de justificación para representar el porcentaje en dicha editorial. Observamos que los comportamientos entre editoriales son diferentes, ya que el EP más utilizado en Anaya y Vicens-Vives es el EP inductivo de un caso, en Santillana, el EP axiomático y en SM, el EP transformacional. 


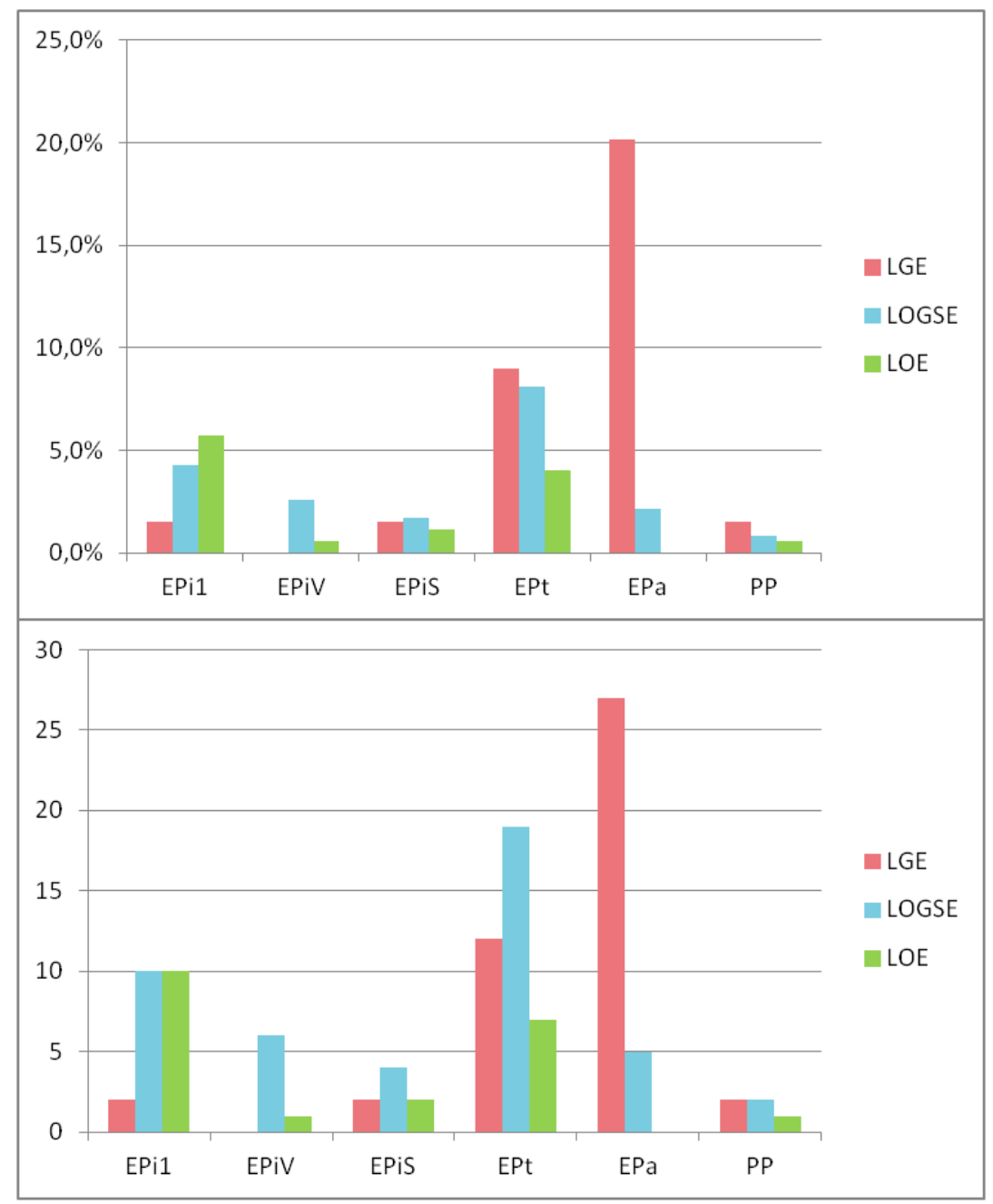

Gráfico IV 4.5.2. Evolución de cada tipo de justificación por periodos educativos, mostrada en números absolutos (abajo) y en porcentajes (arriba).

En el Gráfico IV.4.5.2 se muestran, con números absolutos y porcentajes, la evolución de cada tipo de justificación a lo largo de las legislaciones. Al igual que en el gráfico anterior, en el eje horizontal se presentan cada uno de los tipos de justificación considerada, a excepción de los EP0, y en el eje vertical se representa el número total de justificaciones de ese tipo en cada periodo legislativo en el gráfico superior, y el porcentaje de justificaciones de ese tipo en cada periodo legislativo en el gráfico inferior. Cada periodo lleva asignado un color (según indica la leyenda) que permite observar la evolución seguida a lo largo del tiempo para cada tipo de justificación. Se observa el notable descenso de EP axiomáticos que hay de LGE a LOGSE, desapareciendo totalmente en todas las editoriales en LOE. Aunque sea de forma poco significativa, también descienden los EP inductivos sistemáticos y las pruebas preformales, ya que se encuentran pocos ejemplos en todos los LT. Sin embargo, otros tipos de 
justificación (EP inductivos de 1 caso, de varios casos y los transformacionales) aumentan en LOGSE para descender de nuevo en LOE.

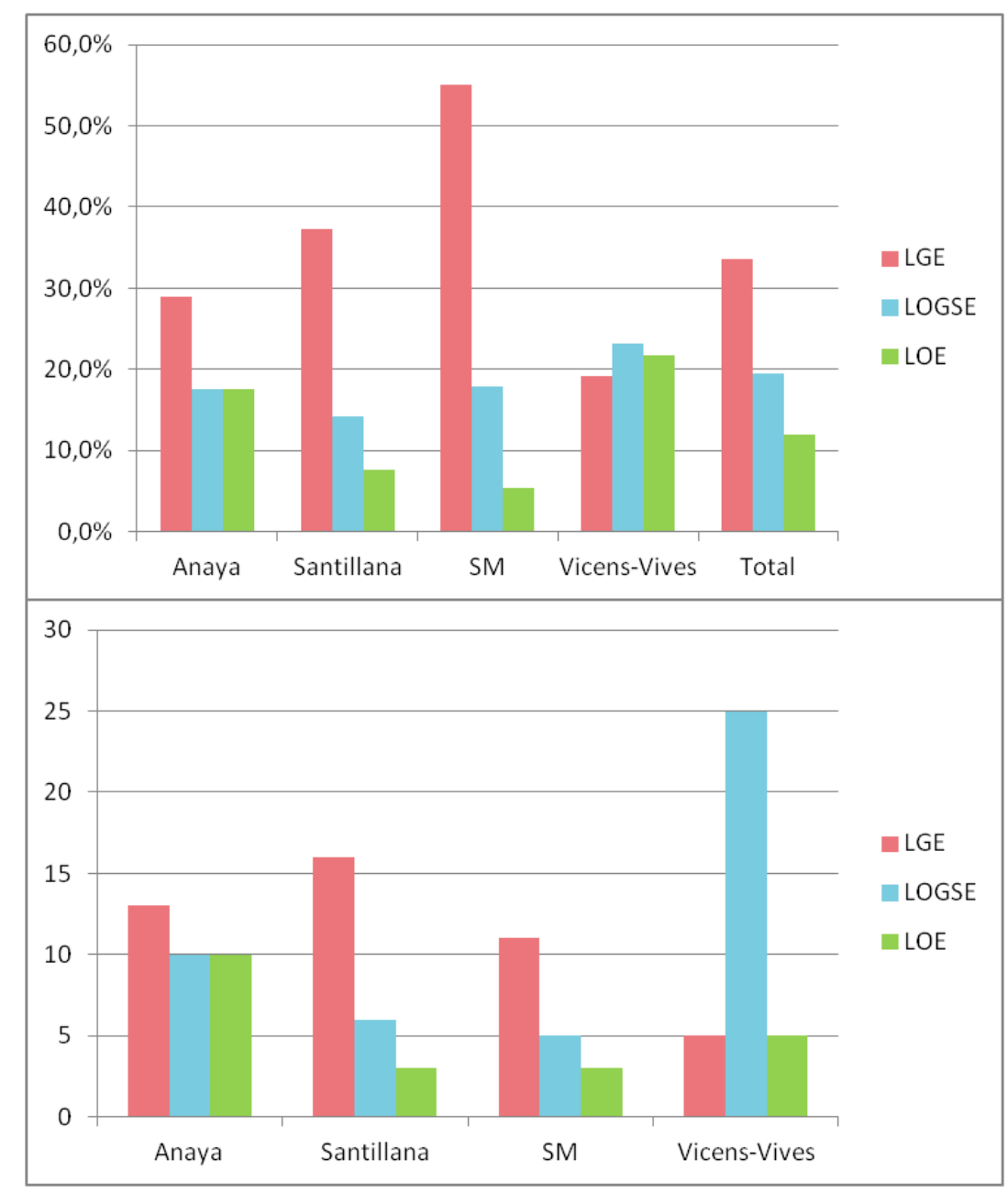

Gráfico IV.4.5.3. Porcentaje (arriba) y número (abajo) de resultados justificados en cada editorial, por legislaciones.

En el Gráfico IV.4.5.3 se muestra el porcentaje de resultados que se justifican en cada editorial, en cada periodo legislativo. En el eje horizontal se representan cada una de las editoriales, así como el recuento total para las cuatro editoriales (en la leyenda, Total). En el eje vertical se representa el porcentaje de resultados justificados. Cada periodo legislativo tiene asignado su color correspondiente, que permite comparar la evolución para cada editorial y la evolución total del porcentaje de resultados que se justifican. Comparando el porcentaje de resultados que se justifican en cada periodo educativo observamos que tres de las editoriales (Anaya, Santillana y SM) muestran un descenso notable del periodo LGE a LOGSE, mientras que Vicens-Vives experimenta un ligero aumento. Anaya se mantiene igual en LOE que en LOGSE (ya hemos comentado que los 
libros de esta editorial de LOGSE y LOE coinciden casi completamente), Santillana y SM experimentan un descenso menos acusado que el de la LGE, y en Vicens-Vives dicho descenso es más suave. En el cómputo total, teniendo en cuenta los datos de las cuatro editoriales, se observa un descenso paulatino del porcentaje de resultados que se justifican en los LT.

Si observamos la evolución de los porcentajes en cada editorial por separado, mostrando dichos porcentajes para cada LT de la muestra, vemos comportamientos diversos en función también de los niveles educativos de los LT y no sólo de las editoriales o los periodos legislativos. También hay que destacar que los LT de COU de la muestra (Anaya, 1989 y SM, 1980) no son muy representativos debido a que, en general, en este nivel educativo no se consideran los límites, ya que se suponen vistos en cursos anteriores, y los que los incluyen, lo hacen de forma breve a modo de repaso.

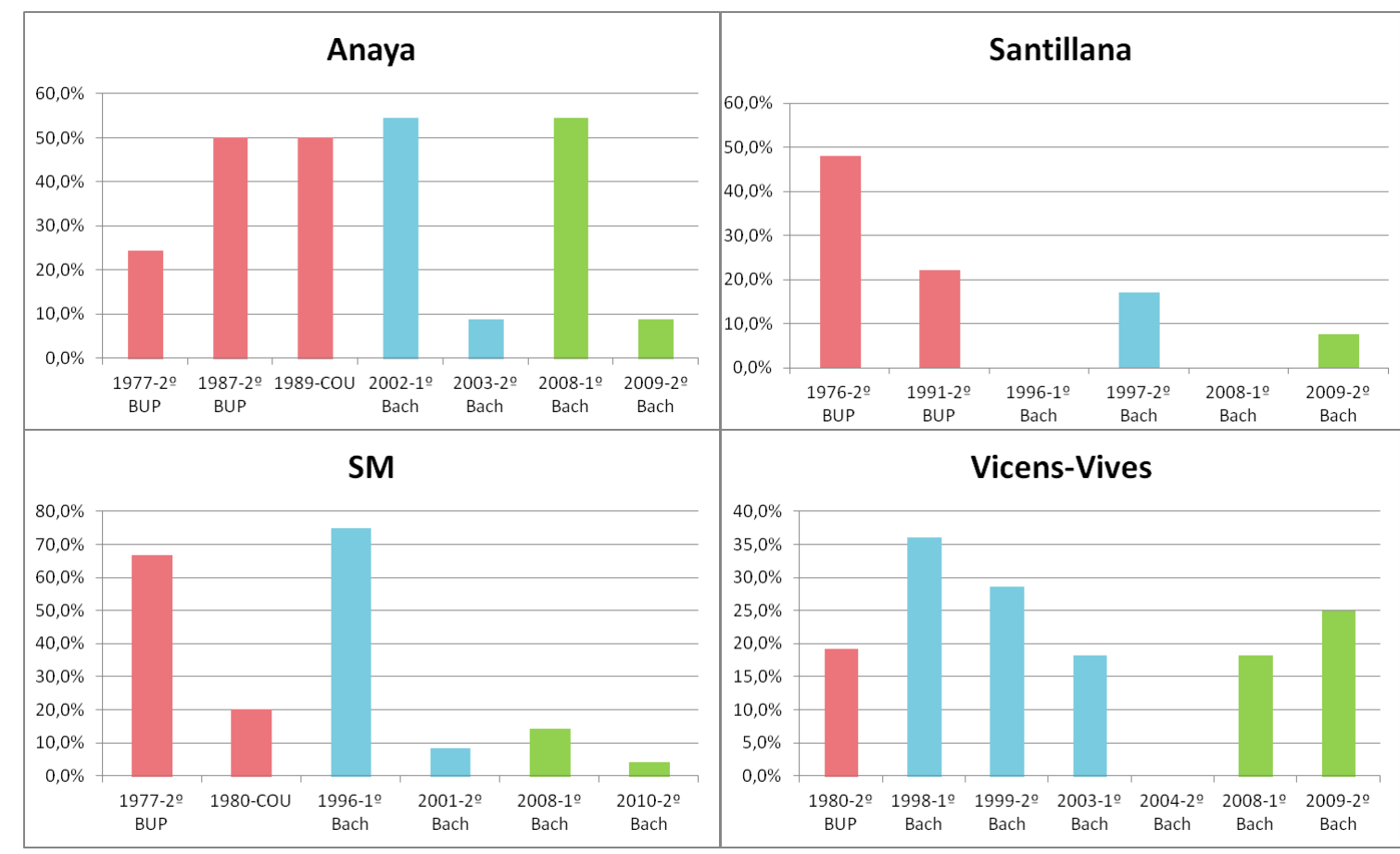

Gráfico IV.4.5.4. Porcentaje de resultados justificados en cada uno de los LT de cada editorial. Se observa la evolución temporal.

Por editoriales, en el Gráficos IV.4.5.4 se observan diferencias importantes en el porcentaje de resultados justificados: la editorial que justifica un porcentaje más alto de resultados en alguno de sus LT es SM (llegando casi al 70\% y al 80\% en dos de sus LT), y la que menos, Vicens-Vives, que el LT que justifica un porcentaje más alto de resultados únicamente llega al 35\%. Llama la atención las diferentes formas que tienen estas gráficas por leyes orgánicas, es decir, que no 
se observa un comportamiento similar en los LT en función de las legislaciones, sino que son las editoriales las que deciden si justifican en un curso más alto o más bajo, o si presentan más o menos justificaciones independientemente de los currículos legales. Este suceso también se observa en el Gráficos IV.4.5.3, en el que además se observan diferencias entre el número y el porcentaje de resultados justificados (SM es la editorial que menos resultados justifica, pero porque es la que menos resultados enuncia, ya que, por otro lado, es la que más resultados justifica proporcionalmente).

Resumiendo, se observa en las cuatro editoriales que, dependiendo del periodo y de los libros de texto, en algunos se observa un mayor número de resultados, aunque cuando esto se produce en los textos de LOGSE o LOE se debe principalmente a una mayor atomización de los mismos resultados que se presentaban en sus predecesores.

Una vez realizados estos análisis previos, que nos permiten tener una idea de la evolución de las justificaciones por editoriales, se presenta el análisis más detallado en función de nuestro marco teórico de los resultados enunciados relacionados con el límite funcional. Para ello, hemos clasificado los resultados en tres grupos en función del tipo de resultado:

1. Teoremas o propiedades asociados al concepto de límite: unicidad, equivalencias entre definiciones, caracterización mediante los límites laterales, conservación del signo en el entorno del límite...

2. Operaciones con límites: aritmética sobre límites finitos y su extensión a los límites infinitos.

3. Resultados asociados a indeterminaciones o familias de funciones: en este caso se consideran los límites de algunas familias de funciones o casos concretos de indeterminaciones que se enuncian (y a veces se justifican) como si de teoremas se trataran, por ejemplo, límite en el infinito de funciones polinómicas, racionales, exponenciales, logarítmicas...

Este análisis se presenta en los apartados IV.5, IV.6 e IV.7, y en ellos se recogen todos los datos del análisis realizado atendiendo a las categorías descritas en nuestro marco teórico. 


\section{IV.5.RESULTADOS ASOCIADOS AL CONCEPTO DE LÍMITE}

Una vez que se han visto los resultados que se enuncian sobre límites, se va a proceder a su análisis. En este epígrafe se muestra el análisis de los resultados asociados al concepto de límite, como por ejemplo, la unidad, la conservación de signo en un entorno del límite, la equivalencia entre definiciones, los límites laterales, signo...

En primer lugar se va a considerar las diferentes formas en que los libros definen el límite de una función, ya que de ello dependen las definiciones que enuncian y si establecen la equivalencia entre ellas. Se han detectado los siguientes planteamientos:

$>$ En algunos de los textos que consideran las sucesiones y los límites de sucesiones en temas anteriores al de límite funcional, definen éste último mediante sucesiones (el límite de una función en un punto $p$ es $L$ si para cualquier sucesión que tiende a $p$, la sucesión definida por las imágenes de los elementos de la sucesión por la función tiende a $L$ ). Estos LT son: Santillana (1991 y 1997), SM (1996) y Vicens-Vives (2003 y 2004). No obstante, al no ser operativo, suelen definirlo de nuevo utilizando otros tipos de definición, aunque no establecen la equivalencia, ni la justifican.

> En algunos textos (Anaya, 2002 y 2008; Santillana, 2008 y 2009) comienzan con los límites laterales, y definen el límite de una función en un punto a partir de éstos.

En el resto de textos definen el límite directamente utilizando la definición métrica, aunque suelen haber considerado una noción ingenua (intuitiva) de éste a modo de introducción.

A pesar de las diferentes presentaciones del límite, todas las editoriales presentan más de una definición, al menos en alguno de los cursos, aunque no suelen justificar la equivalencia entre dichas definiciones. En algunos casos, la definición métrica se presenta en varias versiones (utilizando entornos, valor absoluto, distancias...) y se realizan las transformaciones de una a otra de forma discursiva, pero no las consideramos demostraciones ya que se trata únicamente de una transformación en la expresión por equivalencia entre expresiones. 
Las definiciones utilizadas para el concepto de límite influyen en las pruebas que se pueden realizar en los resultados sucesivos, por lo que nos interesa hacer una breve comparación de las definiciones que utilizan los libros de texto. Algunos presentan más de una definición, por lo que hemos considerado la que presentan en primer lugar, si bien estos libros las "hacen evolucionar" hasta obtener otras diferentes. Además, existen diferencias en qué tipos de límites abordan en primer lugar, límites infinitos o infinitos, en un punto o en el infinito. En función de los libros podemos encontrar diversos comportamientos asociados a la definición del límite, para cualquiera de las definiciones. A continuación mostramos los tipos de definiciones de límite finito de una función en un punto en los LT de la muestra, tomando en cada caso la primera que se enuncia si en los LT se enuncia más de una:

- Definición métrica, en un punto, utilizando valores absolutos.

$\lim _{x \rightarrow a} f(x)=l \Leftrightarrow$ dado $\varepsilon>0$ existe un $\delta$ tal que si $0<|x-a|<\delta$ entonces $\mid f(x)-$ $l \mid<\varepsilon$. (Anaya $2^{\circ}$ BUP, 1976, pp. 76) ${ }^{8}$

Decimos $^{9}$ que la función $f(x)$ tiene por límite $L$ cuando $x$ tiende a 1 , si fijado un ${ }^{10}$ número real positivo $\varepsilon$ se puede determinar un número real positivo $\delta$ dependiente de $\varepsilon$, tal que, para todos los valores de $x$ que verifican la condición $0<|x-l|<\delta$, también se verifica que $|f(x)-L|<\varepsilon$. (SM $2^{\circ}$ BUP, 1977, pp. 61)

Una función $f(x)$ tiene límite $L$ en un punto $p$ si para cada número real $\varepsilon>0$ existe otro número real $\delta>0$ tal que $|f(x)-L|<\varepsilon$ si $|x-p|<\delta$ y $\mathrm{x} \neq \mathrm{p}$, donde $\delta$ se elige en función de $\varepsilon$. Se escribe $\lim _{x \rightarrow p} f(x)=L$. (SM $2^{\circ}$ Bachillerato, 2001, pp. 234)

La expresión $\lim _{x \rightarrow a} f(x)=b$, que se lee el límite de $f(x)$ cuando $x$ tiende a $a$ es $b$, quiere decir que si $x$ toma valores próximos al número $a$, los correspondientes valores de $f(x)$ se aproximan al número $b$. Al final: $\lim _{x \rightarrow a} f(x)=b \Leftrightarrow \forall \varepsilon>0$ se puede encontrar un $\delta>0 \mid$ si $0<|x-a|<\delta \Rightarrow|f(x)-b|<\varepsilon$. (SM 20 Bachillerato, 2010, pp. 209)

El número real $L$ es el límite de la función $f(x)$ cuando $x$ tiende a un valor $a$ finito si y sólo si para todo $\varepsilon>0$, tan pequeño como queramos, existe $\delta>0$, tal que si $a-\delta<x<a+\delta$ y $x \neq a$, entonces se cumple que $L-\mathcal{E}<f(x)<L+\mathcal{E}$. Escribiremos, simbólicamente, $\lim _{x \rightarrow a} f(x)=L$. (Vicens-Vives $2^{\circ}$ Bachillerato, 2009, pp. 166)

- Definición métrica, en un punto, utilizando entornos.

\footnotetext{
${ }^{8}$ Debería enunciar "para todo $\varepsilon$ " o "'para cualquier $\varepsilon$ ". De esta forma parece que basta que se cumpla para un solo $\varepsilon$.

${ }^{9}$ Subjetivismo

${ }^{10}$ El mismo problema señalado en la nota anterior.
} 
Se dice ${ }^{11}$ que la función $f$ tiene por límite el número real $L$ cuando $x$ tiende a $a$ si para todo entorno $\mathrm{E}(L, \varepsilon)$ de $L$ de radio $\varepsilon$ se puede encontrar un entorno $\mathrm{E}_{1}(a, \delta)$ de $a$ de radio $\delta$ tal que si $x \in \mathrm{E}_{1}(a, \delta), x \neq a$, se verifica: $f(x) \in \mathrm{E}(L, \varepsilon)$, y se escribe $\lim _{x \rightarrow a} f(x)=L$. (Santillana $2^{\circ}$ BUP, 1976, pp. 210)

Sea $y=f(x)$ una función real definida en un subconjunto $\mathrm{D}$ de $\mathbb{R}$ y sea $x_{0}$ un punto de acumulación de D. Se dice que el límite de la función $f(x)$ es 1 cuando $x$ tiende hacia $x_{0} \mathrm{y}$ se escribe $\lim _{x \rightarrow x_{0}} f(x)=l$ cuando fijado un ${ }^{12}$ entorno arbitrario de $l, E(l, \varepsilon)$, existe un entorno reducido del punto $x_{0}, \mathrm{E}^{*}\left(x_{0}, \delta\right)$, tal que cualquiera que sea $x \in \mathrm{E}^{*}\left(x_{0}, \delta\right) \cap \mathrm{D}$ se verifica que $f(x) \in \mathrm{E}(L, \varepsilon)$. (SM COU, 1980, pp. 217)

Diremos que $m$ es el límite de $F$ en $a$, si para todo entorno B de $m$ se puede encontrar un "entorno reducido" de $a$ : $\mathrm{A}_{0}=\mathrm{A} \backslash\{a\}$ de modo que: $\mathrm{F}\left(\mathrm{A}_{0}\right) \subset \mathrm{B}$. (Vicens-Vives $2^{\circ} \mathrm{BUP}$, 1980, pp. 235)

- Definición a partir de los límites laterales.

Si $\lim _{x \rightarrow c^{-}} f(x)=\lim _{x \rightarrow c^{+}} f(x)=l$, decimos que $\lim _{x \rightarrow c} f(x)=l$. (Anaya, $1^{\circ}$ Bachillerato, 2002, pp. 277 y Anaya, $1^{\circ}$ Bachillerato, 2008, pp. 277)

El límite de una función $f(x)$, cuando $x$ tiende a un punto $c$, es un número real $L$ cuando $\lim _{x \rightarrow c^{-}} f(x)=\lim _{x \rightarrow c^{+}} f(x)=L$. (Santillana, $1^{\circ}$ Bachillerato, 2008, pp. 228)

El límite de una función $f(x)$ cuando $x$ tiende a un punto $c$ es un número real $L$, lo escribimos como $\lim _{x \rightarrow c} f(x)=L$, si $\lim _{x \rightarrow c^{-}} f(x)=\lim _{x \rightarrow c^{+}} f(x)=L$. (Santillana $2^{\circ}$ Bachillerato, 2009, pp. 206)

- Definiciones a partir de sucesiones. Suelen complementarlas con otras métricas ya que es una definición poco operativa.

$\lim _{x \rightarrow a} f(x)=l \Leftrightarrow$ Siempre que $\lim _{n \rightarrow \infty} x_{n}=a$ (con $x_{n} \neq a$ ), se verifica que $\lim _{n \rightarrow \infty} f\left(x_{n}\right)=l$. (Santillana, $2^{\circ}$ BUP, 1991, pp. 126)

$L$ es el límite de la función $f(x)$ en el punto $x=a$, si y sólo si tomando cualquier sucesión de originales distintos de $a\left(x_{1}, x_{2}, \ldots x_{n} \ldots\right)$ que tiende hacia $a$, la sucesión de sus imágenes $\left(f\left(x_{1}\right), f\left(x_{2}\right), \ldots f\left(x_{n}\right) \ldots\right)$ tiende hacia L. (Santillana $2^{\circ}$ Bachillerato, 1997, pp. 219)

Una función $f(x)$ tiene por límite el número real $L$ en el punto $x=u$, si para toda sucesión de valores $x_{n} \neq u$ del dominio que tenga por límite $u$, al sucesión de los valores correspondientes, $f\left(x_{n}\right)$, tiene por límite $L . u$ puede ser $a, a^{+}, a^{-},+\infty,-\infty . L$ puede ser un número real, $+\infty,-\infty$. (SM $1^{\circ}$ Bachillerato, 1996, pp. 166)

\footnotetext{
${ }^{11}$ Podría parecer como un rumor

${ }^{12}$ Se comete el mismo error que hemos comentado en la nota 8. No se hace referencia explícita a que puede ser cualquier entorno y no basta con que lo cumpla sólo uno. Esto puede conducir a errores de comprensión de demostraciones en las que se requiere de dicha universalidad.
} 
Diremos que el valor $l$ es el límite de la función $f(x)$ cuando $x \rightarrow x_{0}$, si para cualquier sucesión de valores $\left\{x_{n}\right\}$ que tienda a $x_{0}$, la sucesión correspondiente de las imágenes $\left\{f\left(x_{n}\right)\right\}$ converge hacia el valor 1 . Escribiremos $\lim _{x \rightarrow x_{0}} f(x)=l$. (Vicens-Vives $1^{\circ}$ Bachillerato, 2003, pp. 212 y Vicens-Vives $2^{\circ}$ Bachillerato, 2004, pp. 9)

- Definiciones a partir de una descripción ingenua. A veces la complementan con una definición formal, generalmente métrica, en cualquiera de sus formatos.

$\lim _{x \rightarrow c} f(x)=l \Leftrightarrow$ Si queremos que $f(x)$ sea muy próximo a $l$, podremos conseguirlo sin más que darle a $x$ valores tan próximos a $c$ como sea necesario. $\Leftrightarrow \operatorname{Dado}^{13} \varepsilon>0$, podemos encontrar $\delta>0$ tal que si $x \neq c$ y $c-\delta<x<c+\delta$, entonces $|f(x)-l|<\varepsilon$. (Anaya $2^{\circ}$ Bachillerato, 2003, pp. 220 y Anaya $2^{\circ}$ Bachillerato, 2009, pp. 224)

$\lim _{x \rightarrow p} f(x)=l: f(x) \rightarrow l$ cuando $x \rightarrow p \Leftrightarrow|f(x)-l|$ es más pequeño que un ${ }^{14}$ número prefijado $\varepsilon$, para todos los valores de $x$ suficientemente próximos a $p$. (Anaya 2 BUP, 1987, pp. 143)

Intuitivamente se puede pensar en el límite de una función $y=f(x)$ en el punto $x=a$ como el valor al que tienden sus imágenes, $y$, cuando los originales, $x$, tienden hacia $a$. (Santillana $1^{\circ}$ Bachillerato, 1996, pp. 216)

Si $a$ y $b$ son dos números reales, la expresión $\lim _{x \rightarrow a} f(x)=b$ quiere decir que si $x$ toma valores próximos, tanto mayores como menores, al número a, los correspondientes valores de $f$ se aproximan al número $b$. (SM $1^{\circ}$ Bachillerato, 2008, pp. 190)

Decimos que el límite de la función $f(x)$ cuando $x$ a es $L$, y escribimos $\lim _{x \rightarrow a} f(x)=L$, si el valor de $f(x)$ se acerca a $L$ tanto como queramos, siempre que tomemos para $x$ un valor suficientemente próximo al valor $a$. (Vicens-Vives $1^{\circ}$ Bachillerato, 2008, pp. 239)

- Varias definiciones que combinan algunos de los casos anteriores, es decir, relacionan varias definiciones en el mismo texto o varias formas de escribir la misma definición.

$\lim _{x \rightarrow p} f(x)=l \Leftrightarrow \lim _{x \rightarrow p^{-}} f(x)=l$ y $\lim _{x \rightarrow p^{+}} f(x)=l \Leftrightarrow$ dado $^{15} \varepsilon>0$ existe un $\delta$ tal que si $0<|p-x|<\delta$ entonces $|f(x)-l|<\varepsilon \Leftrightarrow$ dado un entorno de $l, \mathrm{E}(l, \varepsilon)$, existe un entorno de $p, \mathrm{E}(p, \delta)$, tal que si $x \in E^{*}(p, \delta)$ entonces $f(x) \in E(l, \varepsilon)$. (Anaya COU, 1989, pp. 227)

Vicens-Vives (1998) de $1^{\text {o }}$ de Bachillerato no tiene una definición de límite, ni siquiera intuitiva, ya que ilustra la idea a partir de un texto explicativo gráficoverbal e indica lo que sería el límite y asíntota (Figura IV.5.1).

\footnotetext{
${ }^{13}$ El comentario de la nota 8 es válido aquí.

${ }^{14}$ El comentario de la nota 8 es válido aquí.

${ }^{15}$ El comentario de la nota 8 es válido aquí.
} 
Su continuación en $2^{\circ}$ de Bachillerato ni siquiera ilustra lo que es el límite, sino que se reduce al cálculo de límites de funciones elementales para continuar con operaciones y otras técnicas de cálculo de límites (representado mediante un asterisco en la Tabla IV.5.1).

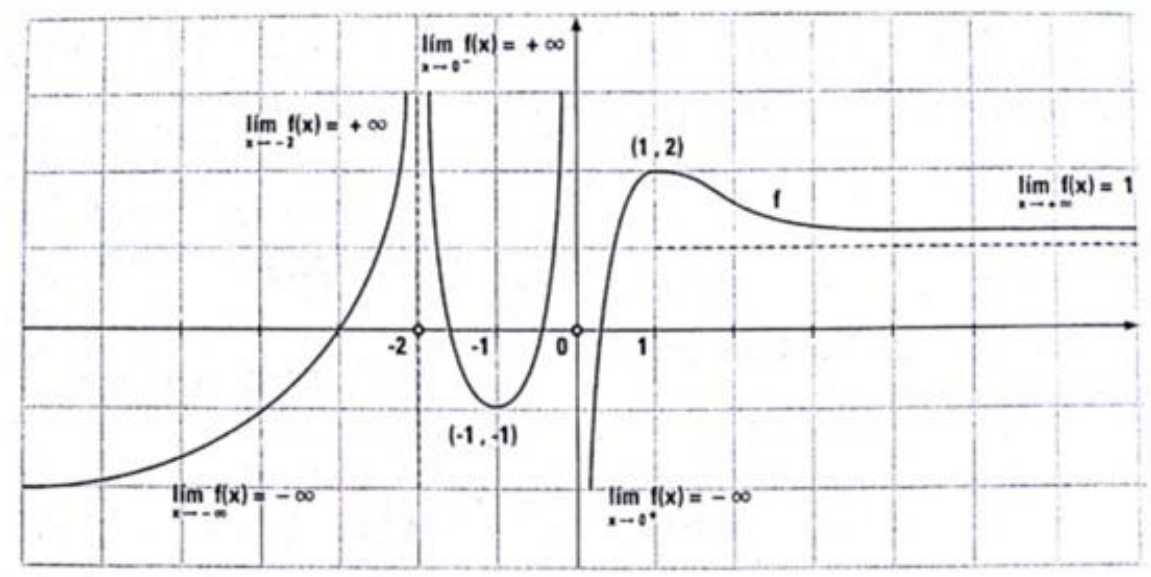

Falta describir cómo se comporta la gráfica en los extremos de los intervalos del dominio. Para ello necesitamos definir un nuevo concepto: "límite".

2.1 Límites en el infinito. Asintotas horizontales

Seguimos con la gráfica anterior.

- Si $x$ aumenta $y$ tiende a infinito (escribimos: $x \rightarrow+\infty$ ), los valores de $f(x)$ tienden a confundirse con 1 , aunque no lo alcancen.

Decimos que:

"el límite de $f$ cuando $x$ tiende $a+\infty$, es 1 "

En símbolos: $\lim _{x \rightarrow . .} f(x)=1$

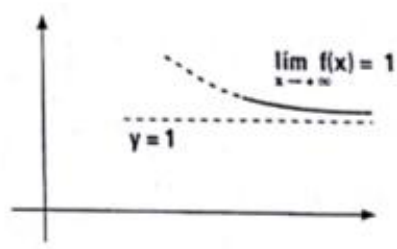

La gráfica parece querer pegarse a la recta $y=1$. Llamamos a esta recta asíntota horizontal.

- Si $x$, negativo, aumenta en valor absoluto y tiende $a-\infty(x \rightarrow-\infty)$, los va lores de $\mathrm{f}(\mathrm{x})$ decrecen más allá de cualquier valor imaginable.

Se dice que:

"el límite de $f$, cuando $x$ tiende a $-\infty$, es $-\infty$ "

En símbolos: $\lim _{x \rightarrow--} f(x)=-\infty$

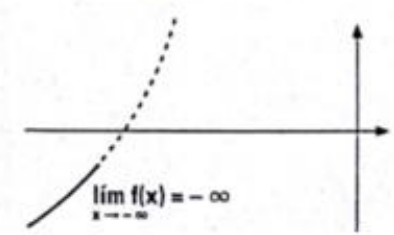

Figura IV.5.1. Concepto de límite en Vicens-Vives (1998), de $1^{\circ}$ de Bachillerato de LOGSE.

Si bien se observa que la primera definición que presenta cada libro puede ser diferente, la mayoría de LT no presenta una sola definición, y complementa la idea inicial con otras formulaciones y tipos de definición. En la Tabla IV.5.1 se 
muestran las definiciones de límite finito de una función en un punto que se encuentran en cada LT. Se podría realizar un estudio similar con las definiciones de límite en el infinito, o límite finito, pero alargaría innecesariamente este estudio sin aportar nueva información ya que los LT, o bien consideran una única definición (e indican que el límite o el punto pueden ser infinito) o bien consideran una definición adaptada al infinito pero del mismo estilo que la definición de límite finito de una función en un punto.

\begin{tabular}{|c|c|c|c|c|c|c|c|}
\hline \multirow{2}{*}{\multicolumn{2}{|c|}{ Periodo }} & \multirow[b]{2}{*}{$\mathbf{L T}$} & \multirow{2}{*}{$\begin{array}{c}\text { Ingenua } \\
\text { (intuitiva) }\end{array}$} & \multirow[b]{2}{*}{ Sucesiones } & \multirow{2}{*}{$\begin{array}{c}\text { Límites } \\
\text { laterales }\end{array}$} & \multicolumn{2}{|c|}{ Métrica } \\
\hline & & & & & & Entornos & Valor \\
\hline \multirow[t]{8}{*}{ LGE } & $2^{\circ}$ & Anaya (1977) & $\bar{\checkmark}$ & & & & $\checkmark$ \\
\hline & BUP & Anaya (1987) & $\checkmark$ & & & & $\checkmark$ \\
\hline & & $\begin{array}{l}\text { Sant. (1976) } \\
\end{array}$ & $\checkmark$ & & & $\checkmark$ & $\checkmark$ \\
\hline & & $\begin{array}{l}\text { Sant. (1991) } \\
\text { (1991) }\end{array}$ & $\checkmark$ & $\checkmark$ & & & $\checkmark$ \\
\hline & & SM (1977) & $\checkmark$ & & & $\checkmark$ & $\checkmark$ \\
\hline & & VV (1980) & $\checkmark$ & & & $\checkmark$ & $\checkmark$ \\
\hline & $\overline{\mathrm{COU}}$ & Anaya (1989) & & & & $\checkmark$ & $\checkmark$ \\
\hline & & SM (1980) & & & & $\checkmark$ & $\checkmark$ \\
\hline \multirow[t]{10}{*}{ LOGSE } & & Anaya (2002) & & & $\checkmark$ & & \\
\hline & & Sant. (1996) & $\checkmark$ & & & & \\
\hline & & SM (1996) & $\checkmark$ & $\checkmark$ & & & \\
\hline & & VV (1998) & $\checkmark$ & & & & \\
\hline & & $\overline{\text { VV (2003) }}$ & & $\checkmark$ & & & $\checkmark$ \\
\hline & $2^{\circ}$ & Anaya (2003) & $\checkmark$ & & & & $\checkmark$ \\
\hline & & Sant. (1997) & $\checkmark$ & & & $\checkmark$ & $\checkmark$ \\
\hline & & SM (2001) & & & & & $\checkmark$ \\
\hline & & VV (1999) & * & & & & \\
\hline & & VV (2004) & & $\checkmark$ & & & $\checkmark$ \\
\hline \multirow[t]{8}{*}{$\overline{\mathrm{LOE}}$} & $1^{\circ}$ & Anaya (2008) & & & $\checkmark$ & & \\
\hline & & Sant. (2008) & & & $\checkmark$ & & \\
\hline & & SM (2008) & $\checkmark$ & & & & \\
\hline & & VV (2008) & $\checkmark$ & & & & \\
\hline & $2^{\circ}$ & Anaya (2009) & $\checkmark$ & & & & $\checkmark$ \\
\hline & & Sant. (2009) & $\checkmark$ & & & & $\checkmark$ \\
\hline & & SM (2010) & $\checkmark$ & & & & \\
\hline & & VV (2009) & & & & & $\checkmark$ \\
\hline
\end{tabular}

Tabla IV.5.1. Tipos de definiciones de límites funcionales que se encuentran en los libros de texto analizados.

Tal y como se aprecia, las definiciones más utilizadas son la definición ingenua y la definición métrica a partir de la función valor absoluto (con la notación $\varepsilon-\delta$ ). Esta última definición es la más utilizada tradicionalmente en las matemáticas de los primeros cursos de universidad, pero no la más sencilla de comprender, sobre todo en estos niveles en los que los alumnos aún no están familiarizados con el lenguaje matemático formal. En nuestra opinión, sería interesante utilizar otra definición que, sin pérdida de rigor, fuera menos formal: la definición de límite 
como aproximación óptima propuesta por Blázquez y Ortega (2002) (y que analizan Blázquez, Gatica y Ortega, 2009) debido a que, tal y como apuntan Blázquez, Gatica, Ortega y Benegas (2008), los alumnos recuerdan las definiciones ingenuas y la definición por aproximación óptima mejor que la definición métrica $\varepsilon-\delta$. Al utilizar estas dos últimas cometen menos errores con la primera que con la segunda.

Definición de límite secuencial: $L$ es el límite de una sucesión $a_{n}$ si para cualquier aproximación $K$ de $L, K \neq L$, existe un término de la sucesión tal que todos los que siguen a éste están más próximos a $L$ que $K\left(a_{n}\right.$ tiende a $L$ cuando $n$ tiende a infinito).

Definición de límite funcional 1: El límite de la función $f$ en $x=a$ es $L$ si para cualquier aproximación $K$ de $L, K \neq L$, existe una aproximación $H$ de $a, H \neq a$, tal que las imágenes de todos los puntos que están más cerca de $a$ que $H$ están más próximas a $L$ que $K$. Se escribelim $\lim _{x \rightarrow a} f(x)=L$ y se lee límite de $f(x)$ cuando x tiende a $a$ es $L$.

Definición de límite funcional 2: El límite de la función $f$ en $x=a$ es $L$ si para cualquier aproximación $K$ de $L, K \neq L$, existe un entorno reducido de $a$ tal que las imágenes de todos sus puntos están más próximas a $L$ que $K$.

Definición de límite funcional 3: El límite de la función $f$ en $x=a$ es $L$ si cuando $x$ tiende a $a$, sus imágenes $f(x)$ tienden a $L$. (Previamente se ha establecido el concepto de tendencia, aproximación óptima, que es distinto del concepto de aproximación)

(Blázquez, Gatica y Ortega, 2009, pp. 160-161)

Por otro lado, no todos los LT acompañan la definición de límite de otros sistemas de representación que no sea el verbal, aunque algunos si incluyen gráficas. Estas gráficas no siempre representan el concepto de límite, sino que, en ocasiones, se limitan a mostrar una función continua (y por tanto, que tiene límite en cualquier punto).

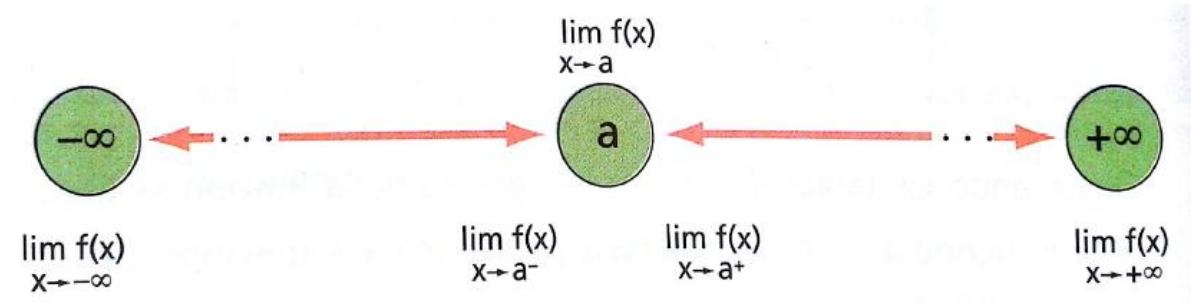

Figura IV.5.2. Representación del límite (1º de Bachillerato de LOGSE de SM, 1996).

En la Figura IV.5.2 no se representa el límite de una función propiamente dicho (no hay función) pero se muestra un diagrama cuya intención es representar la idea intuitiva de límite, la tendencia. 
El gráfico de la Figura IV.5.3 no representa la definición de límite, ya que es un ejemplo en el que se limitan a mostrar una función (que parece ser discontinua, de discontinuidad evitable), y relacionan el valor al que tiende la variable independiente con el valor que debería tomar la variable dependiente para que la función sea continua, que es precisamente una de las formas de enunciarlo de este LT, pero que no refleja lo que ocurre en las inmediaciones del punto.

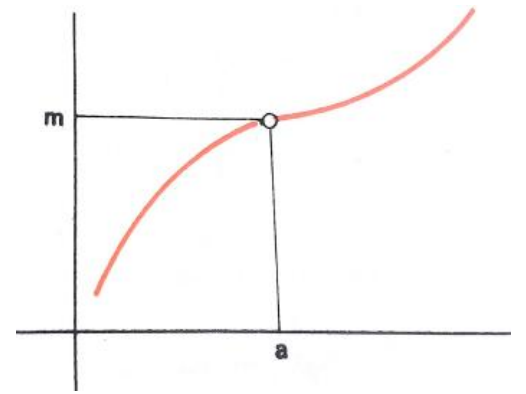

Figura IV.5.3. Representación del límite ( $2^{\circ}$ de BUP de Vicens-Vives, 1980).

En las Figuras IV.5.4, IV.5.5 y IV.5.6 se representa el concepto de límite utilizando entornos alrededor del valor al que tiende la función y de su posible imagen. Al tratarse del límite finito de una función en un punto, los LT han considerado funciones continuas (en el caso de la Figura IV.5.5 se trata de una función en concreto, $f(x)=x^{2}$ ), por lo que se puede identificar el límite con el valor de la función en el punto. No obstante, para evitar dicha identificación, el LT presenta la Figura IV.5.6 en la que ha eliminado el punto correspondiente al límite, y dibujando la gráfica para el resto de puntos.

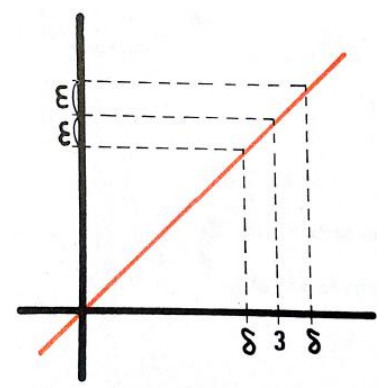

Figura IV.5.4. Representación del límite ( $2^{\circ}$ de BUP de SM, 1977).

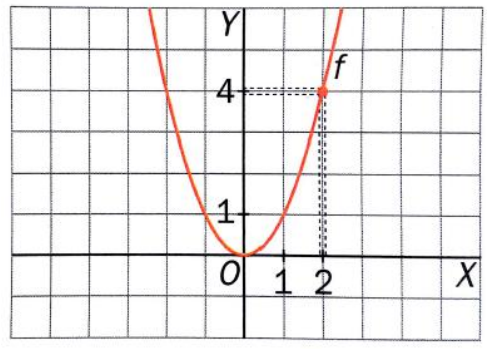

Figura IV.5.5. Representación del límite ( $2^{\circ}$ de Bachillerato de LOE de SM, 2010). 


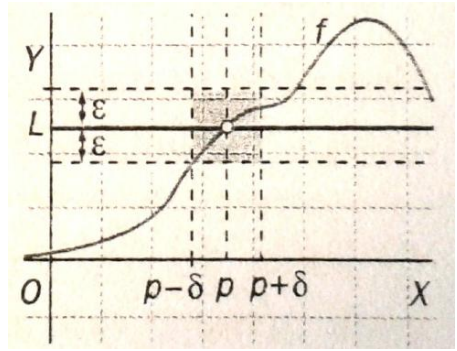

Figura IV.5.6. Representación del límite ( $2^{\circ}$ de Bachillerato de LOE de SM, 2001).

Por otro lado, algunos textos no muestran un gráfico para el límite finito de una función en un punto, sino para los límites laterales, sobre todo aquellos que lo definen como la existencia y coincidencia de los límites laterales en dicho punto. Un ejemplo de gráfico del límite lateral en el que se muestra el intervalo en el que se cumple la definición (se ha considerado para un caso concreto) es el de la Figura IV.5.7.
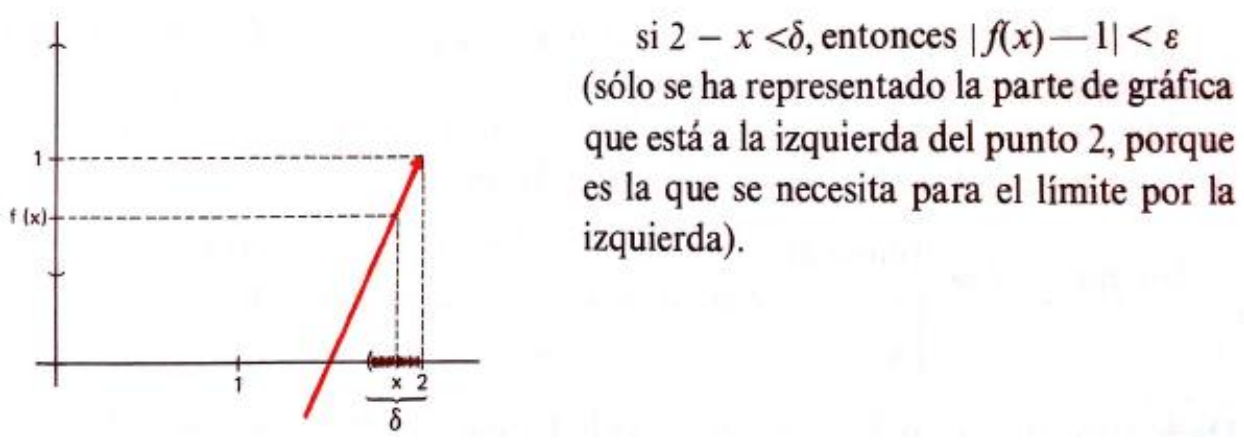

Figura IV.5.7. Representación del límite (2º de BUP de Anaya, 1976).

En el caso de la Figura IV.5.8 vemos que, en primer lugar, se considera el límite lateral, representando la definición $\varepsilon-\delta$, pero, en segundo, para el límite finito de una función en un punto, al establecer la igualdad entre los límites laterales, ya no se representan los intervalos asociados a $\varepsilon$ y a $\delta$.

Además, en las representaciones de los límites se pueden observar también pequeñas diferencias entre el $1^{\circ}$ y $2^{\circ}$ curso de una editorial para un mismo periodo: en la Figura IV.5.9 se muestra la representaciones utilizadas por los LT de LOE de Santillana (de $1^{\circ}$ y $2^{\circ}$ de Bachillerato, respectivamente), que son LT que han definido el límite en un punto a partir de los límites laterales pero que en $1^{\mathrm{o}}$ definen estos últimos de forma ingenua y en $2^{\circ}$ de forma métrica. Las representaciones son muy similares, pero en $1^{\circ}$ utiliza fragmentos de funciones lineales para señalar la aproximación y en $2^{\circ}$ utiliza fragmentos de funciones más generales, aunque en ambos casos, de funciones crecientes. 

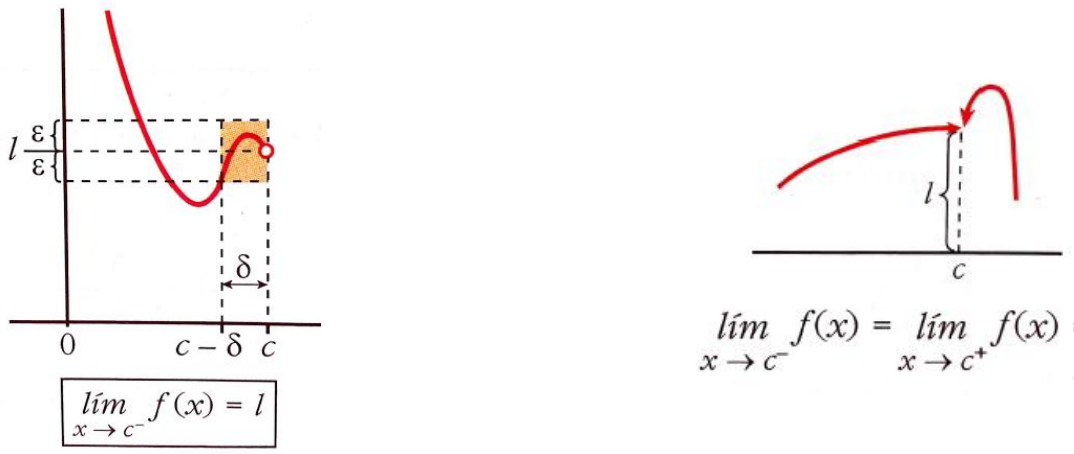

$$
\lim _{x \rightarrow c^{-}} f(x)=\lim _{x \rightarrow c^{+}} f(x)=l
$$

Figura IV.5.8. Representaciones del límite lateral y en un punto ( $2^{\circ}$ de Bachillerato de LOGSE de Anaya, 2003).

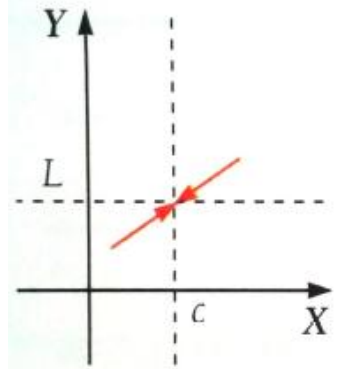

$\lim _{x \rightarrow \epsilon^{-}} f(x)=L$

$\lim _{+} f(x)=L$

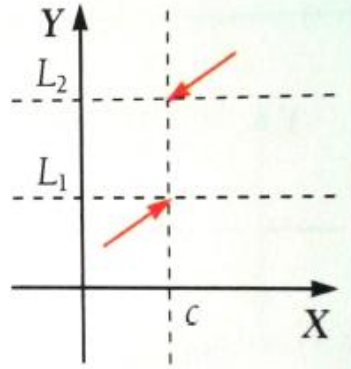

$\lim _{x \rightarrow 0^{-}} f(x)=L_{1}$

$\lim _{x \rightarrow c^{+}} f(x)=L_{2}$

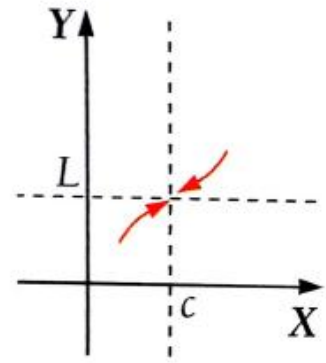

$\lim _{x \rightarrow c} f(x)=L$

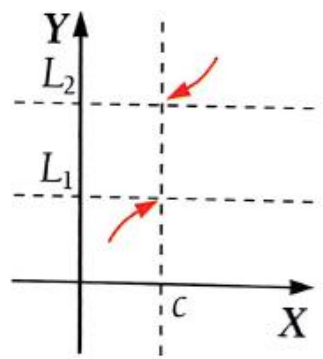

No existe $\lim _{x \rightarrow c} f(x)$.

Figura IV.5.9. Representación del límite finito en un punto: Santillana, 2008 (izquierda) y 2009 (derecha), correspondientes $\mathbf{a}^{\circ}$ y $2^{\circ}$ de Bachillerato respectivamente.

Por su parte, en la Figura IV.5.10 se muestra un ejemplo de representación de límite (Santillana, 1991) en el que sea intentado recoger todos los elementos que conforman el concepto de límite: la función no adopta ninguna forma de función conocida, en el punto no tiene por qué estar definida, se muestran ambos intervalos, tanto en el eje OX como en el eje OY, se indica la dependencia de $\delta$ en función de $\varepsilon$, se muestran a $x$ y $f(x)$ dentro de sus correspondientes intervalos...

Otra diferencia que hemos detectado asociada a la definición del límite son los distintos tratamientos que hacen los LT de los límites laterales. Se presentan en casi todos los libros, pero sólo en algunos se establece como propiedad que la existencia del límite de una función en un punto equivale a la existencia y coincidencia de los límites laterales en dicho punto. Algunos textos lo presentan como definición, como es el caso de Anaya (2002 y 2008) y Santillana (2008 y 2009) y, por tanto, carece de sentido considerar cualquier justificación en estos textos. 


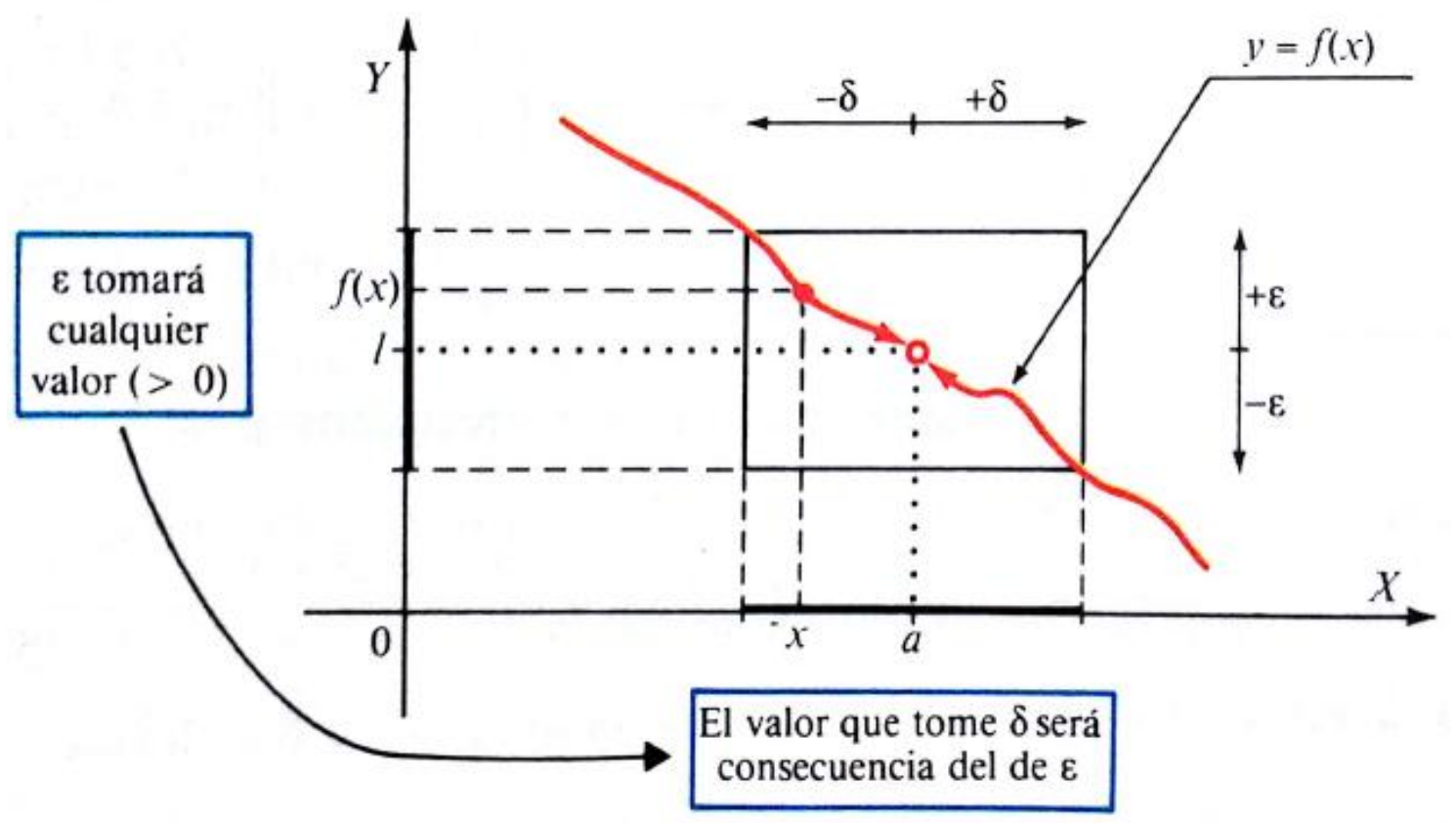

Figura IV.5.10. Representación del límite finito en un punto $\left(2^{\circ}\right.$ de BUP de Santillana, 1991).

No obstante, hay que remarcar que esta definición les permite obviar la definición de límite en un punto de una función y evitar el conflicto del valor absoluto, es decir, estos libros de texto evitan la escritura $0<|x-a|<\delta$. No obstante, también puede haber diferencias en el enunciado de la definición de límite lateral, ya que puede hacerse de forma ingenua (Santillana, 2008) o de forma métrica (Santillana, 2009), aunque la definición de límite en un punto que utilizan sea la misma. Si se pretendiera completar la definición usual (el límite de una función en un punto $c$ es un número real $L$ si para todo $\varepsilon>0$ existe un $\delta>0$ tal que se verifique que $\forall x \in(c-\delta, c+\delta)$, se cumple que $|f(x)-L|<\varepsilon)$ habría que establecer la equivalencia entre esta definición y la de los límites laterales mediante un teorema. Esto estaría obligado si se quiere aplicar la definición general para deducir algunas propiedades del límite sin recurrir a la lateralidad. No obstante, cualquiera que sea la definición que se establezca como tal de las dos consideradas permite la justificación de resultados posteriores (aunque con algunas diferencias asociadas a la definición utilizada). Este hecho suscita algunas preguntas: ¿alguna de las dos sistematizaciones es mejor desde el punto de vista didáctico? Y de ser así, ¿cuál es la más apropiada?

Únicamente se enuncia como un resultado y se justifica en dos de los libros de texto de $2^{\circ}$ de BUP, el de Anaya (1977) y en el de SM (1980), en dos libros de $1^{\circ}$ de Bachillerato de LOE, SM (2008) y Vicens-Vives (2008) y en uno de $2^{\circ}$ de 
Bachillerato de LOE, Vicens-Vives (2009). En las Tablas IV.5.2 y IV.5.3 se muestran los análisis correspondientes.

\begin{tabular}{|c|c|c|c|}
\hline \multicolumn{4}{|c|}{ Caracterización del límite mediante los límites laterales } \\
\hline \multicolumn{2}{|l|}{ Textos } & Anaya $2^{\circ}(1977)$ & SM COU (1980) \\
\hline \multicolumn{2}{|c|}{ Esquema de prueba } & $\begin{array}{l}\text { EP axiomático, con carácter } \\
\text { transformacional } \\
\text { nueva definición a } \\
\text { (deducción de } \\
\text { limites laterales) }\end{array}$ & $\begin{array}{l}\text { EP axiomático (demostración de la } \\
\text { CN y de la CS) }\end{array}$ \\
\hline \multirow[t]{4}{*}{ Técnicas } & Tipo & $\mathrm{CN}$ & $\mathrm{CN}$ y $\mathrm{CS}$ \\
\hline & Método & Silogismo & Silogismo \\
\hline & Estilo & AM local & AM local \\
\hline & Modo & Directo & Directo \\
\hline $\begin{array}{l}\text { Funciones } \\
\text { demostración }\end{array}$ & & comunicación, & comunicación, \\
\hline \multirow{2}{*}{\begin{tabular}{|ll} 
Reconocimie \\
nto & de \\
procesos
\end{tabular}} & $\mathrm{RP}^{16}$ & No & Lo etiqueta como teorema. \\
\hline & $\mathrm{RC}^{16}$ & No & No. \\
\hline \multirow{2}{*}{$\begin{array}{l}\text { Expresiones } \\
\text { que utiliza }\end{array}$} & $\operatorname{Exp}^{16}$ & $\mathrm{SR}^{16}$ : verbal, fórmula. & SR: verbal, fórmula. \\
\hline & $\operatorname{Sig}^{16}$ & No, símbolos habituales en el tema. & No, símbolos habituales en el tema. \\
\hline \multirow{4}{*}{$\begin{array}{l}\text { Consideracio } \\
\text { nes globales }\end{array}$} & $\mathrm{GP}^{16}$ & No. & No. \\
\hline & $\mathrm{CSi}^{16}$ & No. & No. \\
\hline & $\mathrm{DEJ}^{16}$ & No, dentro del texto. & $\begin{array}{l}\text { Enunciado en cursiva y etiqueta de } \\
\text { teorema. No indica la demostración. }\end{array}$ \\
\hline & $\mathrm{OV}^{16}$ & No & No. \\
\hline
\end{tabular}

Tabla IV.5.2. Análisis de las justificaciones asociadas al teorema de caracterización en los LT de la LGE.

Tal y como se ve en la Tabla IV.5.2, el análisis para ambos LT es muy similar: la justificación y la consideración del resultado es diferente, ya que en el LT de Anaya no se enuncia como tal, sino que aparece dentro del texto, como una explicación más y junto a la justificación, y en el LT de SM lo enuncia como teorema y justifica las dos implicaciones.

Por otra parte, en los LT de LOE únicamente se utilizan EP inductivos de 1 caso, es decir, que consideran un ejemplo de función en el que estudian los límites laterales y al coincidir estos, establecen que ese debe ser el valor del límite. Sobre otros aspectos que caracterizan a la justificación se aprecia que son similares en los tres textos (en los dos textos de Vicens-Vives, a pesar de ser de cursos diferentes, realizan la misma justificación y, por tanto, el análisis es el

\footnotetext{
${ }^{16}$ En todas las tablas: Reflexiona sobre el procedimiento (RP); se refiere a sus consecuencias $(\mathrm{RC})$; expresiones (Exp); explica su significado (Sig); explica globalmente el proceso (GP); se refiere a sus consecuencias (CSi); distingue entre el enunciado y la justificación (DEJ) y señala otras posibles vías de justificación (OV); sistemas de representación (SR).
} 
mismo para ambos) excepto en el método, que generalmente no se considera para EP inductivos por la naturaleza del EP, pero que en este caso hemos querido señalar como contraejemplo debido a que el LT, para establecer el resultado, considera un ejemplo donde los límites laterales no coinciden.

\begin{tabular}{|c|c|c|c|c|}
\hline \multicolumn{5}{|c|}{ Caracterización del límite mediante los límites laterales } \\
\hline \multicolumn{2}{|l|}{ Textos } & SM 10 (2008) & VV 10 (2008) & VV 20 (2009) \\
\hline \multicolumn{2}{|c|}{ Esquema de prueba } & EP inductivo de 1 caso & EP inductivo de 1 caso & EP inductivo de 1 caso \\
\hline \multirow[t]{4}{*}{ Técnicas } & Tipo & $\mathrm{CS}$ y $\mathrm{CN}$ & $\begin{array}{l}\mathrm{CN} \quad \text { "para que } \\
\text { exista...tiene que existir" }\end{array}$ & $\begin{array}{ll}\text { CN "para que } \\
\text { exista...tiene } \\
\text { existir" }\end{array}$ \\
\hline & Método & Contraejemplo. & - & - \\
\hline & Estilo & Algebraico y gráfico & Algebraico y gráfico & Algebraico y gráfico \\
\hline & Modo & - & - & - \\
\hline \multicolumn{2}{|c|}{$\begin{array}{l}\text { Funciones de la } \\
\text { demostración }\end{array}$} & Comunicación & $\begin{array}{l}\text { Comunicación, } \\
\text { explicación }\end{array}$ & $\begin{array}{l}\text { Comunicación, } \\
\text { explicación }\end{array}$ \\
\hline \multirow{2}{*}{$\begin{array}{l}\text { Reconoci } \\
\text { miento de } \\
\text { procesos }\end{array}$} & RP & No & No & No \\
\hline & $\mathrm{RC}$ & No & No & No \\
\hline \multirow{2}{*}{$\begin{array}{l}\text { Expresio } \\
\text { nes que } \\
\text { utiliza }\end{array}$} & Exp & $\begin{array}{l}\text { SR: verbal, gráfico, } \\
\text { fórmula. }\end{array}$ & $\begin{array}{l}\text { SR: verbal, tabla, fórmula, } \\
\text { gráfico (función) }\end{array}$ & $\begin{array}{l}\text { SR: verbal, fórmula, } \\
\text { gráfico (función) }\end{array}$ \\
\hline & Sig & $\begin{array}{l}\text { No, habituales en el } \\
\text { tema }\end{array}$ & No, habituales en el tema & $\begin{array}{l}\text { No, habituales en el } \\
\text { tema }\end{array}$ \\
\hline \multirow{4}{*}{$\begin{array}{l}\text { Consider } \\
\text { aciones } \\
\text { globales }\end{array}$} & GP & - & - & - \\
\hline & $\mathrm{CSi}$ & - & - & - \\
\hline & DEJ & Tipográficamente & Tipográficamente & Tipográficamente \\
\hline & $\mathrm{OV}$ & No & No & No \\
\hline
\end{tabular}

Tabla IV.5.3. Análisis de las justificaciones asociadas al teorema de caracterización en los

\section{LT de la LOE.}

Una vez definido el límite funcional, deberían enunciarse sus propiedades. Una de las más importantes, desde el punto de vista conceptual, es la unicidad, ya que dota al concepto de una característica que permite mecanizar su cálculo aunque no se utilice directamente para ello (es decir, este resultado no es necesario para calcular límites). Sin embargo, esta propiedad no se enuncia en todos los libros de texto y, por tanto, no se demuestra. Sí que lo encontramos en algunos de los libros de texto de la LGE, aunque a medida que avanzan las legislaciones, se deja de tener en cuenta. Esto nos indica que existe una tendencia a mayor hacia la profundización en el cálculo de límites, y su mecanización, que hacia la comprensión del concepto. Además, ninguno de los libros de texto lo titulan como teorema de unicidad $\mathrm{y}$, de hecho, muchos ni siquiera lo titulan como teorema. 


\begin{tabular}{|c|c|c|c|c|c|}
\hline \multicolumn{6}{|c|}{ Si existe el límite de una función en un punto, éste es único. } \\
\hline \multicolumn{2}{|c|}{ Textos $\left(2^{\circ} \mathrm{BUP}\right)$} & Santillana (1976) & Santillana (1991) & SM (1977) & Vicens-Vives (1982) \\
\hline \multicolumn{2}{|c|}{$\begin{array}{l}\text { Esquema de } \\
\text { prueba }\end{array}$} & EP axiomático. & $\begin{array}{l}\text { EP axiomático, } \\
\text { incompleto. Se basa } \\
\text { en los resultados para } \\
\text { límites de sucesiones, } \\
\text { aunque sólo indica } \\
\text { los pasos básicos del } \\
\text { razonamiento. }\end{array}$ & $\begin{array}{l}\text { EP } \\
\text { axiomático. }\end{array}$ & $\begin{array}{l}\text { EP } \\
\text { Demuestra el teorema } \\
\text { antes de enunciarlo. }\end{array}$ \\
\hline \multirow[t]{4}{*}{ Técnicas } & Tipo & $\mathrm{CN}$ & $\mathrm{CN}$ & $\mathrm{CN}$. & $\mathrm{CN}$. \\
\hline & $\begin{array}{l}\text { Métod } \\
\text { o }\end{array}$ & $\begin{array}{l}\text { Reducción } \\
\text { absurdo, } \\
\text { constructivo. }\end{array}$ & Reducción al absurdo & $\begin{array}{l}\text { Reducción al } \\
\text { absurdo. }\end{array}$ & $\begin{array}{l}\text { Reducción al absurdo, } \\
\text { constructivo. }\end{array}$ \\
\hline & Estilo & AM local. & AM global. & AM local. & AM local. \\
\hline & Modo & Directo. & Analítico & Directo. & Directo. \\
\hline \multicolumn{2}{|c|}{$\begin{array}{l}\text { Funciones de la } \\
\text { demostración }\end{array}$} & $\begin{array}{l}\text { Comunicación, } \\
\text { verificación. }\end{array}$ & $\begin{array}{l}\text { Comunicación, } \\
\text { verificación. }\end{array}$ & \begin{tabular}{|l|} 
Comunicació \\
$\mathrm{n}$, \\
verificación. \\
\end{tabular} & $\begin{array}{l}\text { Comunicación, } \\
\text { verificación. }\end{array}$ \\
\hline \multirow{2}{*}{$\begin{array}{l}\text { Reconoci } \\
\text { miento de } \\
\text { procesos }\end{array}$} & RP & No. & $\begin{array}{l}\mathrm{Si}, \text { indica que se } \\
\text { comprueba. }\end{array}$ & No. & No. \\
\hline & $\mathrm{RC}$ & No. & No. & No. & No. \\
\hline \multirow{2}{*}{$\begin{array}{l}\text { Expresio } \\
\text { nes que } \\
\text { utiliza }\end{array}$} & Exp & $\begin{array}{l}\text { Usuales. SR: verbal } \\
\text { y fórmula. }\end{array}$ & Usuales. SR: verbal. & $\begin{array}{l}\text { Usuales. SR: } \\
\text { fórmula. }\end{array}$ & $\begin{array}{l}\text { Usuales. SR: verbal y } \\
\text { fórmula. }\end{array}$ \\
\hline & Sig & $\begin{array}{l}\text { No, son expresiones } \\
\text { habituales. }\end{array}$ & $\begin{array}{l}\text { No, son expresiones } \\
\text { habituales. }\end{array}$ & \begin{tabular}{|l|} 
No, son \\
expresiones \\
habituales.
\end{tabular} & $\begin{array}{l}\text { No, son expresiones } \\
\text { habituales. }\end{array}$ \\
\hline \multirow{4}{*}{$\begin{array}{l}\text { Consider } \\
\text { aciones } \\
\text { globales }\end{array}$} & GP & No. & $\begin{array}{l}\mathrm{Si} \text {, es lo único que } \\
\text { hace. }\end{array}$ & No. & No. \\
\hline & $\mathrm{CSi}$ & No. & No. & $\begin{array}{l}\mathrm{Si}, \\
\text { brevemente. }\end{array}$ & $\mathrm{Si}$, brevemente. \\
\hline & DEJ & $\begin{array}{l}\text { Sólo de forma } \\
\text { tipográfica. }\end{array}$ & $\begin{array}{l}\text { Sólo de forma } \\
\text { tipográfica. }\end{array}$ & \begin{tabular}{|l|} 
Sólo de \\
forma \\
tipográfica. \\
\end{tabular} & $\begin{array}{l}\text { Sólo de } \\
\text { tipográfica. }\end{array}$ \\
\hline & $\mathrm{OV}$ & No. & $\begin{array}{l}\text { Sí, aunque lo indica } \\
\text { como ejercicio. }\end{array}$ & No. & No. \\
\hline
\end{tabular}

Tabla IV.5.4. Análisis de las justificaciones asociadas a la unicidad del límite en los LT de la LGE.

Como vemos en la Tabla IV.5.4, la unicidad del límite se justifica en todos los LT en los que se enuncia (los LT de Anaya no enuncian la propiedad) y, además, lo hacen de forma axiomática. Esto puede deberse a que es una demostración sencilla, de pocos pasos, en la que únicamente se utiliza la definición para verificar el resultado y, por tanto, no se requieren razonamientos complicados. Exceptuando el LT de Santillana (1981), que no llega a desarrollar la prueba, ya que sólo indica los pasos en el razonamiento, y utiliza la unicidad demostrada en los límites de sucesiones, el resto de LT utiliza el mismo razonamiento: parte de la definición y, utilizando la reducción al absurdo, llegan a la contradicción que 
justifica el resultado. No obstante, el LT de Santillana (1991) propone esta justificación como ejercicio para el alumno. Cabe destacar la presentación del texto de Vicens-Vives (1982), que justifica el resultado antes de enunciarlo, y presenta el enunciado como la síntesis del razonamiento realizado.

En el periodo de LOGSE, esta propiedad del límite prácticamente desaparece de los libros de texto (Tabla IV.5.5). Se enuncia únicamente en el LT de Santillana (1997), de $2^{\circ}$ de Bachillerato. En el desarrollo del tema, el LT no presenta la demostración del resultado, pero indica que se desarrolla en el apartado de Ejercicios y problemas resueltos.

\begin{tabular}{|c|c|c|}
\hline \multicolumn{3}{|c|}{ Si existe el límite de una función en un punto, éste es único. } \\
\hline \multicolumn{2}{|c|}{ Texto $\left(2^{\circ}\right.$ Bach. $)$} & Santillana (1997) \\
\hline \multicolumn{2}{|c|}{ Esquema de prueba } & EP0 en el texto, EP axiomático en el apartado Ejercicios y problemas resueltos. \\
\hline \multirow[t]{4}{*}{ Técnicas } & Tipo & $\begin{array}{l}\text { Unicidad y CS, aunque no está enunciado en los términos habituales } \\
\text { (Si...entonces). }\end{array}$ \\
\hline & Método & Reducción al absurdo \\
\hline & Estilo & Análisis Matemático local \\
\hline & Modo & Analítico \\
\hline \multicolumn{2}{|c|}{$\begin{array}{l}\text { Funciones de la } \\
\text { demostración }\end{array}$} & Verificación, comunicación, ¿explicación? \\
\hline \multirow{2}{*}{\begin{tabular}{|l|} 
Reconoci \\
miento de \\
procesos
\end{tabular}} & RP & Sí, indica que se demuestra en el apartado Ejercicios y problemas resueltos. \\
\hline & $\mathrm{RC}$ & No \\
\hline \multirow{2}{*}{$\begin{array}{l}\text { Expresio } \\
\text { nes que } \\
\text { utiliza }\end{array}$} & $\operatorname{Exp}$ & $\begin{array}{l}\text { SR: verbal. Símbolos propios de las matemáticas (conectores,...), habituales } \\
\text { durante el tema, en la demostración; en el enunciado, lenguaje coloquial }\end{array}$ \\
\hline & Sig & No \\
\hline \multirow{4}{*}{\begin{tabular}{|l} 
Consider \\
aciones \\
globales
\end{tabular}} & GP & No \\
\hline & $\mathrm{CSi}$ & No \\
\hline & $\mathrm{DE}$ & Tipográficamente, está en un apartado diferente. \\
\hline & $\mathrm{OV}$ & No \\
\hline
\end{tabular}

Tabla IV.5.5. Análisis de las justificaciones asociadas a la unicidad del límite en los LT de la LOGSE.

Algo similar ocurre en el caso de los LT de LOE: la unicidad únicamente se enuncia en el texto de SM (2010), de $2^{\circ}$ de Bachillerato. En los textos de Anaya y Vicens-Vives no aparece en ninguno de los dos cursos y en uno de los textos de Santillana (2008, de $1^{\circ}$ de Bachillerato) aparece en una nota en el margen para límites de sucesiones. Dado que SM (2010) no justifica dicha unicidad, es decir, que se trata de un EP0, en la Tabla IV.5.6 únicamente se presentan las categorías que se pueden analizar cuando no hay una demostración, y se omiten el resto. 


\begin{tabular}{|c|c|c|}
\hline \multicolumn{3}{|c|}{ Si existe el límite de una función en un punto, éste es único. } \\
\hline \multicolumn{2}{|l|}{ Textos } & SM (2010) $2^{\circ}$ curso \\
\hline \multicolumn{2}{|l|}{ Esquema de prueba } & EP0 \\
\hline Técnicas & Tipo & CS. Sin mencionar "entonces" \\
\hline \multicolumn{2}{|c|}{ Funciones de la demostración } & No hay \\
\hline \multirow[t]{2}{*}{ Expresiones que utiliza } & Exp & Sistema de representación verbal. \\
\hline & Sig & No. \\
\hline \multirow[t]{2}{*}{ Consideraciones globales } & $\mathrm{CSi}$ & No. \\
\hline & OV & No. \\
\hline
\end{tabular}

Tabla IV.5.6. Análisis de las justificaciones asociadas a la unicidad del límite en los LT de la LOE.

Algunos libros complementan el estudio del concepto de límite con otros resultados generales sobre límite, pero son una minoría. De hecho, sólo hemos encontrado alguno de ellos justificado en tres libros de $2^{\circ}$ de BUP de LGE, en Santillana (1976), Santillana (1991) y SM (1977), ya que en otros libros, si se enuncia, no se justifica. Los resultados a los que nos referimos son los siguientes:

- $\lim _{x \rightarrow a} f(x)=L$ equivale a $\lim _{x \rightarrow a} f(x)-L=0$.

Se enuncia en uno de los libros de $2^{\circ}$ de BUP de Santillana (1976) con EP axiomático, aunque se puede observar un paso transformacional. El tipo de enunciado es de condición suficiente, ya que sólo se enuncia una implicación, aunque podrían enunciarse en ambos sentidos ( $\mathrm{y}$ justificarse). El método utilizado es el silogismo, con un estilo del Análisis Matemático local, y en modo directo. Las funciones que apreciamos son las de comunicación y verificación. En el LT no se aprecia ningún reconocimiento al proceso, aunque la justificación comienza por "en efecto", lo que parece indicar el comienzo de un razonamiento. Utiliza los sistemas de representación verbal y fórmula, de los que no explica su significado, porque son habituales en el texto. Sin embargo, en la demostración indica "fijado un $\varepsilon$ ", lo que parece contradecir el hecho de que el límite se define para todo $\varepsilon$ : deberían precisarse estas notaciones. Por último, no se explica globalmente el proceso, ni el significado del teorema, ni se señalan otras vías de justificación. No existe una separación clara entre el enunciado y la justificación, ni siquiera tipográfica. Únicamente cambian de párrafo, pero no es suficiente para señalar dicha diferencia.

También se enuncia en el texto de Santillana (1991) y en el de Anaya (1977), aunque lo relacionan con los infinitésimos. En ninguno de los dos LT lo justifican. 
- Si una función tiene límite en un punto c, dicha función está acotada en un entorno de $\mathrm{c}$.

Este resultado se enuncia en el LT de $2^{\circ}$ de BUP de Santillana (1976). Lo justifica mediante un EP axiomático. El enunciado es de tipo de condición suficiente, aunque falta el "entonces". El método es el silogismo, con un estilo del Análisis Matemático local, y en modo directo. Las funciones que se aprecian son comunicación y verificación. No reconoce el proceso como tal, ni explica las consecuencias de haberlo justificado. Los sistemas de representación son el verbal y la fórmula, y no explica ninguna de las expresiones que utiliza ya que son habituales en el tema. No realiza una descripción global del proceso, y en cuanto a consecuencias, podríamos considerar la indicación de quienes serían los candidatos a cotas superior e inferior, aunque no justifica por qué. La distinción es tipográfica, ya que escribe el enunciado en cursiva, y no señala otras vías de justificación.

- Si una función tiene límite positivo en un punto, existe un entorno del límite ${ }^{17}$ en la que la función conserva el signo positivo (respectivamente si el signo es negativo).

Este resultado se enuncia en el Santillana (1976) y en el Santillana (1991), ambos de $2^{\circ}$ de BUP. En el LT más antiguo (Santillana, 1976) este resultado se enuncia complementando los resultados antes descritos, aunque en este caso no se justifica (el propio texto indica que no van a realizar la demostración). En el LT más moderno (Santillana, 1991) se indica que "en los siguientes ejemplos se comprueban dos propiedades importantes de los límites" (pp. 131), y ésta es una de ellas. Realiza un razonamiento axiomático, aunque no transcribe todos los pasos del razonamiento. El enunciado contiene el verbo "probar", como si de un ejercicio se tratase, y es de tipo de condición suficiente. Tal y como está presentado, únicamente se puede apreciar las funciones de comunicación y verificación, pero no la de explicación. Aunque no hace ninguna reflexión sobre el procedimiento, se aprecian algunas indicaciones sobre la intención de "demostrar". El enunciado empieza con el verbo "probar" y se concluye el razonamiento con la expresión "que es lo que había que comprobar", expresión que refleja la función de verificación antes mencionada. En cuanto a los sistemas de representación utilizados, se limita al lenguaje verbal y al simbólico, y los

\footnotetext{
${ }^{17}$ Está mal enunciado. El entorno debe ser del punto (del límite es una obviedad)
} 
símbolos utilizados no se explican, ya que son utilizados habitualmente en el LT. No se revelan las líneas generales de la demostración, ni se establecen relaciones del teorema con otros resultados, ni aplicaciones. El enunciado y la justificación no se distinguen salvo por estar en párrafos diferentes, y no se indican otras formas de justificación.

- Si dos funciones f y g toman los mismos valores en todos los puntos de un entorno reducido de un punto, entonces ambas funciones tienen el mismo límite en dicho punto.

Este resultado lo enuncia y justifica el LT de $2^{\circ}$ de BUP de SM (1977), que presenta varios resultados asociados al concepto de límite, quizá los autores estén pensando en discontinuidades evitable. Lo justifica mediante un EP axiomático, mediante silogismo, con un estilo del Análisis Matemático local, y en modo directo. El enunciado es poco claro y presenta algún error: en primer lugar, es de tipo de condición suficiente, pero no escribe el "entonces"; por otro lado, indica que se debe cumplir en un entorno reducido de la forma $(l+\delta, l+\delta)$, donde el primer más + debería ser - (se trata de una errata del LT), y no indica que 1 es el punto donde el límite coincide, lo que se deduce del razonamiento que lo justifica. No se aprecian otras funciones que la de comunicación y verificación. Tampoco explica el significado del resultado, ni las consecuencias de haberlo demostrado, ni presenta globalmente el proceso que presenta para justificarlo, ni siquiera reconoce que lo está justificando. Hay un cambio tipográfico, pero no se indica qué es el enunciado ni qué es la justificación, y no señalan otras vías probatorias. Además, se limita a utilizar sistemas de representación verbal y fórmula, pero no gráfico ni tabular.

- Si una función $\mathrm{h}(\mathrm{x})$ está comprendida entre otras dos, $\mathrm{f}(\mathrm{x})$ y $\mathrm{g}(\mathrm{x})$, para todos los puntos de un entorno de un punto $1, y \mathrm{f} y \mathrm{~g}$ tienen el mimo límite en $\mathrm{x}=\mathrm{l}$, entonces $\mathrm{h}$ también tiene el mismo límite en $\mathrm{x}=1$. (Comúnmente conocido como el "criterio del sándwich" aunque este libro no lo denote así).

Como en el caso anterior, este resultado se enuncia en el SM (1977) y se justifica mediante un EP transformacional, que es incompleto ya que algunos pasos en el razonamiento los da por supuestos. Como en el caso anterior, no hay referencias a otras formas de justificación, la distinción entre enunciado y justificación es tipográfica, no existen referencias ni al proceso ni a sus consecuencias, ni a las consecuencias del resultado, así como tampoco se explica globalmente el proceso 
de justificación llevado a cabo. Los sistemas de representación utilizados son el verbal y el simbólico, y no se aclaran las expresiones porque son frecuentemente utilizadas.

3. Si una función $h(x)$ está comprendida entre otras dos $f(x)$ y $g(x)$ para todos los puntos de un entorno del punto l y $f(x)$ y $g(x)$ tienen el mismo limite en $x=l, h(x)$ tiene también el mismo limite.

En efecto, si $\forall x \in(1-\delta, 1+\delta)$ se verifica que:

$$
\mathrm{f}(\mathrm{x})<\mathrm{h}(\mathrm{x})<\mathrm{g}(\mathrm{x})
$$

También

$$
f(x)-L<h(x)-L<g(x)-L
$$

Por consiguiente:

$$
\lim _{x \rightarrow 1} h(x)=L
$$

Figura IV.5.11. Justificación ( $2^{\circ}$ de BUP de SM, 1977).

\section{IV.6.OPERACIONES CON LÍMITES}

El siguiente conjunto importante involucrado en el concepto de límite son las propiedades aritméticas de los límites, que tienen una orientación calculista. Se enuncian en casi todos los LT (excepto en los de COU), y se utilizan en todos ellos. Su importancia reside en que permiten la realización de cálculos de límites prescindiendo de la definición, lo que agiliza su mecanización y simplifica el proceso. No obstante, si bien son propiedades muy utilizadas (suponen la base del cálculo de límites de funciones), la mayoría de los LT no las justifican. Nuestra posición no es la de demostrar todas estas propiedades, pero sí justificar al menos la suma, cuya justificación no es muy compleja, al menos como pueden ser la del cociente o el producto, y consideramos que es asequible en estos niveles. Realizar esta justificación tiene varias ventajas, ya que requiere de la aplicación de la definición de límite, lo que contribuye a relacionar el concepto con la propiedad y, además, se muestra la veracidad de un resultado de forma explicativa, y así este proceso matemático, que es muy importante, no queda vacío. No presentar ninguna justificación conllevaría una excesiva mecanización del concepto y podría llevar a la asociación de propiedades que el límite no tiene (por ejemplo, que en el límite de una función no afecta el valor de la función en 
dicho punto, sino lo que ocurre en los entornos del punto, que límite de una función suma de dos es el límite de los límites de las funciones sumando,...).

En este caso, la presentación de los resultados relacionados con las operaciones también es muy diversa. Por un lado, hay que tener en cuenta que se pueden definir varios tipos de límites si los separamos en los casos en los que interviene el concepto de infinito o no: en primer lugar, en función de la tendencia de la variable pueden ser límites en un punto o límites en el infinito; en segundo lugar, en función de la tendencia de la función, pueden ser límites finitos o infinitos. Esta diversidad hace que los libros de texto tengan que posicionarse frente a cómo definir los límites: una definición que englobe a todos (sin distinguir entre finitos e infinitos), distinción sólo en función del resultado (si el límite es finito o infinito), en función de la variable (si se calcula en un punto o en el infinito), las cuatro distinciones (considerando los dos tipos anteriores). Esta posición influye en la presentación de las operaciones, dado que pueden enunciarse en general para cualquier tipo de límite (con algunas excepciones o puntualizaciones) o realizando divisiones en función del tipo de límite. En principio, las operaciones más sencillas de justificar son las que se definen sobre límites finitos en un punto, dado que algebraicamente se prescinde del infinito, un elemento que, por su naturaleza, puede dificultar la comprensión. No obstante, siempre se pueden tratar al mismo tiempo, lo que hacen algunos de los textos.

Esta diversidad ya se reflejó en las tablas de enunciados presentados en los libros del epígrafe IV.5 de este capítulo, en el que se observaban grandes diferencias entre el número de resultados que aparecían en cada LT: estas diferencias se deben principalmente a como enuncian las operaciones, ya que algunos engloban varios casos en un mismo enunciado, y otros los desglosan, o bien hacen diferenciaciones en función del tipo de límite. En todo caso, si se observa un aspecto común a la mayoría de los LT: no se suelen justificar los resultados relacionados con las operaciones con límites, sobre todo en los LT más recientes.

Las operaciones que suelen enunciarse en prácticamente todos los LT, exceptuando los dos de COU, que no enuncian ningún tipo de operación, son las operaciones básicas aritméticas: suma, diferencia, producto y cociente. En algunos textos incluyen otras operaciones: producto por constante, composición de funciones, o funciones elevadas a otras funciones. De estás, la que hemos 
encontrado más frecuentemente justificada es la suma, aunque como ya hemos mencionado en varias ocasiones, no en todos los LT:

- En los siguientes textos ni siquiera las presentan: de la LGE, en el LT de $2^{\circ}$ de BUP de Anaya (1987) y en los LT de COU de Anaya (1989) y de Santillana (1981); en la LOGSE, en el LT de $1^{\circ}$ de Bachillerato de Anaya (2002), de Santillana (1996) y SM (1996); y en LOE, en los LT de $1^{\text {o }}$ de Bachillerato de Anaya (2008) y Santillana (2008).

- En los siguientes LT justifican la suma (en algunos fundamentan algunas operaciones más, pero lo veremos más adelante): en los LT de $2^{\circ}$ de BUP de Anaya (1976), de Santillana (1976 y 1991), de SM (1977) y VicensVives (1980) y en el LT de $2^{\circ}$ de bachillerato de LOGSE de Santillana (1997).

- En el resto de LT se enuncia pero no se justifica.

En resumidas cuentas, los LT se comportan de la siguiente forma con respecto a la función suma de dos funciones:

\begin{tabular}{|c|c|c|c|c|}
\hline \multicolumn{2}{|c|}{ Periodo } & LT & Presentan la suma & Justificación \\
\hline \multirow[t]{8}{*}{$\overline{\mathrm{LGE}}$} & \multirow[t]{6}{*}{$2^{\circ} \mathrm{BUP}$} & Anaya (1976) & $\bar{\checkmark}$ & $\mathrm{EPa}$ \\
\hline & & Anaya (1987) & & \\
\hline & & Sant. (1976) & $\checkmark$ & $\mathrm{EPa}$ \\
\hline & & Sant. (1991) & $\checkmark$ & $\mathrm{EPa}$ \\
\hline & & $\overline{\text { SM (1977) }}$ & $\checkmark$ & $\mathrm{EPa}$ \\
\hline & & VV (1980) & $\checkmark$ & $\mathrm{EPa}$ \\
\hline & \multirow[t]{2}{*}{$\overline{\mathrm{COU}}$} & Anaya (1989) & & \\
\hline & & $\overline{\mathrm{SM}(1980)}$ & & \\
\hline \multirow{5}{*}{\multicolumn{2}{|c|}{ LOGSE $1^{\circ}$}} & Anaya (2002) & & \\
\hline & & Sant. (1996) & & \\
\hline & & $\overline{\text { SM (1996) }}$ & & \\
\hline & & VV (1998) & $\checkmark$ & EP0 \\
\hline & & $\overline{\mathrm{VV}(2003)}$ & $\checkmark$ & EP0 \\
\hline & \multirow[t]{5}{*}{$2^{\circ}$} & Anaya (2003) & $\checkmark$ & EP0 \\
\hline & & Sant. (1997) & $\checkmark$ & $\mathrm{EPa}$ \\
\hline & & $\overline{\text { SM (2001) }}$ & $\checkmark$ & EP0 \\
\hline & & VV (1999) & $\checkmark$ & EP0 \\
\hline & & VV (2004) & $\checkmark$ & EP0 \\
\hline \multirow[t]{8}{*}{$\overline{\mathrm{LOE}}$} & \multirow[t]{4}{*}{$1^{\circ}$} & Anaya (2008) & & \\
\hline & & Sant. (2008) & & \\
\hline & & SM (2008) & $\checkmark$ & EP0 \\
\hline & & VV (2008) & $\checkmark$ & EP0 \\
\hline & \multirow[t]{4}{*}{$2^{\circ}$} & Anaya (2009) & $\checkmark$ & EP0 \\
\hline & & Sant. (2009) & $\checkmark$ & EP0 \\
\hline & & SM (2010) & $\checkmark$ & EP0 \\
\hline & & VV (2009) & $\checkmark$ & EP0 \\
\hline
\end{tabular}

Tabla IV.6.1. Presentación (o no) de la suma y justificaciones utilizadas en los LT. 
En las Tablas IV.6.2 y IV.6.3 se muestra el análisis realizado para los LT que justifican la propiedad de la suma de límites de funciones, que como vemos únicamente se justifica de forma axiomática o no se justifica.

\begin{tabular}{|c|c|c|c|c|c|c|}
\hline \multicolumn{7}{|c|}{ El límite de la suma de funciones es igual a la suma de los límites de dichas funciones. } \\
\hline \multicolumn{2}{|c|}{ Textos $\left(2^{\circ} \mathrm{BUP}\right)$} & Anaya (1976) & Sant. (1976) & Sant. (1991) & SM (1977) & VV (1980) \\
\hline \multicolumn{2}{|c|}{ Esquema de prueba } & \begin{tabular}{|l|} 
EP axiomático \\
(se basa en \\
infinitésimos)
\end{tabular} & $\begin{array}{l}\text { EP } \\
\text { axiomático }\end{array}$ & EP axiomático & \begin{tabular}{|l} 
EP \\
axiomática. \\
Inducción a \\
sumandos \\
finitos
\end{tabular} & \begin{tabular}{|l} 
(En el caso de \\
infinitos) EP \\
axiomático
\end{tabular} \\
\hline \multirow[t]{4}{*}{ Técnicas } & Tipo & CS & $\mathrm{CS}$ & $\mathrm{CS}$ & \begin{tabular}{|l|} 
CS con \\
hipótesis y \\
tesis ocultas \\
\end{tabular} & $\mathrm{CS}$ \\
\hline & Método & Silogismo & Silogismo & Silogismo & Silogismo & Silogismo \\
\hline & Estilo & AM global & AM local & AM local & AM local & AM local \\
\hline & Modo & Analítico & Directo & Directo & Directo & Directo \\
\hline \multicolumn{2}{|c|}{$\begin{array}{l}\text { Funciones de la } \\
\text { demostración }\end{array}$} & $\begin{array}{l}\text { Comunicación, } \\
\text { verificación }\end{array}$ & $\begin{array}{l}\text { Comunicació } \\
\mathrm{n}, \text { verificación }\end{array}$ & $\begin{array}{l}\text { Comunicación, } \\
\text { verificación, } \\
\text { parcialmente } \\
\text { explicativa. }\end{array}$ & $\begin{array}{l}\text { Comunicació } \\
\text { n, } \\
\text { verificación. }\end{array}$ & $\begin{array}{l}\text { Comunicación, } \\
\text { verificación }\end{array}$ \\
\hline \multirow[t]{2}{*}{\begin{tabular}{|l|} 
Reconoci \\
miento de \\
procesos
\end{tabular}} & RP & Sí, etiqueta & $\begin{array}{l}\text { Indica que lo } \\
\text { demuestra }\end{array}$ & Sí, etiqueta & $\begin{array}{l}\text { Menciona "lo } \\
\text { demostrarem } \\
\text { os" }\end{array}$ & No \\
\hline & $\mathrm{RC}$ & No & No & No & No & No \\
\hline \multirow{2}{*}{$\begin{array}{l}\text { Expresio } \\
\text { nes que } \\
\text { utiliza }\end{array}$} & Exp & $\begin{array}{l}\text { SR: verbal y } \\
\text { fórmula }\end{array}$ & $\begin{array}{l}\text { SR: verbal, } \\
\text { fórmula }\end{array}$ & $\begin{array}{l}\text { SR: verbal, } \\
\text { fórmula }\end{array}$ & $\begin{array}{l}\text { SR: verbal y } \\
\text { fórmula }\end{array}$ & $\begin{array}{l}\text { SR: verbal y } \\
\text { fórmula }\end{array}$ \\
\hline & Sig & $\begin{array}{l}\text { No, habituales } \\
\text { en el tema }\end{array}$ & $\begin{array}{l}\text { No, habituales } \\
\text { en el tema }\end{array}$ & $\begin{array}{l}\text { No, habituales } \\
\text { en el tema }\end{array}$ & $\begin{array}{l}\text { No, } \\
\text { habituales en } \\
\text { el tema }\end{array}$ & $\begin{array}{l}\text { No, habituales } \\
\text { en el tema }\end{array}$ \\
\hline \multirow{4}{*}{\begin{tabular}{|l|} 
Consider \\
aciones \\
globales
\end{tabular}} & GP & No & No & $\begin{array}{l}\text { Sí, indica "hay" } \\
\text { que probar. }\end{array}$ & No & No \\
\hline & $\mathrm{CSi}$ & $\begin{array}{l}\text { No en el } \\
\text { resultado, luego } \\
\text { se aplica al } \\
\text { cálculo de } \\
\text { límites }\end{array}$ & \begin{tabular}{|l} 
No en el \\
resultado, lo \\
aplica en \\
otros \\
posteriorment \\
e
\end{tabular} & No & No & $\begin{array}{l}\text { Caso suma - }-\infty \\
\text { indeterminació } \\
\mathrm{n}+\infty-\infty\end{array}$ \\
\hline & DEJ & Sí, etiqueta. & $\begin{array}{l}\text { No, salvo } \\
\text { indicación de } \\
\text { demostrar }\end{array}$ & Sí & $\begin{array}{l}\text { Tipográficam } \\
\text { ente }\end{array}$ & No \\
\hline & $\mathrm{OV}$ & No. & No & No & No & No \\
\hline
\end{tabular}

Tabla IV.6.2. Análisis de la justificación asociada al límite de la suma de funciones en los LT de $2^{\circ}$ de BUP de todas las editoriales.

Tal y como se muestra en la Tabla IV.6.2, hay aspectos del análisis que coinciden en todos los LT (que no se proponen otras vías de justificación, los sistemas de representación utilizados, que no se refiere a las consecuencias de realizar la demostración, el EP utilizado), pero en otros aspectos se muestran pequeñas 
diferencias: la forma de diferenciar entre el enunciado y la justificación, la justificación utilizada, aunque todas sean de tipo axiomático, algunas funciones de la demostración observadas... Esta diversidad nos muestra que, aunque la teoría matemática sea la misma, las diferentes posturas que toman los autores al diseñar LT influyen en la sistematización mostrada en los LT y conviene tener en cuenta el aspecto didáctico de forma que la sistematización utilizada sea la más beneficiosa para los aprendizajes de los alumnos.

En Santillana (1976), la demostración presenta un salto que no está justificado y que podría inducir a error a los alumnos. En el texto, el valor $\delta_{1}$ se determina en función de $\varepsilon$, y no de $\varepsilon / 2$. Este error se resolvería considerando $\varepsilon_{1}=\varepsilon / 2$ en lugar de $\varepsilon$, lo cual permitiría aplicar la definición correctamente.

Como $\lim _{x \rightarrow a} f(x)=L_{1}$, dado $\varepsilon>0$, existe $\delta_{1}>0$ tal que $0<|x-a|<\delta_{1} \Rightarrow \mid f(x)-$ $L 1 \mid<\frac{\varepsilon}{2}$ (Santillana, $2^{\circ}$ BUP, 1976, pp. 214).

\begin{tabular}{|l|l|l|}
\hline \multicolumn{2}{|l|}{ El límite de la suma de funciones es igual a la suma de los límites de dichas funciones. } \\
\hline \multicolumn{1}{|l|}{ Texto ( ${ }^{\circ}$ Bach.) } & Santillana (1997) \\
\hline Esquema de prueba & EP axiomático. \\
\hline \multirow{2}{*}{ Técnicas } & Tipo & $\begin{array}{l}\text { Está expresado en forma de igualdad. No se enuncian hipótesis sobre } \\
\text { las funciones. }\end{array}$ \\
\cline { 2 - 3 } & Método & Silogismo. \\
\cline { 2 - 3 } & Estilo & Análisis Matemático local \\
\cline { 2 - 3 } & Modo & Directo \\
\hline Funciones de la demostración & Verificación, comunicación. \\
\hline \multirow{2}{*}{$\begin{array}{l}\text { Reconocimiento } \\
\text { de procesos }\end{array}$} & RP & $\begin{array}{l}\text { Sí, indica que se demuestra en el apartado Ejercicios y problemas } \\
\text { resueltos. }\end{array}$ \\
\cline { 2 - 3 } & RC & No. \\
\hline \multirow{2}{*}{$\begin{array}{l}\text { Expresiones que } \\
\text { utiliza }\end{array}$} & Exp & $\begin{array}{l}\text { Representación simbólica en el enunciado, verbal y simbólica en la } \\
\text { demostración. }\end{array}$ \\
\cline { 2 - 3 } & Sig & No, habitual del tema. \\
\hline \multirow{2}{*}{$\begin{array}{l}\text { Consideraciones } \\
\text { globales }\end{array}$} & GP & Brevemente. Más que el proceso, explica el enunciado. \\
\cline { 2 - 3 } & CSi & No. \\
\cline { 2 - 3 } & DEJ & Tipográficamente, está en otro apartado. \\
\cline { 2 - 3 } & OV & No. \\
\hline
\end{tabular}

Tabla IV.6.3. Análisis de la justificación asociada al límite de la suma de funciones $\left(2^{\circ} \mathrm{de}\right.$ Bachillerato de Santillana, 1997).

El LT de Santillana (1991) realiza únicamente la demostración de la suma, pero indica el porqué de no realizar las demás:

Aunque con nuestros actuales conocimientos podríamos demostrar todas o casi todas, las anteriores propiedades, no es oportuno hacerlo, ya que, además de ocuparnos un tiempo del que no disponemos, ello encierra una dificultad excesiva y, por otra parte, no 
vendría a ayudarnos, ahora, a la comprensión de estas cuestiones. Ha parecido, pues, que lo aconsejable es pospones estas demostraciones para cuando se disponga de mayor familiaridad experiencia con los límites.

No obstante, la demostración de la primera de las propiedades es notablemente más asequible que las demás y, por ello, la consideramos aquí.

(Santillana, $2^{\circ}$ BUP, 1991, pp. 129)

En nuestra opinión, podría complementar los otros resultados con otro tipo de justificaciones no axiomáticas como pueden ser pruebas preformales o EP inductivos.

Por otra parte, en el periodo de LOGSE, únicamente justifica este resultado el libro de texto de Santillana (1997), como se refleja en la Tabla IV.6.3.

Finalmente, en el caso de la LOE, ninguno de los textos que presentan el resultado lo justifican, sino que se limitan a enunciar las operaciones para aplicarlas al cálculo de límites.

II. Si $\lim _{x \rightarrow a} f(x)=l$ y $\lim _{x \rightarrow a} g(x)=p$, entonces $\lim _{x \rightarrow a}(f \cdot p)(x)=l \cdot p$.

\section{Demostración:}

$$
\begin{aligned}
& f(x) \rightarrow l \Leftrightarrow f(x)-l \text { es infinitésimo en } a . \\
& g(x) \rightarrow p \Leftrightarrow g(x)-p \text { es infinitésimo en } a .
\end{aligned}
$$

También serán infinitésimos $\left\{\begin{array}{l}{[f(x)-l][g(x)-p] \text { producto de infinitésimos }} \\ {[f(x)-l] \cdot p\{\text { producto de un número }} \\ {[g(x)-p] \cdot l \text { por un infinitésimo. }}\end{array}\right.$

La diferencia $f(x) \cdot g(x)-l \cdot p$ la vamos a descomponer asi:

$$
\begin{aligned}
f(x) \cdot g(x)-l p & =f(x) \cdot g(x) f(x) \cdot p-g(x) \cdot l+l p+f(x) \cdot p+g(x) \cdot l-l p-l p \\
& =f(x)[g(x)-p]-l[g(x)-p]+p[f(x)-l]+l[g(x)-p]= \\
& =[f(x)-l] \cdot[g(x)-p]+p[f(x)-l]+l[g(x)-p] . \\
& \text { infinitésimore infinitésimo }
\end{aligned}
$$

$f(x) \cdot g(x)-l p$, suma de tres infinitésimos, es un infinitésimo.

Por tanto, $\lim _{x \rightarrow a}(f+g)(x)=l \cdot p$.

Figura IV.6.1. Justificación del producto de límites ( $2^{\circ}$ de BUP de Anaya, 1976).

Además, algunos de los textos ni siquiera presentan las operaciones con límites: Anaya (1987), de $2^{\circ}$ de BUP, los dos textos de COU, Anaya (1989) y SM (1980), tres textos de $1^{\circ}$ de Bachillerato de LOGSE, Anaya (2002), Santillana (1996), SM (1996), y dos libros de $1^{\circ}$ de Bachillerato de LOE, Anaya (2008), Santillana (2008).

En algunos textos se justifican también otras operaciones, sobre todo de los más antiguos, aunque son una minoría. Por ejemplo, en el LT de $2^{\circ}$ de BUP de Anaya 
(1976) se justifica también el límite del producto de funciones, con un EP axiomático, al igual que la suma, y cuya justificación tiene las mismas características que la de ésta última.

III. El limite del producto de dos funciones es igual al producto de los limites de dichas funciones.

$$
\lim _{x \rightarrow 1}[f(x) \cdot g(x)]=\lim _{x \rightarrow 1} f(x) \cdot \lim _{x \rightarrow 1} g(x)
$$

Sean las funciones $f(x)$ y $g(x)$ que tienen limites respectivos $L$ y $L^{\prime}$ en el punto $x=1$. Es decir, que:

$$
\begin{aligned}
& \lim _{\mathfrak{l} \rightarrow 1} f(x)=L \\
& \lim _{x \rightarrow 1} g(x)=L^{\prime}
\end{aligned}
$$

Scan M y M' dos números tales que:

$$
\mathrm{M}>|\mathrm{L}| \text { y } \mathrm{M}^{\prime}>|\mathrm{L}|
$$

Por definición de limite, para todos los valores de $\mathrm{x}$ de un cierto entorno de 1 de radio $\delta$, se verifica:

$$
\forall x \in(1-\delta, 1+\delta) \Rightarrow\left\{\begin{array}{l}
|\tilde{f}(\mathrm{x})-\mathrm{L}|<\frac{\delta}{2 \mathrm{M}^{\prime}} \\
|\operatorname{g}(\mathrm{x})-\mathrm{L}|<\frac{\varepsilon}{2 \mathrm{M}}
\end{array}\right.
$$

Con estas premisas vamos a probar que:

$$
\left.\lim _{x \rightarrow 1}[\pi x) \cdot g(x)\right]=L \cdot L
$$

En efecto, se tiene que:

$$
\begin{aligned}
\forall x & =(1-\delta, 1+\delta) \Rightarrow|f(x) \cdot g(x)-L \cdot L|= \\
& =\left|(f x) \cdot g(x)-L \cdot g(x)+L \cdot g(x)-L L^{\prime}\right|= \\
& =|g(x) \cdot[f(x)-L]+L \cdot[g(x)-L]|<M^{\prime} \cdot \frac{\varepsilon}{2 M}+M \cdot \frac{\varepsilon}{2 M}=\varepsilon
\end{aligned}
$$

Lucgo:

$$
\lim [f(x) \cdot g(x)]=L \cdot L^{\prime}=\lim _{t \rightarrow 1} f(x) \cdot \lim _{t \rightarrow 1} g(x)
$$

Figura IV.6.2. Justificación del producto de límites ( $2^{\circ}$ de BUP, SM, 1977).

Otro caso es el LT de $2^{\circ}$ de BUP de SM (1977), además de la suma, justifica mediante un EP transformacional los límites de la diferencia y el cociente de funciones, y mediante EP axiomático, el límite del producto de funciones y de una función por una constante (aunque este último caso podría considerarse como un caso particular de producto, tomando la constante como una función constante). En las Figuras IV.6.1 y IV.6.2 se muestran, a modo de ejemplo, las 
justificaciones del producto de límites en los LT de Anaya (1976) y SM (1977), ambos de $2^{\circ}$ de BUP.

\section{IV.7.RESULTADOS ASOCIADOS A FAMILIAS DE FUNCIONES E INDETERMINACIONES}

En este último epígrafe consideramos el análisis de aquellos resultados que no son necesariamente teoremas, pero que, dependiendo del libro, son tratados como tal y que se han derivado del estudio del cálculo de límites: son los resultados asociados a la resolución de indeterminaciones, como por ejemplo, el límite de las funciones racionales en el infinito, el límite de las funciones del tipo $f(x)^{g(x)}$ cuando $f(x) \rightarrow \infty$ y $g(x) \rightarrow 1$, el límite de funciones racionales en un punto cuando de anulan el numerador y el denominador, las equivalencias de infinitos e infinitésimos...

Este tipo de resultados no son generales en todos los libros, ya que una misma situación puede ser considerada a modo de técnica en un libro o bien como un teorema que requiere de una justificación. Por esta razón, únicamente mostramos el análisis de los resultados que son considerados como teoremas en algunos de los textos.

Es necesario señalar que, en realidad, no son propiamente teoremas y que su justificación se derivaría de la aplicación de las propiedades y las operaciones de los límites, y que cualquier consideración de un tipo de indeterminación debería considerarse como una técnica de cálculo de límites, entendiendo como técnica la aplicación compuesta de las propiedades y operaciones de límites a una función. No obstante, dado que algunos textos le dan el carácter de teorema antes mencionado, creemos que es necesario el análisis de estos procesos.

A continuación se describe el análisis realizado para los resultados de este tipo en los libros de texto analizados, organizado por resultados. De cada uno se indica que libros lo consideran como un resultado y lo justifican, y el análisis de dicha justificación. 


\section{IV.7.1. Límite del cociente de polinomios en un punto}

Un resultado bastante común es el límite del cociente de polinomios en un punto cuando se anulan numerador y denominador en dicho punto. Tiene más carácter de técnica que de resultado, pero algunos textos lo enuncian como teorema y lo justifican de forma general.

Por ejemplo, Anaya (1976), de $2^{\circ}$ de BUP, que lo justifica mediante EP inductivo de 1 caso, acaba estableciendo que la simplificación del polinomio se puede realizar siempre y que tras la última simplificación en la que el denominador no se anule en el punto $a$ (valor al que tiende la variable independiente, que llama punto en este LT), se podrá calcular el límite. Este resultado aparece ligado al cociente de funciones polinómicas, en el que la función del denominador no se anula. Por su parte, Anaya (1987), indica la utilidad de dividir "numerador y denominador" por Ruffini, pero no escribe la igualdad para el límite. No obstante, remarca el enunciado en negrita, tras haber mostrado el funcionamiento de la regla con un ejemplo, lo que puede inducir a pensar que se trata de un teorema. Además, como hemos mencionado, se precede de un ejemplo en el que se ilustra la regla, y a partir del cual se extiende para cualquier función de este tipo. En la Figura IV.7.1.1 se muestra el enunciado de esta regla.

Anota la siguiente regla, que es importantísima:

Si el límite cuando $x \rightarrow p$ del cociente de dos polinomios es

del tipo $\frac{\text { cero }}{\text { cero }}$ simplificaremos dividiendo numerador y de-

nominador por $\boldsymbol{x}-\boldsymbol{p}$. Para ello es muy útil la regla de Ruffini.

Figura IV.7.1.1. Enunciado de la regla para el cálculo de límites de cocientes de funciones polinómicas en valores en los que se anula el denominador ( $2^{\circ}$ de BUP de Anaya, 1987).

n Si tanto el numerador como el denominador se anulan, entonces la expresión puede simplificarse.

Si $P(c)=0, Q(c)=0$, entonces el cociente puede simplificarse dividiendo numerador y denominador por $(x-c)$ :

$$
\begin{aligned}
& P(x)=(x-c) \cdot P_{1}(x) \quad Q(x)=(x-c) \cdot Q_{1}(x) \\
& \lim _{x \rightarrow c} \frac{P(x)}{Q(x)}=\lim _{x \rightarrow c} \frac{(x-c) \cdot P_{1}(x)}{(x-c) \cdot Q_{1}(x)}=\lim _{x \rightarrow c} \frac{P_{1}(x)}{Q_{1}(x)}
\end{aligned}
$$

Para hallar este nuevo límite, analizaremos en cuál de los tres casos se encuentra.

Figura IV.7.1.2. Límite del cociente de polinomios en un punto en el que se anulan ambos polinomios ( $1^{\circ}$ de Bachillerato de Anaya, 2002). 
En el texto de $1^{\circ}$ de Bachillerato de Anaya (2002) encontramos el resultado que forma parte del estudio del límite de funciones racionales, y en el que se discuten los tres casos posibles. La igualdad no se establece en el enunciado verbal, sino en el simbólico, y además, dentro de la justificación, tal y como se aprecia en la Figura IV.7.1.2.

En el LT de Vicens-Vives (1999), de $2^{\text {o }}$ de Bachillerato, el enunciado y la justificación también aparecen mezclados, como se aprecia en la Figura IV.7.1.2. Da la impresión de que el LT pretende realizar una construcción del enunciado a medida que lo justifica, pero esta forma de exposición puede confundir a aquellos alumnos que tengan dificultades para distinguir entre enunciado y justificación.

\subsection{Cociente de polinomios}

Veamos el caso en que tanto el numerador como el denominador de un cociente de polinomios se anulan para $\mathrm{x}=\mathrm{a}$.

$$
f(x)=P(x) / Q(x) \text { y } P(a)=Q(a)=0
$$

Es claro que a no pertenece a Dom $f \quad i \lim _{x \rightarrow a} f(x)$ ?

En este caso $\mathrm{P}(\mathrm{x})$ y $\mathrm{Q}(\mathrm{x})$ son divisibles por $(\mathrm{x}-\mathrm{a})$, lo cual permite su factorización mediante la división por $(\mathrm{x}-\mathrm{a})$.

$$
P(x)=(x-a) P_{1}(x) \quad Q(x)=(x-a) Q_{1}(x) \quad \frac{P(x)}{Q(x)}=\frac{(x-a) P_{1}(x)}{(x-a) Q_{1}(x)}=\frac{P_{1}(x)}{Q_{1}(x)}
$$

Se tiene $f(x)=P_{1}(x) / Q_{1}(x)$, salvo quizá para $x=a$, pues $f(a)$ no existe. Pero como sólo interesa el valor de $\mathrm{f}(\mathrm{x})$ en las proximidades de a:

$$
\lim _{x \rightarrow a} f(x)=\lim _{x \rightarrow a} \frac{P_{1}(x)}{Q_{1}(x)}
$$

Si de nuevo se tiene $P_{1}(a)=Q_{1}(a)=0$, se simplifica otra vez. Pronto llegaremos a una situación que sabemos resolver:

- a no es raíz del denominador. Basta sustituir $x$ por a y calcular.

- a es raíz del denominador pero no del numerador. El límte es infinito con un signo que se debe determinar.

Cuando numerador y denominador se anulan para $\mathrm{x}=0$, la factorización se consigue sacando factor común.

Figura IV.7.1.3. Límite del cociente de polinomios en un punto en el que se anulan ambos polinomios ( $2^{\circ}$ de Bachillerato de Vicens-Vives, 1999).

A continuación, en las Tablas IV.7.1.1 y IV.7.1.2 se muestra el análisis de este resultado de los LT que lo justifican, que pertenecen todos a la LGE y a la LOGSE, y los comentarios relacionados con dichas tablas.

Los EP utilizados en los LT que justifican de LGE son EP inductivos de 1 caso (Anaya, 1976 y 1987) o EP transformacionales (Santillana, 1976 y 1991). En el 
caso de los EP inductivos la mayoría de las características coinciden para ambos: son de estilo algebraico, se refleja únicamente la función de comunicación,... En el caso de los dos EP transformacionales se observan algunas diferencias: en el enunciado, en el estilo (AM local frente a algebraico), en la referencia a las consecuencias del resultado, pero coinciden en otros aspectos, como las funciones de la demostración (comunicación y verificación), en no mostrar globalmente el proceso, los sistemas de representación...

\begin{tabular}{|c|c|c|c|c|c|}
\hline \multicolumn{6}{|c|}{ Límite del cociente de polinomios en un punto en el que se anulan ambos polinomios } \\
\hline \multicolumn{2}{|c|}{ Textos $\left(2^{\circ} \mathrm{BUP}\right)$} & Anaya (1976) & Anaya (1987) & Sant. (1976) & Sant. (1991) \\
\hline \multicolumn{2}{|c|}{ Esquema de prueba } & $\begin{array}{l}\text { EP inductivo de } 1 \\
\text { caso }\end{array}$ & $\begin{array}{l}\text { EP inductivo } 1 \\
\text { caso }\end{array}$ & EP transformacional & EP transformacional \\
\hline \multirow[t]{4}{*}{ Técnicas } & Tipo & $\begin{array}{l}\text { No corresponde. } \\
\text { Se trata como } \\
\text { técnica }\end{array}$ & $\begin{array}{l}\text { Enuncia al final } \\
\text { como regla. }\end{array}$ & CS. & $\begin{array}{l}\text { CS. Justificación } \\
\text { implícita en el } \\
\text { enunciado }\end{array}$ \\
\hline & Método & - & & Silogismo & Silogismo \\
\hline & Estilo & Algebraico & Algebraico & AM local & Algebraico \\
\hline & Modo & - & - & Analítico & Analítico \\
\hline \multicolumn{2}{|c|}{$\begin{array}{l}\text { Funciones de la } \\
\text { demostración }\end{array}$} & Comunicación & Comunicación & $\begin{array}{l}\text { Comunicación, } \\
\text { explicación }\end{array}$ & $\begin{array}{l}\text { Comunicación, } \\
\text { explicación }\end{array}$ \\
\hline \multirow[t]{2}{*}{\begin{tabular}{|l} 
Reconoc \\
imiento \\
de \\
procesos
\end{tabular}} & RP & - & - & $\begin{array}{l}\text { Parcialmente. } \\
\text { Justificación previa } \\
\text { mediante un caso } \\
\text { concreto. }\end{array}$ & No \\
\hline & $\mathrm{RC}$ & - & $\begin{array}{l}\text { El propio } \\
\text { resultado }\end{array}$ & No & No \\
\hline \multirow{2}{*}{$\begin{array}{l}\text { Expresio } \\
\text { nes que } \\
\text { utiliza }\end{array}$} & Exp & $\begin{array}{l}\text { SR: verbal y } \\
\text { fórmula }\end{array}$ & $\begin{array}{l}\text { SR: verbal y } \\
\text { fórmula }\end{array}$ & SR: verbal y fórmula & SR: verbal y fórmula \\
\hline & Sig & $\begin{array}{l}\text { No, habitual en el } \\
\text { tema }\end{array}$ & $\begin{array}{l}\text { No, habituales en } \\
\text { el tema }\end{array}$ & $\begin{array}{l}\text { No, habituales en el } \\
\text { tema }\end{array}$ & $\begin{array}{l}\text { No, habituales en el } \\
\text { tema }\end{array}$ \\
\hline \multirow{4}{*}{\begin{tabular}{|l} 
Consider \\
aciones \\
globales
\end{tabular}} & GP & No & No & No & No \\
\hline & $\mathrm{CSi}$ & No & No & No & $\begin{array}{l}\text { Aplicación al cálculo } \\
\text { (ejemplos en los que } \\
\text { repite la } \\
\text { justificación) }\end{array}$ \\
\hline & DEJ & - & Tipográficamente & Tipográficamente & No \\
\hline & $\mathrm{OV}$ & No & No & $\begin{array}{l}\text { Sí, indica que lo ha } \\
\text { justificado } \\
\text { previamente. }\end{array}$ & No \\
\hline
\end{tabular}

Tabla IV.7.1.1. Análisis de la justificación asociada al límite del cociente de polinomios en un punto en el que ambos se anulan en los LT de $2^{\circ}$ de BUP de las editoriales Anaya y Santillana.

En el periodo de LOGSE sólo encontramos dos LT que justifiquen este resultado, Anaya (2002) y Vicens-Vives (1999), de $1^{\circ}$ y $2^{\circ}$ de Bachillerato respectivamente, y en ambos casos se utiliza un EP transformacional. En general, todos los 
aspectos del análisis coinciden excepto los relativos a las técnicas utilizadas: el tipo de enunciado es diferente; en cuanto al estilo, Anaya sólo utiliza el algebraico y Vicens-Vives también utiliza el estilo del Análisis Matemático local. El método es directo en Anaya y analítico en Vicens-Vives.

\begin{tabular}{|c|c|c|c|}
\hline \multicolumn{4}{|c|}{ Límite del cociente de polinomios en un punto en el que se anulan ambos polinomios } \\
\hline \multicolumn{2}{|l|}{ Texto } & Anaya $1^{\circ}(\mathbf{2 0 0 2})$ & Vicens-Vives $2^{\circ}$ (1999) \\
\hline \multicolumn{2}{|l|}{ Esquema de prueba } & EP transformacional & EP transformacional \\
\hline \multirow[t]{4}{*}{ Técnicas } & Tipo & $\begin{array}{l}\text { CS (justificación en el propio } \\
\text { enunciado) }\end{array}$ & $\begin{array}{l}\text { No hay enunciado claro, se concluye la } \\
\text { expresión simbólica al final }\end{array}$ \\
\hline & Método & Silogismo & Silogismo \\
\hline & Estilo & Algebraico & Algebraico, AM local \\
\hline & Modo & Directo & Analítico \\
\hline \multicolumn{2}{|l|}{$\begin{array}{l}\text { Funciones } \\
\text { demostración }\end{array}$} & \begin{tabular}{|l|}
$\begin{array}{l}\text { Comunicación, verificación, } \\
\text { explicación }\end{array}$ \\
\end{tabular} & $\begin{array}{l}\text { Comunicación, } \\
\text { verificación }\end{array}$ \\
\hline \multirow{2}{*}{$\begin{array}{l}\text { Reconocimiento } \\
\text { de procesos }\end{array}$} & RP & No & No \\
\hline & RC & No & No \\
\hline \multirow{2}{*}{$\begin{array}{l}\text { Expresiones que } \\
\text { utiliza }\end{array}$} & Exp & SR: verbal y fórmula & SR: verbal y fórmula \\
\hline & Sig & No, habituales en el tema & No, habituales en el tema. \\
\hline \multirow{4}{*}{$\begin{array}{l}\text { Consideraciones } \\
\text { globales }\end{array}$} & GP & No & No \\
\hline & $\mathrm{CSi}$ & No & No \\
\hline & DEJ & No & No \\
\hline & OV & No & No \\
\hline
\end{tabular}

Tabla IV.7.1.2. Análisis de la justificación asociada al límite del cociente de polinomios en un punto en el que ambos se anulan en dos LT de LOGSE de las editoriales Anaya y Vicens-Vives.

En el periodo de LOE únicamente se justifica en el LT de Anaya (2008) de $1^{\circ}$ de Bachillerato, ya que al ser igual que su homólogo de la legislación anterior, se mantienen resultados y justificaciones y, por tanto, el análisis es el descrito para el Anaya (2002).

\section{IV.7.2. Límite del cociente de polinomios en el infinito}

El tratamiento en este apartado es similar al del anterior, pero en el infinito se pueden considerar más casos y, por lo tanto, se presta más a la justificación. Si bien puede deducirse de la aplicación de las operaciones de límites, muchos libros lo presentan como si de un teorema se tratara. Este tratamiento se observa sobre todo en las legislaciones más modernas, que, junto con el hecho de que se justifica en mayor medida, apunta a que la tendencia de los LT ha sido no sólo 
reducir las demostraciones formales que se presentan, sino disminuir el número de teoremas que se enuncian y tratar a las técnicas de cálculo de límites como teoremas. Este hecho contribuye a afianzar nuestra idea de la progresiva tendencia a la mecanización del cálculo de límites.

Por ejemplo, el LT de $2^{\circ}$ de Bachillerato de SM (2010) lo enuncia y justifica de la siguiente manera:

Cocientes y raices de polinomios en el infinito. Indeterminación $\frac{\infty}{\infty}$ Para deshacer la indeterminación $\frac{\infty}{\infty}$, se puede dividir numerador y denominador por la potencia máxima de $x$ que aparece en la fracción. El cálculo del límite puede realizarse más rápidamente considerando solo los términos de mayor grado del numerador y del denominador.

Ejemplo. Calcula los siguientes limites:

$$
\begin{aligned}
& \begin{array}{l}
\text { a) } I=\lim _{x \rightarrow+\infty} \frac{4 x^{3}-3 x^{2}}{-2 x^{3}-x+5}=\left(\frac{+\infty}{-\infty}\right) \Rightarrow I=\lim _{x \rightarrow+\infty} \frac{\frac{4 x^{3}}{x^{3}}-\frac{3 x^{2}}{x^{3}}}{-\frac{2 x^{3}}{x^{3}}-\frac{x}{x^{3}}+\frac{5}{x^{3}}}= \\
\quad=\lim _{x \rightarrow+\infty} \frac{4-\frac{3}{x}}{-2-\frac{1}{x^{2}}+\frac{5}{x^{3}}}=\frac{4-0}{-2-0+0}=-2
\end{array} \\
& \text { b) I }=\lim _{x \rightarrow-\infty} \frac{-x^{3}-2 x-1}{x^{2}-4 x+1}=\lim _{x \rightarrow-\infty} \frac{-x^{3}}{x^{2}}=\lim _{x \rightarrow-\infty}(-x)=\lim _{x \rightarrow+\infty} x=+\infty \\
& \text { Dados } \operatorname{los} \text { polinomios } P(x)=a_{p} x^{p}+a_{p-1} x^{p-1}+\ldots+a_{0} y Q(x)=b_{q} x^{q}+b_{q-1} x^{q-1}+ \\
& +\ldots+b_{0} \text { se puede demostrar que: } \\
& \text { - Si } p<q \Rightarrow \lim _{x \rightarrow+\infty} \frac{P(x)}{Q(x)}=0 \\
& \text { - Si } p=q \Rightarrow \lim _{x \rightarrow+\infty} \frac{P(x)}{Q(x)}=\frac{a_{p}}{b_{q}} \\
& \text { - Si } p>q \Rightarrow \lim _{x \rightarrow+\infty} \frac{P(x)}{Q(x)}= \pm \infty \text {, según los signos de } a_{p} \text { y } b_{p} .
\end{aligned}
$$

Figura IV.7.2.1. Justificación (prueba preformal) y enunciado del límite de funciones racionales ( $2^{\circ}$ de Bachillerato de $\left.\mathrm{SM}, 2010\right)$.

El enunciado se presenta después de la justificación (prueba preformal en este caso) en la cual se reflejan las líneas generales de la justificación para el caso general. Esta justificación, expresada en un sistema de representación algebraico, contribuye a la tendencia calculista de los libros más modernos, frente a la comprensión del concepto. A continuación se muestran las tablas en las que se recoge el análisis de este resultado en los diversos libros de la muestra. Llama la atención, frente a otros teoremas, que el mayor número de justificaciones en este 
caso se encuentra en el periodo LOE, aunque estas sean EP inductivos de un caso en su mayoría.

\begin{tabular}{|l|l|l|}
\hline \multicolumn{2}{|l|}{ Límite del cociente de polinomios en el infinito } \\
\hline \multicolumn{2}{|l|}{ Textos ( $2^{\circ}$ BUP) } & Santillana (1976) \\
\hline Esquema de prueba & $\begin{array}{l}\text { EP axiomático en grados iguales. EP0 en los otros. Tiene también una } \\
\text { componente transformacional. }\end{array}$ \\
\hline \multirow{4}{*}{ Técnicas } & Tipo & $\begin{array}{l}\text { (Tres enunciados, en función de los grados) No siguen ninguna estructura } \\
\text { establecida: el límite [...] es }\end{array}$ \\
\cline { 2 - 3 } & Método & Silogismo \\
\cline { 2 - 3 } & Estilo & Algebraico, AM global \\
\cline { 2 - 3 } & Modo & Analítico \\
\hline \multirow{2}{*}{$\begin{array}{l}\text { Funciones } \\
\text { demostración }\end{array}$} & de la & Comunicación, verificación \\
\hline $\begin{array}{l}\text { Reconocimiento } \\
\text { de procesos }\end{array}$ & RP & Sí, lo etiqueta como teorema. \\
\cline { 2 - 3 } & RC & No \\
\hline $\begin{array}{l}\text { Expresiones que } \\
\text { utiliza }\end{array}$ & Exp & SR: verbal, fórmula \\
\cline { 2 - 3 } & Sig & No, habituales en el tema \\
\hline $\begin{array}{l}\text { Consideraciones } \\
\text { globales }\end{array}$ & GP & No \\
\cline { 2 - 3 } & CSi & No \\
\cline { 2 - 3 } & DEJ & Ś́, etiqueta el enunciado y la justificación \\
\cline { 2 - 3 } & OV & No \\
\hline
\end{tabular}

Tabla IV.7.2.1. Análisis de la justificación asociada al límite del cociente de polinomios en el infinito en el período de la LGE ( $2^{\circ}$ de BUP de Santillana, 1976).

Como se muestra en la Tabla IV.7.2.1, sólo uno de los LT de la LGE justifica este enunciado. En general, los LT de esta época no suelen considerar las técnicas de cálculo de límites y de resolución de indeterminaciones como resultados en sí y, por tanto, no los justifican, sino que muestran cómo se aplican. Como ya hemos mencionado, el hecho de considerarlos como teoremas aumenta con el paso del tiempo, y vemos que, a diferencia de otros resultados, las justificaciones en este caso aumentan con el tiempo (Tablas IV.7.2.2 y IV.7.2.3).

En el periodo LOGSE hemos encontrado justificaciones diferentes en el texto de Anaya y en los dos de Vicens-Vives. En cada libro que se consideran esquemas de prueba diferentes: un EP inductivo (Anaya), una prueba preformal (VicensVives, 1998) y un EP axiomático-transformacional (Vicens-Vives, 1999). En general, los tres libros coinciden en casi todos los aspectos que analizamos, mostrando algunas diferencias por el tipo de justificación (método, estilo y modo), en las funciones de la demostración (aparte de las funciones de comunicación y verificación en los tres textos, se observa la función de 
explicación en el LT de Vicens-Vives, 1998) y este LT es el único que realiza algún apunte sobre el proceso global de la justificación.

\begin{tabular}{|c|c|c|c|c|}
\hline \multicolumn{5}{|c|}{ Límite del cociente de polinomios en el infinito } \\
\hline \multicolumn{2}{|l|}{ Texto } & Anaya $2^{\circ}(\mathbf{2 0 0 3 )}$ & Vicens-Vives $1^{\circ}$ (1998) & Vicens-Vives $2^{\circ}$ (1999) \\
\hline \multicolumn{2}{|c|}{ Esquema de prueba } & $\begin{array}{l}\text { EP inductivo de } 1 \text { caso } \\
\text { (sólo de un caso) }\end{array}$ & Prueba preformal & $\begin{array}{l}\text { EP axiomático (También } \\
\text { carácter transformacional) }\end{array}$ \\
\hline \multirow[t]{4}{*}{ Técnicas } & Tipo & CS incompleta & $\begin{array}{l}\text { CS incompleta ("si" al } \\
\text { final) }\end{array}$ & CS incompleta ("si" al final) \\
\hline & Método & - & Silogismo & Silogismo \\
\hline & Estilo & Algebraico & Algebraico, AM local & Algebraico, AM global \\
\hline & Modo & - & Analítico & Analítico \\
\hline \multicolumn{2}{|c|}{$\begin{array}{l}\text { Funciones de la } \\
\text { demostración }\end{array}$} & $\begin{array}{l}\text { Comunicación, } \\
\text { verificación }\end{array}$ & \begin{tabular}{|l} 
Comunicación, \\
verificación, explicación
\end{tabular} & Comunicación, verificación \\
\hline \multirow{2}{*}{$\begin{array}{l}\text { Reconoci } \\
\text { miento } \\
\text { de } \\
\text { procesos } \\
\end{array}$} & RP & No & Sí, lo indica & $\begin{array}{l}\text { Si, indica que hace una } \\
\text { demostración formal }\end{array}$ \\
\hline & $\mathrm{RC}$ & No & No & No \\
\hline \multirow{2}{*}{$\begin{array}{l}\text { Expresio } \\
\text { nes que } \\
\text { utiliza }\end{array}$} & Exp & SR: verbal y fórmula & SR: verbal y fórmula & SR: verbal y fórmula \\
\hline & Sig & $\begin{array}{l}\text { No, habituales en el } \\
\text { tema }\end{array}$ & No, habituales en el tema & No, habituales en el tema \\
\hline \multirow{4}{*}{$\begin{array}{l}\text { Consider } \\
\text { aciones } \\
\text { globales }\end{array}$} & GP & - & $\begin{array}{l}\text { Explica el primer paso, } \\
\text { pero no todo el proceso }\end{array}$ & No \\
\hline & $\mathrm{CSi}$ & - & No & No \\
\hline & DEJ & No & \begin{tabular}{|l|} 
No, salvo indicarlo en otro \\
párrafo
\end{tabular} & $\begin{array}{l}\text { No, justificación inmersa en } \\
\text { el resultado }\end{array}$ \\
\hline & $\mathrm{OV}$ & No & No & No \\
\hline
\end{tabular}

Tabla IV.7.2.2. Análisis de la justificación asociada al límite del cociente de polinomios en el infinito en LT del periodo LOGSE de las editoriales Anaya y Vicens-Vives.

Vemos que las justificaciones utilizadas en este resultado son variadas, y encontramos diversos tipos de ellas: EP inductivos, transformacionales y pruebas preformales. También se aprecian diferencias tanto en el tipo de enunciados como en las funciones que se reflejan en la demostración, aunque la que más predomina es la de comunicación. No obstante, otros aspectos como el reconocimiento de procesos, los sistemas de representación y las consideraciones generales son comunes en todos los LT.

En las justificaciones de este resultado observamos un comportamiento diferente a la evolución observada en la presencia de justificaciones en los LT, dado que, en este caso, el número de justificaciones aumenta en el periodo LOE. Esto refuerza nuestra hipótesis de que los LT tienden a perder el interés en la profundización del concepto de límite, aumentando en las técnicas de cálculo. Este resultado se trata de un resultado asociado a la resolución de 
indeterminaciones, y su resolución se basa en un estudio cuidadoso del comportamiento de las funciones y de la aplicación de las propiedades de los límites, más que de una propiedad absoluta.

\begin{tabular}{|c|c|c|c|c|c|c|}
\hline \multicolumn{7}{|c|}{ Límite del cociente de polinomios en el infinito } \\
\hline \multicolumn{2}{|l|}{ Textos } & $\begin{array}{l}\text { Ana. } \\
(2009)\end{array}$ & \begin{tabular}{l|l}
$2^{\circ}$ & $\begin{array}{l}\text { Sant. } \\
(2009)\end{array}$
\end{tabular} & SM 20 (2010) & VV $1^{\circ}$ (2008) & VV 20 (2009) \\
\hline \multicolumn{2}{|c|}{ Esquema de prueba } & $\begin{array}{l}\text { EP inductive } \\
\text { de } 1 \text { caso (sólc } \\
\text { de un caso) }\end{array}$ & \begin{tabular}{l|l|}
$\mathrm{O}$ & EP \\
lo & transformacional \\
(con carácter \\
axiomático)
\end{tabular} & $\begin{array}{l}\text { Prueba } \\
\text { preformal }\end{array}$ & $\begin{array}{l}\text { EP inductivo } \\
\text { de } 1 \text { caso }\end{array}$ & $\begin{array}{l}\text { EP inductivo de } \\
1 \text { caso (igual que } \\
\text { en el curso } \\
\text { anterior) }\end{array}$ \\
\hline \multirow[t]{4}{*}{ Técnicas } & Tipo & CS incompleta & a $\begin{array}{l}\text { CS incompleta } \\
\text { ("si" al final) }\end{array}$ & CS & $\begin{array}{l}\text { Enuncia como } \\
\text { regla }\end{array}$ & $\begin{array}{l}\text { Enuncia como } \\
\text { regla }\end{array}$ \\
\hline & Método & - & Silogismo & Silogismo & - & - \\
\hline & Estilo & Algebraico & $\begin{array}{l}\text { Algebraico, AM } \\
\text { local }\end{array}$ & Algebraico & Algebraico & Algebraico \\
\hline & Modo & - & Analítico & Directo & - & - \\
\hline \multicolumn{2}{|c|}{$\begin{array}{l}\text { Funciones de } \\
\text { demostración }\end{array}$} & Comunicación & $\begin{array}{l}\text { nomunicación, } \\
\text { verificación }\end{array}$ & $\begin{array}{l}\text { Comunicación, } \\
\text { verificación, } \\
\text { explicación }\end{array}$ & Comunicación & Comunicación \\
\hline \multirow{2}{*}{$\begin{array}{l}\text { Reconoci } \\
\text { miento de } \\
\text { procesos }\end{array}$} & $\mathrm{RP}$ & No & $\begin{array}{l}\text { No, lo llama } \\
\text { "calcular" }\end{array}$ & $\begin{array}{l}\text { No. "Se puede } \\
\text { demostrar" }\end{array}$ & No & No \\
\hline & $\mathrm{RC}$ & No & No & No & No & No \\
\hline \multirow{2}{*}{$\begin{array}{l}\text { Expresion } \\
\text { es que } \\
\text { utiliza }\end{array}$} & Exp & $\begin{array}{l}\text { SR: verbal y } \\
\text { fórmula }\end{array}$ & 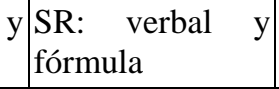 & $\begin{array}{l}\text { SR: verbal } \\
\text { fórmula }\end{array}$ & $\begin{array}{l}\text { SR: verbal y } \\
\text { fórmula }\end{array}$ & $\begin{array}{l}\text { SR: verbal y } \\
\text { fórmula }\end{array}$ \\
\hline & Sig & $\begin{array}{l}\text { No, habituale } \\
\text { en el tema }\end{array}$ & $\begin{array}{l}\text { es } \\
\text { en el tema }\end{array}$ & $\begin{array}{l}\text { No, habituales } \\
\text { en el tema }\end{array}$ & $\begin{array}{l}\text { No, habituales } \\
\text { en el tema }\end{array}$ & $\begin{array}{l}\text { No, habituales } \\
\text { en el tema }\end{array}$ \\
\hline \multirow{4}{*}{$\begin{array}{l}\text { Considera } \\
\text { ciones } \\
\text { globales }\end{array}$} & GP & - & $\begin{array}{l}\text { Indica el inicio, } \\
\text { pero no el final }\end{array}$ & No & No & No \\
\hline & $\mathrm{CSi}$ & - & No & No & - & - \\
\hline & DEJ & No & $\begin{array}{l}\text { Inmerso en el } \\
\text { enunciado }\end{array}$ & $\begin{array}{l}\text { Tipográficament } \\
\text { e }\end{array}$ & No & No \\
\hline & OV & No & No & No & No & No \\
\hline
\end{tabular}

Tabla IV.7.2.3. Análisis de la justificación asociada al límite del cociente de polinomios en el infinito ( $2^{\circ}$ de BUP de Santillana, 1976).

\section{IV.7.3. Límite de las funciones de tipo potencial-exponencial que conducen a la indeterminación $\rightarrow 1^{\rightarrow \infty}$}

Los resultados que englobamos en este apartado, si están asociados a indeterminaciones, están todos ligados a un resultado que, generalmente, los LT ya han presentado en el capítulo de sucesiones. Se trata del límite de la sucesión

$$
\left(1+\frac{1}{n}\right)^{n}
$$


cuando $n$ tiende a infinito y cuyo valor es el número $e$. El límite de esta sucesión se extiende a funciones, considerando en primer lugar la función

$$
f(x)=\left(1+\frac{1}{x}\right)^{x}
$$

cuyo límite cuando $x$ tiende a infinito es el número $e$, pero puede ampliarse a funciones del tipo

$$
\left(1+\frac{1}{f(x)}\right)^{f(x)}
$$

donde el límite de dicha función también es $e$, si $f(x)$ tiende a infinito, o bien,

$$
(1+f(x))^{1 / f(x)}
$$

si $f(x)$ tiende a cero. En última instancia queda considerar el caso más general, que permite resolver cualquier indeterminación del tipo $\rightarrow 1 \rightarrow \infty$, que son las funciones del tipo $f(x)^{g(x)}$ cuando $f(x) \rightarrow 1$ y $g(x) \rightarrow \infty$, y que se resuelve sustituyendo en una fórmula que se obtiene tras la transformación de la función en una de las anteriores.

No todos los LT presentan estos resultados, y mucho menos los justifican. Algunos se limitan a incluirlo como nota al margen, dado que si la única intención del LT es mecanizar el cálculo de límites, basta con dar la fórmula y las instrucciones para aplicarla, sin necesidad de la justificación. En la Tabla IV.7.3.1 se recogen los LT que presentan este tipo de reglas, y cuáles de ellas consideran.

A continuación describimos el comportamiento de los LT que justifican alguno de estos límites. Anaya (1989), de COU, considera el caso más general $\left(f(x)^{g(x)}\right.$ cuando $f(x) \rightarrow 1$ y $g(x) \rightarrow \infty$ ), para sucesiones, en lugar de funciones, y lo justifica mediante un EP transformacional, aunque también se enuncia para funciones y remite a la demostración del caso de sucesiones. Parte de un recordatorio del límite de la sucesión $(1+1 / n)^{n}$, cuando $n \rightarrow \infty$, y, a partir de éste, mediante transformaciones algebraicas, obtiene otros resultados sencillos: los límites, cuando $n \rightarrow \infty$, de $(1+k / n)^{n}$, donde $k$ es un número real, y de $(1-1 / n)^{n}$. Acaba estableciendo el resultado general, que justifica en el margen con un EP transformacional, como ya hemos mencionado. Se realiza una inducción del caso de sucesiones al de funciones. 


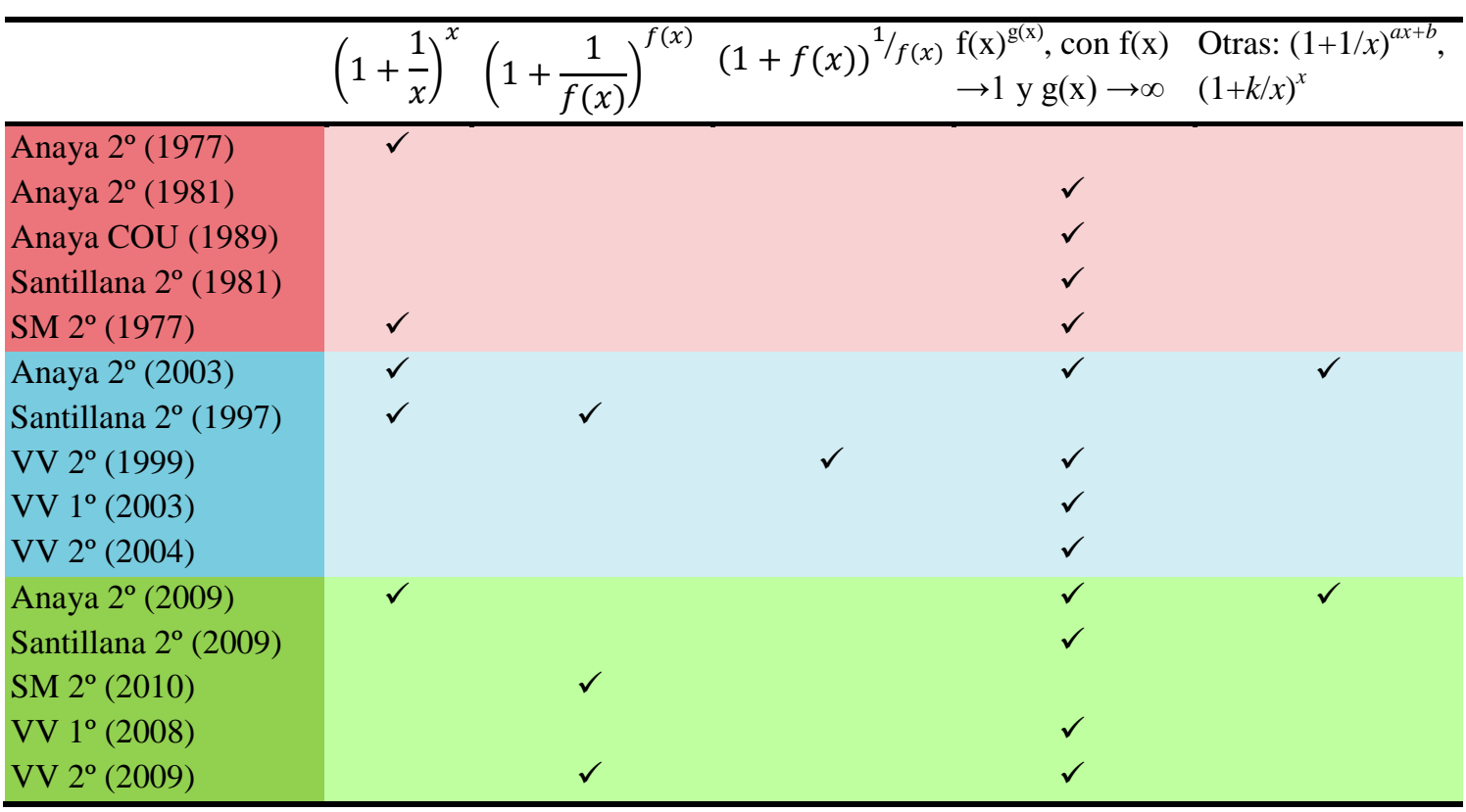

Tabla IV.7.3.1. Presencia de las funciones potenciales-exponenciales en los libros de texto.

Los LT de $2^{\circ}$ de Bachillerato de Anaya (2003 y 2009, recordemos que son muy similares) enuncian una serie de casos particulares $\left((1+1 / x)^{x}, \quad(1-1 / x)^{x}\right.$, $(1+1 / 2 x)^{2 x},(1+1 / x)^{a x},(1-1 / x)^{a x},(1+1 / x)^{a x+b}$ y $(1+k / x)^{x}$, utilizando pequeños EP transformacionales en algunos casos, de forma simbólica) para finalizar estableciendo el resultado más general $\left(f(x)^{g(x)}\right.$ cuando $f(x) \rightarrow 1$ y $\left.g(x) \rightarrow \infty\right)$, que justifica mediante un EP transformacional, y al que llama "regla práctica". Esta discusión la realiza para límites en el infinito, aunque vuelve a enunciar esta regla general para límites en un punto, aunque en este caso ya no realiza ninguna justificación. Sin embargo, en el ejemplo de aplicación de este último caso compara entre aplicar directamente la regla para calcular el límite, o hacerlo "razonadamente", en el que se realizan los pasos de la justificación con el caso concreto propuesto. No obstante, no menciona que se trate de una justificación, ni que su fin sea establecer el enunciado general, sino que se limita a comparar los dos métodos para calcular este tipo de límites. La justificación del límite en el infinito la etiqueta como demostración y, si bien la hemos clasificado como transformacional, estos LT justifican cada una de las transformaciones realizadas, por lo que también tiene un cierto carácter axiomático. Además, algunos de estos pasos explican el proceso que se sigue para realizar la justificación. Hay que señalar una diferencia entre ambos textos y es la importancia que parece dar a la demostración el texto de LOE (Anaya 2009), ya que aparece en un recuadro de otro color, con el título general de "estilo matemático" y como subtítulo, 
“demostración". Parece ser una forma de incidir en el proceso matemático de la demostración. Mostramos el proceso en la Figura IV.7.3.1.

\section{$\checkmark$ ESTILO MATEMÁTICO. Demostración}

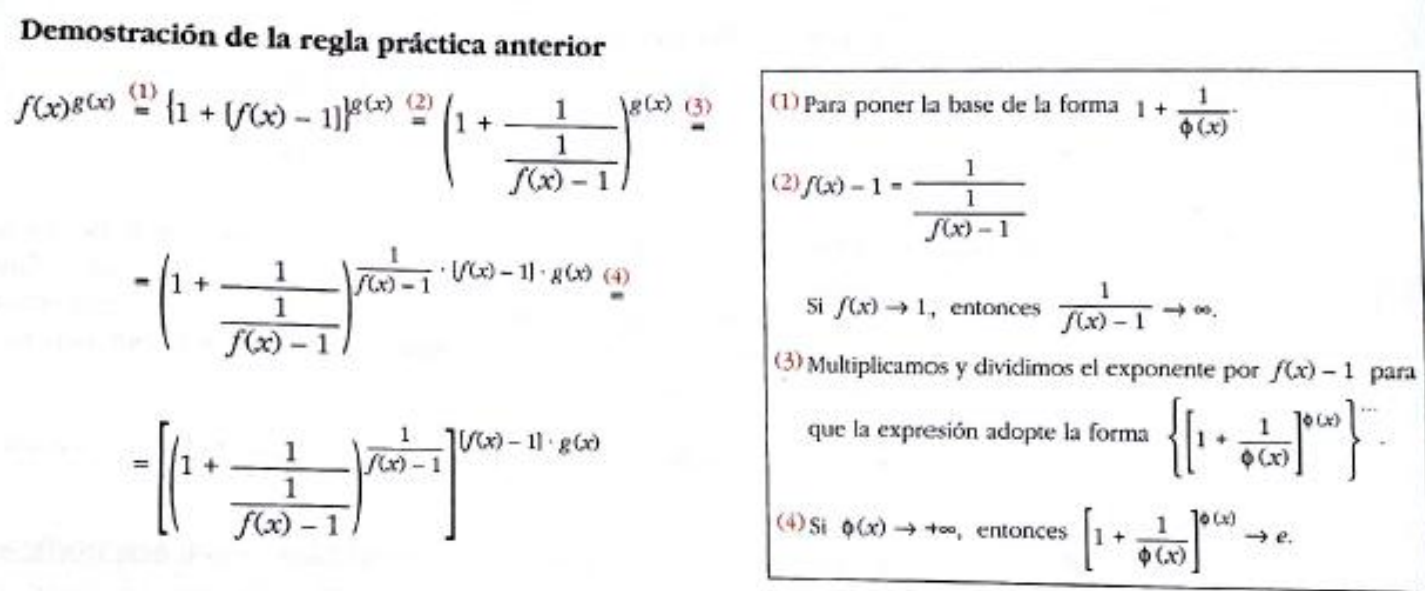

Resolvemos, de nuevo, el ejercicio resuelto de arriba, pero ahora damos todos los pasos:

$$
\begin{aligned}
\left(\frac{x^{2}+x-1}{x^{2}+2}\right)^{3 x-1} & =\left(1+\frac{x-3}{x^{2}+2}\right)^{3 x-1}=\left(1+\frac{1}{\left(x^{2}+2\right) /(x-3)}\right)^{3 x-1}= \\
& =\left(1+\frac{1}{\left(x^{2}+2\right) /(x-3)}\right)^{\frac{x^{2}+2}{x-3} \cdot \frac{x-3}{x^{2}+2} \cdot(3 x-1)}= \\
& =\left[\left(1+\frac{1}{\left(x^{2}+2\right) /(x-3)}\right)^{\frac{x^{2}+2}{x-3}}\right]^{\frac{x-3}{x^{2}+2} \cdot(3 x-1)} \underset{x \rightarrow+\infty}{\underset{\longrightarrow}{3}} e^{3}
\end{aligned}
$$

- Resuelve uno de los ejercicios propuestos arriba, dando ahora todos los pasos.

Figura IV.7.3.1. Justificación de la regla para el cálculo de límites de la forma $f(x)^{g(x)}$ cuando $f(x) \rightarrow 1$ y $g(x) \rightarrow \infty$ ( $2^{\circ}$ de Bachillerato de Anaya, 2009).

El LT de SM (1977), de $2^{\circ}$ de BUP, justifica el límite de la función $(1+1 / x)^{x}$, pero no el de la función general $f(x)^{g(x)}$ cuando $f(x)$ tiende a 1 y $g(x)$ tiende a infinito. De hecho, en este último caso, el LT se limita a indicar que la expresión se reduce a calcular límites que dependen del número $e$ y muestra un ejemplo. En el caso de la función $(1+1 / x)^{x}$, considera su límite en el infinito como una generalización del número $e$, que se ha establecido como el límite de la sucesión $(1+1 / n)^{n}$, y al que se le ha dedicado un tema completo de estudio. Para justificar el paso a la función, considera dos sucesiones, una menor y otra mayor que la función, suponiendo que $x>0$ y que $n$ es la parte entera de $x$.

$$
1+\left(\frac{1}{n+1}\right)<1+\frac{1}{x}<1+\frac{1}{n}
$$


Al elevar a los correspondientes exponentes, como ambas sucesiones tienden al número $e$ y la función está entre ellas, deduce que la función tiene el mismo límite (utiliza el criterio del sándwich $\mathrm{y}$, aunque no la ha establecido previamente, lo considera como evidente. También considera que $\mathbb{R}$ es arquimediano). Consideramos que se trata de un EP transformacional, aunque tiene algún paso axiomático al aplicar la definición de $e$, establecida previamente. Al no justificar el caso general, establecer este resultado permite calcular ese tipo de límites ya que se trata de realizar un cambio de variable (es lo que hace en el ejemplo considerado).

\section{Demostración}

$$
\begin{gathered}
{[f(x)]^{g(x)} \text { es del tipo }\left[1^{\alpha}\right]} \\
{[f(x)]^{g(x)}=(1+f(x)-1)^{g(x)}=(1+f(x)-1)^{\frac{1}{f(x)-1} \cdot(f(x)-1)(g(x)}=\left[(1+f(x)-1)^{\left.\frac{1}{f(x)-1}\right]^{(f(x)-1)(g(x)}}\right.}
\end{gathered}
$$

Si ponemos $f(x)-1=h(x)$, resulta que $\lim _{x \rightarrow \Delta} h(x)=\lim _{x \rightarrow \Delta}(f(x)-1)=0$ y además:

$$
f(x)^{g(x)}=\left[(1+h(x))^{\ln (x)}\right]^{h(x) g(x)} \stackrel{x \rightarrow \Delta}{\longrightarrow} e^{\lim ^{l-1} h(x) g(x)}
$$

Puesto que $h(x)=f(x)-1$, queda probado.

\section{Figura IV.7.3.2. Justificación del teorema que permite resolver de forma general la} indeterminación $\rightarrow 1^{\rightarrow \infty}\left(2^{\circ}\right.$ de Bachillerato de Vicens-Vives, 1999).

El LT de Vicens-Vives (1999), de $2^{\circ}$ de Bachillerato, realiza un estudio bastante detallado de la indeterminación $\rightarrow 1^{\rightarrow \infty}$. En primer lugar introduce, como ejemplo de función que tiende a dicha indeterminación la función $f(x)=(1+1 / x)^{x}$ cuando $x \rightarrow \infty$ e indica que, para valores grandes de $x$, al calcular el valor de la función con la calculadora, esta ofrece como resultado valores que se aproximan al que ofrece la calculadora para el número $e$. A continuación se establece que el número $e$ se define como el límite de la función $f(x)$ definida anteriormente cuando $x$ tiende a infinito. Muestra otros ejemplos de funciones que también tienden a $e$, sin justificar, y que se parecen a $f(x):(1+1 / 2 x)^{2 x},(1+1 /(2+x))^{2+x}, \ldots$ Tras mostrar varios ejemplos, establece el siguiente resultado:

$$
\text { Si } \lim _{x \rightarrow \Delta} f(x)=0 \text {, entonces } \lim _{x \rightarrow}(1+f(x))^{1 / f(x)}=e
$$

(Vicens-Vives, $2^{\circ}$ de Bachillerato, 2009, pp. 198). 
Lo justifica mediante un EP transformacional, utilizando un cambio de variable que ha establecido previamente. Por último, enuncia el resultado general $\left(f(x)^{g(x)}\right.$ cuando $f(x) \rightarrow 1$ y $g(x) \rightarrow \infty$ ), que justifica mediante EP transformacional utilizando los resultados anteriores, tal y como se ve en la Figura IV.7.3.2.

Como se puede observar, el LT etiqueta la justificación como demostración, reconociendo como tal el proceso, de forma que los alumnos identifiquen dichas transformaciones como la demostración de la regla enunciada.

\section{IV.7.4. Límite de funciones exponenciales y logarítmicas}

Algunos LT hacen un tratamiento particular del comportamiento de las funciones exponenciales y logarítmicas dentro del estudio de límites mientras que otros lo consideran en capítulos aparte, que están dedicados específicamente al estudio de dichas familias de funciones. En este epígrafe hemos considerado aquellos que los incorporan como parte del estudio del límite.

No todos los LT realizan el estudio de las dos familias de funciones. Además, al tratarse de dos funciones básicas, generalmente se estudian en apartados separados en los que se indica cuál es el comportamiento de dichas funciones en la recta real. Los LT que las consideran dentro del estudio de límites son los siguientes:

- LT de $1^{\circ}$ de Bachillerato de Anaya (2002 y 2008): en este LT considera tanto las funciones exponenciales como las logarítmicas, y realiza un tratamiento similar en ambas: enuncia de forma diferenciada el resultado para bases menores que 1 y mayores que 1. Cada caso lo justifica con EP inductivos de 1 caso, de tipo gráfico, en el que muestra las gráficas de las funciones exponenciales y logarítmicas para bases genéricas $a$ (separando en los dos casos mencionados). Acompañan a cada gráfica de ciertas características de estas dos familias de funciones: asíntotas, ramas parabólicas, límites (aunque sólo los especifica en el caso de las funciones logarítmicas).

- $\quad$ LT de $2^{\circ}$ de Bachillerato de Santillana (2009): únicamente considera las funciones exponenciales. Lo enuncia tanto para el límite en $+\infty$ como en límite en $-\infty$. En cada enunciado engloba los tres posibles casos de bases: base mayor que 1 , base menor entre 0 y 1 . Lo justifica mediante dos 
gráficos de la función, uno para base mayor que 1 y otro para base entre 0 y 1, razón por la cual lo hemos clasificado como EP inductivo sistemático. Hay que destacar que únicamente se muestran las funciones, pero no se refleja la noción de límite en dichos gráficos.

\subsection{Límite de funciones exponenciales}

$$
\lim _{x \rightarrow+\infty} a^{x}=\left\{\begin{array}{ll}
+\infty & \text { si } a>1 \\
0 & \text { si } 0<a<1 \\
\text { No existe } & \text { si } a<0
\end{array} \quad \lim _{x \rightarrow-\infty} a^{x}= \begin{cases}0 & \text { si } a>1 \\
+\infty & \text { si } 0<a<1 \\
\text { No existe } & \text { si } a<0\end{cases}\right.
$$

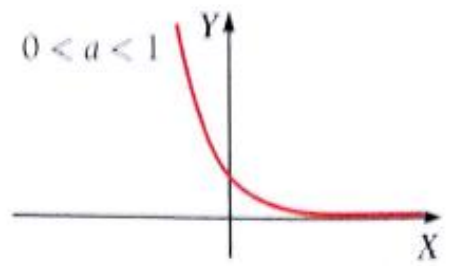

Figura IV.7.4.1. Justificación mediante ejemplos gráficos del límite de las funciones exponenciales ( $2^{\circ}$ de Bachillerato de Santillana, 2009).

- El LT de $2^{\circ}$ de BUP de Vicens-Vives (1980) únicamente considera el límite de la función logarítmica de base 2 en el infinito, mediante un EP axiomático. Para establecer el límite de esta función (en el infinito), justifica que la función no está acotada superiormente y, por tanto, dicho límite en el infinito es infinito. Indica que de forma parecida se comprueba que el límite de dicha función en cero es menos infinito. Además, precede la justificación de la gráfica de la función, lo que vincula la forma que tiene con los límites en los casos calculados.

- El LT de $1^{\circ}$ de Bachillerato LOGSE de Vicens-Vives (1998) considera tanto las funciones exponenciales como las funciones logarítmicas. Se encuentran en un tema aparte del estudio de límites, junto con las funciones trigonométricas, así que el estudio del límite se realiza dentro del estudio de la función. Justifica los límites en \pm infinito de las funciones exponenciales, mediante un EP inductivo de varios casos, que expresa tanto de forma gráfica como tabular, y mostrando los casos en que la base es mayor y menor que 1. En el caso de las funciones logarítmicas muestra una gráfica que ejemplifica este tipo de funciones, y enuncia los límites en cero y en +infinito aunque sin vincularlos a la gráfica, razón por la que no la hemos considerado como EP. 
Sólo trataremos logaritmos en base mayor que 1. Las gráficas, para cualquier base mayor que 1 , son muy parecidas y se comportan de igual modo en el infinito y cuando $x \rightarrow 0^{*}$.

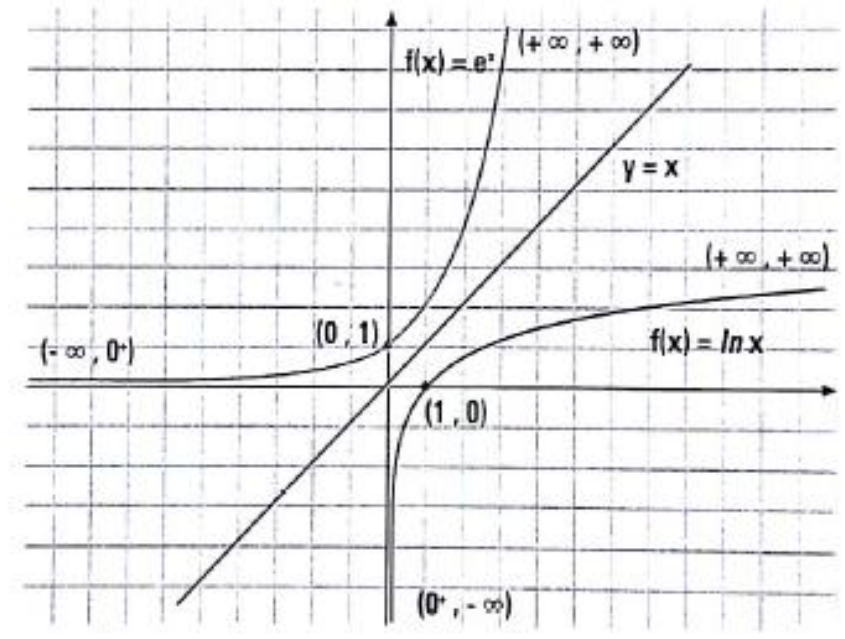

$$
\lim _{x \rightarrow+\infty} \mathrm{e}^{x}=+\infty \quad \lim _{x \rightarrow-\infty} \mathrm{e}^{x}=0^{+} \quad \lim _{x \rightarrow+\infty} \ln x=+\infty \quad \lim _{x \rightarrow 0^{+}} \ln x=-\infty
$$

Podemos poner:

$$
\left[\mathrm{e}^{*=}\right]=+\infty \quad\left[\mathrm{e}^{-\infty}\right]=0 \quad[\ln (+\infty)]=+\infty \quad\left[\ln 0^{*}\right]=-\infty
$$

La función $\mathrm{e}^{x}$ crece muy rápidamente; por ejemplo, $\mathrm{e}^{100} \simeq 2,688 \cdot 10^{43}$. Sin embargo el $\ln \mathrm{x}$ crece muy lentamente.

Para que sea $\ln x=100$, el valor de $x$ debe ser $x=e^{100}$. No obstante $\ln x$ puede llegar a ser tan grande como se quiera. Por ejemplo $\ln x$ puede tomar el valor 1.000.000; basta que sea $\mathrm{x}=\mathrm{e}^{1.000 .000}$

Figura IV.7.4.2. EP inductivo de un caso para el límite de las funciones exponenciales y logarítmicas ( $2^{\circ}$ de Bachillerato de Vicens-Vives, 1999). La inducción se aprecia en el primer párrafo.

- El LT de $2^{\circ}$ de Bachillerato LOGSE de Vicens-Vives (1999), al igual que en el LT anterior, de la misma colección que éste pero del curso anterior, considera tanto las funciones exponenciales como las logarítmicas y justifica el límite en el infinito de ambas con sendos EP inductivos de 1 caso. Hay que recordar que este LT no considera ninguna definición de límite, sino que parte de la idea del concepto, y establece propiedades y reglas a partir de dicha idea. Dentro del tratamiento del tema considera las funciones exponenciales y logarítmicas e indica los límites de estas familias de funciones. Para ello, induce a partir de las funciones $e^{x}$ y $\ln (x)$ los límites de las funciones con otras bases, como se ve en la Figura 
IV.7.4.2, tras la cual se enuncian varios ejemplos de funciones exponenciales y logarítmicas, y sus respectivos límites.

- En el LT de $1^{\circ}$ de Bachillerato LOGSE de Vicens-Vives (2003) sólo se justifica el límite de las funciones exponenciales, utilizando un EP inductivo sistemático. En este LT se plantea una discusión sobre el límite de las funciones potenciales-exponenciales $\left(f(x)=a^{x}\right)$ indicando que depende del valor de la base y de la tendencia del exponente. Se considera dos ejemplos, con bases menor y mayor que 1 respectivamente, y se estudian ambos límites, cuando $x$ tiende a $+\infty$ y cuando $x$ tiende a $-\infty$. No se enuncia el resultado general, sino que es el alumno el que tiene que deducir de la sentencia inicial (el límite en el infinito de una función exponencial depende del valor de la base $a$ y de la tendencia del exponente, Vicens-Vives, 2003, pp. 221) y de ambos ejemplos, cual es el límite en cada caso. Los sistemas de representación utilizados son el verbal, principalmente, y el simbólico. Al contrario que en otros textos, no se ilustran los ejemplos mediante gráficas.

Tal y como hemos visto, únicamente en el LT de LGE (Vicens-Vives de $2^{\circ}$ de BUP, 1980) se utiliza un EP axiomático, el resto de justificaciones encontradas (todas en LT de LOGSE y LOE) son del tipo EP inductivo (ya sean de 1 caso, de varios o sistemático). Creemos que se debe al hecho de que el rigor matemático que caracteriza a los LT de la LGE no requiere de la justificación de los límites de familias de funciones en concreto, ya que basta con la definición de límite, sus propiedades y el conocimiento de las funciones para establecer su límite. Sin embargo, se ha evidenciado esa tendencia a la mecanización del cálculo que hemos mencionado en otras ocasiones provoca que los LT traten de mostrar, e incluso justificar, cualquier límite que pueda ser útil para el cálculo de límites.

\section{IV.7.5. Límite de familias de funciones elementales}

En este apartado reunimos los resultados que se refieren al estudio de límites de familias de funciones básicas elementales identidad, constante, potencial, potencial inversa,....

La consideración de estos resultados en cada LT es diferente, ya que algunos lo incluyen dentro del apartado de límites, sobre todo en aquellos orientados a la mecanización del cálculo, pero otros consideran aparte el estudio de cada familia 
de funciones, y es en el apartado correspondiente en el que se considera el comportamiento de estas funciones y por tanto, los límites.

No obstante, en este trabajo se presenta el análisis realizado para aquellos textos que presentan este tipo de resultados como propiedades dentro del tema relativo a límites. No presentamos el análisis a modo de tablas debido a que no se estudian siempre las mismas familias y por tanto resultaría poco económico utilizar tablas para todos los resultados.

- Función identidad: el límite de la función identidad en un punto es el valor de la abscisa de dicho punto.

Este resultado es un tanto peculiar, ya que no admite todos los tipos de esquema de prueba, ya que se tratar de una función concreta. De hecho, únicamente consideramos que se justifica con EP axiomático en el caso de que se utilice la definición para razonar que el límite coincide con el valor de la abscisa del punto, o que no se justifica, bien sea porque no se realiza ningún razonamiento bien porque se muestra la gráfica asociada a la función como una ilustración gráfica funcional, pero no como límite, ya que no utiliza entornos. Sólo un texto, Santillana $2^{\circ}$ BUP (1976), muestra una justificación axiomática, es decir, utilizando la definición. En nuestra opinión, este resultado es uno de los más importantes para el cálculo de límites, ya que permite sustitución final de valor de tendencia en la variable independiente una vez que se hayan evitado las indeterminaciones en el entorno del punto considerado. A pesar de esta importancia y de ser un resultado que se utiliza en el cálculo de límites, no son muchos los LT que al menos lo enuncian, suponemos que por tratarse de una función en concreto y parecer un resultado evidente. Consideramos que sería un buen ejemplo en el que utilizar un EP axiomático porque permite vincular el cálculo de límites a la definición. Aunque este resultado se enuncia en otros LT, no lo justifican por considerarlo evidente, como Anaya (1976), que dice:

Expresión que es una redundancia. No hace falta acudir a la definición de límite para aceptarla como cierta.

Anaya, $2^{\circ}$ de BUP (1976, pp. 87)

\section{- Función constante}

Un caso similar ocurre con la función constante, pero esta familia de funciones admite más tipos de justificaciones ya que no se trata de una función en concreto. No obstante, únicamente hemos encontrado tres textos que justifican este 
resultado con un EP axiomático, y el resto, o bien se limitan a enunciarlo, o bien ni siquiera lo consideran. Lo textos que los justifican son dos de $2^{\circ}$ de BUP, el de Anaya (1976) y el de Santillana (1976), y uno de $2^{\circ}$ de Bachillerato de LOGSE, el de Santillana (1997).

En el LT de Anaya (1976), de 2 de BUP, lo justifica mediante un EP axiomático, y además, en modo directo, ya que utiliza la definición.

$$
\begin{aligned}
& \lim _{x \rightarrow a} k=k(k \in \mathbb{R}) \\
& \text { Pues si } f(x)=k,|f(x)-k|=|k-k|=0<\varepsilon, \text { para cualquier } \varepsilon .
\end{aligned}
$$

Anaya, $2^{\circ}$ de BUP (1976, pp. 87)

En este caso el LT ha aprovechado una resultado muy sencillo para justificarlo utilizando la definición de límite, algo que podría ser muy complicado en otros resultados, pero conviene llamar la atención que no ha mencionado la validez para cualquier $\delta$.

En el LT de Santillana (1976), de $2^{\circ}$ de BUP, este resultado se justifica como ejemplo de aplicación de la definición de límite (expresada en términos del valor absoluto) para establecer el límite de dos funciones sencillas (la función constante y la identidad). Como en el caso de Anaya (1976), se trata de un EP axiomático, en el que combina el lenguaje verbal y el simbólico, lo que resulta en un razonamiento muy ilustrativo de cómo utilizar la definición de límite para calcularlo. Aunque se justifica en un ejemplo de aplicación de la definición de límite para el cálculo de éste en este caso sencillo, se enuncia también como propiedad, recurriendo al ejemplo para indicar que ya se ha justificado.

En el LT de Santillana (1997), de $2^{\circ}$ de Bachillerato, la justificación de este resultado aparece en el apartado Ejercicios y problemas resueltos (pp. 227), junto con la justificación del límite de la función identidad. El EP utilizado es axiomático, utilizando la definición de límite expresada en términos del valor absoluto. Utiliza, principalmente, el sistema de representación simbólico, y en algún paso añade un comentario verbal. Indica que se demuestra, tanto en el texto del libro donde enuncia el resultado, como en el ejercicio en el que lo demuestra. El enunciado está expresado de forma simbólica y verbal. Las funciones que se consideran son las de comunicación y verificación. No se señalan otras vías de justificación, pero el hecho de indicar que se demuestra refleja que el libro reconoce el proceso como tal. Tampoco se indican las líneas generales de la demostración. 
En ninguno de los LT mencionados se han considerado otras vías de justificación, ni reflexiones sobre el proceso o sus consecuencias, o las líneas generales de la demostración.

- Funciones tipo $x^{n}, 1 / x^{n}, x^{1 / n}$

Varios LT consideran este tipo de funciones como un resultado a justificar y por ello hemos encontrado diferentes esquemas de prueba en los diferentes LT: EP transformacional, prueba preformal, EP inductivo de varios casos o sistemático.

EL LT de Anaya (1976), de $2^{\circ}$ de BUP, enuncia este resultado en un apartado titulado Aplicaciones al cálculo de límites (pp. 87) tras haber enunciado (y justificado) propiedades de los límites. Al igual que se aprecia en otros LT, la intención es proveer al alumno, a través de las operaciones y propiedades de los límites y los límites de algunas funciones sencillas, de las herramientas suficientes para calcular límites de otras funciones. Este límite lo justifica mediante un EP transformacional, y aplica la propiedad del producto considerando que $x^{n}$ es un producto de $\mathrm{n}$ factores donde cada factor es la función identidad, cuyo límite se ha establecido previamente. No lo hemos clasificado como EP axiomático, aunque se aplican axiomas, porque no se indica en el texto los axiomas que se aplican, sino que se da más importancia a la transformación del producto.

El LT de Santillana (1976), de $2^{\circ}$ de BUP, considera las funciones de tipo $x^{n}$ dentro del apartado Limites y operaciones con funciones (pp. 215), asociadas a límites en un punto, y las funciones del tipo $1 / x^{n}$ en el apartado Límites en el infinito. Ramas parabólicas (pp. 220). En ambos casos realiza el mismo tipo de justificación: una prueba preformal basada en el método de inducción (de hecho, sólo quedaría el paso en el que suponiendo que es cierto para $n-1$, se deduce que es cierto para $n$ ). Como se ve en la Figura IV.7.5.1, primero considera los razonamientos sobre casos concretos y luego indica que se tiene el resultado de forma general.

El LT de Santillana (2009), de $2^{\circ}$ de Bachillerato, considera un apartado de cálculo de límites, en el que considera varias familias de funciones básicas, tras haber expuesto las operaciones con funciones. Suponemos que el objetivo de los autores del LT es, a partir de las operaciones y de los límites de algunas familias de funciones elementales, permitir el cálculo de cualquier función. Han considerado un EP inductivo sistemático (exponente par e impar, y $n$ mayor o 
menor que cero), de tipo gráfico, es decir, que muestra una gráfica de cada caso de la cual se deduce el límite. No obstante, hay que señalar que no se ilustra el concepto de límite en las gráficas, tal y como se ve en la Figura IV.7.5.2.

4.3. Sea la función $f(x)=x^{2} ; f=1_{R} \cdot 1_{R}$, ya que

$$
1_{R}(x) \cdot 1_{R}(x)=x \cdot x=x^{2}=f(x)
$$

Aplicando la propiedad d) de 4.1., se tiene:

$$
\lim _{x \rightarrow a} f(x)=\lim _{x \rightarrow a} x^{2}=\lim _{x \rightarrow a} 1_{R}(x) \cdot \lim _{x \rightarrow a} 1_{R}(x)=a \cdot a=a^{2}
$$

Análogamente:

$$
\lim _{x \rightarrow a} x^{3}=\lim _{x \rightarrow a}\left(x^{2} \cdot x\right)=\lim _{x \rightarrow a} x^{2} \cdot \lim _{x \rightarrow a} x=a^{2} \cdot a=a^{3}
$$

En general: $\lim _{x \rightarrow a} x^{n}=a^{n}$.

Análogamente, se tienen las mismas propiedades para los límites cuando $x$ tiende a menos infinito.

Se ha visto que $\lim _{x \rightarrow \infty} \frac{1}{x}=0 ;$ también se verifica que $\lim _{x \rightarrow-\infty} \frac{1}{x}=0$, entonces:

$$
\begin{aligned}
& \lim _{x \rightarrow \infty} \frac{1}{x^{2}}=\lim _{x \rightarrow \infty}\left(\frac{1}{x} \cdot \frac{1}{x}\right)=\left(\lim _{x \rightarrow \infty} \frac{1}{x}\right) \cdot\left(\lim _{x \rightarrow \infty} \frac{1}{x}\right)=0 \cdot 0=0 ; \\
& \text { análogamente, } \lim _{x \rightarrow \infty} \frac{1}{x^{n}}=0 \text { y } \quad \lim _{x \rightarrow-\infty} \frac{1}{x^{n}}=0
\end{aligned}
$$

Figura IV.7.5.1. PP para los límites de funciones de los tipos $x^{n}$ (arriba) y $1 / x^{n}$ (abajo) ( $2^{\circ}$ BUP de Santillana, 1976).

\subsection{Límite de funciones con potencias}

$$
\lim _{x \rightarrow+\infty} x^{n}= \begin{cases}+\infty & \text { si } n>0 \\ 1 & \text { si } n=0 \\ 0 & \text { si } n<0\end{cases}
$$

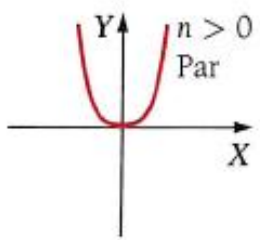

$$
\lim _{x \rightarrow-\infty} x^{n}= \begin{cases}+\infty & \text { si } n>0 \text { y } n \text { par } \\ -\infty & \text { si } n>0 \text { y } n \text { impar } \\ 1 & \text { si } n=0 \\ 0 & \text { si } n<0\end{cases}
$$

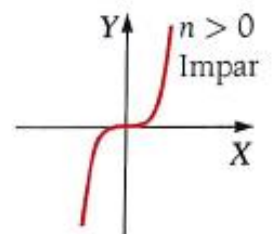

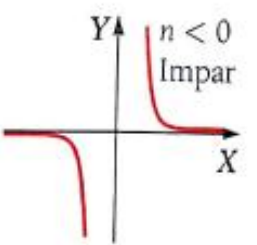

Figura IV.7.5.2. EP inductivo sistemático en el LT de Santillana (2009), de $2^{\circ}$ de Bachillerato para las funciones con potencias. 
El LT de Vicens-Vives (1998), de $1^{\circ}$ de Bachillerato, considera, de forma general, las funciones definidas por potencias $\left(y=x^{k}\right)$ y separa en los casos en que el exponente es natural (Figura IV.7.5.3), entero negativo, o $1 / n$ (raíces). En todos los casos se ilustra la diferencia entre el caso par e impar, y se consideran las gráficas de varias funciones de ese tipo, tras las cuales se enuncian los límites (en el caso de exponente natural y de raíces, en el caso de exponente entero negativo ni siquiera se enuncian los límites). No se acompañan las expresiones simbólicas y gráficas de descripciones verbales, lo que nos lleva a pensar que los autores del libro de texto consideran suficiente las gráficas para deducir los límites y poder aplicarlos a otras funciones que dependan de éstas.

\section{Funciones definidas por potencias: $y=x^{\star}$}

\section{a) Exponente natural}

Exponente par:

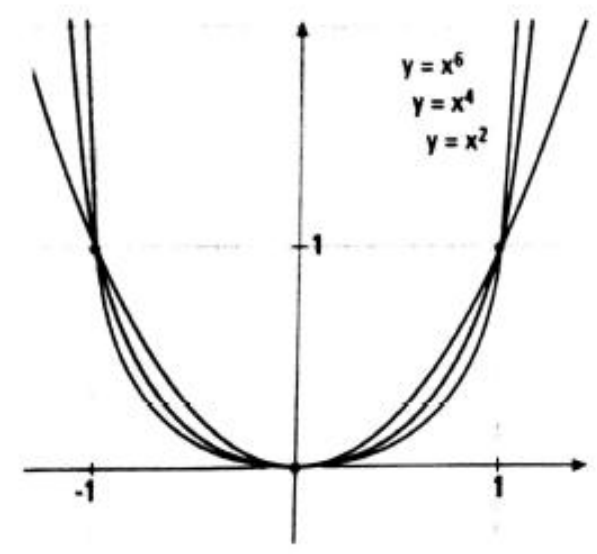

$\lim _{x \rightarrow+\infty} f(x)=\lim _{x \rightarrow-\infty} f(x)=+\infty$

Simétricas respecto de OY

\section{Exponente impar:}

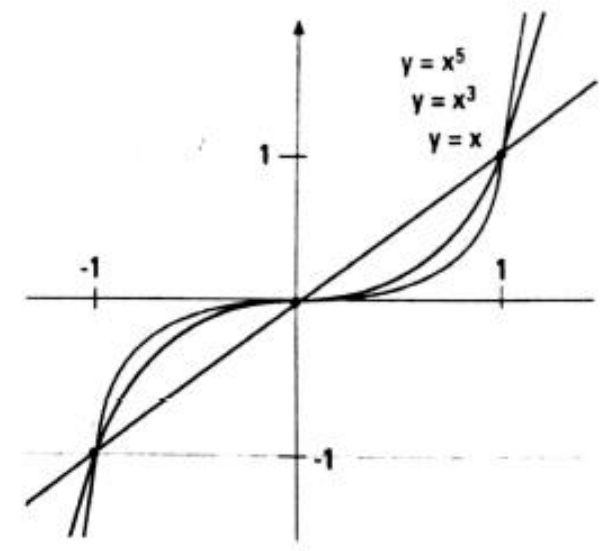

$\lim _{x \rightarrow+\infty} f(x)=+\infty \quad \lim _{x \rightarrow-\infty} f(x)=-\infty$

Simétricas respecto del origen

Figura IV.7.5.3. EP inductivo sistemático en el LT de Vicens-Vives (1998) de $1^{\circ}$ de Bachillerato.

El LT de Vicens-Vives (1999), de $2^{\circ}$ de Bachillerato, tras introducir brevemente la idea de límite (recordemos que este LT no da una definición de límite), considera los límites de familias de funciones elementales (en el LT, el apartado se denomina Límites con funciones elementales, pp. 180). Dentro de este apartado, el primer subapartado se titula Límites básicos (pp. 180), y en él considera los límites de los siguientes tipos de funciones: $x^{n}$ (tanto para $n$ par como impar), $1 / x^{n}$ (a partir de $1 / x$ y $1 / x^{2}$ ), $x^{2}+k$ y $\sqrt{x}$. En todos los casos considera EP inductivos, siendo sistemáticos para $x^{n}$ y $1 / x^{n}$, y de un caso para $x^{2}+k$ (se 
ilustra más adelante). En el caso de $\sqrt{x}$, al tratarse de una función en concreto, no se considera como EP, sino como cálculo. Además, todos ellos son de tipo gráfico, y se limitan a mostrar una gráfica de los casos considerados, estableciendo el límite a partir de ellas.

- Funciones tipo $\mathrm{k} \cdot \mathrm{f}(\mathrm{x})$, con $\mathrm{k}$ un número real

Únicamente tres LT justifican el producto de una función por un número (en muchos se enuncia como otra propiedad aritmética, pero no se justifica). Estos LT son el Anaya (1976), el Santillana (1976) y el SM (1977), todos de $2^{\circ}$ de BUP, aunque en el caso de Santillana, lo que se enuncia y justifica es una versión particular de este resultado

En Anaya (1976), de $2^{\circ}$ de BUP, se justifica mediante un EP transformacional, en el que se aplica el producto, por lo que tiene una parte axiomática, pero no lo hemos considerado como EP axiomático porque el LT no indica que aplica ese axioma.

Como ya hemos dicho, en Santillana (1976) se justifica un caso particular de este resultado en el que la función $f(x)$ es de la forma $x^{n}$, con $n$ un número natural. Lo hemos clasificado como EP axiomático debido a que hace referencia al resultado que utiliza para justificarlo $\left(\lim _{x \rightarrow a}(c \cdot f(x))=c \cdot \lim _{x \rightarrow a} f(x)\right.$, aunque realice transformaciones simbólicas de la expresión del límite.

En el caso de SM (1977), realiza una justificación similar a la de Anaya (1976), es decir, aplica el producto de funciones. En este caso sí que indica que es una consecuencia directa de dicho resultado y luego realiza las transformaciones, razón por la cual lo hemos considerado como EP axiomático. Además, de esta forma la justificación es más explicativa que si sólo se realizan las transformaciones.

\section{- Diferentes casos de funciones polinómicas}

Sólo un LT enuncia un resultado relativo a un caso especial de función polinómica, Vicens-Vives (1999), de $2^{\circ}$ de Bachillerato. Este LT considera de manera particular los límites de las funciones de la forma $f(x)=x^{2}+k$ (no se especifica qué es $k$, aunque es evidente que se trata de un número real), aunque los alumnos podrían calcular este límite utilizando los resultados enunciados posteriormente. Utiliza un EP inductivo de un caso de estilo gráfico en el que se muestra la forma de una función arbitraria de ese tipo, con un $k$ positivo. No se 
refleja la definición de límite pero el LT no ha dado una definición en ese momento, sino que pretende ilustrar la idea de límite mediante ejemplos.

$$
\lim _{x \rightarrow \pm \infty}\left(x^{2}+k\right)=+\infty
$$

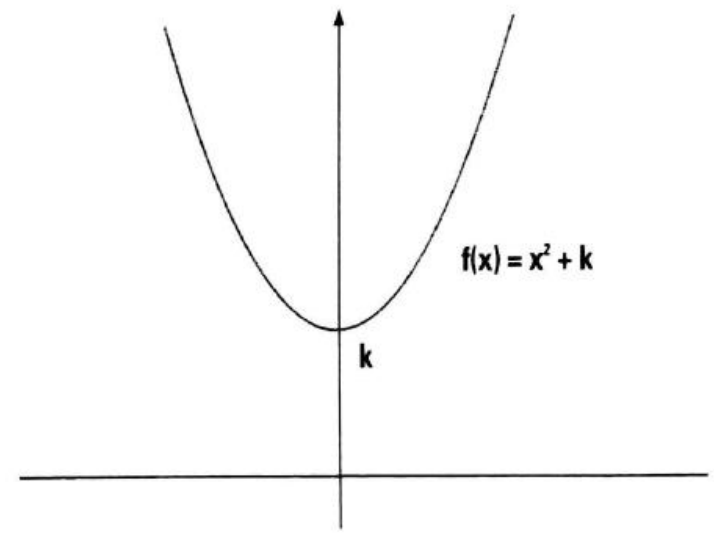

Figura IV.7.5.4. Justificación del límite de una función del tipo $f(x)=x^{2}+k\left(2^{\circ}\right.$ de Bachillerato de Vicens-Vives, 1999).

En este LT, las propiedades de los límites se enuncian tras mostrar varias familias básicas de funciones, por lo que se podría considerar como un EP inductivo más general, en el que se muestran varios ejemplos de los límites de funciones básicas, que luego se operan y se establecen los límites de las funciones que resultan de operar dichas funciones.

\section{IV.7.6. Resultados asociados a los infinitésimos o infinitos equivalentes}

En este apartado se recogen los resultados destinados a facilitar el cálculo de límites en caso de indeterminación, pero que no hacen referencia a funciones en concreto: los infinitos (que son funciones cuyo límite, en un punto o en el infinito, es infinito) y los infinitésimos (que son funciones cuyo límite, en un punto o en el infinito, es cero). Si bien se estudian muchas funciones cuyos límites son cero o infinito, sólo hemos tenido en cuenta aquellos LT que establecen estas definiciones y enuncian propiedades asociadas a ellas que permiten resolver indeterminaciones de forma general (mediante la sustitución por infinitos o infinitésimos equivalentes).

Únicamente se enuncian en algunos LT, ya que la mayoría resuelven las indeterminaciones considerando ejemplos concretos de tipos de funciones y explicando las técnicas que hay que utilizar en dichos casos para eliminar la 
indeterminación y poder aplicar las propiedades y operaciones de los límites. En concreto, los libros de texto que consideran estos resultados son los siguientes:

\begin{tabular}{|c|c|c|c|c|c|}
\hline \multirow[t]{2}{*}{$\overline{\text { LT }}$} & \multicolumn{3}{|c|}{ Infinitos equivalentes } & \multicolumn{2}{|c|}{ Infinitésimos equivalentes } \\
\hline & Definición & Suma & Sustitución & Definición & Sustitución \\
\hline$\overline{\text { Anaya } 2^{\circ}(1976)}$ & & & & $\bar{\checkmark}$ & \\
\hline Santillana $2^{\circ}(1981)$ & & & & $\checkmark$ & \\
\hline $\operatorname{VV} 2^{\circ}(1980)$ & & & & $\checkmark$ & $\checkmark$ \\
\hline Anaya $2^{\circ}(2003)$ & $\checkmark$ & & & & \\
\hline VV $2^{\circ}$ (1999) & $\checkmark$ & & $\checkmark$ & $\checkmark$ & $\checkmark$ \\
\hline Anaya $2^{\circ}(2009)$ & $\checkmark$ & & & & \\
\hline SM $2^{\circ}(2010)$ & & & & $\checkmark$ & $\checkmark$ \\
\hline
\end{tabular}

Tabla IV.7.6.1. LT que consideran los infinitos o los infinitésimos equivalentes.

Los LT que enuncian los resultados asociados a los infinitos o infinitésimos equivalentes los justifican (Anaya, 2003 y 2009, y Santillana, 1981, se limitan a enunciar los infinitos del mismo orden, pero no los utilizan para la resolución de indeterminaciones). El resto de LT, que sí justifican los resultados que enuncian, utilizan EP transformacionales. En cuanto al resto de aspectos que consideramos en nuestro análisis, realizamos las siguientes observaciones. En el LT de VicensVives (1980), de $2^{\circ}$ de BUP, el enunciado que utiliza está expresado en un lenguaje coloquial:

Si F y G son dos infinitésimos equivalentes para $\mathrm{x}=\mathrm{a}$, y se desea calcular el límite para $\mathrm{x}=\mathrm{a}$ de una expresión en la que interviene $\mathrm{F}(\mathrm{x})$ como factor o divisor, se puede cambiar $\mathrm{F}(\mathrm{x})$ por $\mathrm{G}(\mathrm{x})$ sin que varíe el límite buscado.

Vicens-Vives, $2^{\circ}$ de BUP (1980, pp. 259)

El tipo de enunciado al que más se ajusta es el de condición necesaria, aunque está expresado de forma que no parece una verdad general, ya que se utilizan formas verbales del tipo "se desea" o "se puede". La justificación es una serie de transformaciones simbólicas, que podría considerarse silogismo, el estilo es algebraico, y el método, es analítico. Las funciones de la demostración que se observan son las de comunicación y verificación. En este LT se reconoce el proceso, ya que se indica que "se justifica" dicha sustitución, aunque no hay diferencia entre el enunciado y la justificación (ambos forman parte del mismo texto). No se refiere a las consecuencias de haber justificado el resultado, aunque sí indica en qué casos puede ser más útil utilizar este resultado (sustitución de funciones circulares). Utiliza el sistema de representación verbal (coloquial) y simbólico, y no se indica el significado de ninguna expresión, aunque las pocas 
que aparecen son habituales en el tema. Por último, no explica globalmente el proceso, ni señala otras vías de justificación.

Por su parte, en el LT de Vicens-Vives (1999), de $2^{\circ}$ de Bachillerato, es el LT que hace un tratamiento más extenso de infinitos e infinitésimos, siendo el único que los considera a ambos y que enuncia tres resultados relacionados con estos dos elementos: la suma de infinitos es equivalente al sumando de mayor orden, la posibilidad de sustituir infinitos en el cálculo de límites y la posibilidad de sustituir infinitésimos en el cálculo de límites. En los tres casos el LT etiqueta los resultados como teoremas y las justificaciones como demostraciones, con lo que queda claro que reconoce el proceso como una justificación y que distingue sin lugar a error entre el enunciado y la justificación. Ya hemos indicado que las tres justificaciones son EP transformacionales, en las que utiliza un silogismo, con estilo algebraico, y de modo indirecto.

El tipo de enunciado no se ajusta a ninguno de los descritos, sino que son más bien de tipo coloquial, con formas verbales ligadas a una posibilidad ("se puede"):

Una suma de infinitos es equivalente al sumando de mayor orden. (pp. 186)

Un infinito se puede sustituir por otro equivalente cuando actúa como factor o divisor en una expresión (pp. 186)

Un infinito se puede sustituir por otro equivalente, cuando actúa como factor o divisor en una expresión (pp. 201)

Vicens-Vives, $2^{\circ}$ de Bachillerato (1999)

Las funciones de la demostración observadas son las de comunicación y verificación, ya que las justificaciones son simples y no abundan en las explicaciones. Los tres resultados siguen un esquema similar (enunciado, justificación, ejemplos), así que consideramos que, aunque el texto no se refiera a las consecuencias de haber justificado los tres teoremas, sí que indica cuáles son las aplicaciones de ellos en el cálculo de límites. En ningún caso se describen las líneas generales de la demostración ni se señalan otras vías de justificación.

En el LT de SM (2010), de $2^{\circ}$ de Bachillerato, la justificación aparece junto con el enunciado, en un mismo recuadro amarillo, que resalta la importancia del resultado (permite resolver muchas indeterminaciones), tal y como se muestra a continuación:

Cuando dos infinitésimos $\mathrm{f}(\mathrm{x})$ y $\mathrm{g}(\mathrm{x})$ son equivalentes, y uno de ellos aparece como factor en un límite, se puede sustituir por otro, ya que: 


$$
\begin{gathered}
\lim _{x \rightarrow a}(f(x) \cdot \varphi(x))=\lim _{x \rightarrow a}\left(\frac{f(x)}{g(x)} \cdot g(x) \cdot \varphi(x)\right)=\left(\lim _{x \rightarrow a}\left(\frac{f(x)}{g(x)}\right)\right) \cdot \lim _{x \rightarrow a}(g(x) \cdot \varphi(x)) \\
=\lim _{x \rightarrow a}(g(x) \cdot \varphi(x))
\end{gathered}
$$

SM, $2^{\circ}$ de Bachillerato (2010, pp. 216)

Como se puede observar, el EP utilizado es transformacional, de estilo algebraico, y el tipo de enunciado es de condición suficiente, pero sin utilizar los conectores habituales (si...entones). En este caso, las funciones que se reflejan son las de comunicación y verificación. No se hacen referencias al procedimiento, ni a sus consecuencias, ni a las líneas generales del proceso, ni se señalan otras vías de justificación, ni existe una distinción clara entre enunciado y justificación (se encuentran ambos dentro del mismo cuadro de color), ni se explica el lenguaje utilizado (aunque las expresiones son las utilizadas habitualmente).

\section{IV.7.7. Límite en cero de $x / \operatorname{sen}(x)$, en $\operatorname{tg}(x) / x$ o en $(\cos (x)-1) / x$ y límite en infinito de $\operatorname{sen}(x) / x$}

Este tipo de resultados aparecen en numerosos textos, bien en una sola versión (la más común es el cociente de $\operatorname{sen}(x) / x$ ) bien mostrando otros resultados equivalentes a éste último $(\tan (x) / x,(\cos (x)-1) / x, \ldots)$. La mayoría de los textos realizan una prueba similar: se basa en un EP transformacional, en el que se razona a partir de una representación gráfica que permite asegurar un resultado que en ningún texto se enuncia, el criterio del Sandwich. Si bien, estos resultados no se enuncian propiamente como teoremas, ya que se trata del cálculo de un límite de una función en concreto, la mayoría de los textos que los consideran, los tratan como tales, añadiendo a la justificación la etiqueta de "demostración". Además, en el caso de la función de partida, $\operatorname{sen}(x) / x$, el cálculo no es sencillo, sino que necesita de otros teoremas para obtener este límite. Los LT deducen el resto de límites aplicando este resultado. Los libros de texto en los que hemos encontrado este tipo de enunciados como teoremas son los que aparecen en la Tabla IV.7.7.1.

Tal y como se muestra en la tabla, el resultado que más aparece justificado es el límite del cociente de $\operatorname{sen}(x) / x$ en $x=0$. En muchos de los libros se presenta como un resultado de ampliación, como una nota en el margen o como un ejercicio 
resuelto, en lugar de un resultado más del tema. A continuación se muestran algunos ejemplos de las justificaciones encontradas para estos resultados.

\begin{tabular}{lccccc}
\hline & $\lim _{x \rightarrow 0} \frac{\operatorname{sen} x}{x}=1$ & $\lim _{x \rightarrow 0} \frac{x}{\operatorname{sen} x}=1$ & $\lim _{x \rightarrow 0} \frac{\tan x}{x}=1$ & $\lim _{x \rightarrow 0} \frac{\cos x-1}{x}=0$ & $\lim _{x \rightarrow \infty} \frac{x}{\operatorname{sen} x}=1$ \\
\hline VV 2 2 1980 & $\checkmark$ & $\checkmark$ & $\checkmark$ & $\checkmark$ & $\checkmark$ \\
Sant. 2 1997 & $\checkmark$ & & $\checkmark$ & \\
SM 1 1 1996 & $\checkmark$ & $\checkmark$ & & \\
SM 2 2001 & & & & \\
VV 1 1 1998 & $\checkmark$ & & & \\
VV 2 2 1999 & $\checkmark$ & & & \\
VV 20 2009 & & & & \\
\hline
\end{tabular}

Tabla IV.7.7.1. Resultados relacionados con funciones trigonométricas y libros en los que se aparecen y se justifican.

El libro de $2^{\circ}$ de BUP de Vicens-Vives (1980) realiza un razonamiento geométrico, basado en áreas de figuras sencillas a partir de la representación de de un ángulo y del valor del seno correspondiente. De hecho, en primer lugar parte de una exploración experimental numérica, mostrando en una tabla distintos valores del ángulo y su correspondientes valores del seno, a continuación escribe el valor del límite y, finalmente construye una gráfica, Figura IV.7.7.1, para probar el caso general a partir de una visualización de las longitudes y de las áreas de las figuras representadas. Se trata de un EP transformacional y axiomático.

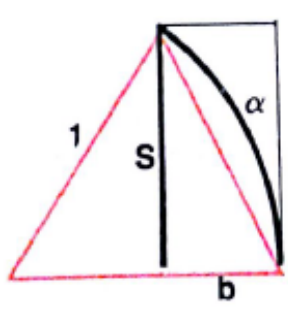

Si la circunferencia es de radio 1 , la medida $\alpha$ del ángulo, en radianes, coincide con la longitud del arco; además, $\operatorname{sen}(\alpha)$, es la longitud del segmento s.
[...] La propiedad que queremos demostrar es:

$$
\lim _{\alpha \rightarrow 0} \frac{\alpha}{s}=1
$$

Para ello, expresamos que el área del triángulo rayado es menor que la del correspondiente sector circular, ésta, menor que la del trapecio, cuyas bases paralelas miden, respectivamente, $1 \mathrm{y} \mathrm{b}$.

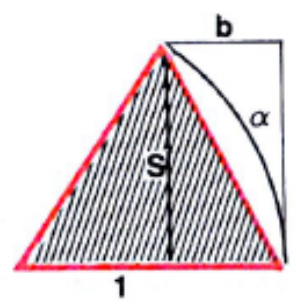

Y completa la justificación calculando las áreas antes descritas y comparando.

Es el único LT que en la justificación sustituye las funciones trigonométricas por longitudes y áreas de elementos geométricos, y razona sobre las figuras 
geométricas para justificar el resultado. El resto de justificaciones que hemos encontrado utilizan las funciones trigonométricas.

En el LT de Santillana (1997) vemos que se limita a realizar algunas transformaciones sobre los límites aplicando las desigualdades, y dando por cierto que dichas desigualdades se extienden a los límites aunque nunca lo hayan justificado (Figura IV.7.7.2).

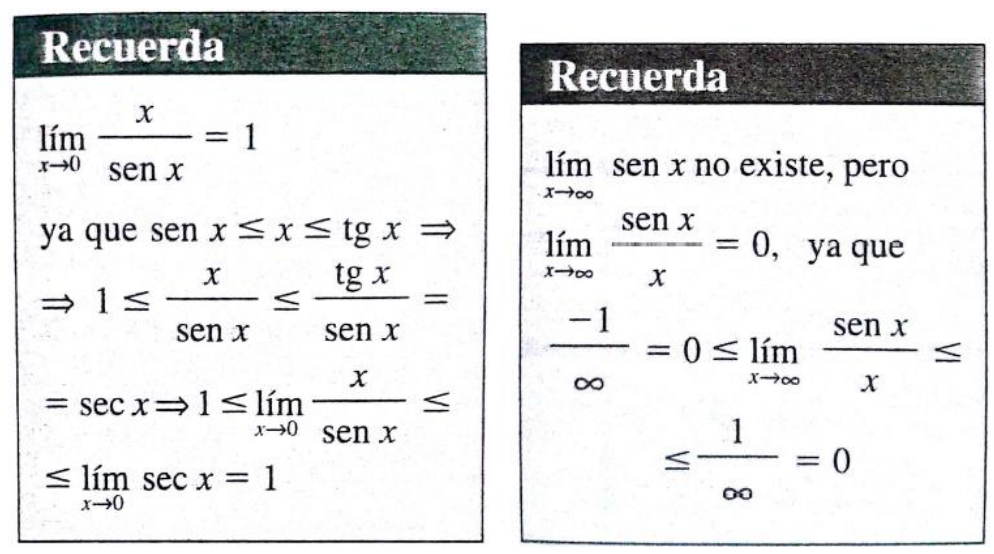

Figura IV.7.7.2. Justificación ( $2^{\circ}$ de Bachillerato de LOGSE Santillana, 1997).

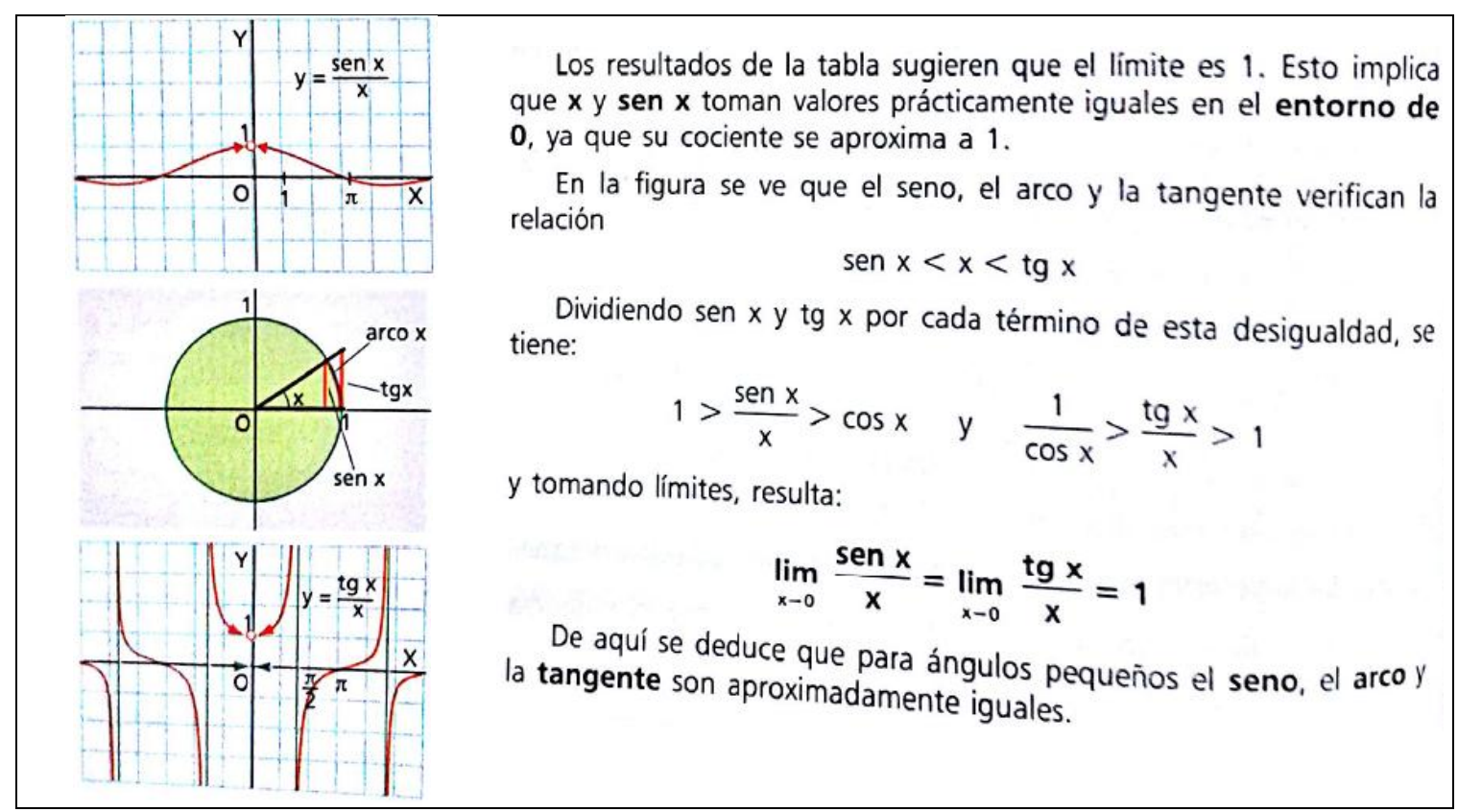

Figura IV.7.7.3. Justificación ( ${ }^{\circ}$ de Bachillerato LOGSE de SM, 1996).

En los libros de SM de $1^{\circ}$ y $2^{\circ}$ de Bachillerato de LOGSE (SM, 1997 y 2001, Figuras IV.7.7.3 y IV.7.7.4) también se justifica este resultado. El LT de $1^{\circ}$ realiza una discusión del límite considerando varios aspectos: que la función no está definida pero tiene límite, también muestra una gráfica de la función, una tabla con valores que se aproximan a cero y sus correspondientes imágenes, y 
acaba realizando el razonamiento transformacional mediante desigualdades que observamos en otros LT, y justificando al mismo tiempo el límite de la función $\operatorname{tg}(x) / x$.

\begin{tabular}{|c|c|c|c|c|c|c|c|c|c|c|c|c|}
\hline$x \rightarrow 0$ & $-0,4$ & $-0,3$ & $-0,2$ & $-0,1$ & $\rightarrow$ & 0 & $\leftarrow$ & 0,1 & 0,2 & 0,3 & 0,4 & $0 \longleftarrow x$ \\
\hline$\frac{\frac{x}{x}}{x}$ & 0,974 & 0,985 & 0,993 & 0,998 & $\rightarrow$ & ¿? & $\leftarrow$ & 0,998 & 0,993 & 0,985 & 0,974 & $x$ \\
\hline$\frac{\cos x-1}{x}$ & 0,197 & 0,149 & 0,100 & 0,050 & $\rightarrow$ & i? & $\leftarrow$ & $-0,050$ & $-0,100$ & $-0,149$ & $-0,197$ & $\frac{\cos x-1}{x}$ \\
\hline
\end{tabular}

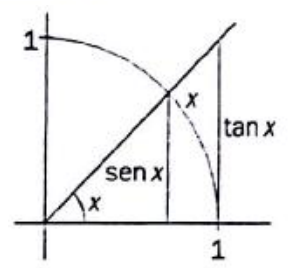

I Para demostrar que $\lim _{x \rightarrow 0} \frac{\operatorname{sen} x}{x}=1$ hay que hacer un razonamiento especial. En el dibujo de la derecha se aprecian las desigualdades: $\operatorname{sen} x<x<\tan x$.

cuando $x$ es un ángulo positivo medido en radianes y $x<\frac{\pi}{2}$.

Dividiendo entre $\operatorname{sen} x$, que es positivo cuando $x$ es positivo $y$ cercano a 0 , se obtiene $1<\frac{x}{\operatorname{sen} x}<\frac{1}{\cos x}$. De aquí se deduce: $\cos x<\frac{\operatorname{sen} x}{x}<1$. Tomando límites cuando $x$ tiende a 0 por la derecha:

$\lim _{x \rightarrow 0^{+}} \cos x \leqslant \lim _{x \rightarrow 0^{+}} \frac{\operatorname{sen} x}{x} \leqslant \lim _{x \rightarrow 0^{+}} 1 \Rightarrow 1 \leqslant \lim _{x \rightarrow 0^{+}} \frac{\operatorname{sen} x}{x} \leqslant 1 \Rightarrow \lim _{x \rightarrow 0^{+}} \frac{\operatorname{sen} x}{x}=1$.

Para calcular el límite por la izquierda, basta hacer el cambio de variable $x=-y$. $\lim _{x \rightarrow 0^{-}} \frac{\operatorname{sen} x}{x}=\lim _{y \rightarrow 0^{+}} \frac{\operatorname{sen}(-y)}{-y}=\lim _{y \rightarrow 0^{+}} \frac{\operatorname{sen} y}{y}=1$

Esto prueba el resultado ya que los limites laterales valen 1.

Figura IV.7.7.4. Justificación del límite de límite de $\operatorname{sen}(x) / x$ y $(\cos (x)-1) / x$ en $x=0\left(2^{\circ}\right.$ de Bachillerato LOGSE de SM, 2001).

En el LT de $2^{\circ}$ (Figura IV.7.7.4) también se introduce una tabla para "predecir" cuál será el límite y luego se procede con el razonamiento que encontramos en otros libros de texto, al que llama "razonamiento especial". Este libro de texto justifica al mismo tiempo el límite de $\operatorname{sen}(x) / x$ y $(\cos (x)-1) / x$.

Este límite también se considera en varios LT de Vicens-Vives, tanto de LOGSE como de LOE (Figuras IV.7.7.5 y IV.7.7.6). En todos ellos se presenta una justificación similar a la que hemos visto anteriormente: se propone una desigualdad basada en la representación geométrica de $\operatorname{sen}(x), x$, etc.... y se realizan transformaciones hasta llegar al límite considerado. Acompañan este resultado con algunos de los que aparecen en la tabla, pero no realiza más justificaciones; tan solo transforma la función mediante las propiedades de las funciones trigonométricas 
Demostración:

A medida que disminuye el arco, arco y seno tienden a cero, de modo que:

$$
\lim _{x \rightarrow 0} \frac{x}{\operatorname{sen} x}=\left[\frac{0}{0}\right]
$$

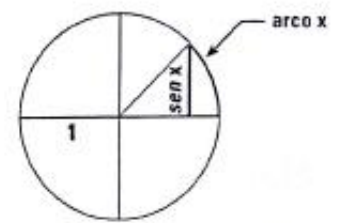

Veamos cómo resolver la indeterminación. Supongamos, de momento, que $x>0$. Es geométricamente claro que $\operatorname{sen} x \leqslant x \leqslant \operatorname{tg} x$

Dividimos entre sen $x$ - positivo, por serlo $x$ - $y$ el sentido de la desigualdad no cambia:

$$
\begin{aligned}
\frac{\operatorname{sen} x}{\operatorname{sen} x} & \leqslant \frac{x}{\operatorname{sen} x} \leqslant \frac{1}{\cos x} \text { (1) } \\
x \rightarrow 0 \quad \downarrow & \downarrow \lim _{x \rightarrow 0} \frac{x}{\operatorname{sen} x} \leqslant 1 \\
1 & \leqslant 1
\end{aligned}
$$

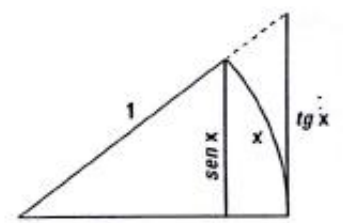

Tomando límites en la desigualdad (1) se obtiene (2), luego $\lim _{x \rightarrow 0} \frac{x}{\operatorname{sen} x}=1$

Nota: si $\mathrm{x}<0$, sirve el mismo razonamiento, salvo que la desigualdad de partida es $\operatorname{sen} x \geqslant x \geqslant \operatorname{tg} x$.

Figura IV.7.7.5. Justificación en el LT del límite en cero de $x / \operatorname{sen}(x)\left(1^{\circ}\right.$ de Bachillerato LOGSE de Vicens-Vives, 1998).

\section{Demostración}

La figura muestra un ángulo de $x$ radianes y su arco, trazado con radio 1 . El arco tiene una longitud igual a $x$ veces el radio. Como el radio mide 1, la longitud del arco es $x$.

Consideramos $x$ positivo. De la figura se deduce $\operatorname{sen} x<x<\operatorname{tg} x=\frac{\operatorname{sen} x}{\cos x}$

Dividimos por sen $\mathrm{x}$ que es positivo:

$$
1<\frac{x}{\operatorname{sen} x}<\frac{1}{\cos x}
$$

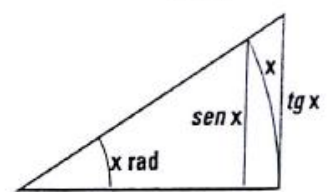

Cuando $x \rightarrow 0^{+}, 1 / \cos x \rightarrow 1$. Así que $1 / \cos x$ empuja a $x / \operatorname{sen} x$ hacia 1 . Por tanto

$$
\lim _{x \rightarrow 0^{+}} \frac{x}{\operatorname{sen} x}=1 \text {, luego } \lim _{x \rightarrow 0^{+}} \frac{\operatorname{sen} x}{x}=1
$$

Teniendo en cuenta que $\frac{\operatorname{sen} x}{x}$ es una función par, el límite por la izquier-

da (cuando $x$ es negativo), es igual que por la derecha:

$$
\lim _{x \rightarrow 0^{-}} \frac{\operatorname{sen} x}{x}=\lim _{x \rightarrow 0^{+}} \frac{\operatorname{sen}(-x)}{-x}=\lim _{x \rightarrow 0^{+}} \frac{\operatorname{sen} x}{x}=1
$$

Como consecuencia

$$
\lim _{x \rightarrow 0} \frac{\operatorname{sen} x}{x}=1
$$

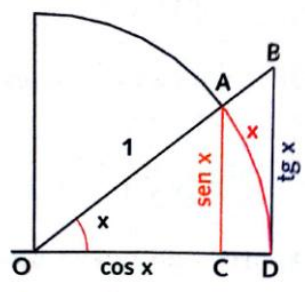

De la figura se deduce que $\operatorname{sen} x \leq x \leq \operatorname{tg} x$, luego:

$$
\begin{gathered}
\frac{\operatorname{sen} x}{\operatorname{sen} x} \geq \frac{\operatorname{sen} x}{x} \geq \frac{\operatorname{sen} x}{\operatorname{tg} x} \Rightarrow \\
\Rightarrow 1 \geq \frac{\operatorname{sen} x}{x} \geq \cos x \\
\text { Cuando } x \rightarrow 0 \text { se verifica que: } \\
1 \geq \lim _{x \rightarrow 0} \frac{\operatorname{sen} x}{x} \geq 1
\end{gathered}
$$

de donde se obtiene:

$$
\lim _{x \rightarrow 0} \frac{\operatorname{sen} x}{x}=1
$$

Figura IV.7.7.6. Justificaciones del límite en cero de $\operatorname{sen}(x) / x$ en cero en los LT de $2^{\circ}$ de Bachillerato LOGSE de Vicens-Vives (1999) a la izquierda y de $2^{\circ}$ de Bachillerato LOE de Vicens-Vives (2009) a la derecha.

Hay aspectos de las justificaciones que son comunes a todos los LT: por ejemplo, el enunciado considerado es la presentación algebraica del límite de $\operatorname{sen}(x) / x$, cuando $x$ tiende a cero; ninguno de los LT considerados utiliza los conectores 
considerados en el marco teórico ni enunciados verbales. El método utilizado es el silogismo; en cuanto al estilo, se trata del análisis matemático global y local, dependiendo de la parte de la justificación que consideran, y gráfico, ya que se apoyan en gráficas para realizar la justificación; el modo es directo en todos los LT menos en el de Vicens-Vives (1980) de $2^{\circ}$ de BUP, que es indirecto.

En cuanto a las funciones de la demostración consideradas, en todos los LT se aprecian las funciones de verificación y comunicación, pero en los casos en los que además complementan con tablas o con las gráficas de las funciones, también tiene función de explicación.

En los casos en que se utilizan etiquetas podemos asegurar que el LT reconoce el proceso como demostración, aunque no se refieren nunca a sus consecuencias, así como tampoco se explica globalmente el proceso, ni se comenta el significado del teorema, que no es un mero cálculo de este límite. La distinción entre justificación y enunciado a veces es tipográfica, otras veces se señala con etiquetas y, en otras ocasiones, no se señala. Vemos que los sistemas de representación son: verbal, gráfico en todos los casos, acompañados de tabular en algunos, y algebraico (fórmula). En ningún caso se explica el significado de las expresiones utilizadas, éstas forman parte del lenguaje habitual del texto y los autores no realizan explicación alguna sobre el significado de las mismas. No se suelen señalar otras vías de justificación, aunque, como hemos visto, algunos LT complementan la justificación con una tabla en la que se muestra cómo evolucionan los valores de la función asociados a los valores de la variable, lo que se puede considerar como otro tipo de justificación, en este caso de tipo inductivo, ya que se utiliza una forma concreta de tendencia de la variable independiente a 0 .

\section{IV.7.8. Otros resultados}

Además de los resultados considerados anteriormente, hemos encontrado otros que aparecen sólo en algunos libros. El tratamiento de todos estos casos constituye este apartado. Son resultados que a veces se encuentra a continuación de otros más comunes, como si de corolarios o casos particulares se tratara, pero que no se consideran en todos los LT dado que se pueden deducir fácilmente del resto de resultados. Estos resultados son los siguientes: 
- Límite de las funciones polinómicas en el infinito

Se trata de un caso simple de límites, dado que se deduce básicamente de la aplicación de las operaciones de los límites a algunas funciones elementales (función potencia, función constante, función identidad). Algunos libros presentan este resultado y lo justifican ya que lo utilizan posteriormente para justificar el comportamiento de las funciones racionales (cociente de funciones polinómicas). Además, hemos encontrado diferentes esquemas de prueba en función de los LT (Tabla IV.7.8.1):

\begin{tabular}{ll}
\hline Límite de las funciones polinómicas en el infinito & \\
LT & EP utilizado \\
\hline Anaya $2^{\circ}$ BUP (1987) & EP inductivo sistemático \\
Anaya $1^{\circ}$ Bachillerato (2002) & EP inductivo de varios casos \\
Vicens-Vives $1^{\circ}$ Bachillerato (1998) & EP inductivo de varios casos \\
Vicens-Vives $2^{\circ}$ Bachillerato (1999) & Prueba Preformal \\
Vicens-Vives $1^{\circ}$ Bachillerato (2003) & EP inductivo de varios casos \\
Anaya $1^{\circ}$ Bachillerato (2008) & EP inductivo de varios casos \\
\hline
\end{tabular}

Tabla IV.7.8.1. EP utilizados en los LT para justificar el límite de las funciones polinómicas en el infinito.

Se observa que, salvo el LT de $2^{\circ}$ de Bachillerato de LOGSE de Vicens-Vives (1999), que utiliza una prueba preformal, el resto de LT que lo justifican lo hacen mediante EP inductivos, bien de 1 caso, de varios o sistemático.

El LT de Anaya (1987), de $2^{\circ}$ de BUP, muestra dos ejemplos de límites, uno que tiende a infinito y otro a menos infinito, y tras formular los ejemplos, enuncia el resultado:

El límite de un polinomio en $x$ cuando $x \rightarrow \infty$ es $\infty$ o $-\infty$ según el signo del coeficiente del término de mayor grado.

(Anaya, $2^{\circ}$ de BUP, 1987, pp. 151).

Indica que se trata de un recordatorio de una regla que ya se conocía para los límites de sucesiones. El enunciado no sigue una estructura lógica determinada. La función que se aprecia es la de comunicación, porque antes de enunciar el resultado muestra varios ejemplos ilustrativos. Los sistemas de representación utilizados son el simbólico en los ejemplos y el verbal en el enunciado. No se hacen referencias al proceso (aunque al ser tan exiguo, es esperable que no los haga) y tampoco se señalan otras vías de justificación. 
Los LT de Anaya (2002 y 2008, recordemos que son iguales), de $1^{\circ}$ de Bachillerato, hacen un planteamiento similar al LT de Anaya (1987), ya que muestran varios ejemplos que ilustran el resultado antes de enunciarlo.

El límite cuando $x \rightarrow+\infty$ de una función polinómica es $+\infty$ o $-\infty$ según el coeficiente del término de mayor grado sea positivo o negativo.

(Anaya, $1^{\circ}$ de Bachillerato, 2003, pp. 283 y 2008, pp. 283)

En ambos casos hablamos únicamente de la función de comunicación porque no explica por qué es el término dominante el que decide cuál es el límite (al crecer más deprisa que los otros términos) sino que los ejemplos muestran un comportamiento similar y de ahí se deduce el resultado.

$$
\begin{aligned}
& \text { - } \frac{2 x^{3}-6 x^{2}+4}{2 x^{3}}=\frac{2 x^{3}}{2 x^{3}}-\frac{6 x^{2}}{2 x^{3}}+\frac{4}{2 x^{3}}= \\
& =1-\frac{3}{x}+\frac{2}{x^{3}} \rightarrow 1 \\
& \underbrace{\begin{array}{lll}
\downarrow & \downarrow & \\
0 & 0
\end{array} \rightarrow-\infty}_{\text {si } x \rightarrow+\infty}
\end{aligned}
$$
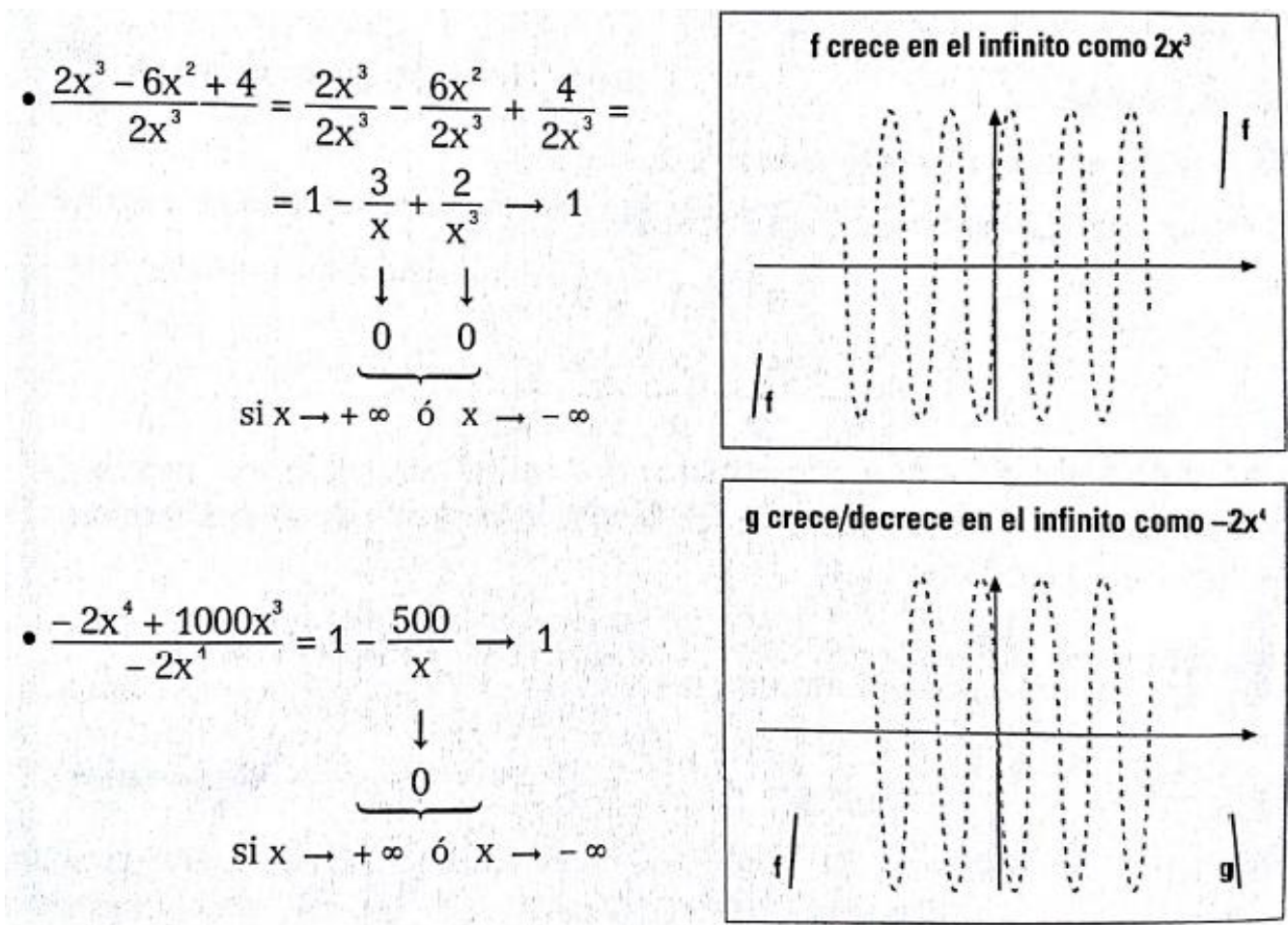

Figura IV.7.8.1. Ejemplos utilizados para justificar que el límite en el infinito de las funciones polinómicas coinciden con los límites de sus términos dominantes en el LT de Vicens-Vives (1998) de $1^{\circ}$ de Bachillerato. Las gráficas no se corresponden con las funciones.

El LT de Vicens-Vives (1998), de $1^{\circ}$ de Bachillerato, que como ya hemos mencionado incorpora los límites en el estudio de funciones, es decir, se centra en estudiar los tipos de funciones y dentro de este estudio, comenta los límites interesantes en cada caso, incorpora este resultado dentro del estudio de los polinomios (aunque debería denotarlo como funciones polinómicas). Indica que, debido a que los polinomios no tienen discontinuidades, sólo tienen interés los 
límites en el infinito. Empieza con la definición de término dominante de un polinomio, e indica que el límite de los polinomios depende del límite del término dominante, y lo ilustra con dos ejemplos, tras los cuales, establece el enunciado general. En ambos ejemplos realiza transformaciones sobre la expresión algebraica del cociente de cada polinomio entre su término dominante para ver que este límite es 1 , pero no indica que el hecho de que el límite de dicho cociente sea 1 implica que tanto el polinomio como el término dominante tengan el mismo límite. Además, ilustra cada ejemplo con dos gráficos que pretenden mostrar el crecimiento similar de ambos polinomios y sus términos dominantes, pero que no se corresponden con los ejemplos seleccionados (Figura IV.7.8.1).

Se trata de un error de sistematización, ya que las gráficas no se corresponden ni con los polinomios considerados $\left(2 x^{3}-6 x^{2}+4\right.$ y $\left.-2 x^{4}+100 x^{3}\right)$ ni con los cocientes. De hecho, los gráficos recuerdan a funciones circulares y no a polinómicas, si tenemos en cuenta que las funciones polinómicas tienen, como máximo, tantas raíces como el grado del polinomio que las define. Estos gráficos, además de ser confusos (desconocemos qué intenciones tenían los autores al utilizarlos) son erróneos, y provocarán errores a los alumnos que deberían ser evitados.

El LT de Vicens-Vives (1999), de $2^{\circ}$ de Bachillerato, justifica este resultado con una prueba preformal, siendo el único LT que lo hace. En primer lugar justifica que el límite del cociente de un polinomio entre su término dominante es 1, y que eso implica que son infinitos equivalentes para, a continuación, justificar que dos infinitos equivalentes tienen el mismo límite (más adelante establece este resultado para infinitos en general, y no sólo en el caso de polinomios). Por último establece el resultado general, enunciado de forma verbal y simbólica, y lo ilustra con dos ejemplos. El carácter de esta prueba preformal es transformacional, de estilo algebraico, y modo analítico. Las funciones que se identifican son las de comunicación y verificación. No se hace mención al proceso, ni a las consecuencias de haberlo justificado, ni se explican las pautas generales de la justificación, sí que se indican ejemplos de aplicación, y el caso general de equivalencia de infinitos equivalentes se establece y se justifica más adelante en el LT, aunque en este momento no se señalen otras vías de justificación. La distinción entre enunciado y justificación es únicamente tipográfica y no se identifica ninguno de ellos. 
El LT de Vicens-Vives (2003), de $1^{\circ}$ de Bachillerato, realiza una discusión previa al enunciado del resultado. Lo considera dentro del apartado de cálculo de límites en el infinito y, en este caso, empieza mostrando dos ejemplos e indicando que es suficiente con observar su comportamiento en los extremos de la función (quiere decir, cuando $x$ tiene a $\pm \infty$ ). Establece cuatro formas diferentes en función de las tendencias de la función en $\pm \infty$, y las ilustra con gráficas de funciones de cada uno de esos tipos (Figura IV.7.8.2). Luego examina un caso concreto, es decir, una función polinómica en concreto, mostrando una tabla de valores $\mathrm{y}$ comparando entre el valor que toma la función para ciertos valores de $x$, los respectivos valores que toma el término dominante y los que toma el resto de la función. De este ejemplo deduce que las funciones polinómicas tienen el mismo límite en el infinito que su término de mayor grado. Tal y como está tratado, podría considerarse que el EP utilizado, en parte, es inductivo sistemático al establecer las formas de las funciones y elegir una de cada tipo, en parte, inductivo de un caso, porque la coincidencia del límite de la función polinómica con el límite de su término dominante se establece únicamente a partir de un ejemplo.

\begin{tabular}{|c|c|c|c|c|}
\hline & Tipo (..$>)$ & $\operatorname{Tipo}(\Lambda, \downarrow)$ & Tірo $(L, \backslash)$ & Tipo $(1, \lambda)$ \\
\hline $\lim _{x \rightarrow-\infty} f(x)$ & $+\infty$ & $+\infty$ & $-\infty$ & $-\infty$ \\
\hline $\lim _{x \rightarrow+\infty} f(x)$ & $+\infty$ & $-\infty$ & $-\infty$ & $+\infty$ \\
\hline
\end{tabular}

(a)

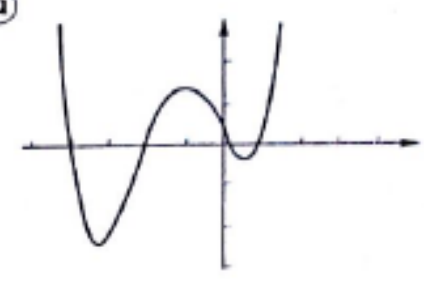

(b)

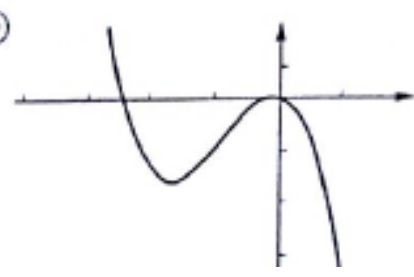

(c)

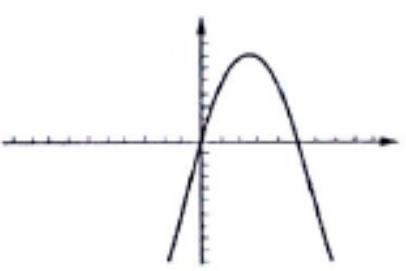

(d)

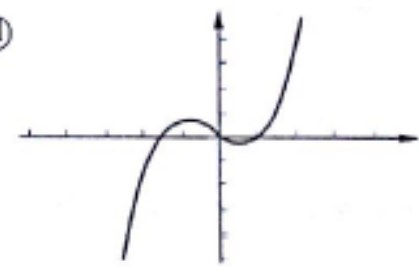

Figura IV.7.8.2. EP inductivo sistemático ( $1^{\circ}$ de Bachillerato de Vicens-Vives, 2003).

- Límite en el infinito de raíces cuadradas de polinomios

Si bien en todos los LT se explica cómo calcular límites de raíces cuadradas de funciones polinómicas, sólo en uno, el LT de Anaya (1987) de $2^{\circ}$ de BUP se 
presenta con una formulación de resultado, incorporándolo al sistema de resultados sobre límites, y lo justifica mediante un EP inductivo sistemático. De hecho, indica que se trata de una regla ya conocida para el cálculo del límite de sucesiones, y que procede a recordarla (junto con la del límite de un polinomio cuando $x$ tiende a infinito). Los ejemplos que muestra son uno en que el polinomio tiende a más infinito y otro que tiende a menos infinito (cuando $x$ tiende a infinito), y una vez indicados ambos ejemplos (sólo muestra el resultado, no realiza una explicación detallada de cómo llega al límite) enuncia el resultado:

El límite cuando $x \rightarrow \infty$ de la raíz cuadrada de un polinomio es infinito si el polinomio tiende a $\infty$. Si no, no existe.

(Anaya, $2^{\circ}$ BUP, 1987, pp. 151).

La estructura lógica del enunciado se aproxima a condición necesaria aunque no está escrita exactamente en esos términos. La única función que podemos atribuir es la de comunicación, ya que ni si quiera explican los ejemplos que muestran, ni se trata de una verificación, ni se conduce al descubrimiento. El sistema de representación utilizado es el simbólico en los ejemplos considerados y el verbal en el enunciado. En cuanto al proceso, el LT no hace ningún reconocimiento especial, aunque al no tratarse de una demostración es normal, ni señala otras vías de justificación.

En el resto de LT no se establece como resultado, sino que se muestran ejemplos de cómo resolver dicha indeterminación.

- Límite de los tipos $\rightarrow \mathrm{k} / \rightarrow \infty y \rightarrow \mathrm{k} / \rightarrow 0$

Los límites de los tipos $\rightarrow k / \rightarrow \infty$ y $\rightarrow k / \rightarrow 0$ suelen presentarse en casi todos los LT, pero al tratarse la aritmética extendida de los límites y no presentarse una indeterminación, no suele justificarse. Únicamente lo hace el LT de VicensVives (1998) de $1^{\circ}$ de bachillerato de LOGSE, que lo justifica mediante un EP inductivo de un caso: en primer lugar presenta el estudio de los límites en $+\infty$, $-\infty, 0^{+}$y $0^{-}$de la función $y=1 / x$, dibujando la gráfica correspondiente $\mathrm{y}$ mostrando una tabla numérica para cada caso, para establecer finalmente ambas reglas, ambas enunciadas en lenguaje verbal y simbólico. Aunque no utiliza la formulación "si...entonces", podríamos considerar que se trata de enunciados de condición necesaria. Los sistemas de representación utilizados son el gráfico y el tabular en la justificación, y verbal y simbólico en el enunciado. Se podría hablar de la función de descubrimiento, al enunciarse la regla tras observas un ejemplo. 
No se señalan otras posibles vías de justificación, aunque no es de extrañar teniendo en cuenta que este LT ni siquiera enuncia el concepto de límite, sino que lo establece a partir de un ejemplo.

\section{IV.8. INTERPRETACIÓN DE LOS DATOS}

Una vez realizado el análisis de los resultados presentados en cada LT, procedemos a la interpretación de los datos obtenidos en dicho análisis. En cada apartado de este epígrafe hemos considerado uno de los grupos de categorías de nuestro marco teórico de forma separada, para facilitar la comparación entre libros y entre legislaciones. En este apartado se presentan las reflexiones que se derivan de los análisis mostrados.

Da las interpretaciones que se realizan de los datos obtendremos las pautas para la realización de la propuesta metodológica, enfocada desde la justificación matemática, que realizaremos posteriormente.

\section{IV.8.1. Esquemas de prueba}

En la Tabla IV.8.1.1 se muestra un recuento de los EP que se han encontrado en los LT por cursos y tipos de EP, con la suma total de resultados justificados por curso. En la última columna se ha añadido el número de LT que se ha analizado de cada curso, que permite ver si un aumento o disminución del número de resultados enunciados en un determinado curso o periodo coincide con una muestra más grande o más pequeña.

Además, en la columna Total EP o PP, que representa el número total de EP de cualquier tipo o PP encontrados en los libros de ese curso y periodo legislativo se ha añadido, entre paréntesis, el porcentaje de EP o PP sobre el número total de resultados enunciados para ese curso y periodo legislativo. Hay que señalar que, aunque se ha incluido el recuento de los libros de COU debido a que en algunos aparece algún resultado sobre límites, la presencia de dicho concepto en ese nivel educativo es meramente anecdótica, y en muchos textos ni siquiera se recuerda, por lo que el bajo número de EP en dicho curso no es significativo. 


\begin{tabular}{|c|c|c|c|c|c|c|c|c|c|c|c|}
\hline \multicolumn{2}{|c|}{ Legislaciones } & \multicolumn{8}{|c|}{ Esquemas de prueba } & \multirow{2}{*}{$\begin{array}{l}\text { Total } \\
\text { resultados }\end{array}$} & \multirow{2}{*}{$\begin{array}{l}\text { LT } \\
\text { muestra }\end{array}$} \\
\hline & & EP0 & EPi1 & EPiV & EPiS & $\mathrm{EPt}$ & $\mathrm{EPa}$ & PP & Total EP o PP & & \\
\hline \multirow[t]{2}{*}{ LGE } & $2^{\circ} \mathrm{BUP}$ & 84 & 2 & 0 & 2 & 11 & 26 & 2 & $43(33.9 \%)$ & 127 & 6 \\
\hline & $\mathrm{COU}$ & 5 & 0 & 0 & 0 & 1 & 1 & 0 & $2(29.6 \%)$ & 7 & 2 \\
\hline \multirow[t]{2}{*}{ LOGSE } & $1^{\circ}$ Bach. & 32 & 6 & 6 & 2 & 5 & 0 & 1 & $20(38.5 \%)$ & 52 & 5 \\
\hline & $2^{\circ}$ Bach. & 156 & 4 & 0 & 2 & 14 & 6 & 1 & $27(14.8 \%)$ & 183 & 5 \\
\hline \multirow[t]{2}{*}{ LOE } & $1^{\circ}$ Bach. & 20 & 7 & 1 & 0 & 1 & 0 & 0 & $9(31 \%)$ & 29 & 4 \\
\hline & $2^{\circ}$ Bach. & 134 & 3 & 0 & 2 & 6 & 0 & 1 & $12(8.2 \%)$ & 146 & 4 \\
\hline Total & & 431 & 22 & 7 & 8 & 38 & 33 & 5 & 113 & 544 & 26 \\
\hline
\end{tabular}

Tabla IV.8.1.1. Resumen del número de EP encontrados en los LT por legislaciones y cursos.

En primer lugar, vemos que el porcentaje más alto de resultados justificados con respecto al total de resultados corresponde con $1^{\circ}$ de Bachillerato de LOGSE, aunque esto se debe, en gran parte, a que el número de resultados enunciados es menor que en otros cursos. Algo similar ocurre con $1^{\circ}$ de Bachillerato LOE, cuyo porcentaje de resultados justificados es superior al $30 \%$ y sin embargo, es el curso con menor número de justificaciones (exceptuando a COU). En números absolutos, el mayor número de justificaciones se encuentra en $2^{\circ}$ de BUP de la LGE, aunque también se trata del curso con mayor LT analizados. Sin embargo, si comparamos la media de resultados justificados por LT en cada curso y periodo legislativo (Total EP o PP/LT muestra), que se muestran en la Tabla IV.8.1.2 observamos que el mayor cociente también corresponde a ese curso, lo que nos permite asegurar que el periodo con una mayor tendencia de justificación es la LGE, seguido por la LOGSE (medias de 4 y 5.4 respectivamente en cada curso) y en último lugar se encuentra al LOE (con medias de 2.25 y 3 en cada curso).

\begin{tabular}{|c|c|c|c|c|c|c|}
\hline Total EP o PP & $\begin{array}{l}\text { LGE } \\
2^{\circ} \text { BUP }\end{array}$ & $\mathrm{COU}$ & $\begin{array}{l}\text { LOGSE } \\
1^{\circ} \text { Bach. }\end{array}$ & $2^{\circ}$ Bach. & $\begin{array}{l}\text { LOE } \\
1^{\circ} \text { Bach. }\end{array}$ & $2^{\circ}$. Bach. \\
\hline LT muestra & 7.16 & 1 & 4 & 5.4 & 2.25 & 3 \\
\hline
\end{tabular}

Tabla IV.8.1.2. Media de resultados justificados por libro en cada curso y periodo legislativo.

Por otro lado, los cursos en los que la media de resultados que se enuncian por libro de texto es más alta son $2^{\circ}$ de Bachillerato de LOGSE y LOE (Tabla IV.8.1.3), y sin embargo, los porcentajes de resultados justificados de los enunciados son los más bajos, lo que contribuye a afirmar que ha habido un descenso de justificaciones a lo largo de las leyes. 


\begin{tabular}{|c|c|c|c|c|c|c|}
\hline Total resultados & $\begin{array}{l}\text { LGE } \\
2^{\circ} \text { BUP }\end{array}$ & $\mathrm{COU}$ & $\begin{array}{l}\text { LOGSE } \\
1^{\circ} \text { Bach. }\end{array}$ & $2^{\circ}$ Bach. & $\begin{array}{l}\text { LOE } \\
\mathbf{1}^{\circ} \text { Bach. }\end{array}$ & $2^{\circ}$. Bach. \\
\hline LT muestra & 21.16 & 3.5 & 10.4 & 36.6 & 7.25 & 36.5 \\
\hline
\end{tabular}

Tabla IV.8.1.3. Media de resultados enunciados por libro en cada curso y periodo legislativo.

\begin{tabular}{llll}
\hline & $\begin{array}{l}\text { Teoremas o } \\
\text { propiedades asociadas } \\
\text { al concepto }\end{array}$ & $\begin{array}{l}\text { Operaciones con } \\
\text { límites }\end{array}$ & $\begin{array}{l}\text { Resultados asociados a } \\
\text { indeterminaciones o familias de } \\
\text { funciones }\end{array}$ \\
\cline { 2 - 4 } LGE & $12(26.7 \%)$ & $11(24.4 \%)$ & $22(48.9 \%)$ \\
LOGSE & $4(8.5 \%)$ & $2(4.3 \%)$ & $41(87.2 \%)$ \\
LOE & $4(19 \%)$ & 0 & $17(81 \%)$ \\
\hline
\end{tabular}

Tabla IV.8.1.4. Número (y porcentaje) de resultados de cada tipo que son justificados.

Ya comentamos la evolución de cada tipo de justificación en el apartado IV.4.5, y se apreciaba en el gráfico IV.4.5.2 que las justificaciones más cercanas a la demostración formal, los EP transformacionales, axiomáticos, e incluso las pruebas preformales, experimentan un descenso notable desde la LGE, siendo en aquel periodo en el que más abundan, en detrimento de los otros tipos de EP, para ser progresivamente sustituidas por EP inductivos de uno o varios casos o sistemáticos. No obstante, hay que señalar que los tipos de resultados que se justifican también cambian a lo largo de las legislaciones (Tabla IV.8.1.4). Los resultados que más se justifican en general en todos los periodos son aquellos asociados con indeterminaciones o familias de funciones, se aprecia un notable descenso de en el número de justificaciones asociadas tanto a teoremas o propiedades asociadas al concepto de límite y a las operaciones con límites. Este hecho es algo que hemos ido apuntando a lo largo del trabajo, es decir, consideramos que los LT conceden más importancia al cálculo de límites que a la profundización en la comprensión del concepto.

Aunque, como hemos dicho, el número de justificaciones ha descendido, no lo ha hecho el número de resultados enunciados, por el contrario, en los cursos de $2^{\circ}$ de bachillerato tanto de LOGSE como LOE el recuento de resultados enunciados mostrado en la Tabla IV.8.1.1 ha aumentado. Este aumento en el número de resultados se debe principalmente a que los LT enuncian las propiedades de los límites de forma más exhaustiva (diferentes enunciados para diferentes casos de una misma propiedad, como por ejemplo, un enunciado para cada caso de la aritmética extendida sobre límites) y por un aumento de técnicas que son formuladas como si de teoremas se tratara. Este hecho apunta a la misma idea que ya hemos comentado: que existe una tendencia mayor a favorecer el cálculo 
de límites que a trabajar con la comprensión del concepto en las legislaciones más recientes.

\section{IV.8.2. Técnicas usadas en la demostración}

En relación a las técnicas empleadas, conviene recordar que existen varias distinciones en función del EP considerado: en el caso de que no se justifique el teorema, estas categorías no admiten ninguna clasificación; si se trata de EP inductivos (de cualquier tipo) las categorías de método y modo tampoco admiten ninguna clasificación, y en el estilo, se clasifica según el ejemplo considerado (algebraico, gráfico, numérico...); por último, sólo tiene sentido considerar todas las categorías si se trata de EP axiomáticos, transformacionales, o pruebas preformales.

En los tipos de enunciados, en general se utiliza el de condición suficiente, con la fórmula "si...entonces...". No obstante, algunas veces se omiten el "entonces" o el "si". Este tipo de enunciados son más propios de los teoremas asociados al concepto de límite, y en algunos casos, en las operaciones o en los resultados asociados a indeterminaciones, se pierde esta estructura puesto que los LT presentan igualdades algebraicas.

En los resultados asociados al concepto de límite, en general, se utilizan silogismos, se utiliza un estilo directo (se parte de la definición) y el estilo es del Análisis Matemático local. También la suma se ajusta a dichas clasificaciones. Esto se debe a que en este tipo de resultados, la mayoría de los LT utilizan un EP de tipo axiomático transformacional. Por otro lado, conviene recordar que la mayoría de estos resultados se enuncian y justifican en los LT de la LGE, que tiene mayor tendencia al formalismo.

En cuanto a los resultados asociados a las indeterminaciones, se utilizan en mayor medida los EP inductivos, de estilo algebraico y gráfico. Parece que los LT consideran suficiente los ejemplos gráficos y algebraicos para la justificación de este tipo de resultados. Esto se une al hecho de tratar los límites de ciertas funciones elementales como teoremas, que refuerza la idea de la importancia que los LT dotan al cálculo de límites, aunque sea de forma mecánica. De este tipo de resultados, el único que llama la atención por recibir una atención diferente es el del límite del cociente $\operatorname{sen}(x) / x$, cuando $x$ tiende a 0 , dado que suelen emplearse 
EP transformacionales: el más abundante es de estilo gráfico, pero también se utilizan de estilo numérico, y alguno algebraico. Todos ellos son de modo analítico y el método suele ser el silogismo (se aplica el criterio del sándwich).

\section{IV.8.3. Funciones de la demostración}

Todas las justificaciones que se presentan atienden a la finalidad de comunicar y verificar. Estas funciones son las más comunes, en parte por la naturaleza implícita del medio en el caso de la comunicación (los LT se diseñan para recoger los contenidos que se quieren comunicar a los alumnos y, por tanto, las justificaciones mostradas cumplen esa función) y por la de las propias justificaciones, cuya función principal en el ámbito de las matemáticas es el de verificar los teoremas que justifican. Esta última función, la de verificación, es más evidente en el caso de EP transformacionales y axiomáticos, por su proximidad a la demostración matemática formal, que en el resto de categorías. En el caso de las PP sería conveniente incidir en su aspecto de verificación.

En algunos casos se ha considerado que la justificación utilizada atiende a la explicación, pero son muy pocos casos, y en algunos de ellos sólo lo hacen de forma parcial. Observamos que las justificaciones más formales (EP axiomáticos o transformacionales) se preocupan más de la cadena de argumentos lógicos que de explicar en cada caso que motiva dicha cadena. Para los aprendices, estas deducciones no tienen por qué ser evidentes y dichas justificaciones serían más explicativas si se explicaran los pasos utilizados. Las pocas PP que hemos encontrado pueden ser más asequibles para los alumnos de estos niveles, pero creemos que tampoco llegan a cumplir la función de explicación, y que sería necesario que indicaran que ese razonamiento se puede generalizar, así como justificar los pasos del razonamiento como en el caso de EP transformacionales y axiomáticos.

En los resultados asociados a este concepto, el límite funcional, no se ha apreciado la función de descubrimiento, pero consideramos que esto se debe al concepto en sí, y no a la intencionalidad de los autores. No todas las justificaciones conducen al descubrimiento de nuevos resultados.

No hemos mencionado la función de sistematización en el análisis de cada justificación, pero como indicamos en la descripción del marco teórico, los LT 
muestran, por su propia naturaleza, una sistematización de los resultados matemáticos. Cabe destacar, que los LT muestran diferentes sistematizaciones para el concepto de límite, y que existen numerosas diferencias en la presentación del concepto: orden, relación con continuidad, resultados que se enuncian, resultados que se justifican...En este sentido, al final del presente trabajo, mostraremos una propuesta didáctica en la que se refleje una sistematización que, teniendo en cuenta los análisis realizados y las reflexiones de dichos análisis, sea más conveniente para favorecer la comprensión del concepto de límite por parte de los alumnos.

Como tarea para el futuro, queda pendiente refinar la relación entre las funciones de la demostración que se han mostrado en los LT analizados y los tipos de EP o PP utilizados.

\section{IV.8.4. Reconocimiento de procesos}

El comportamiento en este aspecto en los LT analizados es muy variado: hay LT que identifican el proceso como una demostración porque ponen una etiqueta (en el caso de que se trate de EP transformacionales o axiomáticas), otros LT, aunque no utilizan una etiqueta, hacen alguna referencia a los verbos "demostrar" o "probar", u otros sinónimos, o incluso mencionan que no se demuestra y el porqué, pero otros LT no realizan ninguna mención de si el razonamiento que presentan justifica el resultado que han enunciado o no.

Sin embargo, ninguno de los LT hace referencias a las consecuencias de justificar un resultado. Este comportamiento es normal en los LT que no justifican, pero tampoco se observan en aquellos que justifican de algún modo. Desde el punto de vista de la enseñanza de la demostración sería interesante resaltar este aspecto en los LT, es decir, indicar explícitamente que una vez que un resultado se ha justificado, no es necesario realizar ninguna comprobación posterior, ni se pueden encontrar contraejemplos,..., ya que resaltaría la función de explicación de la demostración además de trasmitir el valor que estás tienen en el campo de las matemáticas.

Los libros, en general, siguen orientaciones desde la perspectiva de la construcción matemática, no desde la perspectiva didáctica. Por esta razón, no aparecen referencias sobre el alcance de las demostraciones matemáticas. Así, no 
se indica que los resultados demostrados (los teoremas) se pueden aplicar directamente, sin necesidad de repetir los pasos con los datos del problema o ejercicios de aplicación y tampoco se informa sobre la imposibilidad de encontrar contraejemplos. Además, no se observa una intención por parte de la mayoría de LT de enseñar a demostrar, es decir, las justificaciones acompañan a los resultados que justifican pero, salvo en algunas excepciones, el objeto de enseñanza no es la demostración matemática.

\section{IV.8.5. Expresiones que utiliza}

Las expresiones utilizadas en los LT suelen diferir en función de los autores pero, en general, todos usan las mismas. Sin embargo, hemos encontrado algunos abusos de notación que se repiten en todos los LT, asociados al concepto de límite, y que deberían evitarse. Por ejemplo, en el caso de las indeterminaciones, todos los LT consideran el infinito como un número, o se permiten expresiones en forma fraccionaria con denominador cero. Esto conlleva dos errores: el primero, que asocia propiedades a elementos que no las tienen, como por ejemplo, considerar el infinito como un número o que la división entre cero está permitida; el segundo, que mantiene subyacente la idea de que para el concepto de límite de una función en un punto importa lo que ocurre en un punto cuando se trata de todo lo contrario. Consideramos que deberían usarse expresiones que eviten estos deslices, como por ejemplo, debería sustituirse expresiones del tipo $\infty \cdot k$ por $\rightarrow \infty \rightarrow \mathrm{k}$, o bien, sustituir $k / 0$ por $\rightarrow k / \rightarrow 0$. En general, siempre que se consideren propiedades u operaciones en las que los objetos son límites, deberían representarse estos últimos con una notación específica como la que acabamos de utilizar.

Por otro lado, si consideramos los sistemas de representación utilizados vemos que en su mayoría se utilizan el verbal y las fórmulas (o simbólico). Se consideran representaciones gráficas acompañando a las definiciones, en la caracterización del límite mediante los límites laterales en los textos que lo justifican de LOE o en los resultados asociados a familias de funciones, en los que la justificación muchas veces se basa en mostrar la gráfica de la función, y de ella inducir el límite en un punto o en el infinito por la forma de la gráfica. 
Debemos destacar que ninguno de los LT explica el significado de las expresiones que utilizan, principalmente porque son habituales en el LT, y bien suponen que los alumnos las conocen o bien se han explicado al principio del LT.

\section{IV.8.6. Consideraciones globales}

En general, los LT no explican el proceso de la justificación de forma que se aclaren cuáles son las líneas generales de la justificación. Los LT que justifican se limitan a mostrar la justificación, cuando, en nuestra opinión, ésta sería más clara y explicativa del resultado que justifica, si previamente el LT indicara cuales son los pasos que se van a llevar a cabo y por qué se sigue ese camino. Esta explicación contribuiría además a favorecer la adquisición de las competencias asociadas a la demostración, es decir, a la enseñanza de la demostración como proceso en sí.

No se suelen explicar las consecuencias de los resultados enunciados, excepto en los casos de reglas de cálculo, en los que se acompañan de ejemplos en los que se aplica el resultado (por otro lado, esa es la función de enunciar y (o justificar una regla de cálculo de límites, realizar dicho cálculo). En algunos casos, cuando se utilizan resultados anteriores en la justificación de un enunciado, sí que se hacen referencias a dichos resultados, pero son los únicos puntos en los que encontramos alguna indicación de relaciones o utilidad del resultado. Por ejemplo, ningún LT establece que el límite $\lim _{x \rightarrow a} x=a$ es el resultado más importante relacionado con el cálculo de límites, ya que provee de la primera técnica de cálculo de límites mediante la sustitución de la variable independiente de la función por el valor al que tiende dicha variable y que facilita dicho cálculo enormemente (sin este resultado, habría que aplicar la definición a cualquier función en cualquier punto, lo que no siempre es ni fácil ni breve).

La distinción entre enunciado y justificación es diversa en los diferentes LT aunque se mantiene en todos los resultados en un mismo LT. Esta categoría está relacionada con la categoría sobre el reconocimiento de procesos, ya que los LT que etiquetan sus resultados como "teoremas" o "propiedad" y las justificaciones como "demostración" o "justificación", están reconociendo el proceso como una justificación. No obstante, muchos LT no realizan esta distinción de forma tan clara. Algunos se limitan a realizar una distinción tipográfica, que puede basarse 
en resaltar el enunciado mediante otro tipo de letra (enfatización), un cuadro de color, o algo similar.

Ningún LT indica que existan otras vías para justificar los enunciados que establecen ni siquiera cuando utilizan EP inductivos y podrían indicar que se pueden justificar mediante procedimientos más formales y rigurosos.

\section{IV.9.REFLEXIONES}

En este último apartado recogemos una serie de reflexiones obtenidas a partir del trabajo realizado y que se ha expuesto en el capítulo. El objetivo general de nuestro trabajo, consistente en el estudio de la evolución de la demostración matemática en libros de texto preuniversitarios y clasificar los procesos de justificación atendiendo al marco teórico establecido, ha sido el motor que ha impulsado nuestro trabajo y nos ha aportado un mayor conocimiento del tratamiento de los conceptos involucrados en el estudio y no sólo de la demostración.

Han surgido algunas dificultades en el proceso de análisis, y estas dificultades nos han llevado a tener en cuenta otros aspectos al margen de los considerados inicialmente. Una de las primeras dificultades a la que nos hemos enfrentado ha sido la diversidad de sistematizaciones encontradas en los libros de texto. Esta diversidad la hemos encontrado tanto en qué resultados se enuncian (no son los mismo en todos los LT), la definición de los conceptos (no todos parten de la misma idea o definen el límite funcional de la misma manera) y al orden de presentación de los resultados (incluso cuando se consideran los mismos resultados, estos no se ordenan en todos los LT de la misma forma). Esta diversidad ha ocasionado que, en muchos casos, no haya sido posible comparar las justificaciones entre LT debido a que un mismo resultado se enuncia de formas diferentes o bien no se encontraba en todos los LT. También se ha dificultado el análisis cuantitativo, debido a que el número de resultados enunciados influye en el número de resultados justificados, así como la forma de considerar dichos resultados (englobar varios casos en un mismo teorema, enunciarlos como teoremas diferentes...). Para hacer frente a esta dificultad hemos desglosado el análisis en varias etapas: la primera parte hace referencia únicamente al contenido matemático presentado (y su organización), en la 
segunda parte se clasifican los resultados en función del esquema de prueba utilizado en cada caso. Esto nos permite obtener una primera visión de la evolución de los esquemas de prueba y nos posibilita agrupar los resultados en bloques dentro de los cuales sea más fácil la comparación. En último lugar, hemos realizado el análisis más fino, atendiendo a todos los aspectos de nuestro marco teórico y estableciendo comparaciones entre los diversos libros.

En relación a la diversidad en la sistematización de las matemáticas ofrecida en los diversos LT que hemos comentado anteriormente, no se observa ninguna regularidad, ni siquiera dentro de la misma editorial, a excepción de los LT de distinto curso que son de una misma colección, ya que se supone que uno es continuación de otros. Esto nos lleva a pensar que esta diversidad, y por tanto algunas consideraciones en relación a la demostración, dependen más del equipo de autores en concreto que de una política editorial constante en el tiempo.

Sin embargo, sí que se observa una clara diferencia entre los LT del primer periodo (LGE) y los de los otros dos (LOGSE y LOE). Los dos últimos periodos, en general, hacen propuestas más o menos similares, tanto en los resultados que se enuncian, en los que se justifican y en el tipo de justificación utilizada. No así el primer periodo, mucho más formal y riguroso que los dos siguientes, con un mayor número de resultados enunciados y con justificaciones más rigurosas. Creemos que este hecho tuvo una influencia en la localización de la muestra, ya que fue más fácil conseguir los ejemplares de LGE que los de LOGSE a pesar de ser más antiguos, quizás por el valor matemático que se les atribuye en oposición a los libros de LOGSE.

En cuanto a la evolución de la demostración, se ha observado que, en resumidas cuentas, en relación al concepto de límite y los teoremas y propiedades asociados a éste, se produce un descenso notable de las justificaciones, principalmente en el cambio de la LGE a la LOGSE, manteniéndose un nivel similar en la LOE. Además, el tipo de EP que más ha descendido ha sido el EP axiomático (más cercano a las demostraciones formales). Sin embargo, se produce un aumento de EP inductivos en la LOGSE, aunque no siguen aumentando en la LOE, pero en ambas legislaciones la utilización de estos tipos de EP es mayor que en la LGE.

Conviene señalar también que el nivel educativo en el que se consideran estos conceptos es más precoz en la LGE, que se establecen en $2^{\circ}$ de BUP (15 años), y sin embargo, en LOGSE y LOE el límite no se introducen hasta $1^{\circ}$ de 
Bachillerato (16 años), al menos de forma formal e indicando que se trata del límite funcional.

En relación a los objetivos e hipótesis de nuestro trabajo, hemos encontrado números indicios que nos llevan a afirmarnos en nuestra idea sobre que se pretende convencer a los alumnos desde la intuición antes que desde el razonamiento matemático. No obstante, es conveniente puntualizar que estamos considerando únicamente los teoremas relacionados con el concepto de límite, es decir, que puede que esta inclinación hacia la intuición se deba a las dificultades que conlleva este concepto, uno de los más difíciles del Análisis Matemático, pero no en otros conceptos. No obstante, el trabajo del próximo capítulo en el que se analizan las justificaciones realizadas para los teoremas de continuidad nos indicará si esta tendencia se debe a los cambios educativos o sólo al concepto de límite.

También se han encontrado algunos aspectos que, en nuestra opinión, deberían tratarse de otra manera pues pueden conducir a errores de comprensión por parte de los alumnos. Por ejemplo, aunque muchos LT acompañan las definiciones de límite funcional con gráficas, algunos no reflejan el concepto, sino que se limitan a mostrar una función y vinculan un valor de $x$ con un valor de $y$, que incluso se trata, en ocasiones de una función continua (Figura IV.5.3). Sin embargo, para reflejar el concepto de límite se deben evitar tanto las funciones continuas en el punto en el que se estudia el límite (y no inducir la idea de que el límite se alcanza siempre) y mostrar los entornos de los valores de la variable independiente y dependiente, como en la gráfica IV.5.10. También consideramos que deberían evitarse presentar el límite únicamente mediante definiciones ingenuas, pues éstas no permiten profundizar en otras propiedades y tampoco permiten las justificaciones. Otro aspecto a cambiar son las notaciones utilizadas para designar las indeterminaciones: se transcriben cocientes del tipo $0 / 0, \infty / 0 \ldots$ que no están definidos como tal, y que pueden llevar a la idea de que si lo están y son cocientes válidos. Proponemos que se sustituyan por expresiones que reflejen esa idea de límite: $\rightarrow 0 / \rightarrow 0, \rightarrow \infty / \rightarrow 0 \ldots$

En cuanto al marco teórico utilizado, algunas de las categorías que hemos utilizado, si bien complementan la información sobre cada proceso analizado, en general, no aportan mucha información ya que prácticamente todos los LT se comportan de la misma manera: por ejemplo, no se suelen explicar las 
expresiones que se utilizan en los enunciados o justificaciones porque son habituales en los LT y si se han explicado, puede que se haya hecho en otro capítulo, pero queda fuera de nuestro análisis. También hay que recordar que en nuestro trabajo hemos focalizado nuestra atención, principalmente, en los esquemas de prueba utilizados y en las funciones de la demostración, considerando los otros aspectos como complementarios del análisis. Una tarea que queda pendiente para futuras investigaciones es refinar el análisis en los otros aspectos, así como buscar posibles relaciones entre los EP o PP utilizados y las funciones y los otros aspectos de análisis mostrados en los LT.

Por último, sería interesante ampliar la muestra con textos de estas editoriales pero que se correspondan con diferentes momentos del mismo periodo legislativo, ya que como hemos visto con Vicens-Vives, que no tiene por qué existir uniformidad en un mismo periodo legislativo. Este proyecto de futuro pasa por conseguir localizar los ejemplares pertinentes, pero dadas las dificultades que tuvimos para localizar la muestra actual, puede que ni siquiera sea posible localizar dichos ejemplares. 



\section{CAPÍtulO V}

\section{SOBRE LOS TEOREMAS DE CONTINUIDAD}

\section{V.1. INTRODUCCIÓN}

La continuidad de funciones es un concepto muy importante dentro del Análisis Matemático. Su introducción como idea intuitiva es rápida y sencilla y, generalmente, no ofrece problemas para su comprensión. Sin embargo, su definición formal requiere de la definición de límite funcional, lo que puede dificultar su aprendizaje. Como concepto es más sencillo que en el que se apoya, el límite funcional y, por eso, en muchas ocasiones, se trata antes que el límite. Su importancia radica fundamentalmente en que es una característica que tienen que cumplir las funciones para verificar importantes teoremas: Bolzano, de Weierstrass, del valor medio, de derivabilidad,... Se trata, por tanto, de un concepto necesario en la formación matemática preuniversitaria, pues forma parte de los fundamentos de las matemáticas superiores.

En los textos avanzados de Cálculo Infinitesimal, la continuidad de funciones se presenta generalmente a continuación del límite funcional. Por ejemplo, Spivak (1981) introduce la continuidad inmediatamente después del límite funcional y dentro del mismo capítulo, ya que, como hemos indicado, es el orden más razonable desde el punto de vista matemático porque la definición de límite es el soporte de la definición de continuidad. Este autor considera dos capítulos relacionados con la continuidad: en el primero se presenta la definición de continuidad de una función en un punto, las propiedades básicas (continuidad de 
la suma de funciones continuas, del producto, de la función inversa y de la composición) y la extensión de la definición a un intervalo, junto con el teorema de conservación de signo en un entorno de un punto en el que la función no se anula; en el segundo, titulado Tres teorema fuertes, se orienta hacia el estudio de los teorema de Bolzano, Darboux y Weierstrass, junto con otro resultados relacionados. Este orden revela la importancia que se le concede a los teoremas que se apoyan en el concepto de continuidad, más que el propio concepto.

Por su parte, Salas Hille (1994) también considera la continuidad a continuación de los límites, dentro del mismo capítulo. Trata el concepto en tres apartados: el primero contiene las definiciones de continuidad (a partir del límite funcional y en términos de $\varepsilon-\delta$ ), continuidad lateral, continuidad en un intervalo, y las propiedades (suma, producto, cociente, producto por un número, composición); en el segundo se introduce el teorema de la función intermedia (más conocido como criterio del sándwich), que se utiliza para calcular los límites en cero de las funciones $\operatorname{sen}(x)$ y $\cos (x)$, éstos límites se utilizan en el estudio de la continuidad de las funciones trigonométricas; por último, en el tercer apartado, titulado Dos teoremas básicos, se consideran el Teorema del valor intermedio (Darboux) y el Teorema del máximo-mínimo (Weierstrass). No considera de forma individual el Teorema de Bolzano, aunque tras el enunciado del Teorema de valor intermedio lo expone como caso particular de dicho teorema, y lo utiliza para deducir el método de bisección. Aunque este tratamiento supone una diferencia con el que hace Spivak (1981), en ambos textos se subraya la importancia de estos teoremas de continuidad.

Se observa que, aunque ambos textos hacen un planteamiento similar, no denotan con los mismos nombres a los teoremas de continuidad. Este fenómeno ya se detectó en los libros de texto de la muestra en el estudio de límites, y en Conejo y Ortega (2014), en el que se realiza un estudio sobre los esquemas de prueba de los teoremas de continuidad (en el caso concreto de los que Spivak llama tres teoremas fuertes, nomenclatura que también se utilizará en la presente memoria). Por tanto, las discrepancias entre notaciones, tratamiento, orden o demostración de los teoremas no se producen únicamente en los libros de texto, sino también entre manuales más especializados. Al igual que se hizo con el estudio de límites, se han incorporado estas referencias a manuales avanzados de cálculo infinitesimal por tratarse de referentes especializados para los propios profesores de Matemáticas de Secundaria. 
En cuanto al contenido de este capítulo, se encuentra organizado de forma similar al capítulo correspondiente a límites. En primer lugar se recoge el apunte curricular sobre las disposiciones de las tres leyes orgánicas de educación de los libros de nuestra muestra acerca del concepto de continuidad, junto con las referencias encontradas en la última legislación promulgada (LOMCE). A continuación procedemos con el análisis de los libros de texto: en primer lugar, un breve apunte sobre la organización de los contenidos relacionados con la continuidad en los libros de texto, ordenados por legislaciones, cursos y editoriales; en segundo lugar, un primer análisis de los esquemas de prueba localizados en los libros, en el que se resume la información de forma cuantitativa. Este análisis, previo al análisis completo que se realiza posteriormente atendiendo a todas las características del marco teórico, junto con la experiencia obtenida en el apartado anterior, ha permitido dividir los resultados en dos grupos: operaciones y propiedades de la continuidad, y teoremas de continuidad. Finalmente, se acaba el capítulo con las reflexiones realizadas a partir del análisis realizado.

\section{V.2. ANÁLISIS DE LOS CURRÍCULOS}

Al igual que sucedía con el límite funcional, la continuidad de funciones también aparece en todos los currículos de este estudio. En lo relativo a la LGE, en el primer documento en el que se describen los contenidos de BUP (Ministerio de Educación y Ciencia, 1975) se observa que se deben introducir los conceptos básicos de continuidad de funciones reales de variable real en $2^{\circ}$ de BUP, ya que se trata de una iniciación al Análisis Matemático, pero no se especifica que contenidos deben estudiarse. Por su parte, en $3^{\circ}$ de BUP se desarrolla el cálculo diferencial y no aparecen contenidos específicos relacionados con funciones continuas, aunque se indica que:

“Como aplicación de cálculo diferencial se hará el estudio local de las funciones. Podría completarse este estudio con algunos teoremas relativos a las funciones continuas y derivables"

(Ministerio de Educación y Ciencia, 1975, pp. 8065)

En cuanto a COU (Ministerio de Educación y Ciencia, 1978), no aparecen referencias específicas a la continuidad, aunque se menciona la búsqueda de raíces de funciones, lo que estaría relacionado con el teorema de Bolzano. Sin 
embargo, en la modificación de COU que se hace posteriormente (Ministerio de Educación y Ciencia, 1987), en las Matemáticas de las opciones de ciencias, sí se hace una referencia explícita a la continuidad, aunque indica que se debe estudiar la idea intuitiva, y dota de mayor importancia a la derivabilidad. Conviene tener presente que COU era un curso de la Universidad que se impartía en los Centros de Secundaria, pero los contenidos del mismo los regulaba la propia Universidad.

En cuanto al periodo LOGSE, en la primera concreción curricular (Ministerio de Educación y Ciencia, 1992a y 1992b), la continuidad se encuentran tanto en el primer curso de Bachillerato como en el segundo. Por ejemplo, en los contenidos del primer curso de Matemáticas I se refiere al tratamiento intuitivo de algunos conceptos relacionados con funciones, entre ellos la continuidad, y su aplicación para la comprensión de todo tipo de fenómenos. También aparecen en los criterios de evaluación. Sin embargo, en Matemáticas II ( $2^{\circ}$ de Bachillerato) no se hacen referencias explícitas a la continuidad, y se abunda en los contenidos relacionados con el límite y la derivabilidad, aunque se especifica que deben aplicarse éstos al estudio de las propiedades locales de funciones (lo que daría cabida a algunos de los teoremas de continuidad, aunque tal y como se presenta es algo interpretable).

En la modificación de 2001 (Ministerio de Educación, Cultura y Deporte, 2001a y 2001b) también se encuentran referencias a la continuidad: aparece en los contenidos y en los criterios de evaluación, tanto de Matemáticas I como de Matemáticas II, como concepto y como estudio de las propiedades locales y globales de las funciones. En la concreción curricular de la Comunidad de Castilla y León (recordemos que en este momento, las competencias educativas ya se han derivado a las Comunidades Autónomas) encontramos la continuidad tanto en el primer curso como en el segundo, pero además, en Matemáticas II se leen los siguientes contenidos relacionados con la continuidad:

Funciones continuas. Propiedades. Continuidad y función compuesta. Determinación de discontinuidades. Continuidad en intervalos cerrados.

(Consejería de Educación y Cultura de Castilla y León, 2002, pp. 7083)

Aparte de que se consideran las propiedades de las funciones continuas, la mención a la continuidad en intervalos cerrados está relacionada con los teoremas de continuidad. 
En LOE (Ministerio de Educación y Ciencia, 2007; Ministerio de Educación, Política Social y Deporte, 2008), las referencias a la continuidad se encuentran también tanto en el primer curso como en el segundo, en ambos documentos estatales (el de enseñanzas mínimas y el que establece el currículo para los centros que dependen de la gestión directa del Ministerio). Además, en ambos aparecen de forma explícita, aunque en el primer curso se considera de forma más superficial y en el segundo se le dota de más importancia, considerando la continuidad tanto en un punto como en un intervalo. El currículo publicado por la Comunidad de Castilla y León (Conserjería de Educación de Castilla y León, 2008) desarrolla los conceptos de forma muy similar, tanto por los contenidos de continuidad que se describen como por la organización en cursos.

El Real Decreto en el que se establece el currículo básico de las enseñanzas de LOMCE (Ministerio de Educación, Cultura y Deporte, 2015) sigue las mismas directrices que las legislaciones anteriores, y la continuidad aparece en ambos cursos, tanto en los contenidos como en los criterios de evaluación y en los estándares de aprendizaje evaluables, aunque se introduce una novedad en la descripción de estos contenidos, ya que se menciona explícitamente el teorema de Bolzano en los contenidos de Matemáticas II (Ministerio Educación, Cultura y Deporte, 2015). En el desarrollo curricular de Castilla y León también aparece una referencia específica al teorema de Weierstrass (Consejería de Educación de Castilla y León, 2015).

\section{V.3. LA CONTINUIDAD EN LOS LIBROS DE TEXTO}

Antes de acometer el análisis de los esquemas de prueba, presentamos un resumen del tratamiento de la continuidad en los libros de texto analizados. En él se muestra la distribución de los resultados de continuidad en los diferentes cursos, lo que permite conocer en qué textos se podrían encontrar justificaciones de dichos resultados. Se observa que existen tratamientos parecidos entre las editoriales para cada periodo legislativo, y también una relación entre los resultados que se presentan en los cursos más bajos de cada ley, o los superiores.

En todos los casos, cuando se describe los contenidos de continuidad que aparece en los libros de texto, se utilizarán los nombres que les da el libro de texto, 
aunque pueda suceder que un mismo resultado reciba diferentes nombres en función del LT.

\section{V.3.1. Ley general de educación}

En los textos de $3^{\circ}$ de BUP, independientemente de la editorial y del año de edición, no se estudia la continuidad, ya que se supone que se ha estudiado en cursos anteriores. Por esta razón, al igual que con el límite funcional, se ha estudiado la continuidad en los LT de $2^{\circ}$ de BUP, junto con los LT de COU.

\section{V.3.1.1. Libros de $2^{\circ}$ de BUP}

Anaya: se consideran dos ejemplares diferentes de libros de texto de este curso en esta editorial, uno de 1976 y el otro de 1987.

El LT de $2^{\circ}$ de BUP de Anaya de 1976 comienza con varios ejemplos de funciones no continuas, a partir de los cuales propone una definición de continuidad (como lo contrario de discontinuidad) y que primero describe como el cumplimiento de tres condiciones, para condensarlas en una sola (la existencia del límite en el punto cuyo valor es la imagen del punto), y luego enuncia la definición en términos del valor absoluto (teniendo en cuenta la definición de límite). Sigue con las propiedades de funciones continuas: suma, producto, cociente, $f(x)^{g(x)}$, y composición. Define la continuidad en un intervalo, que acompaña con un ejemplo real de lo que implica la continuidad (contexto de temperaturas), y luego considera la continuidad de algunas funciones: polinómicas, racionales, y las funciones de la forma $f(x)^{g(x)}$ donde $f$ y $g$ son funciones polinómicas, que será continua siempre que $f(x) \geq 0$.

El otro LT de Anaya de $2^{\circ}$ de BUP, el de 1987, no dedica ningún tema o capítulo específico a la continuidad, sino que aparece mencionada dentro del capítulo de límites, en el que se indica que "las funciones continuas tienen límite en todos sus puntos y ese límite coincide con el valor de la función en ese punto" (Anaya, $2^{\circ}$ BUP, 1987, pp. 143). Este LT indica que las funciones expresadas mediante polinomios, fracciones algebraicas, potencias, raíces, razones trigonométricas, etc. (suponemos que se refiere a las otras funciones que han estudiado 
anteriormente) son continuas excepto en los puntos en los que no estén definidas. No se da una definición de continuidad propiamente dicha.

Santillana: en esta editorial también se analizan dos ejemplares diferentes de libros de texto, uno de 1976 y el otro de 1991.

El libro de texto de $2^{\circ}$ de BUP de Santillana de 1976 dedica un capítulo a la continuidad, justo a continuación del capítulo dedicado al límite funcional. Tal y como indica en la introducción del capítulo, en la que describe la idea de continuidad, durante el tema se tratará de formalizar la idea intuitiva de continuidad, se estudiará el comportamiento, respecto a la continuidad, de la suma, producto, cociente, composición y otras propiedades y, finalmente, se establecerá una descripción de los tipos de discontinuidad de una función. La definición formal de continuidad (expresada como tres condiciones, existencia de $f(a)$, existencia del límite de $f$ en $a$ y coincidencia de los dos anteriores), se establece a partir de una discusión de casos en los que no se cumple alguna de ellas y que no responden a la idea intuitiva de trazado sin levantar el lápiz del papel. Posteriormente, se enuncian criterios de continuidad, formulados como teoremas, en los que se sustituyen las condiciones anteriores por la definición de límite, dando lugar a definiciones expresadas en términos de valor absoluto y de entornos. A continuación presenta las operaciones con funciones continuas: suma, continuidad de $-f$, diferencia, producto por una constante, producto de funciones, inversa (para la multiplicación), cociente, composición y recíproca (inversa para la composición). El siguiente epígrafe del tema considera el espacio vectorial de las funciones continuas en $] a, b[$, y posteriormente se presentan algunos ejemplos de funciones continuas que el libro considera como importantes: la función constante, la función identidad, la función afín, las funciones potenciales y las funciones polinómicas. Sigue con la algebrización del anillo de las funciones continuas $\mathrm{y}$, finalmente, considera los tipos de discontinuidad.

El libro de texto de $2^{\circ}$ de BUP de Santillana de 1991 presenta la continuidad en el mismo capítulo de límites. Empieza con la definición de continuidad, que enuncia en términos del límite (tres condiciones) pero a continuación la traduce, utilizando la definición del límite, a una definición en términos del valor absoluto. A continuación considera las operaciones con funciones continuas: 
suma, diferencia, producto, cociente y composición, e indica algunas familias de funciones continuas: potenciales, polinómicas, racionales y la raíz cuadrada de $\mathrm{x}$. Por último, presenta los tipos de discontinuidad.

SM: el LT de SM de $2^{\circ}$ de BUP, de 1977, dedica un capítulo a la continuidad. Comienza con la definición de continuidad en un punto y considera tres definiciones: la primera, enunciada en términos del límite, primero con tres condiciones y luego condensando las tres condiciones en una $\left(\lim _{x \rightarrow l} f(x)=\right.$ $f(l)$ ); la segunda en términos del valor absoluto, a partir de la definición de límite vista en el capítulo anterior; la tercera, en términos del incremento de la función y de la variable. Continúa con las discontinuidades y los tipos de discontinuidad, y sigue con la definición de continuidad en un intervalo. Enuncia una regla para determinar la continuidad que consiste en calcular el límite del incremento de la función cuando el incremento de la variable tiende a cero y si se anula en todos los puntos de un intervalo, entonces es continua en dicho intervalo. A continuación se muestran las propiedades de las funciones continuas empezando con el que llama "teorema de las operaciones" (pp. 85) y que considera a la suma, la resta, el producto y el cociente de funciones continuas, y sigue con algunas consecuencias: continuidad de la función potencial, de las funciones de tipo $a \cdot x^{n}$, donde $a$ es una constante y $n$ un número natural, de las funciones polinómicas, y racionales. Por último enuncia la continuidad de la función de función, es decir, de la función compuesta.

Vicens-Vives: el LT de $2^{\circ}$ de BUP de Vicens-Vives, de 1980, presenta la continuidad en dos temas diferentes: en el de funciones reales, junto con la monotonía de funciones, y en el de límites y derivadas, en el que relaciona la continuidad con el límite. En la primera referencia a la continuidad, se establece ésta a partir de ejemplos de continuidad y discontinuidad, y se da una definición expresada como valores cercanos en primer lugar, y que se precisa con entornos en segundo lugar. A continuación se presentan las condiciones para que una función tenga una discontinuidad en un punto. Después de algunos ejemplos y ejercicios, se presenta una nueva definición de continuidad, expresada en términos del valor absoluto, tras lo cual se establecen algunas propiedades: composición de funciones, adición, multiplicación de una función por un número 
(de lo que se deduce que las funciones continuas en un intervalo forman un espacio vectorial) producto, inversa de una función (para el producto) y cociente. En la segunda referencia a la continuidad, el LT presenta un estudio de los límites a partir de funciones que tienen discontinuidades evitables, la identificación del límite de una función en un punto en el que es continua como la imagen del punto por la función, y utiliza las definiciones de continuidad que ha presentado anteriormente para establecer definiciones del límite (en términos de entornos y del valor absoluto).

\section{V.3.1.2. Libros de COU}

Anaya: el LT de COU de Anaya, de 1989, presenta la continuidad en el mismo tema que los límites. En primer lugar define la continuidad en un punto, utilizando una condición e indicando que dicha condición lleva implícitas tres (generalmente los LT lo hacen al revés, primero lo enuncian con las tres condiciones y luego las condensan en una). A continuación muestra otras formas de enunciar la continuidad, utilizando el valor absoluto o en términos de entornos. Continúa con algunas consecuencias de la continuidad de funciones en un punto que llama teoremas: el teorema de conservación de signo y el de acotación en un entorno del punto en el que es continua. A continuación define la continuidad en un intervalo (aunque lo hace en una nota al margen), y enuncia el teorema de Bolzano y el teorema de los valores intermedios. Por último, presenta el teorema de acotación en un intervalo cerrado y el teorema de Weierstrass.

Santillana: el LT de COU de Santillana, de 1981, presenta el capítulo de límites tras el capítulo en el que se exponen algunos fundamentos de los números reales. En la introducción se describe la idea intuitiva de continuidad, y a continuación se presenta una definición formal (expresada en términos del valor absoluto) nada más empezar el tema, que se acompaña de una gráfica. A continuación muestra algunos ejemplos y, además de indicar que en los puntos en que no es continua se dice que la función es discontinua, transcribe una definición, también en términos de valor absoluto para la discontinuidad. Sigue con la definición de continuidad en un intervalo, y enuncia el primer teorema: si una función es continua en un intervalo y existe una sucesión de elementos del intervalo que 
tiene límite $a$ cuando $n$ tiende a infinito, el límite de la sucesión las imágenes de los términos de la sucesión es la imagen del límite de la sucesión por la función, es decir, $f(a)$. A partir de ese teorema, enuncia un criterio de discontinuidad. A continuación enuncia el teorema de Bolzano, precedido del teorema de conservación de signo, y luego enuncia el teorema de los valores intermedios. Continúa con la relación entre continuidad y acotación, enunciando las definiciones de función acotada superiormente, inferiormente y acotada, que utiliza para establecer los siguientes resultados: Si una función es continua en un punto, existe un entorno en el que está acotada, y si la función es continua en un intervalo $[a, b]$, entonces está acotada en dicho intervalo; continúa con el teorema de Bolzano-Weierstrass, enunciado en dos proposiciones, una para la existencia de máximo absoluto y otra para el mínimo absoluto, y que acompaña de una consecuencia: que si una función es continua en un intervalo cerrado, su imagen es un punto o un intervalo cerrado. El siguiente epígrafe se dedica a la continuidad uniforme, una propiedad más fuerte que la de continuidad. Se define la continuidad uniforme, y enuncia que la continuidad uniforme implica continuidad, seguido de un lema previo al teorema de Heine (teorema que se proponen como objetivo del epígrafe) que dice: si $[a, b]$ es un intervalo cerrado contenido en la unión de una familia de intervalos abiertos $\left(\alpha_{i}, \beta_{i}\right)$, entonces existe un conjunto finito de dichos intervalos tales que $[a, b]$ está contenido en su unión. Finalmente, se enuncia el teorema de Heine: toda función continua en un intervalo cerrado es uniformemente continua en dicho intervalo.

SM: en este LT de COU, de SM de 1980, la continuidad se presenta en el tema en el que se tratan también los límites funcionales. Tras establecer las definiciones de límite de una función y límites laterales, se define la continuidad en un punto, utilizando una única condición enunciada en términos del límite. No obstante, se indican otras definiciones equivalentes (en términos de entornos y de incrementos). A continuación se define la continuidad en un intervalo, diferenciando entre intervalos abiertos y cerrados. Tras las definiciones se presentan los tipos de discontinuidad con algunos ejemplos. A continuación se enuncian una serie de propiedades de funciones continuas: las operaciones (suma diferencia, producto, cociente), continuidad de las funciones polinómicas, racionales y composición. Continúa con tres apartados en los que enuncia una serie de teoremas sobre funciones continuas. El primero, que llama "propiedades 
generales de las funciones continuas" (pp. 226) contiene los siguientes teoremas: conservación de signo en un entorno de un punto, anulación en un punto si en cualquier entorno abierto la función toma valores positivos y negativos, si en un punto la función es mayor que un valor real $\mathrm{k}$, existe un entorno del punto tal que $f(x)>k$ y, por último, acotación en un entorno de un punto. En el segundo, que está dedicado a la continuidad uniforme, enuncia que la continuidad uniforme implica continuidad y el teorema de Heine. En el tercero y último apartado dedicado a la continuidad se presentan propiedades sobre funciones continuas en un intervalo cerrado: teorema de acotación, teorema de Weierstrass, teorema de Bolzano, propiedad de Darboux (expresada entre las imágenes de los extremos del intervalo) y un análogo a la propiedad de Darboux pero entre el máximo y el mínimo.

Vicens-Vives: el LT de Vicens-Vives de COU, de 1979, presenta la continuidad a continuación de los capítulos dedicados a las funciones y sus propiedades, y sin haber presentado el límite funcional. No obstante, lo utilizan en la definición de continuidad, por lo que es de suponer que se considera un concepto conocido de cursos anteriores. Establece la definición de continuidad en un punto mediante dos condiciones (existencia del límite en el punto y coincidencia con el valor de la función en dicho punto), y deduce una definición de discontinuidad (sólo considera continuidad o discontinuidad en puntos donde la función esté definida). Sigue con la definición de continuidad en un intervalo, junto con otras definiciones equivalentes de continuidad en un punto (en términos del valor absoluto y en términos de sucesiones), que indica que serán útiles en algunas cuestiones. Según indica el LT, la definición en términos de sucesiones de la continuidad permite aplicar las propiedades de sucesiones a la continuidad y establece la continuidad de $f+\lambda g$, donde $f$ y $g$ son funciones y $\lambda$ es un número real, y con ello, enuncia que las funciones polinómicas forman un anillo. Continúa con la continuidad del producto de funciones, de la función inversa (para el producto) y de la composición de funciones. Seguidamente, presenta diferentes tipos de interpolación, tras los cuales retoma algunas propiedades de las funciones continuas: teorema de conservación de signo en un entorno de un punto, anulación de la función en un punto si en todo entorno abierto de dicho punto la función toma valores positivos y negativos, teorema del cambio de signo (el que conocemos por teorema de Bolzano), teorema del valor intermedio, 
acotación de una función continua en un intervalo cerrado, teorema de máximo y mínimo absolutos y un teorema sin nombre en el que afirma que la imagen por una función continua de un intervalo cerrado es un intervalo cerrado (teniendo en cuenta que en la justificación, si una función es constante, la imagen es un punto $C$ y considera como intervalo cerrado a $[C, C])$.

\section{V.3.2. Ley Orgánica de Ordenación General del Sistema Educativo}

\section{V.3.2.1. Libros de $1^{\circ}$ de Bachillerato}

Anaya: el LT de Anaya de $1^{\circ}$ de Bachillerato de LOGSE, de 2002, presenta la continuidad en el mismo tema que los límites, pero al contrario de lo que suele ser habitual, considera la idea de continuidad antes que la de límite. Empieza con los tipos de discontinuidad y define la continuidad en un punto como "no presentar discontinuidad de ningún tipo en él” (pp. 275). También indica que las funciones definidas por expresiones analíticas elementales (según los editores, las que conocen hasta ahora) son continuas en todos los puntos en los que están definidas. A continuación define el límite funcional en punto y relaciona el límite en un punto con la continuidad en un punto, presentando las tres condiciones necesarias (en términos del límite) para que una función sea continua en un punto, indicando que se pueden condensar en una sola. Por último, indica que si la función es continua en un punto, calcular el límite en dicho punto se reduce a calcular el valor de la función en dicho punto (aplicación de la continuidad). No enuncia ni propiedades ni teoremas relacionados con la continuidad a excepción de la indicación sobre las funciones definidas con expresiones analíticas elementales.

Santillana: el LT de Santillana de $1^{\circ}$ de bachillerato, de 1996, presenta en el mismo tema las nociones de límites, continuidad y derivabilidad. El primer epígrafe dentro del tema se titula "Continuidad", y muestra la diferencia entre una función continua y otra con una discontinuidad a partir de dos ejemplos gráficos, tras lo cual presenta los límites. Una vez definidos los límites funcionales en un punto, define la continuidad en un punto (primero enunciando 
tres condiciones que condensa en una seguidamente) y la continuidad en un intervalo. Continúa con los tipos de discontinuidad, y luego considera los límites no finitos. En el resto del tema considera la función derivada y la función área. No se enuncia ninguna propiedad ni operación con las funciones continuas.

SM: el LT de SM, de $1^{\circ}$ de Bachillerato (1996), presenta los límites y la continuidad en el mismo tema. Tras tratar el concepto de límite funcional, introduce la continuidad, empezando por la definición del concepto. Para ello, introduce una primera aproximación a la definición de continuidad, expresada de forma verbal, en la que se prescinden de simbolismos: una función es continua cuando a variaciones pequeñas de la variable independiente le corresponden pequeñas variaciones de la variable dependiente (pp. 172). Tras la exploración de dos ejemplos, traduce la primera definición en una en la que las pequeñas variaciones las expresa con símbolos matemáticos: $f(a+h)-f(a)$ se aproxima 0 cuando $h$ se aproxima a 0 . Ambas definiciones son poco rigurosas, pues el verbo aproximar no es suficiente para reflejar la tendencia, ya que si consideramos $h$ de la forma $1+1 / n$, con $n$ que tiende a infinito, dichos $h$ se aproximan a cero (sus términos cada vez están más cerca de 0 ), pero no tienden a cero (hemos visto ejemplos en este sentido en el capítulo de límites). Finalmente, enuncia una definición en términos del límite, a la que se ha llegado razonando sobre las anteriores, primero utilizando una única condición que se desglosa seguidamente en las tres condiciones que implican.

Vicens-Vives: tenemos dos libros de texto de esta editorial correspondientes a $1^{\circ}$ de Bachillerato de LOGSE: uno de 1998 y otro de 2003. El LT de Vicens-Vives (1998) presenta la continuidad en el mismo capítulo que los límites. En este LT no se da una definición formal de continuidad, sino que se limita a la idea intuitiva de continuidad en un intervalo: la gráfica puede trazarse sin levantar el lápiz del papel. Tras algunas consideraciones sobre la continuidad y el dominio de la función (según se expone en el libro, en los puntos en los que no está definida no se puede hablar ni de continuidad ni de discontinuidad), establece que todas las funciones definidas por una expresión algebraica elemental son continuas en su dominio, denotándolo por "principio general de continuidad" (pp. 103). Por último, indica a qué se refiere por expresiones elementales: 
potencias, raíces, funciones trigonométricas, exponenciales, logarítmicas y cualquier combinación algebraica entre ellas.

Por su parte, el LT de Vicens-Vives (2003) realiza una presentación más formal del concepto: define la continuidad en términos de aproximaciones del incremento, junto con la definición de continuidad en un intervalo, y tras una discusión de la primera definición, se establece otra en términos del límite, con una sola condición, que se desglosa en las tres condiciones que implica. A continuación presenta los tipos de discontinuidad con los que finaliza el tratamiento de la continuidad.

\section{V.3.2.2. Libros de $2^{\circ}$ de Bachillerato}

Anaya: a diferencia que su correspondiente de $1^{\circ}$ de Bachillerato, el LT de Anaya de $2^{\circ}$ de Bachillerato de 2003 presenta la continuidad tras haber considerado el límite funcional, aunque trata ambos conceptos en el mismo tema. Al igual que en $1^{\circ}$, el tratamiento que se hace de la continuidad en este LT es muy escueto, limitándose a enunciar la definición de continuidad en un punto (con una condición en términos del límite, aunque indica que implica tres condiciones), los tipos de discontinuidades, la continuidad en un intervalo, la continuidad de las funciones elementales que utilizan habitualmente y los teoremas de Bolzano, Darboux, Weierstrass, y la aplicación del teorema de Bolzano para dos funciones que se cortan.

Santillana: el LT de $2^{\circ}$ de Bachillerato de Santillana, de 1997, presenta la continuidad en un tema dedicado exclusivamente a este concepto. En primer lugar, define la continuidad en un punto (primero con tres condiciones y, luego, condensándolas en una formulación que subraya en negrita para darle más importancia). Seguidamente, expresa la continuidad en función de las otras definiciones de límite que presentó en el tema anterior en términos de entornos y del valor absoluto. Continúa con la definición de continuidad lateral, seguido de la continuidad en un intervalo, diferenciando entre intervalo abierto y cerrado. Tras las definiciones, presenta los tipos de discontinuidad y a continuación sigue con las propiedades de las funciones continuas: continuidad de las operaciones con funciones (suma y diferencia, producto, producto por constante, $f(x)^{g(x)}$, 
cociente y composición), teorema del signo (conservación en un entorno de un punto), teorema de acotación (acotación en un entorno de un punto), teorema de los ceros de Bolzano, teorema de los valores intermedios, teorema de los extremos absolutos de Weierstrass e imagen de un intervalo cerrado. El teorema del signo, el de acotación, el de Bolzano, el de los valores intermedios y el de Weierstrass presentan un apartado denominado interpretación, que precede a la demostración, y que explica, de forma verbal, lo que significa el teorema.

SM: el LT de SM de $2^{\circ}$ de Bachillerato, de 2001, no es de la misma colección que el ejemplar de $1^{\circ}$ de Bachillerato de este mismo periodo, a diferencia de los LT de otras editoriales o periodos. Ya hemos señalado este hecho anteriormente, pero conviene recordarlo ya que al no pertenecer a la misma colección, se podría pensar que no existe continuidad en los planteamientos de ambos. En cuanto al tratamiento del concepto de continuidad, en este LT aparece en un tema dedicado exclusivamente al concepto. En primer lugar se presenta el concepto y la definición, tanto en un punto globalmente, como lateral, y se sigue con la definición de continuidad en un intervalo, diferenciando entre el intervalo abierto y el cerrado. A continuación, se presentan las propiedades de las funciones continuas: continuidad de las funciones constante e identidad, suma, diferencia, producto, producto de una función por una constante, cociente y las funciones de la forma $f(x)^{b / n}$, donde $b$ y $n$ son enteros y $n>0$. Se indica que estas propiedades permiten deducir la continuidad de algunas familias de funciones: polinómicas, racionales, y las expresadas como raíces de monomios, pero sin justificar ninguna, y complementa esta casuística con una tabla de funciones elementales en las que se indica el dominio de continuidad: funciones potenciales de exponente positivo o negativo, exponenciales, logarítmicas, trigonométricas y las inversas de las trigonométricas. Tras la tabla, considera la continuidad de las funciones definidas a trozos, y a continuación la de la función compuesta, a partir de la cuál amplía los tipos de funciones continuas ya que considera la composición de las funciones elementales anteriores con una función continua. También enuncia la continuidad de la función valor absoluto. Tras el tratamiento de las propiedades de las funciones continuas, presenta los tipos de discontinuidad. Seguidamente, se considera un epígrafe que llama "Consecuencias de la continuidad. Teorema de Bolzano" (pp. 254) y en el que presenta varios resultados necesarios para la posterior demostración del teorema 
de Bolzano. También enuncia una definición alternativa de continuidad expresada en términos del valor absoluto, y una serie de consecuencias de dicha definición (que ha llamado criterio alternativo de continuidad), como son la conservación de signo en un entorno a un punto, y la existencia de un entorno de un punto $p$ en el que, si la función en $p$ es mayor que un número real $M$, también la función en dicho entorno es mayor que $M$ (respectivamente para menor). Continúa con el teorema de los valores intermedios, los máximos y mínimos de funciones, junto con el teorema de Weierstrass, al que se le concede poca importancia ya que sólo se menciona en un párrafo final y, por último, en un epígrafe final titulado "Procesos y técnicas: demostración por reducción al absurdo", de forma pautada, enuncia y justifica que toda función continua en un intervalo cerrado es acotada en dicho intervalo.

Vicens-Vives: al igual que en $1^{\circ}$ de Bachillerato, tenemos dos LT de este curso, Vicens-Vives (1999) y Vicens-Vives (2004), de las mismas colecciones que sus correspondientes de primero. En el LT de 1999, la continuidad se presenta en el siguiente tema al de los límites funcionales. En primer lugar, define la continuidad en un punto, utilizando una condición, a la que llega tras la discusión de las condiciones que implican dicha condición (en términos del límite). Presenta el álgebra de las funciones continuas (suma, diferencia, producto y cociente en lo que llama "teorema 1" y la composición en el "teorema 2"). Estos teoremas permiten establecer la continuidad de funciones elementales, lo que indica a continuación. El LT hace una distinción entre funciones básicas $\left(x, x^{2}\right.$, $x^{3}, \ldots, x^{n}, \sqrt{ } x, \ldots, \operatorname{sen}(x), \cos (x), \ldots$ etc. $)$ y las funciones elementales, que son aquellas que se obtienen a partir de las básicas mediante las operaciones de composición, suma, diferencia, producto y cociente. Continúa con los tipos de discontinuidad, con algunos ejemplos de funciones discontinuas y con la continuidad del valor absoluto de una función. Finalmente, establece los teoremas sobre funciones continuas, tras haber definido la continuidad en un intervalo: teorema de Bolzano, teorema de los valores extremos y teorema de los valores intermedios.

Por su parte, el LT de Vicens-Vives (2004) presenta la continuidad de funciones junto con la derivabilidad. Introduce el tema con la idea intuitiva de continuidad, para presentar a continuación la definición de continuidad en un punto (en 
términos de distancias y del valor absoluto). Realiza una discusión de la definición para llegar a otras definiciones en términos del límite, estableciendo también la continuidad lateral, y la continuidad en un intervalo abierto y en un intervalo cerrado. También enuncia la continuidad en términos de incrementos. A continuación, establece la continuidad de las funciones elementales principales (potenciales, exponenciales, logarítmicas, trigonométricas y trigonométricas inversas). Sigue con las operaciones de funciones continuas: suma, diferencia, producto de una función por una constante, producto de funciones, cociente y composición. Llama funciones elementales a las que se obtienen mediante operaciones de lo que denomina funciones elementales principales, y que se justifican con las operaciones anteriores. Como consecuencia, establece la continuidad de las siguientes funciones elementales: monómicas, polinómicas y racionales. Continúa con los tipos de discontinuidad, y finaliza con los teoremas sobre funciones continuas: teorema de acotación en un intervalo cerrado, primer teorema de Weierstrass (teorema del valor máximo), segundo teorema de Weierstrass (tomar todos los valores entre el máximo y el mínimo) y teorema de Bolzano.

\section{V.3.3. Ley Orgánica de Educación}

\section{V.3.3.1. Libros de $1^{\circ}$ de Bachillerato}

Anaya: al igual que ocurría con los límites funcionales, el ejemplar de Anaya de LOE (Anaya de $1^{\circ}$ de Bachillerato de 2008) coincide con su predecesor de LOGSE (Anaya de $1^{\circ}$ de Bachillerato de 2002), por lo que los comentarios realizados en para el texto de LOGSE son los mismos que corresponden a este ejemplar.

Santillana: en este LT, de 2008, el tratamiento de la continuidad se realiza en el mismo capítulo de límites. La presentación que se hace es muy reducida, en apenas dos páginas, limitándose a enunciar la definición de continuidad en un punto (a partir de tres condiciones), indicando en el margen la continuidad en un intervalo, y estableciendo, sin ninguna justificación, los dominios de continuidad de las familias de funciones polinómicas, racionales, con radicales, 
exponenciales, logarítmicas y trigonométricas. Por último, define y describe los tipos de discontinuidad.

SM: el LT de $1^{\circ}$ de Bachillerato de LOE de SM, editado en 2008, considera la continuidad en el mismo capítulo que límites, y también hace una presentación bastante reducida. Introduce la idea intuitiva de continuidad, y tras mostrar un ejemplo en el que hay una discontinuidad de salto finito, define la continuidad en un punto (utilizando las tres condiciones), la discontinuidad y la continuidad en un intervalo. Tras eso, presenta las discontinuidades y luego indica que las funciones obtenidas a partir de funciones continuas mediante las operaciones usuales son continuas, relacionándolo con límites, aunque no indica a qué operaciones se refiere, ni presenta ninguna justificación. Muestra un ejemplo y establece los dominios de continuidad de las familias de funciones polinómicas, racionales, y radicales de índice par.

Vicens-Vives: en el LT de Vicens-Vives de $1^{\circ}$ de Bachillerato, de 2008, se presenta la continuidad en el mismo capítulo de límites, a continuación de éstos. En primer lugar, y tras indicar la idea intuitiva de continuidad, se presenta la definición de continuidad en un punto (enunciada mediante las tres condiciones expresadas en función del límite), junto con la discontinuidad en un punto y la continuidad en un intervalo. Se enuncian las propiedades de las operaciones con funciones continuas (suma, diferencia, producto, cociente y composición), indicando que se demuestran aplicando las propiedades de los límites aunque no lo hacen. Presentan la continuidad de algunas funciones: identidad, constante, polinómicas, racionales, exponenciales, logarítmicas y trigonométricas. A continuación muestra la clasificación de discontinuidades y con esto terminan el apartado de continuidad.

\section{V.3.3.2. Libros de $2^{\circ}$ de Bachillerato}

Anaya: al igual que ocurría con los límites funcionales y con los LT de $1^{\circ}$ de Bachillerato, el ejemplar de Anaya de LOE (Anaya de $2^{\circ}$ de Bachillerato de 2009) coincide con su predecesor de LOGSE (Anaya de $2^{\circ}$ de Bachillerato de 
2003), por lo que los comentarios realizados en para el texto de LOGSE son los mismos que corresponden a este ejemplar.

Santillana: este LT, de 2009, sigue en la misma línea que su correspondiente de $1^{\circ}$ de Bachillerato aunque es un poco más abundante ya que considera los teoremas de continuidad. El tratamiento de la continuidad se hace en el mismo capítulo que los límites, y cambia ligeramente el orden frente al LT de $1^{\circ}$. Presenta la misma definición, seguida de los tipos de discontinuidad, aunque en esta ocasión, se describen de forma más breve. Define la continuidad en un intervalo y establece los dominios de continuidad de las familias de funciones polinómicas, racionales, con radicales, exponenciales, logarítmicas y trigonométricas. En el margen recuerda que la función resultante de las operaciones (suma, diferencia, producto y composición de funciones continuas) también es continua. Por último, presenta los tres teoremas de continuidad: el teorema de Bolzano, el teorema de Darboux y el teorema de Weierstrass. En el apartado de ejercicios resueltos se muestra como se determina si dos curvas se cortan en un intervalo, utilizando un ejemplo concreto, lo que podría servir de prueba preformal para la consecuencia del teorema de Darboux que indica que si dos funciones continuas en $[a, b]$ cumplen que $f(a)<g(a)$ y $f(b)>g(b)$ (o viceversa), entonces se cortan en un punto del intervalo $[a, b]$. Sin embargo, el LT se limita a mostrar un ejemplo y ni siquiera se indica que existe un punto en el que coinciden, sino que como pasan por todos los puntos intermedios, en alguno se cortarán. Tal y como se presenta, ni siquiera induce a la enunciación de un teorema, por lo que no lo hemos contabilizado como resultado en este LT.

SM: en el LT de $2^{\circ}$ de Bachillerato de SM, de 2010, la continuidad se presenta en un capítulo independiente, al contrario de lo que ocurría en el LT de $1^{\circ}$ de Bachillerato. Esto ya denota que los editores dan más importancia a la continuidad en este nivel educativo. Tras indicar la idea intuitiva de continuidad de una función, establece las definiciones de continuidad en un punto, utilizando las tres condiciones (existencia del límite en el punto, existencia de la imagen de la función en el punto y coincidencia de ambos) y en términos del valor absoluto (a la que llama definición formal de continuidad; la definición de continuidad lateral y la definición de continuidad en un intervalo, tanto abierto como cerrado. 
Continúa con los tipos de discontinuidades, y sigue con las propiedades: en primer lugar establece la continuidad de las operaciones suma, diferencia, producto y cociente, y aunque no las justifica, indica que son consecuencia directa de las propiedades de los límites. Sigue con la continuidad de las familias de funciones polinómicas, racionales, irracionales, exponenciales, logarítmicas y trigonométricas, y por último, establece la continuidad de la función compuesta. A continuación presenta los teoremas de continuidad: el teorema de Bolzano, que acompaña del método de bisección, el teorema de los valores intermedios, enunciado en dos partes, para $f(a) \leq f(b)$ y para $f(a) \geq f(b)$, y el teorema de Weierstrass, que viene precedido de las definiciones de funciones acotadas superiormente, inferiormente, acotadas, supremos, máximo absoluto, ínfimo y mínimo absoluto. En la parte de ejercicios resueltos se justifican algunas consecuencias del teorema de Bolzano (que $\operatorname{sen}(x)$ y $x$ se cortan en algún punto, y que los polinomios de tercer grado tiene al menos una raíz real) y el teorema de punto fijo.

Vicens-Vives: el LT de Vicens-Vives de $2^{\circ}$ de Bachillerato, de 2009, presenta la continuidad en un tema específico para este concepto, después del tema de límite de funciones. En primer lugar, se presentan las definiciones: la de continuidad en un punto, enunciada primero como una sola condición, que luego se desglosa en tres (en términos del límite), siguen la definición de continuidad lateral y las definiciones de continuidad en un intervalo abierto y en un intervalo cerrado. A continuación enuncia las operaciones con funciones continuas (suma, diferencia, producto, cociente y composición) indicando que se demostrarían aplicando las propiedades de los límites, seguido de la continuidad de algunas funciones: constante, identidad, polinómicas, racionales, exponenciales, logarítmicas y trigonométricas. A continuación, presenta la clasificación de discontinuidades y, por último, se enuncian los teoremas de continuidad: teorema de Bolzano, teorema de Darboux, teorema de Weierstrass y la consecuencia del teorema de Bolzano sobre dos funciones que se cortan. 


\section{V.4. RESULTADOS Y JUSTIFICACIONES ASOCIADOS AL CONCEPTO DE CONTINUIDAD}

A diferencia de lo que sucedía con los límites, la continuidad recibe una menor atención en los LT en cualquiera de los periodos y editoriales considerados. Se trata de un concepto cuya definición se basa en el límite y, por tanto, gran parte de las propiedades que se le asocian a la continuidad las heredan del límite funcional. Por otro lado, al igual que sucedía con el concepto de límite, el tratamiento de la continuidad de funciones en los libros de texto varía de unas editoriales a otras e incluso de unos libros a otros. Sin embargo, se observa una mayor homogeneidad que la observada en límites, quizás por las características propias del concepto. Además, de forma generalizada se ha observado que existe un comportamiento común en los libros de texto en función del curso al que pertenecen: los teoremas asociados a la continuidad en intervalos (ya sean abiertos, cerrados, o en entornos de puntos en los que la función es continua) se enuncian únicamente en el curso más alto (COU en la LGE y $2^{\circ}$ de Bachillerato en la LOGSE y la LOE). Por su parte, en los cursos inferiores ( $2^{\circ}$ de BUP de la LGE o $1^{\circ}$ de Bachillerato de la LOGSE y la LOE) se limitan a enunciar propiedades y operaciones de funciones continuas en un punto, en los casos en los que enuncien teoremas.

Al igual que con el concepto de límite, se ha organizado el análisis en varios pasos: en primer lugar, se ha realizado un recuento de los resultados que se enuncian en cada texto, considerando como resultados cualquier enunciado que el libro presente como algo que se cumple en determinadas condiciones. A diferencia de los límites, aquí no se produce tanta atomización de los resultados y se verá que el recuento es más homogéneo, salvo algunas excepciones puntuales. Junto al número de resultados que se enuncian, se muestra el recuento de los tipos de esquemas de prueba o pruebas preformales que se utilizan, lo que ofrece una primera idea del tratamiento justificativo que realiza el libro y que se expone por editoriales.

En los siguientes apartados (V.4.1, V.4.2, V.4.3 y V.4.4) se presenta el recuento descrito anteriormente para cada texto, organizado por editoriales y presentado en dos tablas para cada editorial, análogas a las presentadas en el caso de límite funcional. La primera muestra el número de resultados que se enuncian en cada 
texto de dicha editorial y de las justificaciones utilizadas. Cada resultado lo hemos clasificado en una única columna correspondiente a un tipo de EP o PP. Hay algunas pruebas que son susceptibles de ser clasificadas en más de un apartado, por ejemplo, algunas tienen carácter transformacional y axiomático al mismo tiempo (casi todos los axiomáticos tienen algún tipo de transformación algebraica), pero con el fin de no duplicar el recuento de algunos resultados, se ha clasificado en el tipo de justificación predominante, y se ha detallado en el análisis posterior si se observa algún tipo de EP o PP adicional.

La segunda tabla complementa la información de la primera: resume los resultados que se justifican en cada libro de texto, organizados por el tipo de justificación utilizada. Esto aporta más información sobre el interés en justificar que tienen los libros de la muestra, si se limitan a justificar propiedades sencillas o presentan demostraciones de teoremas que requieren de más aparataje matemático. Ambas tablas siguen la codificación en colores utilizada anteriormente en función del periodo al que pertenece el LT: rojo claro para LGE, turquesa claro para LOGSE y verde claro para LOE.

Estos primeros análisis de los esquemas de prueba presentes en los libros, que llamaremos análisis previos, nos permiten organizar los resultados y las justificaciones utilizadas, así como comparar entre LT y editoriales. A continuación se describe dicho análisis previo de cada editorial.

\section{V.4.1. Resultados y justificaciones en la editorial Anaya}

Como ya hemos mencionado anteriormente, los LT de LOGSE y LOE de esta editorial coinciden prácticamente en su totalidad, por lo que el análisis de resultados enunciados y justificados es el mismo para cada par de libros iguales (los dos de $1^{\circ}$ de Bachillerato y los dos de $2^{\circ}$ de Bachillerato). Al igual que sucedía con el límite funcional, se observa un cambio en el número de resultados, en el rigor y en profundidad con se aborda la continuidad del LT de $2^{\circ}$ de BUP de 1977 al de 1987, en el que desaparecen los teoremas asociados a la continuidad en intervalos. De hecho, en este último LT los resultados que hemos contabilizado se corresponden con la continuidad de la funciones polinómicas, racionales, expresadas mediante potencias, raíces y razones trigonométricas. Esta misma línea siguen los textos de $1^{\circ}$ de Bachillerato de LOGSE y LOE, en los que 
ni siquiera se presentan las operaciones con funciones continuas. También se observa una disminución en los resultados que se presentan en COU frente a los presentados en $2^{\circ}$ de Bachillerato (LOGSE y LOE), aunque en este nivel sí se incluyen resultados relativos a entornos o intervalos en los que la función es continua.

En primer lugar, vemos que esta editorial no presenta un gran número de resultados en sus LT, con un recuento total de 32 resultados (Tabla V.4.1.1). Esto se debe principalmente a que en esta editorial no se presentan las propiedades y operaciones con funciones continuas, sobre todo en los periodos de LOGSE y LOE, por lo que los resultados que se enuncian se limitan a los teoremas de continuidad y, por tanto, en los cursos en los que no aparecen dichos teoremas (por no corresponder con dicho nivel educativo), no aparecen apenas resultados.

\begin{tabular}{|c|c|c|c|c|c|c|c|c|}
\hline \multirow{2}{*}{$\begin{array}{l}\text { Libros de texto de } \\
\text { Anaya }\end{array}$} & \multicolumn{7}{|c|}{$\mathrm{N}^{0}$ de Esquemas de prueba } & \multirow{2}{*}{$\begin{array}{l}\text { Resultados } \\
\text { totales }\end{array}$} \\
\hline & $E P O$ & EPil & $E P i V$ & EPiS & $E P t$ & $E P a$ & $P P$ & \\
\hline Anaya $2^{\circ}(1977)$ & 6 & 0 & 0 & 0 & 0 & 2 & 0 & 8 \\
\hline Anaya $2^{\circ}(1987)$ & 5 & 0 & 0 & 0 & 0 & 0 & 0 & 5 \\
\hline Anaya COU (1989) & 1 & 0 & 0 & 0 & 1 & 5 & 0 & 7 \\
\hline Anaya $1^{\circ}(2002)$ & 1 & 0 & 0 & 0 & 0 & 0 & 0 & 1 \\
\hline Anaya $2^{\circ}(2003)$ & 1 & 4 & 0 & 0 & 0 & 0 & 0 & 5 \\
\hline Anaya $1^{\circ}(2008)^{18}$ & 1 & 0 & 0 & 0 & 0 & 0 & 0 & 1 \\
\hline Anaya $2^{\circ}(2009)$ & 1 & 4 & 0 & 0 & 0 & 0 & 0 & 5 \\
\hline TOTALES & 16 & 8 & 0 & 0 & 1 & 7 & 0 & 32 \\
\hline
\end{tabular}

Tabla V.4.1.1. Resultados y justificaciones asociados a la continuidad en los libros de texto de la editorial Anaya.

E1 50\% de ellos no se justifican, y de los que si se justifican, o bien se utiliza un EP inductivo de 1 caso (25\%), o bien un EP axiomático (2,9\%). Únicamente hemos encontrado un EP transformacional, en el LT de COU. Por su parte, el LT que más resultados presenta es el ejemplar más antiguo de $2^{\circ}$ de BUP de la LGE, el Anaya de 1977, en el que si se presentan las propiedades de las funciones continuas.

En cuanto a los EP predominantes en cada LT, todos los EP axiomáticos y el EP transformacional se presentan en los LT del periodo de la LGE. En concreto, la mayoría de ellos se presentan en el LT de COU, y sólo dos EP axiomáticos en el de $2^{\circ}$ de BUP, que corresponden a las operaciones de suma y composición en

\footnotetext{
${ }^{18}$ Los libros de texto de Anaya del periodo LOE son prácticamente idénticos a sus correspondientes de LOGSE, por tanto, los datos relativos al análisis son los mismos.
} 
Anaya (1977). En cuanto a los libros de la LOGSE y la LOE (que son iguales excepto en algunas cuestiones de formato), los teoremas que justifican lo hacen utilizando EP inductivos de 1 caso.

Si observamos la evolución de los EP utilizados, es claro que los EP inductivos han sustituido a los EP axiomáticos o transformacionales, utilizándose ejemplos gráficos para convencer de la veracidad de los teoremas de continuidad en lugar de razonamientos deductivos (sólo se presentan $4 \mathrm{EP}$ inductivos de 1 caso como justificaciones en $2^{\circ}$ de Bachillerato de LOGSE y LOE frente a los 5 EP axiomáticos y el EP transformacional de COU).

\begin{tabular}{ll}
\hline Libros de texto & Esquemas de prueba \\
\hline Anaya $2^{\circ}(1977)$ & EPa: suma de funciones continuas y composición de funciones continuas. \\
Anaya $2^{\circ}(1987)$ & $\begin{array}{l}\text { Nada } \\
\text { EPt: Teorema de los valores intermedios. } \\
\text { Anaya COU (1989) }\end{array}$ \\
$\begin{array}{l}\text { EPa: teorema de conservación de signo y teorema de acotación en un entorno } \\
\text { de un punto, teorema de Bolzano, teorema de acotación en un intervalo } \\
\text { cerrado y teorema de Weierstrass. }\end{array}$ \\
Anaya $1^{\circ}(2002)$ & $\begin{array}{l}\text { Nada } \\
\text { EPi1: teorema de Bolzano, teorema de los valores intermedios, consecuencia } \\
\text { de Bolzano para dos funciones que se cortan y teorema de Weierstrass. }\end{array}$ \\
Anaya $2^{\circ}(2003)$ & $\begin{array}{l}\text { Nada } \\
\text { EPi1: teorema de Bolzano, teorema de los valores intermedios, consecuencia } \\
\text { de Bolzano para dos funciones que se cortan y teorema de Weierstrass. }\end{array}$ \\
\hline
\end{tabular}

Tabla V.4.1.2. Resultados y justificaciones asociados a la continuidad en los libros de texto de la editorial Anaya.

En cuanto a los resultados que se justifican (Tabla V.4.1.2), en el LT de $2^{\circ}$ de BUP de 1977 se verifican dos operaciones con funciones continuas (suma y composición), pero en los LT de $\mathrm{COU}$ o de $2^{\circ}$ de Bachillerato los resultados que se justifican son los teoremas asociados a la continuidad en un intervalo o entorno, y no las propiedades y operaciones con funciones continuas. Esto también supone una diferencia entre el planteamiento de los cursos inferiores con respecto a los superiores.

De forma similar a lo observado en el caso de límites, se aprecia un descenso significativo de la demostración como justificación, desapareciendo totalmente en esta editorial con el transcurso de las legislaciones. Además, los EP utilizados son poco variados, ya que no aparecen, por ejemplo, las pruebas preformales, los EP transformacionales apenas se utilizan y en el caso de EP inductivos, se limitan a los de un caso. 


\section{V.4.2. Resultados y justificaciones en la editorial Santillana}

El número de resultados presentados en esta editorial varía a lo largo del tiempo, alcanzando el número más alto en $2^{\circ}$ de BUP de 1976, desapareciendo en $1^{\circ}$ de Bachillerato de LOGSE, aunque en $2^{\circ}$ de Bachillerato se presenta un número similar al de $2^{\circ}$ de BUP de 1991 o a COU, y presentando resultados de nuevo en el nivel inferior en LOE aunque mantiene el mismo número en el nivel superior.

En la editorial de Santillana el número de resultados presentados (71) es más alto que en la de Anaya, ya que en esta editorial sí que se incluyen las propiedades y operaciones de funciones continuas en LT que no son de $2^{\circ}$ de BUP de la LGE. La mayoría de resultados se presentan en los LT del periodo LGE, principalmente en el LT de $2^{\circ}$ de BUP de 1976. De los resultados presentados totales, casi el $55 \%$ de ellos no se justifican. De los que se justifican, el EP más utilizado es el EP axiomático (32,4\% del total), aunque también se utilizan EP transformacionales $(5,6 \%)$, inductivos de varios casos $(4,2 \%)$ e inductivos de 1 caso $(2,8 \%)$.

\begin{tabular}{lllllllll}
\hline $\begin{array}{l}\text { Libros de texto de } \\
\text { Santillana }\end{array}$ & \multicolumn{9}{c}{$\mathbf{N}^{\mathbf{0}}$ de Esquemas de prueba } & \multicolumn{2}{c}{$\begin{array}{l}\text { Resultados } \\
\text { totales }\end{array}$} \\
\hline Santillana $2^{\circ}(1976)$ & 6 & 1 & 1 & 0 & 0 & 10 & 0 & 18 \\
Santillana $2^{\circ}(1991)$ & 9 & 0 & 0 & 0 & 0 & 0 & 0 & 9 \\
Santillana COU (1981) & 1 & 0 & 0 & 0 & 2 & 9 & 0 & 12 \\
Santillana $1^{\circ}(1996)$ & 0 & 0 & 0 & 0 & 0 & 0 & 0 & 0 \\
Santillana $2^{\circ}(1997)$ & 7 & 0 & 0 & 0 & 2 & 4 & 0 & 13 \\
Santillana $1^{\circ}(2008)$ & 6 & 0 & 0 & 0 & 0 & 0 & 0 & 6 \\
Santillana $2^{\circ}(2009)$ & 10 & 1 & 2 & 0 & 0 & 0 & 0 & 13 \\
TOTALES & 39 & 2 & 3 & 0 & 4 & 23 & 0 & 71 \\
\hline
\end{tabular}

Tabla V.4.2.1. Resultados y justificaciones asociados a la continuidad en los libros de texto de la editorial Santillana.

Por libros de texto, vemos que el LT que más resultados presenta es el de $2^{\circ}$ de BUP de 1976 (18) y, además, también es el que más justificaciones presenta, casi todas (10) del tipo de EP axiomático. Al igual que se observó en Anaya, se observa un descenso en el número de resultados en el LT de $2^{\circ}$ de BUP de 1991 (sólo se presentan 9 y se refieren a las operaciones y tipos de funciones continuas). Proporcionalmente, el LT que más resultados justifica, y además con EP axiomáticos en su mayoría, es el LT de COU, que presenta 9 EP axiomáticos y 2 EP transformacionales para justificar 12 resultados. Si bien en el LT de $1^{\circ}$ de 
Bachillerato de LOGSE no se presenta ningún resultado, en $2^{\circ}$ de Bachillerato sí se presentan y se justifican casi la mitad de ellos, mediante EP axiomáticos $(30,8 \%)$ y transformacionales $(15,4 \%)$. En cuanto a los LT de LOE, aunque se presentan resultados en los dos cursos, en $1^{\circ}$ no se justifica ninguno y en $2^{\circ}$ únicamente se justifican tres, mediante EP inductivos (de uno y de varios casos).

En esta editorial también se observa un descenso en el número de justificaciones presentadas en general, así como una progresiva disminución de los EP axiomáticos o transformacionales utilizados. Sin embargo, dicho descenso se aprecia más tarde, en los LT de LOE, aunque esto puede deberse a que los LT de Anaya de LOGSE eran de 2002 y 2003 (posteriores a la modificación de 2001) y los de Santillana son del principio de la LOGSE (1996 y 1997).

\begin{tabular}{|c|c|}
\hline Libros de texto & Esquemas de prueba \\
\hline Santillana $2^{\circ}(1976)$ & $\begin{array}{l}\text { EPi1: Continuidad de las funciones potenciales } \\
\text { EPiV: Continuidad de la función recíproca (inversa para la composición) } \\
\text { EPa: continuidad de la suma, la diferencia, el producto y la composición de } \\
\text { funciones, continuidad de la función constante, identidad, afín y polinómica, y } \\
\text { espacio vectorial de las funciones continuas en }(a, b) \text { y anillo de las funciones } \\
\text { continuas en }(a, b) \text {. }\end{array}$ \\
\hline Santillana $2^{\circ}(1991)$ & Nada. \\
\hline $\begin{array}{l}\text { Santillana } \\
(1988)\end{array}$ & $\begin{array}{l}\text { EPt: teorema de los valores intermedios y teorema de Weierstrass (para el } \\
\text { máximo absoluto). } \\
\text { EPa: las imágenes de una sucesión que tienen límite tienden a la imagen del } \\
\text { límite de la sucesión, teorema de conservación de signo, teorema de Bolzano, } \\
\text { continuidad en un punto implica acotación en un entorno del punto, } \\
\text { continuidad en un intervalo cerrado implica acotación en dicho intervalo } \\
\text { cerrado, la imagen de un intervalo cerrado es un intervalo cerrado o un punto, } \\
\text { la continuidad uniforme implica continuidad, la inclusión de un intervalo } \\
\text { cerrado en una familia finita de intervalos abiertos y el teorema de Heine. }\end{array}$ \\
\hline Santillana $1^{\circ}(1996)$ & Nada. \\
\hline Santillana $2^{\circ}(1997)$ & $\begin{array}{l}\text { EPt: teorema de los valores intermedios y teorema de los extremos absolutos } \\
\text { de Weierstrass. } \\
\text { EPa: teorema del signo, teorema de acotación (ambos en un entorno de un } \\
\text { punto), teorema de los ceros de Bolzano e imagen de un intervalo cerrado. }\end{array}$ \\
\hline Santillana $1^{\circ}(2008)$ & Nada \\
\hline Santillana $2^{\circ}(2009)$ & $\begin{array}{l}\text { EPil: teorema de Darboux. } \\
\text { EPiV: teorema de Bolzano y teorema de Weierstrass. }\end{array}$ \\
\hline
\end{tabular}

Tabla V.4.2.2. Resultados y justificaciones asociados a la continuidad en los libros de texto de la editorial Santillana.

En cuanto a los resultados justificados, se observa el mismo comportamiento señalado anteriormente. En los cursos inferiores, los resultados que se justifican son los ligados a operaciones con funciones continuas o la continuidad de familias de funciones, o bien, no se justifica. En los cursos superiores, los 
resultados que se justifican son los asociados a la continuidad en un intervalo o un entorno, y no se justifican en ningún caso los resultados asociados a las operaciones de funciones continuas.

Como se ha visto, el descenso de los EP más cercanos a la demostración matemática también es evidente en esta editorial, lo que contribuye a afirmar nuestra hipótesis sobre un descenso en la presentación y en el rigor con el que se tratan los conceptos matemáticos a lo largo del tiempo.

\section{V.4.3. Resultados y justificaciones en la editorial SM}

Esta editorial presenta un mayor número de resultados que las anteriores a pesar de que el número de libros sea uno menos que en los dos casos anteriores (es decir, la media de resultados enunciados por libro de texto es superior en los LT de esta editorial). Ya se ha comentado previamente, pero se vuelve a observar en esta editorial: en los periodos de LOGSE y LOE, los LT de $1^{\circ}$ de Bachillerato no presentan apenas resultados, y los que presentan no los justifican.

\begin{tabular}{|c|c|c|c|c|c|c|c|c|}
\hline \multirow{2}{*}{$\begin{array}{l}\text { Libros de texto de } \\
\text { SM }\end{array}$} & \multicolumn{7}{|c|}{$\mathrm{N}^{0}$ de Esquemas de prueba } & \multirow{2}{*}{$\begin{array}{l}\text { Resultados } \\
\text { totales }\end{array}$} \\
\hline & $E P O$ & EPil & $E P i V$ & $E P i S$ & EPt & $E P a$ & $P P$ & \\
\hline$\overline{S M} 2^{\circ}(1977)$ & 5 & 0 & 0 & 0 & 0 & 4 & 0 & 9 \\
\hline SM COU (1980) & 7 & 0 & 0 & 0 & 4 & 7 & 0 & 18 \\
\hline $\mathrm{SM} 1^{\circ}(1996)$ & 0 & 0 & 0 & 0 & 0 & 0 & 0 & 0 \\
\hline $\operatorname{SM} 2^{\circ}(2001)$ & 30 & 0 & 0 & 0 & 2 & 3 & 0 & 35 \\
\hline $\mathrm{SM} 1^{\circ}(2008)$ & 1 & 0 & 0 & 0 & 0 & 0 & 0 & 1 \\
\hline SM $2^{\circ}(2010)$ & 11 & 0 & 0 & 0 & 2 & 4 & 0 & 17 \\
\hline TOTALES & 54 & 0 & 0 & 0 & 8 & 18 & 0 & 80 \\
\hline
\end{tabular}

Tabla V.4.3.1. Resultados y justificaciones asociados a la continuidad en los libros de texto de la editorial SM.

En primer lugar, atendiendo a los resultados justificados, se observa que un $67,5 \%$ de los resultados no se justifica. Si bien esta editorial es la que más resultados presenta, en proporción no es la que más justifica (en comparación con los porcentajes de las dos anteriores). En cuanto las justificaciones utilizadas, esta editorial se limita al uso de EP axiomáticos (22,5\%) y EP transformacionales $(10 \%)$, siendo los primeros los que más se utilizan.

Observando los EP utilizados en cada LT, se aprecia que el LT que más resultados justifica, tanto en cantidad como en proporción es el LT de COU 
(1980), de la LGE, que justifica un 38,9\% de los resultados con EP axiomáticos y un $22,2 \%$ con EP transformacionales. El siguiente LT que más resultados justifica es el de $2^{\circ}$ de BUP, también del periodo LGE, utilizando únicamente EP axiomáticos (44,4\% del total). El LT de $2^{\circ}$ de Bachillerato de la LOGSE es el texto que más resultados contiene, aunque esto se debe a que enuncia todas las operaciones con funciones continuas y la continuidad de varias funciones elementales y de combinaciones de dichas familias de funciones elementales, lo que aumenta el recuento de resultados. Sin embargo, sólo justifica un 14,3\% de los resultados que enuncia, el 8,6\% con EP axiomáticos y el 5,7\% con EP transformacional. Por su parte, en el LT de $2^{\circ}$ de Bachillerato de la LOE, el número de resultados enunciados vuelve a ser menor (similar al número de resultados enunciados en COU), y se justifica un 35,3\% de los resultados enunciados, la mitad de ellos con EP axiomático y la otra mitad con EP transformacional.

En cuanto a la evolución de los EP utilizados en los LT, no se ha producido ninguna sustitución por otro tipo de EP, sino que en todos los periodos se utilizan los EP axiomáticos y los transformacionales. Sin embargo, sí se observa una disminución en el número de justificaciones presentadas en los LT.

\begin{tabular}{ll}
\hline Libros de texto & Esquemas de prueba \\
\hline SM $2^{\circ}(1977)$ & $\begin{array}{l}\text { EPa: suma de funciones continuas, continuidad de la función potencia, } \\
\text { polinómica y de la composición de funciones. }\end{array}$ \\
SM COU (1980) & $\begin{array}{l}\text { EPt: si } f(p)>k \text {, donde } k \text { es un número real, existe un entorno de } p \text { en el que } \\
f(x)>k, \text { teorema de Weierstrass, propiedad de Darboux y una versión análoga } \\
\text { de la propiedad de Darboux entre el mínimo y el máximo. } \\
\text { EPa: composición de funciones, conservación de signo en un entorno, } \\
\text { anulación de la función si en los entornos de un punto toma valores positivos y } \\
\text { negativos, acotación en un entorno, continuidad uniforme implica continuidad, } \\
\text { acotación en un intervalo cerrado y teorema de Bolzano. }\end{array}$ \\
SM $1^{\circ}(1996)$ & $\begin{array}{l}\text { Nada. } \\
\text { EPt: si } f(p) \text { es mayor que un número real } M, \text { entonces existe un entorno de } p \text { tal } \\
\text { que } f(x)>M, \text { teorema de los valores intermedios. }\end{array}$ \\
EPa: conservación de signo en un entorno de un punto, teorema de Bolzano y \\
teorema de acotación en un intervalo cerrado. \\
Nada. \\
EPt: teorema de los valores intermedios y el teorema del punto fijo.
\end{tabular}

Tabla V.4.3.2. Resultados y justificaciones asociados a la continuidad en los libros de texto de la editorial SM. 
En cuanto a los resultados que se justifican, ya se ha indicado anteriormente la separación por cursos de los tipos de resultados enunciados: en general, los resultados asociados a la continuidad en un intervalo (teorema de Bolzano, teorema de Darboux...) se presentan en el curso más alto (COU o segundo de Bachillerato) y en el primer curso, en los casos en que se muestran resultados, se limitan a las propiedades de funciones continuas en un punto (operaciones y continuidad de familias de funciones elementales). En este LT también se realiza esta distinción aunque, como ya hemos mencionado, en los ejemplares de $1^{\circ}$ de Bachillerato de LOGSE y LOE no se enuncia ningún resultado. En el LT de $2^{\circ}$ de BUP se justifican la suma de funciones continuas, la continuidad de la función potencia, de la función polinómica y de la composición de funciones. En todos los LT del curso más alto (COU y $2^{\circ}$ de Bachillerato) se justifica el teorema de Bolzano y el teorema de Darboux, y otros resultados y teoremas que cambian en cada LT. No obstante, la mayoría de resultados están relacionados con la continuidad en un intervalo y no con las operaciones (salvo algunas excepciones).

\section{V.4.4. Resultados y justificaciones en la editorial Vicens-Vives}

Pese a ser la editorial con más libros en nuestra muestra, el número de resultados enunciados es similar al de la editorial Santillana. Tal y cómo se indicó anteriormente, en el periodo LOGSE tenemos dos colecciones completas (dos libros cada una, uno de cada curso) correspondientes a esa ley, y que hemos mantenido ambas por presentar numerosas diferencias en el planteamiento de los contenidos a pesar de pertenecer a la misma editorial. En este caso también se observa que una de ellas presenta más resultados que la otra, aunque únicamente en $2^{\circ}$ de Bachillerato, mientras que la primera presenta un resultado en $1^{\circ}$ frente a la otra editorial, que no presenta ninguno.

Atendiendo los EP utilizados en los LT de esta editorial, se observa que un $63,2 \%$ de los resultados enunciados no se justifican. De los que se justifican, en la mayoría $(20,6 \%)$ se utiliza EP axiomáticos, seguidos por los EP inductivos de 1 caso y de varios casos (5,9\% y 4,4\% respectivamente), de los EP sistemáticos $(4,4 \%)$ y una única prueba preformal $(1,5 \%)$. Es la única editorial que utiliza una prueba preformal en los resultados asociados a la continuidad. 


\begin{tabular}{|c|c|c|c|c|c|c|c|c|}
\hline \multirow{2}{*}{$\begin{array}{l}\text { Libros de texto de } \\
\text { Vicens-Vives }\end{array}$} & \multicolumn{7}{|c|}{$\mathrm{N}^{0}$ de Esquemas de prueba } & \multirow{2}{*}{$\begin{array}{l}\text { Resultados } \\
\text { totales }\end{array}$} \\
\hline & EPO & EPil & $E P i V$ & $E P i S$ & $E P t$ & $E P a$ & $P P$ & \\
\hline $\mathrm{VV} 2^{\circ}(1980)$ & 4 & 0 & 0 & 0 & 0 & 2 & 1 & 7 \\
\hline VV COU (1979) & 6 & 0 & 0 & 0 & 2 & 4 & 0 & 12 \\
\hline VV $1^{\circ}(1998)$ & 1 & 0 & 0 & 0 & 0 & 0 & 0 & 1 \\
\hline VV $2^{\circ}(1999)$ & 5 & 0 & 2 & 0 & 1 & 1 & 0 & 9 \\
\hline $\mathrm{VV} 1^{\circ}(2003)$ & 0 & 0 & 0 & 0 & 0 & 0 & 0 & 0 \\
\hline $\operatorname{VV} 2^{\circ}(2004)$ & 7 & 2 & 1 & 0 & 0 & 4 & 0 & 14 \\
\hline $\mathrm{VV} 1^{\circ}(2008)$ & 12 & 0 & 0 & 0 & 0 & 0 & 0 & 12 \\
\hline VV $2^{\circ}(2009)$ & 8 & 2 & 0 & 0 & 0 & 3 & 0 & 13 \\
\hline TOTALES & 43 & 4 & 3 & 0 & 3 & 14 & 1 & 68 \\
\hline
\end{tabular}

Tabla V.4.4.1. Resultados y justificaciones asociados a la continuidad en los libros de texto de la editorial Vicens-Vives.

En cuanto a las justificaciones presentadas en cada LT, los ejemplares de COU y de $2^{\circ}$ de Bachillerato de LOGSE (2004) son los que más resultados justifican (un $50 \%$ en cada LT), aunque el LT de COU utiliza únicamente EP axiomáticos $(33,3 \%)$ y transformacionales $(16,7 \%) \mathrm{y}$, sin embargo, aunque en el LT de $2^{\circ}$ de Bachillerato el tipo de justificación más utilizada es el EP axiomático (28,6\%), también utiliza EP inductivos de 1 caso $(14,3 \%)$ y de varios casos $(7,1 \%)$. El LT de $2^{\circ}$ de BUP también utiliza EP axiomáticos $(28,6 \%)$ y una prueba preformal (la única encontrada en toda la muestra). Los libros de $1^{\circ}$ de Bachillerato, tanto de la LOGSE como de la LOE, no justifican ningún resultado. Por su parte, el libro de $2^{\circ}$ de Bachillerato (1999) utiliza EP inductivos de varios casos $(22,2 \%)$ y sendos EP axiomático y transformacional (11,1\% cada esquema). En el LT de $2^{\circ}$ de Bachillerato de LOE se observa una reducción en la proporción de resultados justificados, aunque el más utilizado sigue siendo el EP axiomático $(23,1 \%)$, seguido del otro EP utilizado, el inductivo de 1 caso $(15,4 \%)$.

Por último, atendiendo a la evolución de los EP utilizados, esta editorial es bastante uniforme en cuanto a la utilización de EP axiomáticos, que se utilizan en todos los periodos, aunque desparecen los EP transformacionales y se empiezan a utilizar los EP inductivos (de un caso y de varios casos) a partir de LOGSE.

En cuanto a los resultados justificados, siguiendo la misma dinámica que en otras editoriales, en el LT de $2^{\circ}$ de BUP únicamente se justifican operaciones con las funciones continuas. Por el contrario, en el LT de COU se justifican resultados asociados a la continuidad en intervalos y entornos de un punto. En los LT de $2^{\circ}$ de Bachillerato de LOGSE, los EP axiomáticos se utilizan con operaciones de 
funciones o funciones elementales, y los teoremas de continuidad se justifican con EP inductivos. Este comportamiento es diferente al presentado en otras editoriales, que justifican algunos teoremas de continuidad, como el teorema de Bolzano, con EP axiomáticos, y que coincide con el comportamiento de el LT de $2^{\text {o }}$ de Bachillerato de LOE (Vicens-Vives, 2009)

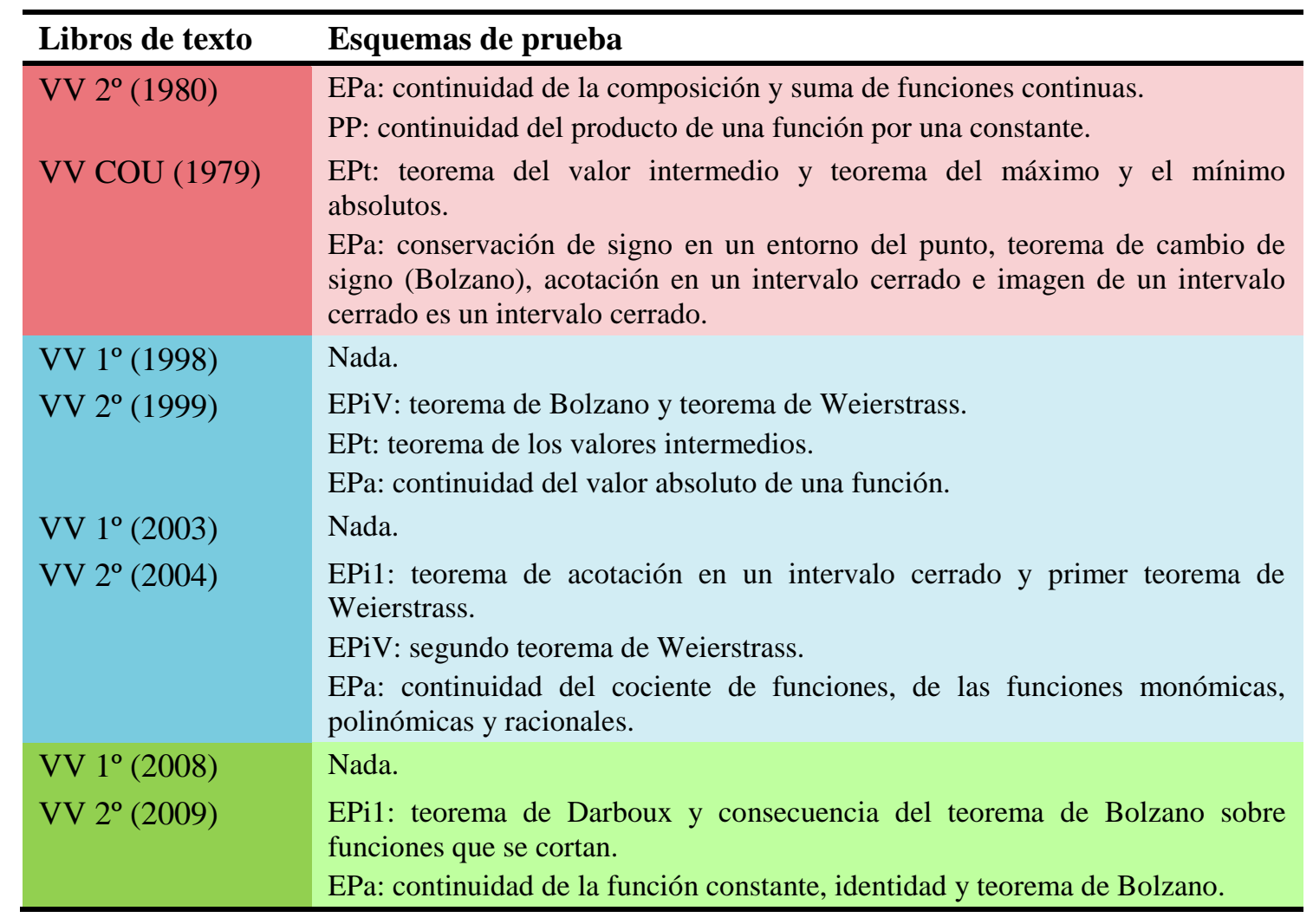

Tabla V.4.4.2. Resultados y justificaciones asociados a la continuidad en los libros de texto de la editorial Vicens-Vives.

\section{V.4.5. Comentarios a los análisis previos}

Según se ha mostrado en los apartados anteriores, cada editorial tiene un comportamiento diferente en relación a la continuidad de funciones, aunque se han observado más similitudes y patrones iguales que en el caso del límite funcional.

En el Gráficos V.4.5.1 se muestra el porcentaje del total de justificaciones de cada tipo que hay en cada editorial (en todos los LT). En el eje horizontal se representa cada tipo de justificación de justificación de nuestra clasificación (EP inductivos de un caso, de varios casos, sistemáticos, transformacionales, axiomáticos y pruebas preformales) a excepción de la categoría EP0 (no se 
justifica), debido a que el alto porcentaje de resultados sin justificar conllevaría una mayor altura del eje vertical, y su lectura sería más incómoda. En el eje vertical se representa el porcentaje de justificaciones de cada tipo que se encuentran en cada editorial. Por último, cada editorial tiene asignado un color, que se utiliza en las barras de cada tipo de justificación para representar el porcentaje en dicha editorial. Al igual que sucedía con los límites, los comportamientos son diferentes en las editoriales: Anaya utiliza en la misma proporción los EP axiomáticos que los inductivos de un caso, Santillana se decanta principalmente por los axiomáticos, SM no utiliza EP inductivos, y Vicens-Vives utiliza casi todos los tipo de EP (exceptuando el EP inductivo sistemático) aunque los más abundantes son los EP axiomáticos. No obstante, todas las editoriales (excepto Anaya, aunque por poco) coinciden en que el EP más utilizado es el EP axiomático. Además, también se observa que, en general, los porcentajes son más altos que en el caso de límites.

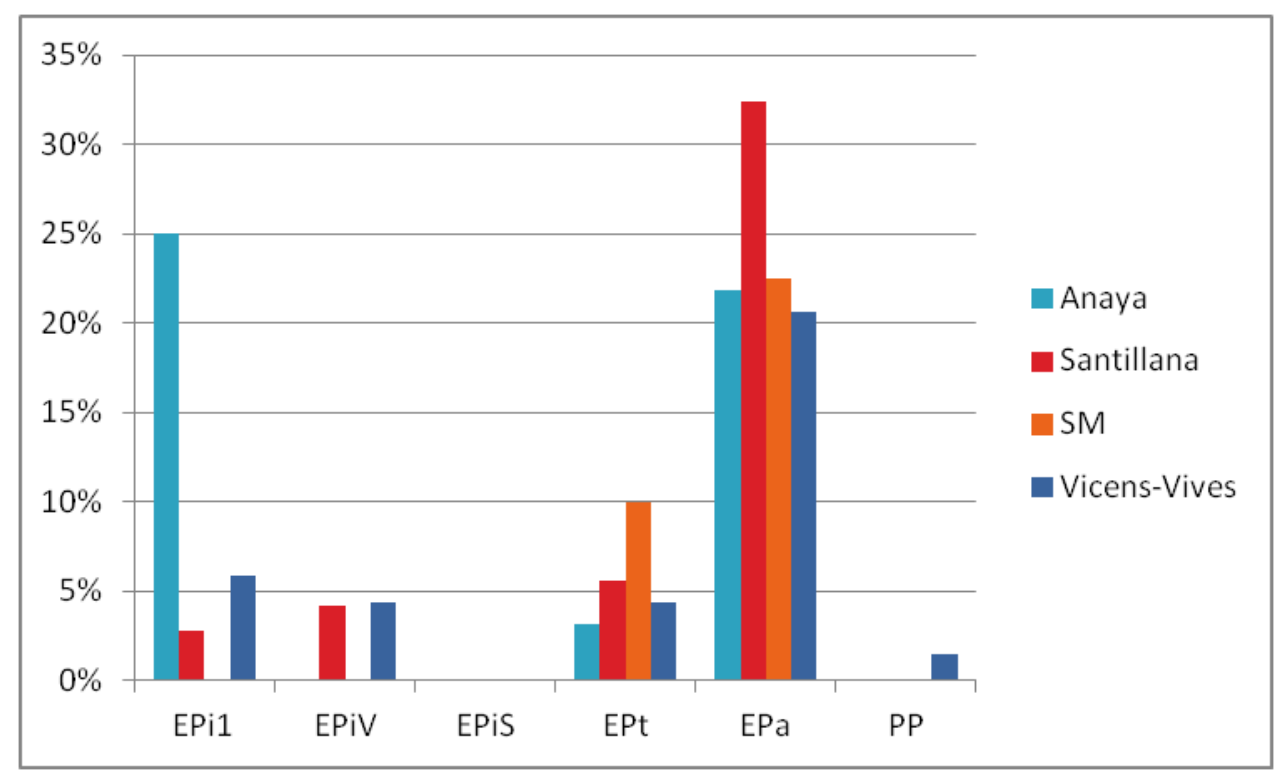

Gráfico V.4.5.1. Porcentaje de EP utilizados en cada editorial.

En el Gráficos V.4.5.2 se muestran, con números absolutos y porcentajes, la evolución de cada tipo de justificación a lo largo de las legislaciones. En el eje horizontal se presentan cada uno de los tipos de justificación considerada (EP y PP), a excepción de los EP0, y en el eje vertical se representa el número total de justificaciones de este tipo en todos los LT de cada periodo legislativo en el gráfico superior, y el porcentaje de justificaciones de ese tipo en todos los LT de cada periodo legislativo en el gráfico inferior. Cada periodo lleva asignado el color que se indica en la leyenda, que coincide con el mismo código de colores 
que se ha usado en el presente trabajo para identificar cada periodo legislativo: rosa para la LGE, azul para la LOGSE y verde para la LOE. Tal y como se puede observar, el número de EP axiomáticos ha disminuido enormemente de la LGE a la LOGSE, y luego a la LOE, que vuelve a disminuir. El número de EP transformacionales se mantiene prácticamente de LGE a LOGSE, pero disminuye en LOE. Sin embargo, se aprecia un aumento sucesivo de los EP inductivos de un caso a lo largo de las legislaciones, y los EP inductivos de varios casos, aunque aumentan en la LOGSE, en la LOE disminuyen con respecto a dicha ley, pero siguen siendo más abundantes que en la LGE. Sólo hemos encontrado una PP, e un LT de la LGE, por lo que dicho EP desaparece en las otras legislaciones (aunque esta evolución no es muy relevante, ya que en sí, este EP es muy poco frecuente).

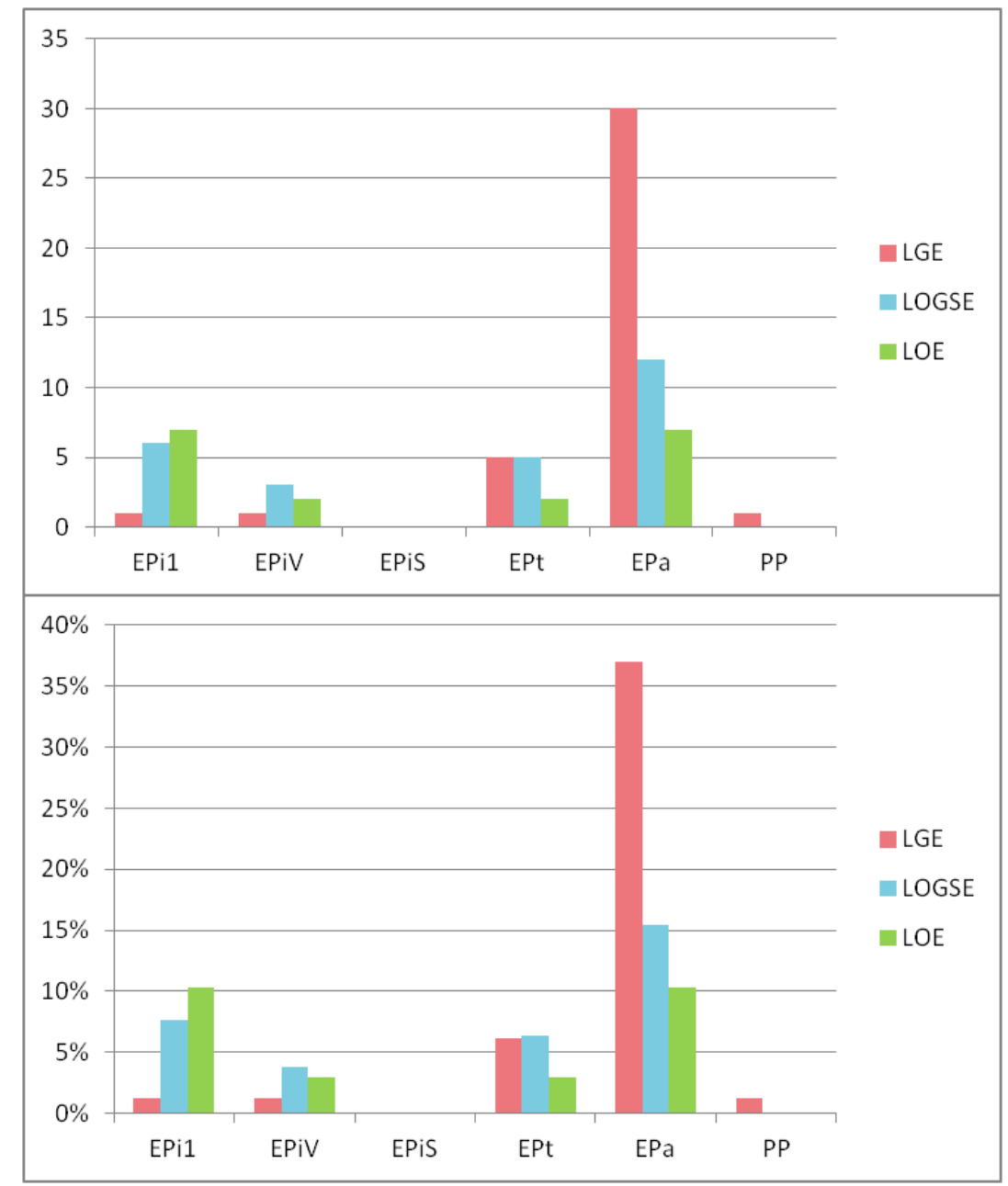

Gráfico V.4.5.2. Evolución de cada tipo de justificación por periodos educativos, mostrada en números absolutos (arriba) y en porcentajes (abajo). 
En cuanto al Gráficos V.4.5.3, se muestra el número absoluto y el porcentaje de resultados que se justifican en cada editorial, en cada periodo legislativo. En el eje horizontal se representan cada una de las editoriales, así como el recuento total para las cuatro editoriales (en la leyenda, Total; sólo en la gráfica de porcentajes, porque en la de números absolutos, las barras de totales serían tan altas que cambiarían la escala de los ejes). En el eje vertical se representa el porcentaje de resultados justificados. Como en la tabla anterior, cada periodo legislativo tiene asignado su color correspondiente, que permite comparar la evolución para cada editorial y la evolución total del porcentaje de resultados que se justifican.

En estas gráficas se observa que la comparación entre alturas de las columnas en el recuento de resultados que se justifican y el porcentaje que representan no se corresponden, es decir, que en algunas editoriales, a pesar de presentar un número mayor de justificaciones en algún periodo que en otros (o incluso que otras editoriales), dicho número representa un porcentaje menor en el total de resultados de dicho periodo, por lo que en este caso resulta de gran utilidad comparar ambas tablas. Por ejemplo, las justificaciones que se presentan en Anaya en la LGE son casi el doble que las que se presentan en la LOGSE, o en LOE, y sin embargo, en LOGSE y LOE los resultados justificados representan más de un $65 \%$ de los resultados enunciados, frente a un $40 \%$ que representan los de la LGE. Eso significa que en las legislaciones más modernas, los LT de Anaya presentan un número de resultados sensiblemente inferior a los presentados en la LGE (20 resultados enunciados en la LGE y 6 en la LOGSE y en la LOE, como se puede comprobar en la Tabla V.4.1.1). No todas las editoriales se comportan de esta manera, y conviene tener en cuenta que el número de LT analizados en cada periodo y editorial varía, pero de forma general, se observa que el número de resultados justificados disminuye en todas las editoriales (excepto en VicensVives) y que en el recuento general, el porcentaje de resultados justificados también desciende a lo largo del tiempo. Este hecho avala nuestra hipótesis de que la demostración matemática ha ido despareciendo de los LT con los sucesivos cambios de legislaciones. 


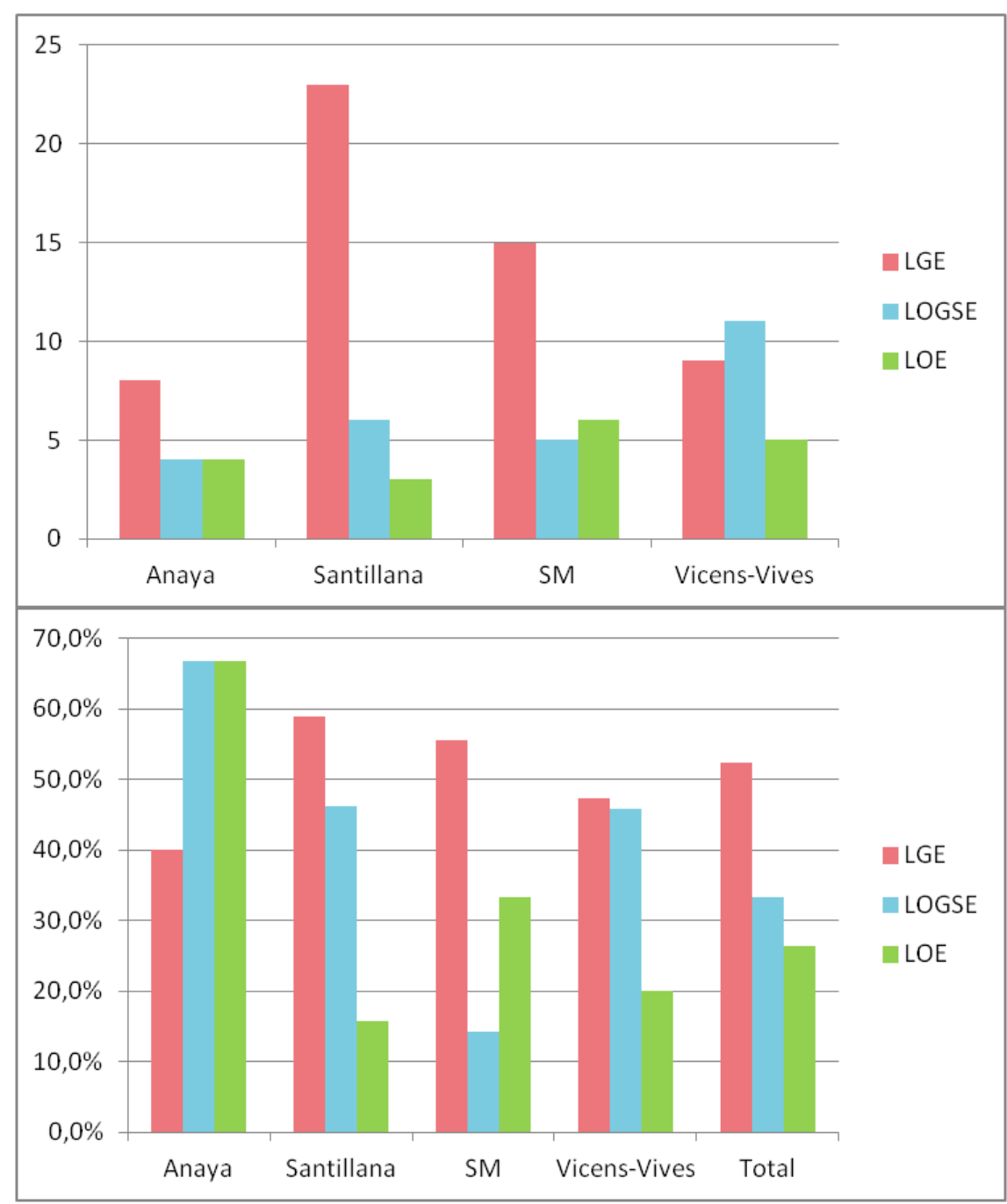

Gráfico V.4.5.3. Porcentaje (abajo) y número (arriba) de resultados justificados en cada editorial, por legislaciones.

En el Gráficos V.4.5.4 se observa la evolución del número de resultados justificados respecto del total de resultados enunciados para cada editorial por separado, y para cada LT de la muestra. Se puede ver un patrón similar en todas las editoriales: en el periodo de la LGE, no se encuentran justificaciones en $2^{\circ}$ de BUP si los LT son del final del periodo (Anaya, 1987 y Santillana, 1991), y se justifica en el curso superior, COU; en la LOGSE y la LOE, las justificaciones asociadas a teoremas y resultados de continuidad sólo se encuentran en el curso superior, $2^{\circ}$ de Bachillerato. No obstante, excepto en Santillana, el número de resultados enunciados en COU es siempre superior a $2^{\circ}$ de Bachillerato. 


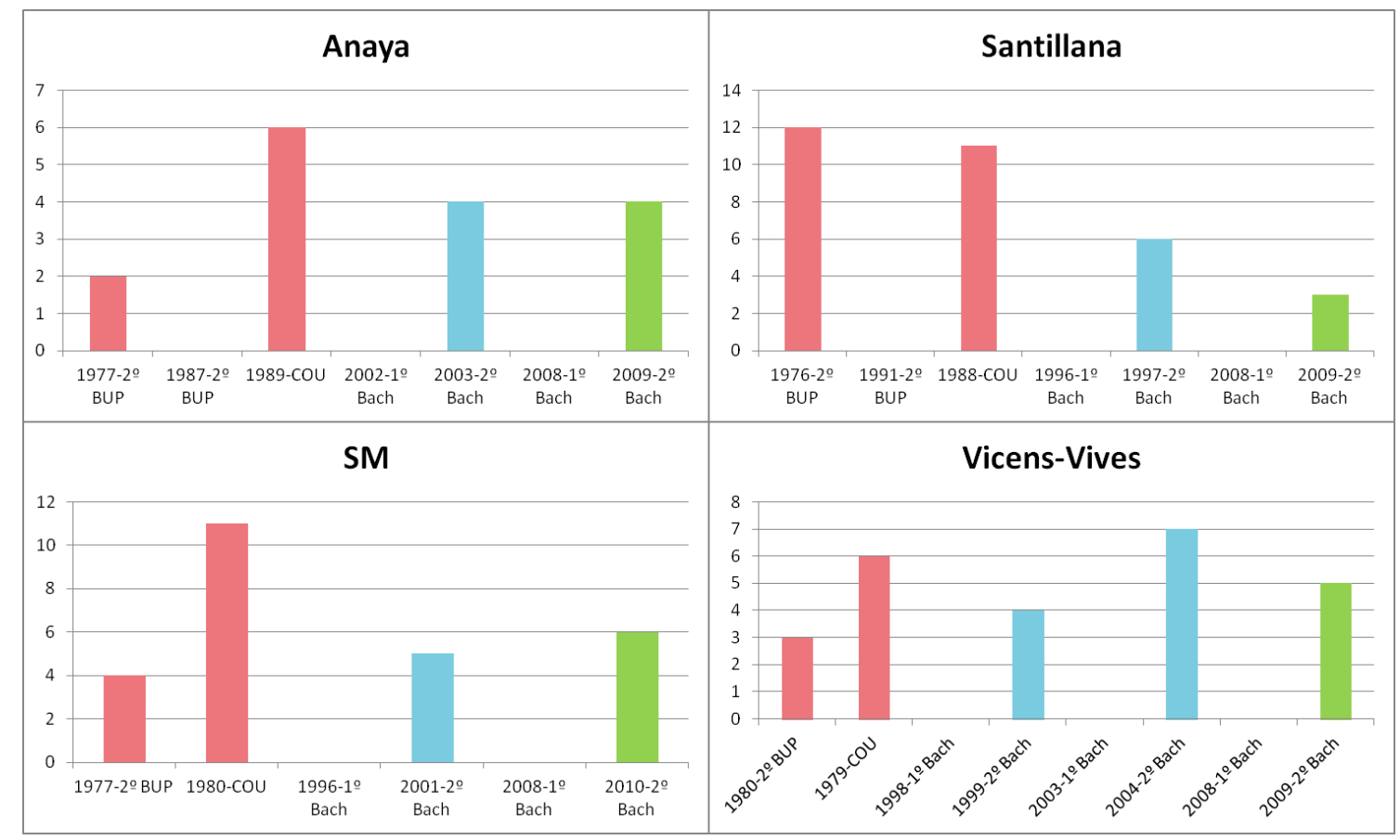

Gráfico V.4.5.4. Número de resultados justificados en cada uno de los LT de cada editorial. Se observa la evolución temporal.

Al igual que en el caso de límites, este primer análisis nos ha permitido observar algunos patrones comunes a todas las editoriales en el tratamiento de la demostración matemática en función del periodo legislativo, aunque cada una tiene sus propias particularidades, que dependerán de los editores que hayan confeccionado cada LT. No obstante, este análisis sólo nos aporta cierta información cuantitativa con respecto al tratamiento de la demostración, y requiere ser completado con los datos que extraídos al aplicar el marco teórico completo, lo que se recoge en los apartados siguientes. Al igual que hicimos en el capítulo de límites, para facilitar la comparación entre textos, hemos agrupado los teoremas en función del tipo de resultado. En este caso, hemos hecho dos grupos:

1. Aritmética y propiedades de funciones continuas.

2. Teoremas de continuidad en entornos e intervalos.

Este análisis se presenta en los apartados V.5 y V.6, y en ellos se recogen todos los datos del análisis realizado atendiendo a las categorías descritas en nuestro marco teórico. 


\section{V.5. ARITMÉTICA Y PROPIEDADES DE FUNCIONES CONTINUAS}

La definición de continuidad, tal y como se presenta en los libros de texto analizados, depende de la función de límite, y por tanto hereda las propiedades que tienen estos últimos. Es por esta razón que los LT parecen conceder menos importancia a las propiedades y operaciones con funciones continuas que la que le concedieron a las propiedades y operaciones con límites. Las encontramos enunciadas en los LT de $2^{\circ}$ de BUP para la LGE, en todos los de $2^{\circ}$ de Bachillerato de LOGSE y LOE (salvo para la editorial Anaya, 2003 y 2009) y en uno de los de $1^{\circ}$ de Bachillerato de LOE, el LT de SM (2008), aunque de forma muy escueta. En cuanto a las justificaciones que se presentan también son más escasas que las presentadas en el caso de límites.

Al igual que sucedía con la definición de límites, no todos los LT definen la continuidad en los mismos términos, aunque las definiciones sean equivalentes. A continuación se clasifican las definiciones que presentan los LT de la muestra para la continuidad en un punto (que utilizan para la definición de la continuidad en un intervalo). Para ello, se ha registrado la definición que el LT considera como principal, es decir, que el LT enuncia en primer lugar o que etiqueta como definición frente a otras, pero los LT suelen reescribir dichas definiciones en otros términos (de 3 condiciones pasan a 1 o viceversa) o enuncian un teorema de caracterización de la continuidad, expresando dichas definiciones en términos de entornos o del valor absoluto.

- Definición de continuidad en términos del límite expresado en 1 condición.

$f$ es continua en $a$ si $\lim _{x \rightarrow a} f(x)=f(a)$ (Anaya, $2^{\circ}$ BUP, 1976, pp. 104).

Se dice que una función $f$ es continua en un punto de abscisa $x_{0}$, cuando se cumple que $\lim _{x \rightarrow x_{0}} f(x)=f\left(x_{0}\right)$ (Anaya, COU, 1989, pp. 235).

Se dice que una función $f$ es continua en un punto de abscisa $c$ cuando se cumple que $\lim _{x \rightarrow c} f(x)=f(c)$ (Anaya, $2^{\circ}$ Bachillerato, 2003, pp. 237 y Anaya, $2^{\circ}$ Bachillerato, 2009, pp. 241).

$f(x)$ es continua en $\mathrm{x}=\mathrm{a} \Leftrightarrow 1^{\circ}$ existe $f(a) ; 2^{\circ}$ existe $\lim _{x \rightarrow a} f(x) ; 3^{\circ} \lim _{x \rightarrow a} f(x)=f(a)$ (Santillana, $1^{\circ}$ Bachillerato, 1996). 
Una función es continua en un punto cuando el valor que toma la función en el punto coincide con el límite de la función en él: $\lim _{x \rightarrow l} f(x)=f(l)$ (SM, $2^{\circ}$ BUP, 1977, pp. 80).

Una función $f(x)$ es continua en un punto de abscisa $p$ de su dominio si se cumple que $\lim _{x \rightarrow p} f(x)=f(p)\left(\mathrm{SM}, 2^{\circ}\right.$ Bachillerato, 2001, pp. 249).

Una función $f$ es continua en el punto $x=a$ si $\lim _{x \rightarrow a} f(x)=f(a)\left(\mathrm{SM}, 1^{\circ}\right.$ Bachillerato, 2008, pp. 198).

Una función $f$ es continua en el punto $x=a$ si $\lim _{x \rightarrow a} f(x)=f(a)$ (SM, $2^{\circ}$ Bachillerato, 2010, pp. 230).

Se dice que $f$ es continua en $a$ cuando $\lim _{x \rightarrow a} f(x)=f(a)$ (Vicens-Vives, $2^{\circ}$ Bachillerato, 1999, pp. 210)

Sea $f$ una función $f$ real de variable real definida en un entorno de $x=a$. Se dice que la función $f$ es continua en $x=a$ si se cumple: $\lim _{x \rightarrow a} f(x)=f(a)$ (Vicens-Vives, $2^{\circ}$ Bachillerato, 2009, pp. 183).

- Definición de continuidad en términos del límite expresado en 2 condiciones.

Sea $y=f(x)$ una función real definida en un subconjunto $\mathrm{D}$ de $\mathbb{R}$. Se dice que la función $f(x)$ es continua en un punto $x_{0}$ interior a D cuando existe el límite de la función cuando $x$ tiende a $x_{0} \mathrm{y}$, además, dicho límite coincide con el valor que toma la función en ese punto, es decir, si se verifica $\lim _{x \rightarrow x_{0}} f(x)=f\left(x_{0}\right)$ (SM, COU, 1980, pp. 221).

Sea I un intervalo de $\mathbb{R}$, y $f: I \rightarrow \mathbb{R}$ una función definida en él. Diremos que la función $f$ es continua en un punto $a \in \mathrm{I}$, si se cumplen las dos condiciones siguientes: 1. Existe el $\lim _{x \rightarrow a} f(x)=\lambda$. 2. $\lambda=f(a)$ (Vicens-Vives, COU, 1979, pp. 233).

- Definición de continuidad en términos del límite expresado en 3 condiciones.

Una función real $f$ se dice continua en $x=a$ si se verifican las tres condiciones: a) Existe $f(a)$, es decir, $a \in \operatorname{Dom}(f)$. b) Existe $\lim _{x \rightarrow a} f(x)$. c) $\lim _{x \rightarrow a} f(x)=f(a)$ (Santillana, $2^{\circ}$ BUP, 1976, pp. 229).

Se dice que $f(x)$ es continua para $x=a$ (o en el punto $a$ ) si se verifica que: 1 ) Existe el límite (no finito) de $f(x)$ para $x \rightarrow a$; 2) existe el valor $f(a)$; y 3) los dos números anteriores son iguales $\lim _{x \rightarrow a} f(x)=f(a)$ (Santillana, $2^{\circ}$ BUP, 1991, pp. 135).

Una función $f(x)$ es continua en un punto $x=a$ si se cumple que: $1^{\circ}$. Existe $f(a) .2^{\circ}$. Existe $\lim _{x \rightarrow a} f(x) .3^{\circ} f(a)=\lim _{x \rightarrow a} f(x)$. (Santillana, $1^{\circ}$ Bachillerato, 2008, pp. 232)

Una función $f(x)$ es continua en un punto $x=x_{0}$ si se cumple que: $1^{\circ}$. Existe $f\left(x_{0}\right)$. $2^{\circ}$. Existe $\lim _{x \rightarrow x_{0}} f(x) .3^{\circ} f\left(x_{0}\right)=\lim _{x \rightarrow x_{0}} f(x)$. (Santillana, $2^{\circ}$ Bachillerato, 2009, pp. 208) 
Sea $f$ una función $f$ real de variable real definida en un entorno de $x=a$. Para que la función $f$ sea continua en el punto $a$ se deben verificar las condiciones siguientes: a) debe existir $\lim _{x \rightarrow a} f(x)$. Por tanto, deben existir los dos límites laterales, $\lim _{x \rightarrow a^{-}} f(x)$ y $\lim _{x \rightarrow a^{+}} f(x)$, y ser iguales. b) Debe existir la imagen $f(a)$. c) El límite y la imagen deben coincidir: $\lim _{x \rightarrow a} f(x)=f(a)$ (Vicens-Vives, $1^{\circ}$ Bachillerato, 2008, pp. 248).

- Definiciones ingenuas o poco formales.

Una función es continua en un punto si no se presenta ningún tipo de discontinuidad (Anaya, $1^{\circ}$ Bachillerato, 2002, pp. 275 y Anaya, $1^{\circ}$ Bachillerato, 2008, pp. 275).

Función continua en un intervalo: la gráfica puede trazarse sin levantar el lápiz del papel (Vicens-Vives, $1^{\circ}$ Bachillerato, 1998, pp. 102).

- Definiciones en términos de aproximación o acercamiento.

Una función $f(x)$, definida en $x=a$, es continua en dicho punto cuando la tasa de variación se aproxima a 0 a medida que el incremento de la variable se hace muy pequeño, es decir, $f(a+h)-f(a)$ se aproxima a 0 cuando $h$ se aproxima a 0 . (SM, $1^{\circ}$ Bachillerato, 1996, pp. 173).

Una función $F$ es continua en $x=a$ si verifica las siguientes condiciones: 1 . $F$ está definida en $a$, es decir, $a$ pertenece a su dominio. 2. Cuando $x$ toma valores muy cercanos a $a$, también las imágenes $F(x)$ toman valores muy cercanos a $F(a)$ (VicensVives, $2^{\circ}$ BUP, 1980, pp. 144).

Una función $f(x)$, definida en $x=a$ y en un entorno de $a$, es continua en $x=a$ cuando el incremento $f(a+h)-f(a)$ se aproxima a cero a medida que la cantidad $h$ se aproxima a cero. (Vicens-Vives, $1^{\circ}$ Bachillerato, 2003, pp. 224)

- Definiciones en términos de $\varepsilon-\delta$.

Sea $f: \mathrm{D} \rightarrow \mathbb{R}$ una función definida sobre un subconjunto $\mathrm{D}$ de $\mathbb{R}$ y $x_{0} \in \mathrm{D}$. La función $f$ se dice continua en $x_{0}$ si para todo número real $\varepsilon>0$ se puede encontrar un número real $\delta>0$ (que, en general, depende de $\varepsilon$ ) tal que $\left|x-x_{0}\right|<\delta$ y $x \in \mathrm{D}$ implica que $\mid f(x)-$ $f\left(x_{0}\right) \mid<\varepsilon$. (Santillana, COU, 1981, pp. 243).

Sea la función $f(x)$ definida en $x_{0}$. Se dice que $f(x)$ es continua en $x_{0}$ si, para cualquier valor $\varepsilon>0$, existe un valor $\delta>0$ tal que para todo $x$ que diste de $x_{0}$ menos que $\delta$, su imagen dista de $f\left(x_{0}\right)$ menos que $\varepsilon$. (Vicens-Vives, $2^{\circ}$ Bachillerato, 2004, pp. 27)

Por último, no se ha considerado la definición de continuidad en el LT de Anaya (1987) porque la única referencia que se ha encontrado es la siguiente:

Límite y continuidad. Las funciones continuas tienen límite en todos sus puntos y ese límite coincide con el valor de la función en ese punto.

(Anaya, $2^{\circ}$ BUP, 1987, pp. 143) 


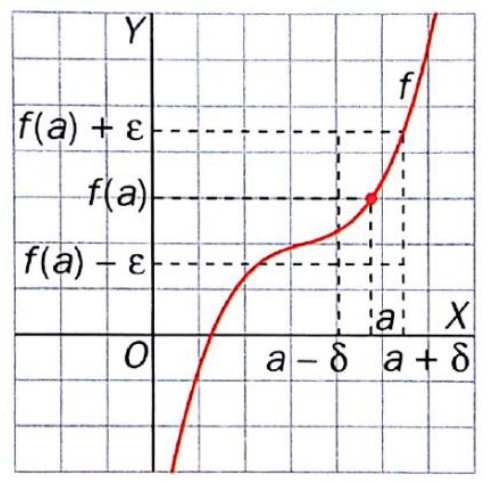

Figura V.5.1. Ilustración de la continuidad utilizando entornos o valor absoluto (SM, $2^{\circ} \mathrm{de}$ Bachillerato, 2010).

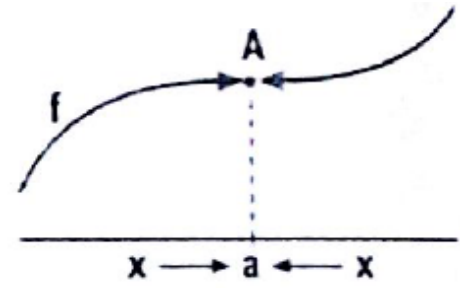

Figura V.5.2. Ilustración de la continuidad utilizando el límite (Vicens-Vives, $2^{\circ}$ de Bachillerato, 1999).

Función continua en un intervalo

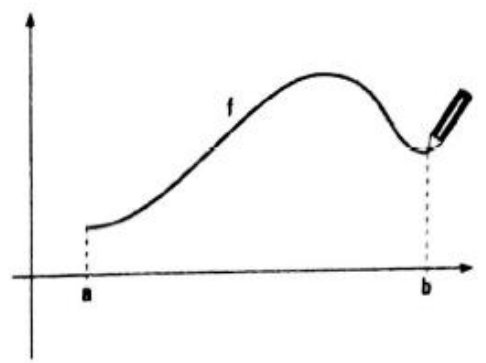

La gráfica puede trazarse sin levantar el lápiz del papel.

Función discontinua en $\mathrm{x}=\mathrm{a}$

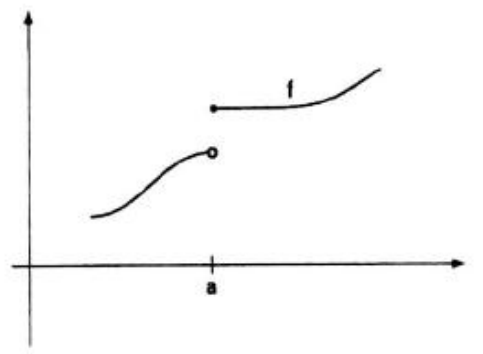

$f$ está definida en a, pero la gráfica presenta una fractura en $\mathrm{x}=\mathrm{a}$.

Figura V.5.3. Definición ingenua de continuidad (Vicens-Vives, $1^{\circ}$ de Bachillerato, 1998). 
No obstante, ya hemos mencionado que la mayoría de los LT presentan más de una caracterización de la continuidad, aunque en la mayoría de los casos no justifican que las distintas definiciones dadas son equivalentes, si bien en muchos casos parten de la definición de límite, por lo que no sería necesario al haberlo establecido previamente. En la Tabla V.5.1 se muestran las distintas definiciones que muestran los LT para caracterizar la continuidad y si consideran gráficas que ilustren la idea de continuidad. En general se pueden encontrar tres tipos de gráficas en función de la caracterización principal asignada por el libro de texto: los LT cuya definición principal está enunciada en términos de valor absoluto o de entornos muestran una gráfica que ilustra dichos entornos (Figura V.5.1); los que parten de las definiciones en términos del límite, muestran una gráfica en la que no aparecen dichos entornos, sólo la función, como por ejemplo en la Figura V.5.2; por último, algunos LT lo que hacen es ilustrar las discontinuidades, o la continuidad frente a la discontinuidad (Figura V.5.3).

Tal y como se observa en la Tabla V.5.1, la caracterización que más aparece es la que enunciada en términos de existencia del límite y coincidencia con el valor de la función en el punto, expresada en tres condiciones ( 21 de los 28 LT la muestran). No siempre se considera la definición principal, pues en ocasiones es una aclaración de la definición expresada en los mismos términos pero enunciada en una sola condición. No obstante, alguno de los LT que no utilizan estas dos definiciones, consideran una reformulación de la misma en dos condiciones, por lo que podemos considerar que son 25 LT de los 28 los que utilizan alguna formulación en términos del límite. Sin embargo, hay tres LT que no la expresan en términos del límite: el LT de $2^{\circ}$ de BUP de Vicens-Vives (1980), el LT de COU de Santillana (1981) y uno de los LT de $1^{\circ}$ de Bachillerato de Vicens-Vives (1998). Los LT de la LGE (Vicens-Vives, 1980 y Santillana, 1981) utilizan una definición más formal, en términos del valor absoluto o de entornos. Sin embargo, en el caso del LT de la LOGSE (Vicens-Vives, 1998) no muestra una definición formal de continuidad, sino que se limita a considerar e ilustrar la idea intuitiva (no levantar la el lápiz del papel al dibujar la gráfica, Figura V.5.3). Por otro lado, sólo 11 LT consideran alguna definición en términos del valor absoluto o de entornos, 7 de los cuales son de la LGE, lo que apunta a la idea de una pérdida de formalidad matemática a lo largo de las legislaciones. 


\begin{tabular}{|c|c|c|c|c|c|c|c|c|c|c|}
\hline \multicolumn{2}{|c|}{ Periodo } & $\mathbf{L T}$ & 1 cond. & $\begin{array}{l}\text { Límite } \\
2 \text { cond. }\end{array}$ & 3 cond. & $\begin{array}{l}\text { Valor } \\
\text { abs. }\end{array}$ & Entornos & Ingenuas & Aprox. & Gráfica \\
\hline \multirow[t]{10}{*}{$\overline{\mathrm{LGE}}$} & $2^{\circ}$ & Anaya (1977) & $\checkmark$ & & $\checkmark$ & $\checkmark$ & & & & No \\
\hline & BUP & Anaya (1987) & Parcial & & & & & & & No \\
\hline & & Sant. (1976) & & & $\checkmark$ & & & $\checkmark$ & & No \\
\hline & & Sant. (1991) & $\checkmark$ & & $\checkmark$ & & & & & No \\
\hline & & SM (1977) & $\checkmark$ & & $\checkmark$ & $\checkmark$ & & & $\checkmark$ & No \\
\hline & & $\overline{\mathrm{VV}(1980)}$ & & & & & $\checkmark$ & & $\checkmark$ & Sí \\
\hline & $\overline{\mathrm{COU}}$ & Anaya (1989) & $\begin{array}{lll} & & \\
\end{array}$ & & $\begin{array}{lll}\checkmark & & \\
\end{array}$ & $\begin{array}{lll}\checkmark & & \end{array}$ & $\checkmark$ & & & No \\
\hline & & Sant. (1981) & & & & $\checkmark$ & & & & Sí \\
\hline & & $\overline{\text { SM (1980) }}$ & & $\checkmark$ & & & $\checkmark$ & & & Sí \\
\hline & & VV (1980) & & $\checkmark$ & & & $\checkmark$ & & & No \\
\hline \multirow[t]{10}{*}{ LOGSI } & & Anaya (2002) & & $\checkmark$ & & & & $\checkmark$ & & Sí \\
\hline & Bach. & 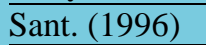 & $\checkmark$ & & $\checkmark$ & & & $\checkmark$ & & No \\
\hline & & SM (1996) & $\checkmark$ & & $\checkmark$ & & & & $\checkmark$ & Sí \\
\hline & & $\overline{\text { VV (1998) }}$ & & & & & & $\checkmark$ & & Sí \\
\hline & & VV (2003) & $\checkmark$ & & $\checkmark$ & & & $\checkmark$ & $\checkmark$ & Sí \\
\hline & $\overline{2^{\circ}}$ & Anaya (2003) & $\checkmark$ & & $\checkmark$ & & & & & Sí \\
\hline & Bach. & Sant. (1997) & $\checkmark$ & & $\checkmark$ & $\checkmark$ & $\checkmark$ & $\checkmark$ & & Sí \\
\hline & & SM (2001) & $\checkmark$ & & $\checkmark$ & $\checkmark$ & & $\checkmark$ & & Sí \\
\hline & & VV (1999) & $\checkmark$ & & $\checkmark$ & & & $\checkmark$ & & Sí \\
\hline & & VV (2004) & $\checkmark$ & & $\checkmark$ & $\checkmark$ & & & $\checkmark$ & Sí \\
\hline \multirow[t]{8}{*}{ LOE } & $1^{\circ}$ & Anaya (2008) & & & $\checkmark$ & & & $\checkmark$ & & Sí \\
\hline & Bach. & Sant. (2008) & & & $\checkmark$ & & & & & No \\
\hline & & $\overline{\text { SM (2008) }}$ & & & $\checkmark$ & & & $\checkmark$ & & Sí \\
\hline & & VV (2008) & & & $\checkmark$ & & & $\checkmark$ & & No \\
\hline & $\overline{2^{\circ}}$ & Anaya (2009) & $\checkmark$ & & $\checkmark$ & & & & & Sí \\
\hline & Bach. & Sant. (2009) & & & $\checkmark$ & & & & & No \\
\hline & & SM (2010) & $\checkmark$ & & $\checkmark$ & $\checkmark$ & & & & Sí \\
\hline & & $\overline{\mathrm{VV}(2009)}$ & $\checkmark$ & & $\checkmark$ & & & & & No \\
\hline
\end{tabular}

Tabla V.5.1. Caracterizaciones de la continuidad en los LT. Utilización de gráficas.

Por otro lado, existen algunas particularidades en los LT. El LT de Vicens-Vives (1980) de COU también la escribe en términos de sucesiones, pero es el único que hemos encontrado que lo hace así, y no lo hemos recogido en la tabla. En cuanto al LT de Anaya (1987), hemos registrado que enuncia la definición en términos del límite, 1 condición, pero de forma parcial, ya que la forma de expresarlo no se ajusta al enunciado usual, tal y como se expuso anteriormente:

Límite y continuidad. Las funciones continuas tienen límite en todos sus puntos y ese límite coincide con el valor de la función en ese punto. (Anaya, 2º BUP, 1987, pp. 143)

Esta diversidad de notaciones influye en las justificaciones que se pueden considerar para resultados posteriores. Por ejemplo, si no se consideran las definiciones en términos de entornos o valor absoluto, difícilmente se podrán considerar justificaciones que utilicen dichos recurso, como se puede ver más adelante en la justificación de la continuidad de las funciones identidad y constante en libros que han utilizado definiciones diferentes. 
En la Tabla V.5.2 se observa que los resultados asociados a las operaciones con funciones continuas se demuestran en mayor número en el periodo de la LGE, desapareciendo prácticamente, excepto algunos ejemplos puntuales, en la LOGSE y en la LOE. Además, apenas se pueden comparar justificaciones entre legislaciones, dado que, a excepción de la suma de funciones continuas y la continuidad de las funciones constante e identidad, que se justifican en un LT de LGE y uno LOE, y la de la función polinómica, que se justifica en un LT de LGE y otro de LOGSE, el resto de resultados se justifican en LT de un periodo únicamente. Hay que señalar que en los únicos LT de la LGE que no se justifica es en los LT de $2^{\circ}$ de BUP de finales del periodo, es decir, en al Anaya (1987) y en el Santillana (1991).

\begin{tabular}{|c|c|c|c|}
\hline & LGE & LOGSE & LOE \\
\hline Suma & $\begin{array}{l}\text { Anaya } 2^{\circ}(1977) \\
\text { Santillana } 2^{\circ}(1976) \\
\text { SM } 2^{\circ}(1977) \\
\text { VV } 2^{\circ}(1980)\end{array}$ & & ${\mathrm{SM} 2^{\circ}(2010)}^{\circ}$ \\
\hline Composición & $\begin{array}{l}\text { Anaya } 2^{\circ}(1977) \\
\text { Santillana } 2^{\circ}(1976) \\
\text { SM } 2^{\circ}(1977) \\
\text { SM COU }(1980) \\
\text { VV 2 } 2^{\circ}(1980)\end{array}$ & & \\
\hline Diferencia & Santillana $2^{\circ}(1976)$ & & \\
\hline Producto & Santillana $2^{\circ}(1976)$ & & \\
\hline Función constante & Santillana $2^{\circ}(1976)$ & & $\operatorname{VV} 2^{\circ}(2009)$ \\
\hline Función identidad & Santillana $2^{\circ}(1976)$ & & $\operatorname{VV} 2^{\circ}(2009)$ \\
\hline Función afín & Santillana $2^{\circ}(1976)$ & & \\
\hline Función polinómica & Santillana $2^{\circ}(1976)$ & $\operatorname{VV} 2^{\circ}(2004)$ & \\
\hline Función recíproca & Santillana $2^{\circ}(1976)$ & & \\
\hline Función potencial & Santillana $2^{\circ}(1976)$ & & \\
\hline Producto por constante & $\operatorname{VV} 2^{\circ}(1980)$ & & \\
\hline Función monómica & & $\operatorname{VV} 2^{\circ}(2004)$ & \\
\hline Valor absoluto & & VV $2^{\circ}$ (1999) & \\
\hline Cociente & & VV $2^{\circ}(2004)$ & \\
\hline Función racional & & $\operatorname{VV} 2^{\circ}(2004)$ & \\
\hline
\end{tabular}

Tabla V.5.2. LT que justifican resultados asociados a las operaciones con límites y a la continuidad de funciones elementales.

Hay que señalar también que las propiedades de las funciones continuas son fácilmente justificables una vez establecida la teoría de límites, dado que son similares a las propiedades sobre límites de funciones. Además, en el caso de la continuidad, lo único que se añade a la definición de límite es que la función está definida en el punto considerado y que coincide con el valor del límite. Así pues, las propiedades de la continuidad se deducen fácilmente de las de límites, pues únicamente se añade el valor de la función en el punto, ya que con las propiedades de los límites ya se ha justificado la parte relativa al límite.Esto 
significa que, por un lado, se puede considerar que las propiedades de las funciones continuas en un punto son demasiado evidentes y no es necesario justificarlas. Por otro, desde el punto de vista de la demostración, estas propiedades ofrecen una buena oportunidad de mostrar un razonamiento matemático formal, adecuado al nivel educativo en el que nos encontramos y que ofrece una mayor vinculación de la definición de límite funcional y de continuidad de una función en un punto.

El hecho de ser propiedades fácilmente justificables a partir de las propiedades del límite provoca dos sucesos: en primer lugar, todos los LT de $2^{\circ}$ de BUP que justifican estas operaciones, justifican la suma y la composición, dado que la suma es un representante de las operaciones aritméticas, y la composición complementa dichas operaciones, y juntas permiten obtener cualquier función a partir de las funciones básicas elementales. En segundo lugar, casi todas las justificaciones ofrecidas para este tipo de resultados son EP axiomáticos.

$$
\begin{aligned}
& \text { Ejemplo. Si f } y \text { g son continuas en } \mathbf{a} \Rightarrow \lim _{x \rightarrow a} f(x)=f(a), y \lim _{x \rightarrow a} g(x)=g(a), y, \text { por tanto: } \\
& \lim _{x \rightarrow a}(f+g)(x)=\lim _{x \rightarrow a}(f(x)+g(x))=f(a)+g(a)=(f+g)(a), \text { lo cual indica que } f+g \text { es } \\
& \text { continua en } x=a \text {. }
\end{aligned}
$$

Figura V.5.4. Justificación de la continuidad de la suma (SM, 2010, pp. 232).

En el caso de la continuidad de la suma de funciones continuas, ésta se justifica en cuatro libros de la LGE de $2^{\circ}$ de BUP (Anaya, 1977; Santillana, 1976; SM, 1977 y Vicens-Vives, 1980) y en un LT de $2^{\circ}$ de Bachillerato de la LOE (SM, 2010). En general, en los LT se enuncian todas las operaciones juntas y, en algunos, se justifica una a modo de ejemplo, que suele ser la suma. En todos ellos, la justificación utilizada es un EP axiomático. En general, la justificación utilizada en la mayoría de los textos se basa en aplicar la suma de límites para establecer la suma de funciones continuas, tal y como se observa en la Figura V.5.4, que es la justificación que presenta el LT de $2^{\circ}$ de Bachillerato de $2^{\circ}$ de SM (2010). En este caso, la etiqueta de ejemplo se utiliza porque en el LT se indica que las operaciones con funciones continuas se justifican utilizando las operaciones con límites y que sólo se muestra una a modo de ejemplo, en este caso, la suma.

Los LT de Anaya (1977) y SM (1977) presentan una justificación similar, basada en la aplicación de la suma de límites. Se trata de justificaciones cuyas funciones 
principales son la de verificación y comunicación, ya que se ofrecen a modo de ejemplo de demostración de una operación con funciones continuas, y que con un proceso análogo, se podrán justificar también las otras operaciones. En los LT de SM (2010) y Anaya (1977) se reconoce el proceso como justificación, ya que se indica que se justifica o se etiqueta como demostración. En SM (1977) cambia la tipografía pero no se hacen alusiones a la demostración. El sistema de representación utilizado es principalmente el simbólico (o fórmula), aunque se utilizan conectores verbales que facilitan seguir el razonamiento. No se presentan gráficas. En todos se indica que se deducen de las propiedades de los límites, pero no se explica globalmente el proceso en ningún LT. En cuanto al significado de la propiedad, ésta se utiliza para establecer la continuidad de funciones obtenidas a partir de combinación de funciones elementales básicas cuya continuidad se conoce o establece posteriormente. La distinción entre enunciado y justificación es principalmente tipográfica y no se indican otras vías de justificación.

No obstante, dos de los LT de $2^{\circ}$ de BUP, Santillana (1979) y Vicens-Vives (1980), presentan algunas variaciones frente a los comentarios expuestos anteriormente. En primer lugar, el LT de Santillana (1976) justifica que la función está definida en el punto considerado, aspecto que no es justificado en el resto de LT (Figura V.5.5). Esto puede deberse a que en el tratamiento de funciones ya se haya justificado que la suma de dos funciones definidas en un punto está definida en dicho punto, o porque los editores de los LT consideren que es algo evidente. Una vez establecido esto, aplica la suma de límites, como en los otros LT.

$$
\begin{aligned}
& \text { Si } f \text { es continua en } x=a \text {, entonces } a \in \operatorname{Dom}(f) \text {; análogamen- } \\
& \text { te } a \in \operatorname{Dom}(g) \text {, luego } \\
& \qquad a \in \operatorname{Dom}(f) \cap \operatorname{Dom}(g)=\operatorname{Dom}(f+g)
\end{aligned}
$$

Por tanto $f+g$ está definida en $x=a$.

Figura V.5.5. Justificación de la definición de $f+g$ en $a$ (Santillana, 1976, pp. 231).

En el caso del LT de Vicens-Vives (1980), se indica que lo que se presenta no es una demostración, sino unas indicaciones (Figura V.5.6). No obstante, estas indicaciones orientan hacia una demostración matemática por lo que hemos clasificado el razonamiento como EP axiomático. En relación a las funciones de 
la demostración, consideraríamos la comunicación y la verificación: la primera, puesto que existe dicha intención al dar ciertas pautas para establecer dicha demostración (en caso contrario no se indicaría nada); por otro lado, consideramos la verificación, puesto que las indicaciones van en la línea de comprobar, demostrar. Sin embargo, en este caso no podemos considerar la función de explicación puesto que las indicaciones dadas no son nada intuitivas a la hora de percibir que el resultado es cierto, y la tarea que queda para el lector no es nada trivial.

Sin pretender hacer la demostración, hagamos algunas indicaciones: Dado un entorno de radio $\varepsilon$ del punto $(F+G)(a)$, podremos determinar dos entornos $A_{1}$ y $A_{3}$
de a, de modo que:

$$
\begin{aligned}
& \mathbf{F}\left(\boldsymbol{A}_{1}\right) \text { esté incluido en un entorno de } \mathbf{F}(\mathrm{a}) \text { de radio } \frac{\frac{5}{2}}{2} \\
& \mathbf{G}\left(\boldsymbol{A}_{2}\right) \text { esté incluido en un entorno de } \mathbf{G}(\mathrm{a}) \text { de radio } \frac{\frac{\varepsilon}{2}}{2}
\end{aligned}
$$

Se comprobaria, finalmente, que en el menor de los dos entornos $\boldsymbol{A}_{1}$ y $\boldsymbol{A}_{\mathrm{t}}$, Las imágenes mediante $\mathbf{F}+\mathbf{G}$ pertenecerian necesariamente al entorno de radio 6 de $(\mathbf{F}+\mathbf{G})(\mathrm{a})$.

Figura V.5.6. Suma en Vicens-Vives (1980, pp. 150).

La otra propiedad que más se justifica en los LT, y que suele acompañar a la suma, es la continuidad de la composición de funciones continuas. Sin embargo, esta propiedad sólo se justifica en los LT de la LGE; en concreto, en los mismos LT de $2^{\circ}$ de BUP en los que se justificaba la suma (Anaya, 1977, Santillana 1976, SM, 1977 y Vicens-Vives, 1980) y uno de los LT de COU (SM, 1980). En todos ellos se justifica mediante un EP axiomático.

En efecto: sea $E$ un entorno de $(g \circ f)(a)=g(f(a))$; como $g$ es continua en $f(a), g^{-1}(E)=E_{1}$ es un entorno de $f(a)$, y como $f$ es continua en $a, f^{-1}\left(E_{1}\right)=E_{2}$ es un entorno de $a$ (Fig. 5); entonces por la propiedad estudiada en el apartado 12.6. del tema 1 se tiene: $(g \circ f)^{-1}(E)=f^{-1}\left(g^{-1}(E)\right)=f^{-1}(E)=E_{2}$.

Hemos visto, pues, que la imagen recíproca de todo entorno de $g(f(a))$ es un entorno de $a$; luego aplicando el teorema 2.2., $g \circ f$ es continua en $x=a$.

Figura V.5.7. Justificación de la composición de la continuidad de funciones (Santillana, 1976, pp. 232 y 233).

Se observan dos demostraciones diferentes por el modo utilizado. La de modo analítico, que utiliza que la propiedad de la composición en límites y se lo aplica 
al caso de las funciones continuas (Anaya, 1977 y SM, 1977) y la de modo directo, que utiliza la definición de continuidad expresada en términos de entornos, como en el ejemplo de la Figura V.5.7 (el resto de LT).

Por lo demás, son justificaciones que presentan características similares a las justificaciones de la suma de funciones continuas.

Aunque no vamos a dar la demostración del teorema, sin embargo, intuitivamente, la justificación es muy elemental, puesto que, al ser f continua, su gráfica se puede trazar sin levantar el lápiz del papel, pero como la gráfica de $\mathrm{f}^{-1}$ es la simétrica de la de $\mathrm{f}$ respecto de la bisectriz del primer y tercer cuadrante, resulta que la gráfica de $\mathrm{f}^{-1}$ a efectos de continuidad tendrá el mismo carácter que la de f; luego si f es continua, también lo será $\mathrm{f}^{-1}$ (Figs.6 y 7)

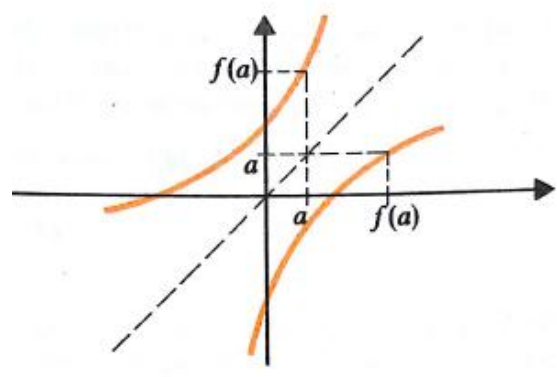

(Fig. 6)

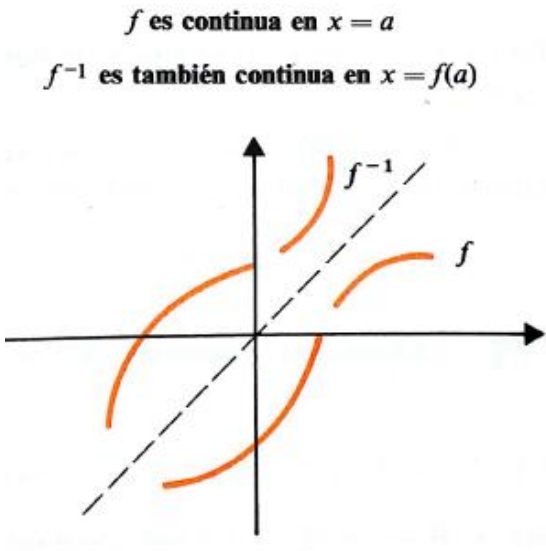

(Fig. 7)

Figura V.5.8. Justificación de la continuidad de la función recíproca (Santillana, 1976, pp. 233).

El resto de propiedades se justifican a lo sumo en dos LT de la muestra, por lo que no se pueden establecer comparaciones de forma general entre editoriales o periodos legislativos, ya que son casos puntuales. Por ejemplo, la mayoría de las otras propiedades que se justifican aparecen en el LT de $2^{\circ}$ de BUP de Santillana (1976), que justifica la diferencia, el producto, la continuidad de las funciones constante, identidad, afín, polinómica, recíproca y potencial. Todas estas justificaciones son EP axiomáticos con características similares a las de la suma o la composición, excepto la justificación de la función recíproca, en la que se utiliza un EP inductivo de varios casos (Figura V.5.8), o la de la función potencial, que se justifica con un EP inductivo de 1 caso. En este caso, se ha clasificado como EP inductivo de un caso porque justifica la continuidad del caso general $x^{n}$ mostrando un ejemplo, $x^{2}$. Sin embargo, la continuidad de $x^{2}$ se justifica mediante un EP axiomático (aplicando al producto de dos funciones identidad la propiedad del producto de funciones continuas). 
Otro caso especial es el de la justificación de la continuidad del producto de una función continua por una constante del LT de $2^{\circ}$ de BUP de Vicens-Vives (1980), en el que se utiliza la única prueba preformal que hemos encontrado en los teoremas de continuidad en toda la muestra. Aunque la hemos clasificado como prueba preformal, sólo se reduce la abstracción en parte: es decir, en el LT se establece, al final de la justificación, que cualquier función de la forma $r \cdot F$, donde $F$ es una función continua en un punto y $r$ un número real, será continua en dicho punto. Sin embargo, lo ha probado para el caso concreto en que $r=3$, de forma que así puede representar gráficamente una función cualquiera y la obtenida al multiplicar por 3 (Figura V.5.9). No obstante, en el gráfico sólo se presentan las dos gráficas, el resto de la demostración (que es analítica, pues aplica la definición de continuidad en términos de entornos) se hace de forma verbal.

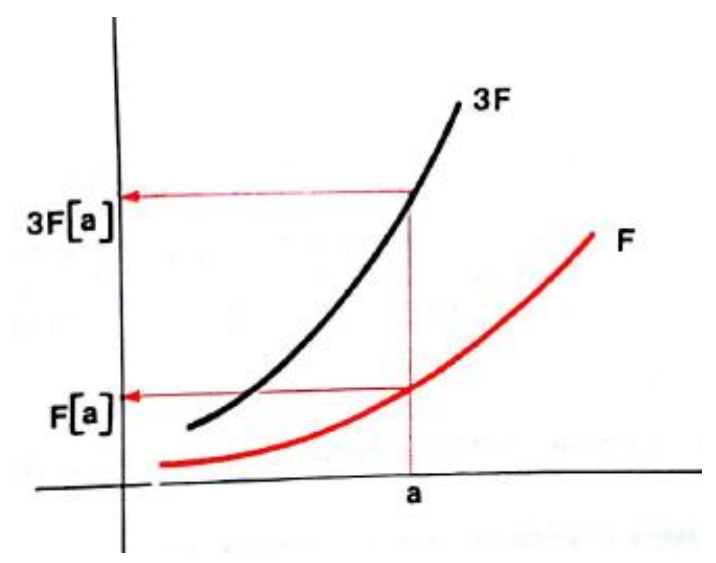

Figura V.5.9. Imagen para ilustra la continuidad del producto de una función por una constante (Vicens-Vives, $2^{\circ}$ BUP, 1980, 151).

También otros resultados se justifican en un solo texto de toda la muestra: la continuidad de la función monómica, del cociente de funciones continuas y de las funciones racionales en Vicens-Vives (2004) y la continuidad de la función valor absoluto en Vicens-Vives (1999).

Por otro lado, se pueden comparar justificaciones de distintos periodos para el caso de la función polinómica, que se justifica en Santillana (1976) y en VicensVives (2004) y para la continuidad de las funciones constante e identidad, que se justifican en Santillana (1976) y en Vicens-Vives (2009). En los casos de las funciones constante e identidad se observan dos justificaciones diferentes, que dependen de la caracterización de la continuidad. En Santillana (1976) utilizan la caracterización de la continuidad expresada en términos del valor absoluto 
(Figura V.5.10) y en el LT de Vicens-Vives (2009), la definición expresada en tres condiciones (existencia del límite, definición en el punto, y coincidencia del límite y el valor de la función en el punto) como se ve en la Figura V.5.11. Es claro que el LT de la LGE trata el concepto de continuidad con mayor nivel de rigor matemático y, sin embargo, el LT de la LOE no enuncia siquiera el límite en términos de $\varepsilon-\delta$, por lo que una justificación como la del Santillana (1976) sería imposible. Desde el punto de vista del alumno, es más sencilla, pues requiere menos abstracción, la justificación del LT de Vicens-Vives (2009).

5.1. Toda función constante es continua en cualquier punto. Sea $f: \mathbb{R} \longrightarrow \mathbb{R}$ la función constante de valor $c$, es decir, $\forall x \in \mathbb{R} f(x)=c$, y sea $a$ un punto arbitrario. Si tomamos $\varepsilon>0$, eligiendo $\delta=\varepsilon>0$, entonces si $|x-a|<\delta$ se tiene que

$$
|f(x)-f(a)|=|c-c|=0<\varepsilon
$$

La gráfica de la función constante de valor $c$ (Fig. 8) muestra que efectivamente $f$ es continua en cualquier punto.

5.2. La función identidad $1_{\mathbf{R}}$ es continua en todo punto.

En efecto: sea el punto $x=a$. Dado $\varepsilon>0, y$ tomando $\delta=\varepsilon>0$ se tiene que si $|x-a|<\delta$ entonces

$$
\left|1_{\mathrm{R}}(x)-1_{\mathrm{R}}(a)\right|=|x-a|<\delta=\varepsilon
$$

luego $1_{R}$ es continua en $x=a$.

La gráfica de la función $1_{R}$, dada por $1_{R}(x)=x$ o $y=x$, de la figura 9 muestra la continuidad de dicha función.

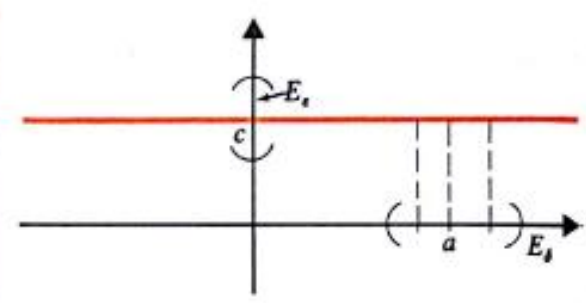

(Fig. 8)

Función constante de valor $c$

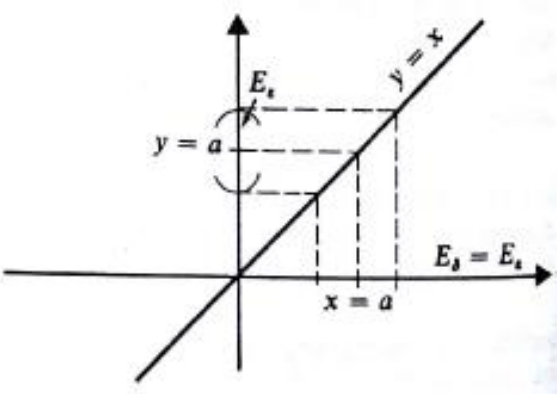

(Fig. 9)

Figura V.5.10. Justificación de la continuidad de las funciones contante e identidad (Santillana, 1976, pp. 234).

1. Una función constante $f(x)=k, k \in \mathbb{R}$, es continua en un punto $a$ cualquiera de su dominio, $\mathbb{R}$, ya que se verifica:
a) $\lim _{x \rightarrow a} f(x)=\lim _{x \rightarrow a} k=k$
b) $f(a)=k$
c) $\lim _{x \rightarrow a} f(x)=f(a)=k$

2. La función identidad $f(x)=x$ es continua en un punto $a$ cualquiera de su dominio, $\mathbb{R}$, pues se cumple:
a) $\lim _{x \rightarrow a} f(x)=\lim _{x \rightarrow a} x=a$
b) $f(a)=a$
c) $\lim _{x \rightarrow a} f(x)=f(a)=a$

Figura V.5.11. Justificación de la continuidad de las funciones contante e identidad (Vicens-Vives, 2009, pp. 185). 
En el caso de la continuidad de la función polinómica, ambos LT, Santillana (1976) y Vicens-Vives (2004), presentan el mismo razonamiento: las funciones polinómicas son continuas por ser suma de funciones continuas, tras haber establecido la continuidad de las funciones monómicas en un caso (VicensVives, 2004) y de las funciones potenciales y del producto de función por constante en el otro (Santillana, 1976). La diferencia es que en el texto de Vicens-Vives, el razonamiento se expresa en una línea contenida en el enunciado, y el caso de Santillana, se razona cada paso.

No abundamos en las justificaciones relacionadas con estas propiedades, dado que al tratarse de pocos libros los que las presentan, no se pueden establecer patrones de comportamiento relacionados con las editoriales o los periodos legislativos. Sin embargo, es cierto que la mayoría de las justificaciones se encuentran en los LT de la LGE, y entre ellos, en los más antiguos, desapareciendo un tanto de los LT de LOGSE y LOE. Además, las que aparecen en estos dos periodos, son generalmente más sencillas y menos rigurosas que las de sus predecesores. Por otro lado, se observa un cambio en el nivel educativo en el que aparecen estas justificaciones: en la LGE, estas propiedades se demostraban en $2^{\circ}$ de BUP (el equivalente a $4^{\circ}$ de la ESO actualmente) y en la LOGSE y la LOE, en $2^{\circ}$ de Bachillerato, el último nivel educativo antes de la universidad.

\section{V.6. TEOREMAS DE CONTINUIDAD EN ENTORNOS E INTERVALOS}

Los teoremas de continuidad únicamente se encuentran y, por tanto, son susceptibles de ser demostrados, en el último curso preuniversitario, es decir, en COU para la LGE y en $2^{\circ}$ de Bachillerato para la LOGSE y la LOE. Los teoremas más importantes relacionados con la continuidad son el teorema de Bolzano, el teorema de Weierstrass y el teorema de los valores intermedios, o de Darboux, algo que ya consideraba Spivak (1981) al denominarlos los Tres teoremas fuertes de continuidad. No obstante, algunos libros de texto enuncian también otros resultados relacionados con la continuidad, aparte de los tres indicados anteriormente. Algunos de ellos son teoremas previos, necesarios para la demostración de los tres teoremas fuertes, y otros, corolarios de éstos últimos. 
En este apartado se recoge el análisis de todos estos teoremas, organizados en dos subapartados: en el primero, se muestra el análisis de los tres teoremas de continuidad, que se describe con mayor detalle por aparecer estos teoremas en todos los libros de la muestra; en el segundo, el análisis de aquellos otros resultados que complementan a los tres teoremas fuertes de continuidad.

\section{V.6.1. Los tres teoremas fuertes de continuidad}

Antes de acometer el análisis detallado para cada teorema de los descritos, se describen algunas observaciones generales sobre el tratamiento de estos teoremas en los LT. En primer lugar, es llamativo el hecho de que no todos los LT expongan los teoremas en el mismo orden. Además, la nomenclatura para referirse a los teoremas y los enunciados utilizados tampoco son iguales en todos los libros. En la mayoría de los libros de texto se considera el orden BolzanoDarboux-Weierstrass, exceptuando en los siguientes LT:

- En el LT de la LGE de SM (1980), en el que considera el orden Weierstrass, Bolzano y Darboux.

- En el LT de la LOGSE de Vicens-Vives (2004), en el que considera el orden Weierstrass, Darboux y Bolzano. Además, este LT titula primer teorema de Weierstrass al propio teorema de Weierstrass y segundo teorema de Weierstrass a una variación del teorema de Darboux, ya que considera los valores intermedios entre el mínimo y el máximo. Después presenta Bolzano como consecuencia de su segundo teorema de Weierstrass.

En ambos casos, la sistematización no es correcta. Desde el punto de vista matemático, una correcta sistematización exige que el teorema de Darboux se enuncie después de Bolzano, ya que su demostración se apoya (se fundamenta) en este último, y si se enuncia en los términos de máximo y mínimo, después de Weierstrass. El orden de Bolzano y Weierstrass es irrelevante, aunque cronológicamente es anterior el primero. En este estudio se presenta el análisis en el orden que más adelante se propone como el más idóneo tanto desde el punto de vista matemático como del didáctico. 
En cuanto a los títulos utilizados y los enunciados mostrados en los libros de texto, se observa cierta diversidad, sobre todo para el teorema de Darboux. Este hecho tiene importancia para el estudio de la demostración, pues como indican Ibañes y Ortega (2001a), los esquemas de prueba dependen en parte de los enunciados utilizados para formular el teorema. Para facilitar la comparación, se recogen en tablas los enunciados y nomenclaturas utilizados. Cada tabla consta de cuatro columnas: en la primera columna aparece el LT al que hacemos referencia; en la segunda, el título que el LT asigna al teorema (cuando le asigna un título) y que acompaña al enunciado; en la tercera, el título del epígrafe en el que se encuentra (que cobra gran importancia en los textos en los que no se asigna un título al teorema); y por último, en la cuarta columna se transcribe el enunciado que propone el libro de texto en cuestión. Como es habitual en la presente memoria, cada tabla está codificada en los colores correspondientes al periodo legislativo al que corresponden.

\begin{tabular}{|c|c|c|c|}
\hline \multicolumn{4}{|c|}{ Teorema de Bolzano } \\
\hline \multicolumn{4}{|l|}{$C O U(L G E)$} \\
\hline $\mathbf{L T}$ & Título & Epígrafe & Enunciado \\
\hline Anaya 1989 & $\begin{array}{l}\text { Teorema de } \\
\text { Bolzano }\end{array}$ & $\begin{array}{l}\text { Continuidad en } \\
\text { un intervalo }\end{array}$ & $\begin{array}{l}\text { Si } f \text { es continua en }[a, b] \subset \mathbb{R} \text { y signo de } f(a) \neq \\
\text { signo de } f(b) \text {, entonces existe un número } s \in(a, b) \\
\text { tal que } f(s)=0 \text {. }\end{array}$ \\
\hline $\begin{array}{l}\text { Santillana } \\
1981\end{array}$ & $\begin{array}{l}\text { Teorema de } \\
\text { Bolzano }\end{array}$ & $\begin{array}{l}\text { Teorema de } \\
\text { Bolzano }\end{array}$ & $\begin{array}{l}\text { Sea } f \text { una función continua en el intervalo }[a, b] \text { tal } \\
\text { que } f \text { toma valores de signos distintos en los } \\
\text { extremos } a \text { y } b \text { del intervalo. Entonces existe } \xi \text { tal } \\
\text { que } a<\xi<b \text { y } f(\xi)=0 \text {. }\end{array}$ \\
\hline SM 1980 & $\begin{array}{l}\text { Teorema de } \\
\text { Bolzano }\end{array}$ & $\begin{array}{l}\text { Propiedades de } \\
\text { las funciones } \\
\text { continuas en un } \\
\text { intervalo } \\
\text { cerrado }\end{array}$ & $\begin{array}{l}\text { Si la función } f(x) \text { es continua en el intervalo } \\
\text { cerrado }[a, b] \text { y además signo } f(a) \neq \text { signo } f(b) \text {, } \\
\text { entonces la función se anula, por lo menos, en un } \\
\text { punto interior al intervalo }[a, b] \text {. }\end{array}$ \\
\hline $\begin{array}{l}\text { Vicens- } \\
\text { Vives } 1979\end{array}$ & $\begin{array}{l}\text { Teorema } \\
\text { (del cambio } \\
\text { de signo) }\end{array}$ & $\begin{array}{l}\text { Signo de una } \\
\text { función } \\
\text { continua }\end{array}$ & $\begin{array}{l}\text { Si } f:[a, b] \rightarrow \mathbb{R} \text { es continua en }[a, b] \text { y } s g f(a) \neq s g \\
f(b), \text { existe por lo menos un punto } c \in] a, b[\text { para el } \\
\text { que } f(c)=0 \text {. }\end{array}$ \\
\hline
\end{tabular}

Tabla V.6.1.1. Título del teorema, del epígrafe y enunciado para el teorema de Bolzano en los LT de COU de la LGE.

En los LT de la LGE (Tabla V.6.1.1), todos los LT, excepto Vicens-Vives (1979) llaman a este teorema como "teorema de Bolzano". En el caso de Vicens-Vives (1979) lo llama teorema del cambio de signo, título que da una idea del contenido del teorema. Se observa que las identificaciones de los apartados de los libros de texto en los que se enuncian son diferentes, pero esto depende de las agrupaciones de contenidos que hayan realizado los editores de los libros, aunque 
no tiene especial relevancia (al estar en todos los casos el teorema identificado por su nombre).

En cuanto a los enunciados, las diferencias que se observan son:

- La forma de escribir la hipótesis en la que se indica que $f(a)$ y $f(b)$ tiene signo distinto: se utiliza la abreviatura de signo, $s g$, o se describe de forma verbal. Esta notación permite considerar ambos casos $(f(a)<0$ y $f(b)>0$ o viceversa) de forma compacta, en una sola expresión.

- En dos de los LT se especifica que pueden existir más de un punto en el que se anule la función (SM, 1980 y Vicens-Vives, 1979), pero no en los otros dos LT. Deberían realizar esa especificación, pues en caso contrario, un alumno que está aprendiendo puede deducir que el punto que cumple dicha condición es único y sólo puede existir uno.

- Todos los LT enuncian el resultado en la forma "si...entonces..." excepto en Santillana (1981), que utiliza la forma "sea" para describir las hipótesis. La diferenciación entre hipótesis y tesis es más clara con la forma "si...entonces..." y es la que debería usarse en los enunciados (Ibañes y Ortega, 2001a).

- Cada LT se refiere a los intervalos con diferentes matices: para indicar el intervalo cerrado, algunos LT utilizan únicamente la notación simbólica “[ $a, b]$ " (Anaya, 1989 y Vicens-Vives, 1979), otro especifica que es un intervalo (Santillana, 1981), y otro, indica también que es cerrado incluso (SM, 1980). En general, para los intervalos abiertos usan la notación "( $a$, b)", pero Vicens-Vives (1979) utiliza " $] a, b[$ ".

En cuanto a los LT de LOGSE (Tabla V.6.1.2), todos llaman a este teorema "Teorema de Bolzano", bien sea en el título propio del teorema (aunque Anaya, 2003 y Santillana, 1997, no lo etiquetan como tal) o en el título del epígrafe, a excepción del LT de Santillana (1997) que lo titula "teorema de los ceros de Bolzano", que aunque no es el enunciado más habitual, aporta algo de información sobre el contenido del teorema.

Se observan algunos comportamientos similares a los vistos en los LT de LGE.

- En relación a la forma de expresar la hipótesis sobre el signo de $f(a)$ y $f(b)$, la mayoría de los LT escriben fórmulas similares a las de sus 
predecesores, indicando que el signo es diferente, pero el LT de SM (2001) lo indica mediante un producto, $f\left(a_{0}\right) \cdot f\left(b_{0}\right)<0$. El LT de VicensVives (2004) también utiliza esa expresión, pero como aclaración de tener signos distintos en los extremos. Es una forma más abreviada de escribir la condición del signo, pero requiere que los alumnos interpreten que dicho producto negativo equivale a que se toman signos distintos en ambos extremos.

- Los LT de Santillana (1997), SM (2001) y Vicens-Vives (2004) indican que existe al menos un punto, lo que abre la posibilidad de que sean varios. Por el contrario, Anaya (2003) lo expresa diciendo "existe c $\in$..." y Vicens-Vives (1999) utiliza el artículo "un", que podría inducir a pensar que el valor que cumple el teorema ha de ser necesariamente único.

- En este caso, todos los LT enuncian el resultado en la forma "si...entonces...", aunque SM (2001) suprime "entonces" y utiliza una coma. Como decíamos anteriormente, utilizar la fórmula completa "si...entonces" ayuda a distinguir entre las hipótesis y las tesis.

- También la notación utilizada para los intervalos es uniforme en todos los LT.

\begin{tabular}{|c|c|c|c|}
\hline \multirow{2}{*}{\multicolumn{4}{|c|}{$\begin{array}{l}\text { Teorema de Bolzano } \\
2^{\circ} \text { de Bachillerato (LOGSE) }\end{array}$}} \\
\hline & & & \\
\hline $\mathbf{L T}$ & Título & Epígrafe & Enunciado \\
\hline Anaya 2003 & Sin título & $\begin{array}{l}\text { Teorema de } \\
\text { Bolzano }\end{array}$ & $\begin{array}{l}\text { Si } f(x) \text { es continua en }[a, b] \text { y "signo de } f(a) \neq \text { signo } \\
\text { de } f(b) \text { ", entonces existe } c \in(a, b) \text { tal que } f(c)=0 \text {. }\end{array}$ \\
\hline $\begin{array}{l}\text { Santillana } \\
1997\end{array}$ & Enunciado & $\begin{array}{lr}\text { Teorema } & \text { de } \\
\text { ceros } & \text { de } \\
\text { Bolzano } & \\
\end{array}$ & $\begin{array}{l}\text { Si } y=f(x) \text { es continua en }[a, b] \text { y } f(a) \text { tiene distinto } \\
\text { signo que } f(b) \text {, entonces existe al menos un punto } \\
c \in(a, b) \text { tal que } f(c)=0 \text {. }\end{array}$ \\
\hline SM 2001 & $\begin{array}{l}\text { Teorema de } \\
\text { Bolzano }\end{array}$ & $\begin{array}{l}\text { Teorema de } \\
\text { Bolzano }\end{array}$ & $\begin{array}{l}\text { Si } f(x) \text { es una función continua en el intervalo } \\
\text { cerrado }\left[a_{0}, b_{0}\right] \subset \mathbb{R} \text { y } f\left(a_{0}\right) \cdot f\left(b_{0}\right)<0 \text {, existe al menos } \\
\text { un número } s \in\left(a_{0}, b_{0}\right) \text { tal que } f(s)=0 \text {. }\end{array}$ \\
\hline $\begin{array}{l}\text { Vicens- } \\
\text { Vives } 1999\end{array}$ & $\begin{array}{l}\text { Teorema de } \\
\text { Bolzano }\end{array}$ & $\begin{array}{l}\text { Teorema de } \\
\text { Bolzano y sus } \\
\text { consecuencias }\end{array}$ & $\begin{array}{l}\text { Si f es continua en un intervalo cerrado y acotado } \\
\mathrm{I}=[a, b] \text { y el signo de } f(a) \text { es distinto del signo de } \\
f(b) \text { entonces existe un número } \alpha \text { en el interior de } \mathrm{I} \text {, } \\
a<\alpha<b \text {, tal que } f(\alpha)=0 \text {. }\end{array}$ \\
\hline $\begin{array}{l}\text { Vicens- } \\
\text { Vives } 2004\end{array}$ & $\begin{array}{l}\text { Teorema de } \\
\text { Bolzano }\end{array}$ & $\begin{array}{l}\text { Teorema } \\
\text { Bolzano }\end{array}$ & $\begin{array}{l}\text { Si la función } f(x) \text { es continua en }[a, b] \text { y es positiva } \\
\text { en un extremo del intervalo y negativa en el otro (lo } \\
\text { que equivale a } f(a) \cdot f(b)<0) \text {, entonces existe al } \\
\text { menos un punto del intervalo }(a, b) \text { donde la } \\
\text { función se anula, es decir, } \exists c \in(a, b) \text { tal que } f(c)=0 \text {. }\end{array}$ \\
\hline
\end{tabular}

Tabla V.6.1.2. Título del teorema, del epígrafe y enunciado para el teorema de Bolzano en los LT de $2^{\circ}$ de Bachillerato de la LOGSE. 
En cuanto a los LT de la LOE (Tabla V.6.1.3), los títulos de teorema (los que los etiquetan) y los títulos de los epígrafes son iguales en todos los LT: teorema de Bolzano, con lo cual no existen diferenciaciones que puedan inducir a error entre los distintos LT.

\begin{tabular}{|c|c|c|c|}
\hline \multicolumn{4}{|c|}{ Teorema de Bolzano } \\
\hline \multicolumn{4}{|c|}{$2^{\circ}$ de Bachillerato (LOE) } \\
\hline $\mathbf{L T}$ & Título & Epígrafe & Enunciado \\
\hline Anaya 2009 & Sin título & $\begin{array}{l}\text { Teorema de } \\
\text { Bolzano }\end{array}$ & $\begin{array}{l}\text { Si } f(x) \text { es continua en }[a, b] \text { y signo de } f(a) \neq \text { signo } \\
\text { de } f(b) \text {, entonces existe } c \in(a, b) \text { tal que } f(c)=0 \text {. }\end{array}$ \\
\hline $\begin{array}{l}\text { Santillana } \\
2009\end{array}$ & Sin título & $\begin{array}{l}\text { Teorema de } \\
\text { Bolzano }\end{array}$ & $\begin{array}{l}\text { Si una función } f(x) \text { es continua en un intervalo [a, } \\
b] \text { y el signo de } f(a) \text { es distinto del signo de } f(b) \text {, } \\
\text { entonces existe al menos un número } c \in(a, b) \text { tal } \\
\text { que } f(c)=0 \text {. }\end{array}$ \\
\hline SM 2010 & $\begin{array}{l}\text { Teorema de } \\
\text { Bolzano }\end{array}$ & $\begin{array}{l}\text { Teorema de } \\
\text { Bolzano }\end{array}$ & $\begin{array}{l}\text { Si } f \text { es una función real y continua en un intervalo } \\
\text { cerrado }[a, b] \text { y, además, signo } f(a) \neq \text { signo } f(b) \text {, } \\
\text { entonces existe al menos un } c \in(a, b) \text { tal que } f(c)=0 \text {. }\end{array}$ \\
\hline $\begin{array}{l}\text { Vicens- } \\
\text { Vives } 2009\end{array}$ & $\begin{array}{l}\text { Teorema de } \\
\text { Bolzano }\end{array}$ & $\begin{array}{l}\text { Teorema de } \\
\text { Bolzano }\end{array}$ & $\begin{array}{l}\text { Sea } f \text { una función continua en un intervalo cerrado } \\
{[a, b] \text { y que toma valores de signo contrario en los }} \\
\text { extremos } a \text { y } b \text { del intervalo. Entonces existe al } \\
\text { menos un punto } c \in(a, b) \text { tal que } f(c)=0 \text {. }\end{array}$ \\
\hline
\end{tabular}

Tabla V.6.1.3. Título del teorema, del epígrafe y enunciado para el teorema de Bolzano en los LT de $2^{\circ}$ de Bachillerato de la LOE.

En cuanto a las observaciones para este periodo:

- También se observan diferentes grados de verbalización de los objetos matemáticos: la función se puede expresar sólo con función simbólica o indicándolo también verbalmente; lo mismo para el intervalo cerrado y acotado $[a, b] \ldots$

- La hipótesis del signo se expresa de forma verbal, indicando explícitamente que los signos son distintos en todos los LT.

- Todos los LT indican que existe "al menos un...", lo que abre la posibilidad de más de un punto, a excepción de Anaya (2009), que al coincidir con Anaya (2003), utiliza la misma notación que su predecesor.

- Todos los LT utilizan la fórmula "si...entonces...", excepto Vicens-Vives (2009), que sustituye "si” por "sea", aunque mantiene el "entonces".

Aunque existen algunas diferencias entre los enunciados e identificaciones del teorema de Bolzano en los distintos LT de la muestra, en general, se observan patrones diferentes, y permite a los alumnos identificar el resultado en cualquiera de los LT. 
En cuando al teorema de Weierstrass, se observan más diferencias en algunos periodos. Por ejemplo, en los LT de la LGE (Tabla V.6.1.4), los títulos que se asignan al teorema son "teorema de Weierstrass" en Anaya (1989) y SM (1979), “teorema (del máximo y mínimo absoluto)" en Vicens-Vives (1979), y no se asigna título al teorema, pero el epígrafe se llama teorema de BolzanoWeierstrass en Santillana (1981).

\begin{tabular}{|c|c|c|c|}
\hline \multicolumn{4}{|c|}{ Teorema de los extremos de Weierstrass } \\
\hline \multicolumn{4}{|l|}{$\operatorname{COU}(L G E)$} \\
\hline $\mathbf{L T}$ & Título & Epígrafe & Enunciado \\
\hline Anaya 1989 & $\begin{array}{l}\text { Teorema de } \\
\text { Weierstrass }\end{array}$ & $\begin{array}{l}\text { Continuidad } \quad y \\
\text { acotación }\end{array}$ & $\begin{array}{l}\text { Una función } f \text {, continua en }[a, b] \text { alcanza su } \\
\text { máximo y su mínimo en dicho intervalo. Es } \\
\text { decir, existen sendos números } c \text { y d del } \\
\text { intervalo para los cuales se cumple que } \\
f(d) \leq f(x) \leq f(c) \text {, para todo } x \in[a, b]\end{array}$ \\
\hline $\begin{array}{l}\text { Santillana } \\
1981\end{array}$ & Sin título & $\begin{array}{ll}\text { Teorema } & \text { de } \\
\text { Bolzano- } & \\
\text { Weierstrass } & \end{array}$ & $\begin{array}{l}\text { Si una función } f \text { es continua en }[a, b] \text {, entonces } \\
\text { existe un punto } \xi \in[a, b] \text { tal que para todo } x \in[a \text {, } \\
b], f(x) \leq f(\xi) \text {. } \\
\text { Sea } f \text { una función continua en }[a, b] \text {; entonces, } \\
\text { existe un punto } \xi \in[a, b] \text { tal que para todo } x \in[a, \\
b], f(\xi) \leq f(x) \text {. Es decir, si } f \text { es continua en un } \\
\text { intervalo cerrado }[a, b] \text {, entonces } f \text { alcanza un } \\
\text { mínimo absoluto en }[a, b] \text {. }\end{array}$ \\
\hline SM 1980 & $\begin{array}{l}\text { Teorema de } \\
\text { Weierstrass }\end{array}$ & $\begin{array}{l}\text { Propiedades de las } \\
\text { funciones } \\
\text { continuas en un } \\
\text { intervalo cerrado }\end{array}$ & $\begin{array}{l}\text { Si una función } f(x) \text { es continua en un intervalo } \\
\text { cerrado }[a, b] \text { entonces la función admite un } \\
\text { máximo y un mínimo. }\end{array}$ \\
\hline $\begin{array}{l}\text { Vicens-Vives } \\
1979\end{array}$ & $\begin{array}{l}\text { Teorema } \\
\text { (del máximo } \\
\text { y mínimo } \\
\text { absolutos) }\end{array}$ & $\begin{array}{l}\text { Acotación de una } \\
\text { función continua } \\
\text { en un intervalo } \\
\text { cerrado }\end{array}$ & $\begin{array}{l}\text { Si } f:[a, b] \rightarrow \mathbb{R} \text { es continua en }[a, b], \text { alcanza en } \\
{[a, b] \text { un máximo y un mínimo absolutos. }}\end{array}$ \\
\hline
\end{tabular}

Tabla V.6.1.4. Título del teorema, del epígrafe y enunciado para el teorema de Weierstrass en los LT de $2^{\circ}$ de Bachillerato de la LGE.

En cuanto a los enunciados:

- El enunciado utilizado en Anaya (1989) es de hipótesis y tesis mezcladas, lo cual dificulta aún más la distinción entre las hipótesis y la tesis del teorema. Además, se expresa de dos formas, primero indicado que se alcanzan el máximo y el mínimo, y luego reformulando dicha tesis para expresarlo con lenguaje más simbólico. El resto de LT enuncia el teorema utilizando la forma "si...entonces...". Sin embargo, Santillana (1981) lo enuncia en dos partes, como si fueran dos teoremas, uno para el máximo y el otro para el mínimo. Además, para el mínimo hace una reformulación 
del primer enunciado, de forma que se emplea un lenguaje más verbal que en el primero (al contrario de lo que hacía Anaya).

- Al igual que en el teorema de Bolzano, algunos libros precisan más los símbolos matemáticos, como la función (usan sólo " $f(x)$ " o indican "la función $f$ "), o los intervalos ([a,b] frente a "el intervalo cerrado $[a, b]$ ").

- En ningún caso se indica que el mínimo o el máximo absoluto se puedan alcanzar en más de un punto del intervalo, y algunos LT (Anaya, 1989 y Vicens-Vives, 1979) no precisan que el máximo y el mínimo al que se refieren son absolutos.

\begin{tabular}{|c|c|c|c|}
\hline \multicolumn{4}{|c|}{ Teorema de los extremos de Weierstrass } \\
\hline \multicolumn{4}{|c|}{$2^{\circ}$ de Bachillerato (LOGSE) } \\
\hline $\mathbf{L T}$ & Título & Epígrafe & Enunciado \\
\hline Anaya 2003 & Sin título & $\begin{array}{l}\text { Teorema de } \\
\text { Weierstrass }\end{array}$ & $\begin{array}{l}\text { Si } f \text { es continua en }[a, b] \text {, entonces tiene un máximo } \\
\text { y un mínimo absolutos en ese intervalo. Es decir, } \\
\text { existen sendos números, } c \text { y } d \text {, del intervalo }[a, b] \\
\text { para los cuales se cumple que: cualquiera que sea } \\
x \in[a, b] \text { es } f(d) \leq f(x) \leq f(c) \text {. }\end{array}$ \\
\hline $\begin{array}{l}\text { Santillana } \\
1997\end{array}$ & Enunciado & $\begin{array}{l}\text { Teorema de } \\
\text { los extremos } \\
\text { absolutos de } \\
\text { Weierstrass }\end{array}$ & $\begin{array}{l}\text { Si } y=f(x) \text { es continua en }[a, b] \text {, alcanza un máximo } \\
\text { y un mínimo absolutos en }[a, b] \text {. }\end{array}$ \\
\hline SM 2001 & $\begin{array}{l}\text { Sin título. En } \\
\text { el texto, } \\
\text { teorema de } \\
\text { Weierstrass }\end{array}$ & $\begin{array}{l}\text { Máximo y } \\
\text { mínimo de una } \\
\text { función }\end{array}$ & $\begin{array}{l}\text { Un resultado importante sobre funciones continuas } \\
\text { es el teorema de Weierstrass. Este teorema } \\
\text { establece que toda función continua en un intervalo } \\
\text { cerrado }[a, b] \text { alcanza su máximo y su mínimo } \\
\text { dentro de este intervalo. }\end{array}$ \\
\hline $\begin{array}{l}\text { Vicens- } \\
\text { Vives } 1999\end{array}$ & $\begin{array}{l}\text { Teorema de } \\
\text { Weierstrass }\end{array}$ & $\begin{array}{l}\text { Teorema de } \\
\text { Weierstrass }\end{array}$ & $\begin{array}{l}\text { Si } f \text { es continúan en } \mathrm{I}=[a, b] \text {, cerrado y acotado, } \\
\text { entonces } f \text { alcanza un máximo y un mínimo } \\
\text { absolutos sobre } \mathrm{I} \text {. }\end{array}$ \\
\hline $\begin{array}{l}\text { Vicens- } \\
\text { Vives } 2004\end{array}$ & $\begin{array}{l}\text { Primer } \\
\text { teorema de } \\
\text { Weierstrass } \\
\text { (teorema del } \\
\text { valor máximo) }\end{array}$ & $\begin{array}{l}\text { Primer } \\
\text { teorema de } \\
\text { Weierstrass } \\
\text { (teorema del } \\
\text { valor máximo) }\end{array}$ & $\begin{array}{l}\text { Si la función } f(x) \text { es continua en un intervalo } \\
\text { cerrado }[a, b] \text {, entonces en este intervalo existe al } \\
\text { menos un punto en el que la función alcanza un } \\
\text { valor máximo, y al menos otro punto en el que la } \\
\text { función tiene un valor mínimo, es decir: } \exists x_{1}, x_{2} \in[a \text {, } \\
b] \text { tales que } f\left(x_{1}\right) \leq f(x) \leq f\left(x_{2}\right) \forall x \in[a, b]\end{array}$ \\
\hline
\end{tabular}

Tabla V.6.1.5. Título del teorema, del epígrafe y enunciado para el teorema de Weierstrass en los LT de $2^{\circ}$ de Bachillerato de la LOGSE.

En cuanto a los LT de la LOGSE (Tabla V.6.1.5), se observa que los títulos de los epígrafes son diferentes en casi todos los LT (Anaya, 2003 y VicensVives, 1999, lo titulan teorema de Weierstrass). También los títulos de los teoremas son diferentes: en algunos no incluyen el título (Anaya, 2003 y Santillana, 1997), SM (2001), otros insertan el título en el texto, y Vicens- 
Vives (2004) lo llama primer teorema de Weierstrass y matiza con "teorema del valor máximo".

En relación a los enunciados:

- Todos los LT menos SM (2001) utilizan la fórmula "si...entonces", aunque en Santillana (1997) el "entonces" ha sido sustituido por una coma. Por su parte, SM (2001) formula un enunciado con tesis e hipótesis mezcladas.

- Todos los LT indican que la función "tiene" o "alcanza" un máximo o un mínimo absolutos en el intervalo, pero además, Anaya (2003) y Vicens-Vives (2004) lo traducen a lenguaje simbólico $\left(\exists x_{1}, x_{2} \in[a, b]\right.$ tales que $f\left(x_{1}\right) \leq f(x) \leq f\left(x_{2}\right) \forall x \in[a, b]$, Vicens-Vives, 2004).

- Al igual que en otros textos y otros resultados, existen diferencias en las aclaraciones verbales que se dan de algunos elementos matemáticos expresados de forma simbólica (las funciones, los intervalos, ...).

- SM (2001) y Vicens-Vives (2004) no indican que el máximo y el mínimo a los que se refiere el teorema sean absolutos, hecho que debería precisar para no ser confundidos con máximos y mínimos relativos.

- Únicamente el LT de Vicens-Vives (2004) indica que se alcanza "al menos" un máximo y un mínimo absolutos (Aunque así dicho parce que tuviera varios en lugar de poder alcanzarlos en distintos puntos), permitiendo deducir que puede existir más de un punto donde se cumpla dicha propiedad.

En los LT de la LOE (Tabla V.6.1.6), se observan algunos patrones similares a los que comentamos para el teorema de Bolzano. Por ejemplo, los títulos, bien sean del teorema, o bien del epígrafe, son el mismo en todos los LT, teorema de Weierstrass.

- Todos los LT utilizan la formulación "si...entonces...".

- Excepto Vicens-Vives (2009), que escribe la tesis del teorema como la existencia de dos puntos del intervalo $c$ y $d$ para los que se cumple la desigualdad $f(c) \leq f(x) \leq f(d)$, todos los demás LT lo escriben en términos de existencia del máximo y el mínimo absoluto. 
- También, a excepción del LT de Vicens-Vives (2009), ninguno de los LT menciona la posibilidad de existencia de más de un punto en el que se verifique la tesis del teorema.

- Al igual que en otros textos y otros resultados, existen diferencias en las aclaraciones verbales que se dan de algunos elementos matemáticos expresados de forma simbólica (las funciones, los intervalos,...).

\begin{tabular}{|c|c|c|c|}
\hline \multicolumn{4}{|c|}{ Teorema de extremos de Weierstrass } \\
\hline \multicolumn{4}{|c|}{$2^{o}$ de Bachillerato (LOE) } \\
\hline LT & Título & Epígrafe & Enunciado \\
\hline Anaya 2009 & Sin título & $\begin{array}{l}\text { Teorema de } \\
\text { Weierstrass }\end{array}$ & $\begin{array}{l}\text { Si } f \text { es continua en }[a, b] \text {, entonces tiene un máximo y } \\
\text { un mínimo absolutos en ese intervalo. Es decir, } \\
\text { existen sendos números, } c \text { y } d \text {, del intervalo }[a, b] \\
\text { para los cuales se cumple que: cualquiera que sea } \\
x \in[a, b] \text { es } f(d) \leq f(x) \leq f(c) \text {. }\end{array}$ \\
\hline $\begin{array}{l}\text { Santillana } \\
2009\end{array}$ & $\begin{array}{l}\text { Teorema de } \\
\text { Weierstrass }\end{array}$ & $\begin{array}{l}\text { Teorema de } \\
\text { Weierstrass }\end{array}$ & $\begin{array}{l}\text { Si una función } f(x) \text { es continua en un intervalo }[a, b] \text {, y } \\
\text { entonces } f(x) \text { alcanza en este intervalo su máximo y } \\
\text { su mínimo absolutos. }\end{array}$ \\
\hline SM 2010 & Sin título & $\begin{array}{l}\text { Teorema de } \\
\text { Weierstrass }\end{array}$ & $\begin{array}{l}\text { Si una función es continua en el intervalo cerrado }[a \text {, } \\
b] \text {, entonces está acotada en }[a, b] \text {. Como } \\
\text { consecuencia de este resultado, si una función es } \\
\text { continua en un intervalo cerrado }[a, b] \text {, entonces tiene } \\
\text { un máximo y un mínimo absolutos en ese conjunto. }\end{array}$ \\
\hline $\begin{array}{l}\text { Vicens-Vives } \\
2009\end{array}$ & $\begin{array}{l}\text { Teorema de } \\
\text { Weierstrass }\end{array}$ & $\begin{array}{l}\text { Teorema de } \\
\text { Weierstrass }\end{array}$ & $\begin{array}{l}\text { Si } f \text { es una función continua en un intervalo }[a, b] \text {, } \\
\text { entonces al menos existen dos puntos } c \text { y } d \text { del } \\
\text { intervalo }[a, b] \text { para los que se cumple que } \\
f(c) \leq f(x) \leq f(d) \text { para todo } x \in[a, b] \text {. }\end{array}$ \\
\hline
\end{tabular}

Tabla V.6.1.6. Título del teorema, del epígrafe y enunciado para el teorema de Weierstrass en los LT de $2^{\circ}$ de Bachillerato de la LOE.

Por su parte, el teorema de Darboux es el que menos regularidad presenta a lo largo de las legislaciones y entre los diferentes LT. Además de las observaciones que hemos hecho para los teoremas anteriores, se aprecian algunas diferencias que provocan un cambio en el teorema: la primera de ellas es si la tesis se establece entre el máximo y el mínimo absoluto de la función, o entre $f(a)$ y $f(b)$, siendo $[a, b]$ el intervalo considerado en las hipótesis. La segunda diferencia es relativa a si el teorema indica que la función toma todos los valores entre dos puntos ( $\operatorname{sean} f(a)$ y $f(b)$ o el máximo y el mínimo absolutos) o si, dado un valor a la imagen en concreto, existe un valor del intervalo para el cuál su imagen coincida con el valor dado.

En los LT de la LGE (Tabla V.6.1.7), se observa que los títulos de los epígrafes son diferentes en todos los LT. Además, los títulos del teorema tampoco son iguales, coincidiendo únicamente en Anaya (1989) y Santillana (1981), que lo 
llaman teorema del valor intermedio, y siendo nombrado en SM (1980) como propiedad de Darboux y en Vicens-Vives (1979) como teorema del valor intermedio. En cuanto a los enunciados:

- Anaya (1989) y Vicens-Vives (1979) formulan el enunciado con "si...entonces...", Santillana (1981) también utiliza dicha formulación, pero en lugar de "si" utiliza "sea". SM (1980) empieza con "si" pero no utiliza "entonces" para diferenciar entre hipótesis y tesis.

- Se pueden repetir los mismos comentarios que hemos realizado anteriormente en relación a las expresiones utilizadas para referirnos a los intervalos, o las funciones, $\mathrm{y}$, sobre la posibilidad de existencia de más de un punto que cumpla la tesis del teorema, cada LT utiliza un nivel de precisión diferente en el enunciado.

- Tres de los LT enuncian el resultado entre $f(a)$ y $f(b)$ (siendo $[a, b]$ el intervalo considerado en las hipótesis del enunciado). El otro LT (VicensVives, 1979) lo enuncia considerando dos puntos $x_{1}$ y $x_{2}$ de [a, b] tales que $f\left(x_{1}\right) \neq f\left(x_{2}\right)$, condición que no exigen los otros LT y puede llevar a un resultado muy simple.

- Tres de los LT enuncian el teorema indicando que se alcanzan todos los valores, excepto Anaya (1989) que establece un valor entre $f(a)$ y $f(b)$ y asegura que existe un valor de $[a, b]$ del que es su imagen.

\begin{tabular}{|c|c|c|c|}
\hline \multicolumn{4}{|c|}{ Teorema del valor intermedio de Darboux } \\
\hline \multicolumn{4}{|l|}{$\operatorname{COU}(L G E)$} \\
\hline LT & Título & Epígrafe & Enunciado \\
\hline Anaya 1989 & $\begin{array}{l}\text { Teorema de } \\
\text { los valores } \\
\text { intermedios }\end{array}$ & $\begin{array}{l}\text { Continuidad en un } \\
\text { intervalo }\end{array}$ & $\begin{array}{l}\text { Si } f \text { es continua en }[a, b] \in \mathbb{R} \text { y } K \text { es un número } \\
\text { comprendido entre } f(a) \text { y } f(b) \text {, entonces existe } \\
\text { un número } s \in(a, b) \text { tal que } f(s)=K \text {. }\end{array}$ \\
\hline $\begin{array}{l}\text { Santillana } \\
1981\end{array}$ & $\begin{array}{l}\text { Teorema de } \\
\text { los valores } \\
\text { intermedios }\end{array}$ & $\begin{array}{l}\text { Teorema } \\
\text { Bolzano }\end{array}$ & $\begin{array}{l}\text { Sea } f \text { una función continua en el intervalo } \\
\text { cerrado }[a, b] \text {; entonces } f \text { toma todos valor } \\
\text { comprendido entre } f(a) \text { y } f(b) \text {. }\end{array}$ \\
\hline SM 1980 & $\begin{array}{l}\text { Propiedad de } \\
\text { Darboux }\end{array}$ & $\begin{array}{l}\text { Propiedades de } \\
\text { las funciones } \\
\text { continuas en un } \\
\text { intervalo cerrado }\end{array}$ & $\begin{array}{l}\text { Si la función } f(x) \text { es continua en el intervalo } \\
\text { cerrado }[a, b] \text { la función alcanza en este } \\
\text { intervalo todos los valores comprendidos entre } \\
f(a) \text { y } f(b) \text {. }\end{array}$ \\
\hline $\begin{array}{l}\text { Vicens- } \\
\text { Vives } 1979\end{array}$ & $\begin{array}{l}\text { Teorema (del } \\
\text { valor } \\
\text { intermedio) }\end{array}$ & $\begin{array}{l}\text { Signo de una } \\
\text { función }\end{array}$ & $\begin{array}{l}\text { Si } f:[a, b] \rightarrow \mathbb{R} \text { es continua, y si } x_{1}<x_{2} \text { son } \\
\text { puntos de }[a, b] \text { tales que } f\left(x_{1}\right) \neq f\left(x_{2}\right) \text {, entonces } f \\
\text { alcanza todos los valores comprendidos entre } \\
f\left(x_{1}\right) \text { y } f\left(x_{2}\right) \text { una vez por lo menos. }\end{array}$ \\
\hline
\end{tabular}

Tabla V.6.1.7. Título del teorema, del epígrafe y enunciado para el teorema de Darboux en los LT de $2^{\circ}$ de Bachillerato de la LGE. 


\begin{tabular}{|l|l|l|l|}
\hline \multicolumn{5}{|l|}{ Teorema del valor intermedio de Darboux } \\
\hline $\mathbf{2}^{\boldsymbol{o}}$ de Bachillerato $($ LOGSE) \\
\hline LT & Título & Epígrafe & Enunciado \\
\hline Anaya 2003 & $\begin{array}{l}\text { Teorema de } \\
\text { los valores } \\
\text { intermedios } \\
\text { (Darboux) }\end{array}$ & $\begin{array}{l}\text { Consecuencias } \\
\text { del teorema de } \\
\text { Bolzano }\end{array}$ & $\begin{array}{l}\text { Si } f \text { es continua en }[a, b] \text {, entonces toma todos los } \\
\text { valores intermedios entre } f(a) \text { y } f(b) \text {. Es decir, } \\
\text { cualquiera que sea el número k comprendido entre } \\
f(a) \text { y } f(b) \text {, existe un número } s, a<s<b \text {, tal que } f(s)=k .\end{array}$ \\
\hline $\begin{array}{l}\text { Santillana } \\
\mathbf{1 9 9 7}\end{array}$ & Enunciado & $\begin{array}{l}\text { Teorema de } \\
\text { los valores } \\
\text { intermedios }\end{array}$ & $\begin{array}{l}\text { Si } y=f(x) \text { es continua en }[a, b] \text { y es cualquier } \\
\text { número comprendido entre } f(a) \text { y } f(b) \text {, entonces existe } \\
\text { al menos un número } c \in(a, b) \text { tal que } f(c)=n \text {. }\end{array}$ \\
\hline SM 2001 & Sin título & $\begin{array}{l}\text { El teorema de } \\
\text { los valores } \\
\text { intermedios }\end{array}$ & $\begin{array}{l}\text { Si } f(x) \text { es una función continua en el intervalo cerrado } \\
{[a, b] \subset \mathbb{R} \text { y } c \text { es un número cualquiera comprendido }} \\
\text { entre } f(a) \text { y } f(b) \text {, existe al menos un número } s \in(a, b) \\
\text { tal que } f(s)=c .\end{array}$ \\
\hline $\begin{array}{l}\text { Vicens- } \\
\text { Vives 1999 }\end{array}$ & $\begin{array}{l}\text { Teorema de } \\
\text { los valores } \\
\text { intermedios }\end{array}$ & $\begin{array}{l}\text { Teorema de } \\
\text { Bolzano y sus } \\
\text { consecuencias }\end{array}$ & $\begin{array}{l}\text { Si } f \text { es continua en }[a, b] \text { entonces } f \text { toma todos los } \\
\text { valores intermedios entre } f(a) \text { y } f(b) .\end{array}$ \\
\hline $\begin{array}{l}\text { Vicens- } \\
\text { Vives 2004 }\end{array}$ & $\begin{array}{l}\text { Segundo } \\
\text { teorema de } \\
\text { Weierstrass }\end{array}$ & $\begin{array}{l}\text { Segundo } \\
\text { teorema de de } \\
\text { Weierstrass }\end{array}$ & $\begin{array}{l}\text { Una función } f(x) \text { continua en un intervalo cerrado }[a, \\
b], \text { toma en este intervalo todos los valores } \\
\text { comprendidos entre el máximo y el mínimo. }\end{array}$ \\
\hline
\end{tabular}

Tabla V.6.1.8. Título del teorema, del epígrafe y enunciado para el teorema de Darboux en los LT de $2^{\circ}$ de Bachillerato de la LOGSE.

En cuanto a los LT de LOGSE (Tabla V.6.1.8), también se observan diferentes títulos para los epígrafes y para el teorema. Dos de los LT (Santillana, 1997, y SM, 2001) no lo etiquetan junto al enunciado, sino que el nombre del teorema aparece únicamente en el título del epígrafe (en ambos se titula teorema de los valores intermedios). Tanto Anaya (2003) como Vicens-Vives (1999) lo consideran una consecuencia del teorema de Bolzano, y ambos lo llaman teorema de los valores intermedios, aunque en Anaya se añade entre paréntesis "Darboux". Por su parte, Vicens-Vives (2004), que establece un orden diferente para estos teoremas, lo llama "segundo teorema de Weierstrass".

En cuanto a los enunciados:

- Todos los LT enuncian el resultado con la fórmula "si...entonces...", excepto Vicens-Vives (2004), cuya formulación es de hipótesis y tesis mezcladas. Además, en el caso de SM (2001), el "entonces" se ha sustituido por una coma.

- Todos los LT enuncian el resultado entre $f(a)$ y $f(b)$, excepto Vicens-Vives (2004), que lo enuncia entre el mínimo y el máximo (aunque no matiza que son absolutos). Esto se debe a que en este LT el teorema de Darboux 
se presenta después del de Weierstrass, lo que permite enunciar un resultado más fuerte.

- Dos de los LT, Santillana (1997) y SM (2001), enuncian el teorema fijando un número entre $f(a)$ y $f(b)$, y estableciendo que existe otro entre $a$ y $b$ cuya imagen es el primero; otros dos LT, Vicens-Vives (1999 y 2004), lo enuncian indicando que se toman todos los valores entre las imágenes de los extremos o entre el máximo y el mínimo. Por su parte, Anaya (2003) utiliza ambas formas de enunciarlo, lo que implica una mayor claridad de la situación que representa el teorema.

- Sólo dos LT, Santillana (1997) y SM (2001), consideran en el enunciado la posibilidad de que exista más de un punto que cumpla la tesis del teorema.

En cuanto a los LT de la LOE (Tabla V.6.1.9), también existe diversidad en los títulos de los teoremas y de los epígrafes que los contienen. Únicamente el LT de SM (2010) titula el epígrafe como "teorema de los valores intermedios", aunque es de suponer que por eso no etiqueta el teorema. El resto de LT denomina al teorema como teorema de los valores intermedios y añaden la etiqueta de Darboux. Anaya (2009) y Vicens-Vives (2009) incluyen este resultado en las consecuencias del teorema de Bolzano. Sin embargo, Santillana (2009) lo incluye en el epígrafe del teorema de Weierstrass. En cuanto a los enunciados:

- Todos los LT utilizan la fórmula "si...entonces...". En el caso de SM (2010), que enuncia el teorema en dos enunciados (considerando dos casos, $f(a) \leq f(b)$ y $f(a) \geq f(b))$ la hipótesis sobre la continuidad de la función la establece antes del "si". Además, existe una incongruencia en los enunciados de este libro ya que no tiene sentido considerar una desigualdad no estricta entre $f(a)$ y $f(b)$ y sin embargo, considera que m y $M$ sean estrictamente menor y mayor que $f(a)$ y $f(b)$, dado que en caso de igualdad, no tendría sentido el enunciado.

- Todos los LT establecen el resultado entre $f(a)$ y $f(b)$.

- Todos los LT enuncian el teorema fijando un valor entre $f(a)$ y $f(b)$ y asegurando que existe una contra imagen entre $a$ y $b$ para dicho valor. Sin embargo, Anaya (2009) lo complementa con el enunciado en el que se indica que la función toma todos los valores entre $f(a)$ y $f(b)$. 
- Dos de los LT (SM, 2010 y Vicens-Vives, 2009) consideran en el enunciado la posibilidad de que exista más de un punto que cumpla la tesis del teorema, los otros dos, no.

\begin{tabular}{|c|c|c|c|}
\hline \multicolumn{4}{|c|}{ Teorema del valor intermedio de Darboux } \\
\hline \multicolumn{4}{|c|}{$2^{\circ}$ de Bachillerato (LOE) } \\
\hline LT & Título & Epígrafe & Enunciado \\
\hline $\begin{array}{l}\text { Anaya } \\
2009\end{array}$ & $\begin{array}{l}\text { Teorema de los } \\
\text { valores intermedios } \\
\text { (Darboux) }\end{array}$ & $\begin{array}{l}\text { Consecuencias } \\
\text { del teorema de } \\
\text { Bolzano }\end{array}$ & $\begin{array}{l}\text { Si } f \text { es continua en }[a, b] \text {, entonces toma todos los } \\
\text { valores intermedios entre } f(a) \text { y } f(b) \text {. Es decir, } \\
\text { cualquiera que sea el número } k \text { comprendido entre } f(a) \\
\text { y } f(b) \text {, existe un número } s, a<s<b \text {, tal que } f(s)=k \text {. }\end{array}$ \\
\hline $\begin{array}{l}\text { Santillana } \\
2009\end{array}$ & $\mid \begin{array}{l}\text { Teorema } \\
\text { valores intermedios } \\
\text { (Darboux) }\end{array}$ & $\begin{array}{l}\text { Teorema de } \\
\text { Weierstrass }\end{array}$ & $\begin{array}{l}\text { Si una función } f(x) \text { es continua en un intervalo }[a, b] \text {, } \\
\text { entonces } f(x) \text { toma en el intervalo }(a, b) \text { todos los } \\
\text { valores m comprendidos entre } f(a) \text { y } f(b) \text {. Es decir: si } \\
f(a)<m<f(b) \text {, existe un número } c \in(a, b) \text { tal que } f(c)=m \text {. }\end{array}$ \\
\hline SM 2010 & Sin título & $\begin{array}{l}\text { Teorema de } \\
\text { los valores } \\
\text { intermedios }\end{array}$ & $\begin{array}{l}\text { Sea } f \text { una función real y continua en }[a, b] \text { : } \\
\text { Si } f(a) \leq f(b) \text { y } M \text { es tal que } f(a)<M<f(b) \text {, entonces } \\
\text { existe al menos un } c \in(a, b) \text { tal que } f(c)=M \text {. } \\
\text { Si } f(a) \geq f(b) \text { y } M \text { es tal que } f(b)<M<f(a) \text {, entonces } \\
\text { existe al menos un } c \in(a, b) \text { tal que } f(c)=M \text {. }\end{array}$ \\
\hline \begin{tabular}{|l|} 
Vicens- \\
Vives 2009
\end{tabular} & $\mid \begin{array}{lr}\text { Teorema de } & \text { los } \\
\text { valores intermedios } \\
\text { o teorema de } \\
\text { Darboux }\end{array}$ & $\begin{array}{l}\text { Consecuencias } \\
\text { del teorema de } \\
\text { Bolzano }\end{array}$ & $\begin{array}{l}\text { Si } f \text { es una función continua en el intervalo }[a, b] \text { y } h \\
\text { es un número real tal que } f(a)<h<f(b) \text {, entonces existe } \\
\text { al menos un número } c \in(a, b) \text { tal que } f(c)=h \text {. }\end{array}$ \\
\hline
\end{tabular}

Tabla V.6.1.9. Título del teorema, del epígrafe y enunciado para el teorema de Darboux en los LT de $2^{\circ}$ de Bachillerato de la LOE.

A partir de las observaciones anteriores se concluye que no existen patrones comunes en los LT en relación a la forma de presentar y enunciar los teoremas, ni en cuanto a editoriales, ni en cuanto a periodos legislativos. Estas observaciones se complementan con el análisis de las justificaciones, que reafirman esta idea. Dada esa diversidad de nombres, se propondrá la utilización de nombre en los teoremas que den la máxima información posible, es decir, que contenga información sobre el matemático al que se le atribuye y sobre el contenido del teorema. Por tanto, el teorema de Bolzano se llamará "teorema de los ceros de Bolzano", el teorema de Weierstrass, "teorema de los valores extremos de Weierstrass" y el teorema de Darboux, "teorema de los valores intermedios de Darboux".

A continuación se presenta el análisis de las justificaciones atendiendo al resto de elementos del marco teórico de cada uno de los tres teoremas fuertes de continuidad, en el mismo orden en el que hemos discutido los enunciados, es decir, en primer lugar, el teorema de los ceros de Bolzano, en segundo lugar, el teorema de los valores extremos de Weierstrass, y en tercer lugar, el teorema de 
los valores intermedios de Darboux. En estos apartados únicamente se comentan los aspectos que llaman la atención de los datos registrados. Los comentarios generales a las categorías más homogéneas se realizan al final, tras la exposición de las tablas de análisis de todos los teoremas y periodos legislativos (apartado V.6.1.4).

\section{V.6.1.1. Teorema de los ceros de Bolzano}

\begin{tabular}{|c|c|c|c|c|c|}
\hline \multicolumn{6}{|c|}{ Teorema de los ceros de Bolzano. } \\
\hline \multicolumn{2}{|c|}{ Textos (COU) } & Anaya (1989) & Santillana (1981) & SM (1980) & Vicens-Vives (1979) \\
\hline \multicolumn{2}{|l|}{ E. de prueba } & EP axiomático & EP axiomático & EP axiomático & EP axiomático \\
\hline \multirow[t]{4}{*}{ Técnicas } & Tipo & $\begin{array}{l}\text { CS, existencia } \\
\text { simple }\end{array}$ & CS, existencia simple & $\begin{array}{l}\text { CS, se anula en un } \\
\text { punto }\end{array}$ & Existencia simple \\
\hline & $\begin{array}{l}\text { Méto } \\
\text { do }\end{array}$ & RA, silogismo & RA, silogismo, casos & $\begin{array}{l}\text { RA, silogismo, } \\
\text { casos }\end{array}$ & RA, casos \\
\hline & Estilo & AM local & AM local & AM local & AM local \\
\hline & Modo & Analítico & Analítico & Analítico & Analítico \\
\hline \multicolumn{2}{|c|}{$\begin{array}{l}\text { Funciones de la } \\
\text { demostración }\end{array}$} & $\begin{array}{l}\text { Comunicación, } \\
\text { verificación }\end{array}$ & $\begin{array}{l}\text { Comunicación, } \\
\text { verificación }\end{array}$ & $\begin{array}{l}\text { Comunicación, } \\
\text { verificación. } \\
\text { Parcialmente } \\
\text { explicación }\end{array}$ & $\begin{array}{l}\text { Comunicación, } \\
\text { verificación. }\end{array}$ \\
\hline \multirow{2}{*}{$\begin{array}{l}\text { Reconoci } \\
\text { miento de } \\
\text { procesos }\end{array}$} & $R P$ & Sí. & No & No & No \\
\hline & $\mathrm{RC}$ & No & No & No & No \\
\hline \multirow{2}{*}{\begin{tabular}{|lr}
\multicolumn{2}{|l|}{ Expresione } \\
$\mathrm{s}$ & que \\
utiliza
\end{tabular}} & $\begin{array}{lll} & \text { Exp } \\
\end{array}$ & $\begin{array}{l}\text { SI: verbal, gráfico } \\
\text { y fórmula }\end{array}$ & $\begin{array}{l}\text { SI: verbal, fórmula, } \\
\text { gráfica (consecuencias) }\end{array}$ & $\begin{array}{l}\text { SI: verbal, gráfico, } \\
\text { fórmula }\end{array}$ & $\begin{array}{l}\text { SI: verbal, fórmula, } \\
\text { gráfico }\end{array}$ \\
\hline & Sig & No & No & No & No \\
\hline \multirow{4}{*}{\begin{tabular}{|l|} 
Considerac \\
iones \\
globales
\end{tabular}} & GP & \begin{tabular}{|l}
$\begin{array}{l}\text { Sí, algunas } \\
\text { indicaciones }\end{array}$ \\
\end{tabular} & \begin{tabular}{|l|} 
No, alguna en el \\
proceso
\end{tabular} & No & No \\
\hline & $\mathrm{CSi}$ & $\begin{array}{l}\text { Interpretación } \\
\text { geométrica previa }\end{array}$ & $\begin{array}{l}\text { Lema anterior } \\
\text { (c.signo), interpretación } \\
\text { gráfica, fallo en las } \\
\text { hipótesis, no unicidad }\end{array}$ & $\begin{array}{l}\text { Interpretación } \\
\text { gráfica }\end{array}$ & $\begin{array}{l}\text { Aproximación de } \\
\text { raíces, intervalos } \\
\text { encajados, ejemplos de } \\
\text { aplicación }\end{array}$ \\
\hline & DEJ & Sí, etiqueta & Tipográficamente & $\begin{array}{l}\text { Tipográficamente, } \\
\text { "en efecto" }\end{array}$ & Tipográficamente \\
\hline & OV & No & No & No & No \\
\hline
\end{tabular}

Tabla V.6.1.1.1. Análisis de las justificaciones utilizadas en los LT de LGE para el teorema de los ceros de Bolzano.

El teorema de Bolzano es uno de los primeros teoremas con nombre del Análisis Matemático que se enuncia y se demuestra en los libros de Bachillerato. Además su justificación axiomática es asequible en este nivel educativo, pues el razonamiento matemático no es demasiado complejo, y no requiere de muchos resultados previos. Por otro lado, la situación que describe es tan evidente desde 
un punto de vista gráfico, que facilita la tarea de convencer a un lector de la veracidad de este teorema. A continuación se muestran las tablas con el análisis correspondiente a éste teorema, organizada por periodos legislativos (Tablas V.6.1.1.1, V.6.1.1.2 y V.6.1.1.3).

\begin{tabular}{|c|c|c|c|c|c|c|}
\hline \multicolumn{7}{|c|}{ Teorema de los ceros de Bolzano. } \\
\hline $\begin{array}{l}\text { Textos } \\
\text { Bach.) }\end{array}$ & $\left(2^{\circ}\right.$ & Anaya (2003) & \begin{tabular}{|l} 
Santillana \\
(1997)
\end{tabular} & SM (2001) & \begin{tabular}{|l} 
Vicens-Vives \\
(1999)
\end{tabular} & $\begin{array}{l}\text { Vicens- Vives } \\
(2004)\end{array}$ \\
\hline $\begin{array}{l}\text { Esquema } \\
\text { prueba }\end{array}$ & de & $\begin{array}{l}\text { EP inductivo de } \\
1 \text { caso }\end{array}$ & EP axiomático & EP axiomático & $\begin{array}{l}\text { EP inductivo de } \\
\text { varios casos }\end{array}$ & $\begin{array}{l}\text { EP inductivo de } \\
1 \text { caso }\end{array}$ \\
\hline \multirow[t]{4}{*}{ Técnicas } & Tipo & $\begin{array}{l}\text { CS. Existe c tal } \\
\text { que... }\end{array}$ & $\begin{array}{l}\text { CS. Existe un } \\
\text { punto }\end{array}$ & \begin{tabular}{|l} 
Existencia \\
simple
\end{tabular} & CS. Existencia & $\begin{array}{l}\text { CS. Existencia } \\
\text { simple }\end{array}$ \\
\hline & Método & . & $\begin{array}{l}\text { RA. Silogismo, } \\
\text { casos }\end{array}$ & $\begin{array}{l}\text { RA, silogismo, } \\
\text { casos }\end{array}$ & - & - \\
\hline & Estilo & Gráfico & AM local & AM local & Gráfico & Algebraico \\
\hline & Modo & - & Analístico & Analítico & - & - \\
\hline \multicolumn{2}{|c|}{$\begin{array}{l}\text { Funciones de la } \\
\text { demostración }\end{array}$} & a Ninguna & $\begin{array}{l}\text { Verificación y } \\
\text { comunicación }\end{array}$ & $\begin{array}{l}\text { Verificación, } \\
\text { comunicación, } \\
\text { descubrimiento } \\
\text { (bisección) }\end{array}$ & $\begin{array}{l}\text { Verificación, } \\
\text { explicación }\end{array}$ & Ninguna \\
\hline \multirow[t]{2}{*}{$\begin{array}{ll}\text { Reconocimie } \\
\text { nto } & \text { de } \\
\text { procesos } & \end{array}$} & RP & - & No & $\begin{array}{l}\text { Menciona } \\
\text { demostrar al } \\
\text { final }\end{array}$ & No & No \\
\hline & $\mathrm{RC}$ & - & No & $\begin{array}{l}\text { Relación con la } \\
\text { búsqueda de } \\
\text { raíces }\end{array}$ & No & No \\
\hline \multirow[t]{2}{*}{$\begin{array}{l}\text { Expresiones } \\
\text { que utiliza }\end{array}$} & $\operatorname{Exp}$ & $\begin{array}{l}\text { SR: gráfico } \\
\text { (varios ceros) }\end{array}$ & $\begin{array}{l}\text { SR: verbal, } \\
\text { fórmula y } \\
\text { gráfico }\end{array}$ & $\begin{array}{l}\text { SR: gráfica, } \\
\text { verbal, fórmula }\end{array}$ & $\begin{array}{l}\text { SR: verbal, } \\
\text { fórmula y } \\
\text { gráfica (un cero } \\
\text { y varios ceros) }\end{array}$ & $\begin{array}{l}\text { SR: verbal, } \\
\text { fórmula y } \\
\text { gráfica (1 caso } \\
\text { concreto) }\end{array}$ \\
\hline & Sig & No & No & No & No & No \\
\hline \multirow[t]{4}{*}{$\begin{array}{l}\text { Consideracio } \\
\text { nes globales }\end{array}$} & GP & - & No & $\begin{array}{l}\text { Sí, de forma } \\
\text { breve }\end{array}$ & No & No \\
\hline & CSi & $\begin{array}{l}\text { Sí, antes del } \\
\text { enunciado. No } \\
\text { hace relaciones. } \\
\text { Ejemplo }\end{array}$ & $\begin{array}{l}\text { Interpretación } \\
\text { del resultado }\end{array}$ & $\begin{array}{l}\text { Búsqueda de } \\
\text { raíces, } \\
\text { bisección, fallo } \\
\text { de las hipótesis }\end{array}$ & $\begin{array}{l}\text { Resolución de } \\
\text { ecuación, fallo } \\
\text { de las hipótesis }\end{array}$ & $\begin{array}{l}\text { Aproximación, } \\
\text { acotación de } \\
\text { raíces }\end{array}$ \\
\hline & DEJ & No & Sí, etiqueta & Tipográficament & No & No \\
\hline & $\mathrm{OV}$ & No & No & No & No & No \\
\hline
\end{tabular}

Tabla V.6.1.1.2. Análisis de las justificaciones utilizadas en los LT de LOGSE para el teorema de los ceros de Bolzano.

Alguna de las funciones de la demostración se ha descrito como "parcial", en concreto, en el LT de SM (1980). En el primer caso, se indica que la justificación cumple parcialmente la función de explicación porque su justificación es la más detallada de las que se han encontrado, explicitando en cada paso los resultados o teoremas necesarios para verificarlos. Aunque todos los LT acompañan las 
justificaciones de gráficas, que son muy explicativas, estas no forman parte de la justificación, por lo que no se ha señalado dicha función en el análisis. Por otro lado, en el caso de Vicens-Vives (1979), aunque se expone el método de bisección como consecuencia del teorema de Bolzano, no se cumple la función de descubrimiento ya que el razonamiento utilizado no contiene el método de encaje de intervalos que llevaría a dicho descubrimiento. En dos LT se indica que la justificación no tiene ninguna función, ni siquiera la de justificación. Se ha considerado así porque, si bien la gráfica o el ejemplo mostrado permiten convencer de la veracidad del teorema, en el LT no se realiza ninguna indicación que induzca a pensar que dichos elementos se utilizan con dicho fin.

\begin{tabular}{|c|c|c|c|c|c|}
\hline \multicolumn{6}{|c|}{ Teorema de los ceros de Bolzano. } \\
\hline $\begin{array}{l}\text { Textos } \\
\text { Bach.) }\end{array}$ & $\left(2^{\circ}\right.$ & Anaya (2009) & Santillana (2009) & SM (2010) & $\begin{array}{l}\text { Vicens-Vives } \\
\text { (2009) }\end{array}$ \\
\hline \multicolumn{2}{|l|}{$\begin{array}{l}\text { Esquema } \\
\text { prueba }\end{array}$} & $\begin{array}{l}\text { EP inductivo de } 1 \\
\text { caso }\end{array}$ & $\begin{array}{l}\text { EP inductivo de } \\
\text { varios casos }\end{array}$ & EP axiomático & EP axiomático \\
\hline \multirow[t]{4}{*}{ Técnicas } & Tipo & $\begin{array}{l}\text { CS. Existe c tal } \\
\text { que... }\end{array}$ & CS. Existencia simple & $\begin{array}{l}\text { CS. Existencia } \\
\text { simple. }\end{array}$ & CS. Existencia simple. \\
\hline & Método & & & $\begin{array}{l}\text { RA, silogismo, } \\
\text { casos (oculto) }\end{array}$ & $\begin{array}{l}\text { RA, silogismo y } \\
\text { casos. }\end{array}$ \\
\hline & Estilo & Gráfico & $\begin{array}{l}\text { Gráfico y de las } \\
\text { coordenadas }\end{array}$ & AM local & AM local \\
\hline & Modo & - & - & Analítico & Analítico \\
\hline \multicolumn{2}{|c|}{$\begin{array}{l}\text { Funciones de la } \\
\text { demostración }\end{array}$} & Ninguna & $\begin{array}{l}\text { Verificación, } \\
\text { comunicación, } \\
\text { explicación }\end{array}$ & $\begin{array}{l}\text { Verificación, } \\
\text { comunicación, } \\
\text { descubrimiento }\end{array}$ & $\begin{array}{l}\text { Verificación, } \\
\text { comunicación }\end{array}$ \\
\hline \multirow{2}{*}{$\begin{array}{l}\text { Reconocimi } \\
\text { ento de } \\
\text { procesos }\end{array}$} & \begin{tabular}{l|l}
$i$ & $R P$ \\
$l e$ &
\end{tabular} & - & $\begin{array}{l}\text { Sí, indica que } \\
\text { demuestra }\end{array}$ & $\begin{array}{l}\text { Sí, hace referencias } \\
\text { a la demostración }\end{array}$ & No \\
\hline & $\mathrm{RC}$ & - & Indica cómo aplicar & $\begin{array}{l}\text { Menciona el método } \\
\text { de la bisección. }\end{array}$ & No \\
\hline \multirow[t]{2}{*}{$\begin{array}{l}\text { Expresiones } \\
\text { que utiliza }\end{array}$} & $\operatorname{Exp}$ & $\begin{array}{l}\text { SR: gráfico } \\
\text { (varios ceros) }\end{array}$ & $\begin{array}{l}\text { SR: verbal, fórmula y } \\
\text { gráfica }(2 \text { monótonas } \\
\text { de } 2 \text { casos }(\mathrm{f}(\mathrm{a}) \lessgtr \mathrm{f}(\mathrm{b}))\end{array}$ & $\begin{array}{l}\text { SR: verbal, fórmula, } \\
\text { gráfica (método de } \\
\text { bisección) }\end{array}$ & $\begin{array}{l}\text { SR: verbal, fórmula y } \\
\text { gráfica (varios puntos) }\end{array}$ \\
\hline & Sig & No & No & No & No \\
\hline \multirow{4}{*}{$\begin{array}{l}\text { Consideraci } \\
\text { ones } \\
\text { globales }\end{array}$} & i GP & - & No & No & No \\
\hline & $\mathrm{CSi}$ & $\begin{array}{l}\text { Sí, antes del } \\
\text { enunciado. No } \\
\text { hace relaciones. } \\
\text { Ejemplo } \\
\end{array}$ & $\begin{array}{l}\text { Indica qué ocurre si } \\
\text { fallan las hipótesis, y } \\
\text { la aplicación. }\end{array}$ & $\begin{array}{l}\text { Método de la } \\
\text { bisección }\end{array}$ & $\begin{array}{l}\text { Ejemplo de } \\
\text { aplicación. Indica la } \\
\text { utilidad para resolver } \\
\mathrm{f}(\mathrm{x})=0 \text {, pero no cómo }\end{array}$ \\
\hline & DEJ & No & $\begin{array}{l}\text { Tipográficamente. } \\
\text { Menciona la } \\
\text { demostración }\end{array}$ & $\begin{array}{l}\text { Tipográficamente, } \\
\text { pero no de forma } \\
\text { clara }\end{array}$ & Sí, etiqueta \\
\hline & OV & No & No & No & No \\
\hline
\end{tabular}

Tabla V.6.1.1.3. Análisis de las justificaciones utilizadas en los LT de LOE para el teorema los ceros de Bolzano. 
Como se ha mencionado repetidas veces, el LT de Anaya de 2009 coincide prácticamente con el de Anaya de 2003, por lo que los comentarios realizados para el ejemplar de 2003 son los mismos que para el ejemplar de 2009. No se aprecia ninguna observación que llame la atención en esta tabla, aparte de los comentarios que se realizan al final, en el apartado correspondiente.

En la Tabla V.6.1.3.4 se observa que la prueba más abundante para el teorema de Bolzano es el EP axiomático, aunque en los ejemplares más recientes hay pasos de la justificación que estarían incompletos. Por editoriales, Anaya sustituye el EP axiomático por una EP inductivo de 1 caso, tanto en LOGSE como en LOE; Santillana utiliza EP axiomático en los LT de los dos primeros periodos y luego lo sustituye por un EP inductivo de varios casos; finalmente, Vicens-Vives, aunque en los LT de LOGSE utiliza EP inductivos, recupera el EP axiomático en el último periodo. La única editorial que mantiene EP axiomáticos en los tres periodos es SM.

\begin{tabular}{lllll}
\hline & Anaya & Santillana & SM & Vicens-Vives \\
\hline LGE & EP axiomático & EP axiomático & EP axiomático & EP axiomático \\
LOGSE & EP inductivo de 1 caso & EP axiomático & EP axiomático & $\begin{array}{l}\text { EP inductivo de varios casos } \\
\text { EP inductivo de 1 caso }\end{array}$ \\
LOE & EP inductivo de 1 caso & $\begin{array}{l}\text { EP inductivo de } \\
\text { varios casos }\end{array}$ & EP axiomático & EP axiomático \\
\hline
\end{tabular}

Tabla V.6.1.1.4. EP reflejados en los LT de la muestra para el teorema de los ceros de Bolzano.

\section{V.6.1.2. Teorema de los valores extremos de Weierstrass}

En cuanto al teorema de Weierstrass, es el teorema que menos se justifica de los tres teoremas fuertes de continuidad. Esto puede deberse al hecho de que su justificación es sensiblemente más compleja (en cuanto a razonamiento matemático y en cuento a los teoremas previos que se requieren para realizarla) que las demostraciones de los otros dos teoremas. Sin embargo, al igual que los otros dos teoremas, la situación que describe en este teorema es sencilla de representar gráficamente, y permite a los alumnos convencerse de la veracidad del teorema sin más que razonar de forma intuitiva sobre representaciones gráficas. Por tanto, aunque su demostración formal sea compleja, no hay razón para descartar otro tipo de razonamientos. 


\begin{tabular}{|c|c|c|c|c|c|}
\hline \multicolumn{6}{|c|}{ Teorema de los valores extremos de Weierstrass. } \\
\hline \multicolumn{2}{|c|}{ Textos (COU) } & Anaya (1989) & Santillana (1981) & SM (1980) & $\begin{array}{l}\text { Vicens-Vives } \\
(1979)\end{array}$ \\
\hline \multicolumn{2}{|l|}{$\begin{array}{l}\text { Esquema } \\
\text { prueba }\end{array}$} & $\begin{array}{l}\text { EP axiomático } \\
\text { (erróneo) }\end{array}$ & $\begin{array}{l}\text { EP axiomático y } \\
\text { transformacional }\end{array}$ & $\begin{array}{l}\text { EP axiomático y } \\
\text { transformacional }\end{array}$ & $\begin{array}{l}\text { EP axiomático y } \\
\text { transformacional }\end{array}$ \\
\hline \multirow[t]{4}{*}{\begin{tabular}{|l|l} 
Técnicas & $\mathrm{T}$
\end{tabular}} & Tipo & $\begin{array}{l}\text { Hipótesis y tesis } \\
\text { mezcladas }\end{array}$ & \begin{tabular}{|l|} 
CS, existencia \\
simple (no indica al \\
menos)
\end{tabular} & $\begin{array}{l}\text { CS, f admite un } \\
\text { máximo y un } \\
\text { mínimo }\end{array}$ & $\begin{array}{l}\text { CS (sin entonces), } \\
\text { alcanza }\end{array}$ \\
\hline & Método & RA & RA & RA & $\begin{array}{l}\text { RA, análogamente } \\
\text { mínimo }\end{array}$ \\
\hline & Estilo & AM global y local & AM global y local & $\begin{array}{l}\text { AM global y } \\
\text { ¿algebraico? }\end{array}$ & AM global y local \\
\hline & Modo & Analítico & Analítico & Analítico & Analítico \\
\hline \multicolumn{2}{|c|}{$\begin{array}{|ll|}\begin{array}{l}\text { Funciones de la } \\
\text { demostración }\end{array} \\
\end{array}$} & $\begin{array}{l}\text { Supuestamente } \\
\text { verificación }\end{array}$ & $\begin{array}{l}\text { Comunicación, } \\
\text { verificación }\end{array}$ & $\begin{array}{l}\text { Comunicación, } \\
\text { verificación }\end{array}$ & $\begin{array}{l}\text { Comunicación, } \\
\text { verificación }\end{array}$ \\
\hline \multirow{2}{*}{\begin{tabular}{|l|} 
Reconocim \\
iento de \\
procesos \\
\end{tabular}} & $\mathrm{RP}$ & No & No & No & No \\
\hline & $\mathrm{RC}$ & No & No & No & No \\
\hline \multirow{2}{*}{\begin{tabular}{ll}
\multicolumn{2}{|l}{ Expresione } \\
S & que \\
utiliza &
\end{tabular}} & Exp & SI: verbal, fórmula & $\begin{array}{l}\text { SI: gráfico, verbal, } \\
\text { fórmula }\end{array}$ & $\begin{array}{l}\text { SI: verbal, gráfica y } \\
\text { fórmula }\end{array}$ & $\begin{array}{l}\text { SI: verbal, fórmula y } \\
\text { gráfico }\end{array}$ \\
\hline & Sig & No & No & No & No \\
\hline \multirow{4}{*}{$\begin{array}{l}\text { Consideraci } \\
\text { ones } \\
\text { globales }\end{array}$} & i GP & No & No & No & No \\
\hline & $\mathrm{CSi}$ & No & $\begin{array}{l}\text { Interpretación } \\
\text { gráfica, necesidad de } \\
\text { las hipótesis }\end{array}$ & $\begin{array}{l}\text { Interpretación } \\
\text { geométrica, utiliza el } \\
\text { teorema anterior }\end{array}$ & $\begin{array}{l}\text { No, aunque enuncia } \\
\text { corolarios, no indica } \\
\text { que son } \\
\text { consecuencias }\end{array}$ \\
\hline & DEJ & Etiqueta & Tipográficamente & Tipográficamente & Tipográficamente \\
\hline & $\mathrm{OV}$ & No & No & No & No \\
\hline
\end{tabular}

Tabla V.6.1.2.1. Análisis de las justificaciones utilizadas en los LT de LGE para el teorema de los valores extremos de Weierstrass.

En el caso de Anaya (1989), en las funciones de la demostración se ha incluido la verificación (supuestamente) ya que el LT pretende ofrecer un razonamiento que verifique el teorema. Además, se podría considerar también la explicación, porque la forma de exposición en el texto pretende ser muy explicativa, pero se ha utilizado la expresión "supuestamente" y no se ha incluido la función de explicación debido a que el razonamiento que se propone es erróneo. En el resto de LT, las justificaciones que se muestran, que son las tradicionales para este teorema, cumplen las funciones de verificación y comunicación, pero no la de explicación, pues al no mostrar una explicación global del proceso, la construcción de la función auxiliar no es nada intuitiva y no permite intuir cual es la motivación para construirla ni el porqué de su consideración (Tabla V.6.1.2.1). 


\begin{tabular}{|c|c|c|c|c|c|c|}
\hline \multicolumn{7}{|c|}{ Teorema de los valores extremos de Weierstrass. } \\
\hline $\begin{array}{l}\text { Textos } \\
\text { Bach.) }\end{array}$ & $\left(2^{\circ}\right.$ & Anaya (2003) & \begin{tabular}{|l} 
Santillana \\
(1997)
\end{tabular} & SM (2001) & \begin{tabular}{|l} 
Vicens-Vives \\
(1999)
\end{tabular} & $\begin{array}{l}\text { Vicens- Vives } \\
\text { (2004) }\end{array}$ \\
\hline \multicolumn{2}{|l|}{$\begin{array}{l}\text { Esquema } \\
\text { prueba }\end{array}$} & \begin{tabular}{|l} 
EP inductivo de \\
1 caso
\end{tabular} & $\begin{array}{l}\text { EP axiomático y } \\
\text { transformacional }\end{array} \mid$ & EP0 & $\begin{array}{l}\text { EP inductivo de } \\
1 \text { caso }\end{array}$ & $\begin{array}{l}\text { EP inductivo de } \\
1 \text { caso }\end{array}$ \\
\hline \multirow[t]{4}{*}{\begin{tabular}{|l|l} 
Técnicas & $\mathrm{T}$ \\
\end{tabular}} & Tipo & $\mid \begin{array}{lrr}\text { CS, } & \text { existen } & \text { y } \\
\text { tiene, } & \text { sendos } \\
\text { números, } & \text { un } \\
\text { máximo } & \text { y } & \text { un } \\
\text { mínimo } & \end{array}$ & \begin{tabular}{|ll} 
CS (parcial, & no \\
usa entonces) \\
Alcanza \\
máximo...
\end{tabular} & $\begin{array}{l}\text { Hipótesis } \\
\text { tesis } \\
\text { mezcladas. } \\
\text { Existencia } \\
\text { simple. } \\
\text { Alcanza } \\
\text { mínimo } \\
\text { máximo } \\
\end{array}$ & $\begin{array}{l}\text { CS, alcanza, un } \\
\text { máximo y un } \\
\text { mínimo }\end{array}$ & $\begin{array}{l}\text { CS, alcanza, } \\
\text { existe, al menos }\end{array}$ \\
\hline & Método & - & RA, casos & - & - & - \\
\hline & Estilo & Gráfico & $\begin{array}{lll}\text { AM } & \text { global y } \\
\text { local }\end{array}$ & - & $\begin{array}{l}\text { Gráfico, de las } \\
\text { coordenadas }\end{array}$ & $\begin{array}{l}\text { Algebraico } \\
\text { gráfico }\end{array}$ \\
\hline & Modo & - & Analítico & - & - & - \\
\hline \multicolumn{2}{|l|}{$\begin{array}{l}\text { Funciones } d \\
\text { demostración }\end{array}$} & a Ninguna & $\begin{array}{l}\text { Verificación, } \\
\text { comunicación }\end{array}$ & - & Verificación & Ninguna \\
\hline \multirow[t]{2}{*}{$\begin{array}{l}\text { Reconocim } \\
\text { iento de } \\
\text { procesos }\end{array}$} & RP & No & $\begin{array}{l}\text { Lo denota } \\
\text { demostración }\end{array}$ & $\begin{array}{l}\text { Sistema de } \\
\text { representación } \\
\text { verbal }\end{array}$ & $\begin{array}{l}\text { Sí, indica que } \\
\text { no la muestra }\end{array}$ & No \\
\hline & $\mathrm{RC}$ & No & No & No & No & No \\
\hline \multirow[t]{2}{*}{\begin{tabular}{|ll}
\multicolumn{2}{|c|}{ |xpresione } \\
s & que \\
utiliza &
\end{tabular}} & Exp & $\begin{array}{l}\text { SR: gráfico } \\
\text { (monótona) }\end{array}$ & $\begin{array}{l}\text { SR: verbal y } \\
\text { fórmula }\end{array}$ & - & 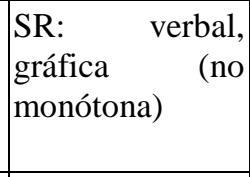 & $\begin{array}{l}\text { SR: verbal, } \\
\text { fórmula, gráfico } \\
\text { (ejemplo, fallo } \\
\text { hipótesis) }\end{array}$ \\
\hline & Sig & No & No & - & No & No \\
\hline \multirow{4}{*}{$\begin{array}{l}\text { Consideraci } \\
\text { ones } \\
\text { globales }\end{array}$} & $\mathrm{Gi}$ & No & No & - & No & No \\
\hline & CSi & No & $\begin{array}{l}\text { Sí. Fallo de las } \\
\text { hipótesis, } \\
\text { imagen de un } \\
\text { cerrado }\end{array}$ & - & \begin{tabular}{|l} 
Explica lo que \\
significa, \\
relaciona con \\
Bolzano
\end{tabular} & $\begin{array}{l}\text { Fallo en las } \\
\text { hipótesis }\end{array}$ \\
\hline & DEJ & $\begin{array}{l}\text { Tipográficament } \\
\mathrm{e}\end{array}$ & Sí, etiqueta & - & No & No \\
\hline & $\mathrm{OV}$ & No & No & No & No & No \\
\hline
\end{tabular}

Tabla V.6.1.2.2. Análisis de las justificaciones utilizadas en los LT de LOGSE para el teorema de los valores absolutos de Weierstrass.

Cuando se clasifican las funciones de la demostración de los EP inductivos (sean de un caso, de varios o sistemáticos) se puede considerar que cumple la función de verificación o no, no es algo que depende directamente del tipo de EP. Si el LT que está utilizando un EP inductivo refleja la intención de justificar que el resultado es cierto, se puede hablar de la función e verificación, pero si no lo hace, dicha función dependerá del lector, y en ese caso, se clasifica el EP como que no cumple dicha función de la demostración. Algo similar ocurre con la función de explicación. Es necesario que los LT muestren indicios de 
explicación, y no sólo que se muestre una gráfica en la que el resultado parezca evidente.

\begin{tabular}{|c|c|c|c|c|c|}
\hline \multicolumn{6}{|c|}{ Teorema de los valores extremos de Weierstrass. } \\
\hline \multicolumn{2}{|c|}{ Textos ( $2^{\circ}$ Bach.) } & Anaya (2009) & Santillana (2009) & \multirow[t]{2}{*}{ SM (2010) } & \multirow{2}{*}{\begin{tabular}{|l|} 
Vicens-Vives \\
$(\mathbf{2 0 0 9 )}$
\end{tabular}} \\
\hline $\begin{array}{l}\text { Esquema } \\
\text { prueba }\end{array}$ & $\mathrm{de}$ & $\begin{array}{l}\text { EP inductivo de } 1 \\
\text { caso }\end{array}$ & $\mid \begin{array}{l}\text { EP inductivo de } \\
\text { varios casos }\end{array}$ & & \\
\hline \multirow[t]{4}{*}{ Técnicas } & Tipo & $\begin{array}{l}\text { CS, existen y tiene, } \\
\text { sendos números, un } \\
\text { máximo y un } \\
\text { mínimo }\end{array}$ & $\begin{array}{l}\text { CS, } \\
\text { utilización } \\
\text { definido } *\end{array}$ & CS, existencia & $\begin{array}{l}\text { CS, } \\
\text { simple }\end{array}$ \\
\hline & Método & - & - & - & - \\
\hline & Estilo & Gráfico & $\begin{array}{l}\text { Gráfico y de las } \\
\text { coordenadas }\end{array}$ & - & - \\
\hline & Modo & - & - & - & - \\
\hline \multicolumn{2}{|c|}{$\begin{array}{l}\text { Funciones de } 1 \\
\text { demostración }\end{array}$} & Ninguna & $\begin{array}{l}\text { Comunicación, } \\
\text { explicación }\end{array}$ & - & - \\
\hline \multirow{2}{*}{$\begin{array}{l}\text { Reconocim } \\
\text { iento de } \\
\text { procesos }\end{array}$} & RP & No & No & No & $\begin{array}{l}\text { Sí, indica que no se } \\
\text { hace. }\end{array}$ \\
\hline & $\mathrm{RC}$ & No & No & No & No \\
\hline \multirow[t]{2}{*}{\begin{tabular}{ll}
\multicolumn{2}{|l}{ Expresione } \\
s & que \\
utiliza &
\end{tabular}} & Exp & $\begin{array}{ll}\begin{array}{l}\text { SR: } \\
\text { (monótona) }\end{array} & \text { gráfico } \\
\end{array}$ & $\begin{array}{l}\text { SR: verbal, fórmula } \\
\text { y gráfico } \\
\text { monótona y no) }\end{array}$ & SR: verbal. & SR: verbal. \\
\hline & Sig & No & & & \\
\hline \multirow{4}{*}{$\begin{array}{l}\text { Consideraci } \\
\text { ones } \\
\text { globales }\end{array}$} & i GP & No & No & - & - \\
\hline & CSi & No & No & No. & $\begin{array}{l}\text { Sí, indican que c y d } \\
\text { del enunciado son } \\
\text { máx. y mín. }\end{array}$ \\
\hline & DEJ & Tipográficamente & Tipográficamente & - & - \\
\hline & $\mathrm{OV}$ & No & No & No & No \\
\hline
\end{tabular}

Tabla V.6.1.2.3. Análisis de las justificaciones utilizadas en los LT de LOE para el teorema de los valores absolutos de Weierstrass.

En el periodo de la LOE (V.6.1.2.3), este teorema ha perdido muchísima importancia en los LT con respecto a periodos anteriores. Se observa que algunos LT lo enuncian al final y que no lo justifican (SM, 2010 y Vicens-Vives, 2009), ni siquiera con una gráfica que ilustre la situación, como en el caso de Anaya (2009), que podría considerarse una prueba visual (tampoco se acompaña de texto alguno). El LT que más profundiza en el LT de Santillana (2009), como se indica más adelante.

En el caso del teorema de Weierstrass (Tabla V.6.1.4.4), los textos de LOGSE y LOE de las editoriales SM y Vicens-Vives no justifican el teorema, se limitan a enunciarlo, quizá porque consideran que el nivel de dificultad de esta demostración es mayor. En estas editoriales, este teorema se enuncia con la única 
finalidad de ser aplicado y no parece buscarse comprensión por parte del alumno. Anaya continua con la tendencia de justificar mediante un EP inductivo de un caso en LOGSE y LOE, y Santillana vuelve a utilizar un EP inductivo de varios casos en LOE. En este texto se presentan dos representaciones gráficas de sendas funciones que cumplen las hipótesis del teorema, en ellas se señalan su máximo y su mínimo (Figura V.6.1.2.1). Es destacable el hecho de que uno de los LT (Anaya, 1989) realiza una demostración errónea del teorema de Weierstrass. Esta editorial trata de hacer una demostración parecida a la del teorema de Bolzano construyendo la sucesión de intervalos encajados y omite la posible argumentación que establecería el teorema, hecho que se describe posteriormente.

\begin{tabular}{|c|c|c|c|c|c|c|c|}
\hline & Anaya & & Santillana & & SM & & Vicens-Vives \\
\hline LGE & $\begin{array}{l}\text { EP axiomático } \\
\text { transformacional }\end{array}$ & & $\begin{array}{l}\text { EP axiomático } \\
\text { transformacional }\end{array}$ & $\mathrm{y}$ & $\begin{array}{l}\text { EP axiomático } \\
\text { transformacional }\end{array}$ & $\mathrm{y}$ & $\begin{array}{l}\text { EP axiomático y } \\
\text { transformacional }\end{array}$ \\
\hline LOGSE & $\begin{array}{l}\text { EP inductivo de } \\
\text { caso }\end{array}$ & & $\begin{array}{l}\text { EP axiomático } \\
\text { transformacional }\end{array}$ & $\mathrm{y}$ & EP0 & & $\begin{array}{l}\text { EP inductivo de } \\
\text { caso } \\
\text { EP inductivo de } 1 \\
\text { caso }\end{array}$ \\
\hline LOE & $\begin{array}{l}\text { EP inductivo de } \\
\text { caso }\end{array}$ & & $\begin{array}{l}\text { EP inductivo } \\
\text { varios casos }\end{array}$ & & EP0 & & EP0 \\
\hline
\end{tabular}

Tabla V.6.1.2.4. EP reflejados en los LT de la muestra para el teorema de los valores absolutos de Weierstrass.
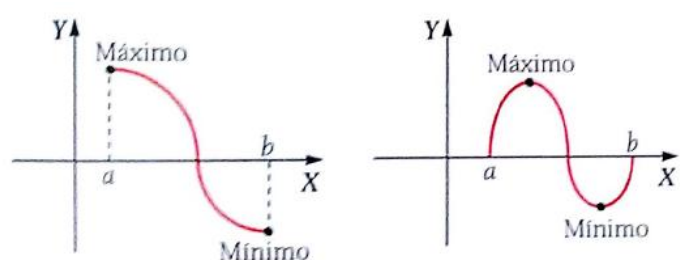

Por ser $f(x)$ continua en el intervalo describirá una curva que unirá los puntos $(a, f(a))$ y

Entonces existe al menos un punto donde la función alcanza su valor máximo absoluto y otro punto donde toma su valor mínimo absoluto.

Figura V.6.1.2.1. EP inductivo de varios casos para el teorema de los valores absolutos de Weierstrass (Santillana, 2009).

\section{V.6.1.3. Teorema de los valores intermedios de Darboux}

El teorema de los valores intermedios de Darboux es un resultado cuya representación gráfica es muy sencilla, y permite convencerse de la veracidad del resultado, al igual que los otros dos teoremas fuertes de continuidad. $\mathrm{Su}$ demostración más usual consiste en la utilización de una función auxiliar, que 
depende de la función sobre la que se quiere probar el teorema, y que cumple las hipótesis del teorema de Bolzano, con lo que basta aplicar este último para demostrar las hipótesis. Desde el punto de vista matemático, esta demostración es sencilla, pues los pasos necesarios que hay que dar en el razonamiento no requieren de aparataje matemático muy avanzado. Por esta razón, es una demostración asequible en el nivel educativo considerado.

\begin{tabular}{|c|c|c|c|c|c|}
\hline \multicolumn{6}{|c|}{ Teorema de los valores intermedios de Darboux. } \\
\hline \multicolumn{2}{|c|}{ Textos (COU) } & Anaya (1989) & Santillana (1981) & SM (1980) & $\begin{array}{l}\text { Vicens-Vives } \\
\text { (1979) }\end{array}$ \\
\hline \multicolumn{2}{|l|}{$\begin{array}{l}\text { Esquema } \\
\text { prueba }\end{array}$} & $\begin{array}{l}\text { EP axiomático y } \\
\text { transformacional } \\
\text { (incompleta) }\end{array}$ & $\begin{array}{l}\text { EP axiomático y } \\
\text { transformacional }\end{array}$ & $\begin{array}{l}\text { EP axiomático y } \\
\text { transformacional }\end{array}$ & $\begin{array}{l}\text { EP axiomático y } \\
\text { transformacional }\end{array}$ \\
\hline \multirow[t]{4}{*}{ Técnicas } & Tipo & $\begin{array}{l}\text { CS, existencia } \\
\text { simple }\end{array}$ & CS & $\begin{array}{l}\text { CS (sin entonces), } \\
\text { alcanza los } \\
\text { valores... }\end{array}$ & CS, alcanza \\
\hline & Método & Silogismo & $\begin{array}{l}\text { Silogismo, sólo un } \\
\text { caso }\end{array}$ & $\begin{array}{l}\text { Silogismo, sólo un } \\
\text { caso }\end{array}$ & Silogismo \\
\hline & Estilo & AM global & AM global & AM global & AM global \\
\hline & Modo & Analítico & Analítico & Analítico & Analítico \\
\hline \multicolumn{2}{|c|}{$\begin{array}{l}\text { Funciones de la } \\
\text { demostración }\end{array}$} & $\begin{array}{l}\text { Verificación, } \\
\text { comunicación. }\end{array}$ & $\begin{array}{l}\text { Verificación, } \\
\text { comunicación }\end{array}$ & $\begin{array}{l}\text { Verificación, } \\
\text { comunicación }\end{array}$ & $\begin{array}{l}\text { Comunicación y } \\
\text { verificación }\end{array}$ \\
\hline \multirow[t]{2}{*}{$\begin{array}{l}\text { Reconocim } \\
\text { iento de } \\
\text { procesos }\end{array}$} & RP & $\begin{array}{l}\text { Menciona "se } \\
\text { prueba" }\end{array}$ & No & $\begin{array}{l}\text { Algunas } \\
\text { indicaciones de que } \\
\text { demuestra }\end{array}$ & No \\
\hline & $\mathrm{RC}$ & No & No & No & No \\
\hline \multirow{2}{*}{\begin{tabular}{|lr}
\multicolumn{2}{|l}{ Expresione } \\
s & que \\
utiliza & \\
\end{tabular}} & Exp & $\begin{array}{l}\text { SI: verbal, gráfico y } \\
\text { fórmula }\end{array}$ & SI: verbal, fórmula & SI: verbal, fórmula & $\begin{array}{l}\text { SI: verbal, fórmula, } \\
\text { gráfico }\end{array}$ \\
\hline & Sig & No & No & No & No \\
\hline \multirow{4}{*}{$\begin{array}{l}\text { Consideraci } \\
\text { ones } \\
\text { globales }\end{array}$} & i GP & Brevemente & No & Parcialmente & No \\
\hline & CSi & \begin{tabular}{|l|} 
Consecuencia \\
inmediata de \\
Bolzano, \\
interpretación \\
geométrica previa
\end{tabular} & $\begin{array}{l}\text { Ejemplos de } \\
\text { aplicación, } \\
\text { utilización de } \\
\text { Bolzano }\end{array}$ & No & No \\
\hline & $\overline{D E J}$ & $\begin{array}{l}\text { No, se encuentra } \\
\text { dentro de la } \\
\text { demostración de } \\
\text { Bolzano }\end{array}$ & Tipográficamente & $\begin{array}{l}\text { Tipográficamente, } \\
\text { "en efecto" }\end{array}$ & Tipográficamente \\
\hline & $\mathrm{OV}$ & No & No & No & No \\
\hline
\end{tabular}

Tabla V.6.1.3.1. Análisis de las justificaciones utilizadas en los LT de LGE para el teorema de los valores intermedios de Darboux.

En la justificación de Anaya (1989) se indica que es incompleta porque no se comprueba que cumple las hipótesis del teorema de Bolzano, aunque sí se indica que se cumple. Se considera que estas justificaciones no cumplen la función se explicación debido a que se centran más en la cadena de razonamientos válidos 
para llegar a establecer el resultado que en la explicación que da lugar a cada uno de esos pasos. Además, dos de los LT (Santillana, 1981 y SM, 1980) no utilizan gráficas para ilustrar el teorema (Tabla V.6.1.3.1).

\begin{tabular}{|c|c|c|c|c|c|c|}
\hline \multicolumn{7}{|c|}{ Teorema de los valores intermedios de Darboux. } \\
\hline \begin{tabular}{|l|} 
Textos \\
Bach.) \\
\end{tabular} & $\left(2^{\circ}\right.$ & $\begin{array}{l}\text { Anaya } \\
(\mathbf{2 0 0 3})\end{array}$ & \begin{tabular}{|l} 
Santillana \\
(1997)
\end{tabular} & SM (2001) & \begin{tabular}{|l|} 
Vicens-Vives \\
(1999)
\end{tabular} & \begin{tabular}{|ll}
$\begin{array}{l}\text { Vicens- } \\
\text { (2004) }\end{array}$ & Vives \\
\end{tabular} \\
\hline \multicolumn{2}{|l|}{\begin{tabular}{|l|}
$\begin{array}{l}\text { Esquema } \\
\text { prueba }\end{array}$ \\
\end{tabular}} & $\begin{array}{l}\text { EP inductivo } \\
\text { de } 1 \text { caso }\end{array}$ & $\begin{array}{l}\text { EP axiomática } \\
\text { (incompleta) }\end{array}$ & \begin{tabular}{|l} 
EP axiomático \\
y \\
transformacional
\end{tabular} & $\begin{array}{l}\text { EP axiomático } \\
\text { y } \\
\text { transformacional }\end{array}$ & $\begin{array}{l}\text { EP inductivo de } \\
\text { varios casos }\end{array}$ \\
\hline \multirow[t]{4}{*}{ Técnicas } & Tipo & $\begin{array}{l}\text { CS y } \\
\text { Existencia }\end{array}$ & $\begin{array}{l}\text { CS. Existe un } \\
\text { número... }\end{array}$ & $\begin{array}{l}\text { Existencia } \\
\text { simple. Existe. }\end{array}$ & CS y existencia & $\begin{array}{l}\text { Hipótesis y tesis } \\
\text { mezcladas, } \\
\text { existencia }\end{array}$ \\
\hline & \begin{tabular}{|l|} 
Méto \\
do
\end{tabular} & - & Silogismo & Silogismo & Silogismo & - \\
\hline & Estilo & Gráfico & $\begin{array}{l}\text { AM global y } \\
\text { algebraico }\end{array}$ & AM global & $\begin{array}{l}\text { AM global y } \\
\text { algebraico }\end{array}$ & Gráfico \\
\hline & Modo & - & Analítico & Analítico & Analítico & - \\
\hline \multicolumn{2}{|c|}{$\begin{array}{l}\text { Funciones de la } \\
\text { demostración }\end{array}$} & a Ninguna & $\begin{array}{l}\text { Comunicación, } \\
\text { verificación }\end{array}$ & $\begin{array}{l}\text { Comunicación, } \\
\text { verificación }\end{array}$ & $\begin{array}{l}\text { Verificación, } \\
\text { comunicación }\end{array}$ & $\begin{array}{l}\text { Verificación, } \\
\text { comunicación, } \\
\text { explicación }\end{array}$ \\
\hline \multirow{2}{*}{\begin{tabular}{|l|} 
Reconocim \\
iento de \\
procesos
\end{tabular}} & $\mathrm{RP}$ & No & No & $\begin{array}{l}\text { Menciona la } \\
\text { demostración }\end{array}$ & No & No \\
\hline & $\mathrm{RC}$ & No & No & No & No & No \\
\hline \multirow[t]{2}{*}{\begin{tabular}{|ll|}
\multicolumn{2}{|l}{ Expresione } \\
s & que \\
utiliza & \\
\end{tabular}} & Exp & SR: gráfico & $\begin{array}{l}\text { SR: verbal y } \\
\text { gráfico }\end{array}$ & $\begin{array}{l}\text { SR: verbal y } \\
\text { gráfico }\end{array}$ & $\begin{array}{l}\text { SR: verbal, } \\
\text { fórmula y } \\
\text { gráfico }\end{array}$ & $\begin{array}{l}\text { SR: verbal, } \\
\text { fórmula y gráfico }\end{array}$ \\
\hline & Sig & No & No & No & No & No \\
\hline \multirow[t]{4}{*}{$\begin{array}{l}\text { Consideraci } \\
\text { ones } \\
\text { globales }\end{array}$} & GP & No & No & \begin{tabular}{|l|} 
Brevemente. Se \\
apoya en \\
Bolzano
\end{tabular} & $\begin{array}{l}\text { Superficialment } \\
\mathrm{e}\end{array}$ & No \\
\hline & $\mathrm{CSi}$ & $\begin{array}{l}\text { Consecuencia } \\
\text { de Bolzano. }\end{array}$ & $\begin{array}{l}\text { Sí, apartado de } \\
\text { interpretación }\end{array}$ & \begin{tabular}{|l|} 
Consecuencia de \\
Bolzano, fallos \\
en las hipótesis, \\
recorrido de \\
funciones \\
continuas \\
(aplicación)
\end{tabular} & $\begin{array}{l}\text { Muestra dos } \\
\text { ejemplos }\end{array}$ & $\begin{array}{l}\text { Muestra dos } \\
\text { ejemplos, la } \\
\text { necesidad de las } \\
\text { hipótesis, la } \\
\text { posibilidad de } \\
\text { existencia de más } \\
\text { de un punto }\end{array}$ \\
\hline & DEJ & No & Sí, etiquetas & $\begin{array}{l}\text { Tipográficament } \\
\text { e }\end{array}$ & Sí, etiqueta & No \\
\hline & $\mathrm{OV}$ & No & No & No & No & No \\
\hline
\end{tabular}

Tabla V.6.1.3.2. Análisis de las justificaciones utilizadas en los LT de LOGSE para el teorema de los valores intermedios de Darboux.

En el periodo de LOGSE (Tabla V.6.1.3.2), todos los LT ofrecen una justificación del teorema, bien sea de tipo inductivo, o de tipo axiomático y transformacional. Se observa una disminución en el formalismo, como ocurre con otros teoremas, pero los LT que utilizan un EP axiomático y transformacional recogen los pasos esenciales de la demostración matemática de 
este teorema. En Anaya (2003) se vuelve a indicar que no existen funciones de la demostración, pues el EP inductivo se limita a una gráfica (como si de una prueba visual se tratara). Por su parte, en el LT de Vicens-Vives (2004) que utiliza un EP inductivo de varios casos, es el único que refleja la función de explicación, ya que explica los que aparece en las gráficas y además lo hace de forma que pretende convencer de que la situación expuesta en el teorema debe ser así y no de otra manera. En el resto de LT, sólo hemos considerado las funciones de verificación y comunicación propias de los tipos de EP utilizados.

\begin{tabular}{|c|c|c|c|c|c|}
\hline \multicolumn{6}{|c|}{ Teorema de los valores intermedios de Darboux. } \\
\hline \multicolumn{2}{|c|}{ Textos ( $2^{\circ}$ Bach.) } & Anaya (2009) & Santillana (2009) & SM (2010) & $\begin{array}{l}\text { Vicens-Vives } \\
(2009)\end{array}$ \\
\hline $\begin{array}{l}\text { Esquema } \\
\text { prueba }\end{array}$ & & $\begin{array}{l}\text { EP inductivo de } 1 \\
\text { caso }\end{array}$ & $\begin{array}{l}\text { EP inductivo de } 1 \\
\text { caso }\end{array}$ & $\mid \begin{array}{lr}\text { EP axiomático y } \\
\text { transformacional }\end{array}$ & $\begin{array}{l}\text { EP inductivo de } 1 \\
\text { caso }\end{array}$ \\
\hline \multirow[t]{4}{*}{ Técnicas } & Tipo & CS y Existencia & CS y Existencia & CS y Ex. Simple & Existencia Simple \\
\hline & Método & - & - & Silogismo & - \\
\hline & Estilo & Gráfico & $\begin{array}{l}\text { Gráfico y de las } \\
\text { coordenadas }\end{array}$ & AM global & Gráfico \\
\hline & Modo & - & - & Analítico & - \\
\hline \multicolumn{2}{|c|}{$\begin{array}{l}\text { Funciones de } \\
\text { demostración }\end{array}$} & Ninguna & $\begin{array}{l}\text { Explicación, } \\
\text { comunicación }\end{array}$ & $\begin{array}{l}\text { Verificación, } \\
\text { comunicación }\end{array}$ & Ninguna \\
\hline \multirow{2}{*}{\begin{tabular}{|l} 
Reconocim \\
iento de \\
procesos
\end{tabular}} & RP & No & No & $\begin{array}{l}\text { Hace una referencia } \\
\text { a la demostración }\end{array}$ & No \\
\hline & $\mathrm{RC}$ & No & Indica cómo aplicar & No & No \\
\hline \multirow[t]{2}{*}{$\begin{array}{l}\text { Expresione } \\
\text { S r que } \\
\text { utiliza }\end{array}$} & Exp & SR: verbal y gráfico & $\begin{array}{l}\text { SR: verbal, fórmula } \\
\text { y gráfico } \\
\text { monótona) }\end{array}$ & $\begin{array}{l}\text { SR: verbal, fórmula } \\
\text { y gráfico. }\end{array}$ & SR: verbal y gráfico \\
\hline & Sig & No & & No & \\
\hline \multirow[t]{4}{*}{$\begin{array}{l}\text { Consideraci } \\
\text { ones } \\
\text { globales }\end{array}$} & $\mathrm{i}$ GP & No & No & \begin{tabular}{|ll} 
Parcialmente. & \\
Aplicación de \\
Bolzano
\end{tabular} & No \\
\hline & $\mathrm{CSi}$ & $\begin{array}{l}\text { Consecuencia de } \\
\text { Bolzano. }\end{array}$ & $\begin{array}{l}\text { No. Muestra alguna } \\
\text { aplicación }\end{array}$ & $\begin{array}{l}\text { Explica la gráfica } \\
\text { antes del enunciado. } \\
\text { Indica que es r una } \\
\text { generalización re } \\
\text { Bolzano }\end{array}$ & Vincula a Bolzano. \\
\hline & DEJ & No & Tipográficamente & Tipográficamente & No \\
\hline & OV & No & No & No & No \\
\hline
\end{tabular}

Tabla V.6.1.3.3. Análisis de las justificaciones utilizadas en los LT de LGE para el teorema de los valores intermedios de Darboux.

Al igual que en el periodo anterior, en la LOE (Tabla V.6.1.3.3), todos los LT justifican este teorema, pero sólo uno, SM (2010), utiliza un EP axiomático y transformacional, mientras que el resto de LT muestran EP inductivos. No obstante, resulta más explicativo el EP inductivo de Santillana (2009) pues lo 
describe de forma que pretende convencer que la situación descrita ha de ser así y no de otra manera, como hacía Vicens-Vives (2004).

\begin{tabular}{|c|c|c|c|c|c|c|c|}
\hline & Anaya & & Santillana & & $\mathbf{S M}$ & & Vicens-Vives \\
\hline LGE & $\begin{array}{l}\text { EP axiomático } \\
\text { transformacional }\end{array}$ & & $\begin{array}{l}\text { EP axiomático } \\
\text { transformacional }\end{array}$ & $\mathrm{y}$ & $\begin{array}{l}\text { EP axiomático } \\
\text { transformacional }\end{array}$ & $\mathrm{y}$ & $\begin{array}{l}\text { EP axiomático } \\
\text { transformacional }\end{array}$ \\
\hline LOGSE & $\begin{array}{l}\text { EP inductivo de } \\
\text { caso }\end{array}$ & & $\begin{array}{l}\text { EP axiomático } \\
\text { transformacional }\end{array}$ & $\mathrm{y}$ & $\begin{array}{l}\text { EP axiomático } \\
\text { transformacional }\end{array}$ & $\mathrm{y}$ & $\begin{array}{l}\text { EP axiomático y } \\
\text { transformacional } \\
\text { EP inductivo de } \\
\text { varios casos }\end{array}$ \\
\hline LOE & $\begin{array}{l}\text { EP inductivo de } \\
\text { caso }\end{array}$ & & $\begin{array}{l}\text { EP inductivo de } \\
\text { caso }\end{array}$ & 1 & $\begin{array}{l}\text { EP axiomático } \\
\text { transformacional }\end{array}$ & $\mathrm{y}$ & $\begin{array}{l}\text { EP inductivo de } 1 \\
\text { caso }\end{array}$ \\
\hline
\end{tabular}

Tabla V.6.1.3.4. EP reflejados en los LT de la muestra para el teorema de los valores intermedios de Darboux.

En las justificaciones del teorema de Darboux (Tabla V.6.1.3.4) se observa una utilización generalizada de EP axiomáticos combinados con EP transformacionales, aunque casi todos los LT que usaban un EP inductivo de $1 \mathrm{o}$ varios casos para el teorema de Bolzano continúan usando ese mismo tipo de esquemas para este teorema. Únicamente dos de los textos de Vicens-Vives cambian de tipo de EP con respeto al resultado anterior. Es destacable el hecho de que la demostración axiomática de este teorema se puede considerar de menor dificultad que las otras dos, ya que ésta es consecuencia directa del teorema de Bolzano. Todos los LT que utilizan EP axiomáticos y transformacionales han enunciado el teorema entre $f(a)$ y $f(b)$, por lo que la justificación utilizada es la usual: consideran una función auxiliar, como diferencia de la función de las hipótesis y el valor, $y_{0}$, dado entre $f(a)$ y $f(b)$, y luego aplican el teorema de Bolzano a esta función, $f(x)-y_{0}$. Únicamente un LT ha enunciado el teorema entre el mínimo y el máximo (Vicens-Vives, 2004) pero este LT altera el orden de los teoremas, enunciando el teorema de Darboux después de Weierstrass. Lógicamente, en los textos que presentan el teorema de Darboux entre el mínimo y el máximo, que es más general que entre $f(a)$ y $f(b)$, previamente tienen que haber establecido el teorema de Weierstrass. En caso contrario no habrían tenido en cuenta la función de sistematización. 


\section{V.6.1.4. Comentarios generales a los tres teoremas fuertes de continuidad}

Atendiendo a la evolución en el tiempo, se observa que la tendencia es sustituir los EP axiomáticos y EP transformacionales por EP inductivos de uno o varios casos, al menos en los teoremas más complicados de demostrar, o que requieren más resultados previos. Este hecho es más claro en el teorema de Weierstrass que sólo se enuncia o, como mucho, se complementa con EP inductivo de uno o de varios casos, bien con gráficos o bien con ejemplos algebraicos, a excepción de los textos de LGE y Santillana de LOGSE.

En cuanto a las técnicas empleadas (tipo de enunciado, método, estilo y modo), no se observa gran variación. En el enunciado, aparte de las diferentes formas verbales utilizadas para la misma acción, la estructura lógica utilizada es, sobre todo, de condición suficiente y existencia simple, aunque dicha simplicidad no se expresa siempre de manera específica (no se indica que existe al menos uno). También existen varios enunciados en los que las hipótesis y tesis están mezcladas y no se distinguen únicamente por forma del enunciado. Para el análisis del método, estilo y modo utilizados, se puede establecer una división: en primer lugar, las justificaciones tipo EP axiomático o transformacional $\mathrm{y}$, en segundo, las que consideran EP inductivos de uno o varios casos (no se consideran los EP0 porque en las ausencias de justificación no se puede encontrar ni método, ni estilo, ni modo). En general, todos los LT que utilizan EP axiomáticos o transformacionales, con mayor o menor completitud, realizan pruebas similares: en el caso de Bolzano, consideran un razonamiento local utilizando el teorema de conservación de signo en un entorno; en el caso de Darboux, consideran la función auxiliar descrita anteriormente; finalmente, en el caso de Weierstrass, construyen una función que contradice las hipótesis. Por tanto, la clasificación de método, estilo y modo en estos casos es similar: el método utilizado en Bolzano y Weierstrass es la reducción al absurdo (combinado con casos y silogismo) y en el teorema de Darboux el silogismo.

En cuanto al estilo, se utiliza fundamentalmente el del Análisis Matemático (global en el caso de Darboux, local en Bolzano, y global y local en Weierstrass), pero también aparece el algebraico en Darboux y Weierstrass; en cuanto al modo, quizá por la naturaleza de los teoremas, es analítico en todos los casos. La demostración del teorema de Weierstrass, utilizada por Anaya (1989), aunque se 
ha clasificado como EP axiomática y transformacional por el carácter de la misma, como ya se ha indicado, es errónea; su intención es repetir un proceso de razonamiento local similar al efectuado para el teorema de Bolzano, pero la conclusión a la que conduce es una nueva situación con las mismas hipótesis del enunciado únicamente resoluble realizando el razonamiento usual llevado a cabo en la demostración de dicho teorema. Además, considera inmediato para el lector el punto en el que esta justificación falla, por lo que la demostración no sólo no es más clara, como indica el LT, sino que es errónea.

\section{Demostración:}

También aquí vamos a utilizar el método de los intervalos encajados.

Como la función $f$ es continua en $[a, b]$ sus valores forman un conjunto acotado de $\boldsymbol{R}$. El extremo superior de estos valores $f([a, b])$ será un número $M$. Vamos a tratar de cazar un punto $c$ de $[a, b]$ tal que $f(c)=M$. Tomamos $m_{0}$ punto medio de $[a, b]$ y consideramos el extremo superior de los valores de $f$ en $\left[a, m_{0}\right)$ y en $\left[m_{0}, b\right]$. En uno al menos de los dos intervalos este extremo superior es también $M$. A aquel intervalo de los dos en que esto ocurre lo llamamos $\left[a_{1}, b_{1}\right]$. Tomamos $m_{1}$, punto medio de $\left[a_{1}, b_{1}\right]$ y consideramos $\left[a_{1}, m_{1}\right)$ y $\left[m_{1}, b_{1}\right]$ y procedemos igual. Obtenemos una sucesión de intervalos cerrados encajados cuyas longitudes tienden a 0 . El extremo superior de los valores de $f$ en cada uno de ellos es $M$.

La intersección de estos intervalos encajados es un punto $c$. El valor de $f$ en $c$ es $f(c)=M$. Pues si fuera $f(c)<M$ entonces sería $f(x)<M$ en todo un entorno de $c$ y esto está en contradicción con nuestra elección de los intervalos $\left[a_{n}, b_{n}\right]$, ya que dentro de ese entorno de $c$ donde $f(x)<M$ acaban por estar los intervalos $\left[a_{n}, b_{n}\right]$.

Figura V.6.1.4.1. Justificación errónea para el teorema de Weierstrass (Anaya, 1989).

La demostración de forma gráfica de este teorema es la siguiente:

Si $f(a)$ y $f(b)$ tienen distinto signo, los puntos $(a, f(a))$ y $(b, f(b))$ estarán situados uno por debajo y otro por encima del eje $X$. Como la función es continua en todo el intervalo, $f(x)$ describirá una curva que unirá los dos puntos.

Por tanto, dicha curva debe cortar, al menos una vez, al eje $X$, es decir, la función se anula en un punto del intervalo.
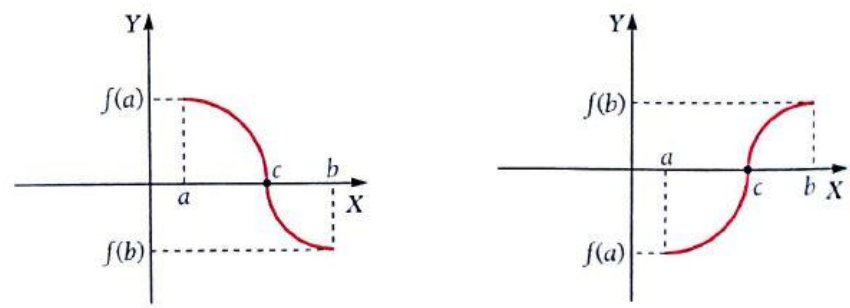

Figura V.6.1.4.2. Utilización de coordenadas en la justificación del teorema de Bolzano en Santillana (2009).

En general, los LT que utilizan EP inductivos de uno o varios casos recurren al estilo gráfico, aunque en ocasiones lo complementan con el algebraico, y en el caso de Santillana (2009) utiliza coordenadas para justificar los teoremas (Figura V.6.1.4.2). Aunque no se trate de demostraciones propiamente dichas, los EP 
inductivos en los que se utilizan gráficas cumplen mejor su función de convencer al lector que aquellos que muestran un EP axiomáticos de manera incompleta. Desde la perspectiva de Balacheff (1987) se trataría de un ejemplo genérico. Sin embargo, en este trabajo no se considera esta clasificación porque se entiende que los Esquemas de Prueba se adaptan mejor al análisis que se está realizando.

En cuanto a las funciones de la demostración, ya se ha indicado que existe un error de sistematización en los textos que alteran el orden usual de estos tres resultados: SM (2010), que considera que Darboux es una generalización de Bolzano y Vicens Vives (2004), que considera que Bolzano es una consecuencia del $2^{\circ}$ teorema de Weierstrass (teorema de los valores intermedios entre el mínimo y el máximo). El resto de los LT consideran que el teorema de Darboux es consecuencia de Bolzano, aunque algunos (Vicens-Vives, 1979; SM, 1980; Santillana, 1981; Santillana, 1997; Vicens Vives, 1999; Vicens Vives, 2004; Santillana, 2009) no lo indican. Por lo demás, las únicas funciones de la demostración que se aprecian en todos los LT son las de comunicación y verificación. Aunque los textos no lo indican, algunos de ellos cumplen también la función de descubrimiento, más concretamente, en dos casos (SM, 2001 y SM, 2010), ya que la sucesión de intervalos encajados que se construye en la demostración del teorema de Bolzano constituye la regla de bisección para calcular los ceros de una función de forma aproximada. En la Figura V.6.1.4.3 vemos un ejemplo de dicha función de descubrimiento.
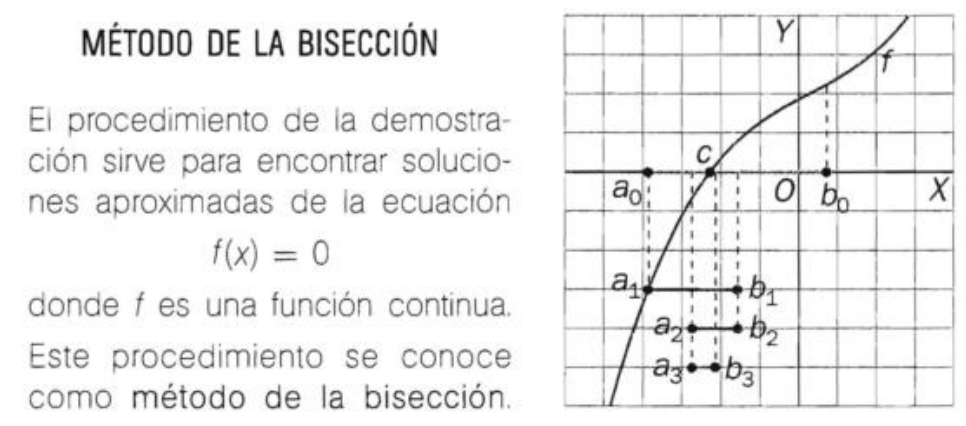

Figura V.6.1.4.3. Función de descubrimiento en el LT de SM (2010).

Como ya se indicó al principio del epígrafe, en la discusión sobre los enunciados y nombres propuestos, en los LT, Ibañes y Ortega (2001a) establecen que los esquemas de prueba dependen de los enunciados y, por esta razón se hace un breve análisis de las acciones verbales de los mismos y del simbolismo presente. El sistema de representación más habitual es el verbal, combinado con algunos símbolos básicos matemáticos, que no se explican, sino que se utilizan de forma 
rutinaria. No se utilizan ni signos de implicaciones, ni de cuantificadores universales, ni existenciales. Por otra parte, se encuentran numerosas acciones verbales diferentes para el mismo teorema: "existe" y "se anula" en el caso de Bolzano, "alcanza", "existe" y "toma" para Darboux y "alcanza", "admite", "existen", "tiene" y "se cumple que" para Weierstrass. La significación de las acciones verbales es muy diferente y, nuevamente, esto contribuye a confusión para los alumnos en sus estudios posteriores. Por ejemplo, existir significa ser real y verdadero, alcanzar tiene muchas acepciones y la más repetida es llegar a tocar o juntarse con algo, tomar tiene muchas más y la que mejor se ajusta es adquirir, admitir significa tener cierta cabida... Esta diversidad de acciones verbales conlleva a errores por la confusión semántica asociada (Socas, 2007).

Todos los LT utilizan gráficas funcionales de forma recurrente en todos los teoremas, a excepción del teorema de Weierstrass en aquellos textos que se limitan a enunciarlo (EP0). La utilización de estas gráficas ilustra o clarifica la situación descrita en el teorema, pero es conveniente ser cuidadoso en la elección que se realiza de éstas. Aunque Socas (2007) relaciona algunos errores con la presencia de esquemas cognitivos inadecuados, Arce y Ortega (2013) detectan que la imprecisión en los trazados de gráficas por parte de los alumnos no representan correctamente las propiedades de las funciones representadas y, por tanto, son fuente de dificultades para el aprendizaje. Aunque en este caso las gráficas estudiadas no corresponden a las realizadas por los estudiantes, dado que se encuentran en una de sus herramientas de estudio, el LT, pueden originar dichas dificultades asociadas a la percepción de estas gráficas, por lo que dichas representaciones deben ser elegidas de forma cuidadosa. En los textos analizados encontramos algunos ejemplos destacables de mala construcción en las representaciones gráficas que ilustran los teoremas. Por ejemplo, en las Figuras V.6.1.2.1 y V.6.1.4.2 observamos que las funciones representadas inducen a pensar que, por facilidad de su trazado, están formadas por cuartos de circunferencia y semielipses. Tales gráficas son poco representativas de funciones generales y pueden confundir a los alumnos, atribuyendo a las funciones características propias de estos ejemplos.

Otro ejemplo de mala elección de una gráfica de una función es la que encontramos en la Figura V.6.1.4.4 (Vicens-Vives, 1979), en la que se muestran varios errores: los puntos que en el enunciado se consideran dentro del intervalo, en la gráfica se representan fuera del mismo; una de las desigualdades está mal 
escrita, $f\left(x_{1}\right)<\eta<f\left(x_{1}\right)$, aunque creemos que puede ser un error tipográfico, pero, en general, la gráfica reproduce una situación diferente a la del enunciado del teorema.

TEOREMA (del valor intermedio): Si $f:[a, b] \rightarrow \mathbb{R}$ es continua, $y$ si $x_{1}<x_{2}$ son puntos de $[a, b]$ tales que $f\left(x_{1}\right) \neq f\left(x_{2}\right)$, entonces $f$ alcanza todos los valores comprendidos entre $f\left(x_{1}\right)$ y $f\left(x_{2}\right)$ una vez por lo menos.

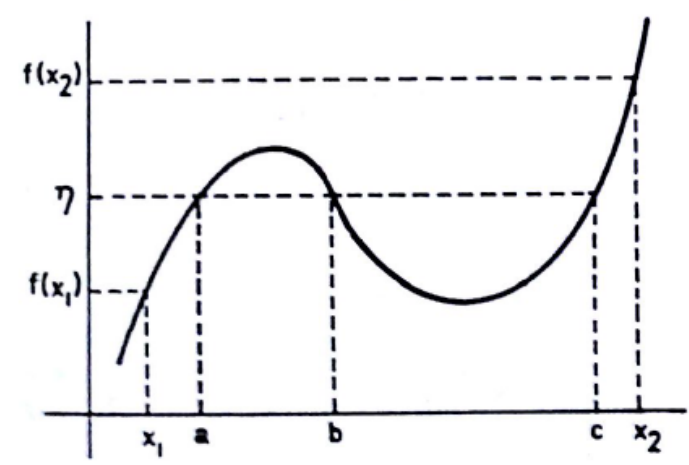

$$
\begin{gathered}
f(a)=f(b)=f(c)=\eta \\
f\left(x_{1}\right)<\eta<f\left(x_{1}\right)
\end{gathered}
$$

Figura V.6.1.4.4. Errores en la representación gráfica del teorema de Darboux en VicensVives (1979).

En el caso de Bolzano se observa que todos los LT complementan sus justificaciones con gráficas en las que se refleja la situación básica descrita en el enunciado, aunque en muchos casos dichas gráficas se restringen a funciones monótonas con un único punto de corte, como se muestra en la Figura V.6.1.4.5. No obstante, tres de los trece LT analizados sí que utilizan gráficas (Figura 6) para mostrar tanto la necesidad de las hipótesis como la posibilidad de existencia de más de un punto en el que la función se anula, lo que refuerza la interpretación más general del teorema y el carácter justificativo del EP utilizado (Santillana, 1981), cuyo esquema de prueba es axiomático (Tabla V.6.1.1.4), es decir, se trata de una demostración.

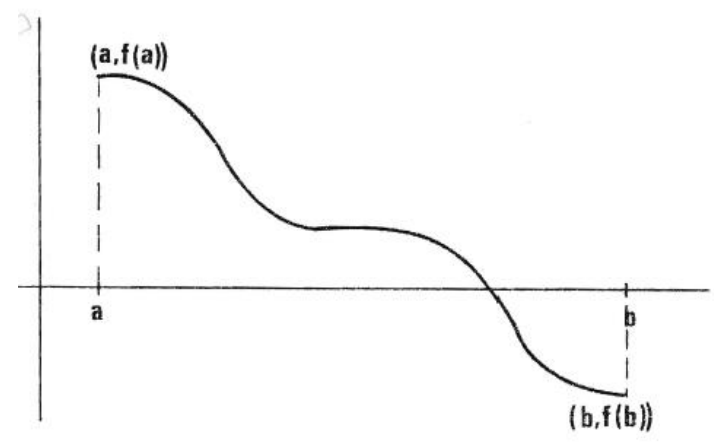

Figura V.6.1.4.5. Ilustración del teorema de Bolzano en el LT de SM (1980). 
Destaca el caso de Darboux donde, en siete de los trece LT analizados, las funciones representadas son o bien monótonas, o bien las imágenes de los extremos del intervalo coinciden con el mínimo y el máximo de la función (Figuras V.6.1.4.7 y V.6.1.4.8). Este hecho explica el que se considere el enunciado de Darboux entre $f(a)$ y $f(b)$ en lugar de entre el mínimo y el máximo de la función (más fuerte), y permite que se enuncie Weierstrass después de Darboux, pero el enunciado puede dar lugar a interpretaciones erróneas. Además, de estas gráficas los alumnos pueden inferir que $f(a)$ es diferente de $f(b)$, situación que no tiene por qué ser así. Por tanto, sería más adecuado enunciar Darboux después de establecer Weierstrass y considerar cualquier valor entre el mínimo y el máximo.

ii) El teorema de Bolzano asegura la existencia de tal $\zeta$, pero no implica que $\xi$ sea único, como se puede observar en la figura 6 .

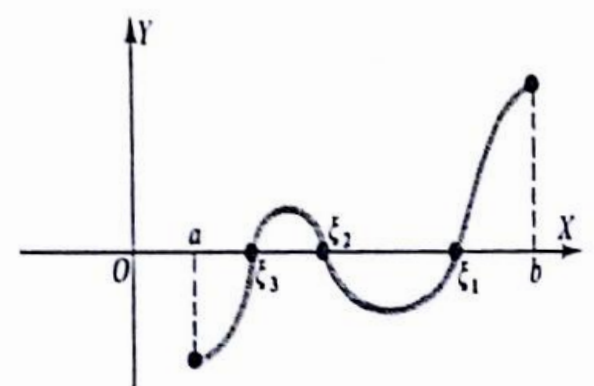

(Fig. 6)

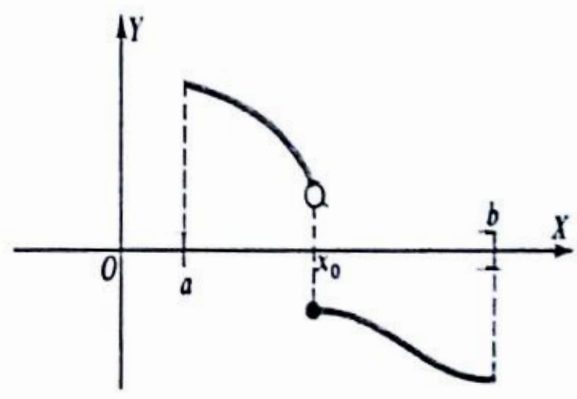

(Fig. 7)

iii) Sin la hipótesis de la continuidad de $f$, el teorema de Bolzano puede ser falso, como indica la figura 7.

$$
\begin{aligned}
& f(a)>0 \\
& f(b)<0 \\
& f(x) \neq 0 \text { para todo } x \in[a, b] \quad\left(f \text { no es continua en } x_{0}\right)
\end{aligned}
$$

Figura V.6.1.4.6. Santillana (1981) representa gráficamente tanto la posibilidad de que exista más de un punto, como la necesidad de las hipótesis para el teorema de Bolzano.

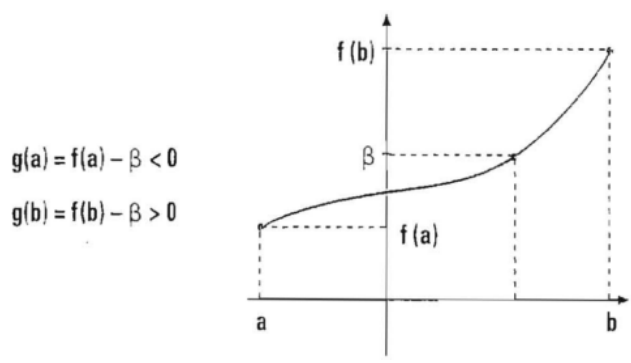

Figura V.6.1.4.7. Gráfica para el Teorema de Darboux en Vicens Vives (1999). 


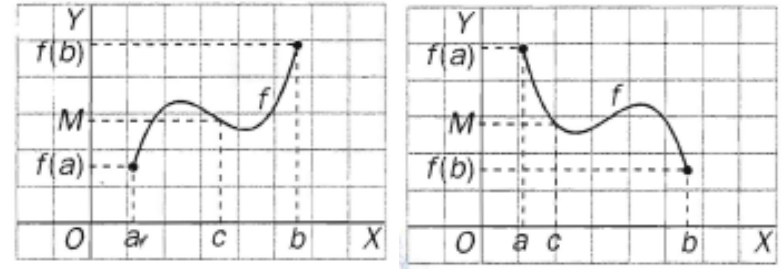

Figura V.6.1.4.8. Gráficas para el Teorema de Darboux en SM (2010).

En aquellos textos que contienen algún tipo de justificación de los teoremas, no se reflexiona sobre el procedimiento que realizan, aunque, cuando se trata de una demostración, en algunos casos sí que la distinguen del enunciado porque la etiquetan o utilizan tipografías diferentes; tampoco se explica globalmente el proceso utilizado, ni se señalan otras vías de justificación. En ocasiones, la prueba se inicia enunciando el resultado que se va a aplicar, pero sin indicar tal comienzo.

\section{V.6.2. Otros teoremas sobre la continuidad en entornos e intervalos}

Ya se ha indicado anteriormente que en los LT se presentan otros teoremas que complementan a los tres teoremas fuertes de continuidad. Estos resultados pueden ser teoremas que se establecen previamente para utilizarlos en las demostraciones de los tres teoremas fuertes de continuidad y facilitar por tanto dicha justificación, consecuencias posteriores que se deducen de alguno los tres teoremas fuertes de continuidad, aplicaciones a casos concretos en los que se busca proponer al alumno otras situaciones en las que aplicar dichos teoremas o resultados que amplían la teoría aunque no estén directamente relacionados con los teoremas de Bolzano, Darboux y Weierstrass. En este trabajo no hemos considerado los enunciados de ejercicios de demostrar resultados sobre funciones concretas o aplicar los teoremas descritos, que generalmente aparecen en los apartados de ejercicios resueltos, dado que este estudio se centra sobre todo en la parte de contenidos de los LT. Sí se consideran aquellas demostraciones o resultados que, aunque aparezcan en la parte de ejercicios resueltos, son resultados generales, y no ejemplos sobre funciones concretas. No obstante, se deja como problema abierto para el futuro, dado que se pueden considerar oportunidades de demostrar para el alumno. 


\begin{tabular}{|c|c|}
\hline Teoremas & Enunciado \\
\hline T1 & $\begin{array}{l}\text { Si } f(x) \text { es una función continua en } p \text { y cumple que } f(p)>k \text { para un número real } k \text {, entonces } \\
\text { existe un entorno de } p \text { tal que } f(x)>k \text { para todo } x \text { perteneciente a dicho entorno. }\end{array}$ \\
\hline $\mathbf{T 2}$ & $\begin{array}{l}\text { Teorema de conservación de signo en un entorno: si } f(x) \text { es una función continua en } p \text {, } \\
\text { entonces existe un entorno de } p \text { tal que } f(x) \text { tiene el mismo signo que } f(p) \text { para todo } x \text { de } \\
\text { dicho entorno. }\end{array}$ \\
\hline T3 & $\begin{array}{l}\text { Si una función toma valores positivos y negativos en cualquier entorno de un unto } x_{0} \mathrm{y} \text {, } \\
\text { además, es continua en él, la función se anula en } x_{0} \text {. }\end{array}$ \\
\hline T4 & Si $f(x)$ es una función continua en $p$ entonces está acotada en un entorno de $p$. \\
\hline T5 & $\begin{array}{l}\text { Si una función } f \text { es continua uniforme en un intervalo }[a, b] \text {, entonces } f \text { es continua en }[a \text {, } \\
b] \text {. }\end{array}$ \\
\hline T6 & $\begin{array}{l}\text { Teorema: si una función es continua en un intervalo cerrado }[a, b] \text {, entonces está acotada } \\
\text { en }[a, b] \text {. }\end{array}$ \\
\hline T7 & $\begin{array}{l}\text { Teorema del punto fijo: sea } f \text { una función en }[a, b] \text { que verifica que para cualquier punto } x \\
\text { del intervalo }[a, b] \text { su imagen pertenece también al intervalo }[a, b] \text {. Demuestra que existe } \\
\text { un punto c de dicho intervalo donde } f(c)=c \text {. }\end{array}$ \\
\hline T8 & $\begin{array}{l}\text { La imagen de un intervalo cerrado por una función continua es un intervalo cerrado o un } \\
\text { punto. }\end{array}$ \\
\hline T9 & $\begin{array}{l}\text { Si } f(x) \text { y } g(x) \text { son dos funciones continuas en }[a, b] \text { y cumplen que } f(a)>g(a) \text { y } f(b)<g(b) \text {, } \\
\text { entonces existe un punto } c \text { perteneciente a }(a, b) \text { tal que } f(c)=g(c) \text {. }\end{array}$ \\
\hline T10 & $\begin{array}{l}((] a, b[),+, \cdot \mathbb{R}) \text { es un espacio vectorial real que se llama el espacio vectorial real de las } \\
\text { funciones continuas en }] a, b[\text {. }\end{array}$ \\
\hline T11 & $\begin{array}{l}((] a, b[),+, \cdot) \text { es un anillo con unidad que se llama el anillo de las funciones continuas en el } \\
\text { intervalo }] a, b[\text {. }\end{array}$ \\
\hline T12 & $\begin{array}{l}\text { Lema: sea }[a, b] \text { un intervalo cerrado que está contenido en la unión de una familia de } \\
\text { intervalos abiertos }] \alpha_{\mathrm{i}}, \beta_{\mathrm{i}}[\text {; entonces existe un conjunto finito de dichos intervalos tales que } \\
{[a, b] \text { está contenido en su unión. }}\end{array}$ \\
\hline T13 & $\begin{array}{l}\text { Teorema de Heine: si } f(x) \text { es una función continua en }[a, b] \text {, entonces } f(x) \text { es } \\
\text { uniformemente continua en }[a, b] \text {. }\end{array}$ \\
\hline
\end{tabular}

Tabla V.6.2.1. Otros teoremas relacionados con la continuidad que se justifican en los LT.

Atendiendo a los enunciados de la Tabla V.6.2.1, éstos se pueden agrupar en función del tipo de información que dan. Por ejemplo, hay dos teoremas que determinan una estructura del conjunto de funciones continuas con algunas operaciones, otros relacionados con la continuidad uniforme... Los grupos que se han establecido son los siguientes:

- Enunciados que, a partir de la continuidad en un punto, establecen conclusiones en entornos de dicho punto: T1, T2, T3 y T4.

- Enunciados que, a partir de la información en un intervalo, establecen conclusiones sobre dicho intervalo: T6, T7, T8 y T9.

- Resultados que establecen una estructura con el conjunto de funciones continuas en un intervalo: T10 y T11.

- Resultados relacionados con la continuidad uniforme: T5, T13 y T12. En realidad, el T12 no está íntimamente relacionado con la continuidad 
uniforme, pero el LT que lo establece lo hace antes del teorema de Heine, pues lo necesita para establecer este último.

\begin{tabular}{|c|c|c|c|c|c|c|c|c|c|c|c|c|c|c|}
\hline Periodo & LT & T1 & $\mathbf{T} 2$ & T3 & T4 & T5 & T6 & T7 & T8 & T9 & T10 & T11 & T12 & T13 \\
\hline $2^{\circ} \mathrm{BUP}$ & Sant. (1976) & & & & & & & & & & $\checkmark$ & $\checkmark$ & & \\
\hline$\overline{\mathrm{COU}}$ & Anaya (1989) & & $\checkmark$ & & $\checkmark$ & & $\checkmark$ & & & & & & & \\
\hline & Sant. (1981) & & $\checkmark$ & & $\checkmark$ & $\checkmark$ & $\checkmark$ & & $\checkmark$ & & & & $\checkmark$ & $\checkmark$ \\
\hline & SM (1980) & $\checkmark$ & $\checkmark$ & $\checkmark$ & $\checkmark$ & $\checkmark$ & $\checkmark$ & & & & & & & \\
\hline & VV (1979) & & $\checkmark$ & & & & $\checkmark$ & & $\checkmark$ & & & & & \\
\hline \multirow{5}{*}{ LOGSE $2^{\circ}$} & Anaya (2003) & & & & & & & & & $\checkmark$ & & & & \\
\hline & $\begin{array}{l}\text { Sant. (1997) } \\
\text { (1997. }\end{array}$ & & $\checkmark$ & & $\checkmark$ & & & & $\checkmark$ & & & & & \\
\hline & SM (2001) & $\checkmark$ & $\checkmark$ & & & & $\checkmark$ & & & & & & & \\
\hline & VV (1999) & & & & & & & & & & & & & \\
\hline & VV (2004) & & & & & & $\checkmark$ & & & & & & & \\
\hline \multirow[t]{4}{*}{$\overline{\mathrm{LOE}}$} & Anaya (2009) & & & & & & & & & $\checkmark$ & & & & \\
\hline & $\begin{array}{l}\text { Sant. (2009) } \\
\end{array}$ & & & & & & & & & & & & & \\
\hline & SM (2010) & & & & & & & $\checkmark$ & & & & & & \\
\hline & VV (2009) & & & & & & & & & $\checkmark$ & & & & \\
\hline
\end{tabular}

Tabla V.6.2.2. LT que justifican los resultados enunciados en la Tabla V.6.2.1.

Estos resultados, al considerarse complementarios a los tres teoremas fuertes, no se enuncian y justifican en todos los LT, depende de la profundidad con la que los autores hayan decidido tratar la continuidad. También puede ocurrir que alguno de esos resultados se justifique en las propias demostraciones de los teoremas que los necesitan. En concreto, los LT que los enuncian y justifican como resultados independientes son los que aparecen en la Tabla V.6.2.2. Se observa que la mayoría de justificaciones se sitúan en los LT de la LGE (21 justificaciones), descendiendo drásticamente en la LOGSE (8 justificaciones) y en la LOE (3 justificaciones). Este dato apunta en la misma línea que el descenso de justificaciones en las propiedades y operaciones con funciones continuas, y es que existe un descenso en el número de teoremas que se enuncian y justifican, es decir, en la profundidad con que se trabaja la continuidad de funciones. Se observa un cambio con respecto a las propiedades y operaciones de funciones continuas, y es que éstas últimas se justificaban principalmente en $2^{\circ}$ de BUP de la LGE, y, sin embargo, estos teoremas se justifican en COU. Hay que señalar que algunos de los resultados aparecen sólo en un LT, es decir, que un equipo de editores ha decidido incorporarlo a la teoría de su LT, pero que no es un contenido que se trabaje de forma general en estos niveles educativos. En concreto, se trata de los resultados que establecen estructuras de anillo y espacio vectorial sobre el conjunto de funciones continuas en un intervalo (T10 y T11), que sólo aparecen en el LT de Santillana (1976) de $2^{\circ}$ de BUP, y la continuidad 
uniforme (T5, T13 y T12), que sólo aparece en dos LT de COU, Santillana (1988) y SM (1980).

A continuación se muestra el análisis de los enunciados que se han justificado en los LT que no son los tres teoremas fuertes de continuidad.

- T1: Si $\mathrm{f}(\mathrm{x})$ es una función continua en $\mathrm{p}$ y cumple que $\mathrm{f}(\mathrm{p})>\mathrm{k}$ para un número real $\mathrm{k}$, entonces existe un entorno de $\mathrm{p}$ tal que $\mathrm{f}(\mathrm{x})>\mathrm{k}$ para todo $\mathrm{x}$ perteneciente a dicho entorno.

Este teorema se justifica en los LT de SM (1980), de COU, y de SM (2001), de $2^{\circ}$ de Bachillerato. El hecho de que ambos textos sean de la misma editorial muestra cierta continuidad en la política adoptada por ésta, ya que no se encuentra en otros LT. En ambos casos, la justificación utilizada se basa en la aplicación del teorema de conservación de signo (T2) a la función auxiliar $g(x)=f(x)-k$. Lo hemos clasificado como EP transformacional por la construcción de esta función auxiliar, si bien tiene una parte axiomática, que es la aplicación del teorema de conservación de signo. En ambos textos se enuncia en forma de condición suficiente, aunque se omite el "entonces", pero en SM (1980) se establece como un único resultado (para el caso $f(x)>k$ y $f(x)<k$ ) y en el SM (2001) se enuncia como dos resultados aunque ambos en el mismo párrafo compartiendo algunas hipótesis comunes ( $f$ continua en $p, k$ un número real). En ambos casos de justifica sólo la primera desigualdad, indicando que la otra se haría de forma análoga. El método utilizado es el silogismo, el estilo, del análisis matemático global, y el modo, analítico.

En relación a las funciones de la demostración, se reflejan tanto la función de verificación como la de comunicación, pero la de explicación sólo se atisba en el LT de SM (2001), ya que ilustra la situación del teorema y justifica la elección de la función auxiliar (trasladar la original para que se adapte a las hipótesis del teorema de conservación de signo).

En cuanto al reconocimiento de procesos, el LT de SM (1980) no identifica la justificación como tal, y sólo existe una diferencia tipográfica entre enunciado y justificación. Sin embargo, aunque tampoco se etiqueta el proceso en SM (2001), sí se hace alguna referencia a "demostrar" en el texto. No se indican consecuencias, ni de haber justificado el teorema ni de los resultados, aunque en el SM (2001) se presenta un ejemplo para justificar la necesidad de la hipótesis 
de continuidad en el teorema. No se explica globalmente el proceso, ni se señalan otras vías de justificación.

En ambos textos se utilizan los sistemas de representación verbal y simbólico, aunque en el SM (2001) también se utiliza el gráfico. No se explican las expresiones utilizadas, por ser utilizadas constantemente en los textos.

- T2: Teorema de conservación de signo en un entorno: si $\mathrm{f}(\mathrm{x})$ es una función continua en $\mathrm{p}$, entonces existe un entorno de $\mathrm{p}$ tal que $\mathrm{f}(\mathrm{x})$ tiene el mismo signo que $\mathrm{f}(\mathrm{p})$ para todo $\mathrm{x}$ de dicho entorno.

Este teorema es uno de los más enunciados y justificados de los que acompañan a los tres teoremas fuertes de continuidad, pues es necesario en la discusión de la reducción al absurdo de la demostración del teorema de Bolzano. Se encuentra en todos los LT de COU y en dos LT de $2^{\circ}$ de Bachillerato de la LOGSE, Santillana (1997) y SM (2001). Este teorema aparece en tantos LT debido a que es un teorema necesario en la prueba del teorema de Bolzano y, de hecho, los LT que lo justifican son precisamente aquellos que usan un EP axiomático para el teorema de Bolzano. Únicamente dos LT que presentan EP axiomático para establecer este teorema no justifican el teorema de conservación de signo: SM (2010), que se limita a enunciarlo sin justificarlo, pero lo utiliza en el teorema de Bolzano, y Vicens-Vives (2009), aunque no lo haya utilizado, lo aplica en la demostración del mencionado teorema, quizás porque lo consideren un resultado evidente desde un punto de vista intuitivo.

En todos los LT se presenta un EP axiomático, en el que se selecciona $\varepsilon$ para que en el entorno se conserve el signo (se han encontrado dos selecciones diferentes en los libros: $\varepsilon$ tal que $0<\varepsilon<f(p)$ o $\varepsilon=f(p) / 2)$. Los enunciados son similares en todos los LT, aunque algunos hablan de entornos y otros de intervalos abiertos (notaciones equivalentes), y todos ellos enunciados de condición suficiente. La justificación se hace mediante la construcción del intervalo en el que se verifica e teorema (selección del $\varepsilon$ adecuado), con un estilo del análisis matemático local y en modo analítico.

En relación a las funciones de la demostración, todos los LT consideran las funciones de verificación y de comunicación. Las más explicativas son las de Anaya 81987) y Santillana (1997), pues acompañan la justificación de gráficas que ilustran la situación descrita en el teorema lo que contribuye a convencerse de su veracidad. 
En cuanto al resto de características, son las mismas que las que presentan otras justificaciones (como la del teorema de Bolzano) en estos mismos LT por lo que no abundamos en ellas.

- T3: Si una función toma valores positivos y negativos en cualquier entorno de un punto $\mathrm{x}_{0} y$, además, es continua en él, la función se anula en $\mathrm{x}_{0}$.

Este resultado se encuentra justificado únicamente en el LT de SM (1980) de COU. Aparece junto con los teoremas T1, T2 y T4, en el apartado de propiedades generales de las funciones continuas. En este resultado se ha utilizado un EP axiomático que consiste en la aplicación directa del teorema T2. El tipo de enunciado es de condición suficiente, aunque se ha omitido el "entonces". El método utilizado es el silogismo, el estilo, del análisis matemático global, y el modo, analítico.

Las funciones son las de verificación y comunicación. No se aprecia la función de explicación, pues la prueba es muy escueta (se limita a decir que si no se cumpliera la tesis, por el teorema anterior se contradice la hipótesis). No se utilizan etiquetas para denotar la demostración, y la distinción con el enunciado es únicamente tipográfica. No se explica globalmente el proceso, ni se señalan otras vías de justificación, ni se indican consecuencias (salvo la aplicación del teorema anterior). El sistema de representación utilizado es verbal.

- T4: Si $\mathrm{f}(\mathrm{x})$ es una función continua en $\mathrm{p}$ entonces está acotada en un entorno de $\mathrm{p}$.

Este resultado es muy similar al que se enuncia en T6, pero un poco más débil ya que se enuncia en un entorno de un punto, y sólo se requiere de la continuidad de la función en dicho punto. Se utiliza para justificar T6 y, por tanto, es necesario para la justificación del teorema de Weierstrass, pero al ser más débil que T6, no aparece justificado en tantos LT (sólo en 4). Se justifica en tres de los LT de COU, Anaya (1989), Santillana (1981) y SM (1980) y en el LT de $2^{\circ}$ de Bachillerato de la LOGSE, Santillana (1997).

Todos los LT utilizan un EP axiomático, con un método constructivo (crean un intervalo en el que está acotada la función fijando $\varepsilon=1$ ), con un estilo del análisis matemático local y en modo directo, pues aplican directamente la definición de continuidad en un punto. No obstante, aunque la prueba utilizada sea 
esencialmente la misma, no todos los LT son igual de explícitos: Santillana (1997) reescribe la definición en términos de límites y la traduce a entornos para construir el intervalo, Santillana (1981) la expresa en términos del valor absoluto y la reescribe como una desigualdad, de donde se establecen las cotas, SM (1980) primero reescribe las definiciones de forma general y luego fija $\varepsilon=1$ y Anaya (1989) presenta dos líneas en las que establece la desigualdad (pero no explicita que lo deduce de la definición).

Estas distintas presentaciones influyen en la función de explicación. Un aspecto a mejorar para contribuir con dicha explicación es que los LT deberían presentar las justificaciones que contienen tantos símbolos matemáticos de forma más espaciada, y no "a texto corrido". La abundancia de símbolos dificulta seguir la línea argumental. En todos los casos se verifica la función de justificación y comunicación.

En relación al reconocimiento de procesos, dos de los LT (Santillana, 1981 y 1997) etiquetan la justificación como "demostración" y los otros dos se limitan a un cambio en la tipografía. No se hace alusión a consecuencias de haber demostrado las justificaciones, ni tampoco del propio resultado, aunque se utiliza más adelante en el teorema de Bolzano. Tampoco se describe el procedimiento globalmente, ni se señalan otras vías de justificación.

En cuanto a los sistemas de representación, ya se ha mencionado que abunda el lenguaje verbal y el simbólico, pero uno de los LT también utilizan el gráfico, y muestran gráficas de funciones continuas y la banda en la que están acotadas (Anaya, 1987).

- T5: Si una función $\mathrm{f}$ es continua uniforme en un intervalo [a, b], entonces $\mathrm{f}$ es continua en $[\mathrm{a}, \mathrm{b}]$.

Este resultado sólo se justifica en los LT en los que se considera la continuidad uniforme, es decir, en los LT de Santillana (1981) y SM (1980), ambos de COU. Aunque ambos enuncian también el teorema de Heine, sólo el ejemplar de Santillana (1981) lo justifica, como veremos más adelante.

En ambos casos la justificación se basa en aplicar la definición de continuidad uniforme a cualquier punto del intervalo, dejando fijo únicamente uno, y sale la definición de continuidad. En ambos casos el enunciado es de condición 
suficiente, el método es el silogismo, el estilo, del análisis matemático global y el modo, analítico.

Debido a la notación no son justificaciones muy explicativas, ya que aparecen varios puntos del intervalo, unos fijos y otros no. Sí que se aprecian las funciones de verificación y comunicación.

En uno de los LT, SM (1980), sí que se reconoce el proceso (se indica "para demostrar") pero en ninguno se etiqueta la demostración como tal, y sólo se distingue del enunciado por un cambio tipográfico. En cuanto a las consecuencias, en ambos LT se indica que el recíproco no es cierto en general, aunque sí bajo ciertas condiciones, lo que les lleva al teorema de Heine. Los sistemas de representación utilizados son el verbal y el simbólico, y no se explican las expresiones pues son utilizadas usualmente en los LT. No se describe el proceso de forma general, ni se señalan otras vías de justificación.

- T6: Teorema: si una función es continua en un intervalo cerrado [a, b], entonces está acotada en [a, b].

Este teorema aparece justificado en más libros que los otros teoremas expuestos en esta sección, al igual que el teorema de conservación de signo, dado que es necesario para la justificación del teorema de Weierstrass. Los libros en los que se muestra su justificación son todos los de COU, y dos de $2^{\circ}$ de Bachillerato de la LOGSE, el de SM (2001) y el de Vicens-Vives (2004).

Todos los LT, excepto el de Vicens-Vives (2004), utilizan un EP axiomático, pero no utilizan el mismo. Los LT de Santillana (1981) y Vicens-Vives (1979) presentan una demostración con el método de reducción al absurdo y construyendo una sucesión de intervalos encajados hasta llegar a una contradicción. Por su parte, el resto de LT construye el conjunto de intervalos de la forma $[a, x]$ tales que en ellos $f$ está acotada y demuestra que es no vacío y que está acotado superiormente, llegando a que $f$ está acotada en $[a, b]$. Aunque ambos EP son axiomáticos, cambian las técnicas empleadas en su justificación. En ambos, el estilo es del análisis matemático local y el modo, analítico. Por su parte, el LT de Vicens-Vives (2004) utiliza un EP inductivo de 1 caso, de estilo gráfico, aunque la acompaña de una interpretación de su significado de forma verbal. 
Otro LT de la muestra, Santillana (1997), aunque no enuncia el teorema como tal, lo demuestra en la parte de Ejercicios y problemas resueltos como parte de la demostración del teorema de Weierstrass, utilizando también la prueba de los intervalos encajados.

En cuanto a las funciones de la demostración, ambos tipos de EP axiomáticos cumplen las funciones de verificación y comunicación. De las pruebas de intervalos encajados, la de SM (2001), que se presenta en un apartado de Procesos y técnicas (pp. 258) destinado a mostrar el método de reducción al absurdo, es la más explicativa, dado que no sólo explica la demostración sino el porqué de los pasos que da, y la acompaña de una ilustración en la que se muestra el encaje de intervalos. Sin embargo, el resto de justificaciones se expresan sólo en los sistemas de representación verbal y simbólico, y resultan más arduas de comprender. Por su parte, de las pruebas en las que se utiliza el conjunto de los puntos $x$ tales que $f$ está acotada en $[a, x]$, la más explicativa es la de Santillana (1981) ya que primero indica que es lo que va a hacer en la demostración (probar que el conjunto es no vacío y que está acotado) y luego separa cada proceso. No obstante, no es una justificación muy explicativa pues requiere de un manejo de las técnicas matemáticas que no son triviales.

En cuanto al LT de Vicens-Vives (2004), no se aprecia una intención de justificar, sino que las explicaciones versan sobre la interpretación del teorema y las condiciones que se necesitan para que se verifique.

El resto de aspectos se asemejan a los que presentan estos textos en otros teoremas justificados en ellos, por lo que no abundamos en esta sección.

- T7: Teorema del punto fijo: sea $\mathrm{f}$ una función en [a, b] que verifica que para cualquier punto $\mathrm{x}$ del intervalo $[\mathrm{a}, \mathrm{b}]$ su imagen pertenece también al intervalo $[\mathrm{a}, \mathrm{b}]$. Demuestra que existe un punto $\mathrm{c}$ de dicho intervalo donde $\mathrm{f}(\mathrm{c})=\mathrm{c}$.

Este resultado aparece en el apartado de Ejercicios resueltos (pp. 237) del LT de SM (2010). En el enunciado se le pide explícitamente al alumno que demuestre, y el enunciado se titula teorema del punto fijo, razones por las cuales lo hemos considerado dentro de los enunciados a analizar. El EP utilizado es transformacional y axiomático: la parte transformacional viene de la función auxiliar considerada $(g(x)=f(x)-x)$ y la parte axiomática, de la aplicación del teorema de Bolzano. Es una justificación que reúne las mismas características 
que la presentada para el teorema de los valores intermedios en este LT, excepto que en este caso no se muestra una gráfica que ilustre el teorema. Aunque es un teorema sencillo, sobre todo, después de haber trabajado el teorema de Bolzano y el teorema de los valores intermedios, consideramos que sería útil mostrar una representación gráfica acompañando el resultado.

- T8: La imagen de un intervalo cerrado por una función continua es un intervalo cerrado o un punto.

Este teorema se enuncia en varios LT, como consecuencia del teorema de Weierstrass, pero únicamente se justifica en tres LT: en Santillana (1981) y Vicens-Vives (1979), de COU, y en Santillana (1997), de $2^{\circ}$ de Bachillerato de la LOGSE. En los tres se utiliza un EP axiomático, basado en la aplicación del teorema de Weierstrass. No obstante, no todos los LT son igual de explícitos en la demostración: por ejemplo, los dos LT de COU indican que aplican tanto el teorema de Weierstrass como el del valor medio, pero el LT de la LOGSE sólo menciona que aplica el teorema de Weierstrass. En todos los casos, son justificaciones demasiado escuetas y menos evidentes de lo que parecen mostrar los LT (aunque la situación descrita en el teorema sea evidente) pero deberían ser más explícitos en la justificación y acompañarla de alguna gráfica.

En este resultado hay diferencia en los enunciados mostrados por los tres LT: por ejemplo, el Santillana (1981) lo enuncia como condición suficiente, el LT de Vicens-Vives (1979) también, pero sólo menciona el intervalo cerrado y en la justificación considera que un punto $\{C\}=[C, C]$ es un intervalo cerrado (para la imagen de una función constante), y el Santillana (1997) lo enuncia con hipótesis y tesis mezcladas. En cuanto al método utilizado, en todos los LT se distingue un estudio por casos y silogismo, el estilo es del análisis matemático global y el modo, analítico.

Ya hemos mencionado que en ningún caso se trata de justificaciones explicativas, pero sí cumplen la función de verificación y comunicación. En cuanto al resto de características, como hemos mencionado en otros casos, reúnen las mismas características que las que los mismos LT exhiben para otros teoremas que demuestran, por lo que no abundamos en este aspecto.

- T9: Si $\mathrm{f}(\mathrm{x})$ y $\mathrm{g}(\mathrm{x})$ son dos funciones continuas en [a, $\mathrm{b}]$ y cumplen que $\mathrm{f}(\mathrm{a})>\mathrm{g}(\mathrm{a})$ y $\mathrm{f}(\mathrm{b})<\mathrm{g}(\mathrm{b})$, entonces existe un punto c perteneciente $a(\mathrm{a}, \mathrm{b})$ tal que $\mathrm{f}(\mathrm{c})=\mathrm{g}(\mathrm{c})$. 
Este resultado es una consecuencia directa del teorema de los valores intermedios de Darboux. La mayoría de los LT ni siquiera lo enuncian, y sólo lo hemos encontrado justificado en los LT de Anaya (2003 y 2009, se recuerda que son casi idénticos) y en el LT de Vicens-Vives (2009).

En cuanto a los EP utilizados, tanto los LT de Anaya (2003) y (2009) como el LT de Vicens-Vives (2009) presentan un EP inductivo de 1 caso, de estilo gráfico, dado que se trata de una prueba sin palabras, en la que únicamente se utiliza el sistema de representación gráfico. Este tipo de prueba había sido utilizada en ambos LT en el teorema de Darboux, que en ambos casos precede a éste. Por tanto, las características de la justificación son las mismas que las del teorema de Darboux en ambos LT.

- T10: $(\mathcal{C}(] \mathrm{a}, \mathrm{b}[),+, \cdot \mathbb{R})$ es un espacio vectorial real que se llama el espacio vectorial real de las funciones continuas en $] \mathrm{a}, \mathrm{b}[$. y $T 11:(\mathcal{C}(] \mathrm{a}, \mathrm{b}[),+, \bullet)$ es un anillo con unidad que se llama el anillo de las funciones continuas en el intervalo $] \mathrm{a}, \mathrm{b}[$.

Se han agrupado estos dos teoremas porque ambos resultados se relacionan con el mismo tema, la estructura que tiene el conjunto de funciones continuas en un intervalo abierto junto con las operaciones correspondientes. Además, ambos se enuncian y justifican en el mismo LT, el LT de $2^{\circ}$ de BUP de Santillana (1976). En ambos casos el tratamiento es similar: para establecer la estructura de espacio vectorial, en primer lugar se recuerda que previamente se ha establecido que las operaciones de suma de funciones continuas en un punto $x$ de $] a, b[$ y que el producto de una función continua en un punto $x$ de $] a, b$ [ por una constante da lugar a funciones continuas en dicho punto $x$ de $] a, b[$. También recuerda las propiedades de la suma de funciones (asociatividad, conmutatividad, existencia de elemento neutro y de opuesto) que se han visto previamente y de ahí deduce que $((] a, b[),+)$ es un grupo abeliano. De lo anterior con las propiedades del producto de una función por un número establece la estructura de espacio vectorial sobre $\mathbb{R}$. En el caso de la estructura de anillo se parte de la estructura previa de grupo abeliano, y se sigue con el producto de funciones continuas y la existencia del elemento unidad para el producto lo que lleva a la estructura de anillo.

En ambos casos, el resultado se establece tras el razonamiento indicado y no existen indicios del resultado que se va a establecer antes de la justificación a 
excepción del título. Aunque ninguna de las dos justificaciones tiene aspecto de demostración (al menos el libro no lo presenta así), se han clasificado como EP axiomáticos puesto que sí que se presenta una cadena de razonamientos en la que se aplican axiomas anteriores (las propiedades estudiadas) para establecer el resultado.

En relación a las técnicas empleadas, los enunciados son de hipótesis implícitas y, además, de hipótesis y tesis mezcladas. Esta forma de enunciado, el orden de los teoremas y su justificación, y el hecho de no utilizar etiquetas como "demostración" dificulta el reconocimiento de este proceso en estos resultados. El método utilizado es el silogismo, el estilo, del análisis matemático global y el modo, analítico.

En el caso de las funciones, se puede considerar la comunicación y la sistematización, entendiendo esta última como la inclusión de un nuevo resultado a la teoría, por la forma en la que se exponen tanto enunciado como justificación (se establece el resultado tras el razonamiento que lo prueba). La función de verificación, aunque está siempre que se considera una justificación, no es evidente en esta forma de exposición, así como tampoco la función de explicación.

El LT no reconoce el proceso de justificación, ni alude a sus consecuencias. En cuanto a su significado, no se hace ninguna alusión, y las únicas relaciones que hay son con las propiedades que se utilizan para establecer ambos resultados. El sistema de representación predominante es el verbal, aunque se utiliza la fórmula (o sistema de representación simbólico) para algunos elementos matemáticos $(((] a, b[),+, \bullet \mathbb{R}), f, g] a,, b[\ldots)$.

- T12: Lema: sea $[\mathrm{a}, \mathrm{b}]$ un intervalo cerrado que está contenido en la unión de una familia de intervalos abiertos ] $\alpha \mathrm{i}, \beta \mathrm{i}[$; entonces existe un conjunto finito de dichos intervalos tales que $[\mathrm{a}, \mathrm{b}]$ está contenido en su unión.

Este teorema sólo se encuentra en enunciado y justificado en el LT de COU de Santillana (1988). Además, se justifica porque el resultado es necesario para la justificación del teorema de Heine. En realidad no se trata de un teorema propio de continuidad, sino que se refiere a propiedades de los intervalos de la recta real, por lo que en realidad es un resultado auxiliar cuya inclusión está justificada (aunque el LT no lo hace) porque se necesita para demostrar el teorema de Heine, aunque pertenezca a la rama de la topología. 
El EP utilizado es un EP axiomático, y en relación a las técnicas empleadas, el enunciado es de condición suficiente, la demostración se realiza por reducción al absurdo (utilizando una sucesión de intervalos encajados), el estilo es del análisis matemático global, y el modo es analítico.

Las funciones son las de verificación y comunicación principalmente, aunque también se puede considerar la función de sistematización entendiéndola como una intención del texto de proveer las herramientas necesarias para establecer un teorema más fuerte. No es una prueba muy explicativa dado que aparece mucho simbolismo matemático, muchos elementos, un proceso infinito, es completamente verbal y no se explica el porqué de cada paso.

No se reconoce el proceso utilizado como una justificación ni se alude a sus consecuencias. La única relación que se muestra del resultado es la utilidad para justificar el teorema de Heine. El teorema y la justificación sólo se distinguen tipográficamente, no se explica globalmente el proceso al empezar el teorema, ni se señalan otras vías de justificación. En cuanto a los sistemas de representación utilizados, el sistema de representación verbal es el predominante aunque también se utiliza el simbólico para denotar algunos elementos como los intervalos, etc.

- T13: Teorema de Heine: si $\mathrm{f}(\mathrm{x})$ es una función continua en [a, b], entonces $\mathrm{f}(\mathrm{x})$ es uniformemente continua en $[\mathrm{a}, \mathrm{b}]$.

Aunque este teorema aparece en dos textos de COU, el LT de (Santillana, 1981 y SM, 1980), sólo se justifica en el LT de Santillana (1981). Se justifica mediante un EP axiomático. El enunciado es de condición suficiente, el método es el silogismo combinado con un proceso constructivo (los intervalos), el estilo es del análisis matemático local y el modo es analítico.

Al igual que en el teorema anterior, la justificación cumple las funciones de verificación y comunicación, pero no es muy explicativa. Vuelve a ser una línea de razonamiento densa, con muchos símbolos matemáticos, procesos infinitos y no se explica cada paso que se da. Sería útil mostrar una gráfica que ilustre el proceso, pues es una justificación que requiere de una gran capacidad de razonamiento abstracto para ser entendida. 
No se reconoce el proceso de demostración como tal, la distinción entre enunciado y justificación es tipográfica, no se indican consecuencias, ni se explica globalmente el proceso, no se señalan otras vías de justificación.

En cuanto los sistemas de representación, si bien los conectores se expresan de forma verbal, todos los objetos matemáticos se expresan mediante notación simbólica, lo que también dificulta su comprensión.

\section{V.7. INTERPRETACIÓN DE LOS DATOS}

Una vez realizado el análisis de los resultados presentados en cada LT, procedemos a la interpretación de los datos obtenidos en dicho análisis. En cada apartado de este epígrafe hemos considerado uno de los grupos de categorías de nuestro marco teórico de forma separada, para facilitar la comparación entre libros y entre legislaciones. En este apartado se muestran los comentarios a los análisis mostrados.

Da las interpretaciones que se realizan de los datos obtendremos las pautas para la realización de la propuesta metodológica, enfocada desde la justificación matemática, que se presentará posteriormente.

\section{V.7.1. Esquemas de prueba}

En la Tabla V.7.1.1 se muestra un recuento de los EP que hemos encontrado en los LT por cursos y tipos de EP, con la suma total de resultados justificados por curso. En la última columna se ha añadido el número de LT que se ha analizado de cada curso, que permite ver si un aumento o disminución del número de resultados enunciados en un determinado curso o periodo coincide con una muestra más grande o más pequeña. Además, en la columna Total EP, que representa el número total de EP de cualquier tipo o PP encontrados en los libros de ese curso y periodo legislativo se ha añadido, entre paréntesis, el porcentaje de EP o PP sobre el número total de resultados enunciados para ese curso y periodo legislativo. Se observa que en todos los periodos legislativos, el porcentaje más alto de resultados demostrados de los resultados enunciados corresponde al curso de mayor nivel (COU y $2^{\circ}$ de Bachillerato), y entre ellos, el porcentaje más alto es COU. Además, aunque el porcentaje fuera mayor en COU que en $2^{\circ}$ de BUP, 
en este último curso también se encuentran muchas demostraciones, no así en los cursos de $1^{\circ}$ de Bachillerato de la LOGSE y de la LOE, en los que no se justifica ningún resultado y se enunciaban muy pocos.

\begin{tabular}{|c|c|c|c|c|c|c|c|c|c|c|c|}
\hline \multicolumn{2}{|c|}{ Legislaciones } & \multicolumn{8}{|c|}{ Esquemas de prueba } & \multirow{2}{*}{$\begin{array}{l}\text { Total } \\
\text { resultados }\end{array}$} & \multirow{2}{*}{$\begin{array}{l}\mathrm{LT} \\
\text { muestra }\end{array}$} \\
\hline & & $\overline{\text { EP0 }}$ & EPi1 & EPiV & EPiS & $\mathrm{EPt}$ & $\mathrm{EPa}$ & $\mathrm{PP}$ & Total EP o PP & & \\
\hline \multirow[t]{2}{*}{ LGE } & $2^{\circ} \mathrm{BUP}$ & 35 & 1 & 1 & 0 & 0 & 18 & 1 & $21(37,5 \%)$ & 56 & 6 \\
\hline & $\mathrm{COU}$ & 15 & 0 & 0 & 0 & 9 & 25 & 0 & $34(69,4 \%)$ & 49 & 4 \\
\hline \multirow[t]{2}{*}{ LOGSE } & $1^{\circ}$ Bach. & 2 & 0 & 0 & 0 & 0 & 0 & 0 & 0 & 2 & 5 \\
\hline & $2^{\circ}$ Bach. & 50 & 6 & 3 & 0 & 5 & 12 & 0 & $26(34,2 \%)$ & 76 & 5 \\
\hline \multirow[t]{2}{*}{ LOE } & $1^{\circ}$ Bach. & 20 & 0 & 0 & 0 & 0 & 0 & 0 & 0 & 20 & 4 \\
\hline & $2^{\circ}$ Bach. & 30 & 7 & 2 & 0 & 2 & 7 & 0 & $18(37,5 \%)$ & 48 & 4 \\
\hline Total & & 152 & 14 & 6 & 0 & 16 & 62 & 1 & 99 & 251 & 26 \\
\hline
\end{tabular}

Tabla V.7.1.1. Resumen del número de EP encontrados en los LT por legislaciones y cursos.

Este tratamiento de la continuidad es diferente del que se hacía en los teoremas de límites, de los que se realizaban justificaciones en todos los cursos. También se observa que el número de resultados de continuidad es sensiblemente inferior al de límites.

Si comparamos la media de resultados justificados por LT en cada curso y periodo legislativo (Total EP o PP/LT muestra), que se muestran en la Tabla V.7.1.2 observamos que el mayor cociente corresponde también a COU $(8,5)$, seguido de $2^{\circ}$ de Bachillerato de $\operatorname{LOGSE}(5,2)$ y $2^{\circ}$ de Bachillerato de la LOE $(4,5)$. Esto reafirma la idea de que el tratamiento de la continuidad de forma más profunda se hace en el último curso de la educación preuniversitaria. Por otro lado, observando el cómputo global por periodos, se encuentran más justificaciones en la LGE, dado que aparecen justificaciones tanto en $2^{\circ}$ de BUP como en COU, y sin embargo en LOGSE y LOE no se justifica nada en $1^{\circ}$ de Bachillerato, hecho que reafirma la hipótesis de la disminución de las demostraciones en los últimos periodos legislativos.

\begin{tabular}{|c|c|c|c|c|c|c|}
\hline Total EP o PP & $\begin{array}{l}\text { LGE } \\
2^{\circ} \text { BUP }\end{array}$ & $\mathrm{COU}$ & $\begin{array}{l}\text { LOGSE } \\
1^{\circ} \text { Bach. }\end{array}$ & $2^{\circ}$ Bach. & $\begin{array}{l}\text { LOE } \\
1^{\circ} \text { Bach. }\end{array}$ & $2^{\circ}$. Bach. \\
\hline LT muestra & 3,5 & 8,5 & 0 & $\overline{5,2}$ & 0 & $\overline{4,5}$ \\
\hline
\end{tabular}

Tabla V.7.1.2. Media de resultados justificados por libro en cada curso y periodo legislativo.

Por otro lado, si observamos la media de resultados enunciados por curso, el mayor número se encuentra en $2^{\circ}$ de Bachillerato de LOGSE $(15,2)$, seguido de cerca por COU $(12,55)$ y $2^{\circ}$ de Bachillerato de LOE (12), aunque considerando el 
periodo de forma global, es en la LGE donde más resultados enunciados se encuentran.

\begin{tabular}{|c|c|c|c|c|c|c|}
\hline Total resultados & $\begin{array}{l}\text { LGE } \\
2^{\circ} \text { BUP }\end{array}$ & COU & $\begin{array}{l}\text { LOGSE } \\
1^{\circ} \text { Bach. }\end{array}$ & $2^{\circ}$ Bach. & $\begin{array}{l}\text { LOE } \\
\mathbf{1}^{\circ} \text { Bach. }\end{array}$ & $2^{\circ}$. Bach. \\
\hline LT muestra & 9,33 & 12,25 & 0,4 & 15,2 & 5 & 12 \\
\hline
\end{tabular}

Tabla V.7.1.3. Media de resultados enunciados por libro en cada curso y periodo

legislativo.

No obstante, nos interesa conocer si los resultados que se justifican son los relacionados con propiedades (que engloban resultados sobre funciones concretas como la continuidad de la función identidad) o sobre teoremas de continuidad en entornos e intervalos, ya que estos últimos son de nivel más avanzado y requieren de un mayor aparataje matemático para llevar a cabo con éxito procesos demostrativos, lo cual significa que el nivel de exigencia matemático sería mayor. En la Tabla V.7.1.4 se recogen el número de resultados de cada tipo que se presenta en cada periodo legislativo y el porcentaje sobre el número de justificaciones del periodo que representan en cada caso. Se observa que de todos los resultados justificados en los LT de la LGE, $35(63,6 \%)$ corresponden a los teoremas de continuidad en entornos e intervalos, y que dicho porcentaje va subiendo con las legislaciones, es decir, que las demostraciones que van desapareciendo son aquellas relacionadas con la aritmética y las propiedades de las funciones continuas. Además, como se ha apuntado en varias ocasiones, existe un descenso generalizado del número de demostraciones presentadas en los LT, aunque también se observa un descenso en el número de resultados que se presentan en torno a la continuidad.

\begin{tabular}{llll}
\hline & LGE & LOGSE & LOE \\
\cline { 2 - 4 } Aritmética y propiedades de funciones continuas & $20(36,4 \%)$ & $5(19,2 \%)$ & $3(16,7 \%)$ \\
Teoremas de continuidad en entornos e intervalos & $35(63,6 \%)$ & $21(80,8 \%)$ & $15(83,3 \%)$ \\
Total & 55 & 26 & 18 \\
\hline
\end{tabular}

Tabla V.7.1.4. Número (y porcentaje) de resultados de cada tipo que son justificados.

\section{V.7.2. Técnicas usadas en las demostraciones sobre continuidad}

Al igual que se indicó en el capítulo de límites, las técnicas empleadas admiten distintas clasificaciones en función del EP utilizado: no hay clasificación si se 
trata de EP0, sólo se identifican el tipo y el estilo si son EP inductivos, y se clasifican todas las categorías si se trata de EP axiomáticos o transformacionales.

En el caso del enunciado, al igual que sucedía con límites, la formulación mayoritaria es de condición suficiente, aunque a veces las hipótesis y tesis están mezcladas o no se explicitan.

Atendiendo a los resultados sobre aritmética y propiedades de funciones continuas, pocos de ellos se justifican, destacando las pruebas relativas a la suma. Suelen aplicarse las propiedades de límites, por lo que la justificación es con un método constructivo, de estilo del análisis matemático global y en modo analítico. En la composición, se encuentran dos justificaciones atendiendo al modo, una directa (se aplica la definición métrica en términos de $\varepsilon-\delta$ ) y una analítica (se aplican las propiedades de límites).

En el caso de los tres teoremas fuertes de continuidad, en general, ya se ha indicado que se aprecia homogeneidad dentro de los mismos EP: en el tipo de enunciado, se encuentra sobre todo condición suficiente y existencia simple, aunque dicha simplicidad no se expresa siempre de manera específica (no se indica que existe al menos uno). Para el análisis del método, estilo y modo utilizados, se establece una división: en primer lugar, las justificaciones tipo EP axiomático o transformacional $\mathrm{y}$, en segundo, las que consideran EP inductivos de uno o varios casos. En general, todos los LT que utilizan EP axiomáticos o transformacionales, con mayor o menor completitud, realizan pruebas similares y la clasificación de método, estilo y modo en estos casos es similar: el método utilizado en Bolzano y Weierstrass es la reducción al absurdo (combinado con casos o silogismo) y en el teorema de Darboux el silogismo. En cuanto al estilo, se utiliza fundamentalmente el del Análisis Matemático (global en el caso de Darboux, local en Bolzano, y global y local en Weierstrass), pero también aparece el algebraico en Darboux y Weierstrass; en cuanto al modo, quizá por la naturaleza de los teoremas, es analítico en todos los casos. Los LT que utilizan EP inductivos de uno o varios casos, en general, utilizan el estilo gráfico, aunque en ocasiones lo complementan con el algebraico, y en el caso de Santillana (2009) utiliza coordenadas para justificar los teoremas.

Para el resto de teoremas, se observa que la clasificación de técnicas suele ser similar a la que se ha hecho en cada LT para los tres teoremas fuertes (si 
justifican estos otros). Es decir, se observa que cada LT sigue una misma tendencia de justificación en todos los LT que presenta).

\section{V.7.3. Funciones de la demostración}

Las funciones de la demostración que hemos apreciado son la de comunicación y la de verificación, que son las más comunes debido a la naturaleza del material estudiado y del objeto analizado (la demostración matemática). No obstante, también sería interesante que apareciera con más frecuencia las función de descubrimiento (que se ha encontrado en alguno de los LT, en el teorema de Bolzano) y la de explicación que, según Hanna (1995), en el campo de la educación matemática sería la función principal de la demostración, razón por la cual ensalza las demostraciones que explican frente a las que sólo prueban. Además, Ibañes y Ortega (2005) ya constataron que los alumnos valoran más las demostraciones explicativas ya que, en ocasiones, les ayudan a identificarlas y a distinguirlas de otros procesos.

Dicha función de descubrimiento depende de los resultados, pues no todas las demostraciones conducen al descubrimiento de nuevos teoremas. No obstante, aun a pesar de haber encontrado dicha función en algunos LT de la muestra, éstos no la reconocen como tal, sino que el resultado descubierto se considera una consecuencia del teorema en sí, y no se relaciona con la demostración.

En algunos casos, los que los LT han utilizado un EP inductivo de un caso gráfico, que no estaba acompañado de descripciones verbales. Aquí se ha indicado que la justificación presentada no atendía a ninguna función, dado que ni existía reconocimiento por parte del LT de proceso, ni de que sirviera como justificación, ni de que fuera útil para los alumnos. Si bien las pruebas visuales son muy potentes, creemos que en estos niveles no debe dejarse al alumno la labor de interpretar dichas pruebas.

No hemos mencionado la función de sistematización en el análisis de cada justificación, pero como indicamos en la descripción del marco teórico, los LT muestran, por su propia naturaleza, una sistematización de los resultados matemáticos. Cabe destacar, que los LT muestran diferentes sistematizaciones para los teoremas de continuidad, y que existen numerosas diferencias en la presentación del concepto: orden, resultados que se enuncian, resultados que se 
justifican...En este sentido, al final de este trabajo, se presentará una propuesta didáctica en la que se reflejará una sistematización que, teniendo en cuenta los análisis realizados y las reflexiones de dichos análisis, sea más conveniente para favorecer la comprensión de los conceptos tratados por parte de los alumnos.

Como tarea para el futuro, al igual que se indicó en el estudio de límites, queda pendiente refinar la relación entre las funciones de la demostración que se han mostrado en los LT analizados y los tipos de EP o PP utilizados.

\section{V.7.4. Reconocimiento de procesos}

Al igual que sucedía en límites, el comportamiento en este aspecto en los LT analizados es muy variado: hay LT que identifican el proceso como una demostración porque ponen una etiqueta (en el caso de que se trate de EP transformacionales o axiomáticas), otros LT, aunque no utilizan una etiqueta, hacen alguna referencia a los verbos "demostrar" o "probar", u otros sinónimos, o incluso mencionan que no se demuestra y el porqué, pero otros LT no realizan ninguna mención de si el razonamiento que presentan justifica el resultado que han enunciado o no. De hecho, los LT suelen ser homogéneos en este aspecto: los LT que etiquetan las demostraciones, unos las etiquetan siempre; otros, no, nunca o casi nunca. Los que hacen pequeñas referencias en el texto, a veces son explícitos y otras no, pero subrayan la demostración. Sí que se ha observado que, en general, hay ciertos resultados que tienden más a acompañarse de etiquetas (tanto enunciado como demostración) como son los teoremas de continuidad (Bolzano, Darboux, Weierstrass...), y en los que, al menos, hay un cambio tipográfico en todos los LT. En cambio, en otros resultados, como las operaciones con funciones continuas, se tiende más a escribir dentro del mismo texto tanto el enunciado como las explicaciones o algunos indicios de justificación si las hubiera.

Al igual que en límites, ninguno de los LT hace referencias a las consecuencias de justificar un resultado. Como se indicó entonces, desde el punto de vista de la enseñanza de la demostración sería interesante resaltar este aspecto en los LT, es decir, indicar explícitamente que una vez que un resultado se ha justificado, no es necesario realizar ninguna comprobación posterior, ni se pueden encontrar contraejemplos,..., ya que resaltaría la función de explicación y la de verificación 
de la demostración además de trasmitir el valor que estás tienen en el campo de las matemáticas.

No obstante, cabe destacar que alguno de los LT ha usado los teoremas de continuidad para dar pautas sobre la demostración, como por ejemplo, el LT de SM (2001), que presenta la demostración del teorema de acotación en un intervalo cerrado en un apartado destinado a la enseñanza del método de reducción al absurdo. Ya indicamos que quizás no es la demostración en la que mejor se perciba dicho proceso, pero desde el punto de vista de la enseñanza de la demostración supone un avance y además es un reconocimiento por parte del LT del proceso de demostrar.

\section{V.7.5. Expresiones que utiliza}

En general, las expresiones utilizadas en los LT difieren en función de los autores, pero los cambios no son muy significativos. Las diferencias más relevantes se encuentran en el análisis de los tres teoremas fuertes de continuidad (Bolzano, Darboux y Weierstrass), en el que se muestra un estudio pormenorizado de los enunciados y se observa que se utilizan distintas formas verbales para decir lo mismo, lo que puede asociar diferentes comportamientos de la función (por ejemplo, un alumno podría no entender lo mismo por "tener un máximo" que por "alcanzar un máximo). Por lo demás, los símbolos matemáticos utilizados son los universales aunque a veces se utilizan algunos diferentes (el intervalo abierto suele representarse como $] a, b[$ en la LGE y como $(a, b)$ en la LOE).

En relación a los sistemas de representación, los más utilizados son el verbal y el simbólico (o fórmula) aunque el simbolismo matemático va disminuyendo con las nuevas legislaciones, así como el lenguaje verbal se vuelve más coloquial. Por otro lado, también aparece con gran frecuencia el sistema de representación gráfico, que en ocasiones, es el principal sistema utilizado en las justificaciones de algunos teoremas (EP inductivos gráficos en los teoremas fuertes de continuidad de algunos LT). Esto puede deberse a la representación gráfica tan fácil que tienen estos teoremas, aparte de su potencia como método para convencer a un lector de la veracidad del teorema. 
Tendencia a utilizar un lenguaje más verbal, menos simbólico y más coloquial. (Ejemplo en enunciados).

Debemos destacar que ninguno de los LT explica el significado de las expresiones que utilizan, principalmente porque son habituales en el LT, y bien suponen que los alumnos las conocen o bien se han explicado al principio del LT.

\section{V.7.6. Consideraciones globales}

En general, las observaciones realizadas para los teoremas de límites se repiten en los teoremas de continuidad: los LT no suelen explicar el proceso de la justificación de forma que se aclaren cuáles son las líneas generales de la justificación. Algunos dan aluna indicación breve (como señalar el resultado que se va a aplicar), pero no es suficiente para dar una idea general del proceso. No obstante, muchos de los resultados de continuidad presentan justificaciones sencillas y fácilmente representables de forma gráfica, por lo que es posible que los LT no presten atención a dichas consideraciones globales porque se consideren superfluas. Aun así, sería interesante dar esa explicación global pues contribuiría con la función de explicación.

No se suelen explicar las consecuencias de los resultados enunciados, salvo en algunos casos en los que se indica que se va a aplicar posteriormente, pero son escasos. En algunos casos, cuando se utilizan resultados anteriores en la justificación de un enunciado, sí se hacen referencias a dichos resultados, pero son los únicos puntos en los que encontramos alguna indicación de relaciones o utilidad del resultado.

La distinción entre enunciado y justificación es diversa en los diferentes LT aunque se mantiene en todos los resultados en un mismo LT. Esta categoría está relacionada con la categoría sobre el reconocimiento de procesos, ya que los LT que etiquetan sus resultados como "teoremas" o "propiedad" y las justificaciones como "demostración" o "justificación", están reconociendo el proceso como una justificación. No obstante, muchos LT no realizan esta distinción de forma tan clara. Algunos se limitan a realizar una distinción tipográfica, que puede basarse en resaltar el enunciado mediante otro tipo de letra, un cuadro de color, o algo similar, aunque la demostración no se distingue de otros textos que no pertenecen a esta última, o realizar también una distinción (por ejemplo, una disminución en 
el tamaño de la letra) en la demostración. Ya hemos mencionado anteriormente que, en el caso de la continuidad, en algunos resultados se hace más evidente dicha distinción que en otros (ver apartado de reconocimiento de procesos).

Ningún LT indica que existan otras vías para justificar los enunciados que justifica, ni siquiera cuando utilizan EP inductivos y podrían indicar que se pueden justificar mediante justificaciones más formales y rigurosas.

\section{V.8. REFLEXIONES}

En resumen, hemos visto que, en general, la demostración matemática rigurosa de los teoremas de continuidad ha perdido protagonismo en los LT con la puesta en vigor de las tres últimas Leyes Orgánicas de Educación españolas, ya que no sólo se producen cambios de una legislación a otra, sino que en diversos momentos de una misma ley, los LT han adoptado posturas diferentes sobre las justificaciones de los teoremas, tratando de seguir las orientaciones de los currículos legales. Se han detectado dos cambios: por un lado, en relación a los tres teoremas fuertes de continuidad (Bolzano, Darboux y Weierstrass, que se enuncian en todos los LT), en las nuevas legislaciones los EP axiomáticos y transformacionales se sustituyen por EP inductivos, o bien los resultados únicamente se enuncian, y en los casos que se mantiene un EP axiomático, se hace con menos rigor, no justificando algunos pasos (EP axiomáticos incompletos). Además, cada LT sigue una línea uniforme en la elección del EP, ya que tienden a justificar todos los resultados con el mismo tipo de EP, salvo en algunos casos en los que el teorema de Weierstrass es únicamente enunciado, independientemente de los resultados anteriores. El segundo cambio es la cantidad de resultados enunciados en los LT, que disminuye sensiblemente, y se dejan de presentar algunos resultados sobre la continuidad en un entorno de un punto o en intervalos, lo que tiene como consecuencia la desaparición de esas demostraciones. Además, las operaciones con funciones continuas dejan de justificarse, limitándose en la última legislación a ser enunciadas.

Por otro lado, el uso de las gráficas es cada vez más significativo, llegando a sustituir éstas a las demostraciones como forma de convencer al lector (algo que ya se apuntaba en el estudio de límites), al menos en los tres teoremas fuertes de continuidad. Desde el punto de vista de la demostración, la enseñanza de ésta se 
ha relegado a un segundo plano, procediendo a convencer desde la intuición antes que desde el razonamiento matemático. Sólo se ha encontrado una prueba preformal (y es posible que los autores no la conozcan como tal), aunque consideramos que sería una justificación muy interesante en este nivel educativo, ya que permite reflejar la esencia del razonamiento de una demostración y, por tanto, no privar al alumno del contacto con este tipo de procesos, preparándolo para la etapa universitaria, pero restando la abstracción que dificulta la comprensión de las demostraciones a público no especializado, ya que se realiza con un caso particular. También se pueden considerar las pruebas preformales como un paso previo a las demostraciones.

En cuanto a la diversidad en el orden de los teoremas, los nombres que reciben, las acciones verbales que se utilizan, o las variaciones del enunciado que se consideran, sería aconsejable unificar estos elementos, para resaltar el carácter de universalidad de la Matemática, ya que, como hemos mencionado, sistematizaciones diferentes pueden confundir a los alumnos en la fundamentación de los teoremas en estudios posteriores y, desde luego, hay que desterrar las pruebas erróneas. No obstante, la diversidad de los resultados considerados es menor que la que se presentaba en límites, y en los teoremas de continuidad ha sido más sencillo establecer comparaciones entre los diversos LT, sobre todo en los tres teoremas fuertes de continuidad, ya que éstos se presentan en todos los LT.

Sobre las técnicas empleadas, en general, se aprecia homogeneidad dentro del mismo EP, aunque en los EP inductivos de uno o varios casos podemos encontrar dos estilos: algebraico y gráfico. Consideramos que los EP inductivos de tipo gráfico son más convincentes que los de tipo algebraico, pero recomendaríamos que, en la medida de lo posible, se utilizaran ambos, independientemente de si se utilizan EP axiomáticos y EP transformacionales y, además, sería útil que se consideraran EP sistemáticos, intentando cubrir todas las casuísticas posibles

No se utilizan apenas conectores matemáticos, se limitan a un lenguaje verbal más coloquial. Sería interesante introducir dichos conectores, para habituar a los alumnos al lenguaje más específico de la matemática. Por otro lado, la utilización de diferentes sistemas de representación para un mismo concepto (verbal, tabular, gráfico y algebraico) debiera ser obligada, ya que sólo la utilización fluida de los mismos garantiza el aprendizaje de los conceptos (Duval, 1998). 
Al igual que se observó en el capítulo de límites, los mayores cambios en el tratamiento de la continuidad y de la demostración matemática se produce en el cambio de LGE a LOGSE, encontrándose semejanzas entre los planteamientos hechos en LOGSE y LOE. Además, se mantiene la precocidad en LGE, que aborda resultados y demostraciones de más alto nivel en edades inferiores (15 años) de lo que se hace en las legislaciones siguientes (a los 17 años).

Sin ánimo de abundar en comentarios que se hicieron en el capítulo de límites y que serían válidos aquí también, se considera que el refinamiento del análisis en los aspectos en los que menos se ha focalizado (reconocimiento de procesos, expresiones,...) y una posible ampliación de la muestra a otras editoriales o a otros libros de las editoriales estudiadas aportarían valor a este estudio dado que permitirían ampliar los resultados obtenidos. 



\section{CAPÍTULO VI}

\section{CONCLUSIONES, PROPUESTA DIDÁCTICA, APORTACIONES, DIFICULTADES Y FORTALEZAS, Y PERSPECTIVAS DE FUTURO}

En este capítulo, el último de la presente memoria, se describen las conclusiones extraídas de los análisis realizados, se presentan las líneas generales de una propuesta didáctica, las implicaciones del estudio realizado y los problemas abiertos, así como posibles continuaciones del presente trabajo.

En el primer apartado (Conclusiones) se describe el grado de consecución de los objetivos planteados al comienzo de la investigación, así como las conclusiones extraídas en función de las hipótesis planteadas a partir de los objetivos.

En el segundo apartado (Propuesta didáctica) se presentan las líneas generales de una propuesta didáctica. Esta propuesta se ha realizado teniendo en cuenta los resultados obtenidos y está orientada hacia la mejora de la docencia, tanto de la demostración matemática como de los conceptos y la sistematización de los teoremas que están relacionados con el límite funcional y la continuidad de funciones.

En el tercer apartado (Implicaciones y perspectivas de trabajo futuro) se describen las implicaciones del presente trabajo y se enumeran una serie de 
problemas que quedan abiertos, así como otras líneas de investigación que podrían derivarse de éstas.

\section{VI.1. CONCLUSIONES}

La investigación realizada tenía como objetivo general estudiar la presencia de la demostración matemática en los libros de texto de $3^{\circ}$ de BUP, COU de la LGE y $1^{o}$ y $2^{\circ}$ de Bachillerato de la LOGSE y de la LOE y, a partir de este estudio, determinar la evolución de la demostración en los libros de texto de los cursos citados, clasificar los esquemas de prueba utilizados según el modelo de Ibañes y Ortega (2001) y determinar los procesos de enseñanza de las matemáticas a través de los LT en relación con la demostración o justificaciones alternativas.

Este objetivo general se concretó en otros cinco objetivos más concretos, que se presentan de nuevo a continuación. Además, a partir de cada objetivo se estableció una hipótesis de partida. Considerando dichos objetivos, y la hipótesis relacionadas, se describen los resultados alcanzados y el grado de consecución de los primeros, así como la comprobación o refutación de la hipótesis relacionada.

O1. Analizar la presencia de la demostración en los libros de texto de las tres últimas leyes educativas.

En el presente trabajo se han analizado un total de 33 LT, 15 de la LGE (6 de $2^{\circ}$ de BUP, 5 de $3^{\circ}$ de BUP y 4 de COU), 10 de la LOGSE (5 de cada curso) y 8 de la LOE (4 de cada curso). No obstante, los resultados que se presentan corresponden a $28 \mathrm{LT}$ de $\operatorname{los} 33$, ya que en $3^{\circ}$ de BUP, curso inicialmente considerado en el estudio, no se presentan los contenidos de límites y continuidad, razón por la cual se amplió la muestra a $2^{\circ}$ de BUP. La localización de esta muestra no ha estado exenta de dificultades, sobre todo para los LT de las legislaciones que ya no están vigentes. Además, en algunos casos se localizó más de un ejemplar de una editorial correspondiente a un mismo curso y un mismo periodo, que presentaban diferencias notables, razón por la cual se incluyeron ambos en la muestra ( 2 LT de $2^{\circ}$ de BUP de Anaya, 2 LT de $2^{\circ}$ de BUP de Santillana y $2 \mathrm{LT}$ de $1^{\circ}$ y $2^{\circ}$ de Bachillerato de Vicens-Vives de la LOGSE). 
H1. La demostración matemática ha perdido paulatinamente importancia en la enseñanza preuniversitaria, reflejándose en los libros de texto con menor presencia de ésta última, desde los años 70.

Conclusión 1. Efectivamente, la demostración matemática como tal, ha perdido importancia en la enseñanza preuniversitaria, sobre todo en el cambio legislativo de 1990, observándose que ha disminuido el número de teoremas que se enuncian, los que se justifican (de los que se presentan), así como se han sustituido las demostraciones formales (EP axiomáticos o transformacionales) por EP inductivos. Además, el análisis realizado sobre los conceptos de límite y continuidad ha permitido observar que no existen patrones regulares de comportamiento ni asociados a legislaciones ni a editoriales. Es decir, si bien todos los LT presentan contenidos relacionados con el límite funcional y la continuidad, no todos lo hacen con la misma organización, el mismo orden, las mismas definiciones o los mismos resultados y, por tanto, también se observan cambios en las demostraciones y justificaciones presentadas.

O2. Establecer una clasificación de los tipos de justificación utilizados según los niveles (esquemas de prueba), la tipología, las funciones de la demostración.

En cada LT se han analizado los temas o unidades del libro en las que aparecían contenidos de límite o continuidad, principalmente en las partes de desarrollo teórico de los contenidos. Se han registrado los teoremas expuestos en dichas unidades, y se han clasificado las justificaciones que los acompañaban: en primer lugar, en función del EP utilizado, y después, teniendo en cuenta las técnicas empleadas, las funciones de la demostración, el reconocimiento de procesos, las expresiones y sistemas de representación utilizados y las consideraciones generales.

H2. Los esquemas de prueba utilizados por los libros de texto tienden a una menor formalidad y rigor matemático con el paso de los años, procediendo a convencer desde la intuición antes que desde el razonamiento. 
Conclusión 2. Se ha observado que las demostraciones que tienden a desaparecer son aquellas que requieren mayor aparataje matemático (por ejemplo, la demostración del teorema de Weierstrass) y que las que se mantienen en las tres legislaciones, a pesar de que en muchas ocasiones se utilizan los mismos razonamientos, son aquellas en las que el lenguaje se vuelve menos formal, se reduce el simbolismo matemático y, a veces, algunos pasos se dejan como evidentes y no se explicitan, lo que da lugar a demostraciones más superficiales y más cortas. Por ejemplo, en la justificación del teorema de Bolzano de VicensVives (2009), que es un EP axiomático, aplica el teorema de conservación de signo, aunque no lo ha enunciado previamente, pero lo hace como si fuera un resultado evidente que no requiere de justificación alguna. Este comportamiento reafirma la idea de que existe una idea a convencer mediante la intuición antes que desde el razonamiento matemático.

Convencer únicamente desde la intuición antes que desde el razonamiento matemático, aunque en un principio pueda ser más rápido y "eficaz", no aborda los objetivos que el currículo actual considera desde el punto de vista de la demostración y, con este planteamiento, quizá los alumnos no lleguen a comprender las significaciones de los teoremas (Hanna, 1995, resalta la importancia de la demostración matemática para la comprensión de las matemáticas). En Bachillerato, el alumno, entre otras actividades, debe realizar demostraciones sencillas de propiedades o teoremas, utilizar diferentes métodos de demostración en función del contexto matemático, reflexionar sobre el proceso de demostración (estructura, método, lenguaje y símbolos), y generalizar y demostrar propiedades de acuerdo con las directrices curriculares de Castilla y León correspondientes a la LOMCE (Conserjería de Educación de Castilla y León, 2015, pp. 32768). Si bien es cierto que no se indica qué teoremas deben demostrarse, consideramos que algunos de los teoremas anteriormente citados podrían servir para abordar este contenido transversal del currículo. Además, Hanna \& Barbeau (2010) afirman que la demostración matemática es esencial en la enseñanza, ya que contiene los métodos, herramientas, estrategias y conceptos que se necesitan para resolver problemas, y éstos elementos suponen la esencia principal de las matemáticas. Por esta razón, se considera que las demostraciones matemáticas son portadoras del conocimiento matemático y, cómo tales, deben utilizarse en la enseñanza preuniversitaria. Sin embargo, también deberían combinarse la intuición con el razonamiento riguroso. Además, cabe destacar el 
hecho de que, aunque la LGE mostrase indicios de la necesidad de la demostración matemática, ésta no aparecía de forma explícita como en LOGSE y LOE, y es precisamente en esa etapa de la LGE cuando más formalismo se aprecia en los LT, lo que no deja de ser contradictorio.

O3. Determinar la evolución de las justificaciones de los teoremas en los periodos en vigor de estas leyes educativas.

En el análisis realizado se ha buscado comparar la presencia de la demostración en los LT entre diversas legislaciones y editoriales. Esto se ha conseguido mediante la realización del análisis en varios pasos: primero, una descripción global de los contenidos trabajados en cada LT; en segundo lugar, un estudio por editoriales de los EP utilizados en cada LT, lo que nos da una idea de la evolución de las justificaciones a lo largo del tiempo en cada editorial; a continuación, una comparación de los cuatro análisis anteriores, observando el comportamiento general de los LT; en último lugar, se ha analizado cada resultado o grupo de resultados en todos los LT y se comparan los comportamientos por legislaciones. Esta estratificación del análisis ha surgido como una necesidad al detectarse que la diversidad de tratamientos en los libros de texto dificultaba la comparación directa, y que el tamaño de la muestra y el número de resultados que había que analizar era tan grande que no permitían extraer conclusiones de forma global sobre los comportamientos de los LT.

H3. Cada cambio de legislación ha rebajado tanto la utilización de demostraciones, como el rigor de las mismas.

Conclusión 3. Tal y como se indicó en la conclusión 2, se ha observado una disminución de la demostración matemática en los libros de texto, así como del rigor utilizado. Este suceso se ha visto más claramente en continuidad, ya que en límites, en el periodo de LOGSE, las operaciones con límites se desglosaron en varios enunciados en función del tipo de límite (infinito, finito, en un punto, en el infinito) lo que también dio lugar a más resultados, aunque como teoría global se tratasen los mismos resultados.

En la Tabla VI.1.1 se recogen el número de resultados enunciados en los LT de cada curso y cada periodo (primera fila de datos), de ellos, los que se justifican 
de algún modo (segunda fila, total EP) y de estos últimos, los que son EP axiomáticos o transformacionales (que se corresponden con la demostración matemática, tercera fila). En las siguientes tres filas se recogen los mismos datos pero agrupados por periodos (es decir, contabilizando ambos cursos a la vez). El cambio más notable se produce entre la LGE y la LOGSE, donde hay un descenso mayor tanto en el número de teoremas que se enuncian como en el número de justificaciones axiomáticas, sobre todo, de las que están relacionadas con el concepto de continuidad. Sin embargo, dicho descenso no es tan notable de la LOGSE a la LOE. En esta transición hemos encontrado una editorial (Anaya) que mantiene prácticamente los mismos LT en las dos legislaciones.

\begin{tabular}{lllllll}
\hline & LGE & & LOGSE & LOE & \\
& $2^{\circ}$ BUP & COU & $1^{\circ}$ Bach. & $2^{\circ}$ BUP & COU & $1^{\circ}$ Bach. \\
\cline { 2 - 6 } T. resultados & 183 & 53 & 54 & 259 & 49 & 194 \\
Total EP & $64(35 \%)$ & $36(67,9 \%)$ & $20(37 \%)$ & $53(20,5 \%)$ & $9(18,4 \%)$ & $30(15,4 \%)$ \\
EPax y trans & $55(30,1 \%)$ & $36(67,9 \%)$ & $5(9,3 \%)$ & $37(14,3 \%)$ & $1(2 \%)$ & $15(7,7 \%)$ \\
& & & Ambos cursos & & \\
\hline T. resultados & 236 & 313 & 243 & \\
Total EP & $100(42,4 \%)$ & $73(23,3 \%)$ & $39(16 \%)$ & \\
EPax y trans & $91(38,6 \%)$ & $42(13,4 \%)$ & $16(6,7 \%)$ & \\
\hline
\end{tabular}

Tabla VI.1.1. Número de teoremas de límites y continuidad enunciados, de EP presentados y de ellos, EP axiomáticos y transformacionales, por cursos y el total por legislaciones.

No obstante, no se ha analizado el mismo número de LT en cada periodo y curso, pero si comparamos las medias de resultados justificados por LT por curso y por periodo (Tabla VI.1.2) también se corrobora este hecho.

\begin{tabular}{|c|c|c|c|c|c|}
\hline \multicolumn{2}{|l|}{$\overline{\text { LGE }}$} & \multicolumn{2}{|l|}{ LOGSE } & \multicolumn{2}{|l|}{ LOE } \\
\hline $2^{\circ} \mathrm{BUP}$ & $\mathrm{COU}$ & $1^{\circ}$ Bach. & $2^{\circ}$ Bach. & $1^{\circ}$ Bach. & $2^{\circ}$ Bach. \\
\hline 10,7 & 9 & 4 & 10,6 & 2,25 & 7,5 \\
\hline \multicolumn{6}{|c|}{ Ambos curso } \\
\hline 10 & & 7,3 & & 4,9 & \\
\hline
\end{tabular}

Tabla VI.1.2. Medias de EP de los teoremas de límites y continuidad en los LT por curso y por legislaciones.

Aún así, no se puede decir que la demostración matemática haya desaparecido totalmente de los LT de Educación Secundaria y, según las directrices de la nueva legislación, LOMCE, debe seguir presente y además debe formar parte de la formación matemática de los alumnos de los itinerarios de Ciencias. 
O4. Descubrir posibles errores relativos a la presentación de los enunciados y de las justificaciones de los teoremas.

El análisis realizado en los LT ha permitido detectar algunos errores presentes en los LT que deben evitarse. Éstos se han descrito en los apartados correspondientes de los capítulos de límites y continuidad.

H4. La demostración matemática y la consiguiente fundamentación de los teoremas están desapareciendo y ello puede conducir a errores tanto en la presentación como en el significado de los resultados propuestos.

Conclusión 4. Se han observado algunos errores en los LT analizados, que deben ser subsanados y evitados en el futuro. Algunos de estos errores han sido puntuales, como la demostración del teorema de Weierstrass en el LT de Anaya de COU de 1989, pero otros son generalizados, como la utilización de simbología imprecisa en el caso de los límites en el infinito y de las indeterminaciones ( $1 / 0$ en lugar de $\rightarrow 1 / \rightarrow 0)$. Esto sin contar las erratas de transcripción que también se han observado (desigualdades que cambian de sentido o se convierten en igualdades,...) pero que se han considerado como involuntarias. Por otro lado, el hecho de no demostrar algunos resultados permite que su presentación en los libros de texto pueda hacerse en otros órdenes diferentes a los que se pudieran considerar "habituales", y algunos de ellos no son adecuados. Este aspecto también se ha intentado solventar en la propuesta didáctica.

O5. Proponer una secuencia didáctica que integre los resultados encontrados.

En el apartado VI.2 se presenta una propuesta didáctica elaborada a partir de las conclusiones extraídas en el análisis de los libros de texto. Para realizarla, se han tenido en cuenta la sistematización a seguir, los sistemas de representación a utilizar y el lenguaje proveniente de los tipos de EP adecuados en cada caso; en todo ello se tienen en cuenta los estudios realizados en torno a la demostración con alumnos (Ibañes, 2001, Ibañes y Ortega, 2001b, y González, 2012). 
H5. Es necesario hacer una propuesta fundamentada sobre el uso de la demostración matemática y de sus posibles alternativas: los Esquemas de Prueba y las Pruebas Preformales.

Conclusión 5. Se han descubierto varios factores que harían necesario la elaboración de una propuesta didáctica que solventara las deficiencias encontradas en el estudio: en primer lugar, sería conveniente unificar la sistematización de las teorías expuestas en estos niveles, con el objetivo de evitar posibles confusiones a los alumnos en estudios posteriores. Esto no significa que haya que plantear las matemáticas como un sistema rígido, que no admite reinterpretaciones, sino que la flexibilidad debería llegar a partir de relaciones que se establecen entre los teoremas y las aplicaciones de éstos, y debería ser algo gradual, que surgiera a medida que el alumno vaya incorporando la teoría a su sistema de estructuras mentales. Sin embargo, la diversidad de sistematizaciones parece responder a las ideas que cada equipo de autores tiene respecto a un tópico, y no cuidan el hecho de que los alumnos en proceso de aprendizaje pueden no comprender la parte flexible de las matemáticas. Por ejemplo, el teorema de los ceros de Bolzano puede considerarse una consecuencia del teorema de los valores intermedios de Darboux (tomando el caso particular de $c=0$ ), o al revés, el teorema de los valores intermedios de Darboux como una aplicación del teorema de los ceros de Bolzano. Desde el punto de vista matemático, ambas consideraciones son equivalentes, pero en la sistematización de la teoría, estas consideraciones afectan al orden en que se presentan los teoremas y las demostraciones utilizadas en cada caso. Si atendemos a las recomendaciones curriculares, esta alternativa queda resuelta, ya que el currículo recomienda tratar los contenidos en orden creciente de la dificultad asociada. En consecuencia, habría que desarrollar en primer lugar el teorema de los ceros de Bolzano.

Por tanto, sería conveniente adoptar una postura uniforme y, para ello, debería estudiarse cuál es la mejor sistematización. En consecuencia, a la hora de sistematizar las teorías matemáticas se deben considerar tres aspectos:

- Orden cronológico (histórico): En los tópicos aquí tratados, el aprendizaje de las matemáticas debe seguir el orden del desarrollo histórico éstas, ya que estos contenidos se han ido construyendo en orden creciente de dificultad, es decir, los primeros teoremas que se han establecido y 
demostrado han sido aquellos que están más cercanos a la intuición, y que han sido más fáciles de probar. A partir de estos, se han creado otros más generales.

- Orden matemático: en muchas ocasiones, la sistematización final de la teoría no se corresponde con el orden histórico en el que se ha establecido (algunos resultados se han enunciado y no se han demostrado hasta mucho después), pero una vez incorporados a la teoría matemática, puede suceder que el orden más lógico no sea el temporal. Además, también puede darse el caso de que haya sistematizaciones diferentes que desde una perspectiva meramente matemática sean equivalentes (como en el ejemplo de Bolzano y Darboux que se han mencionado antes). Esto es particularmente importante cuando un concepto ordena otros, como es el caso del concepto de límite, que ordena al resto de conceptos generales del Análisis Matemático (continuidad, derivabilidad e integrabilidad)

- Orden didáctico: puede suceder que el orden usual matemático o el orden histórico no sean los más recomendables desde un punto de vista didáctico, y no favorezcan el aprendizaje de los nuevos conceptos. En este caso, este aspecto debería prevalecer sobre los demás, pues el objetivo en la educación preuniversitaria no es presentar una teoría matemática completa y rigurosa sino sentar las bases del conocimiento necesarias para aprendizajes posteriores, y es éste último, el aprendizaje de las matemáticas, el objetivo primordial que deberían perseguir los libros de texto.

En los libros de texto se ha observado que las propuestas no cumplen los requisitos que aquí se han considerado importantes y, por tanto, está más que justificado que se realice una propuesta didáctica utilizando las conclusiones extraídas del análisis con el objetivo de resolver las deficiencias encontradas, y que abogue por un mejor aprendizaje de la demostración matemática. Además, como ya se ha mencionado anteriormente, las experiencias con alumnos llevadas a cabo por Ibañes (2001), Ibañes y Ortega (2001b) y González (2012) avalan la utilización de justificaciones alternativas como los esquemas de prueba de diferentes tipos y las pruebas preformales. 


\section{VI.2. PROPUESTA DIDÁCTICA}

Como se ha mencionado anteriormente, uno de los objetivos del presente trabajo es realizar una propuesta didáctica en torno a los conceptos estudiados (límites y continuidad) realizada desde la perspectiva de la demostración matemática y orientada a mejorar la enseñanza, tanto de los conceptos matemáticos que se han considerado como del propio proceso de demostrar.

Ya se ha observado en los documentos curriculares (Ministerio de Educación, Cultura y Deporte, 2015 y Conserjería de Educación de Castilla y León, 2015) que la demostración matemática aparece en el Bloque 1 de las asignaturas Matemáticas $I$ y $I I$ de $1^{\circ}$ y $2^{\circ}$ de Bachillerato, donde se indica que debe haber una "Iniciación a la demostración en matemáticas: métodos, razonamientos, lenguajes, etc." (Conserjería de Educación de Castilla y León, pp. 32769). Aunque estos documentos son posteriores a los LT aquí analizados, en la propuesta didáctica que sigue conviene tener presente esta orientación ya que con ella se pretende que sea tenida en cuenta en el futuro; además, entre otros, se deben conocer los siguientes métodos de demostración: reducción al absurdo, método de inducción, contraejemplos y razonamientos encadenados.

Por otro lado, tal y como defiende Hanna (1995), la demostración matemática contribuye a la comprensión de los conceptos matemáticos y, en el caso que nos ocupa, de los enunciados de los teoremas. Además, la demostración matemática es portadora de los conocimientos matemáticos, ya que contiene los métodos, herramientas, estrategias y conceptos que se necesitan para resolver problemas, y éstos procesos suponen la esencia principal de las matemáticas (Hanna \& Barbeau, 2010). Por tanto, una propuesta racional basada en la justificación de los resultados presentados resulta esencial en estos niveles educativos.

No obstante, la demostración matemática formal, tal y como se concibe en el ámbito de las matemáticas, es un proceso que puede resultar muy complejo para los alumnos de Bachillerato, pues requiere de competencia en el razonamiento lógico, abstracto, y está relacionado con el pensamiento matemático avanzado. Por esta razón, la utilización de otro tipo de justificaciones menos formales y más sencillas puede ser útil en el principio del aprendizaje de la demostración matemática. 
Además, los estudios de Ibañes (2001) y González (2012) ya apuntaron en esta dirección. Por ejemplo: Ibañes observó que los EP de los alumnos de $1^{\circ}$ de Bachillerato podían evolucionar favorablemente (de más intuitivos, los inductivos, a los más formales, transformacionales y axiomáticos) mediante una secuencia didáctica adecuada. Además, los alumnos valoraron positivamente las demostraciones que explicaban frente a las que no, por lo que sería un aspecto a tener en cuenta a la hora de realizar una propuesta didáctica. Por su parte, González detectó que los alumnos aprenden con más facilidad los conceptos mediante el uso de las pruebas preformales, que distinguen de las pruebas formales, y que prefieren antes éstas últimas, puesto que se requiere menor abstracción para ser comprendidas, son más sencillas, más convincentes y más fáciles de aplicar. Además, este autor apunta que las pruebas preformales son complementarias de las formales, y que sirven de explicación a las segundas. Esto supone una inclusión de las pruebas formales en las propuestas didácticas.

Teniendo en cuenta estos factores, la intención es desarrollar una propuesta didáctica que considere todos los aspectos estudiados para los conceptos de límite y de continuidad. No se trata de una unidad didáctica sino de una propuesta educativa que contenga las líneas generales de la docencia relativa a estos conceptos y que contemplará las definiciones, los enunciados de los teoremas y los tipos de justificación que, tras la elaboración de esta tesis, se consideran los más adecuados desde la perspectiva didáctica.

\section{VI.2.1. Contenidos curriculares de la LOMCE}

Con el fin de apreciar mejor la propuesta didáctica derivada del análisis de los LT realizada, se reproducen aquí los contenidos del desarrollo curricular de la LOMCE en Castilla y León.

En la propuesta que se presenta no se indica explícitamente en qué curso debe tratarse cada contenido, pues es el profesor quién, dependiendo del grupo de alumnos, tiene la última palabra a la hora de planificar la docencia, teniendo siempre en cuenta las directrices curriculares. Atendiendo al currículo de Bachillerato de la LOMCE de Castilla y León (Conserjería de Educación de Castilla y León, 2015), se observa que el concepto de límite tiene mayor 
protagonismo en $1^{\circ}$ de Bachillerato que en $2^{\circ}$ (Tabla VI.2.1.1), al contrario de la continuidad, que tiene mayor presencia en $2^{\circ}$ curso (Tabla VI.2.1.2).

\begin{tabular}{|c|c|}
\hline $1^{\circ}$ Bachillerato & $2^{\circ}$ Bachillerato \\
\hline \multicolumn{2}{|l|}{ Contenidos } \\
\hline $\begin{array}{l}\text { Concepto de límite de una función en un } \\
\text { punto y en el infinito. Cálculo de límites. } \\
\text { Límites laterales. Indeterminaciones. }\end{array}$ & $\begin{array}{l}\text { Límite de una función en un punto y en el } \\
\text { infinito. }\end{array}$ \\
\hline \multicolumn{2}{|l|}{ Criterios de evaluación } \\
\hline $\begin{array}{l}\text { 2. Utilizar los conceptos de límite y } \\
\text { continuidad de una función aplicándolos en el } \\
\text { cálculo de límites y el estudio de la } \\
\text { continuidad de una función en un punto o un } \\
\text { intervalo. }\end{array}$ & No hay. \\
\hline \multicolumn{2}{|l|}{ Estándares de aprendizaje } \\
\hline $\begin{array}{l}\text { 2.1. Comprende el concepto de límite, realiza } \\
\text { las operaciones elementales de cálculo de los } \\
\text { mismos, y aplica los procesos para resolver } \\
\text { indeterminaciones. }\end{array}$ & No hay. \\
\hline
\end{tabular}

Tabla VI.2.1.1. Contenidos, criterios de evaluación y estándares de aprendizaje en torno al límite en el currículo de Bachillerato de LOMCE.

\begin{tabular}{|l|l|}
\hline $\mathbf{1}^{\mathbf{0}}$ Bachillerato & $\mathbf{2}^{\mathbf{0}}$ Bachillerato \\
\hline Contenidos & $\begin{array}{l}\text { Tipos de discontinuidad. Continuidad de una } \\
\text { función en un intervalo. Teorema de Bolzano. } \\
\text { Teorema de Weierstrass. }\end{array}$ \\
\hline $\begin{array}{l}\text { Continuidad de una función. Estudio de } \\
\text { discontinuidades. }\end{array}$ & $\begin{array}{l}\text { Continuidad de una función en un punto. } \\
\text { Criterios de evaluación }\end{array}$ \\
\hline $\begin{array}{l}\text { 2. Utilizar los conceptos de límite y } \\
\text { continuidad de una función aplicándolos en el } \\
\text { cálculo de límites y el estudio de la } \\
\text { continuidad de una función en un punto o un } \\
\text { intervalo. }\end{array}$ & $\begin{array}{l}\text { 1. Estudiar la continuidad de una función en } \\
\text { punto o en un intervalo, aplicando los } \\
\text { resultados que se derivan de ello. }\end{array}$ \\
\hline $\begin{array}{l}\text { Estándares de aprendizaje } \\
\begin{array}{l}\text { 2.2. Determina la continuidad de la función en } \\
\text { un punto a partir del estudio de su límite y del } \\
\text { valor de la función, para extraer conclusiones } \\
\text { en situaciones reales. }\end{array}\end{array}$ & $\begin{array}{l}\text { 1.1 Conoce las propiedades de las funciones } \\
\text { continuas, y representa la función en un } \\
\text { entorno de los puntos de discontinuidad. } \\
\text { 2.3. Conoce las propiedades de las funciones } \\
\begin{array}{l}\text { continuas, y representa la función en un } \\
\text { entorno de los puntos de discontinuidad. }\end{array}\end{array}$ \\
\hline
\end{tabular}

Tabla VI.2.1.2. Contenidos, criterios de evaluación y estándares de aprendizaje en torno a la continuidad en el currículo de Bachillerato de LOMCE.

De dicho documento se desprende que ambos conceptos aparecen en ambos cursos, y deberían, por tanto, definirse en los dos, pero el cálculo de límites y 
resolución de indeterminaciones debería establecerse en $1^{\circ}$, así como las propiedades de las funciones continuas (extensión de las propiedades de límites), y en $2^{\circ}$ debería darse mayor importancia a los teoremas de continuidad en entornos de un punto y en intervalos.

La propuesta educativa de estos contenidos se describe a continuación, siguiendo las orientaciones curriculares, que son de obligado cumplimiento, aunque sin incidir en la organización por cursos de los contenidos planteados.

\section{VI.2.2. Propuesta didáctica para límite de una función}

El primer elemento a considerar en relación al límite funcional es precisamente la definición de este concepto. Algunos LT presentan algunos ejemplos previos de funciones y el límite en algún punto, de forma que al establecer la definición los alumnos ya se hayan enfrentado a ejemplos del concepto que se está definiendo. En ese caso, se deben presentar ejemplos gráficos y verbales de diversas funciones: continuas, no continuas, con límite finito, con límites infinitos, que no tienen límite... También sería interesante presentar ejemplos de funciones concretas que provengan de distintas funciones elementales: polinómicas, racionales, exponenciales, trigonométricas...

Una vez expuesta la idea, se debe definir el límite, y la definición debe ser lo suficientemente rigurosa como para que permita la realización de algunas demostraciones, pero, en lo posible, exenta de formalismo. Una de las definiciones más extendida es la definición métrica expresada en términos de $\varepsilon-\delta$, pero esta definición suele ser fuente de problemas de comprensión para los alumnos (por ejemplo, Blázquez, Gatica, Ortega, y Benegas, 2006, comprobaron que la definición métrica tiene unas dificultades asociadas al simbolismo $\varepsilon-\delta$ y al valor absoluto difíciles de superar por los alumnos. Por otra parte, según Blázquez, Gatica y Ortega, 2009, la definición métrica es más difícil de recordar) que la definición que aquí se reproduce dada por Blázquez y Ortega (2002). Por esta razón, y atendiendo a las investigaciones en torno al límite realizadas desde la perspectiva de los alumnos, se considera que la definición propuesta por Blázquez y Ortega es la más apropiada para este nivel educativo, pues es tan rigurosa como la métrica, pero menos formal, y es susceptible de aplicarla con 
suma facilidad para demostrar teoremas. Se presentan dos definiciones equivalentes:

Definición 1: el límite de la función $f$ en $x=a$ es $L$ si para cualquier aproximación $K$ de $L, K \neq L$, existe una aproximación $H$ de $a, H \neq a$, tal que las imágenes de todos los puntos que están más cerca de $a$ que $H$ (excluido a) están más próximas a $L$ que $K$. Se escribe $\lim _{x \rightarrow a} f(x)=L$

O bien, expresándolo en términos de entornos, que puede resultar más cómodo de trabajar, la definición 1 se puede traducir a la definición 2.

Definición 2: el límite de la función $f$ en $x=a$ es $L$ si para cualquier aproximación $K$ de $L, K \neq L$, existe un entorno reducido de $a$, tal que las imágenes de todos los puntos de dicho entorno están más próximas a $L$ que $K$. Se escribe $\lim _{x \rightarrow a} f(x)=L$

Análogamente, se definen en estos términos el límite infinito de una función en un punto, el límite finito de una función en el infinito y el límite infinito de una función en el infinito. Una vez establecidas las definciones, se estudiarán algunas propiedades del límite de forma axiomática. En concreto se deben demostrar los dos teoremas que siguen. En ambos casos se escriben sus demostraciones correspondintes porque la definición precedente no figura en los textos de Secundaria (ni en otros) y, por tanto, puede resultar un tanto extraña su aplicación. Para ello se considara que cualquier número real es una aproximación de otro (aunque estén muy alejados uno de otro y la aproximación sea muy grosera, viene a ser equivalente a $\forall \varepsilon>0$ ):

Teorema 1: Si una función tiene límite en $x=a$, entonces dicho límite es único.

Este teorema se puede justificar con un EP axiomático, de tipo directo (se utiliza la definición) dado que es muy sencillo y, además, permite utilizar el método de reducción al absurdo.

Demostración: supongamos que la función $f$ tiene límite finito en un punto $x=a$, y que dicho límite no es único, es decir, existen $L$ y $M, L<M$, tales que

$$
\lim _{x \rightarrow a} f(x)=L \operatorname{yim}_{x \rightarrow a} f(x)=M
$$

Se considera $K=\frac{L+M}{2}$. Como $K$ es una aproximación de $L$, existe un entorno reducido $E$ de $a$ tal que las imágenes de todos sus puntos son menores que $K$.

Por otro lado, como $K$ es una aproximación de $M$, existe un entorno reducido $G$ de $a$ tal que las imágenes de todos sus puntos son mayores que $K$.

Pero entonces, $E$ y $G$ son dos entornos reducidos de $a$ tales que las imágenes de su intersección son mayores y menores que $\mathrm{K}$, lo cual es imposible.

Hemos llegado a una contradicción y, por tanto, no puede ser que $L<M$. 
Análogamente, se justificaría que no puede ser $L>M$, y por tanto, la única opción posible es $L=M$, es decir, que el límite de $f$ en $x=a$ ha de ser único.

Además, También, como alternativa, se puede presentar una prueba preformal como utilizada por González (2012, pp. 316). Sólo hay que considerar una función particular y seguir con esa función todos los razonamientos descritos; por ejemplo, considerando la función seno y $a=\pi / 4$, en la prueba anterior sólo hay que sustituir $f$ por sen y a por $\pi / 4$.

Teorema 2: Si el límite, $L$, de una función en un punto $x=a$, es positivo, existe un entorno reducido de $a$ en el que la función es positiva (Análogamente, si $L$ es negativo, existe un entorno reducido de $a$ en el que la función es negativa).

Demostración: Como 0 es una aproximación de $L$, existe un entorno reducido de $a$ en el que las imágenes de todos sus puntos mejoran dicha aproximación y, por tanto, todas deben ser positivas. Análogamente, se demostraría para el caso en que $L$ sea negativo.

También debe establecerse el siguiente teorema, que será de utilidad en el capítulo de continuidad, y que se deduce directamente de la definición 2 de límite

Teorema 3: Si una función, $f$, tiene límite, $L$, en $x=a$, entonces existe un entorno reducido de $a$ en el que la función está acotada.

A continuación, deben definirse los límites laterales, utilizando una definición análoga a la planteada anteriormente para, a continuación, establecer el siguiente teorema:

Teorema 4: $L$ es el límite de una función $f$ en $x=a$, si, y sólo si, existen los límites laterales de $f$ en $x=a$ y ambos coinciden ( $\operatorname{son} L$ ).

En este caso se debe justificar este teorema mediante un EP axiomático, escribiendo las tres definiciones y explicado verbalmente que la definición de límite es equivalente a la conjunción de las definiciones de límites laterales. También podría utilizarse un EP inductivo de 1 caso con ayuda de un diagrama.

Lo siguiente a considerar es la aplicación del concepto de límite funcional al cálculo de límites. Si bien existe una serie de teoremas y propiedades que simplifican el cálculo, y que se presentan más adelante, es más importante que los alumnos entiendan el concepto que el cálculo mecánico y repetitivo. Por esta razón, los alumnos debieran comprender que las aproximaciones de $x$ a $a$ (el entorno reducido de $x=a$ ) dependen del propio punto, de la función y de la aproximación fijada $K$ de $L$. En el caso de la definición métrica, esta dependencia se expresaba en términos del $\delta$, que debía depender de $\varepsilon$, de la función, y de $a$. 
En el caso de las definiciones 1 y $2, H$ (o el entorno reducido de $a$ ) depende de la función, de a y de la aproximación tomada, $K$. Esto permite el cálculo de límites aplicando directamente el concepto, y utilizando diferentes sistemas de representación. Por ejemplo, se pueden utilizar tablas numéricas en las que se realiza un proceso como el descrito en la definición, proceso que sin ser un método riguroso y formal, permite una mejor comprensión del significado de límite funcional. Supongamos que $f(x)=x^{2}-1$, y que queremos determinar el límite de $f$ en el punto $x=1$. Se genera una tabla de aproximaciones a $x=1(x \neq 1) \mathrm{y}$ de las correspondientes imágenes.

\begin{tabular}{llll}
\hline \multicolumn{4}{l}{ Tabla de evaluación de $\boldsymbol{f}(\boldsymbol{x})=\boldsymbol{x}^{\mathbf{2}}-\mathbf{1}$ en puntos próximos a $\boldsymbol{x}=\mathbf{1 .}$} \\
$\boldsymbol{x}$ & $\boldsymbol{f}(\boldsymbol{x})$ & $\boldsymbol{x}$ & $\boldsymbol{f}(\boldsymbol{x})$ \\
\hline 1,1 & 0,21 & 0,9 & $-0,19$ \\
1,01 & 0,0201 & 0,99 & $-0,0199$ \\
1,001 & 0,002001 & 0,999 & $-0,001999$ \\
1,0001 & 0,00020001 & 0,9999 & $-0,00019999$ \\
1,00001 & 0,0000200001 & 0,99999 & $-0,0000199999$ \\
1,000001 & 0,000002000001 & 0,999999 & $-0,000001999999$ \\
$\rightarrow 1^{+}$ & $\rightarrow 0^{+}$ & $\rightarrow 1^{-}$ & $\rightarrow 0^{-}$ \\
\hline
\end{tabular}

Tabla VI.2.2.1. Ejemplo de tabla para el cálculo numérico del límite de una función en un punto, aplicando la definición.

Atendiendo a la Tabla VI.2.1.1, se puede observar que cuando $x$ tiende a $1, f(x)$ tiende a 0 . Teniendo en cuenta los valores de la tabla o de otras similares, los alumnos concluyen sin dificultad que el límite es 0 . Si se considera una aproximación del límite de $f$ en $x=1$, por ejemplo, 0 ’02, se puede buscar en la tabla un valor de $x$ tal que las imágenes de cualquier aproximación de 1 que esté más cerca de 1 que la encontrada mejoran la aproximación de 0’21 (En este caso $\mathrm{H}=1,001$ o bien $\mathrm{H}=0,999)$, que es precisamente lo que dice la definición 1 . Observa que la Tabla VI.2.1.1 es un pequeño ejemplo, es decir, muestra muy pocas aproximaciones, pero se podrían considerar otras tablas más extensas, otras funciones y otros puntos en los que calcular el límite para comprobar la dependencia de H. De esta forma, antes de empezar con el cálculo algebraico en el que se aplican una serie de reglas, y que permite la mecanización hasta el punto de no necesitarse la comprensión del concepto, un trabajo basado en estos ejemplos permite "visualizar" la esencia del mismo, y fundamentar el cálculo posterior. Además, también pueden utilizarse otros sistemas de representación para realizar esta visualización, como por ejemplo, el gráfico. 
Una vez comprendido el concepto, deben presentarse aquellos teoremas que facilitan el cálculo de límites.

Teorema 5: $\lim _{x \rightarrow a} x=a$.

Teorema 6: si f y g son dos funciones tales que $L_{1}$ es el límite de $f$ en $x=a$ y $L_{2}$ es el límite de $g$ en $x=\mathrm{a}$, entonces se cumple que:

- $\lim _{x \rightarrow a}(f(x)+g(x))=L_{1}+L_{2}$

- $\lim _{x \rightarrow a}(f(x)-g(x))=L_{1}-L_{2}$

- $\lim _{x \rightarrow a}(f(x) \cdot g(x))=L_{1} \cdot L_{2}$

- Si existe un entorno de $a$ tal que para todo $x$ de dicho entorno, $g(x) \neq 0$, y $L_{2} \neq 0$, entonces $\lim _{x \rightarrow a}(f(x) / g(x))=L_{1} / L_{2}$

Además, se debe establecer que la primera regla para el cálculo de límites es sustituir la variable dependiente por el valor en el que se quiere calcula el límite. Es decir, con la aplicación de los teoremas 5 y 6 anteriores, puede realizarse el cálculo de muchos límites sencillos. Del teorema 6, sería suficiente con demostrar con un EP axiomático (en la misma línea que los teoremas anteriores o una prueba preformal) el límite de la suma y obviar las otras dos, ya que son pruebas más complejas y quizá se deba invertir demasiado tiempo en la presentación de las mismas.

A continuación, debería establecerse el límite de las funciones básicas elementales (potenciales, exponenciales, logarítmicas, trigonométricas) que, junto con la composición de funciones, permitiría el cálculo de la mayoría de funciones que pueden aparecer en estos niveles.

Esto permite establecer la aritmética del cálculo de límites. Dicha aritmética debe extenderse al cálculo de límites en los que interviene el infinito, teniendo en cuenta la aritmética extendida:

$$
\frac{\rightarrow \infty}{\rightarrow \mathrm{K}}=\rightarrow \infty ; \frac{\rightarrow 0}{\rightarrow \mathrm{K}}=\rightarrow 0 ; \frac{\rightarrow 0}{\rightarrow \infty}=\rightarrow 0 ; a^{\rightarrow+\infty}=\rightarrow \infty \text {, si } a>1 ; \text { etc. }
$$

Por último, quedaría el estudio de las indeterminaciones, que son casos en que la sustitución de la variable por el valor al que tiende no es suficiente para establecer el límite de la función considerada, sino que es necesario realizar el estudio en cada caso.

$$
\stackrel{\rightarrow 0}{\rightarrow 0} ; \frac{\rightarrow \infty}{\rightarrow \infty} ; \rightarrow 0 \cdot \rightarrow \infty ; \rightarrow 1^{\rightarrow \infty} ; \rightarrow \infty \rightarrow 0 ; \rightarrow 0^{\rightarrow 0} ; \rightarrow \infty-\rightarrow \infty
$$

En este momento se expondrían una serie de técnicas, ilustradas mediante ejemplos variados, de cálculo de límites para cada tipo de indeterminación (como las que se han visto en el apartado correspondiente del capítulo de límites). 
En todos los casos en los que se han presentado límites (aritmética extendida e indeterminaciones), se ha utilizado el símbolo " $\rightarrow$ " para denotar que lo que se expresa es un límite, y no un número. Téngase en cuenta que cuando se calcula el límite de una función en un punto, se indica el valor al que tiende la función, y no el valor que toma en dicho punto (ya que ni siquiera tiene por qué existir esa imagen). Por otro lado, algunas de las expresiones que se han escrito $\left(\frac{\rightarrow 0}{\rightarrow 0}\right)$ ni siquiera existirían, pues, por ejemplo, la división entre cero no está definida y, sin embargo, si lo está el cociente entre números que son aproximaciones a cero.

Por otro lado, obsérvese que todos los teoremas enunciados están expresados en términos de condición suficiente (o condición necesaria y suficiente) y con las hipótesis y la tesis bien diferenciadas, para facilitar al estudiante su diferenciación y su posterior justificación.

\section{VI.2.3. Propuesta didáctica para continuidad}

El concepto de continuidad es más sencillo que el límite para quien haya comprendido este último, al menos su presentación de forma intuitiva. Muchos LT lo introducen mediante la idea de que las funciones continuas son aquellas que pueden dibujarse sin levantar el lápiz del papel. Esta imagen puede ser un buen punto de partida, así como una serie de ejemplos de funciones continuas, presentados de forma gráfica y verbal, y elegidos sistemáticamente, de forma similar a la propuesta de límites.

En cuanto a la formalización del concepto, conviene tener en cuenta que la continuidad es una "extensión" del concepto de límite, en el que se sustituye el trabajo en entornos reducidos del punto en el que se calcula el límite por entornos de dicho punto, es decir, que contienen al punto. Por esta razón, la definición que debe presentarse de continuidad es la que está expresada en función del límite mediante tres condiciones:

Definición 1: Una función $f$ es continua en un punto $x=a$, si se cumplen las siguientes condiciones:

1. La función está definida en a, es decir, existe $f(a)$.

2. La función tiene límite en $x=a$, es decir, existe $\lim _{x \rightarrow a} f(x)=L$.

3. $f(a)=L$. 
No es necesaria la traducción de esta definición a enunciados en términos del valor absoluto, o de $\varepsilon-\delta$, como se ha observado en algunos LT, dado que es suficientemente formal para ser utilizada en demostraciones o justificaciones, y porque el trabajo realizado en límites habría sido en vano. Por el contrario, todos los teoremas establecidos para límites se pueden extender a funciones continuas sin más que incluir al punto $x=a$ de la definición y sustituir $L$ por $f(a)$.

Una vez definida la continuidad, deben plantearse ejemplos en los que alguna de las condiciones falle. Esto da lugar a las discontinuidades (evitables, no evitables de salto finito, de salto infinito o de no existencia de algún límite lateral)

El siguiente paso, donde la continuidad se vuelve una propiedad interesante, es la extensión del concepto a intervalos cerrados. De hecho, la continuidad en un punto carece de interés por sí sola, salvo en los casos de discontinuidad, por lo que resulta imprescindible enunciar la continuidad en intervalos. Para ello, de forma análoga a lo realizado en límites, se presentaría la definición de continuidad lateral y, seguidamente, la definición de continuidad en un intervalo cerrado.

La continuidad en un intervalo cerrado da lugar a teoremas muy interesantes. Dos de ellos, deben aparecer obligatoriamente en los LT puesto que las directrices curriculares los incluyen en los contenidos de $2^{\circ}$ de bachillerato (Conserjería de Educación de Castilla y León, 2015): teoremas de Bolzano, Darboux y de Weierstrass. A continuación se presentan dichos teoremas, en un orden adecuado desde el punto de vista didáctico y matemático, en cuya redacción (inspirada en Spivak, 1981), se evita la utilización de palabras excesivamente coloquiales (toma, alcanza,...) y se presentan expresiones más propias del lenguaje matemático, dejando que el profesor utilice vocabulario más general en sus explicaciones o debates. Además, los títulos incluyen referencias al contenido del teorema y no sólo el nombre del matemático que les da nombre (en el caso de Bolzano, Darboux y Weierstrass), aunque una vez presentados, se puede hacer referencias a ellos sólo por el nombre que contiene al matemático (para abreviar).

Teorema de acotación: Si una función $f$ es continua en un intervalo cerrado y acotado $[a, b]$, entonces la función $f$ está acotada en dicho intervalo $[a, b]$.

En el caso de este teorema es conveniente utilizar un EP inductivo de varios casos. Se pueden considerar las funciones $x^{3}-2 x+3, \tan (x), \log _{2}(x)$ en intervalos 
cerrados y acotados apropiados y ver qué ocurre con las dos últimas en intervalos abiertos,

Teorema de los ceros de Bolzano: Si una función, $f$, es continua en un intervalo cerrado y acotado $[a, b]$ y las imágenes de los extremos del intervalo tienen (son de) signos distintos $(f(a)<0$ y $f(b)>0$ o $f(a)>0$ y $f(b)<0)$, entonces, existe al menos un punto $c \in(a, b)$ tal que $f(c)=0$.

Entre las posibles justificaciones de este teorema se pueden considerar las siguientes: como una posible alternativa a la demostración formal, se propone una prueba preformal con una función sencilla y conocida por los alumnos, por ejemplo, $f(x)=x^{3} / 2-2 x+5 / 3$ en el intervalo $[-3,2]$. En esta prueba se reproduciría el método de bisección, se construiría la sucesión de intervalos encajados, y además su representación gráfica muestra la posibilidad de más de un punto en el que se anula la función. Por otra parte, no se trata de una función monótona y es un representante de las funciones más usuales en estos niveles, las polinómicas. Además, el ejemplo nos permite el tratamiento algebraico del modelo, aislando las raíces y mostrando cómo se aplica el método de bisección (lo que se relaciona con la función de descubrimiento de la demostración). También acompañaríamos la justificación con algunos ejemplos de funciones que no cumplen las hipótesis, uno para cada una de estas hipótesis, además de representaciones gráficas tanto de la función considerada, del proceso de encaje de intervalos, y de los ejemplos en los que fallan las hipótesis.

Teorema de los valores extremos de Weierstrass: Si una función es continua en un intervalo cerrado y acotado $[a, b]$, entonces la función tiene un mínimo y un máximo en dicho intervalo, es decir, existen al menos dos valores $c$ y $d$ del intervalo $[a, b]$ tales que $f(c) \leq f(x) \leq f(d)$ para todo $x$ del intervalo $(f(c)$ es el mínimo de la función en $[a, b]$ y $f(d)$ es el máximo). .

En este caso, al tratarse de uno de los teoremas de mayor dificultad de demostración de los considerados en la propuesta didáctica realizada, se dejaría a juicio del profesor el EP que debe considerar, en función del nivel de su grupo de alumnos. Dado que se ha establecido previamente el teorema de acotación, se puede realizar tanto la prueba axiomático-transformacional del teorema, o bien, la prueba preformal correspondiente (como la presentada por González, 2012, pp. 320). En el caso de que cualquiera de los procesos anteriores sea demasiado complejo, se puede utilizar un EP inductivo de varios casos, tanto de forma gráfica como algebraica, considerando representantes de algunas familias de 
funciones elementales: polinómicas, racionales, exponenciales, trigonométricas o logarítmicas. También sería adecuado mostrar ejemplos en los que no se cumplen las hipótesis.

Teorema de los valores intermedios de Darboux: $\operatorname{Si} f$ es continua en $[a, b]$, entonces todos los valores entre el mínimo, $m$, y el máximo, $M$, de la función en $[a, b]$ son imágenes de al menos un valor del intervalo $[a, b]$. Es decir, para cualquier número $y_{0}$ del intervalo $[m, M]$, existe al menos un $x_{0} \epsilon[a, b]$ tal que $f\left(x_{0}\right)=y_{0}$ (en realidad, si el mínimo y el máximo son las imágenes de $x_{1}$ y $x_{2}$, respectivamente, $x_{0} \epsilon\left[x_{1}, x_{2}\right]$ o $\left.x_{0} \in\left[x_{2}, x_{1}\right]\right)$.

En este caso se puede optar por un EP axiomático, ya que la prueba es inmediata como una aplicación del teorema de Bolzano. De esta manera, se muestran al alumno pruebas realizadas sobre objetos generales, y no sólo sobre ejemplos concretos (pruebas preformales). Además, convendría acompañar la justificación de ejemplos gráficos que ilustren la situación del teorema en funciones no solo monótonas (que son las que suelen presentar en su mayoría los LT).

Además, se deben presentar otros resultados que complementen a estos tres y tales que sus justificaciones sean fáciles de establecer aplicando los teoremas anteriores, pero como ejercicios de aplicación para que los puedan realizar (intentar) los alumnos.

\section{VI.3. APORTACIONES DE LA TESIS}

Fruto de la investigación aquí desarrollada, se obtienen unos resultados que realizan una aportación al campo de conocimiento que nos ocupa, la Didáctica de la Matemática. Estas aportaciones, enriquecen el conocimiento en este campo sobre uno de los elementos más importante de las matemáticas, la demostración matemática, y en torno a uno de los elementos más usados en las aulas de Educación Secundaria, el libro de texto. Las aportaciones que se han realizado en este campo son las siguientes:

- Desarrollo de un marco teórico adecuado para el análisis de los teoremas y sus demostraciones en los libros de texto.

Como ya se ha mencionado anteriormente, la demostración matemática es un elemento vital de las Matemáticas, y ha recibido una atención especial por parte 
de los investigadores del campo de la Didáctica de la Matemática. Esta especial atención ha hecho que la investigación en torno a este elemento haya sido abundante, estudiándose desde diferentes perspectivas. También el análisis de libros de texto ha recibido una especial atención. Sin embargo, la combinación de estos dos elementos, hasta no hace muchos años, no ha sido objeto de muchas investigaciones.

En este caso, el germen de esta investigación se encuentra en los trabajos de Ibañes (2001), Ibañes y Ortega (2001b) y González (2012). En estos trabajos, estos autores observaron que la utilización de los esquemas de prueba y las pruebas preformales es un recurso valioso para favorecer el aprendizaje de los teoremas matemáticos y de la demostración matemática. Teniendo en cuenta estos resultados, se hacía imprescindible el estudio del tratamiento de este elemento en los libros de texto, razón por la cual se planteó esta investigación. Ibañes y Ortega $(1997,2001 b)$ ya hicieron algunos análisis en este sentido y comenzaron la construcción de un marco teórico orientado hacia este tipo de análisis. Tomando como punto de partida dicho marco teórico, se ha desarrollado el que aquí se presenta, que ha resultado de extrema utilidad para realizar el análisis previsto.

El desarrollo de este marco no ha sido inmediato ni trivial. Del trabajo de Ibañes y Ortega se desarrolló una primera versión, utilizada en Conejo y Ortega (2013) y presentada para su discusión en el seno del grupo de investigación de Didáctica del Análisis Matemático en la reunión intermedia de Alicante de 2013. Esta primera presentación ante un grupo de investigadores expertos provocó una redefinición de algunas categorías, que mejoró el marco y facilitaba su aplicación. Un proceso similar se ha llevado a cabo en congresos posteriores (Conejo, Arce y Ortega, 2014 y 2015), lo que ha llevado al establecimiento de las categorías de análisis tal y como se presentan en esta memoria, y que han permitido un análisis completo del elemento seleccionado, la Demostración Matemática, en los libros de texto.

- Revisión histórico-curricular tanto de los documentos curriculares como de los libros de texto (perspectiva histórica del tema).

Previo al análisis de los libros de texto, y dado que los documentos curriculares son el primer nivel de concreción curricular en nuestro sistema educativo, se 
realizó una revisión histórica de los documentos curriculares correspondientes a los libros analizados en el presente trabajo. Esta revisión, que no es la primera que se hace en este sentido, se efectuó desde la perspectiva de la demostración matemática en primer lugar, y desde la perspectiva de los conceptos analizados en segundo lugar.

Ibañes y Ortega (2002a) ya hicieron una revisión histórica en este sentido, en la que incluyeron legislaciones anteriores a las consideradas en este trabajo, y que nos sirvió de punto de partida. No obstante, se han producido dos cambios de legislación educativa desde entonces (LOE y LOMCE), por lo que ha sido necesaria una actualización de dicha revisión. Esta revisión nos ha servido para comprobar que la demostración matemática tiene un papel importante en el currículo de este nivel educativo, y que su presencia no sólo no ha sido relegada a un segundo plano, sino que cada vez tiene mayor importancia, apareciendo como elemento transversal en el Bloque 1 de las Matemáticas I y II de LOMCE (Ministerio de Educación, Cultura y Deporte, 2015 y Conserjería de Educación de Castilla y León, 2015).

- Análisis de los enunciados y las justificaciones de los teoremas que aparecen en los libros de texto de los últimos cursos de la Educación Secundaria (BUP, COU y Bachillerato).

Si bien los conceptos de límites y continuidad se han estudiado en los libros de texto en otras investigaciones (consultar el capítulo de Antecedentes), no se han realizado hasta la fecha análisis históricos de libros de texto desde la perspectiva de la justificación de los teoremas relacionados con estos conceptos del Análisis Matemático. Por ello, el presente trabajo supone una innovación en este campo y muestra una perspectiva histórica del tratamiento de la demostración.

- Realización de una propuesta didáctica fundamentada en los resultados extraídos del análisis realizado.

En el apartado anterior se ha presentado una propuesta didáctica fundamentada en los resultados de esta investigación. El objetivo de esta propuesta es mejorar las que aparecen en los libros de texto, subsanando los errores y deficiencias encontrados e introduciendo elementos innovadores, como la utilización de las 
pruebas preformales. Todo ello está encaminado hacia una mejora de la docencia de los teoremas del Análisis Matemático relacionados con el límite funcional y la continuidad, desde la perspectiva de la demostración. Por esta razón, se ha buscado un equilibro en el que ambos elementos se combinen para dar lugar a propuestas que favorezcan ambos aprendizajes.

\section{VI.4. DIFICULTADES Y FORTALEZAS}

Como todo trabajo de investigación, en el desarrollo del que aquí se presenta se han tenido que superar algunos obstáculos que han dificultado su realización, pero dicha superación ha conseguido algunas fortalezas, que hacen que el aprendizaje obtenido en esta investigación sea mayor y más valioso. Entre las dificultades encontradas están:

- La distancia entre los centros de trabajo de la doctoranda (Facultad de Educación de Soria, Universidad de Valladolid) y el director de la tesis (Facultad de Educación y Trabajo Social, Universidad de Valladolid). Esta distancia provoca que las reuniones de trabajo en torno a la tesis no sean tan frecuentes o extensas como se desearía, o que, en ocasiones, no se puedan resolver directamente las dudas que al investigador se la han presentado en el desarrollo del trabajo en el momento en que se producen haya que esperar a la siguiente reunión. No obstante, la atención incondicional del director, y la utilización de otros medios de comunicación como el correo electrónico o el teléfono, ha permitido salvar dicha distancia, y ha facilitado la consecución de esta memoria.

- La búsqueda y localización de los ejemplares de los libros de texto que componen la muestra de las legislaciones derogadas, sobre todo, del periodo de la LOGSE. Se ha recurrido a los profesores conocidos por el director de la tesis o la doctoranda, que han consultado las bibliotecas de los institutos en los que trabajan, y a la Red de Bibliotecas Universitarias Españolas (REBIUN), a través de la cual hemos localizado varios ejemplares. No obstante, al tratarse de textos de naturaleza efímera (por las constantes actualizaciones que realizan las editoriales, el público especializado hacia el que se dirigen y los sucesivos cambios de legislaciones) no es habitual que se conserven muchos ejemplares. 
Además, los LT más difíciles de encontrar han sido los del periodo de la LOGSE, ya que, al parecer, los LT de la LGE son mejor valorados por los contenidos matemáticos que se encuentran en ellos (mayor nivel, mayor rigor). Por otro lado, de alguna de las editoriales se han localizado más de una colección de un mismo periodo, y se han observado notables diferencias, lo que suscita un interés en la comparación de LT de la misma editorial y del mismo periodo, pero cuyo estudio está sujeto a la disponibilidad de la muestra.

Por otro lado, entre las fortalezas de este trabajo se encuentran los siguientes aspectos:

- A pesar de las dificultades en la localización de LT, se ha reunido una extensa colección de libros de texto. Además de los que se han utilizado en el estudio (28 analizados de los 33 correspondientes a la muestra del estudio), se han localizado otros que no se han utilizado por pertenecer a las ramas de Ciencias Sociales: 2 de COU y uno de $2^{\circ}$ de Bachillerato de LOGSE. Dichos ejemplares nos permitieron observar que en dicha rama se presentaban menos teoremas y menos justificaciones que en las de Ciencias, y que no resultaban de interés en nuestro estudio. Además, la localización de esta muestra nos permite conservar esta colección para estudios futuros.

- En el desarrollo de este trabajo se han utilizado la combinación de dos metodologías, el método histórico de investigación en Educación de RuizBerrio (1976) y la metodología de investigación en Educación de Fox (1981), dando lugar a una nueva metodología creada propiamente para este estudio. Se considera que la metodología creada resulta totalmente adecuada para este tipo de estudios, en los que se analizan documentos, algunos con un carácter histórico (libros de texto y documentos curriculares de las legislaciones derogadas), bajo la perspectiva de un marco teórico, que se ha adaptado a las características del estudio. Además, esta metodología sirve como guía en el estudio y permite su elaboración de forma sistemática y científicamente adecuada.

- El estudio realizado es totalmente reproducible y se puede aplicar a otros contenidos curriculares de Bachillerato, sean o no de Análisis Matemático 
y, por qué no, a contenidos de grados universitarios de cualquier rama de la matemática En todos los casos se utilizaría el marco teórico desarrollado en esta tesis doctoral para analizar los contenidos correspondientes, aunque quizá en algún caso habría que adaptar alguna categoría de análisis.

- El marco teórico utilizado puede ser útil como herramienta profesional para docentes en ejercicio, tanto a la hora de comparar LT desde el punto de vista del tratamiento de la demostración, como a la hora de diseñar secuencias didácticas relacionadas con la demostración y el razonamiento.

\section{VI.5. PERSPECTIVAS DE FUTURO}

Si bien la presente investigación ha realizado varias aportaciones al corpus de conocimiento de la Didáctica de la Matemática, no es un trabajo cerrado, sino que abren nuevos caminos de estudio para futuras investigaciones. Algunos de los nuevos caminos son los siguientes:

- Elaborar un "mapa" de la justificación en Bachillerato. El objetivo sería realizar un análisis completo de los libros de texto de los niveles de $1^{\circ}$ y $2^{\circ}$ de Bachillerato, de todas las áreas de las matemáticas integradas en estos niveles educativos, y establecer qué teoremas aparecen en cada curso, cuáles de ellos se demuestran, qué características diferencian las demostraciones de distintas ramas... No obstante, entre los criterios de evaluación de las asignaturas de Matemáticas I y II de Bachillerato se indica que el alumno debe "realizar demostraciones sencillas de propiedades o teoremas relativos a contenidos algebraicos, geométricos, funcionales, estadísticos y probabilísticos" (Conserjería de Educación de Castilla y León, 2015, pp. 32729). Además, este estudio podría suponer el inicio de una investigación que analice la presencia y evolución de la demostración matemática en otras etapas educativas: en qué momento empiezan a aparecer demostraciones y justificaciones, de qué tipo, en qué área. No obstante, en el panorama internacional se han encontrado otros trabajos en los que se analiza la demostración matemática, las justificaciones o el razonamiento en libros de texto, y en los que se han desarrollado marcos teóricos que parten del concepto de esquema de 
prueba (Stacey \& Vincet, 2008 y 2009, Dolev, 2011, Dolev \& Even, 2015, y Silverman \& Even, 2015), por lo que la presente investigación contribuye a ampliar el conocimiento sobre este campo.

- En la misma línea del punto anterior, sería interesante realizar una comparación profunda de los marcos teóricos desarrollados a partir del concepto es esquema de prueba para el análisis de la demostración en los libros de texto, en concreto, del marco que se ha presentado en la presente investigación y el desarrollado por Stacey \& Vincent (2008 y 2009) y utilizado posteriormente (Dolev, 2011, Dolev \& Even, 2015, y Silverman \& Even, 2015).

- Otro aspecto interesante a estudiar sería explorar las oportunidades de justificación ofrecidas en los LT, siguiendo el ejemplo de Hanna \& de Bruyn (1999). En el presente trabajo se ha analizado principalmente la parte de contenidos de los LT, y sólo se ha incluido algún ejercicio o problema resuelto cuando el propio LT ha hecho referencia a él en el desarrollo de la teoría. Por tanto, es una cuestión abierta el análisis de los ejercicios y problemas propuestos y/o resueltos en el LT desde el punto de vista de la demostración: si se piden demostraciones, de qué tipo de resultados, con qué frecuencia...

- Ya se ha mencionado en el desarrollo del trabajo que las categorías en las que más se ha puesto el foco de atención son las de esquemas de prueba y funciones de la demostración, si bien se han considerado otras en el marco teórico. Sería conveniente refinar los análisis y estudiar las relaciones entre las diversas categorías y como unas influyen en otras. Por ejemplo, Ibañes (2001) observó que la estructura de los enunciados condiciona el esquema de prueba. Aunque en esta investigación se han analizado los enunciados, no se ha profundizado en la relación existente entre ellos reflejada en los libros de texto, por lo que queda como una cuestión abierta. Otros análisis interesantes serían:

La vinculación entre el tipo de EP utilizado por los libros de texto y el grado de función explicativa en las justificaciones, y que la combinación de ambos aspectos puede categorizar a los libros de texto en niveles explicativos. 
$>$ La utilización de gráficas y de pruebas visuales y su relación con la función de explicación.

$>$ El lenguaje utilizado, la relación con los esquemas de prueba y las funciones que se reflejan.

- En última instancia, continuando con el trabajo desarrollado por Ibañes(2001), Ibañes y Ortega (2001b) y González (2012), en los que se llevaron a cabo experiencias de aula con alumnos utilizando diferentes esquemas de prueba los primeros, y pruebas preformales el segundo, sería conveniente investigar si las recomendaciones planteadas en el apartado de propuesta didáctica contribuyen a una mejora de la enseñanza y el aprendizaje de la demostración matemática y elaborar unidades didácticas que puedan sean implementadas en el aula por profesores en ejercicio para responder a los siguientes interrogantes: ¿Favorece la comprensión de los conceptos? ¿Favorece la comprensión de la demostración? ¿Son viables?

Por tanto, son varias las líneas abiertas para trabajos de investigación posteriores, con lo que se concluye que el trabajo aquí presentado no supone más que otro paso que ha generado conocimiento sobre la enseñanza y el aprendizaje de la demostración matemática, que parte de los muchos trabajos realizados previamente, pero que de ningún modo supone el final del camino. 


\section{REFERENCIAS}

Alibert, D. y Thomas, M. (1991). Research on mathematical proof. En Tall (Ed.): Advanced Mathematical Thinking. Kluwer Academic Publishers, 215-230.

Aparicio, E. y Cantoral, R. (2003). Sobre la noción de continuidad puntual: Un estudio de las formas discursivas utilizadas por estudiantes universitarios en contextos de geometría dinámica. Epsilón 56 (2), 169-198.

Aparicio, E. y Cantoral, R. (2006). Aspectos discursivos y gestuales asociados a la noción de continuidad puntual. RELIME, 9 (1), 7-30.

Arcavi, A. (2003). The role of visual representations in the learning of mathematics. Educational Studies in Mathematics. 52(3), 215-241.

Arce, M. y Ortega, T. (2013). Deficiencias en el trazado de gráficas de funciones en estudiantes de bachillerato. En Berciano, A., Gutiérrez, G., Estepa, A. y Climent, N. (Eds.), Investigación en Educación Matemática XVII (147-155). Bilbao: Sociedad Española de Investigación en Educación Matemática.

Arsac, G. (1988). Les recherches actuelles sur l'apprentissage de la démonstration et les phénomènes de validation en France. Recherches en Didactique des Mathématiques, 9(3), 247-280.

Artigue, M. (1995). La enseñanza de los principios del cálculo: problemas epistemológicos, cognitivos y didácticos. En P. Gómez (Ed.), Ingeniería didáctica en educación matemática: un esquema para la investigación y la innovación en la enseñanza y el aprendizaje de las matemáticas, pp. 97-140. México: Grupo Editorial Iberoamérica.

Azcárate, C. y Camacho, M. (2003).Sobre la Investigación en Didáctica del Análisis Matemático. Boletín de la Asociación Matemática Venezolana, X (2), 135-149.

Azcárate, P. y Serradó, A. (2006). Tendencias didácticas en los libros de texto de matemáticas para la ESO. Revista de Educación, 340, 341-378. 
Baker, M. (2003). Computer-mediated argumentative interactions for the co-elaboration of scientific notions. In J. Andriessen, M. Baker \& D. Suthers (Eds.), Arguing to learn: Confronting cognitions in computer-supported collaborative learning environments, pp. 4770. Dordrecht: Kluwer.

Balacheff, N. (1987). Processus de preuve et situations de validation. Educational Studies in Mathematics, 18, 147-176.

Balacheff, N. (1988). Aspects of proof in pupils' practice of school mathematics. Mathematics Teachers and Children, 216, 235.

Ball, D. L. \& Bass, H. (2003).Making mathematics reasonable in school. In J. Kilpatrick, W. G. Martin \& D. Shifter (Eds.), A research companion to principles and standards for school mathematics, pp. 27-44. Reston, VA: National Council of Teachers of Mathematics.

Bell, A. W. (1976). A study of pupils' proof-explanations in mathematical situations. Educational Studies in Mathematics, 7, 23-40.

Bell, A. W. (1979). The learning of process aspects of mathematics. Educational Studies in Mathematics, 10, 361-387.

Bero, P. (1994). Pupil's understanding of mathematical proof. En: Bazzini (Ed.) Theory and practice in Mathematics Education. Proceedings of the "Fifth international conference on systematic cooperation between theory and practice in Mathematics Education", 27-33. Grado, Italia.

Berthelot, R y Berthelot, C. (1983): Études en Didactique des Mathématiques. Quelques apports de la théorie des situations á l'étude de l'introduction de la notion de limite en classe première A. Bordeaux: Université de Bourdeaux I.

Bieda, K. N., Ji, X., Drwencke, J., \& Picard, A. (2014). Reasoning-and-proving opportunities in elementary mathematics textbooks. International Journal of Educational Research, 64, 7180 .

Blázquez, S. (1999). Noción de límite en matemáticas aplicadas a las ciencias sociales. Tesis doctoral. Universidad de Valladolid: Valladolid.

Blázquez, S. y Ortega, T. (1999): Didáctica del Análisis en las Matemáticas Aplicadas a las Ciencias Sociales. Concepto de límite. En, T. Ortega (Ed.): Temas controvertidos en Educación Matemática. Valladolid: SAE de la Universidad de Valladolid, 121-154.

Blázquez, S. y Ortega, T. (2000). El concepto de límite en la educación secundaria. En El futuro del cálculo infinitesimal. Grupo Editorial Iberoamérica. México.

Blázquez, S. y Ortega, T. (2001a). Los sistemas de representación en la enseñanza del límite. RELIME, 4 (3), 219-236. México.

Blázquez, S. y Ortega, T. (2001b). Rupturas en la comprensión del concepto de límite en alumnos de Bachillerato. AULA, 10, 117-133. Salamanca.

Blázquez, S. y Ortega, T. (2002). Nueva definición de límite funcional. UNO, vol. 30, 67-82. Graó. Barcelona. 
Blázquez, S., Gatica, N. y Ortega, T. (2007). Diversas conceptualizaciones de límite funcional. Análisis comparativo. Epsilón, 68, 24(3), pp. 7-29. Sociedad Andaluza de Educación Matemática "THALES", Utrera. Sevilla.

Blázquez, S., Gatica, N. y Ortega, T. (2009). Análisis de diversas conceptualizaciones de límite funcional. Gaceta de la Real Sociedad Matemática Española, 12(1), 145-168.

Blázquez, S., Gatica, S. N., Ortega, T., Benegas, J. (2006). Una conceptualización de límite para el aprendizaje inicial de análisis matemático en la universidad. RELIME. Vol 9. №2, 189210. CLAME. ISSN: 1665-2436. México DF.

Blum, W., \& Kirsch, A. (1991). Preformal proof: examples and reflections. Educational Studies in Mathematics, 22(2), 183-203. Doi: 10.1007/BF00555722.

Bourbaki, N. (1970). Éléments de Mathématique (Théorie des ensembles). París: Hermann.

Bouvier, A y George, M. (1984). Diccionario de Matemáticas. Madrid: AKAL.

Cai, J. \& Cirillo, M. (2014). What do we know about reasoning and proving? Opportunities and missing opportunities from curriculum analyses. International Journal of Educational Research, 64, 132-140.

Calsamiglia, H. (1994). Perspectiva discursive en l'anàlisis del contingut informatiu del text. En A. Camps (coord.) (1994a). Context $i$ aprenentatge de la llengua escrita (pp.68-88). Barcelona: Barcanova.

Camargo, L. y Gutiérrez, Á. (2010). El aprendizaje de la demostración visto desde la teoría de la práctica social. En M. M. Moreno, A. Estrada, J. Carrillo, \& T. A. Sierra, (Eds.), Investigación en Educación Matemática XIV (pp. 245-258). Lleida: SEIEM.

Campillo, P. (1999). La noción de continuidad desde la óptica de los niveles de Van Hiele, Tesis Doctoral, Universidad Politécnica de Valencia.

Camps, A. (1994a). Context i aprenentatge de la llengua escrita. Barcelona: Barcanova.

Camps, A. (1994b). L'ensenyament de la composició escrita. Barcelona: Barcanova.

Camps, A. (1998). Ensenyar a escriure a l'educació secundària. En A. Camps y T. Colomer (coords.). L'ensenyament $i$ l'aprenentatge de la llengua $i$ la literatura en l'educació secundària (pp. 69-84). Barcelona: ICE Horsori.

Cantoral, R. (1995). Los textos de cálculo: una visión de las reformas y contrarreformas. Documento inédito.

Cañadas, M.C. y Castro, E. (2003). Razonamiento inductivo puesto de manifiesto por alumnos de secundaria. En Castro, E.; Ortega, T. (Eds.), Actas del VII Simposio de la SEIEM, pp. 1521.

Carrol, B. J. (1980). Testing communicative performance. An interim study. Oxford: Pergamon Press.

Chevallard, Y. (1985). La transposition didactique: du savoir savant au savoir enseigné, Grenoble, La Pensée Sauvage. 
Chevallard, Y. y M. A. Johsua (1982). Un exemple d'analyse de la transposition didactique: La notion de distance, Recherche en Didactique des Mathématiques, 3(1), pp. 159-239.

Choppin, A. (1993), L'histoire des manuels scolaires. Un bilan bibliométrique de la recherche française, Histoire de l'Éducation, 58, pp. 165-185.

Clark, P. (2005). The emergence of a classroom community of practice in a mathematical structures course. Doctoral Dissertation. Department of Philosophy, Arizona State University.

Claros, F., Sánchez, M., y Coriat, M. (2009). Sobre la equivalencia entre sucesiones con límite finito y sucesiones de Cauchy. En M.J. González, M.T. González \& J. Murillo (Eds.), Investigación en Educación Matemática XIII (pp.197-209). Santander: SEIEM.

Cobo, B. y Batanero, C, (2004). Significados de la media en los libros de texto de secundaria. Enseñanza de las Ciencias, 22 (1), 5-18.

Cobo, P., Figueras, O., Fortuny, J. M., González, M. J., Gutiérrez, A., Martínez Recio, A. y Murillo, J. (2005). Investigación en Tecnologías de la Información y Comunicación (TIC). En Educación Matemática (Seminario de Investigación I), en Maz, A.; Gómez, B.; Torralbo, M. (Eds.), Actas del IX Simposio de la SEIEM, pp. 3-78.

Commission Pédagogie du Texte (1985a). Les conditions de production écrite à l'école. Contributions à la pedagogie du texte I. Génova: Universidad de Génova, 3-20.

Commission Pédagogie du Texte (1985b). Contributions à la pedagogie du texte I. Cahiers de la Section des Sciences de l'Éducation, 40, Génova: Universidad de Génova.

Conejo, L. y Ortega, T. (2013). La demostración matemática en los libros de texto de $2^{\circ}$ de B.U.P. y $1^{\circ}$ de Bachillerato de LGE, LOGSE y LOE para el concepto de límite. Fase inicial. En A. Estepa, y N. Climent (Eds.), Investigación en Educación Matemática. Comunicaciones de los grupos de investigación. XVI Simposio de la SEIEM (121-132). Baeza: SEIEM.

Conejo, L. y Ortega, T. (2014). Las demostraciones de los teoremas de continuidad en los libros de texto para alumnos de 17-18 años correspondientes a las tres últimas leyes educativas españolas. NÚMEROS, Revista de didáctica de las Matemáticas, 87, 5-23.

Conejo, L., Arce, M., Ortega, T. (2014). Justificación de las reglas de derivación en libros de texto de cuatro editoriales desde LGE hasta LOE. En M. T. González, M. Codes, D. Arnau y T. Ortega (Eds.), Investigación en Educación Matemática XVIII (pp. 257-266). Salamanca: SEIEM.

Conejo, L., Arce, M., Ortega, T. (2015). A case study: how textbooks of a Spanish Publisher justify results related to limits from the 70's until today. Comunicación en el 9th Congress of European Research in Mathematics Education.

Consejería de Educación de Castilla y León (2008). Decreto 42/2008, de 5 de junio, por el que se establece el currículo de Bachillerato en la Comunidad de Castilla y León. Boletín Oficial de Castilla y León, 111, de 11 de junio de 2008, 11306-11380.

Consejería de Educación y Cultura de Castilla y León (2002). Decreto 70/2002, de 23 de mayo, por el que se establece el currículo de Bachillerato en la Comunidad de Castilla y León. Boletín Oficial de Castilla y León, 102, de 29 de mayo de 2002, 7041-7114. 
Conserjería de Educación de Castilla y León (2015). Orden EDU/363/2015, de 4 de mayo, por la que se establece el currículo y se regula la implantación, evaluación y desarrollo del bachillerato en la Comunidad de Castilla y León. Boletín Oficial de Castilla y León, 86, de 8 de mayo de 2015, 32481- 32984.

Contreras, A. (2001). La enseñanza del análisis matemático en el Bachillerato y primer curso de universidad. Una perspectiva desde las teorías de los obstáculos epistemológicos y los actos de comprensión. En L. C. Contreras, J. Carrillo, N. Climent y M. Sierra (Eds.) Cuarto Simposio de la Sociedad Española de Investigación en Educación Matemática. (71-85). Huelva: Universidad de Huelva.

Contreras, A., Luque, L. y Ordoñez, L. (2003). Una perspectiva de la enseñanza-aprendizaje de la continuidad y la derivada de una función en bachillerato y universidad. Revista de Educación, 330, 419-447.

Cornu, B. (1983): Apprentissage de la notion de limite: conceptions et obstacles. Thèse de 3ème cycle, Mathématiques. Grenoble: Université I de Grenoble.

Courant, R y Robbins, H. (1964). ¿Qué es la matemática? Madrid: Aguilar, S.A.

Courant, R. y Robbins, H. (2002). ¿Qué son las matemáticas? Conceptos y métodos fundamentales. Prefacio y avances recientes. Ian Stewart. México: Fondo de Cultura Económica.

Crespo, C. R. (2005). La importancia de la argumentación matemática en el aula. Premisa (Revista de la sociedad argentina de educación matemática), 24, pp. 23-29

Davis, J. D. (2012). An examination of reasoning and proof opportunities in three differently organized secondary mathematics textbook units. Mathematics Education Research Journal, $24,467-491$.

Davis, J. D., Smith, D. O., Roy, A. R. \& Bilgic, Y. K. (2014). Reasoning-and-proving in algebra: The case of two reform-oriented U.S. textbooks. International Journal of Educational Research, 64, 92-106.

De la Torre, E. (2003): Didáctica de la geometría y demostración de propiedades. En E., Castro, Ortega, T. (Eds.), Actas del VII Simposio de la SEIEM, pp.3-78.

de Villiers, M. (2012). An illustration of the explanatory and discovery functions of proof, Pythagoras, 33 (3), http://dx.doi.org/10.4102/pythagoras.v33i3.193

de Villiers, M. (1993). El papel y la función de la demostración en matemáticas. Épsilon, 26, 15-30. Original de 1990.

de Villiers, M. (2007). An example of the discovery function of proof. Mathematics in School, $36(4)$, pp. 9-11.

Delgado, C. (1995). Estudio de la evolución de los esquemas conceptuales de alumnos universitarios en su proceso de aprendizaje de los conceptos de límite y continuidad. Tesina del Dpto. de Didáctica de las Matemáticas y las Ciencias Experimentales. Universidad Autónoma de Barcelona.

Dhombres, J. (1984). French Mathematical Textbooks from Bézout to Cauchy. Historia Scientarum, 28, 91-137. 
Dolev, S. \& Even, R. (2015). Justifications and explanations in Israeli 7th grade math textbooks. International Journal of Science and Mathematics Education 13, Issue 2 Supplement, 309327

Dolev, S. (2011). Justifications and proofs of mathematical statements in $7^{\text {th }}$ grade textbooks. Rehovot: MSc thesis-Weizmann Institute of Science.

Dos Santos, C. (2010). A demostraçao matemática e o profesor. Formulaçao e ensino. Tesis doctoral. Valladolid: Universidad de Valladolid.

Dos Santos, C., \& Ortega, T. (2013). Perfiles del Profesorado sobre la Enseñanza y Uso de la Demostración. Avances de Investigación en Educación Matemática, 4, 27-45.

Dreyfus, T. (1999). Why Johnny can't prove. Educational Studies in Mathematics, 38, 85-109.

Duval R. (1998). Registros de representación semiótica y funcionamiento cognitivo del pensamiento. Editorial Iberoamérica. En F. Hitt (Ed.), Investigaciones en Matemática Educativa II (pp. 173-201). México: Grupo

El Bouazzaoui, H. (1988). Conceptions des élèves et des professeurs a propos de la notion de continuité d'une fonction, Tesis doctoral, Université de Bordeaux I.

Espinoza, L. (1998): Organizaciones matemáticas y didácticas en torno al objeto límite de función. Del pensamiento del profesor a la gestión de los momentos del estudio. Tesis doctoral. Dpto. de didáctica de las matemáticas y las ciencias experimentales. Universidad Autónoma de Barcelona.

Fernández-Plaza, J. A. (2011). Significados puestos de manifiesto por estudiantes de Bachillerato respecto al concepto de límite finito de una función en un punto. Un estudio exploratorio. Trabajo de tercer ciclo. Granada: Universidad de Granada.

Fernández-Plaza, J. A., Castro, E., Rico, L., y Ruiz-Hidalgo, J.F. (2012). Concepto de límite finito de una función en un punto: aspectos estructurales y definiciones personales. En A. Estepa, Á. Contreras, J. Deulofeu, M. C. Penalva, F. J. García y L. Ordóñez (Eds.), Investigación en Educación Matemática XVI (pp. 229 - 237). Jaén: SEIEM.

Fernández-Plaza, J. A., Ruiz-Hidalgo, J. F., \& Rico, L. (2012). The Concept of Finite Limit of a Function at one Point as Explained by Students of Non-Compulsory Secondary Education. In T. Y. Tso (Ed.), Proceedings of the 36th Conference of the International Group for the Psychology of Mathematics Education (Vol. 2), (pp. 235-242). Taipei, Taiwan: PME.

Fernández-Plaza, J. A., Ruiz-Hidalgo, J. F., Rico, L. y Castro, E. (2013). Variación de las concepciones individuales sobre límite finito de una función en un punto. En A. Berciano, G. Gutiérrez, A. Estepa y N. Climent (Eds.), Investigación en Educación Matemática XVII, pp. 253-261). Bilbao: SEIEM

Fiallo, J. E. y Gutiérrez, A. (2006). Unidad de enseñanza de las razones trigonométricas en un ambiente Cabri para el desarrollo de las habilidades de demostración. En Actas del X Simposio de la SEIEM, pp. 41-62.

Fiallo, J. E. y Gutiérrez, A. (2007). Tipos de demostración de estudiantes del grado $10^{\circ}$ en Santander (Colombia), En M. Camacho, P. Flores y M. P. Bolea (Coords.). Investigación en Educación Matemática XI: comunicaciones de los grupos de investigación del XI Simposio de la SEIEM, pp. 355-368, La Laguna: SEIEM. 
Fiallo, J. E., Camargo, L. y Gutiérrez, Á. (2013). Acerca de la enseñanza y el aprendizaje de la demostración en matemáticas. Revista integración. Escuela de matemáticas Universidad Industrial de Santander, 31 (2), pp. 181-205.

Filloy, E. y Rojano, T. (1984). From an Arithmetical to an Algebraic Thought (A clinical study with 12-13 year old). En J. Moser (Ed.). Proceedings on the Sixth Annual meeting for the Psychology of Mathematics Education, North American Chapter (pp. 51-56). Wisconsin: Madison.

Fishbein, E. (1982). Intuition and proof. For the Learning of Mathematics, 3 (2), pp. 9-19.

Fox, D.J. (1981). El proceso de investigación en educación. Pamplona: EUNSA.

Fujita, T., Jones, K. and Kunimune, S. (2009). The design of textbooks and their influence on students' understanding of 'proof' in lower secondary school. In, Fou-Lai Lin, Feng-Jui Hsieh, Gila Hanna and Michael de Villiers (Eds.) Proceedings of the ICMI Study 19 Conference: Proof and Proving in Mathematics Education. Taipei, Taiwan, National Taiwan Normal University, 172-177.

Galbraith, P.L. (1981). Aspects of proving: a clinical investigation of process. Educational Studies in Mathematics, 12, 1-28.

García-Rodeja, I. (1997) ¿Qué propuesta de actividades hacen los libros de primaria? Alambique, 11, 35-43.

Gatica, N., Maz-Machado, A., May, G., Cosci, C., Echevarría, G. y Renaudo, J. (2010). Un acercamiento a la idea de continuidad de funciones en estudiantes de ciencias económicas. Unión, Revista Iberoamericana de Educación Matemática, 22, 121-131.

Gea, M. M., Batanero, C., Cañadas, G. R., y Contreras, J. M. (2013). Un estudio empírico de las situaciones-problema de correlación y regresión en libros de texto de Bachillerato. En A. Berciano, G. Gutiérrez, A. Estepa y N. Climent (Eds.), Investigación en Educación Matemática XVII, pp. 293-300). Bilbao: SEIEM.

Goizueta, M. y Planas, N. (2012). Análisis de interpretaciones escritas del profesorado sobre la argumentación en clase de matemáticas. En A. Estepa, Á. Contreras, J. Deuloufeu, M. C. Penalva, F. J. García y L. Ordóñez (Eds.), Investigación en Educación Matemática XVI, pp. 295-302. Jaén: SEIEM

Gómez, B. (1995a). Los métodos de cálculo mental vertidos por la tradición reflejada en los libros de aritmética. UNO. Revista de Didáctica de las Matemáticas, 5, 91-101.

Gómez, B. (1995b). Los viejos métodos de cálculo. Un dominio para transitar de la aritmética al álgebra. Suma, 20, 61-68.

Gómez, B. (1996). Desarrollo histórico de la enseñanza de la aritmética. El caso de los algoritmos de cálculo. Aula de innovación educativa, 50, 11-16.

Gómez, B. (1999). Tendencias metodológicas en la enseñanza de la proporcionalidad derivadas del análisis de los libros antiguos: el caso de los problemas de "compañías". Revista latinoamericana de investigación en Matemática Educativa (RELIME), 2 (3), 19-29.

Gómez, B. (2000). Los libros de texto en Matemáticas. Números. Revista de didáctica de las Matemáticas, 43-44, 77-80. 
Gómez, B. (2001). La justificación de la regla de los signos en los libros de texto: ¿Por qué menos por menos es más? En P. Gómez y L. Rico (Eds.). Iniciación a la investigación en didáctica de la matemática. Homenaje al profesor Mauricio Castro (pp. 257-275). Granada: Universidad de Granada.

Gómez, B. (2011). El análisis de manuales y la identificación de problemas de investigación en Didáctica de las Matemáticas. PNA, 5 (2), 49-65.

González, J. C. (2012). Estudio de contraste sobre la preferencia y significación de pruebas formales y preformales. Tesis doctoral. Valladolid: Universidad de Valladolid.

González, M. T. (2002). Sistemas simbólicos de representación en la enseñanza del análisis matemático: perspectiva histórica acerca de los puntos críticos. Tesis doctoral. Salamanca: Universidad de Salamanca

González, M. T. y Sierra, M. (2003). El método de investigación histórico en la didáctica del análisis matemático. En Castro, Encarnación (Ed.), Investigación en educación matemática: séptimo Simposio de la Sociedad Española de Investigación en Educación Matemática (109130). Granada: Universidad de Granada.

Gutiérrez, Á. (2005). Aspectos metodológicos de la investigación sobre aprendizaje de la demostración mediante exploraciones con software de geometría dinámica. En A. Maz, B. Gómez y M. Torralbo (Eds.). Actas del IX Simposio de la Sociedad Española de Investigación en Educación Matemática. Córdoba: SEIEM, pp. 33-50.

Han, I. (2005). A study on intuitive verification and rigor proof in geometry of Korean and Russian 7-8 grade's mathematics textbooks. Journal of the Korean Society of Mathematical Education, Serie A: Mathematical Education, 44 (4). 535-546.

Hanna G. et al. (Eds.). (2010). Explanation and Proof in Mathematics: Philosophical and Educational Perspectives, DOI 10.1007/978-1-4419-0576-5_1

Hanna, G. \& Barbeau, E. (2010). Proofs as bearers of Mathematical Knowledge. In G. Hanna et al. (Eds.), Explanation and proof in mathematics: philosophical and educational perspectives. (85-100). New York: Springer.

Hanna, G. (1989). Proofs that prove and proofs that explain. Proceedings of the $13^{\text {th }}$ International Conference on the Psychology of Mathematics Education, 45-51. Paris.

Hanna, G. (1990). Some pedagogical aspects of proof. Interchange, 21, 6-13

Hanna, G. (1995). Challenges to the Importance of Proof. For the learning of Mathematics, 15(3), 42-49.

Hanna, G. (2000). Proof, explanation, and exploration: An overview. Educational Studies in Mathematics, 44 (1-2), 5-23.

Hanna, G., \& de Bruyn, Y. (1999). Opportunity to learn proof in Ontario grade twelve mathematics text. Ontario Mathematics Gazette. 37(4), 23-29.

Harel, G., \& Sowder, L. (1998). Students' Proof Schemes: Results from exploratory studies. En: Dubinski, E.; Schoenfeld, A. y Kaput, J. (Eds.), Research on Collegiate Mathematics Education, vol. III, 234-283. American Mathematical Society, Providence, USA. 
Harel, G., \& Sowder, L. (2007). Towards comprehensive perspectives on the learning and teaching of proof. In F. Lester (Ed.), Second handbook of research on mathematics teaching and learning, (pp. 805-842). Reston, VA: National Council of Teachers of Mathematics.

Henning, A. \& Hoffkamp, A. (2013). Developing an intuitive concept of limit when approaching the derivative function. In B. Ubuz, E. Haser \& M.A. Mariotti (Eds.). Proceedings of the Eigth Congrees of the European Society for Research in Mathematics Education. (pp. 2574-2583). Ankara: Middle East Technical University.

Herdeiro, C. (2010). La resolución de problemas en los libros de texto de matemáticas del $9^{\circ}$ año de escolaridad. Tesis doctoral. Huelva: Universidad de Huelva.

Hersh, R. (1993). Proving is convincing and explaining. Educational Studies in Mathematics, 24, 389-399.

Howson, G. (1995), Mathematics Textbooks: A Comparative Study of Grade 8 texts, Vancouver, Pacific Educational Press.

Ibañes, M. (2001). Aspectos cognitivos del aprendizaje de la demostración matemática en alumnos de $1^{\circ}$ curso de bachillerato. Tesis doctoral. Valladolid: Universidad de Valladolid.

Ibañes, M. (2002). Cuatro cuestiones en torno al aprendizaje de la demostración. Actas de V Simposio de SEIEM, pp. 11-26

Ibañes, M. y Ortega, T. (1997). La demostración en matemáticas. Clasificación y ejemplos en el marco de la Educación Secundaria. Educación matemática. 9 (2), pp. 65-104.

Ibañes, M. y Ortega, T. (2001a). Interpretación de algunas expresiones usuales en los enunciados de los teoremas, Quadrante. Revista teorica e de Investigaçao. Vol. 10, $\mathrm{N}^{\circ} 2$, pp. 97-123. Associação de Professores de Matemática ISNN 00872-3915. Lisboa

Ibañes, M. y Ortega, T. (2001b). Un estudio sobre los esquemas de prueba en alumnos de primer curso de bachillerato. UNO, 28, 39-60.

Ibañes, M. y Ortega, T. (2002a). La demostración en el currículo; una perspectiva histórica. SUMA, 39, pp. 53-61

Ibañes, M. y Ortega, T. (2002b). Analizadores específicos para la demostración matemática. Aplicación a los textos en el tema de Trigonometría en Bachillerato. Actas del VI Simposio de la Sociedad Española de Investigación en Educación Matemática.

Ibañes, M. y Ortega, T. (2004a). Textos argumentativos. UNO. 35, pp. 39-52. Graó. ISSN: 1133-9853. Barcelona.

Ibañes, M. y Ortega, T. (2004b). Un análisis del tratamiento de la demostración matemática en los libros de texto de bachillerato. NÚMEROS, 57, pp. 19-32

Ibañes, M. y Ortega, T. (2005). Dimensiones de la demostración matemática en bachillerato. NÚMEROS, 61, pp. 19-40

Instituto Nacional de Evaluación Educativa (2013). PIAAC. Programa internacional para la evaluación de las competencias de la población adulta. 2013. Informe español. Madrid: Ministerio de Educación, Cultura y Deporte. Tomado de http://www.mecd.gob.es/inee/Ultimos_informes/PIAAC.html 
Instituto Nacional de Evaluación Educativa (2014). PISA 2012. Programa para la evaluación internacional de los alumnos. Informe español. Resultados y contexto. Madrid: Ministerio de Educación, Cultura y Deporte. Tomado de http://www.mecd.gob.es/inee/estudios/pisa.html

Janvier, C. (1987). Translation Processes in Mathematics Education. En C. Janvier (Ed.), Problems of Representation in the Teaching and Learning of Mathematics. Hillsdale, NJ: Lawrence Erlbaum Associates.

Jefatura del Estado (1970). Ley 14/1970, de 4 de agosto, General de Educación y Financiamiento de la Reforma Educativa. Boletín Oficial del Estado, 187, de 6 de agosto de $1970,12525-12546$.

Jefatura del Estado (1990). Ley Orgánica 1/1990, de 3 de octubre de 1990, de Ordenación General del Sistema Educativo. Boletín Oficial del Estado, 238, de 4 de octubre de 1990, 28927- 28942.

Jefatura del Estado (2002). Ley Orgánica 10/2002, de 23 de diciembre, de Calidad de la Educación. Boletín Oficial del Estado, 307, de 24 de diciembre de 2002, 45188-45220.

Jefatura del Estado (2006). Ley Orgánica 2/2006, de 3 de mayo, de Educación. Boletín Oficial del Estado, 106, de 4 de mayo de 2006, 17158-17207.

Jefatura del Estado (2013). Ley Orgánica 8/2013, de 9 de diciembre, para la mejora de la calidad educativa. Boletín Oficial del Estado, 295, de 10 de diciembre de 2013, 9785897921.

Johnson, G. J., Thompson, D. R., \& Senk, S. L. (2010). Proof-related reasoning in high school textbooks. Mathematics Teacher, 103 (6), 410-418.

Karatas, I., Guven, B. \& Cekmez, E. (2011). A cross-age study of students' understanding of limit and continuity concepts. (A compreensãon dos conceitos de limite e continuidade: um estudo desenvolvido com alunos em distintos mementos de um curso de formação inicial para professores.) Bolema, 24(38), 245-264.

Kitcher, P. (1983). The nature of mathematical knowledge. Oxford University Press, New York.

Lakatos, I. (1978). Pruebas y refutaciones. Alianza Editorial. Madrid. (El original es de 19631964).

Lin, F. (2005). Modelling students' learning in argumentation and mathematics proof. En Chick, H. L. (ed.) et al., Proceedings of the 29th annual conference of the International Group for the Psychology of Mathematics Education, PME 29, Vol 1-4. Melbourne: University of Melbourne, Dep. of Science and Mathematics Education.

Llanos, V. C.; Otero, M. R.; Banks Leite, L. (2007). Argumentación matemática en los libros de texto de la enseñanza media. Revista Electrónica de Investigación en Educación en Ciencias 2 (2), 39-53. ISSN 1850 - 6666 / NIECYT.

López, M. C. (2011). La formación inicial de maestros en Aritmética y Álgebra a través de los libros de texto. Tesis doctoral. Salamanca: Universidad de Salamanca.

Lowe, E. y D. Pimm (1996), This is so: a text on texts, en A. Bishop, K. Clements, C. Keitel, J. Kilpatrick y C. Laborde (Eds.), International Handbook on Mathematics Education, Dordrecht, Reidel, pp. 371-410. 
Macnab, D. y Cummine, J. (1992). La enseñanza de las matemáticas de 11 a 16. Un enfoque centrado en la dificultad. Madrid: Visor.

Mansfield, M. (1993). Real World Writing and the English Curriculum. College Composition and Communication, 44 (1), 69-83.

Mariotti, M. A. (2006). Proof and proving in mathematics education. In A. Gutierrez \& P. Boero (Eds.), Handbook of research on the psychology of mathematics education, pp. 173203. Rotterdam: Sense.

Mariotti, M. A. (2012). Proof and proving in the classroom: Dynamic Geometry Systems as tools of semiotic mediation. Research in Mathematics Education, 14 (2), 163-185, DOI: $10.1080 / 14794802.2012 .694282$

Martin, W. G., \& Harel, G. (1989). Proof frames of preservice elementary teachers. Journal for Research in Mathematics Education, 20, 41-51.

Maz, A. (2000). Tratamiento dado a los números negativos en libros de texto publicados en España en los siglos XVIII y XIX. Memoria de Tercer Ciclo. Granada: editorial de la Universidad de Granada.

Maz, A. (2005). Los números negativos en España en los siglos XVIII y XIX. Tesis doctoral. Granada: editorial de la Universidad de Granada.

Maz, A. (2009). Investigación histórica de conceptos en los libros de Matemáticas. En M. J. González, M. T. González y J. Murillo (Eds.), Investigación en Educación Matemática XIII, pp. 5-20. Santander: SEIEM.

Maz, A. y Rico, L. (2007). Situaciones asociadas a los números negativos en textos de matemáticas españoles de los siglos XVIII y XIX. PNA, 1(3), 113-123.

Maz, A. y Rico, L. (2009a). Las Liciones de Thomas Cerda: doscientos cincuenta años (17582008). Suma, 60, 35-41.

Maz, A. y Rico, L. (2009b). Números negativos en los siglos XVIII y XIX: fenomenología y representaciones. Revista de Investigación Psicoeducativa, 17 (1), 117-129.

Maz, A., Torralbo, M. y Rico, L. (Eds.) (2006). José Mariano Vallejo, el matemático ilustrado. Una mirada desde la Educación Matemática. Córdoba: Servicio de Publicaciones de la Universidad de Córdoba.

McCrory, R., \& Stylianides, A. J. (2014). Reasoning-and-proving in mathematics textbooks for prospective elementary teachers. International Journal of Educational Research, 64, 119131.

Mills, M. (2014). A framework for example usage in proof presentations. Journal of Mathematical Behavior, 33, 106-118.

Ministerio de Educación y Ciencia (1974). Decreto 2531/1974, de 20 de julio, sobre autorizaciones de libros de texto y material didáctico. Boletín Oficial del Estado, 220, de 13 de septiembre de 1974, 18852-18853 
Ministerio de Educación y Ciencia (1975a). Orden de 22 de marzo de 1975 por la que se desarrolla el Decreto 160/1975, de 23 de enero, que aprueba el Plan de Estudios del Bachillerato y se regula el Curso de Orientación Universitaria. Boletín Oficial del Estado, 93, de 18 de abril de 1975, 8049-8068

Ministerio de Educación y Ciencia (1975b). Resolución de las Direcciones Generales de Ordenación Educativa y de Universidades e Investigación por la que se desarrolla la disposición transitoria cuarta de la Orden de 22 de marzo de 1975, sobre el Curso de Orientación Universitaria. Boletín Oficial del Estado, 214, de 6 de septiembre de 1975, 18925-18929

Ministerio de Educación y Ciencia (1978). Resolución por la que se establecen los contenidos y orientaciones metodológicas del Curso de Orientación Universitaria y se dictan instrucciones sobre el mismo de 17 de marzo de 1978. Boletín Oficial del Estado, 65, de 17 de marzo de $1975,6445-6452$

Ministerio de Educación y Ciencia (1987). Orden de 3 de septiembre de 1987 por la que se modifican las Órdenes de 22 de marzo de 1975 y de 11 de septiembre de 1976, en los apartados relativos al Curso de Orientación Universitaria. Boletín Oficial del Estado, 220, de 14 de septiembre de 1987, 27702-27703.

Ministerio de Educación y Ciencia (1988). Resolución de 20 de enero de 1988, de las Direcciones Generales de Enseñanza Superior y de Renovación Pedagógica, por la que se aprueba el programa y orientaciones pedagógicas de las «Matemáticas II» del Curso de Orientación Universitaria. Boletín Oficial del Estado, 25, de 29 de enero de 1988, 31213123.

Ministerio de Educación y Ciencia (1991). Real Decreto 1700/1991, de 29 de noviembre, por el que se establece la estructura del Bachillerato. Boletín Oficial del Estado, 288, de 2 de diciembre de 1991, 39061-339062.

Ministerio de Educación y Ciencia (1992a). Real Decreto 1178/1992, de de 2 de octubre, por el que se establecen las enseñanzas mínimas del Bachillerato. Boletín Oficial del Estado, 253, de 21 de octubre de 1992, 35583-35585

Ministerio de Educación y Ciencia (1992b). Anexo al Real Decreto 1178/1992, de de 2 de octubre, por el que se establecen las enseñanzas mínimas del Bachillerato. Suplemento al Boletín Oficial del Estado, 253, de 21 de octubre de 1992.

Ministerio de Educación y Ciencia (1992c). Real Decreto 1179/1992, de 2 de octubre, por el que se establece el currículo del Bachillerato. Boletín Oficial del Estado, 253, de 21 de octubre de 1992, 35585-35588

Ministerio de Educación y Ciencia (1992d). Anexo al Real Decreto 1179/1992, de 2 de octubre, por el que se establece el currículo del Bachillerato. Suplemento al Boletín Oficial del Estado, 253, de 21 de octubre de 1992.

Ministerio de Educación y Ciencia (2007). Real Decreto 1467/2007, de 2 de noviembre, por el que se establece la estructura del bachillerato y se fijan sus enseñanzas mínimas. Boletín Oficial del Estado, 266, de 6 de noviembre de 2007, 45381-45477 
Ministerio de Educación, Cultura y Deporte (2001a). Real Decreto 3474/2000, de 29 de diciembre, por el que se modifican el Real Decreto 1700/1991, de 29 de noviembre, por el que se establece la estructura del bachillerato, y el Real Decreto 1178/1992, de 2 de octubre, por el que se establecen las enseñanzas mínimas del Bachillerato. Boletín Oficial del Estado, 14 , de 16 de enero de 2001, 1858-1922.

Ministerio de Educación, Cultura y Deporte (2001b). Real Decreto 938/2001, de 3 de agosto, por el que se modifica el Real Decreto 1179/1992, de 2 de octubre, por el que se establece el currículo de Bachillerato. Boletín Oficial del Estado, 215, de 7 de septiembre de 2001, 33795-33879.

Ministerio de Educación, Cultura y Deporte (2015). Real Decreto 1105/2014, de 26 de diciembre, por el que se establece el currículo básico de la Educación Secundaria Obligatoria y del Bachillerato. Boletín Oficial del Estado, 3, de 3 de enero de 2015, 169-546.

Ministerio de Educación, Política Social y Deporte (2008). Orden ESD/1729/2008, de 11 de junio, por la que se regula la ordenación y se establece el currículo del bachillerato. Boletín Oficial del Estado, 147, de 18 de junio de 2008, 27492-27608.

Mizayaki, M. (2000). Levels of proof in lower secondary school mathematics. Educational Studies in Mathematics, 41, 47-68.

Monterrubio, M. C. (2007). Modelos de valoración de manuales escolares de matemáticas. Tesis doctoral. Valladolid: Universidad de Valladolid.

Monterrubio, M. C. y Ortega, T. (2009). Creación de un modelo de valoración de textos matemáticos. Aplicaciones. En M. J. González, M. T. González y J. Murillo (Eds.), Investigación en Educación Matemática XIII, pp. 37-54. Santander: SEIEM.

Monterrubio, M. C. y Ortega, T., (2011). Diseño y aplicación de instrumentos de análisis y valoración de textos escolares de matemáticas. PNA. Revista de Investigación en Didáctica de la Matemática, 5 (3). Granada: Universidad de Granada. pp. 105-127, ISSN: 1886-1350.

Monterrubio, M. C. y Ortega, T., (2012). Creación de un modelo exhaustivo de análisis de textos escolares matemáticos. Revista de Educación, 351, pp. 471-495. Madrid: Ministerio de Educación. ISSN: (en línea) 1988-592X 0034-8082; (impreso) 0034-8082

Muñoz, Oller y Ortega, T. (en prensa). Análisis de problemas de proporcionalidad compuesta en libros de texto de $2^{\circ}$ de ESO. RELIME México

National Council of Teachers of Mathematics (1991). Estándares curriculares y de evaluación para la educación matemática. Sevilla: SAEM THALES. (Obra original publicada en 1989)

National Council of Teachers of Mathematics (2000). Resumen Ejecutivo, Principios y Estándares para la Educación Matemática. (Claudia Matus, trad.) Comité Interamericano de Educación Matemática. (Obra originalmente publicada en 2000)

Niss, M. (2002). Mathematical competencies and the learning of mathematics: the Danish KOM Project. Tomado de http://w3.msi.vxu.se/users/hso/aaa_niss.pdf, el 5 de mayo de 2012.

Nordström, K., \& Löfwall, C. (2005). Proof in Swedish upper secondary school mathematics textbooks - the issue of transparency. Proceedings of CERME4, pp. 448-457. Sant Feliu de Guixols, Spain: ERME 
OCDE (1999). Measuring Student Knowledge and Skills - A New Framework for Assessment, Paris: OCDE.

OCDE (2003). Marcos teóricos de PISA 2003: la medida de los conocimientos y destrezas en matemáticas, lectura, ciencias y resolución de problemas /OCDE. Madrid: Ministerio de Educación y Ciencia.

Oehrtman, M. (2009). Collapsing dimensions, physical limitation, and other student metaphor for limit concept. Journal for Research in Mathematics Education, 40 (4), 396-426.

Ortiz, J. J. (1999). Significados de los conceptos probabilísticos elementales en los textos de Bachillerato. Tesis doctoral. Universidad de Granada.

Otte, M. (1986). What is a text? En B. Christiansen, A. g. Howson, M. Otte (Eds.). Perspectives on mathematics education, pp. 173-203. Dordrecht: D. Reidel Publishing Company.

Otten, S., Males, L. M., \& Gilbertson, N. J. (2014). The introduction of proof in secondary geometry textbooks. International Journal of Educational Research, 64, 107-118.

Pedemonte, B. (2005). Quelques outils pour l'analyse cognitive du rapport entre argumentation et démonstration. Recherches en Didactique des Mathématiques, 25 (3), 313-347.

Pelczer, I. \& Voica, C. (2008). Proof in Romanian high school introductory analysis textbooks-a historical review. Paper in topic group study 18: reasoning, proof and proving in mathematics education. ICM 11 México. Tomado de http://tsg.icme11.org/tsg/show/19, el 30 de julio de 2015.

Pepin, B. et al. (2001). Mathematics textbooks and their use in English, French and German classrooms: a way to understand teaching and learning culture. Zentralblatt für Didaktik der Mathematik, 33 (5), 158-175.

Perelman, L. (1986). The Context of Classroom Writing. College English, 48 (5), 471-479.

Petitjean, A. (1982). Pratiques d'écriture. Raconter et d'écrier. París: CEDIC.

Pfeiffer, K. (2010). How do students evaluate and compare mathematical proofs? Research in Mathematics Education, 12 (2), 161-162, DOI: 10.1080/14794802.2010.496986

Pimm, D. (1987). Speaking mathematically, Nueva York, Routledge y Kegan Paul. [Versión en español: (1990), El lenguaje matemático en el aula, Madrid, Ministerio de Educación y Ciencia-Ediciones Morata].

Pimm, D. (1994). Mathematics classroom language, form, function and force, en R. Bielher, R. W. Cholz, R. Sträber y B. Winkelmann (Eds.), Didactics of Mathematics as a Scientific Discipline, Dordrecht, Kluwer, pp. 159-169.

Pons, J., Valls, J. y Llinares, S. (2013). Características de la tematización del esquema de límite de una función. En A. Berciano, G. Gutiérrez, A. Estepa y N. Climent (Eds.), Investigación en Educación Matemática XVII, pp. 449-457).

Puig, L. (1997). Análisis fenomenológico, en L. Rico (Coord.), La educación matemática en la enseñanza secundaria, Barcelona, ICE, Universidad de Salamanca-Horsori, pp. 61-94.

Rav, Y. (1999). Why do we proof theorems? Philosophia Mathematica, 7 (1), 5-41. 
Reid, D.A. (1996). The role of proving: students and mathematicians. En M. de Villiers (Coord.): Proofs and Proving: Why, when and how? 185-199. The Association for Mathematics Education of South Africa (AMESA), PO Box 12833, Centrahil 6006. South Africa.

Rico, L. y Maz, A. (2007). Libros de texto de matemáticas en España durante los siglos XVIII y XIX. En M. Guzmán (Ed.), Humanidades y Ciencias: aspectos disciplinares y curriculares. Granada: Editorial Atrio.

Robinet, J. (1983). Une expérience d'ingénierie didactique sur la notion de limite de fonction. Recherches en Didactique des Mathématiques, 4 (3), 223-292.

Ruiz-Berrio, J. (1976). El método histórico en la investigación histórica de la Educación. Revista Española de Pedagogía, 134, 449-475.

Salas, S. L. \& Hille, E. (1994). Calculus. Tercera edición. Barcelona: Editorial Reverté, S.A.

Sánchez Cobo, F. T. (1998). Significado de la correlación y regresión para los estudiantes universitarios. Tesis doctoral no publicada. Universidad de Granada.

Sánchez, C. (1997). Estudio estadístico sobre el proceso de enseñanza-aprendizaje de la noción de límite de una función. Tesis doctoral. Dpto. de Estadística e Investigación Operativa. Universidad de Granada.

Sanz, I. (1995). La comprensión del lenguaje matemático a través de libros escolares de matemáticas. Las configuraciones gráficas de datos. Tesis doctoral. Vizcaya: Universidad del País Vasco.

Schubring, G. (1987). On the Methodology of Analysing Historical Textbooks: Lacroix as textbook author. For the Learning of Mathematics, 7(3), 41-51.

Schwarz, B. B., Hershkowitz, R. \& Prusak, N. (2010). Argumentation and mathematics. In C. Howe \& K. Littleton (Eds.), Educational dialogues: Understanding and promoting productive interaction, pp. 115-141. London: Routledge.

Sears, R. \& Chávez, Ó. (2014). Opportunities to engage with proof: the nature of proof tasks in two geometry textbooks and its influence on enacted lessons. ZDM - The International Journal on Mathematics Education, 46 (5), 767-780.

Senk, S. L., Thompson, D. R. \& Johnson, G. (2008). Reasoning and proof in high school textbooks from the USA. Retrieved from http://tsg.icme11.org/document/get/282

Sierpinska, A. (1985). Obstacles épistémologiques relatifs à la notion de limite. Recherches en Didactique des Mathématiques, 6 (1), 5-67.

Sierpinska, A. (1987). Humanities students and epistemological obstacles related to limits. Educational Studies in Math. 18, 371-397.

Sierpinska, A. (1990). Some remarks on understanding in mathematics. For the Learning of Mathematics, 10 (3), 24-36.

Sierpinska, A. (1994). Understanding in mathematics. London: Falmer.

Sierpinska, A. (1997). La compréhension en mathématiques, in Boeck \& Larcier, S.A. (Ed.), Paris, Bruxe-Iles. 
Sierra, M. (2009). Introducción al Seminario de Investigación Análisis de libros de texto. En M. J. González, M. T. González y J. Murillo (Eds.), Investigación en Educación Matemática XIII, pp. 3-4. Santander: SEIEM.

Sierra, M., González, M. T. y López, C. (1999). Evolución histórica del concepto de límite funcional en los libros de texto de Bachillerato y Curso de Orientación Universitaria (COU), 1940-1995, Enseñanza de las Ciencias, 17 (3), pp. 463-476.

Sierra, M., González, M. T. y López, C. (2003). El concepto de continuidad en los manuales españoles de enseñanza secundaria de la segunda mitad del siglo XX. Educación Matemática, 15 (1), 21-49. Santillana: México

Sierra, M., González, M. T. y López, M. C. (1998). Límite funcional y continuidad: desarrollo histórico y concepciones de los alumnos. Actas del V Seminario Castellano-Leonés de Educación Matemática. Toro: SCLPM

Sierra, M., González, M.T. y López, C. (2005). Evolución histórica de la enseñanza de las Matemáticas a través de contenidos y edades (Memoria Proyecto de investigación inédita).

Sierra, M., Rico, L. y Gómez, B. (1997). El número y la forma: libros e impresos para la enseñanza de la Aritmética y la Geometría. En A. Escolano (Ed.), Historia Ilustrada del Libro escolar en España. Del antiguo Régimen a la Segunda República, pp. 373-398. Madrid: Fundación Germán Sánchez Ruipérez.

Silverman, B. \& Even, R. (2015). Textbook explanations: modes of reasoning in 7th grade Israeli mathematics textbooks. Comunicación en el CERME 9.

Socas, M. (2007). Dificultades y errores en el aprendizaje de las matemáticas. Análisis desde el enfoque lógico semiótico. En Camacho, M., Flores, P. y Bolea, P. (Eds.), Investigación en Educación Matemática XI (19-52). La Laguna, Tenerife: Sociedad Española de Investigación en Educación Matemática.

Spivak, M. (1981). Calculus. Cálculo Infinitesimal. Barcelona: Reverté.

Stacey, K. \& Vincent, J. (2008). Modes of reasoning in explanations in Year 8 textbooks. In M. Goos, R. Brown \& K. Makar (Eds.), Navigating currents and charting directions, Proceedings of the 31st annual conference of the Mathematics Education Research Group of Australasia, pp. 475-481. Brisbane: MERGA.

Stacey, K., \& Vincent, J. (2009). Modes of reasoning in explanations in Australian eight-grade mathematics textbooks. Educational Studies in Mathematics, 72 (3), 271-288

Stylianides, A. J. \& Al-Murani, T. (2010). Can a proof and a counterexample coexist? Students' conceptions about the relationship between proof and refutation. Research in Mathematics Education, 12 (1), 21-36, DOI: 10.1080/14794800903569774

Tall, D. y Schwarzenberger, R. (1978). Conflicts in the Learning of Real Numbers and Limits. Mathematics Teaching, 82, 44-49.

Tall, D. y Vinner, S. (1981). Concept image and concept definition in mathematics with particular reference to limits and continuity. Educational Studies in Mathematics, 12, 151169. 
Thompson, D. R. (2014). Reasoning-and-proving in the written curriculum: Lessons and implications for teachers, curriculum designers, and researchers. International Journal of Educational Research, 64, 141-148.

Thompson, D. R., Senk, S. L., \& Johnson, G. J. (2012). Opportunities to learn reasoning and proof in high school mathematics textbooks. Journal for Research in Mathematics Education, 43 (3), 253-295.

van Ash, A.G. (1993). To prove, why and how? International Journal Mathematics Education Science and Technology, 2, 301-313.

van Dormolen, J. (1977). Learning to understand what giving a proof really means. Educational Studies in Mathematics, 8, 27-34.

van Dormolen, J. (1986), Textual analysis, en B. Christiansen, A. G. Howson y M. Otte (Eds.), Perspectives on Mathematics Education, Dordrecht, Reidel, pp. 141-147.

Vicario, V. y Carrillo, J. (2005). Concepciones del profesor de secundaria sobre la demostración matemática. El caso de la irracionalidad de $\sqrt{2}$ y las funciones de la demostración. En Maz, A.; Gómez, B.; Torralbo, M. (eds.), Actas del $9^{\circ}$ Simposio de la SEIEM, pp. 145-152.

Vinner, S. (1991): The Role of Definitions in the Teaching and Learning of Mathematics. En Tall, D. (Ed.), Advanced Mathematical Thinking. Dordrecht: Kluwer, 65-81.

Ward, E., Inzunsa, S., Hernández, S. y López, F. (2013). Conceptualización y uso de representaciones sobre el concepto de límite en docentes de Bachillerato. En A. Berciano, G. Gutiérrez, A. Estepa y N. Climent (Eds.), Investigación en Educación Matemática XVII, pp. 523-534). Bilbao: SEIEM.

Wenger, E. (1998). Communities of practice. Learning, meaning and identity. Cambridge, Cambridge University.

Yackel, E. \& Cobb, P. (1996). Sociomathematical norms, argumentation, and autonomy in mathematics. Journal for Research in Mathematics Education, 27, 458-477.

Yackel, E. \& Hanna, G. (2003). Reasoning and proof. In J. Kilpatrick, W. G. Martin \& D. Schifter (Eds.), A research companion to principles and standards for school mathematics, pp. 227-236. Reston, VA: National Council of Teachers of Mathematics.

Zamora, R. M. F. (2014). Análisis de las pruebas de acceso a las universidades de Castilla y León (Matemáticas II). Tesis doctoral. Valladolid: Universidad de Valladolid. 



\section{ANEXOS}

\section{ANEXO 1: LIBROS DE TEXTO UTILIZADOS EN LA MUESTRA}

En las tablas se muestran las fichas de los libros de texto analizados, con la siguiente información por columnas: título, autores, año de edición y editorial. Por filas, están organizados por cursos, ordenados en primer lugar por la editorial (Anaya, Santillana, SM y Vicens-Vives) y en segundo lugar, cronológicamente.

\begin{tabular}{|c|c|c|}
\hline LGE & & \\
\hline \multicolumn{3}{|l|}{$2^{\circ}$ BUP } \\
\hline Matemáticas $2^{\circ}$ & Etayo, J., Colera, J. y Ruiz, A. & 1976 Anaya \\
\hline Matemáticas. Bachillerato 2 & Guzmán, M., Colera, J. y Salvador, A. & 1987 Anaya \\
\hline Matemáticas 2 Bachillerato & Anzola, M., Coruncho, J., Gutiérrez, M. & 1976 Santillana \\
\hline Matemáticas $2^{\circ} \mathrm{BUP}$ & Garzo, F., Burgos, J. y Gil, J. & 1991 Santillana \\
\hline Matemáticas 2 Bachillerato & López, V. y Sánchez, J.L. & $1977 \mathrm{SM}$ \\
\hline $\begin{array}{l}\text { Matemáticas Vectores BUP } 2^{\circ} \\
\text { curso }\end{array}$ & Agustí, J. M. y Vila, A. & 1980 Vicens-Vives \\
\hline \multicolumn{3}{|l|}{$\mathbf{3}^{\circ} \mathrm{BUP}$} \\
\hline Matemáticas $3^{\circ}$ & Etayo, J., Colera, J. y Ruiz, A. & 1977 Anaya \\
\hline Matemáticas. Bachillerato 3 & Guzmán, M., Colera, J. y Salvador, A. & 1988 Anaya \\
\hline Matemática 3 Bachillerato & Coruncho, J., Vázquez, C. y Rivera, M. & 1977 Santillana \\
\hline $\begin{array}{l}\text { Funciones 3. Matemáticas } 3^{\circ} \\
\text { BUP }\end{array}$ & $\begin{array}{l}\text { Vizmanos, J. R., Anzola, M. y Primo, } \\
\text { A. }\end{array}$ & $1981 \mathrm{SM}$ \\
\hline $\begin{array}{l}\text { Matemáticas. Integral. BUP } \\
\text { curso } 3\end{array}$ & Agustí, J. M. y Vila, A. & 1977 Vicens-Vives \\
\hline \multicolumn{3}{|l|}{$\mathrm{COU}$} \\
\hline Matemáticas I. Opciones A y B & de Guzmán, M. y Colera, J. & 1989 Anaya \\
\hline Matemática & Gil, J., Rivera, M. y Vázquez, C. & 1981 Santillana \\
\hline
\end{tabular}


Matemáticas. Curso de Primo, A. 1980 SM orientación universitaria

Matemáticas. Espacios.

Trillas, E. y Vila, A.

1979 Vicens-Vives

Tabla A1.1. Libros de texto pertenecientes al periodo LGE.

\begin{tabular}{|c|c|c|}
\hline LOGSE & & \\
\hline $1^{\circ}$ Bachillerato & & \\
\hline Matemáticas I & Colera, J., García, R. y Oliveira, M.J. & 2002 Anaya \\
\hline Matemáticas 1 & Grupo Azul 21 & 1996 Santillana \\
\hline Matemáticas I & Vizmanos, J.R. y Anzola, M. & $1996 \mathrm{SM}$ \\
\hline Límites 1 Matemáticas I & Ruíz, A. y Álvarez, F. & 1998 Vicens-Vives \\
\hline Omega 1 Matemáticas & $\begin{array}{l}\text { Corbalán, F., Álvarez, J. L., González, A. E. y } \\
\text { Queralt, T. }\end{array}$ & 2003 Vice \\
\hline $2^{\circ} \mathrm{Bac}$ & & \\
\hline Matemáticas II & Colera, J., García, R. y Oliveira, M.J. & 2003 Anaya \\
\hline Matemáticas 2 & $\begin{array}{l}\text { Grupo Azul 21: Negro, A., Benedicto, C., } \\
\text { Martínez, M. y Nevot, A. }\end{array}$ & 1997 Santillana \\
\hline Euler. Matemáticas 2 & Hernández, E., Quirós, A. y Tarrés, J. & $2001 \mathrm{SM}$ \\
\hline Límites 2 Matemáticas & Ruíz, A. y Álvarez, F. & 1999 Vicens-Vives \\
\hline Omega 2 Matemáticas & $\begin{array}{l}\text { Corbalán, F., Fernández, J., Muñoz, J. y } \\
\text { Queralt. T. }\end{array}$ & 2004 Vicens-Vives \\
\hline
\end{tabular}

Tabla A1.2. Libros de texto pertenecientes al periodo LOGSE.

\begin{tabular}{|c|c|c|c|}
\hline \multicolumn{4}{|l|}{ LOE } \\
\hline \multicolumn{4}{|l|}{$1^{\circ}$ Bachillerato } \\
\hline Matemáticas I & Colera, J., Oliveira, M.J., García, R. y Santaella, E. & 2008 & Anaya \\
\hline $\begin{array}{l}\text { Matemáticas I } 1 \\
\text { Bachillerato }\end{array}$ & $\begin{array}{l}\text { Antonio, M., González, L., Lorenzo, J., Molano, A., } \\
\text { del Río, J., Santos, D. y de Vicente, M. }\end{array}$ & 2008 & Santillana \\
\hline Matemáticas 1 & Vizmanos, J.R., Hernández, J. y Alcaide, F. & 2008 & SM \\
\hline Matemáticas-1 & Pancorbo, L. & 2008 & Vicens-Vives \\
\hline \multicolumn{4}{|l|}{$2^{\circ}$ Bachillerato } \\
\hline Matemáticas II & Colera, J. y Oliveira, M.J. & 2009 & Anaya \\
\hline $\begin{array}{l}\text { Matemáticas II } 2 \\
\text { Bachillerato }\end{array}$ & $\begin{array}{l}\text { Escoredo, A., Gómez, M. D., Lorenzo, J., Machín, } \\
\text { P., Pérez, C., del Río, J. y Sánchez, D. }\end{array}$ & 2009 & Santillana \\
\hline Matemáticas 2 & Vizmanos, J.R., Hernández, J. y Alcaide, F. & 2010 & SM \\
\hline Matemáticas-2 & Pancorbo, L. & 2009 & Vicens-Vives \\
\hline
\end{tabular}

Tabla A1.3. Libros de texto pertenecientes al periodo LOE. 